\title{
Handbook
}

for the Protection

of Lniteเnally

Displaced laelsons

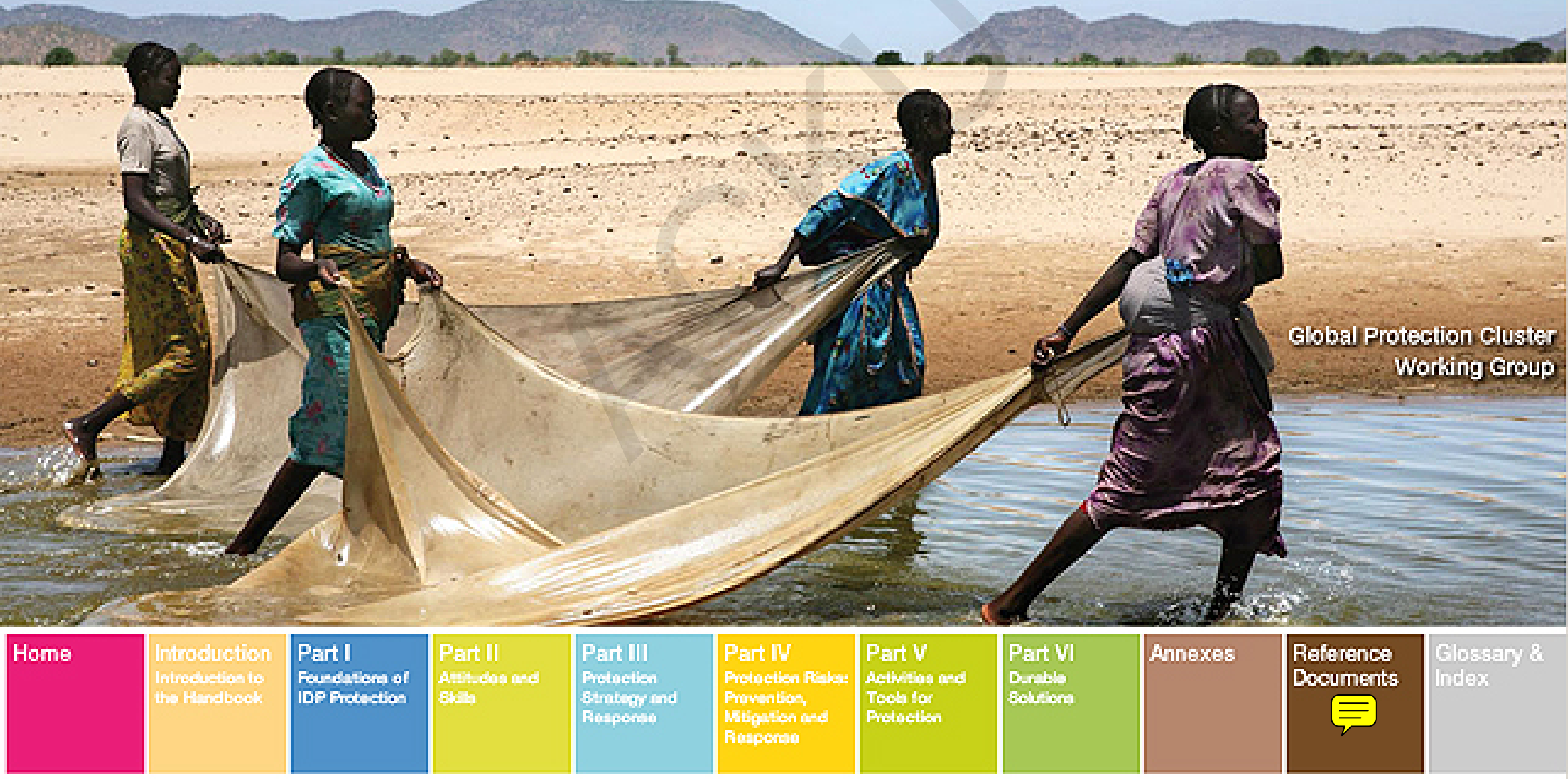




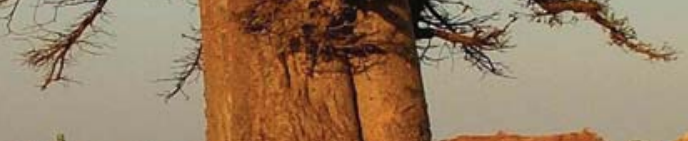

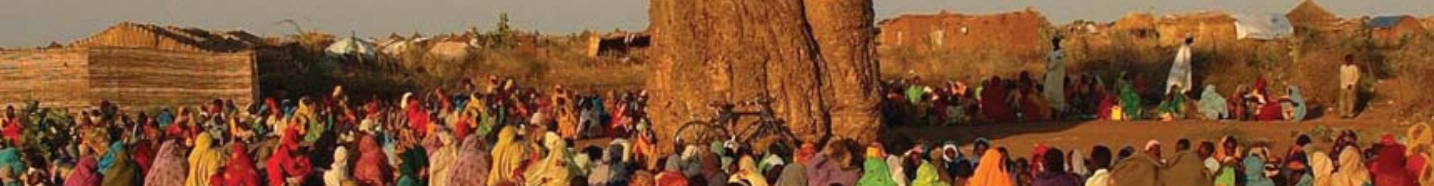

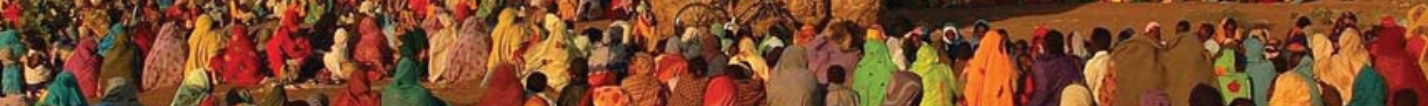

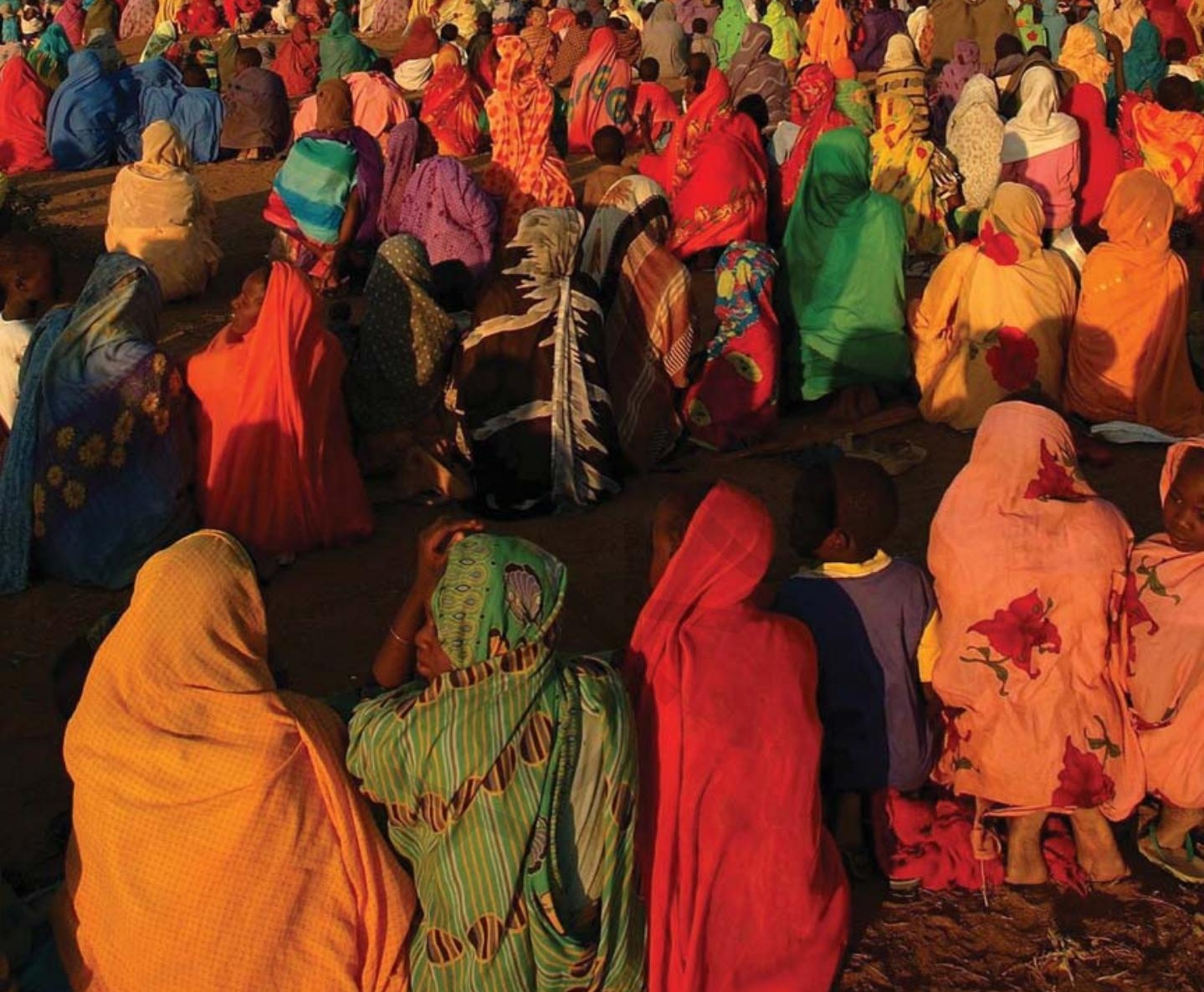

INTRODUCTION 


\section{Introduction to the Handbook}

In more than 50 countries around the world, some 26 million individuals are uprooted from their homes and displaced in their own countries as a result of conflict or human rights violations. In addition, natural disasters caused the displacement of 36 million persons worldwide in 2008.

Internally displaced persons, or "IDPs," are part of the broader civilian population that needs protection and assistance because of conflict and human rights abuses or due to natural disasters. The focus on IDPs in this Handbook is not intended to encourage preferential treatment of IDPs to the exclusion of other populations at risk but, rather, to improve the quality of the response developed for IDPs whose needs have been, until recently, inadequately addressed by the international humanitarian response.

Forced from their homes, IDPs also experience specific forms of deprivation, such as loss of shelter, and often face heightened or particular protection risks. These risks may include: armed attack and abuse while fleeing in search of safety; family separation, including an increase in the number of separated and unaccompanied children; heightened risk of sexual and gender-based violence, particularly affecting women and children; arbitrary deprivation of land, homes and other property; and displacement into inhospitable environments, where they suffer stigmas, marginalization, discrimination or harassment.

In the face of such risks, internally displaced women, men, girls and boys have to demonstrate a remarkable degree of resilience and strength, drawing on their own capacities to develop basic support mechanisms and seek protection.

The prevention of displacement and the protection of IDPs and other affected populations ${ }^{1}$ within their own country are the responsibility of national authorities. Particularly in situations of armed conflict, IDPs may find themselves in territories over which State authority is absent or difficult to enforce. In such situations, the prevention of displacement and the protection of IDPs are also the responsibility of non-State actors.

In those situations where States require support or where national protection is not ensured, a critical protection role falls to the international community. It has been difficult to address this "protection gap" not only because of the sensitivity of the subject within the country concerned, but also because of various gaps within the international framework.

Concerted efforts are also being made to address institutional gaps in humanitarian response, including in situations of internal displacement. The reform of the humanitarian system initiated in 2005 identified protection as a persistent gap and created institutional mechanisms to ensure that protection is a core component, and cross-cutting element of humanitarian response. The key mechanism introduced to help fill the gap is known as the "cluster" approach.

Although the critical test for any humanitarian response is what happens on the ground, until now there has been no comprehensive, practical guidance on how to operationalize protection in situations of internal displacement.

\footnotetext{
In the context of internal displacement, "affected populations" have been defined as: "host communities where IDPS are living; host communities in areas of IDP return; and persons or communities at risk of displacement if their protection problems are not addressed" (Progress Report of the Cluster Working Group on Protection to the IASC Principals, 12 Dec 2005). Other affected populations may also include those who are unable to flee (i.e. those trapped by the fighting, those who cannot move into the "displacement zone" due to ethnic or other tensions, or because of illness, injuries, handicaps, etc.). Throughout this Handbook, operational guidance referring to IDPs should generally be understood to include not only IDPs but also other affected populations.
} 


\section{Goals and objectives of the Handbook}

This Handbook is the result of joint efforts by the staff of over $\mathbf{3 0}$ international organizations, most of which are members of the Global Protection Cluster who contributed to the provisional version in 2007. This includes United Nations agencies, non-governmental organizations and intergovernmental organizations. The Handbook was then field-tested in the course of 2008 in over fifteen countries, involving the staff of a wide variety of inter-governmental, governmental and non-governmental agencies or bodies. A list of countries and contributors is included in Annex 3 of the Handbook (See Annex 3 Acknowledgments $[$ ). All contributors since 2007 have provided highly valuable experience and insight into the various subjects dealt with in the Handbook and have done so over and above their existing duties. The Global Protection Cluster would like to pay tribute to these contributions that make the value of the final document.

The handbook provides operational guidance and tools to support effective protection responses in situations of internal displacement.

Specifically, the Handbook seeks to:

ansure staff members are familiar with the core concepts, principles and international legal standards that form the framework for protection work;

assist staff in operationalizing these concepts, principles and legal standards and in carrying out their protection responsibilities;

- improve understanding of the particular protection risks faced by internally displaced women, men, boys and girls of various backgrounds;

a provide guidance on how to prevent and respond to the protection risks faced by IDPs through a range of different activities;

enhance staff skills for carrying out protection work; and

promote a consistent and well-coordinated protection response in different operations.

Whereas the focus of the Handbook is mainly on the protection of IDPs and other affected populations in situations of internal displacement in complex emergencies, much of the guidance provided is relevant as well during natural disasters when internal displacement and protection risks also often arise ${ }^{2}$. A specific annex on Protection in Natural Disasters has been added to the final edition of the Handbook.

\section{Intended audience of the Handbook}

This Handbook is primarily intended for use by staff, particularly field staff, of international organizations engaged in responding to internal displacement. This includes not only human rights and protection officers but also humanitarian and development actors more broadly. Protection is a cross-cutting issue that all staff should address and promote.

Indeed, the Handbook should be a source of information and guidance for all partners involved in a protection response, including State authorities and civil society.

2 See also IASC, Protecting Persons Affected by Natural Disasters: IASC Operational Guidelines on Human Rights and Natural Disasters, 2006. 


\section{How to use the Handbook}

The Handbook is divided into six parts. These six parts and their individual chapters are interconnected, but they can also stand alone as self-contained modules.

- Part I covers the foundations of protection. It sets out core concepts, approaches and humanitarian principles for protection work and provides an overview of the legal and institutional frameworks for the protection of IDPs.

- Part II outlines skills, both professional and interpersonal, which are required to support protection work.

- Part III focuses on building a protection response, providing guidance on how to assess and analyse a protection situation; develop protection strategies for response; and monitor and evaluate protection programmes.

1 Part IV provides guidance on how to prevent, mitigate and respond to specific protection risks and rights violations commonly faced by IDPs, suggesting actions for supporting IDPs to realize their rights and for the State to fulfil its protection responsibilities.

- Part $\mathrm{V}$ provides more detailed information about key protection activities that contribute to an effective protection response, identifying the operational challenges that may arise and the principles that should guide our action.

- Part VI focuses on durable solutions and the importance of having a solutions-oriented approach to protection. It is largely based on the Framework for Durable Solutions developed by the Brookings-Bern Project on Internal Displacement with the support and guidance of Representative of the Secretary General for the Human Rights of IDPs. Part VI provides practical suggestions for the application of this Framework in Field Operations.

The Handbook builds on a growing body of information on internal displacement and on existing tools and guidance materials on protection. It refers to other relevant resources for additional information in greater depth.

Hyperlinks have been built in the electronic version of the Handbook for key references and connections between chapters.

This Handbook remains a living tool and will be revised at regular intervals. Users are encouraged to provide continuous feedback, updates and good practices. These will be incorporated, to the extent feasible, into forthcoming editions.

Please send your feedback to HQIDPHB@unhcr.org. 


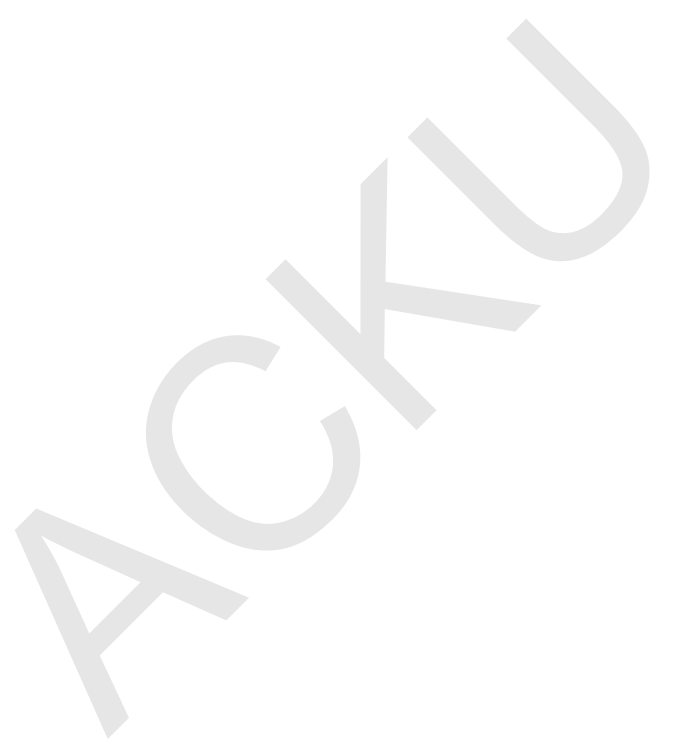



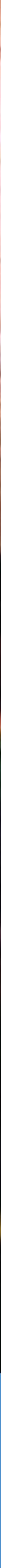

\section{FOUNDATIONS OF IDP PROTECTION}




\section{Overview}

Part I of the Handbook for the Protection of Internally Displaced Persons gives an overview of the main bases of protection responses. These include protection principles, legal and institutional frameworks. The four chapters respond to fundamental questions relating to the protection of internally displaced persons (IDPs) that protection actors are faced with: What does protection mean? Who are the IDPs? Are they legally protected? If so, by what instruments and by which authorities?

Thus, Chapter 1 provides definitions of protection and key related principles and approaches. It also explains the specific protection needs of IDPs. Chapter 2 describes the legal framework applicable to the protection of IDPs. The primary legal framework is national but should also take into account the State's international legal obligations. This chapter also gives guidance on how such legal frameworks can be used to support and strengthen protection.

Chapter 3 describes the role of the international community in providing protection and assistance to IDPs, when the national authorities lack the capacity or are unwilling to ensure an effective response to a humanitarian crisis. This chapter examines the collaborative response and the cluster approach which guide humanitarian action, and provides guidance on peacekeeping operations and integrated missions. Lastly, Chapter 4 elaborates on the national protection framework, identifying key national actors and their impact on the protection of IDPs. 


\section{Part I.1}

\section{Key concepts and approaches}

Key message 7

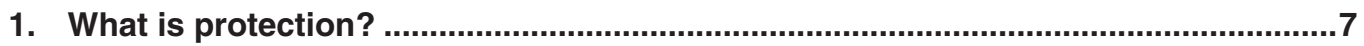

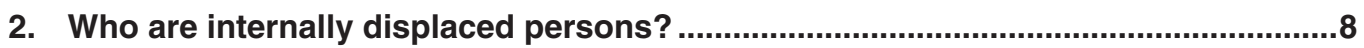

3. Who is responsible for protecting internally displaced persons? .............................9

4. Operationalizing protection ….................................................................................10

4.1 Protection is about securing human rights (a rights-based approach) ..................10

4.2 Individuals and communities are equal partners in protection (a community-based approach) .....................................................................11

4.3 Protection promotes full and equal respect for the human rights of all individuals, without discrimination of any kind (age, gender and diversity

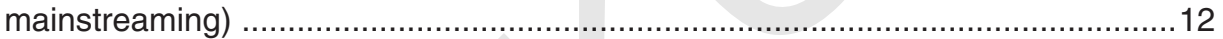

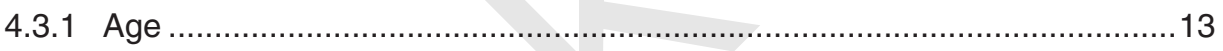

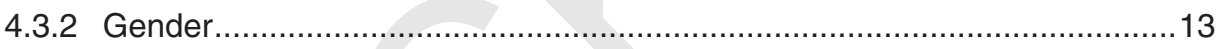

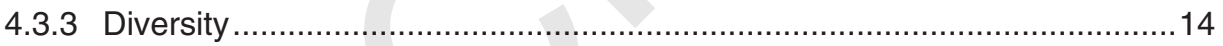

5. The core principles of humanitarian action ……..................................................15

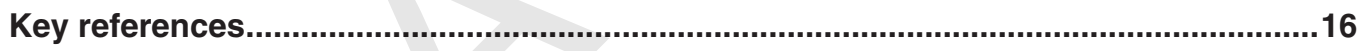

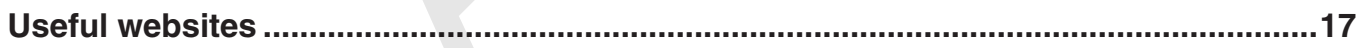




\section{Key message}

Protection aims to ensure the full and equal respect for the rights of all individuals, regardless of age, gender, ethnic, social, religious or other background. This requires a common understanding of protection and the means by which it is achieved. This chapter provides a definition of protection, explains who internally displaced persons (IDPs) are and why they need protection and assistance, and outlines the key approaches and core principles that should guide and underpin all protection efforts.

\section{What is protection?}

Protection is defined as all activities aimed at obtaining full respect for the rights of the individual in accordance with the letter and spirit of the relevant bodies of law, namely human rights law, international humanitarian law and refugee law. ${ }^{1}$

Protection can be seen as:

- an objective;

- a legal responsibility; and

an activity.

Protection is an objective which requires full and equal respect for the right of all individuals, without discrimination, as provided for in national and international law. Protection is not limited to survival and physical security but covers the full range of rights, including civil and political rights, such as the right to freedom of movement, the right to political participation, and economic, social and cultural rights, including the rights to education and health.

Protection is a legal responsibility, principally of the State and its agents. In situations of armed conflict, that responsibility extends to all parties to the conflict under international humanitarian law, including armed opposition groups. Humanitarian and human rights actors play an important role as well, in particular when States and other authorities are unable or unwilling to fulfil their protection obligations. ${ }^{2}$

Protection is an activity because action must be taken to ensure the enjoyment of rights. There are three types of protection activities that can be carried out concurrently:

- responsive - to prevent or stop violations of rights;

- remedial - to ensure a remedy to violations, including through access to justice and reparations; and

- environment-building - to promote respect for rights and the rule of law. ${ }^{3}$

This definition, which was originally developed over a series of ICRC-sponsored workshops involving some 50 humanitarian and human rights organizations, has been adopted by the IASC. See Protection of Internally Displaced Persons, Policy Paper Series, No. 2, 2000 and ICRC, Strengthening Protection in War: A Search for Professional Standards, 2001.

2 Several international organizations, namely OHCHR, UNHCR, UNICEF and ICRC, have express protection mandates. All United Nations and partner agencies, however, have a responsibility to integrate human rights into their work and to approach their work with due regard to protection issues. See Renewing the United Nations: A Programme for Reform, Report of the Secretary-General to the United Nations General Assembly (UN doc. A/51/950) and IASC, Protection of Internally Displaced Persons, 2000. See also Part I.3 of this Handbook.

3 ICRC, Strengthening Protection in War, 2001, p. 20. 
In our work, we can...

Protection requires working with all relevant stakeholders, including populations at risk, local communities and the authorities, to:

- prevent violations of rights from occurring or recurring;

- stop ongoing violations;

- provide remedies, through reparation and rehabilitation, if violations have occurred; and

- foster an environment conducive to respect for the rights of women, men, girls and boys in accordance with the law.

\section{Who are internally displaced persons?}

All persons, including those who are internally displaced, are equally entitled to protection. As defined by the Guiding Principles on Internal Displacement, ${ }^{4}$ IDPs are:

Persons or groups of persons who have been forced or obliged to flee or to leave their homes or places of habitual residence, in particular as a result of or in order to avoid the effects of armed conflict, situations of generalized violence, violations of human rights or natural or human-made disasters, and who have not crossed an internationally recognized State border.

Involuntary departure and the fact that the individual remains within his/her country are the two defining elements of an IDP. The first element distinguishes IDPs from individuals who left their homes out of choice and could have otherwise safely remained where they lived. ${ }^{5}$ The second element explains why IDPs are not refugees. Refugees, by definition, are outside their country of nationality or habitual residence. ${ }^{6}$ In other respects, however, both categories of displaced persons often face similar risks and deprivations.

The definition mentions some of the main causes of internal displacement, including armed conflict, violence, violations of human rights and disasters. This is not an exhaustive list; the phrase "in particular" means that it does not exclude the possibility that other situations might meet the two key criteria of involuntary movement within one's country.

The term "homes or places of habitual residence" does not necessarily refer to a house or a building but can also designate land on which groups traditionally live or depend for their livelihoods, as in the case of nomads or pastoralists.

It is important to understand that the IDP definition is a descriptive definition rather than a legal definition. It simply describes the factual situation of a person being uprooted within his/her country of habitual residence. It does not confer a special legal status or rights in the same way that recognition as a refugee does. This is not necessary for IDPs because, unlike refugees who require a special legal status as result of being outside their country and without its protection, IDPs remain entitled to all the rights and guarantees as citizens and other habitual residents of a particular State. ${ }^{8}$

4 See Annex 1 of the Handbook.

5 It is important to keep in mind that persons who did not leave might face similar risks as those who left but were simply unable to travel due to health reasons or because they were trapped in the conflict. Some might find it even more dangerous to move out of their places of origin because of tension with surrounding communities or insecurity along the way.

6 A refugee is defined as a person who owing to a well-founded fear of being persecuted for reasons of race, religion, nationality, membership of a particular social group or political opinion, is outside the country of his/her nationality or habitual residence, and is unable, or owing to such fear, is unwilling to avail himself/herself of the protection of that country. See Art. 1 of the 1951 Convention Relating to the Status of Refugees.

See Guiding Principles on Internal Displacement, Principle 9. Pastoralist groups can be displaced when, for instance, their migratory routes are blocked due to insecurity, such as landmines or conflict, or when the presence of IDP camps in the middle of migratory routes leads to competition over scarce resources.

8 Some countries do accord IDPs, or certain groups of IDPs, a status under national legislation. However, this does not affect the rights enjoyed by all IDPs under international human rights and humanitarian law. 
The purpose of highlighting the situation of IDPs and working to enhance their protection is not to privilege IDPs over other groups; IDPs have the same rights as others in their country. They often experience many of the same risks as other civilians caught in conflict, who also are in need of protection. Yet, the experience of internal displacement also creates heightened as well as distinct protection risks. These particular risks need to be understood and addressed so that the rights of IDPs are protected along with those of other civilians.

IDPs have been compelled to leave their homes and often cannot return because they face risks at their places of origin from which State authorities are unable or unwilling to protect them, because they might have been specifically prohibited to return, or because their homes have been destroyed or are being occupied by someone else. They also may face the risk of forced return to an area that is unsafe.

Some of the particular factors of internal displacement that tend to heighten protection risks are indicated below.

- IDPs have lost their homes and, as a result, may be in need of shelter. In some cases, they may be compelled to seek shelter in crowded camps or settlements, which can give rise to various protection risks.

- They have often lost access to their land and other property and are cut off from their normal livelihoods and sources of income. As a result they may suffer poverty, marginalization, exploitation and abuse.

- Access to adequate food, safe water and public services, such as education and health care becomes difficult, often leading to high levels of hunger, malnutrition and disease.

- Family and community-structures often collapse and family members become separated. Unaccompanied and separated children, single-headed households (in particular when headed by women or children), older persons and persons living with disabilities are often at heightened risk of abuse, including sexual exploitation, child labor or forced recruitment into armed forces or groups.

- Identity documents often are lost, destroyed or confiscated in the course of displacement. As a result IDPs often face difficulties in accessing public services, such as education and health care, limits on freedom of movement and heightened risk of harassment, exploitation or arbitrary arrest and detention.

- In many cases, IDPs are displaced to areas where they face marginalization, discrimination and hostility, are exposed to landmines or explosive remnants of war, or are targeted for abuse and attack. In addition, tensions in these areas can be exacerbated by, for instance, competition over scarce resources or an increased risk of attacks because of the presence of IDP settlements.

\section{Who is responsible for protecting internally displaced persons?}

Primary responsibility for protecting IDPs and all persons within their own country rests with the national authorities of the country. National responsibility is a core concept of any response to internal displacement. It is a fundamental operating principle of the international community and is routinely emphasized by governments themselves, as a function of their sovereignty.

Yet, it is sometimes the very governments responsible for protecting and assisting their internally displaced populations that are unable or even unwilling to do so and, in some cases, they may even be directly involved in forcibly uprooting civilians.

Even then, however, the role of international actors is to reinforce, not replace, national responsibility. This requires a two-pronged approach to encourage States and other 
authorities to meet their protection obligations under international law while also supporting the development of national and local capacities to fulfil these protection responsibilities.

The Framework for National Responsibility identifies 12 steps that governments should take towards ensuring an effective national response to internal displacement. ${ }^{9}$ These are detailed in part V.9 $\square$ and summarized below.

\section{National responsibility in situations of internal displacement}

In addition to ensuring the protection of rights in accordance with international law, national responsibility in situations of internal displacement entails:

1. preventing displacement and minimizing its adverse effects;

2. raising national awareness about the problem;

3. collecting data on the number and condition of IDPs;

4. supporting training on the rights of IDPs;

5. creating a legal framework upholding the rights of IDPs;

6. developing a national policy on internal displacement;

7. designating an institutional focal point on IDPs;

8. encouraging national human rights institutions to address internal displacement;

9. ensuring that IDPs participate in decision making;

10. supporting durable solutions;

11. allocating adequate resources to address internal displacement; and

12. cooperating with the international community when national capacity is insufficient.

In situations of armed conflict, all parties to the conflict - both State and non-State actors have a responsibility to respect and ensure respect for international humanitarian law, including by providing protection and assistance to the civilian population.

\section{Operationalizing protection}

Effective field-based protection strategies are built around three common and inter-connected approaches:

- Protection must be rights-based (a rights-based approach);

- individuals and communities are active and equal partners in protection (a community-based approach); and

n protection promotes full and equal respect for the human rights of all individuals, without discrimination of any kind.

Use of these approaches is fundamental to ensure that a protection perspective is integrated throughout the different sectors of humanitarian response.

\subsection{Protection is about securing human rights (a rights-based approach)}

Because protection is about respect for rights, it requires an approach grounded upon and geared towards the full and equal enjoyment of rights.

This way of working requires that we recognize individuals as rights-holders with legal entitlements to protection and assistance. Unlike "needs," rights generate responsibilities to

9 See Brookings-Bern Project on Internal Displacement, Addressing Internal Displacement: Framework for National Responsibility, 2005. 
ensure the protection and well-being of individuals. The State and other authorities are duty-bearers with responsibilities to respect and protect individuals' rights.

These rights and responsibilities are firmly rooted in international law, particularly human rights and international humanitarian law and, where relevant, refugee law. ${ }^{10}$

A rights-based approach means that all of our policies, programmes and activities:

- are based on rights, as provided in international law;

- further the realization of rights; and

n seek to strengthen the capacities of rights-holders (women, men, girls and boys) to claim their rights, and the capacities of duty-bearers (State and other authorities) to meet their obligations to respect, protect and fulfil those rights.

A rights-based approach can strengthen our work by anchoring it in a system of rights and corresponding obligations established by international law. By empowering people to claim their rights and strengthening the capacities of duty-bearers to fulfil these rights, a rights-based approach also promotes and strengthens the sustainability of our efforts.

\section{In our work, we can ...}

Apply a rights-based approach in situations of internal displacement which requires that we:

- be familiar with international legal standards, i.e. rights and obligations, that underlie protection;

- use rights as the basis for our activities including situation analysis and participatory needs assessments, strategy development, protection activities and programme planning, design, implementation, monitoring and evaluation;

- analyse why individuals or groups cannot enjoy their rights, including by examining underlying and structural obstacles as well as barriers based on age, gender or diversity;

- ensure that our policies, programmes and activities aim to support internally displaced women, men, girls and boys in enjoying their rights; and

- strengthen the capacity and accountability of national and local authorities to meet their protection responsibilities.

While a "rights-based approach" to humanitarian action is a relatively recently coined expression, the concept behind it is based on decades-old principles. According to the Charter of the United Nations, one of the core purposes of the United Nations is to promote and encourage "respect for human rights and for fundamental freedoms for all without distinction as to race, sex, language or religion." Human rights are, therefore, a concern that cuts across humanitarian and development activities, entailing a responsibility for all parts of the United Nations and NGOs to integrate human rights into their work. ${ }^{11}$

\subsection{Individuals and communities are equal partners in protection (a community-based approach)}

IDPs, like other civilians at risk, develop their own strategies to reduce exposure to, and mitigate the effects of, protection risks. Such coping mechanisms are based on local knowledge and build upon existing capacities and resources within the displaced community, as well as the host communities. Experience has shown that for protection efforts to be effective and sustainable, they must be designed to recognize, support and strengthen the protection capacities of individuals and communities themselves.

\footnotetext{
${ }^{10}$ Refugee law does not apply to the protection of IDPs, although some refugee law principles are relevant by analogy. The international legal framework for the protection of IDPs is discussed in Part I. 2.

11 UN Programme for Reform, 1997. See also OHCHR, Frequently Asked Questions on a Human Rights-based Approach to Development Cooperation, Geneva, 2006, p. 35.
} 
A community-based approach ${ }^{12}$ is a way of working that:

- ensures that women, men, girls and boys of all ages and diverse backgrounds are regarded and engaged as active partners in all aspects of our work;

- recognizes their resilience, capacities and resources; and

nobilizes and builds on the capacities of communities to enhance their own protection.

By recognizing that all members of the community are active participants in decision making, a community-based approach reinforces the dignity and self-esteem of people and promotes their empowerment. People are empowered when they are able to become informed and active agents in addressing their own situation.

This way of working requires a thorough understanding of the context of displacement, including the socio-economic context, gender roles, and power dynamics within the community as well as the role of other actors, such as armed groups or the host population. It seeks to understand the community's protection concerns and priorities and to identify its existing capacities to access and enjoy human rights.

\section{In our work, we can...}

Apply a community-based approach in situations of internal displacement, which requires that we:

- understand gender roles, power relations and community dynamics (among different generations, among diverse groups, and between IDPs and the local community) and how this affects their protection;

- recognize the ways in which IDPs enhance their own protection and enjoy their rights, and work to reinforce these efforts; and

- build an equal and active partnership with internally displaced women, men, girls and boys by ensuring that they participate in identifying and addressing protection risks and priorities, including through participatory assessments and in decision making on programme design, implementation, monitoring and evaluation.

Our role as international humanitarian and human rights actors is to build or rebuild and strengthen the community's capacity to respond to its own concerns and to take decisions as to how best to address these concerns. We must recognize the temporary nature of our presence, our role as facilitators, and our limitations in capacities, resources and local knowledge.

Applying a community-based approach is widely recognized within the international humanitarian community as an essential element of humanitarian response, including in situations of internal displacement. ${ }^{13}$

\subsection{Protection promotes full and equal respect for the human rights of all individuals, without discrimination of any kind (age, gender and diversity mainstreaming)}

Conflict and displacement can affect individuals in different ways depending on factors such as age, gender, and ethnic, social, religious and other backgrounds. Certain groups of persons, including women, children, older persons and minorities, are often marginalized within communities and less represented in formal decision-making structures. As a result, their specific concerns are often overlooked in needs assessments and in programme planning.

12 See A Community-Based Approach in UNHCR Operations, UNHCR, 2008.

${ }^{13}$ IASC, Guidance Note on Using the Cluster Approach to Strengthen the Humanitarian Response, November 2006. A community-based approach is also part of the Terms of Reference for sector leads at the country level. 
Failure to acknowledge the particular risks faced by diverse members of a community not only results in a failure to address those concerns, but it might lead to actions that inadvertently increase these risks and reinforce discrimination and exclusion.

Incorporating diversity analysis into all aspects of our work is essential to understand and address the different protection risks within a community. ${ }^{14}$

In practical terms, mainstreaming diversity involves:

- recognizing that, within a community, different members face particular inequalities, risks and needs depending on their age, gender and social or other background;

- identifying and analysing the different protection risks faced by women and men of different ages and backgrounds (including protection risks arising from their particular situation and the protection implications of our own activities); and

- taking targeted action to address and prevent these risks and inequalities and to empower groups within the community to claim their rights.

\subsubsection{Age}

Displacement also affects individuals in different ways, depending upon their age. Children, adolescents and older persons are often excluded from formal decision-making structures and, consequently, the specific risks that they face are often not taken into account.

- Children, generally defined as persons under 18 years of age, are exposed to a range of risks when forced to flee from their homes. Children, in particular when separated from their families, are often at risk of neglect, abuse or exploitation, forced recruitment into armed forces or armed groups, child labor, deprivation of access to food, shelter, education and health care, and other violations of their rights. Such factors seriously threaten their well-being and undermine their cognitive, emotional and social development.

- Adolescents, generally considered children aged 10 years and older, face distinct risks compared with younger children but are often neglected within a displaced community. Seen as young adults, they are at high risk of sexual violence or exploitation and forced recruitment into armed forces or armed groups. When separated from parents or adult caretakers, they often assume the daunting responsibility of caring for younger siblings but may lack sufficient resources and support to manage a household.

- Older persons often suffer social and economic hardship as a result of displacement, in particular where they become separated from their families and other support structures. In some cases, they may have been unable to flee along with other members of their family. They also may also be at increased risk of violence, exploitation or abuse and often lose their traditional role or standing within the community. In addition, while facing these specific protection risks, they may at the same time be called upon to act as primary caregivers for at-risk children and adolescents.

\subsubsection{Gender}

The term "gender" refers to the socially constructed and assigned characteristics, roles and responsibilities of women and men in any given culture. These social characteristics are constructed on the basis of sex combined with other factors, such as age, religion, national, ethnic and social origin. Gender is not static; it responds to changes in the social, political and cultural environment.

\footnotetext{
${ }^{14}$ The IASC has highlighted the importance of mainstreaming age, gender and diversity into all aspects of a humanitarian response, including into all sectors and clusters within the "cluster approach." See IASC, Guidance Note on Using the Cluster Approach to Strengthen the Humanitarian Response, November 2006.
} 
Gender equality refers to the equal rights, responsibilities, treatment and valuation of women and men, and girls and boys. Gender equality exists when individuals rights and opportunities are independent of their sex. When there is gender equality, women's and girls' interests, needs and concerns shape political, social and economic decisions as much as those of men or boys. All humanitarian agencies have a responsibility to mainstream a gender perspective into their work. ${ }^{15}$

Conflict and displacement can affect women and men, girls and boys in different ways, often resulting in changes in gender roles and power dynamics. Gender too, often perceived strictly as a "women and girls' issue," also relates to men and masculinity. A gender analysis helps identify not only the particular protection risks that women and girls face but also those faced by men and boys.

Sexual violence and exploitation, which primarily targets women and children, has become one of the most disturbing and common features of contemporary armed conflict and displacement crises. Displaced women and girls are often forced to assume different and/or additional responsibilities as a result of being separated from their families. During displacement, there is usually a dramatic increase in the number of women and children who head households and who, as a result, are at particular risk of rights violations. At the same time, because of existing and even exacerbated inequalities within the community, women and children might enjoy even less social, economic and political power and be less represented in formal leadership structures than men, with the result being that their rights and particular needs often are overlooked.

\subsubsection{Diversity}

In addition to gender and age, other factors might lead to significant inequalities and place persons at risk. These include ethnicity, language, culture, religion, disability, family status and socio-economic status.

Other differences might also arise between, for instance, newly-displaced and long-term displaced, IDPs in camps and those in urban settings, and IDPs and the local host community.

\section{In our work, we can...}

Mainstream age, gender and diversity in situations of internal displacement, which requires that we:

- understand how conflict and internal displacement affects individuals of different ages, gender and backgrounds differently, and how this affects the relationships between them and the realization of their rights;

- incorporate age, gender and diversity analysis into assessments, analysis, strategy development, design, implementation and monitoring of protection programmes and activities;

- work in partnership with internally displaced women, men, girls and boys to identify protection risks faced by different members of the community, and to prevent and address such risks through targeted action to empower disadvantaged groups to enjoy their rights;

- work towards the elimination of violence in all forms, including sexual and gender-based violence, in close collaboration with IDPs, local communities, civil society and the national government; and

- ensure that our strategies, programmes and activities do not inadvertently lead to, or reinforce, discrimination or the exclusion of different groups but, rather, promote equality and rights for all.

${ }^{15}$ ECOSOC, Agreed Conclusions on Gender Mainstreaming, 1997/2. These Conclusions identify principles for mainstreaming gender equality throughout the United Nations system and contain specific actions that should be implemented by United Nations agencies in order to institutionalize gender mainstreaming. Security Council Resolution 1325 (2000) on the protection of women in armed conflict as well as in resolutions on protecting children in armed conflict, call upon all States, United Nations actors and other agencies to mainstream a gender perspective in their work. 


\section{Communities, culture, tradition and rights}

The universality of human rights often is challenged on the grounds that local culture and tradition should take precedence. For example, some humanitarian workers have resisted taking action to promote and protect the rights of women and girls on the grounds that doing so "would interfere with local culture."

However, cultural beliefs are not homogenous and cultures are not static; they are continually being renewed and reshaped. Cultural change is the result of many factors, including conflict and displacement. Change also results from deliberate efforts to influence values through revisions of law or government policy.

International law obliges States to take measures to modify cultural patterns of conduct when this is required to eliminate customary and other practices based on the superiority or inferiority of either sex or on stereotyped roles for women and men. When the United Nations' relevant human rights organ deems a tradition or practice directly contrary to an international human rights instrument or standard, humanitarian staff is to be guided by the human rights instrument or standard and to work to promote its application.

As humanitarian actors, we have an obligation to respect and promote the rights of all. Working with the community is critical to ensure respect for the rights of all of its members. Because many human rights violations occur within the community and because individuals and groups may be stigmatized or isolated by their communities based on their age, gender and diversity, it is only by working with communities that we will be able to ensure their protection.

\section{The core principles of humanitarian action}

Several core principles guide all humanitarian action and should be respected by all staff and partners at all times. Respect for these principles is critical to the integrity of our work and the credibility and safety of humanitarian operations.

- Do no harm: Action, as well as inaction, can have unintended negative consequences. We must ensure that our actions and interventions (or lack thereof) do not adversely affect individuals or their communities, our partners or our colleagues, and that they do not expose them to harm. Before taking action, we must anticipate the consequences, assess any potential risk factors and take measures to eliminate and minimize such risks.

- Humanity and the humanitarian imperative: The prime motivation and purpose of our work is to save lives and to prevent and alleviate human suffering, wherever it is found. Individuals must be treated humanely, with dignity and respect, and have a full and equal right and ability to receive humanitarian assistance.

- Impartiality: Humanitarian action must be taken without any adverse distinction based on nationality, ethnic origin, religion, class, political opinion or other ground. Priorities for humanitarian action must be determined on the basis of rights and needs alone. The principle of impartiality, therefore, establishes two clear rules of conduct for humanitarian work: non-discrimination and proportionality according to need.

- Independence: Humanitarian action must be free from interference, whether political, ideological, economic or military.

- Neutrality: Humanitarian action must not take or be perceived to take sides in an armed conflict or other dispute. The principle of neutrality neither prevents us from taking action nor provides an excuse for inaction; indeed, failure to take action could even amount to taking sides. It provides important guidance on how we should act, by considering how our actions might be interpreted by others. We, therefore, need to be aware of our own prejudices as well as the ways in which aid can be manipulated, diverted or exploited for 
political or military purposes. Our actions and activities must be transparent, balanced and based on objective criteria.

In addition to the core principles, several key considerations should guide us in our work.

- Confidentiality: Respecting confidentiality and guaranteeing the privacy and security of individuals, their families and wider communities must be of paramount consideration at all times. Breach of confidentiality or careless handling of information can have serious consequences for persons of concern as well as for our partners, our colleagues and even the humanitarian operation as a whole. We must always assess potential risk factors and seek informed consent for the gathering and use of information. Vigorous data-protection methods must be in place to guarantee the security of recorded information.

- Sensitivity: Many IDPs have experienced violence, abuse and other forms of personal harm. We should be sensitive to their suffering, treat them with respect and dignity, and avoid creating more harm by requiring them to relive painful experiences through repeated interviewing. We must also be careful to avoid creating false hopes and unrealistic expectations about what protection and assistance we can offer; failure to do so risks increased anxiety and hopelessness, and might even put people at greater risk by giving them a false sense of security.

- Strengthen local capacities: The role of humanitarian actors is not to substitute, but rather to support and strengthen, local capacities: both the capacity of individuals to claim their rights and the capacity of States and other authorities to fulfil their responsibilities to ensure protection of these rights. To this end, humanitarian actors should identify and work to strengthen effective local coping strategies and protection mechanisms.

- Understand the context, including as it is perceived by others: To ensure that we "do no harm" and act in an impartial, independent and neutral manner, it is essential that we have a sound understanding of the country, the culture and the communities in which we work. This must include an awareness of the political agendas, interests and perceptions of all those with whom we work. Information must come from a wide range of sources and be verified to ensure that we gain an objective picture of the situation.

- Professionalism: Our actions and activities must be consistent with, and guided by, the highest standard of personal and professional integrity. In particular, we need to ensure that our conduct and that of our colleagues and partners respects the dignity and worth of all women and men, girls and boys of concern, that it is consistent with national laws and customs, and that it respects international human rights and humanitarian law standards. Any form of sexual abuse or exploitation, including entering into sexual relations with a beneficiary or exchanging aid for sexual favours is unlawful and amounts to gross misconduct.

\section{Key references}

- Addressing Internal Displacement: A Framework for National Responsibility, Brookings-Bern Project on Internal Displacement, 2005.

- A Community-Based Approach in UNHCR Operations, UNHCR, 2008.

- Human Rights Guidance Note for Humanitarian Coordinators, IASC, June 2006.

- Guidelines for Gender-based Violence Interventions in Humanitarian Settings, IASC, 2005.

- Protection of Internally Displaced Persons, Policy Paper Series, No. 2, IASC, 2000.

- Women, Girls, Boys and Men: Different Needs - Equal Opportunities, Gender Handbook in Humanitarian Action, IASC, 2006. 
- Strengthening Protection in War - A search for professional standards, Ed. S. Giossi Caverzasio, ICRC, 2001.

- Protection: An ALNAP Guide for Humanitarian Agencies, by Slim, H., and Bonwick, A., Overseas Development Institute, 2005.

- Child Rights Programming: How to Apply Rights-based Approaches to Programming, Save the Children, 2002.

- Handbook for the Protection of Women and Girls, UNHCR, 2008.

- Frequently Asked Questions on a Human Rights-based Approach to Development Cooperation, OHCHR, 2006.

- The Concept of Internal Displacement and the Case for Internally Displaced Persons as a Category of Concern, by E. Mooney in Refugee Survey Quarterly, Vol. 24, Issue 3, 2005.

- Manual for Applying a Community-based Approach in UNHCR Operations, UNHCR, 2008.

- Participation by Crisis-Affected Populations in Humanitarian Action: A Handbook for Practitioners, ALNAP/ODI, 2003.

- Displaced Women and Girls at Risk: Risk Factors, Protection Solutions and Resource Tools, WCRWC, 2006.

- Addressing the Needs of Women Affected by Armed Conflict: An ICRC Guidance Document, ICRC, 2004.

- Gender Resource Package for Peace-Keeping Operations, DPKO, 2004.

- Women and War and International Humanitarian Law, ICRC.

- Humanitarian Action and Older Persons: An Essential Brief for Humanitarian Actors, IASC, 2008.

- Older People in Disasters and Humanitarian Crisis: Guidelines for Best Practice, HelpAge International / UNHCR.

- Protecting and Assisting Older People in Emergencies, HPN Paper 53, ODI, 2005.

- Older People and Discrimination in Crisis, World Disasters Report (Chapter 3), IFRC, 2007.

- Strong and Fragile: Learning from Older People in Emergencies, HelpAge International / IASC / UNFPA, 2007.

- Disabilities: Handbook for Parliamentarians, OHCHR / IPU, 2007.

- Disabilities among Refugees and Conflict-Affected Populations: Resource Kit for Field-Workers, WCRWC, 2008.

- Convention on the Rights of Persons with Disabilities, 2006.

- United Nations Principles for Older Persons (General Assembly Resolution 46/91 of 16 Dec 1991).

\section{Useful websites}

- Humanitarian Reform: www.oneresponse.info

- Global Protection Cluster Working Group: www.protection.oneresponse.info

- International Committee of the Red Cross: www.icrc.org

- Sphere Project: www.sphereproject.org 


\section{Part I.2 \\ The legal framework}

Key message

1. How international law is relevant to our work .....................................................19

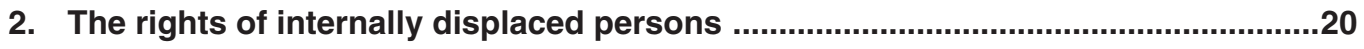

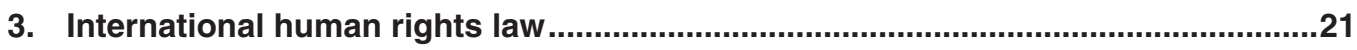

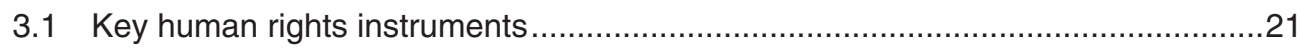

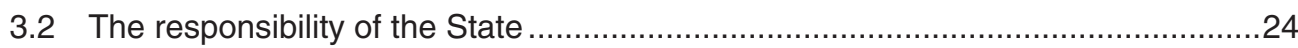

3.3 Monitoring respect for international human rights law........................................26

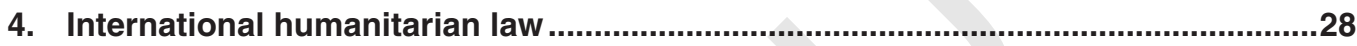

4.1 Key instruments of international humanitarian law ........................................28

4.2 Protection of civilians: key principles of international humanitarian law .................29

4.3 International humanitarian law and internal displacement ....................................

4.4 Responsibility to respect and ensure respect for international humanitarian law ........30

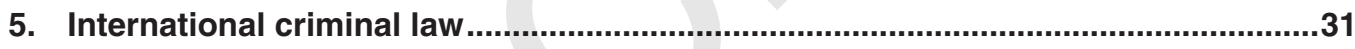

6. The Guiding Principles on Internal Displacement ...................................................32

6.1 The Guiding Principles on Internal Displacement: Overview ...............................33

6.2 The Guiding Principles as a protection tool........................................................34

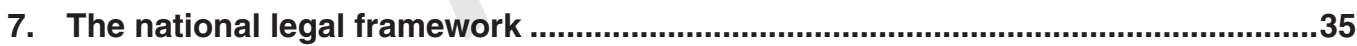

7.1 National legislation on internal displacement ……............................................35

7.2 Ensuring respect for rights under national law .................................................37

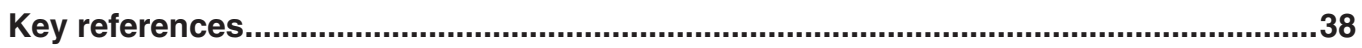

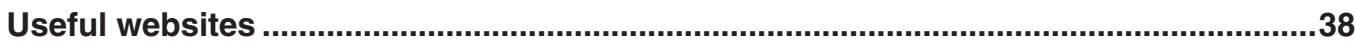

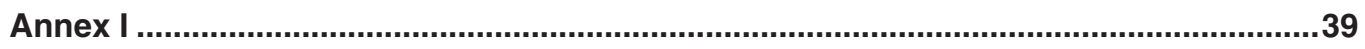




\section{Key message}

Protection is about ensuring that all women, girls, boys and men are able to enjoy their rights on an equal basis, in safety and dignity, including in times of internal displacement. National laws constitute the primary legal framework for protection activities and should reflect a State's international legal responsibilities. An understanding of the rights of internally displaced persons (IDPs) and the legal obligations of States and other authorities under international law is, therefore, essential when working within domestic legal systems.

This does not mean that one must have the specialist knowledge of a lawyer: in fact, protection often requires non-legal skills and practical initiatives. Protection efforts, nonetheless, must be anchored in national and international law and be based on rights.

This chapter provides an overview of the legal framework and gives guidance as to how that framework can be mobilized to support and strengthen protection.

\section{How international law is relevant to our work}

International law sets out the rights of every individual and the responsibility of States and other authorities to ensure the protection of these rights, and it is essential to carrying out protection activities at the national and international levels. When working within domestic legal systems and alternative dispute resolution mechanisms, international law provides clear and objective criteria for protection that can help to:

- assess to what extent human rights are being respected and identify the risks or obstacles that individuals face in exercising their rights;

- clarify the responsibility of the national authorities and the actions that must be taken to fulfil that responsibility;

- develop a sound operational response to humanitarian crisis, using rights- and community-based approaches that strengthen the capacity of individuals to protect themselves;

- provide a basis for advocacy, awareness raising, training, capacity building and other similar activities; and

- guide our own activities, conduct, and interactions with populations of concern. 


\section{What is international law?}

International law is the body of law which governs the conduct of, and relations between, States. International law is derived from two primary sources: international treaties and customary law.

- International treaties are agreements between States. A treaty is legally binding on all States that have agreed to be bound by it, for instance by way of ratification or accession. A treaty can also be known as a covenant, convention, charter or protocol.

- Customary international law or custom results from a general and consistent practice of States followed out of a sense of legal obligation. It is binding on all States, unless a State has persistently objected to the practice.

In addition, international law contains peremptory norms (jus cogens) which are accepted and recognized by States as norms from which no derogation can ever be permitted. These include, for instance, the prohibition against genocide, slavery and racial discrimination. Resolutions of the United Nations Security Council are also binding on States when adopted under Chapter VII of the United Nations Charter. Resolutions and declarations of States, such as those adopted in the United Nations General Assembly and the United Nations Human Rights Council, although non-binding, can be important normative statements and might even provide an indication of emerging international custom. Also important but not binding are the secondary sources of international law, i.e. doctrine and jurisprudence. In this regard, it can be useful to look into the jurisprudence relating to the protection of IDPs of courts and tribunals, such as regional courts or commissions on human rights, special tribunals or the permanent International Criminal Court established to judge crimes of genocide, war crimes and crimes against humanity.

\section{The rights of internally displaced persons}

IDPs are entitled to enjoy, equally and without discrimination, the same rights and freedoms under international and national law as do other persons in their country. International law does not specifically address the plight of IDPs, but this does not mean that they are not protected under the law. In fact, the following three bodies of law provide a comprehensive legal framework for protection in all situations of internal displacement, including during armed conflict:

\section{- international human rights law;}

- international humanitarian law; and

- international criminal law.

IDPs are entitled to enjoy, equally and without discrimination, the same rights and freedoms under international and domestic law as do other persons in their country.

As citizens or habitual residents ${ }^{1}$ of their country, IDPs remain entitled to full and equal protection under the State's national law, which should be compatible with the State's obligations under international law.

The challenge for international agencies, NGOs, and States has been to identify the rights and guarantees dispersed in the rich body of international law that respond to the particular needs and protection risks that arise during IDPs are entitled to enjoy, equally and without discrimination, the same rights and freedoms under international and domestic law as do other persons in their country. displacement. 
The Guiding Principles on Internal Displacement ${ }^{2}$ bring together in one document the main rules of international law, drawn from international human rights law and international humanitarian law $^{3}$ that are relevant to protection in situations of internal displacement. The Guiding Principles set out the rights of IDPs and the responsibilities of States and other authorities towards them. The Guiding Principles are comprehensive and cover protection from displacement, protection during displacement, principles of humanitarian assistance and issues relating to return, resettlement and reintegration. Although not binding, these Guiding Principles are consistent with international human rights law and international humanitarian law and international refugee law. ${ }^{4}$

To fully understand and most effectively use the Guiding Principles, it is important to situate them within the broader international legal framework.

\section{International human rights law}

Human rights are freedoms and entitlements that every individual should enjoy.

International human rights law, which consists of both customary and treaty law, guarantees these rights and obliges States to respect, protect and fulfil the human rights of all persons without discrimination of any kind, such as on the grounds of age, gender, ethnic origin, language, religion, political or other opinion, national or social origin, property, birth or other status, including on the grounds of being or having been internally displaced.

\subsection{Key human rights instruments}

The Universal Declaration on Human Rights (UDHR) of 1948, the first human rights instrument developed by the United Nations, establishes the main civil, political, economic, social and cultural rights to which all persons are entitled, without discrimination of any kind. Although not a binding instrument in itself, many of its principles constitute customary law and/or have been incorporated into treaties, thus gaining binding force.

Building upon the UDHR and incorporating its principles into legally binding instruments are two Covenants that, together with the UDHR, constitute what is regarded as the "International Bill of Rights." These are:

- International Covenant on Economic, Social and Cultural Rights (ICESCR) and

- International Covenant on Civil and Political Rights (ICCPR).

Several additional instruments reinforce the protection of human rights relating to:

- particular issues, such as torture or racial discrimination; or

- specific groups of persons, including women, children and indigenous persons, who have faced particular obstacles to the full and equal enjoyment of their rights.

\footnotetext{
2 Prepared by the Representative of the United Nations Secretary-General on Internally Displaced Persons, at the request of the United Nations General Assembly and United Nations Commission on Human Rights, UN Doc. E/CN.4/1998/53/Add.2. See Annex 1 of the Handbook $\square$.

3 Refugee law, which applies to persons fearing persecution who are displaced outside their country, does not apply directly to IDPs and therefore references to refugee law "by analogy" should be avoided. However, given its focus on issues arising during displacement, some of its principles are instructive, in particular that of non-refoulement, the core principle of international refugee law, which prohibits the forcible return of refugees to a place where their lives or freedom would be at risk. In fact, this principle is based on human rights law, particularly the rights to freedom of movement, life, liberty, and protection against torture or cruel, inhuman and degrading treatment. On these grounds, IDPs similarly have the right to be protected against forcible return or resettlement to a place where their life, safety, liberty and/or health would be at risk.

4 Introductory Note to the Guiding Principles on Internal Displacement, Representative of the Secretary-General on Internally Displaced Persons, Francis Deng.
} 
Although none of these instruments specifically addresses internal displacement, they do cover a range of risks that IDPs often face and reinforce protection for particular groups of persons who tend to be disproportionately affected by displacement (as summarized in Table 1).

Protection of human rights is also reinforced in a number of regional human rights instruments (as outlined in Annex I at the end of this chapter [D]).

Many human rights are also part of international customary law. Norms of customary international law include, for example, the rights to life, freedom from torture, freedom from discrimination on grounds of gender, race or ethnic origin, freedom from slavery, and freedom from genocide - all of which also are affirmed in international conventions.

States have the duty to respect customary international human rights law as well as all human rights treaties which they have committed to implement. They must ensure that their domestic laws, policies and practices are consistent with these obligations.

DO YOU KNOW that you can find the text of all international human rights instruments online? Go to the link below to find them: www2.ohchr.org/english/law/
DO YOU KNOW which international human rights instruments the State in which you work has committed to respect? You can find out at: www.ohchr.org/EN/countries/

Table 1: Overview of selected international human rights instruments

\begin{tabular}{lll}
\hline Name & Description \\
\hline $\begin{array}{l}\text { Universal Declaration of Human } \\
\text { Rights } 1948 \text { (UDHR) }\end{array}$ & $\begin{array}{l}\text { Worldwide instrument setting out the basic human rights of } \\
\text { all persons on the basis of equality and non-discrimination. }\end{array}$ \\
\hline $\begin{array}{l}\text { International Covenant on } \\
\text { Economic, Social and Cultural } \\
\text { Rights 1967 (ICESCR) }\end{array}$ & $\begin{array}{l}\text { Sets out economic, social and cultural guarantees, } \\
\text { including the rights to adequate food, shelter, clothing, } \\
\text { health care, an adequate standard of living, and guarantees } \\
\text { concerning work, social welfare, education and } \\
\text { participation in cultural life. }\end{array}$ \\
\hline $\begin{array}{l}\text { International Covenant on Civil and } \\
\text { Political Rights 1967 (ICCPR) }\end{array}$ & $\begin{array}{l}\text { Sets forth a broad catalogue of civil and political rights, } \\
\text { including the rights to life, physical integrity, recognition } \\
\text { before the law, political participation, freedom of movement } \\
\text { and choice of residence, and protection of the family. }\end{array}$ \\
\hline $\begin{array}{l}\text { Convention Against Torture and } \\
\text { Other Cruel, Inhuman or } \\
\text { Degrading Treatment or }\end{array}$ & $\begin{array}{l}\text { Defines and prohibits torture under all circumstances. } \\
\text { Punishment 1984 (CAT) }\end{array}$ & $\begin{array}{l}\text { State if there are grounds for believing that s/he will be } \\
\text { tortured (principle of non-refoulement). }\end{array}$ \\
\hline $\begin{array}{l}\text { International Convention on the } \\
\text { Elimination of All Forms of Racial } \\
\text { Discrimination 1965 (ICERD) }\end{array}$ & $\begin{array}{l}\text { Prohibits racial discrimination: when a person or group is } \\
\text { treated differently because of race, colour, descent, } \\
\text { national origin or ethnic origin with the aim or effect of } \\
\text { denying their human rights and fundamental freedoms. }\end{array}$ \\
\hline $\begin{array}{l}\text { Convention on the Prevention and } \\
\text { Punishment of the Crime of } \\
\text { Genocide 1948 }\end{array}$ & $\begin{array}{l}\text { Defines genocide as acts committed with the intent to } \\
\text { destroy, in whole or in part, a national, ethnical, racial or } \\
\text { religious group, and declares it as a crime, whether } \\
\text { committed during peacetime or war. }\end{array}$ \\
\hline
\end{tabular}




$\begin{array}{ll}\begin{array}{l}\text { Convention on the Elimination of All } \\ \text { Forms of Discrimination against } \\ \text { Women } 1979 \text { (CEDAW) }\end{array} & \begin{array}{l}\text { Sets a framework for national action for ensuring women } \\ \text { enjoy, on an equal footing with men, their rights in all fields, } \\ \text { including employment, education and administration of } \\ \text { property, and for ensuring the protection of women, } \\ \text { especially against threats to their physical safety and } \\ \text { against rape and sexual exploitation. }\end{array}\end{array}$

Convention on the Rights of the

Child 1989 (CRC), together with:

Optional Protocol on the sale of

children, child prostitution and child pornography 2000

Optional Protocol on the involvement of children in armed conflict 2000

Convention on the Rights of Persons with Disabilities 2006 (CPD)

International Convention for the Protection of all Persons against Enforced Disappearances 2006 (CED)

Convention concerning the Prohibition and Immediate Action for the Elimination of the Worst Forms of Child Labour (ILO Convention No. 182) 1999

International Convention on the Protection of all Migrant Workers 1990 (CMW)

Indigenous and Tribal Peoples (ILO Convention No. 169) 1989
A comprehensive code to protect the rights and best interests of children (below 18 years of age). Obliges States to take measures to ensure protection, care, psychological recovery and social reintegration of children affected by armed conflict, including unaccompanied or separated children. The Optional Protocol on the involvement of children in armed conflict prohibits compulsory recruitment and direct use in hostilities of persons under 18.

Reaffirms human rights and emphasizes their particular importance to persons living with disabilities. Also provides guidance to States on ways to ensure that those with disabilities, including survivors of landmines and explosive remnants of war, can exercise their rights on a full and equal basis with others.

Defines and prohibits enforced disappearance under any circumstances and obliges States to prevent such acts, to prosecute and punish or extradite those responsible, and provide reparations for victims and their families.

Obliges States to take all necessary measures to eliminate the worst forms of child labor, such as slavery, trafficking, prostitution or forced labor, including recruitment of children (under 18 years) for use in armed conflict.

Provides a framework for the protection of the human rights of migrant workers during all stages of the migration process; before departure, during transit and in the country of employment.

Sets a framework for ensuring indigenous and tribal peoples enjoy their rights on an equal footing with other persons. Specifically addresses the issue of the relocation of peoples, establishing conditions and guarantees to be fulfiled for this to be lawful.

The text of these and other instruments is available online at:

www2.ohchr.org/english/law/index.htm\#core 


\subsection{The responsibility of the State}

States have a responsibility to ensure the full and equal enjoyment of human rights of all individuals on their territory or under their jurisdiction. This duty extends to all agents of the State, including the military and the police, and all public authorities, whether at the national, regional or local level. ${ }^{5}$

This responsibility has three dimensions: to respect, protect and fulfil human rights.

- The duty to respect requires the State to ensure that all agents of the State act in compliance with human rights law and refrain from any act that might interfere with, or impair, the exercise of rights. As an example, the State must not restrain freedom of movement: people must be allowed to flee to safer areas within or outside the country and IDPs must be able to move freely in and out of camps and settlements.

- The duty to protect obliges the State to take all necessary measures to prevent, or put a stop to, any violations of rights by third parties, including other individuals or groups. The State must also investigate, prosecute and punish violations of rights and ensure that victims/survivors have access to an adequate and effective remedy under domestic law. As an example, if the State is aware or reasonably should have been aware that women are being raped or that children are being recruited into a guerilla group but does not take action to prevent and put an end to such acts, it would have failed to fulfil its duty to protect.

- The duty to fulfil requires the State to take all possible measures to ensure that individuals under its jurisdiction are able to exercise their human rights. This requires that States put in place a legal and administrative framework that respects human rights and builds national capacity to support the implementation of rights. As an example, ensuring the right to a fair trial requires that an effective judicial system be put in place, and ensuring the right to freedom from torture requires that police and prison guards are adequately trained and supervised. In other words, to ensure the realization of rights, a State must invest its resources.

Many countries experiencing conflict and displacement have significant resource constraints. Human rights law recognizes that States with very limited resources might not have the capacity to ensure the full realization of certain economic, social and cultural rights. However, a State cannot use a lack of resources as an excuse to do nothing. A State is obliged to take steps "to the maximum of its available resources, with a view to achieving progressively the full realization" of such rights. ${ }^{6}$ It must:

- at a minimum, ensure access to rights essential to survival (i.e. food and water, basic shelter, medical services and sanitation); and

- request international assistance when State resources are insufficient.

Although human rights instruments are not formally binding on non-State actors, the latter can be expected to uphold the values that underpin these instruments. ${ }^{7}$

5 For a more detailed discussion on State's obligations under international human rights law, see for example General Comment No. 31(1980) of the Human Rights Committee on the nature of the general legal obligation imposed on States Parties to the Covenant (CCPR/C/21/Rev.1/Add.13).

6 ICESCR, Article 2(1). For further discussion, see for example General Comments of the Committee on Social, Economic and Cultural Rights No. 12 (1999) on the right to adequate food (E/C.12/1999/5) and No. 14 (2000) on the right to the highest attainable standard of health (E/C.12/2000/4).

While human rights law applies primarily to States, non-State actors, in particular when in charge of territory, are increasingly being seen as having an obligation to respect and protect human rights. In some cases, such actors have expressly agreed to be bound by human rights law when, for instance, concluding ceasefire and peace agreements. Depending on the context, it may be possible and appropriate to undertake human rights advocacy with non-State actors. 


\section{Can human rights be restricted?}

Some human rights instruments allow States to restrict or limit the effects of certain rights for specific purposes, such as to protect other rights and freedoms. Such restrictions are subject to strict conditions. They must always be provided for by law and be necessary and proportionate to achieve a legitimate aim, such as to protect national security or public order, safety, health or morals or the rights and freedoms of others. Restrictions must be consistent with other human rights, including that of non-discrimination and, where applicable, with the State's other international legal obligations, including international humanitarian law.

\section{Can human rights be suspended?}

The duty of the State to respect, protect and fulfil human rights applies at all times, including during armed conflict and disasters.

In certain circumstances, such as during a declared state of emergency, the State may temporarily derogate from (suspend) certain rights. Such derogations are exceptional measures that are subject to strict requirements. There must be an actual or imminent danger that threatens the physical safety of the population or the political independence or territorial integrity of the State. Any derogation of rights must not go beyond what is necessary to address this danger, must not last longer than required by the circumstances, and must not be inconsistent with the State's other obligations under international law. In addition, such measures may never be discriminatory, that is, applied solely to members of a particular race, religion, ethnic, gender, linguistic or other group.

However, a number of human rights can never be suspended, whatever the situation, including in armed conflict. In addition to the principle of non-discrimination, these include:

n the right to life;

- the prohibition of genocide;

- freedom from torture and cruel, inhuman and degrading treatment or punishment;

- freedom from slavery;

- freedom of thought, conscience and religion;

- the right to due process of law; and

- the prohibition of punishment for any act that was not a crime when the act was committed. ${ }^{8}$

In our work, we can ...

As a general rule, human rights law applies equally in times of peace and war. While a State can temporarily suspend the fulfilment of certain rights during war or other public emergencies it can only do so to a limited extent and subject to strict conditions. National authorities should be encouraged to continue to respect human rights at all times. Where rights have been lawfully suspended, we can continue to monitor and advocate for the respect of those rights which cannot be suspended.

8 See, for example, Article 4(2) of ICCPR. Some regional treaties, such as the American Convention on Human Rights (AmCHR), contain a more extensive list of non-derogable rights, including the rights of the child, the right to juridical personality, the rights to a name, family and nationality and to participate in government. 


\subsection{Monitoring respect for international human rights law}

There are several mechanisms charged with monitoring and encouraging State compliance with human rights law at the international, regional and national levels. At the international level, the United Nations treaty-monitoring bodies and the "Special Procedures," created by the United Nations Human Rights Council are of particular importance. ${ }^{9}$

United Nations treaty-monitoring bodies: For each of the main human rights treaties, there is a corresponding committee composed of independent experts, charged with monitoring State compliance with the treaty. ${ }^{10}$ In general, the Committees fulfil this role in three ways:

n by examining State reports and issuing concluding observations that outline the main concerns and provide recommendations to the State;

- by issuing general comments that provide guidance on the interpretation of particular rights; and

- by examining individual complaints of alleged violations of human rights, subject to the consent of the State to do so. ${ }^{11}$ The treaty-monitoring bodies have been devoting increasing attention to the obstacles that impede the enjoyment of human rights during internal displacement.

\section{In our work, we can ...}

- consult the treaty-monitoring reports for the country where we work, in particular the recommendations for improving respect for human rights, including those of IDPs;

- promote, monitor and support follow-up to the recommendations, including by strengthening the State's capacity, through training, to respect human rights; and

- provide information about protection concerns when the State report is reviewed (for which your office might have a focal point).

The treaty-monitoring reports are available at: www.universalhumanrightsindex.org

United Nations Human Rights Council's Special Procedures: ${ }^{12}$ A whole network of independent human rights experts has been appointed by the United Nations Human Rights Council to examine, monitor, advise and publicly report on particular human rights themes or country situations.

- Thematic experts cover a range of issues relevant to the protection of IDPs, such as: violence against women, minority issues, the rights of indigenous peoples, and the rights to education, to adequate housing, to food, and to physical and mental health. One mandate specifically focuses on promoting the rights of IDPs (as outlined in the Box below).

- Country-specific experts address particularly serious situations of human rights violations. Such situations almost inevitably include large numbers of IDPs. Country situations currently covered include: the Democratic Republic of Congo, Myanmar, Somalia, and the Sudan.

9 For more guidance on how you can make use of these mechanisms to support your efforts to protect the rights of IDPs, see Brookings-Bern Project on Internal Displacement, Guide to International Human Rights Mechanisms for Internally Displaced Persons and Their Advocates, 2006, www.brookings.edu/projects/idp/2006_guidebook.aspx.

10 The United Nations human rights treaty-monitoring bodies are: the Human Rights Committee (ICCPR), the Committee on Economic, Social and Cultural Rights (CESCR), the Committee against Torture and other forms of Inhuman or Degrading Punishment (CAT), the Committee on the Elimination of Racial Discrimination (CERD), the Committee on the Elimination of Discrimination against Women (CEDAW), the Committee on the Rights of the Child (CRC) and the Committee on the Protection of the Rights of All Migrant Workers and Members of their Families (CMR).

11 Specifically, the HRC, CERD, CAT and CEDAW, though the procedural requirements vary. For guidance, see www.ohchr.org/english/bodies/petitions/index.htm.

${ }_{12}$ For more information on the Special Procedures, see www.ohchr.org/english/bodies/chr/special/index.htm. 
A global advocate for IDPs: The Representative of the Secretary-General on the Human Rights of Internally Displaced Persons, who reports to the United Nations Human Rights Council and United Nations General Assembly, engages in dialogue and advocacy with governments and other actors concerning the rights of IDPs, and works to strengthen the international response to internal displacement. Activities include:

- promoting the rights of IDPs as articulated in the Guiding Principles on Internal Displacement,

- engaging governments and other actors on specific situations of internal displacement and the human rights of IDPs, including by undertaking country visits; and

- sponsoring national and regional seminars and undertaking research on issues related to internal displacement.

The reports and recommendations are available at the following address:

http://ap.ohchr.org/documents/dpage_e.aspx?m=71

In our work, we can ...

- consult reports by Special Procedures that address the human rights situation in the country where we work (which may provide valuable insight into the range of protection concerns and can assist in developing a protection strategy);

- provide information to specific country and thematic experts (which might lead them to send a written communication to the State concerned, conduct a country mission and raise the issue directly with national officials, make a public statement, and/or report on the issue to the United Nations Human Rights Council and/or General Assembly);

- seek technical guidance and advice, as needed, from Special Procedures on issues related to their mandate, such as on national legislation;

- suggest a country mission by the Special Procedure to examine and discuss the human rights situation with national authorities and other stakeholders, including IDPs, NGOs, national human rights institutions;

- disseminate the recommendations, which might be directed not only to States but also to non-State actors and United Nations agencies, to relevant stakeholders, including the government, civil society, IDP associations, international agencies, and donors; and

- promote, monitor and support follow-up to the recommendations, including by strengthening the State's capacity, through training, to respect human rights.

The reports of the Special Procedures are available at the following address:

www.universalhumanrightsindex.org.

At the regional level, in Africa, the Americas and Europe, there are also human rights monitoring mechanisms that provide important protection, especially since rights can be enforced in regional human rights courts. (See Annex I at the end of the chapter $\square$.) Regional mechanisms have become increasingly engaged in addressing human rights issues in situations of internal displacement and in protecting the rights of IDPs.

At the national level, national courts and human rights institutions have a critical role to play in providing a channel for individuals to claim their rights. These institutions also can work to ensure that domestic legislation, policies and programmes respect human rights, including in situations of internal displacement. 


\section{International humanitarian law}

In situations of armed conflict, international humanitarian law comes into effect and applies together with human rights law. Also known as the law of armed conflict or the law of war, international humanitarian law aims to limit human suffering in times of armed conflict. This body of law:

- protects persons who do not, or no longer, take part in hostilities, namely civilians, prisoners of war, and sick, wounded or shipwrecked combatants; and

- regulates the method and means of warfare between parties to a conflict, such as by prohibiting particularly barbarous weapons and tactics, including the use of chemical and biological weapons, military attacks on civilian targets and "indiscriminate attacks" that strike military objects and civilians without distinction.

International humanitarian law applies in all situations of armed conflict, both international conflict (between States) and non-international conflict (between a State and a non-State actor, or between two or more such actors). It is binding on all parties to an armed conflict: States, their armed forces and non-State armed groups, whether these are insurgent groups opposing the State or groups such as paramilitary groups supported by the State.

Because some human rights can be temporarily limited or suspended during armed conflict, the protection provided by international humanitarian law is particularly important. The more specific rules of international humanitarian law also assist in interpreting applicable human rights principles in situations of conflict. For example, evacuations of civilians on grounds of military necessity that are permissible under international humanitarian law are a legitimate limitation of the right to freedom of movement under human rights law.

\subsection{Key instruments of international humanitarian law}

The core instruments of international humanitarian law are the four Geneva Conventions of 1949 and their two Additional Protocols of $1977 . .^{13}$ Many of the key principles contained in these instruments also constitute customary international law, which means that they are automatically binding in all situations of armed conflict and on all parties to a conflict.

\begin{tabular}{lll}
\hline Type of conflict & Description & $\begin{array}{l}\text { International humanitarian law } \\
\text { applicable }\end{array}$ \\
\hline $\begin{array}{l}\text { International } \\
\text { armed conflict }\end{array}$ & $\begin{array}{l}\text { Armed conflict between two } \\
\text { or more States }\end{array}$ & $\begin{array}{l}\text { Customary law } \\
\text { - The four Geneva Conventions, in } \\
\text { particular the Fourth Convention on } \\
\text { Protection of Civilians }\end{array}$ \\
& $\begin{array}{l}\text { - Additional Protocol I to the } \\
\text { Geneva Conventions }\end{array}$ \\
\hline $\begin{array}{l}\text { Non-international } \\
\text { armed conflict }\end{array}$ & $\begin{array}{l}\text { Armed conflict between the } \\
\text { State and a non-State actor, } \\
\text { or between two or more } \\
\text { such actors }\end{array}$ & $\begin{array}{l}\text { Customary law } \\
\text { Geneva Conventions }\end{array}$ \\
& $\begin{array}{l}\text { - Additional Protocol II to the } \\
\text { Geneva Conventions }\end{array}$ \\
\hline
\end{tabular}

In addition, several important treaties prohibit or regulate the use of certain weapons, such as the Mine Ban Treaty and the Conventional Weapons Convention and its Protocols.

\footnotetext{
${ }_{13}$ The text of these instruments is available at www.icrc.org. In 2006, the Geneva Conventions achieved universal ratification, meaning that every State in the world is now a party to, and therefore has committed itself to respect, these instruments.
} 


\subsection{Protection of civilians: key principles of international humanitarian law}

Fundamental to international humanitarian law is the distinction between the civilian population, persons who do not take a direct part in hostilities, and combatants. The parties to a conflict must at all times distinguish between the civilians and combatants, in order to spare the civilian population and civilian property. The civilian population shall not be the object of attack; attacks shall be directed solely against military objectives.

IDPs, provided they are not taking a direct part in hostilities, are entitled to the same protection under international humanitarian law as any other civilians.

\section{Key principles of international humanitarian law}

Parties to the conflict must distinguish at all times between combatants/fighters and military objects, on the one hand, and civilians and civilian property on the other. Any attacks must be directed only against military objects and all feasible measures must be taken to protect civilians from the indiscriminate effects of hostilities.

\section{The following acts are prohibited at all times:}

- targeted or indiscriminate attacks against civilians or civilian objects;

- starvation of civilians as a method of warfare, and attacking, destroying, removing or rendering useless any objects indispensable for the civilian population's survival;

- reprisals or collective punishments against civilians;

- using civilians to shield military objectives from attack or to shield, favor or impede military operations;

- acts of violence intended to spread terror;

- using weapons that are inherently indiscriminate, cause superfluous injury or unnecessary suffering, or cause widespread, long-term and severe damage to the environment.

\section{Principles of humane treatment}

- Persons who do not, or have ceased to, take in part in hostilities must be treated humanely and protected against violence to life, health and physical or mental well-being, including murder, mutilation, torture and cruel, humiliating or degrading treatment.

- Rape, enforced prostitution and any form of indecent assault as well as sexual slavery, exploitation and abuse are prohibited in all circumstances and at all times.

\section{Forced displacement}

- Unless essential for the security of civilians or imperative military reasons, parties to an international armed conflict may not deport or forcibly transfer the civilian population of an occupied territory, and parties to a non-international armed conflict may not order the displacement of the civilian population.

- Displaced persons have a right to voluntarily return in safety to their homes or places of habitual residence as soon as the reasons for their displacement cease to exist.

- States may not deport or transfer parts of their own civilian population into a territory they occupy.

\section{Assistance and basic living conditions}

- All parties to the conflict must grant and facilitate the unimpeded passage of relief assistance necessary for the survival of civilians.

- All possible measures must be taken so that displaced civilians receive satisfactory conditions of shelter, hygiene, health, safety and nutrition.

\section{Individuals and groups with specific rights or needs}

- The specific protection, health and assistance needs of women must be respected.

- Children are entitled to special respect and protection. Children under 15 must not be recruited into armed forces or armed groups or be allowed to take part in hostilities, whether directly or indirectly.

- Older persons, disabled and the infirm are entitled to special respect and protection.

- The sick and wounded must be protected and provided with needed medical care and attention with the least possible delay and to the fullest extent practicable.

- The family should be protected. Measures should be taken to ensure that family members are not separated and, if separation occurs, that they are reunited as soon as possible. 


\subsection{International humanitarian law and internal displacement}

Because internal displacement so often occurs in situations of armed conflict, international humanitarian law is especially important for the protection of IDPs and other affected populations. Indeed, in many instances, respect for international humanitarian law would prevent the displacement of civilians.

International humanitarian law prohibits any party to an armed conflict from compelling civilians to leave their places of residence. Temporary evacuations may be carried out only if the security of civilians or military imperatives absolutely requires it and, even then, such evacuations are subject to strict conditions. All possible measures must be taken to ensure that family members are not separated and that the displaced population is received under satisfactory conditions of shelter, hygiene, health, safety and nutrition. Moreover, such evacuations must be temporary, and those affected have the right to return in safety to their homes as soon as the reasons for their displacement cease to exist. ${ }^{14}$

In addition to this express prohibition of displacement, the rules of international humanitarian law that are intended to spare civilians from the effects of hostilities help prevent forced displacement. It is often the violation of these rules that causes civilians to flee their homes and become displaced.

If displacement occurs, IDPs, like all other civilians, are entitled to protection and assistance, as required. Parties to a conflict have a duty to allow humanitarian access and assistance to civilian populations in need.

"When civilians flee a conflict zone, this is a good indication that the warring parties are indifferent to their rights under IHL or, worse, are deliberately targeting them."

ICRC, 2007

\subsection{Responsibility to respect and ensure respect for international humanitarian law}

Each party to a conflict has an obligation to respect and ensure respect for international humanitarian law by its armed forces and any other persons or groups acting on its instructions or under its direction or control. In particular, States must:

- provide instruction and training on international humanitarian law to the armed forces and the public;

- criminalize violations of the law and put in place adequate legal, administrative and disciplinary structures to prevent, monitor and investigate violations; and

- prosecute and punish or extradite those responsible for serious violations of the law.

The International Committee of the Red Cross (ICRC) is an independent and neutral organization mandated by international humanitarian law and its Statute to provide assistance and protection to victims of armed conflict and to promote and monitor respect for international humanitarian law. For further information, see www.icrc.org.

International humanitarian law obliges other (neutral) States to work to ensure that the parties to a given conflict respect this law. This can be accomplished through advocacy, capacity building, support to humanitarian operations, and prosecution or extradition of those responsible for violations of the law.

In a landmark resolution in April 2000, the Security Council for the first time identified violations of international humanitarian law and human rights as a threat to peace. It reaffirmed its grave concern at the harmful and widespread impact of armed conflict on civilians as well as its

${ }^{14}$ See ICRC, Rules 129-133 of Customary International Humanitarian Law: Volume I, 2005. See also Art. 49 of the

Fourth Geneva Convention and Art. 17 of Additional Protocol II. 
intentions to provide adequate mandates and resources to peacekeeping missions in order to protect civilian victims of conflict, the majority of whom are IDPs, ${ }^{15}$ by providing the rapid deployment of military peacekeepers, civilian police, humanitarian workers and civilian administrators. ${ }^{16}$

All States, regardless of whether or not they are parties to a given conflict, have the duty to prosecute and punish in their own courts or to extradite those responsible for serious violations of international humanitarian law, such as war crimes and/or grave breaches of the law, regardless of where the crime took place or the nationality of the perpetrator. ${ }^{17}$ Members of armed forces and armed groups can be held individually responsible for violations of international humanitarian law, regardless of their rank and whether or not they were acting under orders. Military commanders can also be held responsible for either ordering or failing to take measures to prevent such violations from taking place. Individual criminal responsibility has been further developed under international criminal law (as further discussed below).

The fundamental principles and rules of international humanitarian law are also applicable to military forces under United Nations command in peacekeeping operations. In case of violations of international humanitarian law, United Nations military personnel are subject to prosecution under their own national systems of military justice. Military forces under United Nations command must make a clear distinction between civilians and combatants and direct military operations only against combatants and military objectives. ${ }^{18}$

\section{International criminal law}

National authorities have an obligation to criminalize violations of international human rights and humanitarian law in national legislation and to prosecute and punish those responsible before national courts and tribunals. In some cases, individuals can be brought to justice under international criminal law.

The Statute of the International Criminal Court (ICC) ${ }^{19}$ defines a number of crimes that are considered to be of international concern and which can be investigated and prosecuted by the Court, provided that the Court has jurisdiction over the act. These include:

- war crimes, which include grave breaches of the Geneva Conventions and serious violations of international humanitarian law, cover a range of acts (e.g. wilful killing, torture and inhuman treatment; rape and sexual slavery; starvation of civilians; recruitment of children under 15 years of age into armed forces or armed groups or using them to participate in hostilities; launching attacks against the civilian population or civilian objects; and ordering the displacement of the civilian population, unless required for the security of civilians or military imperatives) $;^{20}$

- crimes against humanity, which are acts committed as part of a widespread or systematic attack directed against a civilian population, whether in times of war or peace (e.g. murder, extermination, enslavement, deportation or forcible transfer of population, arbitrary imprisonment or other severe deprivation of liberty, rape and sexual violence,

${ }^{15}$ Security Council Resolution 1296 specifically referred on several occasions to IDPs, noting that the overwhelming majority of IDPs are civilians in armed conflicts. Security Council Resolution 1296 on the Protection of Civilians in Armed Conflict, 19 April 2000,

http://daccessdds.un.org/doc/UNDOC/GEN/N00/399/03/PDF/N0039903.pdf?OpenElement.

${ }^{16}$ Brookings-SAIS, A New Challenge for Peacekeepers: the Internally Displaced, William G. O'Neill, 2004.

17 Grave breaches are defined in each of the four Geneva Conventions, Articles 50, 51, 130 and 147 respectively, and Additional Protocol I, Articles 11 and 85. They include willful killing, torture and inhuman treatment, willfully causing great suffering or serious injury to body or health, and unlawful deportation or transfer of populations.

${ }^{18}$ DPKO, Handbook on UN Multidimensional Peacekeeping operations, December 2003.

${ }^{19}$ Statute of the International Criminal Court, 1998, UN Doc. A/CONF.183/9. For further information, including the text of the Statute, visit www.icc-cpi.int.

${ }^{20}$ Article 8 of the Statute of the International Criminal Court. 
persecution, enforced disappearance, and other inhuman acts intentionally causing great suffering or serious injury to body or to mental or physical health); ${ }^{21}$

- genocide, which are acts committed with the intent to destroy, in whole or in part, a national, ethnical, racial or religious group (e.g. killings, inflicting serious bodily or mental harm, imposing conditions of life calculated to bring about the group's destruction, preventing births, and/or forcibly transferring children to another group). ${ }^{22}$

International criminal law is complementary to national law in the sense that international courts, such as the ICC, generally only exercise jurisdiction when national courts have proven unwilling or unable to prosecute and punish the crimes in question. To date, the ICC has opened investigations into four situations in Northern Uganda, the Democratic Republic of the Congo, the Central African Republic, and Darfur.

The international community has also established a number of ad hoc criminal tribunals, whose decisions may be drawn upon for interpretations of international criminal law. These tribunals include the International Criminal Tribunal for the Former Yugoslavia and the International Criminal Tribunal for Rwanda, which were established by the United Nations Security Council and use foreign judges. The United Nations has also supported the creation of hybrid tribunals such as the Special Court for Sierra Leone and the Extraordinary Chambers in the Courts of Cambodia, which have both foreign and domestic judges.

\section{The Guiding Principles on Internal Displacement}

The Guiding Principles on Internal Displacement bring together and give an overview of the rights of IDPs and the responsibilities of national authorities and non-State actors towards them. Although not a binding document, like a treaty, the Guiding Principles are based on and reflect existing standards of international law, which are binding. ${ }^{23}$

The Guiding Principles' authority is reinforced by the wide international acceptance that they have received. They are recognized by States as "an important international framework for the protection of internally displaced persons" as well as serving as a "tool" and "standard" to guide governments, international organizations and all other relevant actors in situations of internal displacement. ${ }^{24}$

The Guiding Principles provide a definition of an IDP and a comprehensive statement of what protection should mean during internal displacement. It covers all phases of displacement:

- the pre-displacement phase, providing protection from unlawful displacement;

- protection and assistance during displacement; and

- durable solutions, namely return, local integration at the place of displacement or resettlement in another part of the country and reintegration.

\footnotetext{
${ }^{21}$ Article 7 of the Statute of the International Criminal Court.

${ }^{22}$ Article 6 of the Statute of the International Criminal Court. See also the 1948 Convention on the Prevention and Punishment of the Crime of Genocide.

${ }^{23}$ The basis in international law for each Principle is summarized in Guiding Principles on Internal Displacement: Annotations, American Society of International Law, Walter Kälin, 2000, www.brookings.edu/reports/2008/spring_guiding_principles.aspx.

${ }^{24}$ United Nations General Assembly, 2005 World Summit Outcome Resolution adopted by Heads of State, UN doc. A/RES/60/1, 15 September 2005, para. 132. See also United Nations Commission on Human Rights Resolution 2003/1, 23 April 2003; and United Nations General Assembly Resolution 58/177, 22 December 2003.
} 
The Guiding Principles address a range of particular needs and protection risks that typically arise in situations of internal displacement, such as family separation, loss of documentation, freedom of movement in and out of camps, and loss of property. They also identify the corresponding rights and guarantees to address these concerns. Incorporating civil and political rights as well as economic, social and cultural rights, the Guiding Principles cover the broad spectrum of rights, including those not typically at the forefront of humanitarian action. It covers rights relating to:

- physical security and integrity (e.g. the rights to life, protection from torture and rape);

- basic necessities of life (e.g. the rights to food, water, shelter, health and sanitation);

- other economic, social and cultural protection needs (e.g. access to education, property restitution or compensation); and

- other civil and political protection issues (e.g. the rights to personal documentation and to political participation).

\subsection{The Guiding Principles on Internal Displacement: Overview}

\begin{tabular}{|c|c|}
\hline Section & Key points \\
\hline Introduction & $\begin{array}{l}\text { - Provides a definition of IDPs. } \\
\text { international humanitarian law. } \\
\text { - Explains the purpose of the Principles, namely to provide guidance in } \\
\text { situations of displacement. }\end{array}$ \\
\hline $\begin{array}{l}\text { I. General } \\
\text { Principles } \\
\text { (Principles 1-4) }\end{array}$ & $\begin{array}{l}\text { - National authorities have the primary responsibility to protect and assist } \\
\text { IDPs within their jurisdiction. } \\
\text { - IDPs are entitled to enjoy in full equality the same rights and freedoms as } \\
\text { other persons in their country and shall not be discriminated against. } \\
\text { Certain IDPs, especially unaccompanied minors, expectant mothers, } \\
\text { mothers with young children, female heads-of-households, persons with } \\
\text { disabilities and older persons, might require specific attention. }\end{array}$ \\
\hline $\begin{array}{l}\text { II. Protection } \\
\text { from Arbitrary } \\
\text { Displacement } \\
\text { (Principles 5-9) }\end{array}$ & $\begin{array}{l}\text { - Articulates a right not to be arbitrarily (unlawfully) displaced and spells out } \\
\text { the situations in which displacement is absolutely prohibited. } \\
\text { - States have a duty to avoid the displacement of populations unless } \\
\text { absolutely necessary and to protect against the displacement of groups } \\
\text { with a special dependency on their lands. } \\
\text { When displacement is unavoidable, certain guarantees must be } \\
\text { established for displacement to be lawful. }\end{array}$ \\
\hline $\begin{array}{l}\text { III. Protection and } \\
\text { Assistance } \\
\text { during } \\
\text { Displacement } \\
\text { (Principles 10-23) }\end{array}$ & $\begin{array}{l}\text { All persons, including IDPs, should enjoy, a broad range of civil, political, } \\
\text { economic, social and cultural rights, including the rights: } \\
\text { - to life and to protection against acts of violence and torture, sexual and } \\
\text { gender-based violence, landmines, and recruitment of children into armed } \\
\text { forces or groups and their participation in hostilities; } \\
\text { - to safe access to essential food, potable water, basic shelter, appropriate } \\
\text { clothing, medical services and sanitation; } \\
\text { - to freedom of movement, including in and out of IDP camps; } \\
\text { to seek asylum in another country; } \\
\text { to personal documentation; } \\
\text { to respect for family life and unity; } \\
\text { to education and training, equally for women and girls; } \\
\text { to employment and participation in economic activities; } \\
\text { to vote and participate in government and public affairs. }\end{array}$ \\
\hline
\end{tabular}




\begin{tabular}{l|l}
\hline $\begin{array}{l}\text { IV. Access to } \\
\text { Humanitarian }\end{array}$ & $\begin{array}{l}\text { When State authorities are unable or unwilling to provide assistance to the } \\
\text { displaced, international organizations have the right to offer their services } \\
\text { (Principles 24-27) }\end{array}$ \\
$\begin{array}{ll}\text { and to enjoy rapid and unimpeded access to the displaced. } \\
\text { - Humanitarian assistance shall be provided consistent with the principles of } \\
\text { humanity and impartiality and without discrimination. }\end{array}$ \\
$\begin{array}{l}\text { - Humanitarian actors should take into account and work to address both the } \\
\text { assistance and the protection concerns of IDPs. }\end{array}$ \\
$\begin{array}{l}\text { V. Durable } \\
\text { Solutions }\end{array}$ & $\begin{array}{l}\text { IDPs should have access to a durable solution to displacement, which would } \\
\text { include the rights to: } \\
\text { - return to their place of origin, integrate locally at the displacement site, or } \\
\text { resettle elsewhere in the country voluntarily, safely and in dignity; }\end{array}$ \\
& $\begin{array}{l}\text { - participate in the planning associated with their return or settlement and } \\
\text { reintegration; } \\
\text { - return of lost property or, where not possible, compensation; and } \\
\text { - equal access to public services. }\end{array}$ \\
\hline
\end{tabular}

\subsection{The Guiding Principles as a protection tool}

The Guiding Principles are more than a simple compilation and restatement of legal rules. They provide a comprehensive framework for identifying protection concerns and for planning, implementing and monitoring protection activities in situations of internal displacement. They can be used by governments, international agencies, NGOs and IDPs themselves to promote and protect the rights of IDPs.

In our work, we can...

The Guiding Principles on Internal Displacement can be used to support our work in a number of ways, helping us to:

- assess and monitor the extent to which IDPs are able to enjoy their rights and identify what protection risks they face;

- inform IDPs of their rights and empower them to claim respect for their rights;

- collect data using a systematic frame of reference to identify and gather information about protection concerns, causes of displacement, and groups with particular vulnerabilities;

- develop strategies and determine programming priorities for a coordinated national and international response to internal displacement;

- raise awareness of, and advocate with, national authorities and other actors for respect for the rights of IDPs;

- provide training for displaced individuals and communities, national authorities, including the military and the police, non-State actors where relevant, civil society and human rights, humanitarian, development and peacekeeping staff;

- build the capacity of States and other authorities to support them in fulfiling their protection responsibilities (through, for example, training, technical assistance and advisory services);

- offer advice on national law, policy or action plans relating to IDPs to ensure respect for the rights of IDPs is ensured in them (as explored further in the section below on the national legal framework). 
In addition to the Guiding Principles on Internal Displacement, other principles and guidelines that address potential protection issues and certain types of internal displacement, include the following:

- Principles on Housing and Property Restitution for Refugees and Displaced Persons (2005);

- Basic Principles and Guidelines for Development-based Evictions and Displacement (1997) and Comprehensive Human Rights Guidelines on Development-based Displacement (2006);

- Protecting Persons Affected by Natural Disasters: IASC Operational Guidelines on Human Rights and Natural Disasters (2006); and

- Paris Principles: Principles and Guidelines on Children Associated with Armed Forces or Armed Groups (2007).

\section{The national legal framework}

National laws form the primary legal basis for IDP protection activities. However, all States have a responsibility to ensure that their national laws and policies respect and reflect their obligations under international law, including those contained in international human rights and humanitarian law. States, therefore, must take action, by all appropriate means, to give effect to their international legal obligations at the national level.

More specifically, national legislative and policy frameworks should respect the rights and guarantees to which IDPs are entitled under international law, and they should be consistent with the State's international legal obligations. Protection strategies and activities should also take into account relevant traditional, customary, or religious dispute resolution mechanisms at the national level (as discussed in more detail in Part IV.18 [D).

\subsection{National legislation on internal displacement}

States are generally encouraged to strengthen the legal frameworks for the protection of IDPs and to promote the Guiding Principles on Internal Displacement through national legislation. ${ }^{25}$ This does not mean that it is necessary or even appropriate in all contexts to adopt IDP-specific legislation. IDPs are citizens or habitual residents of the country in which they live and, as such, are entitled to the same rights and freedoms as other persons in the country.

However, internal displacement can create specific problems and obstacles for IDPs and, thus, action may be required to ensure that they can exercise their rights on a full and equal basis with others.

Two distinct types of national legislation should be considered in any given situation of internal displacement:

- Generally applicable norms and laws, which, although they will probably not explicitly address internal displacement, nonetheless relate to issues affecting IDPs. The hierarchy of legal norms of the country should be considered, as judges and courts will normally ensure compliance with the highest norms. The highest legal norm in domestic legal systems is traditionally the constitution of the country. Rights relevant to the protection of IDPs can be found in most constitutions. Laws and other regulations need to be compatible with the constitution and can include administrative provisions determining how individuals can regain lost personal documents, property laws setting

${ }^{25}$ United Nations Economic and Social Council (ECOSOC) Resolution 2003/5, 15 July 2003, para. 8; In Larger Freedom, Report of the Secretary-General, 21 March 2005, A/59/2005, para. 210. Regional organizations have similarly encouraged States in this regard. 
out rules and procedures for claiming compensation, electoral codes determining voter eligibility criteria, and education laws defining admissibility criteria and languages of instruction. Decisions or rulings of courts on displacement can also play a role in setting the legal framework or in interpreting legal provisions relating to the rights of IDPs.

- Laws specifically focused on addressing situations of internal displacement ${ }^{26}$

Laws specific to the situations of internal displacement could take a number of forms. In some instances, governments have adopted laws on a specific phase of displacement outlining for instance, the minimum standards to be observed during the return or resettlement and reintegration processes. In other cases, governments have adopted comprehensive national laws on internal displacement covering all phases of displacement, from prevention to solutions, and all causes of displacement, including conflict and disasters.

Any specific legislation on internal displacement must have as its aim and effect to ensure that IDPs enjoy their rights equally with other citizens or habitual residents of the country. Caution must be exercised to ensure that the consequence of an IDP-specific law is not to isolate IDPs as a separate legal category which, in extreme cases, might lead to their marginalization from the rest of the community and even the violation of their rights.

Whether IDP-specific legislation would be necessary to ensure the protection of IDPs' rights will depend on the context. In many cases, modification of existing legislation might well be sufficient to address the particular protection concerns that arise in situations of internal displacement. Indeed, even when there is IDP-specific legislation, amendments to general legislation often will be essential. For instance, to address the particular obstacles that IDPs face in enjoying their rights to property, documentation, education or political participation, simply affirming these rights in an IDP law usually will not be sufficient; rather, it will be necessary to amend the relevant piece of general national legislation (e.g. civil status legislation, education act or electoral code) to remove the legislative impediments that IDPs face or to establish simplified procedures.

It, therefore, is important to review and analyse national legislation in terms of its compatibility with international legal standards and, on this basis, to identify any legislative reform needed to ensure respect for the rights of IDPs. In some countries, local lawyers' groups have conducted studies of national legislation and then worked with the governments to revise national laws so that they conform to the Guiding Principles and the international standards that underpin them. ${ }^{27}$ Indeed, national laws and policies are most effective when developed in consultation with civil society, including IDPs themselves.

To assist such efforts, the Representative of the United Nations Secretary-General on the Human Rights of Internally Displaced Persons has developed Protecting Internally Displaced Persons: a Manual for Law and Policy Makers providing guidance on key elements to consider in national legislation to ensure protection of the rights of IDPs. This document is available in the annexes of the electronic version of this Handbook and also on the CD-rom.

International humanitarian and protection agencies can also help States ensure that their national laws and policies conform to international standards by providing technical assistance and advice.

\footnotetext{
${ }^{26}$ A number of countries have adopted national legislation specifically relating to internal displacement, including Angola, Bosnia and Herzegovina, Colombia, Georgia, Peru, Russia, and Turkey. These are available from the Database on National and Regional Laws and Policies on Internal Displacement at: www.brookings.edu/projects/idp/Laws-and-Policies/idp_policies_index.aspx.

${ }^{27}$ See American Society of International Law and the Brookings Institution Project on Internal Displacement, The Guiding Principles on Internal Displacement and the Laws of the South Caucasus, Studies in Transnational Legal Policy, no. 34, Cohen, R., Kälin, W., and Mooney, E., (eds.), 2003.
} 
In our work, we can ...

It is important to understand the national legal framework and its relevance to the protection of the rights of IDPs. In particular, we should:

- be aware of the national laws and policies, and the jurisprudence of national courts that relate to internal displacement and to the issues of concern to IDPs;

- understand the extent to which these policies are consistent with the State's obligations under international law and are in accordance with the Guiding Principles on Internal Displacement,

- offer advice, as appropriate, to the government in strengthening national laws to ensure that IDPs do not face any legislative barriers to realizing their rights;

- raise awareness among IDPs of those national laws and policies relevant to their protection, empowering them to advocate and claim their rights;

- advocate for, and monitor the implementation of, national laws and policies of particular relevance in situations of internal displacement;

- support the capacity of national authorities to implement national legislation and policies that would protect the rights of IDPs, including through training and awareness raising, technical assistance and advice, programme support and resource mobilization; and

- provide legal aid to assist IDPs in accessing legal mechanisms to protect their rights.

\subsection{Ensuring respect for rights under national law}

A number of different mechanisms for enforcing national laws and policies may exist within a State and could include formal (State-run) justice mechanisms, such as courts, tribunals and quasi-judicial mechanisms, or they could include alternative mechanisms, such as religious courts, tribal councils, or grievance committees. For more guidance about how to work within national legal systems to defend human rights and ensure accountability for crimes, violence, and abuse, please refer to Part IV.18 $\square$.

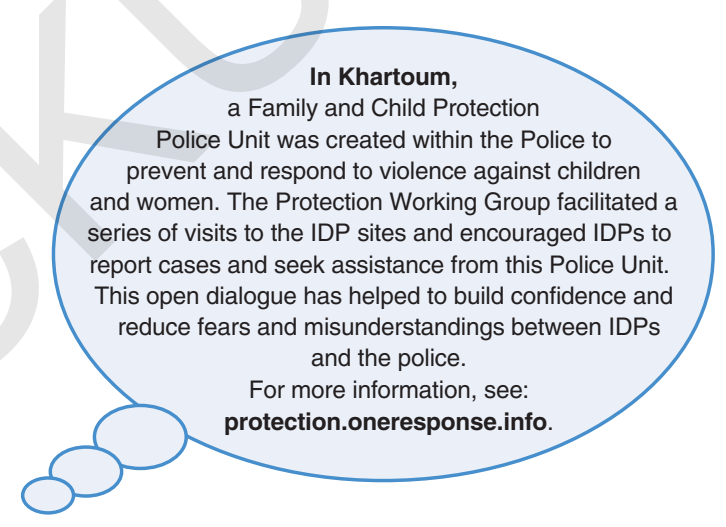




\section{Key references}

- Guiding Principles on Internal Displacement, UNHCR, 1998.

- Guiding Principles on Internal Displacement: Annotations, by Walter Kälin, Studies in Transnational Legal Policy No. 32, American Society of International Law, $2^{\text {nd }}$ edition 2008.

- Human Rights: A Basic Handbook for UN Staff, Office of the United Nations High Commissioner for Human Rights.

- Internally Displaced People, ICRC, January 2007.

- Protecting Internally Displaced Persons: A Manual for Law and Policy Makers, Brookings-Bern Project on Internal Displacement, 2008.

- Guide to International Human Rights Mechanisms for Internally Displaced Persons and Their Advocates, Brookings-Bern Project on Internal Displacement, 2006.

- Customary International Humanitarian Law, Volume I: Rules. ICRC, 2005.

\section{Useful websites}

- Compilation of International Human Rights Law www2.ohchr.org/english/law/index.htm\#core

- International Humanitarian Law Database www.icrc.org/ihl

n United Nations Treaty Body Database (Ratifications and Reservations) www.unhchr.ch/tbs/doc.nsf/Statusfrset?OpenFrameSet

- Universal Human Rights Index of United Nations Documents www.universalhumanrightsindex.org/

- Database on National and Regional Laws and Policies on Internal Displacement www.brookings.edu/projects/idp/Laws-and-Policies/idp_policies_index.aspx

- Websites of the United Nations Human Rights Bodies (Charter Bodies and Treaty-Monitoring Bodies)

www.ohchr.org/EN/HRBodies/Pages/HumanRightsBodies.aspx 


\section{Annex I}

\section{Regional human rights law and mechanisms relevant to IDPS}

Several regional human rights instruments that enhance human rights protection for all persons in the region, including IDPs, help reinforce international human rights law. In Africa, Latin America and Europe, the regional human rights framework is particularly important because rights can be enforced in regional human rights courts.

\section{In Africa}

The African Charter on Human and Peoples' Rights affirms the range of civil, political, economic, social and cultural rights, including the right of every individual to freedom of movement and choice of residence, and to the right to property.

The African Charter on the Rights and Welfare of the Child and the Protocol to the African Charter on Human and Peoples' Rights on the Rights of Women in Africa supplement the Charter's provisions for the protection of the rights of women and children.

Both instruments include specific provisions relating to State obligations to respect human rights in times of armed conflict, and they reiterate the responsibility of States to respect and ensure respect for international humanitarian law, including the protection of civilians. The African Charter on the Rights of the Child also affirms that no child under 18 years of age is to be recruited or, otherwise, to take direct part in hostilities, and it makes express reference to the need to protect and assist internally displaced children and to ensure family reunification in situations of displacement. The Protocol on the Rights of Women also includes commitments to:

- protect internally displaced women against all forms of violence, rape and sexual exploitation and ensure that perpetrators are brought to justice;

n ensure the increased participation of displaced persons, particularly women, in the management of camps and settlements; and

n devote attention to widows' property rights, which is key for women heads-of-households whose numbers tend to increase dramatically during displacement.

The African Commission on Human and Peoples' Rights monitors the implementation of States' commitments under the African Charter. In a landmark decision on forced evictions in Nigeria in October 2001, this Commission found that the African Charter on Human and Peoples' Rights guarantees the right to adequate housing, including a prohibition on forced eviction. However, this important decision has not yet been reflected in the jurisprudence throughout the continent or in governmental practices.

Individuals, including IDPs, can submit individual complaints of rights violations to the Commission for consideration by the African Court on Human and Peoples' Rights.

The Commission also has a Special Rapporteur on Refugees, Asylum seekers and Displaced Persons in Africa who is mandated to: seek, receive, examine and act upon information concerning the rights of refugees, asylum-seekers and IDPs; undertake fact-finding missions to displacement situations; engage in dialogue with States and others relevant actors; develop strategies to better protect the rights of these groups; and raise awareness of the legal standards for their protection.

The African Union (formerly the Organization of African Unity) also adopted a regional Convention for the Protection and Assistance of Internally Displaced Persons on the 22 October 2009. 
At the sub-regional level, there are instruments specifically relating to internal displacement, including:

- Great Lakes Protocol on the Protection and Assistance to Internally Displaced Persons and Model Law (2006), the Protocol on the Property Rights of Returning Persons (2006), and the Protocol on the Prevention and Suppression of Sexual Violence against Women and Children (2006) which are legally binding on countries that have ratified them; and

- the non-binding Khartoum Declaration of the Inter-Governmental Authority on Development (IGAD) Ministerial Conference on Internal Displacement (2003) which contains important commitments by States in East Africa to protect the rights of IDPs.

\section{In the Americas}

The Organization of American States (OAS), composed of the governments of Latin America, the Caribbean, and North America, has adopted a number of human rights instruments, most notably the American Convention on Human Rights (1969).

The Inter-American Commission on Human Rights and, for judicial issues, the Inter-American Court of Human Rights monitor the implementation of the American Convention.

- The Commission, composed of independent human rights experts, has been active in monitoring and reporting on situations of internal displacement and making recommendations to governments for more effective national responses. Spearheading these efforts has been a Special Rapporteur on Internally Displaced Persons (1996-2004). IDPs can submit complaints of human rights violations directly to the Commission for referral to the Court.

- The Court has increasingly considered cases and issued decisions, which are binding on the State concerned, on issues relating to internal displacement. In two particularly important cases in 2005, concerning IDPs in Colombia, the Court concluded that arbitrary displacement violates Article 22 of the American Convention (concerning the right to freedom of movement) and also insisted that governments must protect persons from displacement.

The OAS has called on all States in the region to address the causes of displacement and, if displacement occurs, to commit to providing IDPs with protection and assistance in accordance with the Guiding Principles on Internal Displacement (OAS Resolution 2229 of 2006).

\section{In Europe}

The Council of Europe has adopted several human rights instruments, most notably the European Convention for the Protection of Human Rights and Fundamental Freedoms (1950) and its 14 Protocols, which contain important provisions relevant to IDPs, including the right to property.

The Council of Europe recommends that States confronted with internal displacement base their national legislation and practice on the Guiding Principles on Internal Displacement in addition to all relevant instruments of human rights and international humanitarian law. These Principles explain how the European Convention on Human Rights can be applied to the specific needs faced by IDPs, including safeguarding the civilian nature of camps, facilitating family reunification, and providing protection from forcible return to an area where the physical safety of IDPs would be at risk. The Council of Europe has specifically affirmed the rights of IDPs to replacement documentation, compensation for deprivation of property, education, and 
Part I.2 - The legal framework

political participation. See Recommendation 6 on Internally Displaced Persons adopted by the Committee Ministers on 5 April 2006.

The European Court of Human Rights reviews cases of alleged violations of the Convention and its protocols. IDPs can bring cases directly to the European Court for consideration. In recent years, the Court has issued a number of important binding judgements relating to rights violations suffered by IDPs, particularly regarding the right to property, and awarded victims of such violations financial compensation.

Also relevant are the "human dimension" commitments adopted by the Organization for Security and Cooperation in Europe (OSCE), comprising 56 States across Europe including all the successor States of the former Soviet Union, Canada and the United States. Although not binding, these commitments reinforce and promote international human rights. The OSCE's Office for Democratic Institution and Human Rights (ODIHR) and its High Commissioner for National Minorities both undertake work relevant to IDP protection.

International Humanitarian Law Database (http://www.icrc.org/ihl)

41 
Part I.2 - The legal framework

political participation. See Recommendation 6 on Internally Displaced Persons adopted by the Committee Ministers on 5 April 2006.

The European Court of Human Rights reviews cases of alleged violations of the Convention and its protocols. IDPs can bring cases directly to the European Court for consideration. In recent years, the Court has issued a number of important binding judgements relating to rights violations suffered by IDPs, particularly regarding the right to property, and awarded victims of such violations financial compensation.

Also relevant are the "human dimension" commitments adopted by the Organization for Security and Cooperation in Europe (OSCE), comprising 56 States across Europe including all the successor States of the former Soviet Union, Canada and the United States. Although not binding, these commitments reinforce and promote international human rights. The OSCE's Office for Democratic Institution and Human Rights (ODIHR) and its High Commissioner for National Minorities both undertake work relevant to IDP protection.

International Humanitarian Law Database (http://www.icrc.org/ihl)

41 
Part I.2 - The legal framework

political participation. See Recommendation 6 on Internally Displaced Persons adopted by the Committee Ministers on 5 April 2006.

The European Court of Human Rights reviews cases of alleged violations of the Convention and its protocols. IDPs can bring cases directly to the European Court for consideration. In recent years, the Court has issued a number of important binding judgements relating to rights violations suffered by IDPs, particularly regarding the right to property, and awarded victims of such violations financial compensation.

Also relevant are the "human dimension" commitments adopted by the Organization for Security and Cooperation in Europe (OSCE), comprising 56 States across Europe including all the successor States of the former Soviet Union, Canada and the United States. Although not binding, these commitments reinforce and promote international human rights. The OSCE's Office for Democratic Institution and Human Rights (ODIHR) and its High Commissioner for National Minorities both undertake work relevant to IDP protection.

International Humanitarian Law Database (http://www.icrc.org/ihl)

41 
Part I.2 - The legal framework

political participation. See Recommendation 6 on Internally Displaced Persons adopted by the Committee Ministers on 5 April 2006.

The European Court of Human Rights reviews cases of alleged violations of the Convention and its protocols. IDPs can bring cases directly to the European Court for consideration. In recent years, the Court has issued a number of important binding judgements relating to rights violations suffered by IDPs, particularly regarding the right to property, and awarded victims of such violations financial compensation.

Also relevant are the "human dimension" commitments adopted by the Organization for Security and Cooperation in Europe (OSCE), comprising 56 States across Europe including all the successor States of the former Soviet Union, Canada and the United States. Although not binding, these commitments reinforce and promote international human rights. The OSCE's Office for Democratic Institution and Human Rights (ODIHR) and its High Commissioner for National Minorities both undertake work relevant to IDP protection.

International Humanitarian Law Database (http://www.icrc.org/ihl)

41 


\section{Part I.3}

\section{The international institutional framework}

Key message

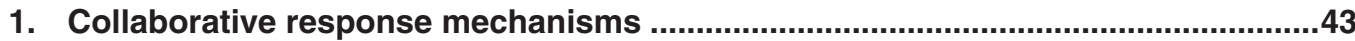

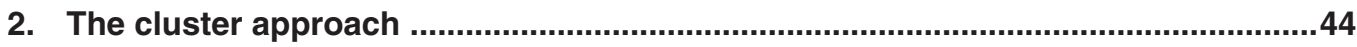

2.1 Global clusters and sectors of humanitarian response .......................................44

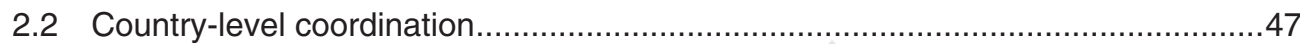

2.2.1 Role and responsibilities of country-level cluster/sector leads ......................48

2.2.2 Protection: a key area for country-level coordination..................................49

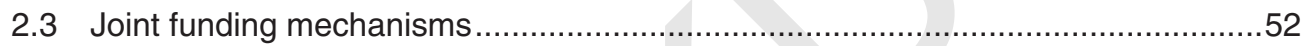

2.4 Protection staffing and standby arrangements ...............................................52

3. United Nations Peacekeeping Operations and Integrated Missions ......................53

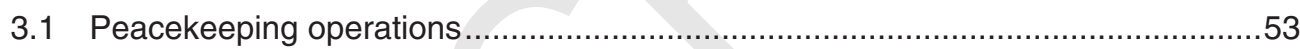

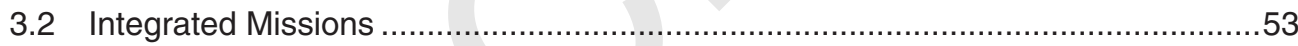

3.3 The role of peacekeeping operations in the protection of IDPs and

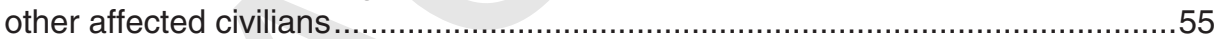

3.4 Working with peacekeeping missions: opportunities and challenges...................56

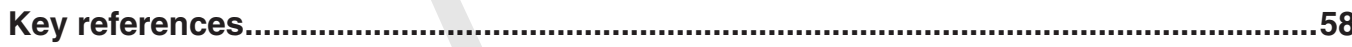

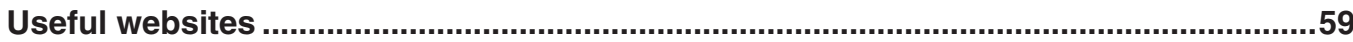

Annex I

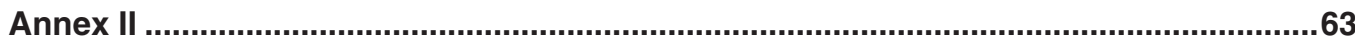

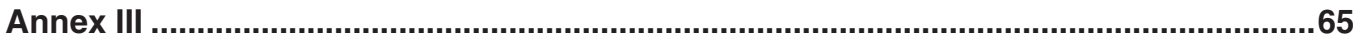




\section{Key message}

Providing protection and assistance to IDPs is first and foremost the responsibility of the State and its institutions. The international community has an important role to play when the national authorities lack the capacity, or are unwilling, to ensure an effective response to humanitarian crises. This requires a coordinated effort that can involve human rights and humanitarian, developmental, political, military and other actors. This chapter gives an overview of various elements of a collaborative response, the cluster approach, guiding humanitarian action at global and country levels. It also provides an overview of the integrated approach to multi-dimensional peacekeeping operations.

\section{Collaborative response mechanisms}

Internal displacement and humanitarian crises often occur in the context of complex emergencies, characterized by the partial or complete breakdown of State authority which affects its capacity and, in some cases, its willingness, to ensure the protection of civilians. Responding to such crises typically requires a multi-dimensional response - humanitarian, human rights, development, security, political - as well as the combined efforts of various actors at national and international levels.

The scale and scope of such crises exceed the mandate or capacity of a single agency or organization, and require action by a range of humanitarian, human rights and development actors, within and beyond the United Nations system. Activities in support of IDPs and other civilians at risk, thus, require a joint, collaborative, effort for which coordination mechanisms exist.

The Emergency Relief Coordinator (ERC), also the United Nations Under-SecretaryGeneral for Humanitarian Affairs, is responsible for the coordination of inter-agency humanitarian action, both in complex emergencies and in natural disasters. This function comprises advocating for protection and assistance, mobilizing political and financial support, briefing the Security Council, and engaging in dialogue with governments, humanitarian agencies, and other relevant actors.

The Inter-agency Standing Committee (IASC), chaired by the ERC, is the principal inter-agency forum for coordination and decision making on issues of humanitarian action. It brings together a broad range of United Nations humanitarian, human rights and development agencies, the International Organization for Migration (IOM), three consortia of major international NGOs, and the Representative of the United Nations Secretary-General on the Human Rights of Internally Displaced Persons. The International Committee of the Red Cross (ICRC) and the International Federation of Red Cross and Red Crescent Societies (IFRC) participate as observers.

The IASC develops humanitarian policies and tools, ${ }^{1}$ advocates for the respect of humanitarian principles, agrees on a division of responsibility for various humanitarian actions, and works to bridge any identified gaps in the overall response. 


\section{IASC policies and tools relevant to IDP protection include:}

- Protection of Internally Displaced Persons, Policy Paper (1999);

- Implementing the Collaborative Response to Situations of Internal Displacement: Guidance for United Nations Humanitarian and/or Resident Coordinators and Country Teams (2004);

- Growing the Sheltering Tree: Protecting Rights Through Humanitarian Action (2002);

- Gender Handbook for Humanitarian Action (2007);

- Operational Guidelines on Human Rights and Natural Disasters (2006); and

- Guidelines on Mental Health and Psycho-social Support in Emergency Settings (2007).

Publications are available in various languages.

A collaborative response requires teamwork that draws on the varying mandates, expertise and operational capacities of the wide range of actors involved, pooling their efforts to ensure a comprehensive and predictable response. ${ }^{2}$

In practice, however, this has presented a challenge, owing to the absence of clearly defined responsibilities and inconsistent coordination giving rise to a number of critical gaps, particularly regarding the protection of IDPs. ${ }^{3}$ To bridge these gaps, the IASC agreed to a comprehensive reform of the humanitarian response system in 2005, thus adopting the so-called "cluster approach" as described below.

\section{The cluster approach}

This approach aims to ensure greater leadership and accountability in key sectors where gaps in humanitarian response have been identified and to enhance partnerships among humanitarian, human rights and development actors, including the United Nations, NGOs and other organizations. It also calls for a more predictable, effective and accountable inter-agency response to ensuring protection and assistance for IDPs.

The collaborative response mechanisms and the cluster approach operate at both global (headquarters) and country-levels, and have come to be applied in all major natural disasters and complex emergencies.

\subsection{Global clusters and sectors of humanitarian response}

An overview of global clusters and sectors is found in Table 1 below. Protection is one of the areas of humanitarian activity identified as being in critical need of strengthened coordination and response.

The clusters complement the existing "sectors" of humanitarian activity - food and refugees for which clear leadership and accountability already existed The objectives of both sectors and clusters are the same: to fill gaps and ensure adequate preparedness and response in a given area of humanitarian activity.

Each cluster/sector is led by an international agency or organization with particular expertise in the area. This agency is accountable to the ERC for ensuring predictable and effective inter-agency preparedness and response in the area.

IASC, Implementing the Collaborative Response to Situations of Internal Displacement, September 2004.

Brookings-SAIS Project on Internal Displacement and OCHA, Protect or Neglect, 2004; and OCHA, Humanitarian Response Review, 2005.

4 IASC, Guidance Note on Using the Cluster Approach to Strengthen Humanitarian Response, November 2006. 
The cluster lead is also responsible for chairing and coordinating the work of the relevant global cluster working group, which brings together all other international actors involved. The cluster working groups are responsible for:

- setting and disseminating standards and policies, and identifying best practices;

- building response capacity, in particular through training at the local, national, and international levels, establishing and maintaining surge capacity and standby rosters, and establishing and maintaining material stockpiles; and

- providing operational support, including assessing needs in terms of human, financial and institutional response capacity, promoting emergency preparedness and long-term planning, securing access to relevant technical expertise, ensuring advocacy, mobilizing and pooling resources, and ensuring the complementarity of efforts through enhanced partnerships.

Table 1: Overview of global clusters and sectors

\begin{tabular}{|c|c|c|}
\hline & Area of activity & Lead agency \\
\hline \multicolumn{3}{|l|}{ CLUSTERS } \\
\hline \multirow[t]{6}{*}{ Cross-cutting areas } & \multirow[t]{3}{*}{ Protection } & UNHCR \\
\hline & & $\begin{array}{l}\text { UNHCR / OHCHR/ } \\
\text { UNICEF }^{5}\end{array}$ \\
\hline & & \\
\hline & \multirow{2}{*}{$\begin{array}{l}\text { Camp coordination and } \\
\text { management }\end{array}$} & UNHCR \\
\hline & & IOM \\
\hline & Early recovery & UNDP \\
\hline \multirow[t]{7}{*}{ Technical areas } & \multirow[t]{2}{*}{ Emergency shelter } & UNHCR \\
\hline & & IFRC $^{6}$ \\
\hline & Health & WHO \\
\hline & $\begin{array}{l}\text { Water, sanitation and } \\
\text { hygiene }\end{array}$ & UNICEF \\
\hline & Nutrition & UNICEF \\
\hline & Education & $\begin{array}{l}\text { UNICEF / Save the } \\
\text { Children }\end{array}$ \\
\hline & Agriculture & FAO \\
\hline \multirow[t]{2}{*}{ Common service areas } & Logistics & WFP \\
\hline & $\begin{array}{l}\text { Emergency } \\
\text { telecommunications }\end{array}$ & $\begin{array}{l}\text { OCHA / UNICEF / } \\
\text { WFP }\end{array}$ \\
\hline \multicolumn{3}{|l|}{ SECTORS } \\
\hline & Food & WFP \\
\hline & Refugees & UNHCR \\
\hline
\end{tabular}

5 While UNHCR leads the global protection cluster, the choice of lead agency in disaster situations or in complex emergencies without significant displacement, is made among UNHCR, OHCHR and UNICEF, under the leadership of the $\mathrm{HC} / \mathrm{RC}$. Further information on the cluster approach at the country level is provided in section 2.2 of this chapter.

6 IFRC convenes this cluster in disasters, providing leadership, consolidating best practices, mapping capacity and gaps, and leading a coordinated response. However, IFRC does not accept obligations beyond those defined in its constitutions and policies. It remains independent from, and not accountable to, the United Nations system. 
Human rights, age, gender, diversity, HIV/AIDS and the environment are cross-cutting issues (outlined in Table 2) that need to be mainstreamed into the work of each cluster/sector and of each agency or organization. Focal points guide and support these efforts.

Table 2: Cross-cutting Issues

\begin{tabular}{ll} 
Human rights & $\begin{array}{l}\text { Focal point } \\
\text { IASC Reference Group on Human Rights in Humanitarian } \\
\text { Action }\end{array}$ \\
\hline Age, gender and diversity $\mathrm{OHCHR}$ ) & $\begin{array}{l}\text { IASC Sub-Working Group on Gender and Humanitarian } \\
\text { Action (led by UNFPA) }\end{array}$ \\
\hline HIVIAIDS & Inter-agency Task-Team on HIV/AIDS (led by UNAIDS) \\
\hline Environment & United Nations Environment Programme (UNEP) \\
\hline
\end{tabular}

The Global Protection Cluster Working Group (PCWG) is the main forum for the coordination of protection activities in humanitarian action. It is chaired by UNHCR and includes United Nations humanitarian, human rights and development agencies as well as non-governmental and other international organizations active in protection. ${ }^{8}$

The Mission Statement and Terms of Reference for the Protection Cluster Working Group, issued in March 2007, defines the role of the PCWG as setting standards and policies on protection, identifying and disseminating good practices, and supporting the development of strengthened protection capacity.

The PCWG also provides, within the limits of its capacity, operational field support to humanitarian country teams, in both cluster and non-cluster countries, by:

- undertaking support missions to assist country teams in identifying protection gaps and developing strategies for response;

- providing guidance and support for mainstreaming human rights, age, gender and diversity, and HIVIAIDS;

- supporting advocacy on protection;

- providing technical support and policy advice on protection issues;

- strengthening the protection capacity of humanitarian actors and other stakeholders, including, national and local authorities, and affected populations, through training programmes;

- supporting efforts to address specific protection concerns in a given country; and

- participating in resource mobilization for protection activities.

Since protection covers a wide range of activities, the work of the PCWG is subdivided into specific areas of responsibility, each led by a focal point agency. These are listed below.

This Reference Group, which pre-dates the cluster approach, works closely with the Global Protection Cluster in supporting the integration of protection and human rights into all areas of humanitarian activity.

8 For further information on the participants and work of the PCWG, see http://www.humanitarianreform.org/. 
Table 3: Areas of protection activity

\begin{tabular}{ll}
\hline Area of responsibility under the global protection cluster & Focal Point(s) \\
\hline Rule of law and justice & UNDP / OHCHR \\
\hline Prevention of and response to gender-based violence & UNFPA / UNICEF \\
\hline Protection of children & UNICEF \\
\hline Mine action & UNMAS \\
\hline Land, housing and property rights & UN HABITAT \\
\hline
\end{tabular}

Protection is also a cross-cutting issue that should be integrated into the work of all humanitarian actors, in view of the shared responsibility to ensure that activities do not lead to or perpetuate discrimination, abuse, violence, neglect or exploitation but, rather, that they promote human rights and enhance protection.

The protection cluster thus has an oversight function to ensure that protection issues are effectively integrated into the work of other clusters and sectors. The following means can help achieve this objective:

- encouraging the cluster/sectors to establish focal points for protection;

- offering technical expertise and advice to other clusters/sectors, individual agencies, organizations and governmental counterparts;

- supporting and participating in joint assessments and analyses, development of joint strategies, monitoring exercises and evaluations;

- providing or supporting training on protection and human rights, with a special focus on internal displacement;

- participating in the meetings of other clusters/sectors and inviting their representatives to participate in the meetings of the protection cluster, as appropriate;

- convening joint meetings or workshops among different clusters/sectors on themes of common concern; and

- maintaining a regular dialogue and sharing information on issues of common concern.

\subsection{Country-level coordination}

The United Nations Humanitarian Coordinator $(\mathrm{HC})$ is responsible for ensuring the coordination of humanitarian action, including protection and assistance to IDPs, in complex emergencies at the country level. The $\mathrm{HC}$ is appointed by the $\mathrm{ERC}$, in consultation with the IASC. In a number of cases, the United Nations Resident Coordinator (RC), who is the most senior United Nations official in the country, is also designated as $\mathrm{HC}$. In countries affected by displacement, where an $\mathrm{HC}$ has not been appointed, the $\mathrm{RC}$ is responsible for ensuring an effective international response to internal displacement. ${ }^{9}$

The HC's responsibilities, as redefined by the IASC in 2009, include:

- ensuring that any protection gaps are addressed;

- promoting respect for human rights and humanitarian law and for the Guiding Principles on Internal Displacement;

- advocating with the national authorities and other actors for respect for humanitarian principles, including unimpeded access to affected populations;

- promoting gender mainstreaming and women's rights at the policy, planning and implementation levels; and 
- mobilizing resources for the humanitarian response. ${ }^{10}$

In carrying out these responsibilities, the $\mathrm{HC}$ and/or RC acts in consultation with organizations on the ground, including NGOs and the International Red Cross and Red Crescent Movement. An inter-agency humanitarian country team is often created to convene these actors and facilitate consultation and coordination.

Under the leadership of the $\mathrm{HC} / \mathrm{RC}$, and in consultation with relevant partners, this team decides on specific coordination arrangements to be put in place at the country level. According to the circumstances, it may choose to adopt the cluster approach as a means of strengthening collaboration. ${ }^{11}$

To enhance predictability and accountability, coordination structures at the field level should mirror those in place at the global level. This principle should be applied flexibly, however, depending upon the situation on the ground and taking into account the mandate, expertise and capacities of the organizations that are operating in the country or region concerned. In some cases, a particular cluster or sectoral group may not be necessary (an emergency telecommunications or logistics cluster may not be required, for example, beyond the early stages of major new emergencies), or it might be appropriate for certain sectors to be merged (such as health with nutrition, or food with agriculture). For early recovery, rather than establishing a country-level cluster, it is recommended that early recovery planning be integrated into the work of all field-level clusters/sectors, supported if necessary by the creation of an ad hoc "early recovery network."12

\subsubsection{Role and responsibilities of country-level cluster/sector leads}

At the field level, each cluster/sector lead agency is accountable to the HC/RC for ensuring effective and timely assessment and response in the particular area of activity. The responsibilities of the cluster/sector lead agency are outlined below. ${ }^{13}$

- Ensuring effective inter-agency coordination, including through: chairing and coordinating the work of the cluster; joint needs-assessments and analyses; contingency planning and preparedness; planning and strategy development; ensuring compliance with relevant international law, policies and standards; monitoring and reporting; advocacy; mobilizing resources; and supporting training and other capacity-building efforts.

- Coordinating with national and local authorities, state institutions, local civil

\section{Cluster coordinators}

Effective coordination requires an investment of time and experienced staff with solid leadership and managerial skills. The cluster lead agency has a responsibility to deploy personnel with the necessary seniority, skills and technical expertise to perform the role of a cluster coordinator. Many of the skills needed, particularly leadership, consensus-building and diplomacy are discussed in Part II. society and other relevant actors, including displaced and other affected communities.

- Ensuring that participatory and community-based approaches are used in all needs assessments, analyses, planning, monitoring and response.

10 IASC, Revised Terms of Reference for the Humanitarian Coordinator, 2009.

${ }^{11}$ Even if the cluster approach is not formally adopted in a given country operation, it is recommended that its basic principles, particularly the delineation of clusters/sectors, designation of an accountable lead agency, and the principle of partnership be applied. For this, country teams should be guided by IASC, Implementing the Collaborative Response to Situations of Internal Displacement: Guidance for United Nations Humanitarian and/or Resident Coordinators and Country Teams, 2004.

12 IASC, Guidance Note on Using the Cluster Approach, November 2006.

13 IASC, Generic terms of reference for sector/cluster leads at the country level, 24 November 2006, included in Annex I of this chapter 
- Ensuring that cross-cutting issues, such as age, gender, diversity, human rights, HIV/AIDS and the environment, are integrated and mainstreamed in all activities. This must include gender-sensitive programming that addresses the needs, contributions and capacities of women and girls as well as those of men and boys.

- Acting as both a "first point of call" for the HC and "provider of last resort" for the particular area of humanitarian activity. The lead agency is not expected to carry out all required activities in a cluster. However, where critical gaps exist, it is responsible for filling such gaps, provided that access, security and resources allow. If such constraints impede a response, the lead agency must work with the $\mathrm{HC}$ and relevant partners to mobilize resources, continue advocacy efforts and attempt to fill the gap to the extent possible. ${ }^{14}$

The cluster lead should also plan for, and ensure a timely and effective transition from, emergency relief to longer-term recovery and development, including by putting in place early recovery strategies and procedures for a gradual phasing out and seamless handover of activities.

The clusters are forums that bring together the various relevant humanitarian actors on the basis of an equal partnership. Participation in each cluster is based on each agency's or organization's mandate, expertise and operational capacity in the area of activity concerned. Participating agencies are expected to share actively in all aspects of the response in the area of humanitarian activity concerned, including assessments, development of strategies, implementation of joint projects and programmes, resource mobilization, and monitoring and evaluation. Agencies or organizations which are not members of the cluster may be invited to participate as observers in the interest of sharing information, as in the case of the ICRC and IFRC each of which is invited as observers to the protection cluster.

Any concerns about the way in which a lead or focal point agency carries out its responsibilities can be discussed within the cluster or brought to the attention of the HC/RC who can recommend alternative arrangements, if necessary. Should gaps still remain, the ERC can raise concerns at the global level in the IASC.

\subsubsection{Protection: a key area for country-level coordination}

Experience has shown that an effective, collaborative country-level response to protection needs, regardless of whether or not the cluster approach is applied, can best be ensured by identifying a protection focal point and by establishing a protection cluster or working group to ensure effective inter-agency coordination on protection issues.

\section{Step 1: Identifying a protection focal point/lead agency}

In complex emergencies, such as conflicts, UNHCR usually assumes primary responsibility for the protection of internally displaced and other affected populations, ${ }^{15}$ in keeping with its role as lead agency for the global protection cluster. ${ }^{16}$

In other situations, such as complex emergencies without significant displacement, or in situations relating to natural or human-made disasters, the protection-mandated agencies (OHCHR, UNHCR and UNICEF) and the HC/RC decide together which agency is best placed to assume the lead role for protection. In the event that none can assume the lead, all

14 Op.cit. IASC, Guidance Note on Using the Cluster Approach, November 2006.

${ }_{15}$ The PCWG has defined the term "affected populations" as including host communities where IDPs are living, host communities in IDP return areas, and persons or communities at risk of displacement if their protection issues are not addressed.

${ }^{16}$ Certain criteria also determine UNHCR's operational involvement. They include the consent of the State and UNHCR's ability to operate without undue political or military influence. It assumes the role of protection cluster lead only after it has determined that this will not undermine its mandated protection responsibilities. Should this risk exist, the protection-mandated agencies (UNHCR, OHCHR and UNICEF), in consultation with the HC/RC, will agree upon alternative arrangements. 
stakeholders are expected to contribute to the HC's/RC's capacity to coordinate the protection response ${ }^{17}$.

The country team should decide the extent to which the various focal points for specific protection areas, such as mine action or rule of law and justice, operating at the global level, should be replicated at the field level. This decision is likely to depend on the context and implies an assessment of protection risks and gaps (which may change over time) as well as the presence, expertise and operational capacity of the different focal point agencies.

\section{$\Rightarrow$ Step 2: Establishing a protection working group}

Establishing a protection working group (PWG) at the country level can be essential to ensure that protection receives focused attention and is effectively addressed in the collaborative humanitarian response. Regardless of the particular format for such a group, including whether it is formally designated as a cluster, PWGs should aim to bridge gaps, build partnerships, and improve the protection response through increased accountability, predictability and effectiveness.

Specific areas of activity of a PWG can include:

- conducting joint needs assessments and analyses that incorporate a participatory approach;

- forging consensus on common priorities for response;

- developing joint protection strategies and plans of action;

- mapping operational capacity, agreeing on geographic areas of responsibility when appropriate, identifying gaps, and mobilizing resources;

- adapting and applying inter-agency tools to support operational responses;

- raising awareness of the human rights situation and protection concerns;

- advocating with relevant stakeholders, such as parties to a conflict, State authorities, United Nations bodies, and donors;

- measuring the protection impact of the inter-agency response; and

- linking up with the Global Protection Cluster, as appropriate, regarding protection activities, impact, best practices, and challenges, to inform the global response and

- prompt efforts at the country level.

In general, a PWG should be established at least at the national level, tasked with overseeing and coordinating the country-wide protection response. In emergency situations spanning large geographical areas or where protection concerns differ significantly from one part of the country to another, PWGs may also be needed at the provincial or local level. Close coordination between the national PWG and any regional/local level PWGs is essential.

- A checklist on the establishment and basic modalities of a PWG is provided in Annex I/ of this chapter.

- Additional guidance on facilitating its effective functioning can be found in the Chapter on Facilitating Protection Coordination Meetings in Part // of this Handbook.

The national PWG should be chaired by the protection lead agency for the country. Ideally, this would also be the case for provincial or local PWGs. However, if the lead agency is not present in the area, this role can be delegated to other agencies or organizations, including NGOs that are present and have the required expertise and operational capacity to fulfil this role. In acute protection crises, coordinating and supporting the work of the country-level PWG might require a full-time staff with the necessary seniority, skills and expertise.

\footnotetext{
${ }^{7}$ For further predictability, Standard Operating Procedures for designating a protection sector/cluster lead agency in the event of a natural disaster at country level have been finalized by the Global Protection Cluster, and are pending IASC endorsement (forthcoming 2010).
} 
PWGs should bring together all relevant international human rights, humanitarian and developmental actors. Participation will vary in different contexts, depending on which protection actors are present and active on the ground. The nature of participation might vary with some actors choosing to serve as observers.

In situations where peacekeeping or peace support missions are present, particularly when they have a mandate to protect civilians, it can be useful to involve them as observers in the PWG. (See further in this chapter, Part I.3.3 $\square$ ) At the very least, the PWG should liaise closely with them.

The participation of national, regional or local authorities may also be advisable (as elaborated further in the box below).

\section{National authorities and PWGs}

National authorities bear the primary responsibility for the protection of all persons within their jurisdiction. In order to address root causes of protection concerns and ensure the sustainability of protection efforts, it is important to engage national authorities and to work to strengthen their capacity to fulfil their protection responsibilities.

\section{To what extent and how should government officials be included in the work of the PWG?}

In some cases, the participation of government representatives has proven beneficial to protection efforts, for instance by facilitating the PWG's access to populations. In other situations, such as when the government is involved in human rights violations, this would clearly not work; it might deter group members from discussing protection concerns, and it might prompt fears of retaliation.

Defining an appropriate relationship between the national authorities and the PWG requires reflection and discussion among PWG members. Some steps that may be involved in developing this relationship are noted below.

- Encouraging the national human rights commission, where one exists, to participate in the work of the PWG. Such commissions are officially established and recognized by the government, with varying degrees of independence and with membership that might include leading members of civil society. They can play a valuable protection role, and be an important partner and link for protection actors. In addition, national and local human rights NGOs should be actively involved in the work of the PWG when appropriate.

- Informing the national and regional/local authorities about the establishment of the PWG, and encouraging them to regard it as a resource to support an enhanced national protection response.

- Offering technical advice and support to national and local authorities, for instance through training programmes or in developing national laws and policies to enhance protection.

- Exchanging information on the PWG's activities and protection concerns in meetings with national authorities and other relevant actors.

- Establishing a regular forum, such as a protection liaison group, to facilitate dialogue and cooperation.

- Inviting relevant authorities to participate in specific meetings on protection issues of concern.

- Considering inviting the relevant authorities to participate regularly in, and possibly to co-chair, the PWG, when the authorities demonstrate an interest in contributing actively to the process.

In all cases, the PWG must ensure the confidentiality of information and maintain independence, neutrality, and impartiality in its work. Doing so is critical to the safety of IDPs and other affected populations and to the security of humanitarian personnel, particularly national staff. A primary concern should be the protection of witnesses and other affected persons. (See Part I.1.5 $\mathrm{Ld}$.) 


\subsection{Joint funding mechanisms}

During complex emergencies, the $\mathrm{HC} / \mathrm{RC}$ oversees an annual consolidated appeals process (CAP). This entails formulating a Common Humanitarian Action Plan (CHAP): a joint strategy analysing the political, social and security situation of the particular country or crisis; projecting short-term and long-term humanitarian needs; assessing the capacities of the agencies involved in addressing these needs; and proposing a common set of objectives, actions and indicators for success. A CAP, then, sets out the specific projects and resources required to meet these objectives. Together, these documents serve as the primary tool to mobilize resources at the field level, although agencies and organizations can also apply for bilateral funding. A shorter Flash Appeal can also be prepared to enable more rapid resource mobilization and response.

In addition, grants and/or loans are available from the Central Emergency Response Fund (CERF) to support activities to respond to rapid onset or under-funded emergencies. Managed by the ERC, the CERF is intended to complement existing funding mechanisms by providing seed funds to jump-start critical operations, and fund life-saving programmes that are not yet funded.

All appeals, as well as funding needs and contributions, can be accessed online through the Financial Tracking Service (FTS), hosted by OCHA. ${ }^{18}$

These common funding mechanisms are important channels to mobilize resources needed to enhance protection. To make effective use requires:

- familiarity with the CAP process, and shared efforts to ensure timely submission of protection programmes and projects for inclusion;

- consultation with other clusters/sectors to identify and develop projects that contribute directly or indirectly to enhanced protection, and assist in mainstreaming protection concerns into project submissions;

- possible requests, in the case of a rapidly evolving or under-funded emergency, for funding from the CERF for certain projects; and

- potential consideration of funding from the private sector.

\subsection{Protection staffing and standby arrangements}

Protection work requires adequate skilled, knowledgeable and experienced staff. Several stand-by arrangements provide "surge" protection capacity, deploying personnel at short notice for temporary assignments (three to 11 months) with United Nations agencies. Such arrangements include those with the International Rescue Committee (IRC), the Danish Refugee Council (DRC), the Norwegian Refugee Council (NRC), Save the Children (Denmark, Sweden, Norway), Canadem, RedR and ActionAid.

The Protection Capacity Project (ProCap) consists of a core team of Senior Protection Officers on permanent rotation to the field, deployed on a short-term basis (two to nine months) to support and strengthen the strategic and operational response of the Humanitarian Country Team and/or individual protection agencies. ${ }^{19}$

\footnotetext{
${ }^{18}$ Available at: http://ocha.unog.ch/fts2.

${ }^{19}$ Further information about ProCap and other protection stand-by arrangements is available at: http://ocha.unog.ch/ProCap/Online.
} 


\section{United Nations Peacekeeping Operations and Integrated Missions}

Peacekeeping operations have an important role to play in the protection of civilians, including displaced persons. These missions are often deployed in countries where large numbers of people have been displaced and civilians live in fear of violence, human rights violations and threats to their security. In the late 1990s, the United Nations Security Council began to focus attention on the protection of civilians, including the role of peacekeeping missions. Since then, numerous Security Council resolutions have addressed the protection of civilians, both generally and in specific country situations. ${ }^{20}$ International and regional peacekeeping operations have increasingly been tasked by the Security Council not only to contribute to the protection of civilians but also with specific roles in respect of displaced populations.

\subsection{Peacekeeping operations}

Since the end of the Cold War, United Nations peacekeeping operations have evolved from traditional, military tasks to more complex, multidimensional ventures, aimed at helping countries torn apart by conflict to build lasting peace. Beyond monitoring ceasefire agreements, assisting in the disarmament, demobilization and reintegration of former combatants, including seizure and disposal of arms or ensuring the security and protection of humanitarian personnel as well as their facilities and equipment, Peacekeeping missions increasingly engage in non-military tasks such as helping to build institutions for good governance, engaging in human rights monitoring and supporting reform of the security sector. ${ }^{21}$ The protection activities undertaken by peacekeeping operations depend upon the political context, the formal mandate of the mission, and the capacities and resources at its disposal. In a number of cases, human rights officers, gender and child-rights specialists are deployed to these missions to monitor and report on human rights concerns. Peacekeeping operations also often include a civilian police component to help restore law and order as well as justice and correction components to help national authorities strengthen their judicial, legal and corrective systems.

\subsection{Integrated missions}

Since 2000, the United Nations approach to complex operations in conflict and post-conflict countries has given increasing prominence to the concept of integrated missions. Such an approach brings together, under a single, comprehensive strategic framework, the various components (relating to political, military, human rights, gender issues, development, rule of law and humanitarian activities), of its engagement in a given country. The principle of integration has been applied to peacekeeping missions in Afghanistan, Burundi, Central African Republic/ Chad, Côte d'Ivoire, the Democratic Republic of Congo (DRC), East Timor, Haiti, Kosovo, Liberia and Sudan (and Darfur).

Integrated peacekeeping missions are not led by a military commander but by a Special Representative of the Secretary General (SRSG) who is the most senior United Nations official in a country and is responsible for ensuring that all the components of the United Nations presence pursue a coordinated and coherent approach, taking into account individual agency mandates.

In some countries, the position of Deputy Special Representative of the Secretary General (DSRSG) may be designated as a function that is combined with that of the United Nations Resident Coordinator (RC), responsible for development affairs, and the United Nations

\footnotetext{
20 Security Council Resolution 1265 (1999), Resolution 1296 (2000), and Resolution 1674 (2006).

${ }^{21}$ Further information on United Nations Peacekeeping is available at: http://www.un.org/Depts/dpko/dpko/.
} 
Humanitarian Coordinator $(\mathrm{HC})$, responsible for humanitarian affairs. ${ }^{22}$ The "triple hatted" DSRSG/RC/HC function reports directly to the SRSG, with the aim of bringing strategic coherence to the political, development, humanitarian, human rights and rule of law dimensions of a peace operation. ${ }^{23}$ Support for the Humanitarian Coordinator function may be provided by a separate OCHA office (the "one foot in, one foot out" model), or from within the mission itself (the "two feet in" model).

Recent approaches to integration have focused less on the issue of structural integration and more on enhancing the strategic coherence of United Nations operations. This includes a shared vision of the United Nations's strategic objectives and integrated planning, monitoring and evaluation capacities (as explored further in Annex III of this chapter [D). ${ }^{24}$ The emphasis has come to be placed on flexible, context specific arrangements at the country level rather than a unique institutional model. The new approach also emphasizes the importance of humanitarian principles and the protection of humanitarian space.

\section{Table 1: Setting Priority Objectives ${ }^{25}$}

One of the goals of an integrated United Nations mission is to identify strategic objectives in a conflict or post-conflict situation. The table below provides examples of how an Integrated Mission, in consultation with members of the Protection Cluster Working Group (PCWG) can set these objectives based on an analysis of conflict factors.

\begin{tabular}{ll}
$\begin{array}{l}\text { Conflict Factor } \\
\begin{array}{l}\text { Unequal participation in political representation } \\
\text { or access to power }\end{array}\end{array}$ & $\begin{array}{l}\text { Priority Objective } \\
\text { Support inclusive form of government as key } \\
\text { component of a negotiated settlement }\end{array}$ \\
\hline $\begin{array}{l}\text { Militarization of politics perpetuates violent } \\
\text { conflict and impedes peaceful resolution of } \\
\text { disputes }\end{array}$ & $\begin{array}{l}\text { Establish comprehensive process of } \\
\text { disarmament, demobilization and reintegration } \\
\text { of armed groups following a ceasefire }\end{array}$ \\
\hline $\begin{array}{l}\text { High level of impunity for sexual violence used } \\
\text { as a tactic of warfare or as a means of } \\
\text { destabilizing communities }\end{array}$ & $\begin{array}{l}\text { Develop security sector, justice and corrective } \\
\text { sector strategies to prevent sexual violence in } \\
\text { line with UN Security Council Resolutions } \\
1820,1888 \text { and } 1889\end{array}$ \\
\hline
\end{tabular}

Political and social inequality in access to economic and social rights fuels grievances and conflict

Massive population displacement resulting in increased instability and insecurity, serious protection problems, the need for humanitarian assistance and pressures on local services and resources

Weak civil society leading to lack of progress in local reconciliation and peace building efforts
Establish inclusive system of government; provide population with equal access to services and entitlements

Provide protection and assistance to displaced populations and seek durable solutions to their plight, namely safe and voluntary return, local integration or settlement elsewhere in the country

Support strengthening of civil society in conflict resolution and peace building efforts

${ }^{22}$ In some missions (such as in DRC and Liberia), there also may be a second DSRSG who is responsible for the rule of law.

${ }^{23}$ Roles and reporting lines are specified in the Note from the Secretary General: Guidance on Integrated Missions, February 2006,

www.undg.org/docs/8483/8039-SG_s_Note_of_Guidance_on_Integrated_Missions_Feb_2006.pdf.

${ }^{24}$ See Secretary General Policy Committee, Decision No. 2008/24 - Integration, 26 June 2008, www.undg.org/docs/9898/Integration-decision-SG-25-jun-08.pdf.

${ }^{25}$ See UN Strategic Assessment Guidelines, May 2009. 
Systematic human rights violations representing one of the root causes of the conflict
Monitoring and public reporting on the human rights situation in the country; support to the National Human Rights Institutions (NHRIs) and human rights civil society organizations and activists;

technical assistance to the government to improve compliance with international human rights standards

\subsection{The role of peacekeeping operations in the protection of IDPs and other affected civilians}

This role can take many forms as part of integrated, multi-dimensional operations. They can include the following: providing physical protection by means of patrols around IDP camps; improving the security conditions in which humanitarian assistance is provided; establishing humanitarian corridors; assisting in the safe, voluntary and sustainable return of refugees and IDPs; contributing to a secure environment for economic reconstruction and development; contributing to the promotion and respect of human rights, with particular attention to women, children and persons with special needs; monitoring and investigating human rights violations, reporting publicly on the human rights situation in the country and contributing to efforts to bring those responsible for serious human rights violations to justice; and assisting in strengthening the rule of law, the implementation of a transitional justice strategy and the development of a legal framework, in consultation with the relevant authorities. In addition, peacekeeping operations have been mandated to train the police, armed forces and non-State armed groups on human rights, international humanitarian law, IDP protection, child protection and the prevention of, and effective response to, sexual and gender-based violence.

\section{Peacekeeping missions with protection mandates}

Examples of peacekeeping missions with protection mandates include those of MONUC in the DRC, UNAMID in Darfur, UNMIS in Sudan, and UNMIL in Liberia. In all of these missions, as in more traditional military peacekeeping tasks, mandates have included the protection of displaced people and civilians at risk, and the facilitation of humanitarian assistance.

In the DRC, for example, the United Nations Security Council made the protection of civilians, humanitarian and United Nations personnel a top priority when it extended the mandate of MONUC in December $2009^{26}$. The renewed mandate tasks MONUC to use force to a) ensure the protection of civilians, including humanitarian personnel, under imminent threat of physical violence and b) contribute to the improvement of the security conditions in which humanitarian assistance is provided, and assist in the voluntary return of refugees and IDPs.

In Darfur, the joint African Union/United Nations operation, UNAMID, is mandated to "contribute to the protection of civilian populations under imminent threat of physical violence and prevent attacks against civilians ${ }^{27}$." This specifically includes the deployment of police units in areas where IDPs are concentrated and contribute to the creation of "necessary security conditions for the provision of humanitarian assistance and to facilitate the voluntary and sustainable return of refugees and internally displaced persons to their homes ${ }^{28}$."

${ }^{26} \mathrm{~S} / \mathrm{RES} / 1906$ (2009).

${ }^{27} \mathrm{~S} / 2007 / 307 / R e v .1$.

${ }^{28}$ Ibid. 
There are, however, obstacles to the implementation of protection mandates by peacekeeping missions. In particular, the need for greater clarity of mandates for protection against sexual violence, which have still not been fully implemented by peacekeeping operations, has been highlighted. ${ }^{29}$

A recent study on protecting civilians in the context of UN Peacekeeping Operations makes concrete recommendations on how to overcome these challenges through improved planning, policy and strategy development, training of mission staff, more clearly defined roles for police and military personnel and closer follow-up of the mission's aims by the Security Council. ${ }^{30}$

\subsection{Working with peacekeeping missions: opportunities and challenges}

Since many peacekeeping operations now have mandates to protect civilians and engage in a broad range of protection activities and, since they dispose of human, financial and military resources to achieve this goal, there are clear opportunities for human rights and humanitarian actors to engage with various elements of a peacekeeping mission. An effective interface can require putting in place liaison and information-sharing mechanisms. In some countries, civilian branches of peacekeeping missions have participated in the Protection Cluster or PWG; the protection team on the ground is best placed to determine which formula is the most appropriate in a given context.

Peacekeeping forces can work closely with humanitarian, protection and development actors to provide security, and their presence can prevent attacks by armed groups on IDPs and humanitarian actors. Peacekeeping missions and humanitarian actors can also cooperate in developing contingency plans for possible displacement, leading to the deployment of patrols to areas at risk of attack. Finally, humanitarian workers can provide training and guidance to peacekeeping forces on humanitarian and human rights principles. In the DRC, for example, the Protection Cluster and MONUC have developed a training booklet ${ }^{31}$ for peacekeepers with guidance on specific measures to protect civilians at risk.

Humanitarian action within the context of a peacekeeping mission can also present challenges for humanitarian workers. In situations where conflict is ongoing, maintaining a visibly distinct identity for humanitarian actors may be critical to retaining access to conflict-affected populations. Too close an association with peacekeeping actors may blur the lines between humanitarian and military action, constraining humanitarian space and potentially putting civilians and aid workers at greater risk. Humanitarian actors should engage constructively with peacekeeping missions to address these issues but endeavour to maintain a separate presence and identity from the political and military wings of a peacekeeping mission by, for example, carrying out distinct tasks with a separate coordination forum. In this respect, it is generally desirable that the $\mathrm{OCHA}$ office be located apart from the mission offices and that it remain separate from the mission structure and operations.

${ }^{29} \mathrm{UN}$, Report of the Secretary-General on the protection of civilians in armed conflict, 29 May 2009, S/2009/277.

30 Protecting Civilians in the Context of UN Peacekeeping Operations, Sucesses, Setbacks and Remaining Challenges, OCHA, DPKO, November 2009.

31 Protection Cluster DRC/MONUC, Protection in Practice, 2008. 
Below are some suggestions of ways in which human rights and humanitarian actors can overcome these challenges and engage constructively with peacekeeping missions to maximize the protection of IDPs and other civilians at risk.

\section{In our work, we can....}

- ensure that protection concerns are adequately addressed in the planning stages of peacekeeping operations and integrated missions by providing information and analysis on protection issues, including the specific protection risks affecting IDPs and other at-risk groups;

- establish procedures within the country Protection Cluster or PWG for the consolidation of any feedback or recommendations provided by members into the integrated mission planning process (IMPP), including the integrated strategic framework;

- provide training and guidance to peacekeeping forces on military-civil cooperation, humanitarian and human rights principles and practice (e.g. international human rights, humanitarian and refugee law; the Sphere Humanitarian Charter and Minimum Standards, the Guiding Principles on Internal Displacement) and the use of military assets in humanitarian operations (as discussed in Part II.2.8 $\square$ ) ;

- ensure that all United Nations peacekeeping and integrated mission staff as well as other United Nations and non-United Nations international staff are aware of, and receive training on, the Statement of Commitment on Eliminating Sexual Exploitation and Abuse by UN and Non-UN Personne ${ }^{22}$ and that an effective reporting and complaints mechanism for cases of sexual exploitation and abuse is established and addresses complaints in a timely manner;

- agree to effective modalities within the Protection Cluster or Protection Working Group for liaison and interface with peacekeeping missions, including the possibility to invite representatives from the civilian component of the mission to attend or have regular separate consultations with the Protection Cluster or PWG;

- use the Protection Cluster or PWG forum to alert peacekeepers to protection problems faced by civilians and to discuss possible solutions (e.g. deployment of patrols to prevent attacks on a village etc.);

- exchange analyses with relevant components of Peacekeeping Missions for the purpose of contingency planning and early warning signs analysis;

- establish, through the Protection Cluster or Protection Working Group, information-sharing protocols on protection and human rights issues with peacekeeping missions, in particular regarding human rights, the protection of civilians, rule of law, civilian police and peacekeeping, and develop procedures for discussing and analysing trends and patterns in human rights violations that may arise; and

- set up a system between peacekeepers, national authorities, and humanitarian actors to facilitate information sharing about gaps in essential services, as observed by peacekeepers during their regular patrols.

\footnotetext{
${ }^{32}$ The full text is available at: http://www.un.org/Depts/dpko/CDT/statement.pdf.
} 


\section{Ilin Key references}

\section{General Collaborative Response}

- Human Rights Guidance Note for Humanitarian Coordinators, IASC, June 2006.

- Humanitarian Response Review, OCHA, 2005.

- Implementing the Collaborative Response to Situations of Internal Displacement: Guidance for United Nations Humanitarian and/or Resident Coordinators and Country Teams, IASC, Sept. 2004.

- Protect or Neglect: Toward a More Effective United Nations Approach to the Protection of Internally Displaced Persons, OCHA/Brookings-SAIS Project on Internal Displacement, 2004.

- Protection of Internally Displaced Persons, IASC, Policy Paper, 1999.

- Revised terms of reference for the Humanitarian Coordinator, IASC, 2003.

\section{Cluster Approach}

- Cluster Working Group on Protection Progress Report, Annex 2: Responsibility-Sharing for the enhancement of protection in humanitarian emergencies, IASC Principals Meeting, 12 December 2005.

- Guidance Note on Using the Cluster Approach to Strengthen Humanitarian Response, IASC, 24 November 2006.

- Ibid. Annex 1, Generic Terms of Reference for Sector/Cluster Leads at the Country Level.

- Generic Terms of Reference for Cluster Coordinators at the Country level, IASC September 2006.

- Protection Cluster Working Group, Mission Statement and Terms of Reference, IASC, 21 March 2007.

- Operational Guidance on Designating Sector/Cluster Leads in Major New Emergencies. IASC Task Team on the Cluster Approach Geneva, 23 May 2007.

- Operational Guidance on the Responsibilities of Cluster/Sector Leads and OCHA in Information Management, endorsed by the IASC Working Group, 17 October 2007.

- Operational Guidance on the Concept of "Provider of Last Resort," endorsed by the IASC Working Group on 20 June 2008.

- Operational Guidance for Humanitarian Country Team, IASC, 18 November 2009.

- Principles of Partnership, endorsed by the Global Humanitarian Platform, July 2007.

- Questions and Answers on the Cluster Approach and Cluster Implementation Issues, OCHA, 2006.

\section{Protection of civilians}

- Protecting Civilians in the Context of UN Peacekeeping Operations, Successes, Setbacks and Remaining Challenges, OCHA, DPKO, November 2009.

- Improving the Safety of Civilians: A Protection Training Pack, Oxfam, 12 December 2008.

- Report of the Secretary-General on the protection of civilians in armed conflict, UN Doc S/2009/277, 29 May 2009. 


\section{United Nations Peacekeeping Operations}

- Civil-military Guidelines \& References for Complex Emergencies, UN/IASC, OCHA, New York, 2008.

- United Nations Civil-Military Coordination Officer Field Handbook, OCHA, March 2008.

- UNHCR and the Military: A Field Guide, UNHCR, 1 November 2006.

- Guidelines on the Use of Military and Civil Defence Assets to Support United Nations Humanitarian Activities in Complex Emergencies, OCHA, March 2003.

- Civil-Military Relationship in Complex Emergencies: An IASC Reference Paper, IASC, 28 June 2004.

- Use of Military or Armed Escorts for Humanitarian Convoys. Discussion Paper and Non-Binding Guidelines, IASC, 21 September 2001.

\section{Integrated Missions}

- Note from the Secretary General: Guidance on Integrated Missions, UN, February 2006.

- Decision No. 2008/24 - Integration, Secretary General Policy Committee, 26 June 2008.

- IMPP Guidelines: Role of the Headquarters Integrated Planning for UN Field Presences, May 2009.

- Strategic Assessment Guidelines, UN, May 2009.

- Humanitarian reform: fulfiling its promise?, Forced Migration Review, Issue No. 29, December 2007.

- United Nations Integrated Missions and Humanitarian Assistance, Oxfam International Policy Compendium Note, January 2008.

- Report on Integrated Missions: Practical Perspective and Recommendations, Independent study by UNDG-ECHA Core Group, May 2005.

\section{Useful websites}

n Global Protection Cluster Working Group (PCWG): www.protection.oneresponse.info

- Humanitarian Appeal: www.humanitarianappeal.net

- Central Emergency Response Fund: www.ochaonline2.un.org/Default.aspx $?$ tabid $=8770$

- Financial Tracking Service (FTS): www.ocha.unog.ch/fts2

- Protection Standby Capacity Project (ProCap): www.oneresponse.info/GlobalClusters/Protection/ProCap

- Oxfam International: www.oxfam.org/

- UNHCR: www.unhcr.org

n United Nations Peacekeeping: www.un.org/Depts/dpko/dpko/

- UN OCHA: www.ochaonline.un.org/

Peacekeeping Mission Mandates at:

- www.un.org/Depts/dpko/missions/monuc/mandate.html (MONUC)

n www.un.org/Depts/dpko/missions/unamid/mandate.html (UNAMID)

- www.un.org/Depts/dpko/missions/unmil/mandate.html (UNMIL) 


\section{Annex I}

\section{Generic Terms of Reference for Sector/Cluster Leads at the Country Level}

\section{IASC, November 2006}

The Cluster Approach operates at two levels. At the global level, the aim is to strengthen system-wide preparedness and technical capacity to respond to humanitarian emergencies by designating global Cluster Leads and ensuring that there is predictable leadership and accountability in all the main sectors or areas of activity. At the country level, the aim is to ensure a more coherent and effective response by mobilizing groups of agencies, organizations and NGOs to respond in a strategic manner across all key sectors or areas of activity, each sector having a clearly designated lead, as agreed by the Humanitarian Coordinator and the Humanitarian Country Team (to enhance predictability, where possible, this should be in keeping with the lead agency arrangements at the global level).

The Humanitarian Coordinator, with the support of OCHA, retains responsibility for ensuring the adequacy, coherence and effectiveness of the overall humanitarian response and is accountable to the Emergency Relief Coordinator.

Sector/cluster leads at the country level are accountable to the Humanitarian Coordinator for facilitating a process at the sectoral level aimed at ensuring:

\section{Inclusion of key humanitarian partners}

- Ensure inclusion of key humanitarian partners for the sector, respecting their respective mandates and programme priorities.

\section{Establishment and maintenance of appropriate humanitarian coordination mechanisms}

- Ensure appropriate coordination with all humanitarian partners, including national and international NGOs, the International Red Cross/Red Crescent Movement, IOM and other international organizations, through the establishment/maintenance of appropriate sectoral coordination mechanisms, including working groups at the national and, if necessary, local levels;

- Secure commitments from humanitarian partners in responding to needs and filling gaps, ensuring an appropriate distribution of responsibilities within the sectoral group, with clearly defined focal points for specific issues where necessary;

- Ensure the complementarity of different humanitarian actors' actions;

- Promote emergency-response actions while at the same time considering the need for early recovery planning and prevention and risk-reduction concerns;

- Ensure effective links with other sectoral groups;

- Ensure that sectoral coordination mechanisms are adapted over time to reflect the capacities of local actors and the engagement of development partners; and

- Represent the interests of the sectoral group in discussions with the Humanitarian Coordinator and other stakeholders on prioritization, resource mobilization and advocacy.

Coordination with national/local authorities, State institutions, local civil society and other relevant actors

- Ensure that humanitarian responses build on local capacities; and 
- Ensure appropriate links with national and local authorities, State institutions, local civil society and other relevant actors, such as peacekeeping forces, and ensure appropriate coordination and information exchange with them.

\section{Participatory and community-based approaches}

- Ensure utilization of participatory and community-based approaches in sectoral needs assessment, analysis, planning, monitoring and response.

\section{Attention to priority cross-cutting issues}

- Ensure integration of agreed priority cross-cutting issues, such as age, diversity, environment, gender, HIV/AIDS and human rights, into sectoral needs assessment, analysis, planning, monitoring and response; contribute to the development of appropriate strategies to address these issues; ensure gender-sensitive programming and promote gender equality; ensure that the needs, contributions and capacities of women and girls, as well as men and boys, are addressed.

\section{Needs assessment and analysis}

- Ensure effective and coherent sectoral needs-assessment and analysis, involving all relevant partners.

\section{Emergency preparedness}

- Ensure adequate contingency planning and preparedness for new emergencies.

\section{Planning and strategy development}

Ensure predictable action within the sectoral group for:

- Identifying gaps;

- Developing/updating agreed response strategies and action plans for the sector and ensuring that these are adequately reflected in overall country strategies, such as the Common Humanitarian Action Plan (CHAP);

- Drawing lessons learned from past activities and revising strategies accordingly; and

- Developing an exit, or transition, strategy for the sectoral group.

\section{Application of standards}

- Ensure that sectoral group participants are aware of relevant policy guidelines, technical standards and relevant commitments that the government has undertaken under international human rights law; and

- Ensure that responses are in line with existing policy guidance, technical standards, and relevant government human rights legal obligations.

\section{Monitoring and reporting}

- Ensure adequate monitoring mechanisms are in place to review the impact of the sectoral working group and progress against implementation plans; and

- Ensure adequate reporting and effective sharing of information, with OCHA support, with due regard for age and gender disaggregation.

\section{Advocacy and resource mobilization}

- Identify core advocacy concerns, including resource requirements, and develop messages for broader advocacy initiatives by the $\mathrm{HC}$ and other actors; and 
Advocate for donors to provide funding for humanitarian actors to carry out priority activities in the sector concerned, while at the same time encouraging sectoral group participants to mobilize resources for their activities through their usual channels.

\section{Training and capacity-building}

- Promote/support training of staff and capacity-building of humanitarian partners; and

- Support efforts to strengthen the capacity of the national authorities and civil society.

\section{Provision of assistance or services as a last resort}

- As agreed by the IASC Principals, sector leads are responsible for acting as the provider of last resort (subject to access, security and availability of funding) to meet agreed priority needs and will be supported by the $\mathrm{HC}$ and the ERC in their resource-mobilization efforts in this regard.

- This concept is to be applied in an appropriate and realistic manner for cross-cutting issues such as protection, early recovery and camp coordination.

Humanitarian actors who participate in the development of common humanitarian action plans are expected to be active partners in assessing needs, developing strategies and plans for the sector, and implementing agreed priority activities. Provisions should also be made in sectoral groups for those humanitarian actors who may wish to participate as observers, mainly for information-sharing purposes. 


\section{Annex II}

\section{Checklist: Establishing a Protection Working Group}

Establishing an inter-agency forum where protection issues are regularly discussed can be critical for ensuring that these concerns are addressed effectively, comprehensively and in a coordinated protection response. In any given situation, the specific shape that such a protection working group takes will depend upon an assessment of the context, taking into account any other protection coordination forums at the local, national or international level that already exist. When setting up such a forum, it is essential to consult with the Humanitarian Coordination and Country Team.

\section{Initial Phase: Establishing a Protection Working Group}

- Identify and assess any existing protection coordination arrangements and structures, international and national, ensuring that any protection working group that is to be established complements and coordinates with these mechanisms.

- Identify all relevant partners. These should include all human rights, humanitarian and development actors that form part of the United Nations and broader international inter-agency country team. It might also include national partners, both government and NGOs. (See below on Participation and the Box above on the relationship between national authorities and protection working groups.) Peacekeeping Missions can also be involved when it's relevant.

- Convene all relevant stakeholders within the country team to discuss and come to agreement on the following issues:

- Terms of reference: These should be based on the generic terms of reference for cluster/sector leads at country level (as seen in Annex I), adapted to the particular context and the common priorities of key protection actors. While information sharing might be among the aims, the role of the PWG must not be limited to this, but be strategic and action-oriented, focused on ensuring a coordinated and comprehensive protection response.

- Chairing arrangements: Various chairing arrangements are possible. Preferably, the cluster lead agency for protection will chair or at least co-chair with a partner agency/NGO. It might be decided to rotate responsibility for chairing periodically among the different participating agencies. However, overall responsibility and accountability for the work of the PWG rests with the lead agency.

- Coordination arrangements: These should mirror arrangements adopted at the global level, taking into account the local context and existing operational capacities. The establishment of task-forces, sub-working groups or focal points on specific issues might facilitate the work of the group. It is important to consider whether a country-level PWG will suffice or whether regional/local PWGs will also be required and, if so, to ensure that these different levels of PWGs coordinate effectively with one another.

- Participation: The PWG should be a broad-based inclusive forum for protection actors. All international agencies and NGOs that are engaged in protection should be invited, whether as participating agencies or as observers. The PWG should discuss and decide upon the participation of local NGOs/civil society and how the PWG will relate to national/local and other authorities.

- Meeting arrangements: How often the PWG will meet and who will take responsibility for convening meetings, drafting the agenda, recording meeting notes and action points for follow-up must be clearly agreed upon. It will usually be most practical for the lead agency and chair of the PWG to assume these functions. 


\section{Ongoing:}

- Meet regularly, at least monthly; in emergency contexts, meeting more frequently, even weekly, might be advisable; set clear agendas.

- Ensure that the discussion goes beyond information sharing and is action-oriented, resulting in agreed action points, with clearly defined responsibilities and timeframe for implementation.

- Follow up on agreed action points, revisiting these at subsequent meetings, particularly if implementation is outstanding.

- Maintain regular contact and close cooperation and coordination with any other PWGs established in the country (such as between the national PWG and any regional/local PWGs), sharing information on protection activities and concerns and developing, as appropriate, joint response strategies. Support and assistance may be sought from the global-level PCWG as needed.

- Ensure that the work of the PWG is in line with international standards, laws, policies and good practice, including the humanitarian principles of independence and impartiality, and that adequate safeguards are put in place to maintain the confidentiality of protection information that could put individuals at risk.

- Ensure that cross-cutting issues, including age, gender and diversity, HIV/AIDS, the environment and early recovery issues, are mainstreamed into the work of the PWG and into the activities of individual partners. 


\section{Annex III}

\section{Integrated missions planning process (IMPP)}

This procedure is used for planning purposes by new multi-dimensional peacekeeping missions. It also serves for the revision, transition or downsizing of existing missions. ${ }^{33}$ It involves the designation of an inter-agency headquarters-based integrated mission task force (IMTF), and field-based integrated mission planning teams (IMPT). IMTFs are usually led by the United Nations Department of Peacekeeping Operations (DPKO). Integrated Tasks Forces (ITFs) are led by the United Nations Department of Political Affairs (DPA). They include representatives from all relevant United Nations entities. Non-United Nations organizations, including NGOs, may also be asked to attend IMTF meetings on an ad hoc basis, to provide briefings on specific country situations. IMTFs are most active during the mission start-up period when they are responsible for analyses and field visits to help set up the mission.

A key responsibility of the IMTF is to conduct Strategic Assessments where the United Nations needs to formulate, or reformulate, its strategy for engagement in a political crisis, conflict or post-conflict situation. The Strategic Assessment provides concrete recommendations on how the United Nations can best respond to crisis, as recommended in the Strategic Assessment Guidelines issued by the United Nations in May 2009. The IMTF is also responsible for organizing technical assessment missions (TAMs) gathering information for use in preparing the Secretary General's report for discussion by the Security Council, with detailed recommendations for the mandate of a new peacekeeping mission, If the Security Council so decides.

An integrated field mission is responsible for setting up a field-based integrated mission planning team (IMPT), that carries out joint strategic analysis and planning, and develops an integrated strategic framework (ISF). ${ }^{34}$ The ISF identifies priority areas where the United Nations can make an impact in consolidating peace within a country, as well as a set of agreed timelines, responsibilities and division of labour for achieving these goals.

\footnotetext{
${ }^{33}$ United Nations, IMPP Guidelines: Role of the Headquarters Integrated Planning for UN Field Presences, approved by the UN Secretary General, May 2009.

34 UN Secretary-General Policy Committee, Decision No. 2008/24 - Integration, 26 June 2008.
} 


\section{Part I.4}

\section{National actors}

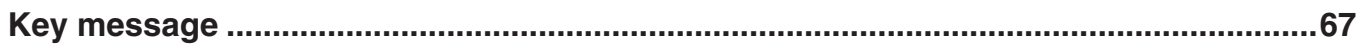

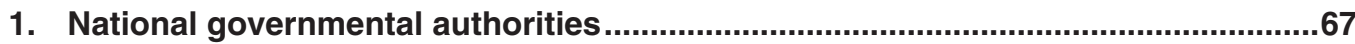

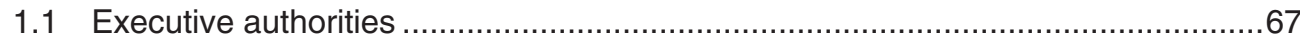

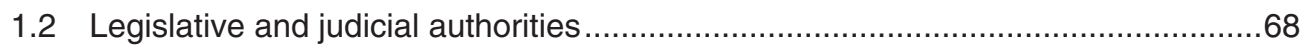

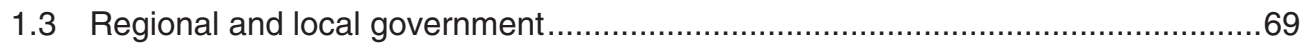

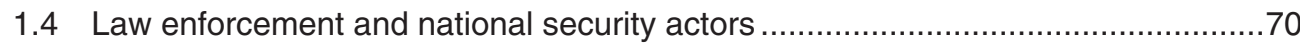

1.5 National human rights institutions ..................................................................

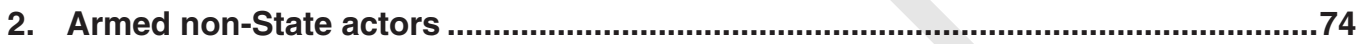

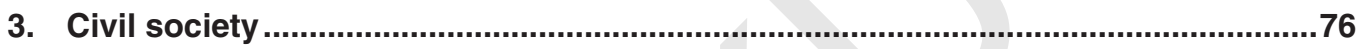

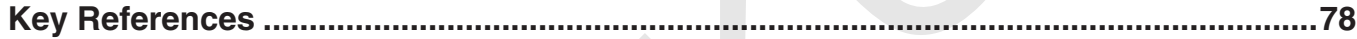

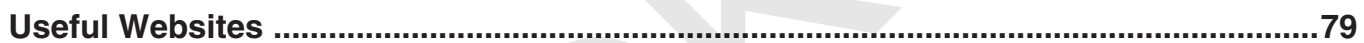




\section{Key message}

A broad range of State and non-State actors are involved in protecting and assisting IDPs. This chapter provides a brief introduction to their roles, highlighting opportunities for interaction and challenges to overcome, and also proposes a number of practical steps that can be taken. It contains cross references to other chapters, where more detailed information can be found as to the specific roles of national actors in IDP protection.

\section{National governmental authorities}

The Guiding Principles on Internal Displacement emphasize that the primary responsibility for protecting and assisting IDPs lies with national governments (Guiding Principle 3). It is, therefore, important to understand how this responsibility applies in order to ensure that IDPs can benefit from effective, appropriate and sustainable protection and assistance. It is also important to help national governments build their capacity to prevent and respond to situations of internal displacement, and to support them in early recovery efforts following humanitarian crises. ${ }^{1}$ The Framework for National Responsibility is a key document, which sets out 12 steps for governments to take (and also addressed further in Part I.1, and Part V.9 ㅁ. $)^{2}$ to ensure IDP protection assistance. It must also be recalled that the government itself may be a party to the conflict that causes internal displacement and, in that way, may be responsible for serious human rights violations against civilians and violations of international humanitarian law.

\subsection{Executive authorities}

Executive authorities have the primary responsibility for directing all protection and assistance activities on behalf of IDPs. This responsibility mainly involves preventing conditions that lead to internal displacement, protecting citizens and habitual residents of the country against arbitrary displacement, mitigating the adverse effects of displacement when it occurs, and ensuring that durable solutions are identified as soon as possible for those displaced.

Their responsibility implies collecting data on the number of IDPs, their location and living conditions (as outlined in Part V.1). This information is essential as a basis for effective policies and programmes and to alert the public, relevant authorities and the international community about the scale of the problem. In some cases, however, national governments may be unwilling to acknowledge the presence of IDPs in their territory, and data on IDPs may be disputed.

National executive authorities are also responsible for ensuring that an appropriate legal framework and national policy or strategy, in line with international standards, are in place to address internal displacement. In some cases, governments may adopt new legislation specifically on internal displacement. Amendments to existing legislation may be needed to ensure compatibility with the Guiding Principles on Internal Displacement and to address the particular protection concerns of IDPs, such as access to documentation and education (outlined further in Part I, Chapter 2 ㅁ] ).

To ensure a coherent, coordinated and sustained response to internal displacement at all levels, national executive authorities should designate a national focal point or lead agency for internal displacement, and allocate specific tasks to national and local government institutions and different government departments. It is the responsibility of national executive authorities to mobilize and allocate sufficient resources to address the needs of IDPs and to ensure that government staff (including the military and police) and policy makers at all levels are adequately trained on the rights of IDPs and the government's responsibility towards them.

Cluster Working Group on Early Recovery, Guidance note on Early Recovery, April 2008, www.oneresponse.info/protection.

Brookings-Bern Project on Internal Displacement, Addressing Internal Displacement: A Framework for National Responsibility, Erin Mooney, May 2005, http://www.brookings.edu/fp/projects/idp/20050401_nrframework.pdf. 
Finally, national executive authorities are responsible for identifying and implementing durable solutions for IDPs. This may involve establishing the conditions for IDPs to return voluntarily and in safety and dignity to their places of habitual residence or to settle in their place of displacement (local integration) or elsewhere in the country (as discussed further in Part VI $\mathrm{D}$ ). Securing durable solutions for IDPs also entails early recovery efforts to build a secure environment, restore livelihoods, prevent the recurrence of the crisis and create the conditions for future development.

When a government lacks sufficient financial and technical capacity to cope with a situation of internal displacement, it should invite or accept offers of international assistance. It is the responsibility of national executive authorities to cooperate with regional and international organizations offering assistance and protection to IDPs and not to regard such offers as "an unfriendly act or interference in a State's internal affairs." ${ }^{3}$ National authorities are also responsible for protecting humanitarian staff, preventing attacks on them, and prosecuting those responsible should such attacks occur. National authorities should facilitate free and unimpeded humanitarian access to IDP populations for international humanitarian organizations.

\subsection{Legislative and judicial authorities}

The legislative authority (national parliament), is responsible for reviewing and adopting legislation, approving the budget and generally overseeing the government's response to internal displacement. Judicial authorities (courts and tribunals) ensure that domestic, regional and international laws relating to IDPs are properly applied and those responsible for violating these laws are brought to justice (as explored further in Part IV.18 $\mathrm{DD}$ ). Specific tasks of the legislative and judicial authorities as regards IDPs include the following:

National Legislative Authorities
Review existing national legislation to ensure that it Investigate, prosecute, redress and
adequately addresses the protection needs of IDPs, is compensate for crimes and violations
non-discriminatory and is in line with the Guiding against IDPs
Principles on Internal Displacement and regional
instruments; as necessary enact amendments to existing
legislation and/or develop new legislation to address
IDPs issues

Ratify international and regional treaties relevant to the Ensure access to justice for individuals protection of IDPs (e.g. human rights, international and groups of IDPs who wish to bring humanitarian law, and international criminal law treaties, complaints against the national regional instruments such as the $A U$ Convention on the authorities and seek recourse if their Protection and Assistance of Internally Displaced Persons rights are violated in Africa, 2009)

Approve the budget for the implementation of IDP laws, Adjudicate claims for restitution or policies and strategies

compensation for property and possessions lost during displacement

Monitor and oversee the response of national Monitor the government's response to government to situations of internal displacement, situations of internal displacement, in including through site visits to IDP camps and particular to ensure that it is in settlements and establishing working groups or accordance with national law (including sub-committees on IDP issues the Constitution) and international law

Raise public awareness on internal displacement and the role of national authorities 


\subsection{Regional and local government}

Regional and local governmental authorities are likely to have closer contact with IDPs than the central government and, thus, a better understanding of the problems they face. While national policy decisions are made at the central level, the involvement of local government authorities is essential for the implementation and coordination of protection and assistance activities on the ground. They also play a critical role in allowing access to IDPs and other civilian populations at risk. Moreover, in decentralized States, or where national authorities lack sufficient capacity, provincial, regional or local government authorities may be the main interlocutor for humanitarian agencies. In some countries, where traditional leadership structures wield power, it may also be necessary to be in contact with their leaders as well as with local government officials.

\begin{tabular}{|c|c|}
\hline & In our work, we can ... \\
\hline Knowledge & $\begin{array}{l}\text { - understand the structure, composition, roles and activities of the different } \\
\text { branches and levels of government. }\end{array}$ \\
\hline $\begin{array}{l}\text { Capacity building } \\
\text { and funding } \\
\text { (See Part V.9 } \square \text { ) }\end{array}$ & $\begin{array}{l}\text { - help to build the capacity of national government actors to prevent and } \\
\text { respond to situations of internal displacement; } \\
\text { help to build the capacity of judicial and security sector authorities to } \\
\text { strengthen their ability to provide protection and justice for IDPs in line with } \\
\text { international human rights standards; and } \\
\text { provide sufficient and sustained (medium-term) funding to government } \\
\text { agencies to help ensure a sustainable response to IDP protection and } \\
\text { assistance. }\end{array}$ \\
\hline $\begin{array}{l}\text { Training } \\
\text { (See Part V.9 } \square \text { ) }\end{array}$ & $\begin{array}{l}\text { - provide training and guidance to government authorities on IDP rights and } \\
\text { the government's responsibility towards IDPs, including training on the } \\
\text { Guiding Principles on Internal Displacement and on the underpinning } \\
\text { human rights and international humanitarian law. }\end{array}$ \\
\hline $\begin{array}{l}\text { Information and } \\
\text { data collection }\end{array}$ & $\begin{array}{l}\text { provide governments with IDP profiling information (numbers and } \\
\text { conditions of IDPs), and possibly undertake joint needs assessments. }\end{array}$ \\
\hline $\begin{array}{l}\text { Technical } \\
\text { assistance }\end{array}$ & $\begin{array}{l}\text { provide technical assistance (e.g. on data collection, policy development, } \\
\text { legal analysis, standards for humanitarian assistance) to government } \\
\text { institutions. }\end{array}$ \\
\hline $\begin{array}{l}\text { Advocacy } \\
(\text { See Part V. } 3 \square \text { ) }\end{array}$ & $\begin{array}{l}\text { advocate with national authorities to adopt and implement laws, policies } \\
\text { and programmes to ensure the protection and assistance of IDPs; and } \\
\text { remind national authorities of their obligations towards IDPs when they are } \\
\text { failing to fulfil them. }\end{array}$ \\
\hline Coordination & $\begin{array}{l}\text { - coordinate with national authorities in the development and } \\
\text { implementation of programmes for IDPs; and } \\
\text { - support governments in their resource mobilization for programmes that } \\
\text { will protect and assist IDPs. }\end{array}$ \\
\hline $\begin{array}{l}\text { Legal assistance } \\
\text { (See Parts IV.18 } \\
\text { and V.8 } \square \text { ) }\end{array}$ & $\begin{array}{l}\text { - work with lawyers, paralegals, law students and NGOs to provide legal aid, } \\
\text { information, counselling and assistance to IDPs to help them access } \\
\text { courts and judicial procedures; and } \\
\text { - help establish and support witness protection schemes for IDPs. }\end{array}$ \\
\hline
\end{tabular}




\subsection{Law enforcement and national security actors}

The military and the police have an important role to play in ensuring a safe and secure environment for all civilians, including IDPs, as well as for humanitarian workers and the delivery of humanitarian assistance. It may also be the case, however, that these actors are themselves responsible for serious human rights abuses against civilians, including IDPs, and the military may be a party to the conflict and responsible for the forcible displacement of civilians.

The principal task of the police with regard to IDPs is to prevent and investigate all complaints of attacks, abuse and harassment of IDPs and security incidents against humanitarian workers, to work with the judicial authorities to bring the alleged perpetrators to justice, and to enforce penalties in cases of conviction and punishment. The police may set up posts in IDP camps or settlements and carry out regular patrols to help safeguard the physical security of IDPs. The police can also provide special protection to groups facing particular protection risks, such as women and girls and ethnic, religious or political minorities. This may entail setting up special police desks or task forces for at-risk groups, such as women and girls, or setting up special units to investigate particular crimes, such as incidents of domestic and/or sexual violence.

Humanitarian actors often have to interact and liaise with military actors, especially when working in situations of armed conflict and complex emergencies. The nature and scope of such interaction will depend on the circumstances. It can range from mere coexistence with civilian and military actors, to closer coordination to ensure the effectiveness of respective efforts. This may include the provision of logistical, technical or military support to humanitarian operations by military actors ${ }^{4}$ to secure the environment in order to facilitate safe and rapid humanitarian access or military support for the physical security of IDPs and affected populations in displacement or upon return. (See Part I.3 and Part II $\square$.)

\section{Challenges and constraints:}

When working with, or alongside, the military, it is important to maintain a clear distinction between humanitarian and military activities, in order to avoid undermining the independence, neutrality and impartiality of humanitarian action and placing persons of concern and humanitarian staff at risk (discussed further in Part II.2 $\square$ ). The presence of the military in IDP camps and settlements blurs the lines between combatants and non-combatants and represents an acute risk for civilians in times of conflict. IDPs may be seen as collaborators or sympathizers with one side to the conflict. The presence of the military in IDP settlements also hampers the independent delivery of humanitarian assistance, and humanitarian assistance may even be diverted by the military for their own use (explored further in Part II $\square d$ ). 


\begin{tabular}{l|l} 
Knowledge & In our work, we can ... \\
\hline gain an understanding about the structure, composition and roles of the \\
police and military.
\end{tabular}

\subsection{National human rights institutions}

National human rights institutions (NHRIs) may take the form of human rights commissions, ombudsmen, or specialized national institutions to protect a specific at-risk group. While these bodies receive their mandate and authority from governmental authorities (by an Act of Parliament, under the Constitution, or by decree), they should be independent. The Paris Principles, ${ }^{6}$ adopted by the General Assembly in 1993, set out the following six core criteria for the proper functioning of NHRIs: ${ }^{7}$

- independence guaranteed by statute or constitution;

- autonomy from government;

- pluralism including in membership;

5 Training on IHL should be done in close consultation with the ICRC.

6 Principles relating to the Status and Functioning of National Institutions for the Protection and Promotion of Human Rights (Paris Principles). See OHCHR, National Institutions for the Promotion and Protection of Human Rights, Fact Sheet No. 19, www.ohchr.org/Documents/Publications/FactSheet19en.pdf

7 The International Coordinating Committee of National Institutions for the Promotion and Protection of Human Rights (ICC) grades NHRIs according to their compliance with the Paris Principles. Those that comply with all six criteria are given an "A" status. 
- broad mandate based on universal human rights standards to both promote and protect all human rights at the national level;

- adequate resources which the State must provide; and

- a bridge between civil society and the government.

The unique position of NHRls gives them credibility and access to information not often available to government officials or to NGOs. Although they form part of State institutions they, nevertheless, can offer objective criticism of the government and other State actors, enjoying the status of "credible outsiders." As national institutions, they have a good understanding of the country, the social and political environments within which they operate, and key national actors. ${ }^{8}$

Depending on their mandates, NHRIs can play a number of important roles with regard to IDP protection. ${ }^{9}$ These include:

- monitoring the conditions of IDPs to ensure they do not face discrimination and can receive protection and assistance, and monitoring the return of IDPs and their settlement elsewhere in the country;

- monitoring and reporting on the government's implementation of national legislation and compliance with international treaty obligations;

- conducting inquiries into serious violations of IDPs' human rights;

- following up on early warnings of displacement and ensuring that the government takes effective measures to protect populations against arbitrary displacement;

- receiving individual complaints from IDPs or organizations about violations of IDP's human rights;

- working with national legislative bodies to develop new national laws on internal displacement, ensuring that existing national laws are in compliance with the Guiding Principles on Internal Displacement, and helping the government to frame policies and plans of action to address situations of internal displacement;

- conducting public awareness raising and training programmes, especially for State institutions, the military and law enforcement agencies on the rights of IDPs;

- launching public information campaigns for IDPs on their rights; and

- networking with civil society and NHRIs in other countries.

\section{Challenges and constraints:}

The effectiveness of NHRIs depends largely on their specific mandates, the degree to which they can operate independently from governments and whether they are adequately staffed and resourced. In some countries, NHRIs may be too closely aligned with the government and lack independence and credibility. Where NHRIs are actively engaged in monitoring and critiquing governments, this may cause resentment and retaliation, including a withdrawal of NHRIs' funding, the closing down of offices and the targeting of staff. IDPs may face difficulties in accessing NHRIs; they may, for instance, lack information or knowledge about their existence, or they may experience physical difficulties reaching the NHRI office or language constraints should they reach it. In this regard, it is important for NHRIs to engage in local outreach initiatives in order for IDPs to have better access to their services. NHRI staff who are engaged with international organizations on IDP protection issues may face security risks, and interaction with them should always be guided by the principle of "do no harm."

\footnotetext{
8 Brookings-SAIS Project on Internal Displacement, National Human Rights Commissions and Internally Displaced Persons, An Occasional Paper, Mario Gomez, July 2002, http://www.brookings.edu/fp/projects/idp/articles/gomez2002.pdf.

9 Brookings-Bern Project on Internal Displacement, Addressing Internal Displacement: A Framework for National Responsibility, Erin Mooney, May 2005; Internal Displacement Monitoring Centre (IDMC) Training on the Protection of IDPs: National Human Rights Institutions and Internally Displaced Persons, http://www.internal-displacement.org and Brookings-Bern Project on Internal Displacement resources on NHRIs, http://www.brookings.edu/projects/idp/Article-Index-Pages/nhri.aspx.
} 


\section{In our work, we can ...}

\begin{tabular}{|c|c|}
\hline Knowledge & $\begin{array}{l}\text { gain an understanding about the mandate, structure and composition of } \\
\text { NHRIs; and } \\
\text { ascertain their independence and compliance with the Paris Principles } \\
\text { and avoid inadvertently legitimizing a NHRI that is neither effective nor } \\
\text { independent. }\end{array}$ \\
\hline $\begin{array}{l}\text { Training and } \\
\text { capacity building } \\
\text { (See Part V.9 } \square \text { ) }\end{array}$ & $\begin{array}{l}\text { provide funding and support to NHRIs that are genuinely independent and } \\
\text { comply with the Paris Principles; } \\
\text { - support NHRIs to enhance their professionalism, geographic coverage } \\
\text { and capacity to protect IDPs; and } \\
\text { provide training to NHRI staff on IDP protection principles and practices. }\end{array}$ \\
\hline $\begin{array}{l}\text { Advocacy } \\
\text { (See Part V.3 } \square \mathbb{D})\end{array}$ & $\begin{array}{l}\text { advocate with NHRIs to include IDP protection in their monitoring, } \\
\text { reporting, public awareness and training activities. }\end{array}$ \\
\hline Joint training & $\begin{array}{l}\text { - consider running joint trainings with NHRIs for State institutions, the } \\
\text { police, military and local NGOs on IDP protection. }\end{array}$ \\
\hline $\begin{array}{l}\text { Information } \\
\text { sharing }\end{array}$ & $\begin{array}{l}\text { set up procedures and lines of communication for sharing information with } \\
\text { NHRIs on cases of human rights violations against IDPs and serious } \\
\text { breaches of government's obligations under international human rights } \\
\text { and humanitarian law. }\end{array}$ \\
\hline $\begin{array}{l}\text { Protection } \\
\text { monitoring and } \\
\text { reporting } \\
(\text { See Part V.2 } \square \text { ) }\end{array}$ & $\begin{array}{l}\text { consider setting up joint protection monitoring and reporting projects with a } \\
\text { view to a potential handover of these activities to NHRIs when } \\
\text { international organizations withdraw. }\end{array}$ \\
\hline $\begin{array}{l}\text { Joint } \\
\text { assessments and } \\
\text { reports }\end{array}$ & $\begin{array}{l}\text { - consider carrying out joint assessments, site visits and inquiries with } \\
\text { NHRIs regarding IDP conditions; } \\
\text { consider issuing joint reports and statements with NHRIs on IDP } \\
\text { protection; and } \\
\text { support NHRIs to conduct assessments of the national legal framework } \\
\text { and its compliance with the Guiding Principles. }\end{array}$ \\
\hline Protection Cluster & $\begin{array}{l}\text { consider a potential role for NHRIs in the Protection Cluster or Protection } \\
\text { Working Group, including a possible handover to the NHRI of coordination } \\
\text { activities upon the de-activation of the Protection Cluster. }\end{array}$ \\
\hline
\end{tabular}




\section{Armed non-State actors}

According to the United Nations definition, non-State armed groups "have the potential to employ arms in the use of force to achieve political, ideological or economic objectives; are not within the formal military structures of States, State-alliances or intergovernmental organizations; and are not under the control of the State(s) in which they operate." ${ }^{\prime 10}$ The ICRC distinguishes combatants from civilians as follows: "In non-international armed conflict, organized armed groups constitute the armed forces of a non-State party to the conflict and consist only of individuals whose continuous function it is to take a direct part in hostilities ('continuous combat function')."11

Armed non-State actors are active in many of the countries where there are internally displaced populations, in particular when the displacement was caused by armed conflict. They may be a party to the conflict and may also be responsible for violations against civilians, including forcing people to flee their homes. Armed non-State actors, thus, may have a significant impact on the safety and security of IDPs and the environment of humanitarian workers.

There are various types of armed non-State actors. They include groups exercising quasi-governmental functions, with de facto control over territory including their own police, military and legislative branches; others that are a party to the conflict with a formal command structure but no control over territory; so-called "paramilitary" groups that may be politically affiliated to, and supported or controlled by, the government although not belonging to State-run forces; and more loosely structured armed groups or criminal gangs with no formal command structure that are not a party to the conflict but are engaged in criminal activities, such as raids on IDP camps and settlements, theft, rape and attacks on IDPs and humanitarian workers.

The degree of engagement with non-State actors depends on their structure and role and the context within which internal displacement occurs. For example, quasi-governmental groups controlling territory where IDPs are living may be the main actor with whom humanitarian workers have to interact. They may control access to the IDPs and be responsible for providing IDPs with protection and assistance. Engagement with these groups is necessary to obtain free and unimpeded humanitarian access to IDPs and, thus, to ensure both the safe delivery of humanitarian assistance and the security of humanitarian workers. On the other hand, there is likely to be limited interaction with loosely formed non-State armed groups or criminal gangs, even though they may pose a serious threat to the safety and security of IDPs and humanitarian workers.

Non-State actors that are a party to the conflict are bound by obligations under international humanitarian law, including the protection of civilians and, in particular, IDPs. (See Part I.2 $\square$ ). The Guiding Principles on Internal Displacement is a particularly important tool in promoting accountability for non-State actors. These Principles spell out the responsibilities of all actors to protect IDPs regardless of their legal status (Guiding Principle 2.1) and apply to all situations of "generalized violence," including those that fall short of armed conflict (Guiding Principle 2). ${ }^{12}$

${ }^{10} \mathrm{OCHA}$, Humanitarian Negotiations with Armed Groups, http://ochaonline.un.org/humanitariannegotiations/Documents/Manual.pdf.

11 ICRC, Interpretive Guidance on Direct Participation in Hostilities, http://www.icrc.org/web/eng/siteeng0.nsf/htmlall/p0990?opendocument.

12 ASIL-Brookings Project on Internal Displacement, Guiding Principles on Internal Displacement: Annotations, Studies in Transnational Legal Policy, No. 32, Walter Kälin, 2000, pp. 99-106. See also OHCHR, Training Manual on Human Rights, 2001 Chapter XVI: Monitoring During Periods of Armed Conflict, p. 331,

http://www.ohchr.org/Documents/Publications/training7Introen.pdf. 


\section{The ICRC and non-State armed actors:}

The ICRC, as the custodian of International Humanitarian Law (IHL) which applies to all parties to a conflict, works with all sides of a conflict and, thus, systematically engages in dialogue not only with the government but also with non-State actors party to an armed conflict. The ICRC, thus, may have exclusive access to areas of a country under the control of non-State actors, providing a unique and crucial insight into the humanitarian situation in these areas. While the ICRC is often not in a position to share specific information due to confidentiality, it is advisable to consult with and inform them of any planned initiatives with armed groups especially if these concern the promotion of principles of IHL. As the mandated authority on IHL, the ICRC systematically engages in awareness raising and promotion of the respect of IHL by all parties to a conflict.

\section{Challenges and constraints:}

Humanitarian actors should be aware that engaging with non-State actors can be perceived as giving recognition or legitimacy to their cause and can be manipulated by these groups to gain publicity. ${ }^{13}$ As with the military, interaction with non-State actors that are a party to the conflict can also undermine perceptions of independence, impartiality and neutrality of humanitarian actors. IDPs may be seen by non-State parties to the conflict as collaborators or sympathizers with one particular side of the conflict. As with the military, the presence of non-State actors in IDP camps or amongst civilians, especially if they are not uniformed, can blur the lines between combatants and non-combatants and hamper the delivery of humanitarian assistance. There can be security risks for humanitarian workers when engaging with armed non-State actors. IDPs and humanitarian workers can be used by non-State actors in military campaigns against the government or other armed groups (e.g. hostage-taking or use of human shields). Finally, several donors or the United Nations place restrictions on interaction with certain groups considered terrorists in nature.

\begin{tabular}{|c|c|}
\hline & In our work, we can ... \\
\hline Knowledge & $\begin{array}{l}\text { understand the command structure of non-State armed actors to } \\
\text { determine who are the most reliable and influential interlocutors and } \\
\text { understand their composition, political agenda and motivation, political or } \\
\text { ethnic affiliation, control over territory and relationship with IDPs. }\end{array}$ \\
\hline $\begin{array}{l}\text { Monitoring, } \\
\text { reporting and } \\
\text { advocacy } \\
\text { (See Parts V.2 and } \\
\text { V.3 Da) }\end{array}$ & $\begin{array}{l}\text { monitor and report on abuses against IDPs and other civilians by the } \\
\text { non-State armed actors; } \\
\text { ensure that non-State armed actors understand the principle of preserving } \\
\text { the humanitarian character of IDP camps and settlements and monitor } \\
\text { and report on the militarization of camps; and } \\
\text { advocate with non-State armed actors to protect IDPs, put a stop to } \\
\text { violations and ensure respect for international human rights and } \\
\text { humanitarian law, as applicable (e.g. through public exposure of } \\
\text { violations; private dialogue directly with non-State armed actors; passing } \\
\text { information to other bodies with influence). }{ }^{14}\end{array}$ \\
\hline
\end{tabular}

${ }^{13}$ Common Article 3 of the Geneva Conventions is explicit that application of IHL to non-State actors does "not affect the legal status of the Parties to the conflict" (emphasis added).

${ }^{14}$ Humanitarian and human rights organizations should be aware of possible repercussions and potential security risks if they choose to publicly expose human rights violations by non-State armed actors. 


\begin{tabular}{|c|c|}
\hline $\begin{array}{l}\text { Compliance with } \\
\text { international } \\
\text { human rights and } \\
\text { humanitarian law }\end{array}$ & $\begin{array}{l}\text { - seek commitments by non-State armed actors to abide by international } \\
\text { human rights and humanitarian law and the Guiding Principles through } \\
\text { different mechanisms (e.g. "special agreements" between the parties to } \\
\text { the conflict; "unilateral declarations" (e.g. public statements); "codes of } \\
\text { conduct;" or the inclusion of IHL commitments in ceasefire or peace } \\
\text { agreements). }\end{array}$ \\
\hline Training & $\begin{array}{l}\text { provide information, training and guidance to non-State armed actors on } \\
\text { international human rights and humanitarian law and the Guiding } \\
\text { Principles; IDP protection and humanitarian principles; and the role, } \\
\text { mandates and activities of humanitarian, human rights and development } \\
\text { organizations; }{ }^{16} \text { and } \\
\text { provide training and guidance for humanitarian workers on rules of } \\
\text { engagement with non-State actors. }\end{array}$ \\
\hline $\begin{array}{l}\text { Coordination and } \\
\text { communication }\end{array}$ & $\begin{array}{l}\text { set up liaison arrangements and clear lines of communication between } \\
\text { humanitarian actors and non-State armed actors, as necessary. }\end{array}$ \\
\hline $\begin{array}{l}\text { Information } \\
\text { sharing }\end{array}$ & $\begin{array}{l}\text { set up clear procedures for sharing information with non-State armed } \\
\text { actors, for example on the security situation, and clear guidance for } \\
\text { humanitarian staff on information sharing. }\end{array}$ \\
\hline
\end{tabular}

\section{Civil society}

Civil society also makes an important contribution to national responses to internal displacement. It comprises a broad range of voluntary civic and social organizations and institutions, ${ }^{17}$ which can play a role in protecting IDPs. They include national and local NGOs, ${ }^{18}$ human rights defenders (individuals and organizations), ${ }^{19}$ community-based organizations, ${ }^{20}$ community and religious leaders, the national and local media and IDP associations.

Their activities on behalf of IDPs, include:

- investigating, documenting and reporting on human rights violations against IDPs;

- advocating on behalf of IDPs to government and other authorities;

- monitoring and reporting on governments' implementation of laws and policies on internal displacement and their compliance with international human rights and humanitarian law;

- participating in protection monitoring, data collection and registration of IDPs

${ }^{15}$ For example, the Sudan People's Liberation Movement agreed to a set of Ground Rules with Operation Lifeline Sudan (OLS) regarding the delivery of humanitarian assistance in Southern Sudan and the humanitarian principles which guided OLS activities. See OHCHR Training Manual on Human Rights, 2001, Chapter XVI, Appendix 1, http://www.ohchr.org/Documents/Publications/training7/ntroen.pdf.

${ }^{16}$ For example, in Southern Sudan, UNICEF disseminated information on IHL and the Convention on the Rights of the hild to influential military, religious, women, and traditional leaders, as well as civilian and humanitarian officials and Sudanese NGOs. In Eastern DRC, Somaliland and Cote d'Ivoire, the national Red Cross included non-State armed actors in training workshops on IDP protection. The ICRC also works to promote awareness, understanding and respect of $\mathrm{IHL}$ via extensive dissemination of information through formal IHL training courses or by combining this training with other courses (e.g. first aid courses) in cooperation with the National Red Cross/Red Crescent Society of a given country.

17 London School of Economics Centre for Civil Society, http://www.Ise.ac.uk/collections/CCS/what_is_civil_society.htm.

18 Principles of Partnership, Global Humanitarian Platform, 12 July 2007. http://www.globalhumanitarianplatform.org/pop.html

${ }^{19} \mathrm{OHCHR}$, Human Rights Defenders: Protecting the Right to Defend Human Rights Fact Sheet No. 29, http://www.ohchr.org/Documents/Publications/FactSheet29en.pdf.

${ }^{20}$ See Part IV.10 and Part I.4 of this Handbook $\square$. See also Brookings-Bern Project on Internal Displacement, Moving beyond rhetoric: consultations and participation with populations displaced by conflict or natural disaster, October 2008, http://www.brookings.edu/ /media/Files/rc/reports/2008/10_internal_displacement/10_internal_displacement.pdf. 
- participating in the planning, design and implementation of protection and assistance activities for IDPs;

- providing essential services to IDPs (e.g. health, education, shelter, water and sanitation);

n providing legal information, advice and assistance to IDPs;

- promoting grassroots initiatives to support IDPs;

- sensitizing the public on causes and conditions of displacement;

- providing information to IDPs on their rights and services available to them;

- monitoring and reporting on the relief efforts of governmental and humanitarian organizations; and

- conducting awareness raising and training on human rights and IDP protection issues.

\section{Challenges and constraints:}

Potential security risks accompany the work of civil society actors on behalf of IDPs. The principle of "do no harm," therefore, should guide the interaction with these actors.

\begin{tabular}{|c|c|}
\hline & , we can ... \\
\hline Knowledge & $\begin{array}{l}\text { carry out a mapping of the skills, knowledge, scope and affiliations of local } \\
\text { civil society actors at the earliest possible stage of a humanitarian } \\
\text { response. }\end{array}$ \\
\hline $\begin{array}{l}\text { Capacity building } \\
\text { and training } \\
\text { (See Part V.9 } \square \text { ) }\end{array}$ & $\begin{array}{l}\text { provide capacity building and support to civil society actors as well as } \\
\text { training (e.g. on IDP protection and humanitarian principles, human rights } \\
\text { monitoring and reporting); and } \\
\text { support the establishment of groups advocating IDPs rights, in particular } \\
\text { IDP associations such as associations of IDP women and children. }\end{array}$ \\
\hline $\begin{array}{l}\text { Monitoring, } \\
\text { reporting and } \\
\text { advocacy } \\
\text { (See Parts V.2 and } \\
\text { V.3 DU) }\end{array}$ & $\begin{array}{l}\text { - advocate with the national authorities to respect the humanitarian } \\
\text { character of civil society and ensure the safety of civil society actors; and } \\
\text { monitor and report to the authorities on any abuses against civil society } \\
\text { actors, including human rights defenders. }\end{array}$ \\
\hline $\begin{array}{l}\text { Community } \\
\text { participation/ } \\
\text { protection } \\
\text { activities }\end{array}$ & $\begin{array}{l}\text { consult with and encourage the active participation of IDP and host } \\
\text { community organizations in the planning, design and implementation of } \\
\text { assistance and protection programmes from the earliest stage of the } \\
\text { humanitarian response in order to ensure that programmes are } \\
\text { appropriate and sustainable and to avoid sources of conflict between IDPs } \\
\text { and the host community; } \\
\text { involve civil society actors in protection initiatives, such as protection } \\
\text { monitoring and reporting; and } \\
\text { advocate for the participation of civil society actors in the development of a } \\
\text { national IDP legal and policy framework. }\end{array}$ \\
\hline $\begin{array}{l}\text { Conflict } \\
\text { resolution and } \\
\text { peacebuilding }\end{array}$ & $\begin{array}{l}\text { work with IDPs and host communities and traditional and religious leaders } \\
\text { to promote peaceful coexistence within and between communities, } \\
\text { including through conflict mediation and conflict resolution; and } \\
\text { encourage dialogue with, and representation by, excluded groups in the } \\
\text { community. }\end{array}$ \\
\hline
\end{tabular}




\begin{tabular}{l|l}
\hline $\begin{array}{l}\text { Public } \\
\text { information and } \\
\text { awareness raising }\end{array}$ & $\begin{array}{l}\text { work with the local and national media to ensure an accurate and objective } \\
\text { portrayal of the IDP situation, including reasons for and conditions of } \\
\text { displacement; } \\
\text { use the local media for public information announcements and campaigns } \\
\text { on IDP rights and humanitarian relief programmes; and } \\
\text { - work with the local media to reflect positive images of IDPs and to help } \\
\text { combat racial or ethnic prejudice, discrimination and stigmatization of } \\
\text { IDPs. }\end{array}$ \\
\hline Coordination and \\
protection cluster
\end{tabular}

\section{Key references}

\section{General}

- Training Manual on Human Rights Monitoring Professional Training, Series No. 7, OHCHR , 2001.

- Guidance note on Early Recovery, Cluster Working Group on Early Recovery, April 2008.

- Policy on Early Recovery, UNDP, August 2008.

\section{Government and judiciary}

n Operational Guidance for Cluster Lead Agencies on Working with National Authorities, IASC, Draft, November 2009.

- Protecting Internally Displaced Persons: A Manual for Law and Policy Makers, Brookings-Bern Project on Internal Displacement, 2008.

- Addressing Internal Displacement: A Framework for National Responsibility, Brookings-Bern Project on Internal Displacement, available in 11 languages, 2005.

- National Responsibility and Internal Displacement: A Framework for Action in Forced Migration Review, MOONEY Erin, available in 4 languages, 2005.

- Human Rights Handbook for Parliamentarians No. 8, Inter-Parliamentary Union/OHCHR, 2005.

- Access to Justice Practice Note, UNDP, 2004.

- Programming for Justice: Access for All - A Practitioner's Guide to a Human Rights-Based Approach to Access to Justice, UNDP Bangkok, 2005.

\section{Military, police and non-State armed actors}

- Gender Sensitive Police Reform in Post Conflict Societies: Policy Briefing Paper, October, UNIFEM, 2007.

- Gender and Security Sector Reform Toolkit, Geneva Centre for the Democratic Control of Armed Forces, OSCE-ODIHR, UN-INSTRAW, 2008.

- Protection of IDPs: An ICRC View, ICRC.

- Humanitarian Negotiations with Armed Groups: A Manual for Practitioners, UN, January 2006.

- Guidelines on Humanitarian Negotiations with Armed Groups, UN, January 2006.

- Getting Non-State Actors to Protect IDPs, Forced Migration Review, ZEENDER Greta, 2005. 
- BRUDERLEIN Claude, The Role of Non-State Actors in Building Human Security The Case of Armed Groups in Intra-State Wars, 2000.

See also Part II.2.8 $\square \square$ for key references on working with the military.

\section{National human rights institutions}

- National Institutions for the Promotion and Protection of Human Rights Fact Sheet No. 19, OHCHR.

- GOMEZ Mario, National Human Rights Commissions and Internally Displaced Persons, Brookings-SAIS Project on Internal Displacement, an Occasional Paper, July 2002.

- UNCT Toolkit on National Human Rights Institutions (UNDP - forthcoming).

\section{Civil Society}

- Moving beyond rhetoric: consultations and participation with populations displaced by conflict or natural disaster, Brookings-Bern Project on Internal Displacement, October 2008.

- Human Rights Defenders: Protecting the Right to Defend Human Rights Fact Sheet No. 29, OHCHR.

- UNHCR Tool for Participatory Assessment in Operations, UNHCR, May 2006.

\section{Useful websites}

- Brookings-Bern Project on Internal Displacement: www.brookings.edu/projects/idp.aspx

- Forced Migration Review: www.fmreview.org

- Geneva Call: www.genevacall.org/home.htm

- London School of Economics Centre for Civil Society: www.Ise.ac.uk/collections/CCS/ 


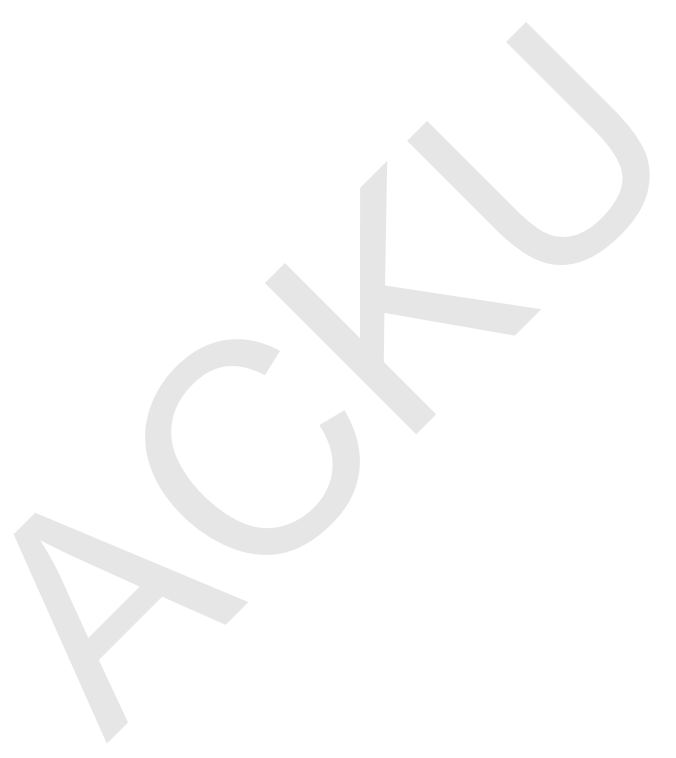




\section{Overview}

Part I of the Handbook provided the legal framework and the main basis for the protection of internally displaced persons (IDPs), but humanitarian and protection actions require more than theoretical knowledge to be fully efficient.

The manner in which protection interventions are delivered determines their success. Protecting internally displaced and other affected communities requires that humanitarian and human rights actors have not only the requisite knowledge but also appropriate attitudes and skills. Many of these are not inherent in people; however, they can be developed and refined over time at both the individual and institutional levels. Part II of the Handbook focuses on the attitudes and skills required of humanitarian and human rights actors, and it provides key tips to know and to apply in daily work.

Essential attitudes include:

- respecting core humanitarian principles;

- remaining open-minded;

n remaining positive and proactive;

- remaining empathetic;

- being a team player; and

- being self-aware.

Eight generic skills, each of which is equally valuable and deemed critical to protection work, are presented in no particular order of priority:

- analysis and problem-solving;

- decision-making;

n. communication;

- negotiations;

- leadership;

- coordination;

- facilitation of meetings; and

n. work with military actors. 


\section{Part II.1 \\ Attitudes}

Key message 83

1. Respecting core humanitarian principles ............................................................83

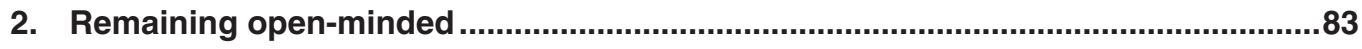

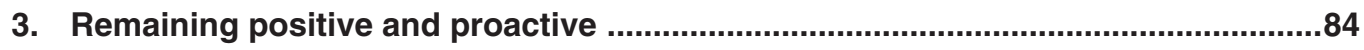

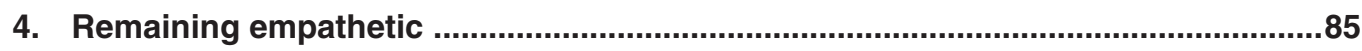

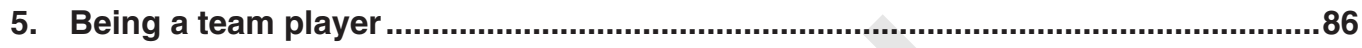

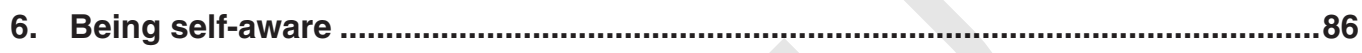




\section{Key message}

An attitude is the manner of behaving, feeling or thinking that demonstrates a person's disposition or opinion. The attitude of a humanitarian worker can benefit or damage an operation greatly and, with it, the quality of protection enjoyed by internally displaced persons (IDPs) and other affected communities.

\section{Respecting core humanitarian principles}

\begin{tabular}{l|l}
\hline What is it? & Being humanitarian requires respect for the basic principles of humanitarianism, \\
including the humanitarian imperative, neutrality, independence and \\
impartiality. These are outlined in Part I.1 of this Handbook and are also \\
often reflected in the codes of conduct of various humanitarian organizations.
\end{tabular}

\section{Remaining open-minded}

\begin{tabular}{l|l}
\hline What is it? & Humanitarian workers need to be receptive to new and different ideas and the \\
opinions of others to best effect a humanitarian mandate.
\end{tabular}


It helps to develop an understanding of complex situations, which allows for better planning and more appropriate interventions.

It helps to deal with complex negotiations and is essential for effective leadership and coordination (as explored further in Part II.2, sections 4, 5 and 6 below $\square$ ).

How can it be enhanced?
Improve listening and genuine inquiry skills (as outlined in Part II.2, section 3 below $\square$ ).

Learn about developmentally appropriate ways to work with children and ensure their ideas and opinions are taken into consideration.

Understand personal values and assumptions and minimize their impact on our work.

Review with colleagues and other partners discussions that have been held but have been unsuccessful resulting in divergent views and conflicts in order to understand why the discussions have been unsuccessful and how such situations could have been resolved differently.

Encourage continuous learning, both formal and informal, as it exposes us to a range of interests and issues and broadens our horizons.

\section{Remaining positive and proactive}

What is it?
improved and solutions achieved. The complexity of an operation should not
prompt despair.
Being proactive is to seek ways to improve programmes and interventions
rather than habitually reproducing activities. This includes seizing opportunities
rather than remaining passive.
Why is it
important?
conflict or natural disasters that have devastating effects on thousands of lives.
The magnitude of the crisis, disorganization, lack of resources, security
concerns, overwhelming amounts of information, policy gaps, failed
negotiations and poor living conditions can all lead to feelings of negativity and
resignation. Negative emotions can affect an individual and ultimately spread
throughout a team and adversely affect an operation.
As humanitarian organizations can sometimes be the last hope for IDPs and
other affected communities, humanitarian workers are entrusted with that hope
and have the duty to make all efforts to ensure the protection of persons of
concern.
It helps in finding the right approach, identifying opportunities, being
creative and making decisions that are in the best interests of IDPs and others
of concern.
It contributes to effective protection interventions, successful negotiations,
and sustainable partnerships and ensures that a team works effectively and
energetically.
It is essential for leading a team, an operation or a project, and is also
necessary to ensure the welfare of colleagues.
It can help humanitarian workers control their environment rather than let the
environment control them.


How can it be enhanced?
Taking care of oneself by eating and resting well, even during emergencies in hardship locations, is essential.

Finding a safe way to dispel frustrations regularly, such as by talking with colleagues or friends, exercising, spending personal time away from colleagues, and maintaining personal space in crowded living conditions, is helpful.

Staff welfare, improvements in living conditions and peer support networks are essential for keeping staff morale high.

Team-building exercises are useful and help team members to learn to support each other.

Strong leadership that empowers all staff and provides focus in the operation is crucial to keep a team motivated.

\section{Remaining empathetic}

\begin{tabular}{l|l}
\hline What is it? & Empathy is the ability to identify oneself with the situation of others. Empathy \\
should not be confused with being emotionally involved with a situation, which \\
can mar objectivity, adversely affect standards of professionalism, and be \\
perceived as bias by various parties even compromising in turn the neutrality of \\
an operation. \\
\hline Why is it & It helps to understand the situation and the concerns of IDPs and affected \\
important? & communities, to build trust, and to encourage others to share their views and \\
concerns, thus improving planning and programming. \\
It helps to understand the concerns of humanitarian partners, governments \\
and colleagues that might be difficult to express publicly but nevertheless \\
affect a humanitarian operation. It helps to be tactful in sensitive situations and \\
to enhance partnerships and negotiations. \\
It helps to respond to personal and professional concerns of colleagues, not \\
least to maintain an effective team. \\
\hline How can it be \\
Managers can help sensitize their teams and partners on the root causes of \\
enhanced? \\
protection concerns and the challenges that IDPs face every day. This may help \\
staff better understand and commit to protecting IDPs and other affected \\
communities. \\
Participatory assessments and planning bring humanitarian workers closer \\
to IDPs and affected communities. It encourages humanitarian workers to \\
understand the situation of IDPs and simultaneously empowers IDPs to claim \\
ownership of a programme. This process also helps to build empathy towards \\
IDPs. \\
Active listening can help to ensure that humanitarian workers understand \\
others before they make themselves understood. It also leads to a more \\
empathetic approach to discussions and communication.
\end{tabular}




\section{Being a team player}

\begin{tabular}{ll}
\hline What is it? & The ability and willingness to work together with other colleagues and \\
& organizations. \\
Why is it & We all have the same goal: To ensure protection and provide assistance to \\
important? & affected communities. However no single individual or agency has the capacity \\
& or ability to deal with the range of issues that need to be addressed in a \\
humanitarian operation. & Resources, which are frequently limited, need to be shared and used optimally. \\
- & Working alone will not only adversely affect the quality and impact of an \\
intervention by an individual or an agency but that of the broader humanitarian \\
community and, consequently, the situation of IDPs and other affected \\
populations themselves.
\end{tabular}

How can it be enhanced?
Work with other humanitarian organizations and participate in joint activities where needed and beneficial. Share information (i.e. be transparent), ensure that communication channels are open at all times, and avoid having "hidden agendas."

Actively seek the views and ideas of colleagues and other partners and respect their contributions. Try to understand their positions, even if you might not agree with them.

- Put aside personal interests and considerations, and be ready to adapt your priorities to those of the team.

Offer constructive criticism, but avoid being pessimistic. Persuade, but do not force ideas onto others.

- Share successes and failures with the team, bring problems out in the open and actively seek to resolve them.

- Be flexible, avoid being "territorial" over issues and aim to be as inclusive as possible.

Encourage team-building activities and spend time helping others who need support.

\section{Being self-aware}

\begin{tabular}{|c|c|}
\hline What is it? & $\begin{array}{l}\text { A personal understanding of ourselves, especially our strengths and } \\
\text { weaknesses, and our personal biases and prejudices. }\end{array}$ \\
\hline $\begin{array}{l}\text { Why is it } \\
\text { important? }\end{array}$ & $\begin{array}{l}\text { Self-awareness allows us to acknowledge and use our strengths to support } \\
\text { an operation and simultaneously work towards improving our weaker areas. } \\
\text { This can include gaps in knowledge, skills or other attitudes. } \\
\text { Maximizing and building on individual strengths within a team optimizes the } \\
\text { effectiveness and impact of the team and mitigates weaknesses. } \\
\text { Ignoring weaknesses leads us to perpetuate them at the expense of IDPs and } \\
\text { other persons of concern and colleagues. }\end{array}$ \\
\hline $\begin{array}{l}\text { How can it be } \\
\text { enhanced? }\end{array}$ & $\begin{array}{l}\text { Review each day's/week's events and determine what was successful and why } \\
\text { as well as what could have been done better. } \\
\text { Take psychometric and emotional quotient tests, available in management } \\
\text { courses or on the Internet, to establish personal strengths and areas for } \\
\text { improvement. } \\
\text { Discuss with and seek constructive feedback from colleagues, friends and family } \\
\text { regularly. Our personal behaviour is often reflected in our professional lives. }\end{array}$ \\
\hline
\end{tabular}




\section{Skills}

Key message

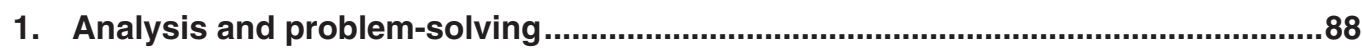

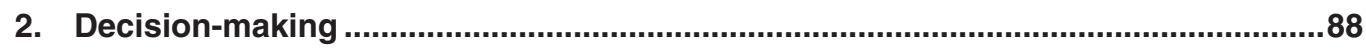

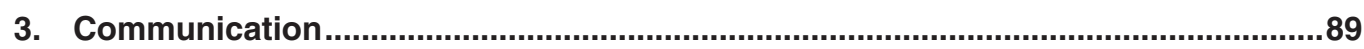

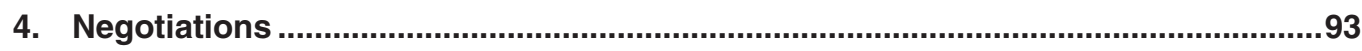

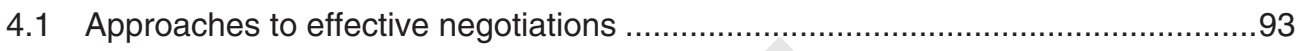

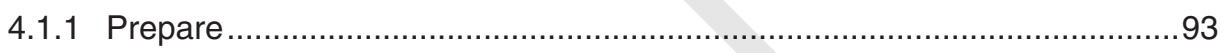

4.1.2 Communicate effectively ................................................................94

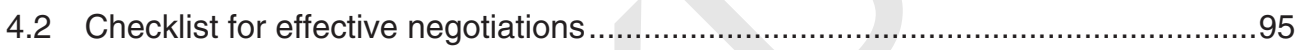

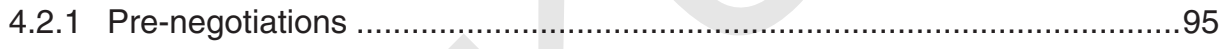

4.2.2 During negotiations ........................................................................

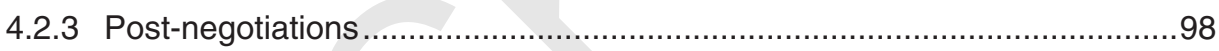

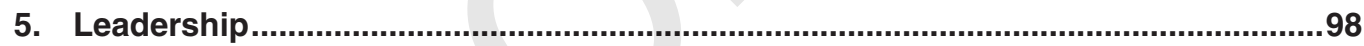

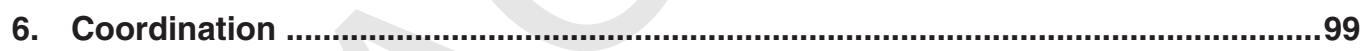

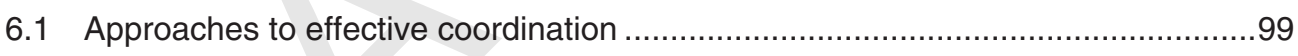

6.2 Checklist for effective coordination..............................................................100

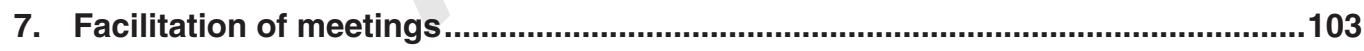

7.1 Approaches to organizing and facilitating meetings .........................................103

7.2 Checklist for facilitating meetings ..............................................................104

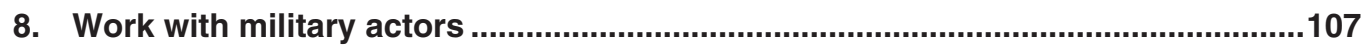

Key references \& useful websites ...............................................................................110 


\section{Key message}

A skill is a talent or ability that is acquired and developed through training or experience. Refining a skill and adapting it to an ever-changing humanitarian operation can often be difficult. While various learning opportunities and courses can be useful in developing and refining some of these skills, the right attitude and approach, a good supervisor and a supportive environment also help.

\section{Analysis and problem-solving}

Analysis refers to a detailed study of an issue in order to find new information or reach a better understanding. Situation analysis is one type of analysis undertaken by humanitarian organizations. Analysis is also necessary when monitoring human rights and IDP operations, planning a negotiation or when designing a protection intervention. Problem-solving is often a natural component to any analysis and an essential aspect of every humanitarian worker's function. (See Part III.5.

\section{Approaches to effective analysis and problem-solving}

- Collect Data: Collecting relevant information from a variety of sources and compiling it in a systematic manner is the first step to proper analysis and problem-solving. Sources can include primary sources (e.g. firsthand accounts, such as interviews with persons of concern or government officials, policy documents and/or legislation) or secondary sources (e.g. the media, human rights reports, and reports by other humanitarian organizations).

Since the quality and quantity of data collected affects the analysis, the data has to be credible, relevant, sufficient and verifiable. From the outset, attention must be paid to the methodology of information gathering, the ethics of interviewing, the confidentiality of information, and the safety of the interlocutors and staff. It is also useful to determine how the data will be processed before collecting it, and to ensure that humanitarian organizations do not duplicate efforts when collecting data.

- Think critically: Critical thinking is the ability to interpret and evaluate information, observations and arguments with the aim of determining what to believe and what action to take. Critical thinking ensures that the data collected is properly interpreted so that the conclusions reached most accurately reflect the reality of the situation and the actions agreed are the most appropriate.

- Be solution-oriented: Humanitarian workers undertake analyses with the view of responding appropriately to a problem. This requires that they be creative and think of possible solutions to problems at all times. Being solution-oriented is also an important leadership quality. Pre-conceived notions, lack of effective analyses as well as unclear and orthodox thinking often results in ineffective solutions.

\section{Decision-making}

Decision-making is a key behavioral process of an organization that is closely linked to other processes, such as communication, cooperation, conflict resolution, problem solving, and leadership.

When making rational decisions, managers usually adopt a structured approach and follow a number of steps including the following:

analyse the situation and define the problem;

state goals; 
I- devise criteria for choosing between alternative options;

- identify alternative options;

- obtain information on the likely consequences of each option;

- assess options against criteria; and

n select the best option.

Obstacles may be encountered when applying the structured approach. For example, generating solutions when following each step of the process may be particularly time consuming. This is why managers often opt for "bounded rationality", a model of decision-making in which managers settle for satisfactory, rather than optimal, courses of action. This allows them to limit their search and choose the first solution they deem "good enough" - a solution that may have worked before and which is expected to involve limited change and disruption.

\section{Communication}

Communication is the basis of all our work and is used extensively during interviews, assessments and negotiations as well as when coordinating or demonstrating leadership, advocating for a position, and building trust with persons of concern, the authorities and humanitarian partners. Refining our communication skills is therefore of vital importance.

\section{Approaches to effective communication}

There are various types of communication, including active listening, oral, non-verbal, written and visual communication. The guide below should be read with the following points in mind.

- The cultural context: Different cultures and communities typically communicate in different ways. Cultural differences may include universalism versus particularism, communitarianism versus individualism, a range of involvement from diffuse to specific, different ways of expressing feelings, time orientation, etc. To avoid misunderstandings, it is important to keep an open mind and to spend time understanding how people communicate in their culture and the meaning of specific words, expressions, mannerisms, tones and approaches.

Gender differences: Working with men and women of different ages and in various cultures might require different approaches and different ways of speaking.

- Age differences: A child's developmental stage must be considered when working with children. Effective and ethical communication with children requires age-appropriate communication skills and methodologies.

Note: Avoid intimidating, condescending or otherwise inappropriate communication styles. Special care must be taken when working with children or persons with specific concerns, including victims/survivors of torture or sexual violence. A specialist may be required for highly sensitive cases. 
Active listening

Oral

communication

\section{What is it and why is it important?}

Active listening refers to the ability to listen and understand people without any pre-conceived notions. Active listening helps in obtaining information, broadening our horizons, and building trust with, and respect for, other people. It can also help in "reading between the lines." Listening does not indicate that we necessarily agree with the person; rather, it shows that we understand, and are willing to consider, what the person is saying.

\section{Barriers to active listening}

The lack of interest in a subject, pre-conceived notions about an issue or subject, focusing on the speaker rather than the issue, physical distractions, time constraints and cultural differences, beliefs and attitudes are some reasons why we do not listen actively. This is demonstrated by negative body language, by a willingness to be distracted by other people or things, and/or by not responding appropriately.

\section{Tips for active listening}

Be physically attentive: Face the speaker, nod, maintain eye contact, if appropriate, and maintain an open posture (for example, avoid crossing arms). Do not be distracted by the environment.

Remain interested yet neutral in the discussion to allow the speaker to feel more relaxed.

Understand what is being said, including how it is being said and what is not being said, the tone of voice, and the emotions expressed by the speaker.

Ask open questions and seek clarifications when necessary. Rephrase what the speaker says occasionally to clarify your own understanding of what was said.

Do not interrupt or express your views until the speaker has completed his/her point.

\section{What is it and why is it important?}

Oral communication refers not only to what is being said, but also how it is being said (paralanguage). It is important to ensure that oral communication is effective largely because the listening and retention capacity of most recipients is extremely limited.

\section{Barriers to oral communication}

Speaking to people about issues in which they have no interest, not addressing their primary concerns, not getting to the point, culturally different approaches to conversations, the tone of voice or rate of speech, and simple language barriers may all adversely affect oral communication.

\section{Tips for effective oral communication}

Determine the audience to which you are speaking. Ensure that what is said is appropriate to the environment (work or pleasure), culturally appropriate, relevant and spoken in a language that the audience understands.

Encourage a discussion rather than a speech (unless a speech is being delivered), and ensure that active listening and proper body language is part of every discussion.

Think before speaking. If necessary, write down what you would like to say.

Speak on issues with which you are comfortable. Admit you do not know something or will check something to ensure that what you say is credible. 
Speak clearly and use short sentences to communicate complex ideas. Ensure that key messages, such as action points and main findings, are highlighted in a presentation. Summarize the main points at the beginning or end of a discussion.

Determine what feelings you would like to communicate by controlling the tone, volume and speed of what is said. Pauses, silences and emphasis on specific words also can communicate a feeling.

\section{Non-verbal communication}

\section{What is it and why is it important?}

Non-verbal communication includes body language, facial expressions and the tone of the voice that reveal what a person feels or would like to say but cannot or prefers not to reveal. It helps to convey messages and underscore what is being said, but it can also be misinterpreted, due for instance to cultural or linguistic differences.

\section{Barriers to non-verbal communication}

Body language may be interpreted differently in different cultures. For instance, looking a person in the eyes can be interpreted as a sign of honesty, but also hostility, depending on the context. Individuals who are particularly expressive or emotional may inadvertently display their feelings when it might not be appropriate to do so.

\section{Tips for effective non-verbal communication}

Be aware of natural facial expressions and body expressions that may be misinterpreted.

Understand cultural differences that may be expressed through non-verbal communication.

When listening, adopt a posture that clearly shows that you are listening. Maintain a neutral face when appropriate.

Practice in teams, with other colleagues and friends, or film each other to see how you perform. Practice in front of a mirror to ensure that your body language communicates the same message as what is being said, including how it is said, through tone and emphasis.

\section{Written communication}

\section{What is it and why is it important?}

Unlike oral or non-verbal communication, written communication is more permanent and cannot be retracted with ease. It is thus the most official manner of communication at work. Indeed, verbal agreements are often written down to mitigate the possibility of misunderstandings in the future. Written communication also provides fewer opportunities for error or mistakes.

\section{Barriers to written communication}

Emails and letters cannot communicate a tone or feeling as easily as speaking. Written messages can sound overly formal, be circulated to a wider audience than initially anticipated, and be misinterpreted or misunderstood, in particular in a multi-cultural environment where people have different working language skills. Details such as spelling, punctuation and grammar can also affect the reader. 


\section{Tips for effective written communication}

Write with the primary audience in mind at all times. To the extent possible, avoid writing for a variety of audiences in the same communication.

Use short and simple sentences and avoid complex words or long paragraphs (6-8 lines maximum). Remember to date the document and include filing or reference numbers if needed.

Explain, at the beginning, what a letter or memoranda is about, how it concerns the reader and what is being requested of him/her. This can be followed by more detailed background information.

Summarize the main findings/recommendations/highlights of reports and other longer documents at the beginning to ensure that the main messages are effectively communicated to the reader.

Pay attention to detail and ensure that the document does not transmit inaccurate or inappropriate tone to the reader: poor choice of words, bad grammar and misspellings reflect negatively on the writer. Always proofread a document before it is shared publicly. It can help to read the document again, after a break, to verify its accuracy and content, or ask a colleague to review it.

Ensure that official letters and communications are formal in vocabulary, grammar, punctuation and tone at all times.

The approach to a situation will determine the type of communication used. For example:

\begin{tabular}{|c|c|}
\hline Advc & Inquiry \\
\hline $\begin{array}{l}\text { Where we express our own perspective, } \\
\text { opinions and reasoning and share what we } \\
\text { think. } \\
\text { State assumptions } \\
\text { Explain your reasoning } \\
\text { Describe the context } \\
\text { Provide examples } \\
\text { - Invite testing of your assertions } \\
\text { - Reveal where you are least clear or least sure } \\
\text { of your assumptions } \\
\text { Refrain from being defensive } \\
\text { Examples: } \\
\text { "Here's what I think, and this is how I arrived at } \\
\text { this conclusion..." } \\
\text { "I assumed that..." } \\
\text { "Does my thinking make sense to you?" } \\
\text { "Is there anything that I said that does not make } \\
\text { sense?" } \\
\text { "I'm unclear about this aspect and maybe you } \\
\text { can help me think this through." }\end{array}$ & $\begin{array}{l}\text { Where we seek to understand fully the } \\
\text { perspective, opinions and reasoning of } \\
\text { others and look into what we do not know } \\
\text { yet. } \\
\text { Gently probe to understand } \\
\text { Draw out other people's reasoning } \\
\text { Explain the reason for inquiring } \\
\text { Ask for examples } \\
\text { Check your understanding } \\
\text { Listen with an open mind } \\
\text { Refrain from preparing to destroy the other } \\
\text { person's agenda or promote a separate own } \\
\text { agenda } \\
\text { Examples: } \\
\text { "What is it that leads you to say that?" } \\
\text { "What are you basing your conclusions on?" } \\
\text { "Can you help me understand your thinking } \\
\text { here?" } \\
\text { "Can you provide me with an example of ...?" } \\
\text { Have I correctly understood you when you } \\
\text { say....?" }\end{array}$ \\
\hline
\end{tabular}




\section{Negotiations}

A negotiation is a discussion between two or more parties with the aim of reaching an agreement on specific issues. It is a process through which we determine what we want and how we will achieve it, and through which we learn what the other party wants and how to satisfy them enough to reach an agreement.

Negotiations take place several times a day in a humanitarian operation among a variety of actors: governments, civil society, the IDP and affected communities, humanitarian organizations and non-State actors. Humanitarian organizations regularly negotiate on issues as diverse as gaining physical access to IDPs in situations of armed conflict - also known as "humanitarian negotiations" (further examined in Part V.4 DD ) - ensuring that communities send girls to schools, determining how to raise public awareness about gender-based violence or even how to prioritize interventions within the protection cluster or working group.

\section{Myths and misconceptions regarding negotiations}

Negotiation is a natural ability: False! While some people are able to demonstrate negotiating skills better than others, most negotiators have developed their skills through learning and experience.

Experience is enough: False! Many people keep making the same mistakes despite negotiating frequently. Analysing and learning from experience take significant effort, but they are essential. A good mentor, courses and books on negotiation can help.

Good negotiators often improvise: False! Successful negotiations require good preparation that anticipates various scenarios and factor in some degree of flexibility. Planning a negotiation is often the most critical, yet underrated, phase of any negotiation process. Poor planning is often cited as the most common reason for a failed negotiation.

Negotiators rely on intuition: False! Critical to a good negotiation is the ability to understand ourselves and the people with whom we are negotiating and to respond to their concerns.

Simple negotiations can involve two individuals discussing an issue face-to-face and reaching an agreement in a single meeting. More complex negotiations, such as those that precede peace agreements, may require a phased approach, detailed preparations and a series of discussions (face-to-face, exchange of letters and/or phone calls) over a period of time among a range of parties representing a variety of interests. Despite the varied nature of negotiations, there are some common approaches that may help to reach a successful outcome.

\subsection{Approaches to effective negotiations}

\subsubsection{Prepare}

Preparing for a negotiation is crucial. The steps indicated below may help prepare for a negotiation.

Understand the issue: Understand the issue and how best to achieve your objective. This will help determine whether a negotiation is needed, whether the issue at hand is negotiable and, if so, what needs to be negotiated, how and with whom.

- Establish a "bottom line": Decide which issues you are not willing to compromise (the "bottom line"). The human rights standards and principles of humanitarianism that form the basis for our work, such as neutrality, must not be compromised and thus form the broad "bottom line" of any negotiation. 
1- Decide on a BATNA: "The Best Alternative To a Negotiated Agreement" (or BATNA) refers to the action that needs to be taken if the negotiation will not succeed in meeting the bottom line. It not only provides a safety net but, when carefully planned, can also be used as leverage in a negotiation. For example, if a negotiation to access IDP areas has failed, you can increase your leverage by creating an alliance with other powerful actors. This must be carefully planned as the tactic can backfire if it is perceived as a threat by the counterpart.

- Determine your representative, counterpart and communication channel: The parties involved in the negotiation should have a stake in the issue or be legitimate representatives of those that do. Respect government and agency protocol at all times. When necessary, work through or with intermediaries, such as national NGOs or former government officials, who may have better access and credibility with the counterparts. The Humanitarian Coordinator may help in resolving issues of a sensitive nature and can represent organizations that wish to address common concerns (collective bargaining). Determine what channels of communication will be used, whether face-to-face meetings, an exchange of letters or both.

Inderstand the other perspectives: Analyse, understand and anticipate the views of the other parties prior to the negotiation. A proper understanding of other parties is often achieved through direct contact over time. Focus on common areas of concern and understand how differences can be narrowed or eliminated.

understand power relations: Power relations are often determined by the bargaining power of each party to a negotiation. Humanitarian actors can be perceived to be in a weaker position than government counterparts, IDP communities and even non-State actors if they do not have anything to offer that is of interest to the other party. Being "right" or doing "the right thing" will not necessarily place a party in a strong negotiating position. When in a weaker position, it might be helpful to resort to collective negotiations, which are undertaken by a group of agencies rather than individual agencies. Do not abuse a situation in which you are in a stronger position, as that might undermine your ability to establish trust and long-term relationships.

- The approach: Determine whether the negotiation approach will be soft (between parties that trust each other), hard (in adversarial situations), or principled (focusing on the issues rather than the people).

The time and location: Select a location and time where the parties are not distracted by other issues. Negotiations should be reasonably time-bound so that the parties do not lose track of their objective. It also places pressure on parties to reach an agreement.

\subsubsection{Communicate effectively}

Follow-up: Negotiations often require that parties either implement a final agreement or undertake various activities in preparation for the next meeting. These activities and preparations should be undertaken in a timely manner to maintain credibility and ensure that the agreement is not breached by any party for lack of follow-up. Provide feedback on these follow-up actions to all parties to keep the negotiated agreement intact and continue to build trust between the parties.

Prepare for a breakdown of negotiations: In the event of a breakdown of negotiations, you should not only analyse why the negotiation was unsuccessful but also take the next steps to achieve your objective through a BATNA. Given the issues at stake, humanitarian workers may find that it is imperative to return to the negotiating table to resolve all outstanding issues and reach a final agreement.

Improvised negotiations may occur during a security incident, such as an unexpected roadblock or an ambush. These are not discussed in this chapter. It is best to refer to security guidelines for information on these kinds of negotiations. 


\subsection{Checklist for effective negotiations}

\subsubsection{Pre-negotiations}

\begin{tabular}{|c|c|c|}
\hline Issue & Activity & Check \\
\hline The issue & $\begin{array}{l}\text { There is a clear reason why a negotiation is necessary on a } \\
\text { particular issue. } \\
\text { Tips: } \\
\text { Review all documentation relevant to the issue. Speak to persons } \\
\text { who may be more familiar with the issue. Consider how the matter } \\
\text { might have been addressed on other occasions, including successes } \\
\text { and failures. }\end{array}$ & \\
\hline My position & $\begin{array}{l}\text { The objectives, bottom-line and BATNA have been prepared. } \\
\text { Tips: } \\
\text { Ensure that your objective is realistic and can be accepted by all } \\
\text { parties. } \\
\text { Be willing to consider options that may be tabled by other parties. } \\
\text { Determine what issues cannot be compromised ("bottom-line"). } \\
\text { Prepare a BATNA and use it to measure the success of the } \\
\text { negotiation, as leverage during the negotiation, and/or to determine } \\
\text { the next steps if the negotiation fails. } \\
\text { Consider collective bargaining on behalf of other parties if it would } \\
\text { strengthen your position and would not adversely affect the outcome. }\end{array}$ & {$[\triangleleft]$} \\
\hline The parties & $\begin{array}{l}\text { The parties to the negotiation have been determined. } \\
\text { Tips: } \\
\text { The persons who will be negotiating are authorized to act on behalf of } \\
\text { the agency, either as messengers or as decision-makers. } \\
\text { Consider using an intermediary before or during the negotiation if } \\
\text { s/he is better placed to further your position or better understand the } \\
\text { other party's position. } \\
\text { Complex negotiations may involve a range of individuals and/or } \\
\text { parties, and may require the intervention of the Humanitarian } \\
\text { Coordinator. }\end{array}$ & {$[\checkmark]$} \\
\hline Their position & $\begin{array}{l}\text { The other parties/concerns have been anticipated. } \\
\text { Tips: } \\
\text { Determine the possible common areas of interest shared by all } \\
\text { parties prior to the negotiation. } \\
\text { Understand the potential differences among all parties prior to the } \\
\text { negotiation as well as the reasoning behind them, and determine how } \\
\text { best to bridge these differences. }\end{array}$ & {$[\checkmark]$} \\
\hline
\end{tabular}

Power relations
The power relations between the parties and the source of this [ $\checkmark$ ] authority are understood.

Tips:

Sources of power can vary and must be understood:

- Organizational power refers to the authority one has to represent a well-respected or credible organization.

Reward power relates to what an agency or individual can provide the other party. Financial resources, food, shelter and other items that humanitarian organizations can provide can serve as sources of power. 
Coercive power relates to the ability of a party to levy sanctions, bring shame or withdraw support, such as when a humanitarian organization informs the international community that it is being denied access.

- Information power is essential for anticipating and addressing the other party's interests with the aim of reaching an agreement. This power is often denied to humanitarian organizations by preventing them from accessing IDPs. Humanitarian organizations that prepare their BATNA effectively can often overcome this obstacle.

- Legitimate power is the authority vested in a person by the organization or society to represent its interests.

- Referent power refers to the power an individual derives from his/her community due to the respect, admiration or prestige s/he enjoys with them. Natural leaders in a community often possess this power and are in a stronger position to represent their community.

- Expert power is derived from special knowledge, skills or expertise that others may not possess.

Connection power refers to the perception or reality that an individual is well known and can influence other allies. Intermediaries to a negotiation often possess this power.

- Avoid abusing a strong position as it can undermine trust and the potential for a long-term relationship.

The approach The approach to use during the negotiation has been determined [ $\checkmark$ ] (hard, soft, and principled).

Tips:

- A soft approach is often used between those who work well together and trust each other. The goal is to reach an agreement, and concessions are made on both sides to cultivate the relationship. Both parties are fully transparent and conflict is generally avoided.

- A hard approach is often adapted between adversaries where one party wins at the other's expense. There is often no trust between the parties. This approach does not strengthen long-term relations and might even place IDPs at risk. This is not an approach that humanitarian workers are encouraged to use with regard to protection issues, but it might be necessary in extreme cases.

- A principled approach is used when all parties want to focus on the issue and solve a problem, rather than take opposing positions. Parties do not focus on the people but on the issue at hand, and they try to understand all positions and find common ground. This helps to develop a trusting and long-term relationship among parties and identify solutions. Both parties must agree to use this approach, which does not always happen. Over time, however, it might be possible for one party who remains principled to gain the trust of another party and use this approach in subsequent negotiations.

Location and time
The location and time suits all parties and will not adversely affect [ $\checkmark$ ] the negotiations.

Tips:

- Ensure that the location and time is convenient to all parties and that it does not distract them from the issues at hand.

An agreement may not always be forthcoming at the first meeting; other interactions might be necessary. 


\subsubsection{During negotiations}

\begin{tabular}{|c|c|c|}
\hline Issue & Activity & Check \\
\hline Communication & $\begin{array}{l}\text { Appropriate communication skills, especially listening skills, } \\
\text { are used to ensure that the position of the other parties is } \\
\text { better understood and that the issue at hand is appropriately } \\
\text { addressed. } \\
\text { Tips: } \\
\text { See section on communication skills. }\end{array}$ & \\
\hline Building trust & $\begin{array}{l}\text { Efforts have been made to build trust with the other parties } \\
\text { involved. } \\
\text { Tips: } \\
\text { Share information, be transparent with all parties, follow up on } \\
\text { issues you are responsible for, and remain committed to finding a } \\
\text { solution that is acceptable to all parties. }\end{array}$ & \\
\hline $\begin{array}{l}\text { The issue and } \\
\text { positions }\end{array}$ & $\begin{array}{l}\text { The positions of the other parties are clearly understood } \\
\text { during the negotiations. } \\
\text { Tips: } \\
\text { During difficult negotiations, it is important to look out for and } \\
\text { address specific approaches. In particular: } \\
\text { Intimidating environment: Negotiators can create an } \\
\text { intimidating environment, either through the physical layout of the } \\
\text { room or by the tone and nature of their comments. Acting } \\
\text { confidently or even asking for a break may help dispel that } \\
\text { atmosphere. } \\
\text { "Good-guy/bad-guy" routine: At times, a negotiator could try to } \\
\text { get an agreement by convincing his/her counterparts that s/he is } \\
\text { "easier" to deal with than her/his colleagues. It might be best to } \\
\text { confront the person on this issue with the aim of agreeing to focus } \\
\text { on the issue and its merits. } \\
\text { Threats and anger: When people threaten others or display their } \\
\text { anger, it can sometimes force others to compromise their } \\
\text { position. This is best countered by either ignoring the anger or by } \\
\text { defusing the situation by taking a break or talking to the person } \\
\text { about what is really upsetting him/her. } \\
\text { "Take it or leave it": There may be pressure to accept what is } \\
\text { offered or nothing at all. This can be resolved by testing their } \\
\text { commitment, temporarily breaking off negotiations, appealing to } \\
\text { a sense of fairness and comparing their offer to the BATNA. } \\
\text { Claiming limited authority: The negotiator may claim that s/he } \\
\text { has limited power to change the situation. This can be resolved by } \\
\text { speaking directly to the decision-maker or treating the negotiator } \\
\text { as a messenger. } \\
\text { Forcing deadlines (real or artificial): While negotiating within a } \\
\text { limited period of time is useful, it can sometimes be forced and } \\
\text { artificial. This can be addressed by questioning the reasoning } \\
\text { behind the deadline and proposing alternative deadlines. If the } \\
\text { deadline is real, determine whether the negotiation will bring any } \\
\text { benefits within the limited time period. }\end{array}$ & \\
\hline
\end{tabular}




\subsubsection{Post-negotiations}

$\begin{array}{ll}\text { Issue } & \text { Activity } \\ \text { Follow-up } & \text { Follow up on issues that have been agreed upon. } \\ & \text { Tips: } \\ & \text { Remain in contact with all parties and provide updates on the } \\ & \text { progress. } \\ & \text { If the negotiation has failed, follow up on the fall-back options } \\ & \text { (BATNA). } \\ & \text { Analyse why the negotiation has succeeded or failed to understand } \\ & \text { how to improve subsequent negotiations. }\end{array}$

\section{Leadership}

Leadership is a process by which a person influences others to accomplish an objective and directs the organization in a way that makes it more cohesive and coherent. Leadership means influencing other people in ways that are acceptable to them regarding core issues that the group or organization is confronting. Leadership is also a key skill in humanitarian operations to ensure that agencies and cluster members coordinate efficiently and effectively to address the concerns of IDPs and other affected communities.

While a manager or supervisor is entrusted with the authority to accomplish certain tasks and objectives in the organization, leadership can be exercised from any position in an organization by using the right skills and attitudes. Like other skills and attitudes, they can be developed and enhanced with experience and training.

\section{Leadership styles}

There are six basic leadership styles, many of which can be used simultaneously.

Coercive: The leader demands immediate compliance (using the "Do what I tell you" approach). The leader is driven to achieve, has initiative and wants to remain in control. This leadership style is occasionally suitable in a crisis to kick-start or to fix a problem but generally has adverse effects on the atmosphere.

Authoritative: The leader mobilizes people towards a vision (using the "Come with me" approach). The leader is self-confident, empathetic and a catalyst for change. This approach is suitable when change and a new vision are required. It has a mostly positive effect on the atmosphere.Pace-setting: The leader sets high standards for performance (using the "Do as I do, now" approach). The leader is conscientious, driven and takes initiative. This style is helpful in getting quick results from a highly motivated and competent team but can result in a negative atmosphere.

Affiliative: The leader creates harmony and builds emotional bonds (using the "People come first" approach). The leader is empathetic, builds relationships and is an excellent communicator. This is a suitable style when trying to build teams and motivate people during stressful times. It has a positive effect on the atmosphere.

Democratic: The leader forges consensus through participation (using the "What do you think?" approach). The manager is adept at building partnerships and teams and is also a good communicator. This approach is most useful to build consensus among staff, and it frequently results in a positive atmosphere.

Coaching: The leader aims to develop people for the future (using the "Try this" approach). The leader is empathetic, self-aware and concerned about others. This is a useful style when helping staff improve performance and strengths, and it often creates a positive atmosphere. 


\section{Approaches to effective leadership}

- Know your leadership style: A key attitude required of all humanitarian workers is that of self-awareness (as outlined in Part II.1 Attitudes above $\square$ ). Being aware of your personal leadership style will help improve it.

- Know your team: We should be empathetic and aware of the strengths and weaknesses of individuals working with us and use these strengths to support the humanitarian operation. We should be aware of the responsibilities of individuals and understand how they can best work together. We should try to develop a team whose members can complement each other's skills and personalities rather than duplicate them.

Support your team: We should look out for the personal and professional well-being of colleagues, help them develop positive character traits and keep the team informed of various developments so that they have a sense of ownership. This means that a leader must invest considerable time and effort to support a team, have excellent communication skills, and ensure that all members of the team are aware of what needs to be done and how. Building a team can often be a challenge and may require regular team-building activities or training before embarking on a project.

- Be responsible and take responsibility: We should find ways to improve the way our organization works. We should not blame others for failures but, rather, try to solve any related problems. A leader needs to take sound and timely decisions in order to move ahead at work, rather than shift responsibility, and needs to prioritize activities when the workload exceeds the financial and human resources available.

- Be technically proficient: We should be aware of the technical aspects of the work that needs to be undertaken, the mandates of our agency and other agencies and governments, and the work of civil society. This facilitates effective coordination within the team and with partners.

Manage resources effectively: Proper allocation and prioritization of often limited resources is important. Understanding and using additional resources effectively, such as additional funding or staff, technical expertise and support, will benefit the agency and the broader humanitarian community on the ground.

\section{Coordination}

Humanitarian coordination is "the systematic use of policy instruments to deliver humanitarian assistance in a cohesive and effective manner. Such instruments include strategic planning, gathering data and managing information, mobilizing resources and ensuring accountability, orchestrating a functional division of labour, negotiating and maintaining a serviceable framework with host political authorities and providing leadership."1

\subsection{Approaches to effective coordination}

Determine what needs coordination: It is not necessary to set up a sophisticated coordination mechanism when individuals and agencies are working well together. However, given the complexities of humanitarian operations and the need to reconcile mandates and objectives of the different United Nations agencies, NGOs and international organizations, especially as they pertain to protection issues, coordination is often required to develop a common understanding and response to an operation.

UN Coordination of the International Humanitarian Response to the Gulf Crisis 1990-1992, by L. Minear, U. Chelliah, J. Crisp, J. Mackinlay and T. Weiss, Occasional Paper 13, Thomas J. Watson Institute for International Studies, Providence, Rhode Island, 1992. 
Coordination involves: sharing assessments and other information; agreeing upon and using common standards, tools and policies; ensuring that protection is mainstreamed in other clusters/sectors; prioritizing activities and allocating resources to further these priorities; reducing or eliminating overlaps in activities; representing a common position vis-a-vis governments, the media or other parties; and addressing cross-cutting issues, such as staff security.

netermine who needs to coordinate: Coordination needs to take place within agencies, between agencies, and with governments, peacekeeping missions, civil society and the IDPs themselves. All stakeholders should be included. In situations where there are a number of groups representing similar positions, representatives of those groups, rather than every stakeholder, can meet. For example, inter-cluster coordination can take place primarily through the cluster leads. However, this does not preclude members of each cluster from working together on specific issues.

netermine coordination mechanism: Coordination mechanisms may be formal, such as in a cluster-coordination mechanism, or informal, such as ad hoc communication between parties when necessary. The concerned parties might communicate through meetings, telephone conversations, email exchanges or joint activities. Any coordination mechanism should be agreed jointly by the parties involved.

- In some cases, existing coordination mechanisms might not be effective or productive, or they might address issues that are not a priority. A simple realignment of the existing mechanisms may be necessary rather than implementing an entirely new coordination mechanism.

- The best coordination mechanisms are those that do not place significant time, human or other resource constraints on the various agencies or individuals. This is particularly important for smaller agencies that may not be able to attend meetings or exchange emails regularly.

1. Coordinate, do not control: A designated coordinator is not always necessary; instead, various parties can agree to work together and build consensus. In some situations, especially in complex emergencies, where a specific coordinator is designated, s/he helps facilitate a process that ensures that various parties work together to achieve a common objective. In such situations, a coordinator may also be authorized to take certain decisions on behalf of a group or represent the interest of the group with others. The coordinator needs to have negotiation, meeting-management and leadership skills, to remain neutral, objective and impartial, to build consensus rather than dictate, and to provide support to the various parties working together.

Demonstrate the value of coordination: Frequently, stakeholders will only coordinate with each other if there is a tangible benefit in doing so. Some benefits of coordination include: streamlining operations; raising and sharing human and financial resources; sharing information; raising the public profile of an agency; reducing workloads; resolving outstanding problems that an agency might not be able to address alone, and providing an umbrella under which smaller agencies can operate safely.

\subsection{Checklist for effective coordination}

The need

Better coordination is needed in order to improve the operation. [ $\checkmark$ ]

Tips:

Protection coordination mechanisms are essential in complex emergencies.

The institutional framework is outlined in Part I.3 $\square$ of this Handbook. 
mechanism are agreed upon by the protection agencies and other partners.

Tips:

Activities that often require coordination include:

- developing a collective protection response, including through joint assessments, planning, and programming;

agreeing on common standards, tools and policies and sharing of information;

ensuring that protection is mainstreamed in other clusters/sectors;

raising and channelling funds together;

sharing human, financial and other resources (office space, Internet access, vehicles) where necessary;

prioritizing activities, reducing overlaps and ensuring that gaps are filled in a timely and appropriate manner;

representing a common position to governments, the media or other parties; and

addressing cross-cutting issues, such as staff security.

The parties Key humanitarian partners that will participate have been $[\checkmark]$ identified.

The potential role and participation of the government has been [ $\checkmark$ ] defined.

The potential role and participation of representatives of civil society, including IDPs and other affected communities, has been determined.

Tips:

It is important that the government, United Nations agencies, international and national NGOs and other international agencies, such as ICRC and IOM, work together.

- Obtain contact details of key United Nations and NGO partners from the country office or from OCHA, which in emergencies may have the most recent contact list.

Members of other clusters/sectors should be encouraged to participate in protection-related activities.

The participation of representatives of civil society, including organizations of IDPs and other affected communities, can be valuable and should be considered, weighing the potential benefits against the risk they may face. The representatives should include both men and women and reflect a cross-section of the community. Participatory assessment and planning processes should be used in developing and implementing a protection strategy and other activities.

The potential role and participation of the government may be best determined after the protection mechanism is formed and its objectives have been agreed upon, and in consultation with the Humanitarian Coordinator.

Different coordination structures may be necessary in different regions of a country or for different thematic issues. Care must be taken to avoid overlaps. 
The structure An existing coordination structure is enhanced or a new [ $\checkmark$ ] coordination mechanism has been established.

Tips:

Ensure that the coordination structure is as simple as possible.

- Ensure that all parties have agreed upon the structure, membership, scope and function of the coordination mechanism. The agreement should be outlined in the terms of reference, which should broadly be in line with the generic terms of reference agreed upon by the IASC (as outlined in Part I.3 $\square$ ). These can be revised regularly to suit the requirements of the operation.

- The institutional framework and the different coordination structures, including the cluster approach, are discussed in Part I.3 of this Handbook.

- Guidelines and tools agreed upon by the IASC and other fora should be used and implemented (thus negating the need to develop new tools and also ensuring standardization).

The coordinator
An appropriate and effective coordinator/facilitator has been [ $\checkmark$ ] identified.

Tips:

- An organization can take responsibility for the coordination of protection activities in an operation but must have the capacity to do so. If need be, an individual should be designated to lead this process.

- The coordinating organization must be prepared to coordinate activities beyond those stated in its mandate. For instance, UNICEF will need to address issues beyond child protection and UNHCR will need to address issues beyond refugee/IDP protection.

Avoid changing the facilitator to ensure consistency in the operation.

- The coordinator should have knowledge and understanding of protection and human rights. Knowledge of the local language is also useful. The profile and job description of a cluster coordinator is noted in Part I.3.2 below $\square$. It can be used for non-cluster operations as well.

Tips for the coordinator:

Make yourself available to the partners and provide guidance when required.

Be familiar with the mandate, expertise and experience of different partners, understand their concerns and determine how they can best be addressed.

Have a clear work plan, terms of reference and ground rules to ensure that the coordination mechanism is used effectively.

Encourage and support joint activities, such as assessments, planning and implementation.

Be inclusive and try building a team whose members support and complement each other's work. Reach out and create links with other sectors/clusters.

- Be credible by demonstrating commitment, professionalism, sound technical knowledge and understanding of the situation.

Acknowledge the value and contribution of all parties and ensure they can all contribute to and benefit from joint activities. 
The outcome With coordination, humanitarian organizations are more effective. [ $\checkmark$ ]

Tips:

- Continually and jointly evaluate the manner in which coordination is taking place to determine how it can produce more effective results. Determine how it can be simplified, and, where necessary, change the terms of reference, manner of working and division of responsibilities among the members.

\section{Facilitation of meetings}

If managed well, meetings can be a useful tool to ensure that protection activities are well coordinated. If poorly managed, meetings waste time and undermine the credibility of a protection operation.

\section{Approaches to organizing and facilitating meetings}

- Meet for a purpose: Meetings require a significant investment of time and effort from both the facilitator and participants and should only be convened if and when needed. Instead of convening a large meeting, use email correspondence, phone calls or even smaller meetings with partners that have an interest in a particular matter.

- Prepare, prepare, prepare: To ensure maximum results, all participants should prepare in advance for the meeting. Providing relevant information to participants in a timely manner, outlining what is expected of each participant, and preparing the group for contingencies (e.g. ensuring translations and copies of background documents are available), are some key preparations that need to be made in advance of a meeting.

- Keep it short and simple: Meetings do not have to be lengthy to be useful. The facilitator should set the tone and pace of the meeting and ensure that participants remain focused on the issues at hand. The facilitator should seek agreement on administrative and behavioural ground rules to ensure meetings run smoothly.

- Facilitate rather than dictate: A facilitator (derived from the Latin term facere, which means "to do" or "to make easy") should create an environment that allows participants to work on an equal basis and take joint ownership. Encouraging participation, listening actively, focusing on a common ground rather than on differences, summarizing long and complex discussions, remaining neutral (as elaborated below), and taking decisions when necessary are some essential skills of a facilitator. The facilitator can often contribute the most by speaking the least.

- Remain neutral: A facilitator may need to remain neutral during coordination meetings, especially as the facilitating agency will need to address issues beyond the mandate and operational capacity of that specific agency. For example, if a United Nations agency is facilitating a meeting, it will need to ensure that other issues besides its mandate are equally addressed.

- Address differences: Differences in opinion can be resolved by remaining neutral and addressing the issue on its merits rather than personalizing them. Some issues may require bilateral discussions or a series of meetings to reach a common understanding.

- Address difficult group dynamics: Difficulties may arise when some participants are overly vocal, repetitive, speak for a long time without focus, resist all suggestions and ideas, disrupt meetings through side conversations, or simply have difficulties in articulating their ideas. It is also a problem when a participant remains quiet and does not share his opinions. The facilitator can resolve many of these problems in a non-threatening and neutral manner by reframing inflammatory statements, summarizing interventions, utilizing techniques that enable all members to participate in 
the debates, asking probing questions, and using ground rules agreed with the members of the meeting beforehand. In extreme cases, the facilitator can address the issue via a private discussion with the participant before or after the meeting.

- Be inclusive: Meetings provide a forum where diverse views can be presented and debated. Individuals whose opinions are different than those of the majority should not be excluded as they have a valuable contribution to make. In some cases, discussions may need to be translated. ICRC/IFRC observers should be welcomed as should coordinators of other sector/cluster working groups, given the cross-cutting nature of protection.

- Build trust, build a team: As the participants meet more regularly, they should be able to forge trust and create effective working mechanisms. The facilitator can be a catalyst in this process by remaining neutral and facilitating dialogue among partners with diverse viewpoints.

- Follow-up to meetings: A meeting is not an end in itself; rather, it provides the basis for taking action. It is essential to summarize the action points agreed upon (who is responsible for doing what and by when) and, when necessary, work with participants to achieve their objectives. This also helps make subsequent meetings more productive and focused.

\subsection{Checklist for facilitating meetings}

Time Issue
Pre-meeting Invitation to attend the meeting
A meeting invitation is sent out in a timely manner to all relevant
parties.
Tips:
Have a clear and relevant objective and expected outcome for the
meeting. Simply holding a meeting must never be deemed
sufficient; a clear objective must be sought. In emergencies, OCHA
often has the most updated contact list for humanitarian actors.
All correspondence should be clearly and consistently marked in
the "subject" line of an email to ensure effective follow-up by all
participants.
The meeting invitation can include the following issues:
information about the purpose of the meeting;
who should attend, why their attendance is requested and what is
expected of them;
the date, time, duration and location of the meeting (as outlined
further below);
a tentative agenda (as outlined further below);
any necessary documentation, such as background documents,
evaluations, or minutes of the previous meeting (as outlined further
below); and
a request or offer to invitees to share any further information that
may be helpful and a request for confirmation of their attendance.


Meeting

arrangements
Date, time and location

The date, time and location has been arranged and communicated to invitees.

Tips:

The date and time of the meeting should not coincide with other meetings (a master calendar of which OCHA may have).

In a field location, meetings may be preferred either as the first or last activity of the day, as staff may be in the field during the day.

- The meeting location is accessible to all and can accommodate all participants. Basic amenities (e.g. bathrooms, a sufficient number of chairs) must be available and other amenities (e.g. flip-charts, an overhead projector) may need to be provided. Beverages (i.e. water, coffee, tea) may be appreciated.

Regular meeting hours (same time and location) may be useful.

The facilitator should be present at the venue before the meeting in order to prepare the room and welcome the participants as they arrive.

\section{Documents}

Necessary documents have been prepared and shared with the participants.

Tips:

- For cluster meetings, the first invitation may include the background documents that introduce the cluster approach and decisions made by the Global Protection Cluster Working Group affecting the coordination mechanism, such as the division of responsibilities among agencies, the standard terms of reference for a protection-coordination team, etc.

In subsequent invitations, the minutes of the previous meeting, which were circulated previously, should also be included.

- It may be necessary to provide copies of the documents at the meeting in the event the participants have not brought their own copies.

Avoid sending bulky or numerous documents by email: It might discourage participants from reading the documents before the meeting.

\section{Opening of the meeting}

\section{Basic "housekeeping"}

Participants introduce themselves.

The facilitator collects information about attendance at the meeting (e.g. name, organization, contact details), which will be reflected in the minutes of the meeting.

All participants understand and agree on the purpose/procedures of the meeting.

All participants agree on administrative and behavioural ground rules.

A colleague (perhaps the facilitator) is designated to take the minutes of the meeting.

Tip:

Determine the language to be used. It may be necessary to make arrangements for translations for certain individuals and groups. 


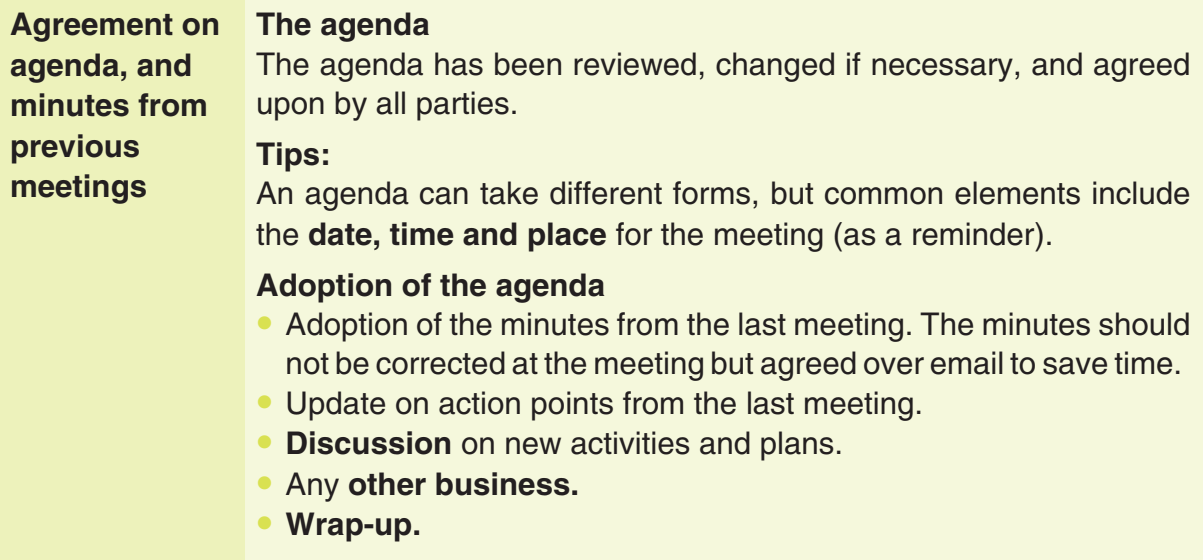

To ensure that time is managed effectively, set a time period to discuss each agenda item.

\section{Adoption of minutes from previous meetings}

All participants have agreed on the minutes of the previous meeting.

\begin{tabular}{|c|c|}
\hline $\begin{array}{l}\text { Update on } \\
\text { follow-up } \\
\text { activities } \\
\text { previously } \\
\text { agreed }\end{array}$ & $\begin{array}{l}\text { Update on follow-up actions decided during the previous } \\
\text { meeting } \\
\text { The participants provide an update on the various actions points } \\
\text { agreed at the last meeting. } \\
\text { Tip: } \\
\text { It may be useful to reflect follow-up actions in the form of a matrix. } \\
\text { Parts of this information also could be integrated into the "who is } \\
\text { doing what and where" tool or be incorporated as part of the } \\
\text { protection-strategy document. }\end{array}$ \\
\hline $\begin{array}{l}\text { Substantive } \\
\text { discussions }\end{array}$ & $\begin{array}{l}\text { Discussions about substantive issues and future action-points } \\
\text { Issues of a substantive nature are discussed in order of priority at the } \\
\text { meeting. } \\
\text { Tips: } \\
\text { A range of substantive issues may need to be discussed (although } \\
\text { not all issues can or need to be discussed at all meetings). The } \\
\text { facilitator should ensure that most of the meeting is spent on } \\
\text { addressing such substantive issues in a structured manner and in } \\
\text { order of priority. The discussion should lead to clear and agreed } \\
\text { upon action points. } \\
\text { Specific thematic issues can be discussed in bilateral or smaller } \\
\text { meetings. In general, however, the protection working group } \\
\text { should be the primary forum, and issues should not be } \\
\text { compartmentalized or confined to sub-group discussions on a } \\
\text { regular basis. }\end{array}$ \\
\hline
\end{tabular}

\section{Any other business}

Participants are able to raise and discuss other issues.

\section{Closing of the meeting}

\section{Wrap-up}

A summary of decisions and follow-up action points is provided verbally, and a decision is taken regarding the next meeting. 
The minutes have been drafted and circulated in a timely manner.

Tips:

- The minutes should be short but include all main issues and actions points. They do not need to be a verbatim documentation of the discussion. Care must be taken with confidential information.

- Follow-up action (who is expected to do what by when) should be clearly stated at the beginning or the end of the minutes for ease of reference.

- The minutes should be circulated to all relevant stakeholders, including the participants and possibly the Humanitarian Coordinator and other important protection actors, within 1-2 days of the meeting.

Comments and corrections should be invited over email within a reasonable deadline and a final version circulated prior to the next meeting.

\section{Follow-up actions}

Follow-up actions have been undertaken in time for the next meeting.

Tip:

The facilitator may need to follow up on a number of action points or assist other actors in doing so.

\section{Work with military actors}

Military or armed actors, whether national, international armed forces or other armed groups, are present in most complex emergencies. In natural responses, the army is often required to facilitate relief assistance due to its logistical expertise. Humanitarian actors therefore frequently interact with military actors and need to develop specific skills to handle such interaction appropriately.

Humanitarian action must be guided by the core principles of humanity, impartiality and neutrality at all times. This requires a clear distinction and division of labor between humanitarian action on the one hand, and military or military-related activity on the other. Legitimate armed forces which respect international humanitarian and human rights law play a vital role in ensuring a safe and secure environment for all civilians, More detailed guidance is provided in 'Civil-military Relationship in Complex Emergencies' (IASC, 2004). including the internally displaced.

\section{Practical considerations for civil-military coordination}

Regardless of the level of cooperation foreseen with the military, the principles of humanity, neutrality and impartiality should never be jeopardized or subordinated to military or political objectives. There must be a clear distinction between civilians and combatants/fighters at all times; humanitarian operations must act, and be perceived to act, independent from the military. What follows are some practical considerations for humanitarian workers engaged in civil-military coordination. 
Gain

understanding of the military

Learn about the type, objectives and structure of the different military actors operating in the area, and understand how they are perceived by both the displaced and the host community.

Type: Armed forces can be affiliated with a country, a group of countries or international bodies. Non-State actors or armed groups have no such affiliation, although they can be supported by a national government.

Objective: Armed forces and armed groups may be parties to a conflict or armed forces can be part of a peacekeeping operation, which in some cases are mandated to support humanitarian operations.

Structure: Humanitarian and military actors have different institutional structures, cultures and even languages. Armed forces usually have clear hierarchical structures and a strict chain of command, while armed groups may be more decentralized. Understanding the structure will help to identify the best interlocutor and the appropriate channel of communication and also help to facilitate interaction, as required.

\section{Be aware of}

liaison

arrangements and levels of interaction
Liaison arrangements and clear lines of communication should be established at the earliest possible stage and at all relevant levels between the formal military forces and the humanitarian community, to guarantee timely and regular exchange of relevant information.

- Before engaging with armed groups, we should ascertain the humanitarian country team's general and specific position in relation to the armed actors in our area of operation. We should be well aware from the start of the nature and scope of such arrangements, including at what level it takes place, whether it will be formal or ad hoc, whether it will be transparent or confidential, etc.

Interaction with armed forces can take place at various levels:

At the senior level, between senior military officials and the Humanitarian Coordinator/heads of agencies. All negotiations that affect the relationship and interaction between the two parties, including information exchanges, procedures at checkpoints and training, should be conducted at this level.

At the working level (CIMIC or civil affairs office), based on the agreements reached by senior staff. These include day-to-day interaction between humanitarian organizations and the military, such as reporting vehicle movements, security clearances, airlifts, etc. Humanitarian staff with the appropriate profile for civil-military coordination should be available for liaison tasks.

Forces representing the United Nations, including integrated missions, AU or NATO may appoint a civilian-military liaison officer (CIMIC officer) and establish a CIMIC centre where the military and humanitarian community can work together on common issues.

At the field level, the United Nations will usually be represented by the United Nations focal point/area security coordinator. NGOs may also decide to appoint a representative to relay communications.

At the security level, field security officers frequently maintain their own contacts with the military for staff safety purposes.

On the road, interaction with armed forces can occur while passing checkpoints and other military installations. At this level, all staff members need to follow the agreed procedures. Soldiers at this level usually have no authority to discuss substantial issues, and any disagreement on procedure or other issues should be discussed with higher-level offices.

If in doubt, it is best to seek clarification from your agency leadership, the protection cluster/working group coordinator or the Humanitarian Coordinator. 
Information sharing

- As a general principle, information gathered by humanitarian actors should not be shared with military actors, except if and to the extent necessary to protect the lives and well-being of persons of concern. Even in such cases, care must be taken to safeguard privacy and confidentiality to avoid placing individuals or communities at risk or jeopardizing the principles of neutrality and impartiality.

- Certain levels of information-sharing may be necessary, however (e.g. as it relates to security information, location, movement or activities of humanitarian staff, ongoing population movement, and relief activities of the military).

Decide and give guidance to staff on what information can or cannot be shared.

Establish a clear, simple and effective information-sharing structure.

Use of military
escorts for
humanitarian
convoys

- The use of military or armed escorts for humanitarian convoys or operations is an extreme precautionary measure that should be taken only in exceptional circumstances and on a case-by-case basis.

- The decision to request or accept the use of military or armed escorts must be made by humanitarian organizations, not political or military authorities, based solely on humanitarian criteria.

- Detailed guidance in this regard is provided in a discussion paper and non-binding guidelines on the Use of Military or Armed Escorts for Humanitarian Convoys (UN, 2002).

Joint
civil-military
relief
operations

Operations undertaken jointly by humanitarian organizations and military forces can have a negative impact on the actual or perceived impartiality and neutrality of humanitarian action.

- Any joint civil-military cooperation should be determined by a thorough assessment of the actual needs on the ground and a review of civilian humanitarian capacities to respond to them in a timely manner.

To the extent that joint operations with the military cannot be avoided, they may be employed only as a means of last resort.

Use of military assets for humanitarian operations
In general, the use of military assets in support of humanitarian operations in complex emergencies should only take place on an exceptional basis and as a last resort.

- Where civilian/humanitarian capacities are not adequate or cannot be obtained in a timely manner to meet urgent humanitarian needs, military and civil defense assets, such as aircraft or vehicles, can be deployed. A decision to that effect must be taken at the highest level within an organization and in consultation with the Humanitarian Coordinator.

In addition to the principle of 'last resort', key criteria include:

unique capability: no appropriate alternative civilian resources exist;

timeliness: the urgency of the task at hand demands immediate action; clear humanitarian direction: civilian control over the use of military assets; time-limited: the use of military assets to support humanitarian activities is clearly limited in time and scale.

Further guidance in this regard is available in the Guidelines on the Use of Military and Civil Defense Assets to Support United Nations Humanitarian Activities in Complex Emergencies (UN, 2003). 


\begin{tabular}{|c|c|}
\hline $\begin{array}{l}\text { Military } \\
\text { operations for } \\
\text { relief purposes }\end{array}$ & $\begin{array}{l}\text { Relief operations by military actors, even when purely 'humanitarian' in nature, } \\
\text { may have a detrimental effect on humanitarian efforts by blurring the distinction } \\
\text { between humanitarian and military action. This may jeopardize the neutrality of } \\
\text { humanitarian action, result in limited access to areas under the control of other } \\
\text { parties to the conflict, and place persons of concern as well as humanitarian } \\
\text { staff at risk. } \\
\text { Military forces should be strongly discouraged from playing the role of the } \\
\text { humanitarian aid providers. } \\
\text { Diplomatic efforts may prove helpful in this regard. }\end{array}$ \\
\hline $\begin{array}{l}\text { Conduct of } \\
\text { humanitarian } \\
\text { staff }\end{array}$ & $\begin{array}{l}\text { Humanitarian staff should interact with military personnel in a tactful manner } \\
\text { on every occasion. } \\
\text { Humanitarian staff should be able to convey in a clear manner the } \\
\text { independent and civilian nature of humanitarian assistance. } \\
\text { A clear distinction must be retained between the identities, functions and roles } \\
\text { of humanitarian personnel and those of military forces, i.e. clearly marked } \\
\text { vehicles, clearly marked offices and relief supplies, etc. } \\
\text { Weapons should not be allowed on the premises or transportation facilities of } \\
\text { humanitarian organizations. } \\
\text { Humanitarian personnel should not travel in military vehicles, aircraft, etc., } \\
\text { except as a last resort or for security reasons. } \\
\text { Humanitarian personnel should at no time collect military intelligence or } \\
\text { military strategic information, or have an attitude that may lead to such a } \\
\text { perception. } \\
\text { Humanitarian workers should not wear any military-like clothing. }\end{array}$ \\
\hline $\begin{array}{l}\text { Training and } \\
\text { awareness- } \\
\text { raising }\end{array}$ & $\begin{array}{l}\text { States have an obligation to ensure respect for relevant bodies of law, in } \\
\text { particular humanitarian and human rights law, including by raising awareness } \\
\text { of, and providing training on, humanitarian law and principles to their armed } \\
\text { forces and any other armed groups under their control. } \\
\text { Humanitarian actors can play an important role in supporting, facilitating or } \\
\text { even providing such training. Such efforts should be undertaken in } \\
\text { consultation with specially mandated actors, such as the ICRC. }\end{array}$ \\
\hline
\end{tabular}

\section{Key references \& useful websites}

\section{Analysis}

Critical Thinking: www.austhink.org/critical/

\section{Communication}

- Senge,P., The Fifth Discipline Fieldbook: Strategies and Tools for Building a Learning Organization, Doubleday Books, USA, 1994.

Mackay, I., Listening Skills, $2^{\text {nd }}$ edition, CIPD, London, 1995.

\section{Coordination}

- Humanitarian Coordination: Lessons from Recent Field Experiences, N. Reindrop, and P. Wiles, OCHA, June 2001.

"UN Coordination of the International Humanitarian Response to the Gulf Crisis 1990-1992”, L. Minear, U. Chelliah, J. Crisp, J. Mackinlay, and T. Weiss, Occasional Paper 13, Thomas J. Watson Institute for International Studies, Providence, Rhode Island, 1992. 


\section{Leadership}

"Leadership that Gets Results," N. Reindrop, and P. Wiles, in Harvard Business Review, OnPoint, 2000.

- Primal Leadership: Realizing the Power of Emotional Intelligence, D. Goleman, R. Boyatzis, and A. McKee, Harvard Business School Press, USA, 2002.

\section{Negotiation}

- Beyond Machiavelli: Tools for Coping with Conflict, R. Fisher, E. Kopelman, A. Kupfer Schneider, $2^{\text {nd }}$ edition, Harvard University Press, London, 1994.

- Getting Past No: Negotiating Your Way From Confrontation to Cooperation, W. Ury, $2^{\text {nd }}$ edition, Bantam Books, USA, 1993.

- Getting to Yes: Negotiating Agreement Without Giving In, R. Fisher, W. Ury, and B. Patton, Penguin Books, USA, 1991.

- Guidelines on Negotiations with Armed Groups, G. McHugh and M. Bessler, United Nations, January 2006.

- Humanitarian Negotiations: A Handbook for Securing Access, Assistance and Protection for Civilians in Armed Conflict, M. Mancini-Griffoli and A. Picot, Centre for Humanitarian Dialogue, Geneva, October 2004.

\section{Working with the military}

- Civil-military Relationship in Complex Emergencies: An IASC Reference Paper, IASC, 2004.

- Guidelines on the Use of Military and Civil Defence Assets in Disaster Relief, "Oslo Guidelines," OCHA, 2006.

- Guidelines on the Use of Military and Civil Defence Assets to Support United Nations Humanitarian Activities in Complex Emergencies, United Nations, 2003.

- Handbook for Emergencies, UNHCR, $3^{\text {rd }}$ edition, February 2007.

- Note of Guidance on Integrated Missions, United Nations, 9 February 2006.

I UNHCR and the Military: A Field Guide, UNHCR, 2006.

\section{Meeting Management}

"How to Manage Meeting Effectively," R. McGuire, The Pharmaceutical Journal, Vol. 268, June 2002.

- Planning Basics, chapter IV Managing Meetings, NC Division of Aging and Adult Services, August 2004. 


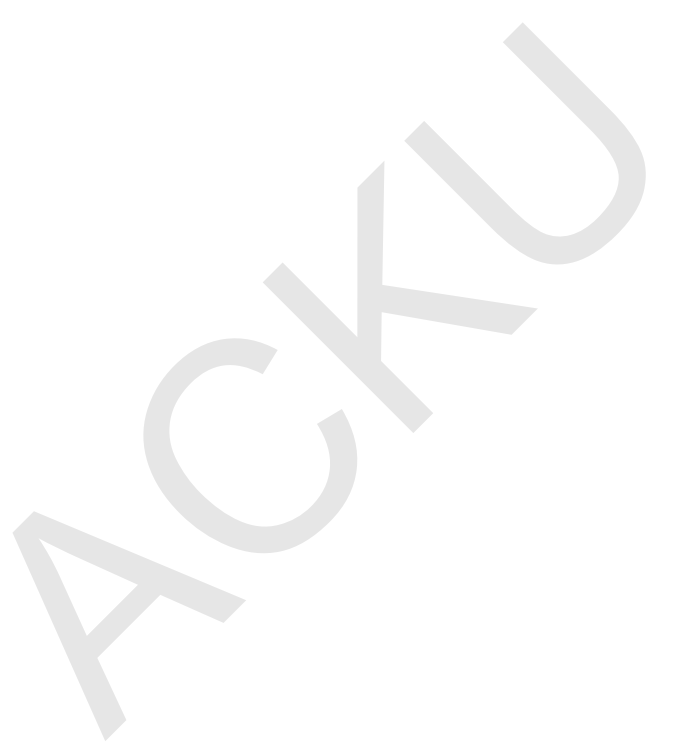




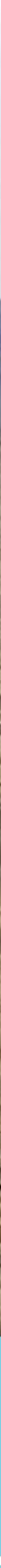

\section{PROTECTION STRATEGY AND RESPONSE}




\section{Overview}

The central concepts, frameworks and approaches to the protection of internally displaced persons (IDPs), as described in Parts I and II, provide the basis for a protection response to a given situation. In responding to any specific situation, however, the relevance, appropriateness and potential effectiveness of your actions in terms of the protection impact will depend on whether your efforts are part of a protection strategy.

A strategy provides the analysis and direction for responding to a challenging situation: it identifies priorities, defines desired outcomes and sets objectives. It, thus, provides a carefully designed, time bound roadmap, which seizes opportunities, while anticipating and adjusting to possible setbacks to achieving the desired outcomes.

Without a strategy, even well-intentioned protection efforts are likely to be ad hoc, reactive, and of limited long-term impact. They may even present a risk of unintended negative consequences. Thinking and acting strategically is, thus, inherent to applying the fundamental principle of humanitarian action - to "do no harm."

Every situation of internal displacement is unique and requires a particular protection strategy. The specific content of a strategy is determined by the context, including the cause of displacement (e.g. conflict or natural disaster), the phase of displacement, the actors present and the specific protection concerns that arise. Notwithstanding these varying factors, any protection strategy should address the following four basic questions:

- Who needs protection and from what?

- What can be done to promote and ensure this protection?

- How can this be achieved?

- When and how can success be measured?

Answering these questions requires the following four steps, as groundwork for a strategic protection response:

Step 1 - Situation analysis and protection assessment

Step 2 - Setting protection outcomes and objectives

Step 3 - Designing and implementing protection activities

Step 4 - Monitoring and evaluating protection impact

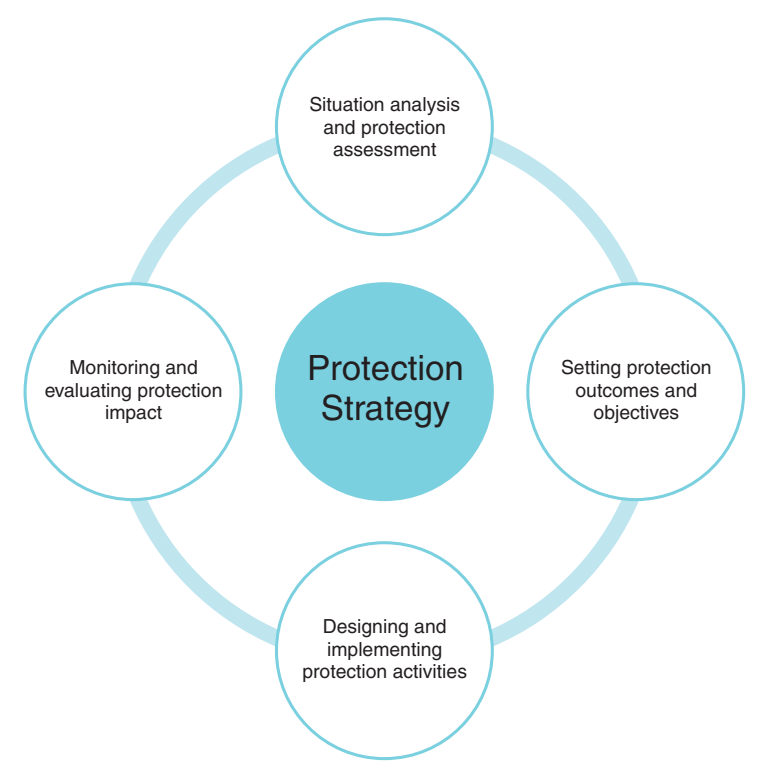


These steps represent the cornerstones of an effective protection response. They ensure that efforts are based on a sound understanding of the situation and of the protection concerns it creates, that they are tailored to the specific characteristics, constraints and opportunities of the situation, and that they adapt over time to lessons learned and to an inevitably changing environment.

These steps need not be time-consuming nor delay the response to protection concerns. On the other hand, they are critical to ensuring that actions are informed and relevant, and lead to the most effective protection impact. The following four chapters provide guidance on each step. A fifth and final chapter explains how strengthened results can be obtained through a collaborative approach and provides guidance as to how different actors can and should work together to develop and deliver a joint protection strategy. 


\section{Part III.1}

\section{Situation analysis and protection assessment (Step 1)}

1. Introduction.

2. Undertaking a situation analysis and protection needs assessment. 118

2.1 Documentary review. 118

2.2 Participatory assessment. 118

2.3 Consultations with relevant authorities and other local actors 120

2.4 Reviewing and analysing information 120 


\section{Introduction}

Informed protection action is guided by a sound understanding of the current protection risks facing the populations, and an evidence-based analysis of the situation. A situation analysis is a two-step process comprising:

(1) the collection of all relevant baseline information, using a variety of methods and sources, as a means of assessing protection needs, cross-checking information from other clusters where possible; and

(2) the examination of these data to detect patterns and trends, constraints and opportunities for response, in order to determine priority objectives for action.

This first step - the very foundation of an effective protection strategy - is the key to answering the core question: who needs protection and from what? (which groups of people need protection and from what kinds of threats, violations and effects of war and disaster?), ${ }^{1}$ and how do protection risks and responses (by the authorities, other groups, communities themselves) vary across different groups of people?

Answering these questions first requires an understanding of the rights of IDPs as set out in international law and national law, ${ }^{2}$ and regular monitoring of the respect of these rights in practice. ${ }^{3}$ This helps determine the main threats and violations experienced by IDPs and define the circumstances under which protection risks occur, the perpetrators, and the response of the authorities and that of the affected populations.

Other important factors to be analysed include:

actor mapping, identifying not only persons at risk, other affected communities, but also perpetrators, authorities at various levels, humanitarian agencies, peacekeeping missions, etc., their interests and the influence they have on each other; ${ }^{4}$

- political analysis, comprising the overall context and the relationship between ethnic, religious, social or tribal groups, etc.;

protection strategies applied by the communities at risk to prevent, stop and mitigate protection risks and their impacts;

- political commitment to protection on the part of national and local authorities, and of non-State actors, and their capacities to deliver on these commitments; and

- protection capacity of international agencies present, in terms of expertise, operational capacity and resources.

The combined analysis of these factors helps identify the populations at risk and the nature of violations or threats they face, determine which violations and threats have the most devastating impact on the safety and well-being of these populations at risk, and identify the perpetrators and critical gaps in national and international responses.

A scenario analysis, considering the best, worst and most likely future scenarios is also useful, given the volatile nature of contexts in which humanitarian crises occur, particularly in situations of armed conflict and complex emergencies but also in areas at high risk of natural disasters. A protection response, like the broader humanitarian response, needs to remain flexible to respond to unfolding changes of a given situation. Anticipating various scenarios facilitates this flexibility and can help correct assumptions that may change or prove invalid with time.

\footnotetext{
Adapted from Hugh Slim and Andrew Bonwick, Overseas Development Institute, Protection: An ALNAP Guide for Humanitarian Agencies, 2005, http://www.alnap.org/publications/protection/index.htm, p. 58.

See Part 1.2

See Part IV.1.

4 Guidance on actor mapping is available at: http://www.hdcentre.org. Proactive Presence, Humanitarian Dialogue, L.Mahony, 2006, Chapt 4, p 48 and Humanitarian Negotiation, Humanitarian Dialogue, D. Mancini-Griffoli/A.Picot, 2004 Chapt 5, p 51.
} 
Situation analysis is not a one-off activity but a process that should be ongoing and continuously updated, taking into account rapidly changing conditions, especially during an emergency phase.

\section{Situation Analysis and Protection Needs Assessment: An Overview}

Who?

When? In a sudden crisis or in the face of an emerging situation: Aim to understand

- All actors engaged in protection activities should undertake a situation analysis and protection assessment before undertaking protection activities.

- A joint exercise is strongly recommended in order to avoid any duplication of efforts or repeated assessments of the same population by different organizations. It also will facilitate a shared understanding of protection gaps and, thus, the formulation of joint strategic planning. (See Part III.5.

- The Protection Cluster, where this exists, should lead and coordinate this joint exercise, and use its results to inform and guide the Cluster's work.

- A team of representatives of key protection partners and non-protection actors, possessing different areas of expertise (e.g. child protection, gender analysis, camp management, food security, rule of law, etc.) should be engaged.

- The situation analysis and needs assessment should be done in coordination with:

the Humanitarian Coordinator, who oversees the entire humanitarian response;

the United Nations Humanitarian Information Centre, if one exists in the operation, which can assist in providing and processing the information;

other relevant actors with a potential protection role, e.g. an international or regional peacekeeping mission if one is deployed; and

- relevant authorities to the extent possible, depending on the situation and their commitment to protection. the overall situation and identify most urgent protection issues in order to quickly plan a protection strategy and mobilize a relevant protection response.

- In post-emergency and protracted operations: Aim to obtain a more thorough understanding of the situation, including critical response gaps, in order to strengthen existing activities and reorient efforts towards durable solutions.

On an ongoing basis: Aim to ensure accurate, up-to-date information on changes in the overall context and specific protection concerns.

Where?

- For an overall IDP protection strategy, the situation analysis and protection assessment should cover all locations of actual or threatened displacement as well as areas of IDP return, relocation or local integration.

- For a specific aspect or phase of displacement, the scope of inquiry can be more narrowly defined but should cover all relevant geographic areas. For instance, for a strategy focusing on durable solutions, the protection environment will need to be examined not only in actual or potential areas of return, relocation or local integration but also in the places where IDPs are while in displacement.

- Where several locations are covered, use of common methodology, to the extent possible, facilitates comparative analysis and helps determining priorities.

- Bear in mind that, even when the geographic scope of displacement is limited to a certain area or areas of the country, the situation analysis and protection assessment nonetheless should have a national dimension, in terms of analysis of the national legal and policy framework and the role of national authorities.

Whom to cover?
- The assessment should focus not only on communities in the broad sense but should also capture the protection concerns of persons of different ages, gender and backgrounds, ${ }^{5}$ and identify the different concerns and perceptions of IDPs, other affected populations and the broader community as well as how these different communities relate to one another. 
How? Four sets of activities, each with its specific methodology are required (and addressed further below):

(i) a documentary review of existing information;

(ii) participatory assessments with IDPs and other affected communities;

(iii) consultations with government and other stakeholders; and

(iv) a review and analysis of the information.

\section{Undertaking a situation analysis and protection needs assessment}

Methodologies for assessing and analysing the protection situation of a specific population or groups include rapid assessments, standard assessments, and profiling. ${ }^{6}$ The choice of methodology usually depends upon factors, such as the urgency of the situation and the level of access to affected areas. However, the four essential steps apply to every assessment method.

More detailed guidance may be found in: Protection for Conflict-induced IDPs: Assessment for Action, ${ }^{7}$ an inter-agency tool developed by the Protection Cluster and Early Recovery Cluster that provides overall guidance and specific checklists for each step of the analysis and assessment process.

\subsection{Documentary review}

This requires compiling all reliable protection-relevant information available from reports by human rights organizations, protection-monitoring and profiling exercises, previous needs assessments and evaluations, etc.

Based on this background information, a draft analysis should be prepared, using the checklists referred to above or, if time is limited, the broad themes outlined in the chapter headings. The draft should be revised following participatory assessments and consultations with national authorities and other actors.

\subsection{Participatory assessment}

IDPs and affected populations have the right to participate in decisions that affect them. Their participation is essential to ensure that programmes address their priority concerns and build upon their own capacities to create a more protective environment. Participatory assessment involves: ${ }^{8}$

- identifying leadership in the community (both official and de facto leaders or influential individuals) and understanding the power relationships;

mapping diversity to identify protection concerns and capacities according to age, gender or background;

selecting themes of particular interest to the community; and

n facilitating discussions on these themes in order to understand specific protection concerns, and identify possible solutions. (See Part V.10.

In undertaking participatory assessments, a number of ethical guidelines must be observed to protect the rights, dignity and security of the individuals consulted and to safeguard the confidentiality of data.

6 See Part V.1.

Inter Agency Standing Committee Protection Cluster Working Group and Early Recovery Cluster Working Group, Protection for Conflict-induced IDPs: Assessment for Action, Pilot version for field testing, November 2007.

8 Ibid. More detailed guidance on methodology for Participatory Assessment is provided in the Protection for Conflict-induced IDPs: Assessment for Action. See also Useful references at the end of Part III. 


\section{"Do"s and "Don't"s of Participatory Assessment ${ }^{9}$}

The rights, dignity, and well-being of IDPs and of other participating communities must be safeguarded during a participatory assessment. Those conducting the assessment must be trained in participatory assessment methodology and the ethical guidelines to be followed.

The dialogue initiated through the assessment process should be subsequently maintained through regular contact, using feedback from communities as part of an ongoing situation analysis. Such feedback can provide an indication as to whether the protection strategy needs to be adjusted in response to changes in the situation.

\section{DO}

Consider first the potential risks to communities. Singling out IDPs could expose them to heightened security risks and increase tensions with the host community, particularly if IDPs are perceived as receiving preferential treatment. In this case, an option could be to first hold joint discussions including IDPs and others affected, and follow up with IDPs separately.

Explain the nature and objectives of the assessment to the participants, community leaders and authorities, to avoid unrealistic expectations (e.g. specific responses to all individual concerns expressed, or direct financial benefit in return for participation) while highlighting the potential benefits of learning directly from IDPs and other affected communities about their conditions and priority concerns.

Obtain consent from all participants, and inform them that they can refuse to take part in the assessment, without negative consequences. When seeking the participation of a child, explain the nature and objectives of the assessment to the child's parents or adult guardian, and secure permission to speak with the child.

Reassure participants that they do not have to give personal information that embarrasses them, makes them feel uncomfortable or revives traumatic experiences.

Ensure that participants represent a range of different groups within the community, in terms of age, gender and other distinctive characteristics, creating separate groups for women, children, etc., where such groups can speak freely.

Explain and ensure that the confidentiality of information will be protected, including the names and identities of participants. This may be difficult when local authorities participate in the process and should be taken into account as a potential risk when considering their involvement.

Allow participants to express themselves freely, without interruption and without questioning the credibility of the information they provide.

Ensure that female participants are interviewed by females (with the assistance of female interpreters, if used).

Be aware of, and make allowance for, potential biases of interpreters and others present.

Provide participants with the names of contact staff with whom they can follow up in case they have personal questions or concerns.

Maintain contact and dialogue with the communities, keeping them informed of how information they shared is being used and of any follow-up actions.

\section{DO NOT}

Record names and reveal identities of interviewees, or take pictures or videos.

Ask questions, particularly those related to protection, in front of armed personnel, security personnel and officials.

Ask intrusive questions, taking into due account the cultural context.

Probe for information when it appears that a person would rather not give an answer.

Talk to other participants about a specific interview (which breaches confidentiality).

Make promises if you are not certain you can keep them. 


\subsection{Consultations with relevant authorities and other \|ocal actors}

The long-term effectiveness of efforts to enhance the protection of IDP communities largely depends upon the participation and engagement of relevant national and local authorities, as well as local NGOs and other actors (also addressed in Part I.4 $\mathrm{D}$ ) ). Consultations with these actors provides invaluable data for deepening the understanding of the situation and assessing the protection commitment and capacities of the actors. Depending on the context, the process of consultations can also serve to encourage the cooperation of these actors in designing and implementing a protection strategy in response to specific concerns.

Subject to the advice of the Humanitarian Coordinator, non-State actors in de facto control of territory where IDPs and other affected populations reside, may also be consulted to obtain a better understanding of their approach to the displacement crisis and their perception of the humanitarian community and affected populations. While such actors do not represent a State, international law places certain obligations on their conduct towards civilians (further addressed in Part 1.2 QD ).

During consultations with national actors, it is critical for international humanitarian and other protection actors to maintain their neutrality and impartiality (further addressed in Part I.1 $\square$ ).

\subsection{Reviewing and analysing information}

The review and analysis of the information collected should help to identify and understand the main protection gaps in a given situation, their causes, as well as the capacity and constraints of local communities, authorities and other actors (including at the international level) to bridge these gaps. The analysis should also look at possible barriers to protection commitments, how best they could be overcome, and what support might be needed to bolster capacities. ${ }^{10}$

This analysis should be consigned to a written document, for which guidance is provided in the Protection for Conflict-induced IDPs: Assessment for Action.

It should, then, be validated by stakeholders following a review meeting or workshop with representatives of the community and partner organizations. Where feasible, the final analysis should be discussed with national authorities, in order to promote a shared understanding of the protection gaps identified.

\section{The Timeline}

A situation analysis and protection assessment is essential to inform the response but does not need to be a lengthy process. Recall that the purpose is to inform response. Moreover, undertaking the necessary exercise of situation analysis and protection assessment must, under no circumstances, bar interventions to prevent or put a stop to ongoing violations and threats that endanger the life, safety or security of IDPs and other affected populations. Much of the information and analysis required is likely to be already available to actors having worked in the country for any length of time. The documentary review, for example, should not take more than a week, and a participatory assessment can be carried out in one week or less and in various locations simultaneously.

A collaborative and coordinated process with other relevant actors, moreover, is recommended for more expeditious and comprehensive findings (further addressed below, Part III.5

${ }^{10}$ Op. cit. Protection: An ALNAP Guide, p. 68. 


\section{Part III.2 \\ Setting protection outcomes and objectives (Step 2)}

1. Defining protection priorities

2. Specifying protection outcomes 122

3. Setting protection objectives 123 
A clear vision of protection outcomes and of objectives ${ }^{1}$ required to achieve these outcomes is essential for the design of protection programmes and for the proper monitoring and evaluation of their implementation.

\section{Defining protection priorities}

The most pressing protection gaps as revealed by the situation analysis and protection needs assessment provide the basis to define priorities for action. Setting these priorities can be facilitated by answering the following questions:

Which violations and threats pose the greatest risks or have the most severe impact on individuals and communities?

- Which violations and threats are the most prevalent and/or persistent?

Is it feasible for protection actors to address these violations and threats and, if so, can they do so adequately?

The top three priorities in a particular context, for example, could be: to protect IDP adolescent boys and girls from recruitment by armed forces; to protect women and youth from widespread gender-based violence (GBV) in and near IDP camps and urban settlements; and to secure durable solutions for IDPs in a protracted situation of displacement.

\section{Specifying protection outcomess}

Protection outcomes, based on priority concerns, aim to improve the respect for peoples' rights, to enhance the safety and well-being of those at risk, and to preserve their dignity. They entail significantly reducing the incidence of violations, the severity of threats, and the risks to which populations are exposed.

Protection outcomes must be specific, measurable and achievable, with practical descriptions of realistic improvements to people's daily lives in terms of respect of their rights. They should be phrased affirmatively on the assumption that they will be realized.

The achievement of outcomes is measured against specific indicators, providing benchmarks for monitoring and evaluating the effectiveness of activities (Step 4).

\section{Examples of Protection Outcomes:}

Women and girls have safe access to water and firewood and can move freely to collect it without intimidation or abuse.

IDPs have knowledge of their rights and are increasingly able to claim them from responsible authorities without intimidation.

Efficient and fair redress is provided for violations of land and property rights.

IDPs (both in camps and urban areas) have sufficient and safe access to food aid until their free movement is 


\section{Setting protection objectives}

While protection outcomes define improvements to the lives of IDPs and other populations of concern, protection objectives describe what must be achieved in order to realize these desired outcomes.

Objectives can be short, medium or long term. Some objectives, such as delivering humanitarian assistance or reducing immediate risks, can be implemented relatively quickly; others, such as securing access to all areas where there are IDPs and other populations at risk or securing durable solutions to a protracted IDP situation, are likely to be longer term, as they require overcoming significant constraints and structural challenges. A combination of short-, medium- and long-term objectives is often required to achieve desired outcomes.

Protection objectives should define the aim of protection activities, and convey specific actions introduced by an active verb, such as "to stop, prevent, support, change, persuade, mobilise, secure, restore, redress, provide, monitor or report..." .

Once set, objectives should be tested against realistic expectations of achieving the desired protection outcomes, asking questions such as:

- What assumptions are being made about external events, access, resources, influence and the contributions of others? Are they realistic or overly optimistic?

- Is there anything more to be done individually, or in partnership with other agencies, to make success more likely?

\section{Examples of Protection Objectives:}

Prevent statelessness among IDPs.

Stop international troops from sexually exploiting vulnerable women and girls.

- Reduce the number of rapes in IDP camps.

Support IDPs in protracted displacement to become economically self-reliant.

For examples of protection outcomes, objectives, activities and indicators, please see the Annexes to this chapter in the electronic version of this chapter (Uganda and DRC Protection Cluster Strategies). 


\section{Designing and implementing protection activities (Step 3)}

Mapping out how objectives and outcomes will be achieved requires answering the following questions:

What specific activities will be deployed and when?

With whom?

What other resources are required?

Answers to these questions should result in a list of activities to be undertaken by organizations, individually or (preferably) collectively. These should be proactive, creative, practical, realistic and relevant to the country context. They should also take account of the situation analysis and protection needs assessment, of response capacities currently available (requisite expertise and resources), as well as prevailing conditions and constraints (humanitarian access, security, etc.).

Guidance on the design of protection activities for any country context is provided in the following sections of this Handbook:

Part IV: provides guidance on how to prevent, mitigate and respond to specific protection risks and rights violations commonly faced by IDPs e.g. threats to life, safety and security, gender-based violence, mines etc.

Part V: defines a range of core protection activities, such as protection monitoring, advocacy, community mobilization and capacity building.

Part VI: focuses on durable solutions to displacement and identifies activities relevant to achieve this objective.

The activities to be undertaken should be listed and briefly described in a written Activity or Action Plan, grouped according to the objective to which they contribute, and listed in order of priority or sequence. The description should specify the following information:

n target populations for whom and/or with whom (IDPs and/or host communities etc.) the activity will be implemented;

geographic area where the activity will be undertaken;

- timeframe for implementation of the activity;

actor(s) responsible for implementation as well as responsibilities to which the designated actor(s) have agreed and which take account of the organization's mandate and expertise as well as its operational capacity;

n partner organizations, national governmental and non-governmental, as well as international actors, each of which may have a key role to play, as defined in the actor mapping undertaken as part of the situation analysis (further addressed in Part III.1 above $[\mathrm{d}$ );

- indicators which measure the progress made toward achieving the objectives set (as addressed in the next chapter, Part III.4 $\square$ ); and

- costs, namely an assessment of the total cost of implementing activities, especially when new funds are needed (the Action Plan of which can serve as a tool for resource mobilization). 


\section{Part III.4 \\ Monitoring and evaluating protection impact (Step 4)}

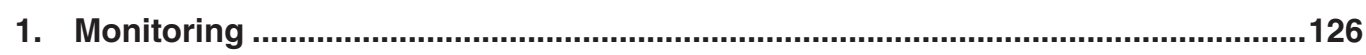

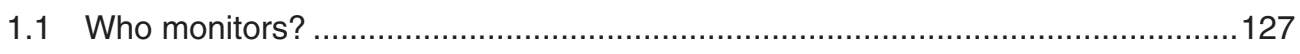

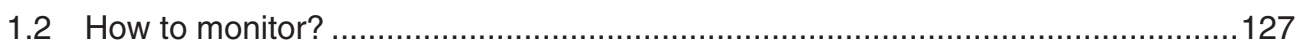

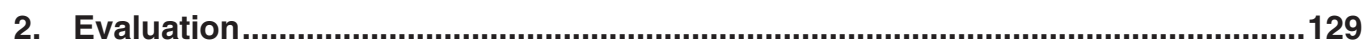

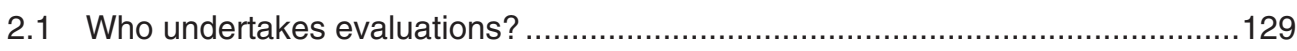

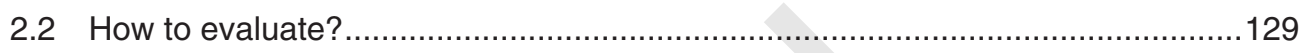


Monitoring the implementation of activities is critical for gauging what works well, or less well, in efforts to protect IDPs and other populations at risk. It helps to ensure that activities are carried out as planned and to focus on achieving stated objectives. Monitoring also serves to measure the extent to which protection outcomes are being achieved and to reveal any unintended negative consequences, which may even be putting the populations at greater risk. Monitoring, thus, identifies revisions that may be needed to the design or delivery of activities, so as to ensure that they contribute to the achievement of agreed objectives while observing the principle of "do no harm."

Although closely related, monitoring ${ }^{1}$ and evaluation are distinct activities, as described in the box below.

Monitoring is an ongoing process involving a continuous review to determine whether activities are being undertaken as planned (by the designated actor, within the specified timeframe, within estimated costs, etc.) and whether they are meeting agreed objectives and contributing towards achieving the desired outcomes. It is usually conducted during implementation and serves to provide early indications of progress, or lack thereof, so that any revisions required can be made swiftly.

An evaluation is a specific time-bound exercise that is usually conducted after completion of the implementation of a programme of activities or a given phase (such as emergency response) of an operation. ${ }^{2}$ It examines all aspects, including the design, dynamics, implementation, and results of a specific activity or an overall programme. Its findings are usually intended to inform and improve future programmes.

Both monitoring and evaluation are strategic planning, management and accountability tools.

\section{Monitoring}

As indicated above, monitoring serves as a rapid means of measuring the implementation of activities, identifying corrections needed to their design, and ensuring that they remain focused on the achievement of agreed protection objectives and outcomes. This is particularly important in emergency operations that require frequent revisions in response to rapid changes in the environment.

Monitoring is also extremely difficult in situations of war, widespread human rights violations and natural disasters. As observed in the ALNAP Protection Guide:

"When access, security and resources are a constant challenge, it can be a major achievement just to get something done. To know how well it was done (efficiency), how much has changed (impact) and how far these changes are due to your agency's own actions (attribution) can be extremely difficult to gauge. But it is vital to try."

\footnotetext{
Use of the term "monitoring" in this chapter and elsewhere in Part III refers to a generic programming assessment tool, distinct from "protection monitoring," i.e. monitoring and reporting on violations of human rights, which is addressed in Part IV.1.

"Real-time" evaluations, on the other hand, are conducted while operations are ongoing.

Ibid Protection: An ALNAP Guide, p. 104
} 


\section{There are three main types of monitoring, as outlined below.}

\section{Situation monitoring:}

The conditions in a given operation can change. Measuring these changes requires baseline or subsequent data, drawn from participatory assessments, discussions with stakeholders and even a desk review. They should be disaggregated by gender, age, location of the IDPs (i.e. whether they live in camps or non-camp settlements or in urban or rural areas) and, to the extent possible, socio-economic factors.

\section{Performance monitoring:}

This measures progress in achieving results in relation to an implementation plan. It includes:

- input monitoring: determining whether human, financial and material resources are mobilized and deployed as planned;

output monitoring: establishing whether products or services are being delivered or planned; and process monitoring: reviewing the processes by which an operation is managed.

\section{Impact monitoring:}

This assesses whether a programme is having the expected impact and, if not, what changes should be made to improve it. It also verifies whether any aspect of the response has produced any adverse effects on members of the community or on any other actor.

While all three types are relevant to protection, impact monitoring is particularly useful to determine the consequences - intended or unintended, positive or negative - of activities undertaken in pursuit of protection objectives.

\subsection{Who monitors?}

The agency that funds or implements an activity is normally responsible, in terms of financial accountability, for monitoring its implementation. However, monitoring the protection impact of activities goes beyond generic monitoring of programme implementation as a management tool. It requires not only an understanding of monitoring methodology but also protection knowledge, skills and attitudes and, therefore, calls for individuals with protection expertise.

\subsection{How to monitor?}

Monitoring should not be conducted or perceived as an inquisitorial, one-way process but, rather, as an opportunity for ongoing solutions-oriented communication among various stakeholders, to measure and improve the impact of operations.

Monitoring can be undertaken through various activities, including:

a scheduled or random visits to local communities;

- discussions with focus groups among IDPs and other populations of concern;

- regular consultations with relevant authorities;

- periodic analysis of baseline data gathered during these visits and consultations, and from monitoring reports by human rights, humanitarian, and development organizations (local as well as international); and

analysis of programme and financial reports indicating levels of implementation against planned activities.

Indicators are instrumental to monitoring, providing benchmarks against which to measure both the achievement of objectives and the effective implementation of activities towards these objectives. 
While critical to the monitoring process, indicators must be specified before activities are undertaken, that is when objectives are set and activities are designed (Steps 2 and 3 ). This ensures that objectives and planned activities are sufficiently specific, targeted and realistic.

Indicators can be:

n Qualitative, reflecting opinions, judgements and attitudes about a given situation or issue; or

- Quantitative, measuring levels such as the percentage of IDP girls and boys who attend primary school as compared to a baseline level.

Some agencies make a distinction between impact indicators and performance indicators.

Impact indicators are signs of change in conditions or institutional practice that affect the population of concern and its welfare. They are set at the objective level.

\section{Examples of Impact Indicators:}

90\% primary school enrolment and $80 \%$ attendance ratio for IDP girls and boys

Number of arbitrary arrests of IDPs reduced by at least $75 \%$.

$100 \%$ of IDPs whose homes were destroyed by earthquakes in Districts $X$ and $Y$ have access to permanent adequate housing

\section{Examples of Performance Indicators:}

A ten-minute radio programme promoting girls' school attendance is broadcast weekly, from April to September 2010 , in $70 \%$ of districts the population.

Legal clinics are opened in 3 major cities, with staff capacity to receive and document the complaints of 100 IDPs or other persons of concern each month.

IDP committee, with at least $50 \%$ female members, is established in every officially recognized IDP camp and collective centre.

First draft of IDP legislation reviewed in parliamentary committee by 30 June.

It is important that all types of indicators (qualitative or quantitative; impact or performance), specifically integrate factors of diversity such as age and gender. 


\section{Evaluation}

\subsection{Who undertakes evaluations?}

Evaluations should be undertaken by individuals or teams with knowledge of, and experience on, the issue to be addressed, such as IDP protection, civil-military cooperation etc. The person(s) undertaking the evaluation may be working in the operation or be external to it, such as staff employed by the agency but not engaged in the operation under review. This "one-step removed" approach helps to mitigate concerns as to objectivity and can be especially useful when issues of compliance with internal administrative procedures and policies are primary criteria against which the programme is being evaluated. Moreover, when the main purpose is to evaluate the protection impact of a given programme, self-evaluation by the agency is not generally advisable, due to institutional bias and potential conflict of interest. Such evaluations are best conducted by individuals who are familiar with, but independent from, the organization(s) concerned.

An evaluation undertaken by a team, as opposed to an individual, brings certain advantages by allowing different perspectives and areas of expertise.

\subsection{How to evaluate?}

Pre-defined criteria are needed for an evaluation to be as rigorous and objective as possible. Such criteria are determined by the evaluation's objective and scope and should incorporate the aspects indicated below.

Inclusiveness and representation: Were the concerns and views of women, men, girls and boys of all ages among IDPs and other affected communities included in designing the programmes and activities?

- Relevance: Was the protection activity or programme consistent with the priority protection concerns of the communities themselves?

Effectiveness: Did the protection activity or programme achieve its objectives and expected outcomes?

Efficiency: Were the planned actions implemented in the most timely and cost-efficient manner?

- Impact: Were there direct or indirect positive or negative long-term effects, intended or unintended, on IDPs and other affected communities, as a result of the programme?

n Sustainability: Will the achieved outcomes continue after the activity ceases, and to what extent are the government, IDPs and other affected communities ready to assume responsibility for achieving its objectives and outcomes on an ongoing basis? 


\section{Possible methodologies for evaluations are indicated below.}

Participatory or community-based evaluations help understand how IDPs and other affected communities perceive and assess the humanitarian operation. To be effective, such evaluations should be carried out over an extended period of time by a person or team with sociological research skills.

Real-time evaluations are atypically conducted in the acute phase of an emergency some four to six weeks after the onset of a crisis. Such evaluations often focus on overall performance issues and provide findings and recommendations that can be put to immediate use by managers and field staff engaged in the operation.

Self-evaluations are undertaken by teams involved in a country operation to assess the impact of their work and plan future activities. All stakeholders, including IDPs and other populations of concern, should be involved.

Lessons-learned evaluations are undertaken upon completion of a major humanitarian operation. They provide a record of accomplishments and problems encountered, which can be used to plan and implement similar activities and programmes in other countries or regions.

End-of-project evaluations are undertaken at the end of a programme or of a fiscal year. They provide a comprehensive review of achievements and impact and ensure better planning for the following year.

When monitoring or evaluating, it is essential to capture both good and bad outcomes and to pinpoint key causal factors, in order to improve the protection activity or programme under review as well as to inform other activities undertaken in the same context. As indicated in the flowchart in the Overview to Part III, the design of a protection strategy is a dynamic process. The findings and analysis produced through monitoring and evaluation should feed into the ongoing process of situation analysis and assessment which, in turn, informs possible revisions to the protection outcomes and objectives and, hence to the design and delivery of protection programmes.

Documenting and disseminating (subject to the approval of the agency concerned) the findings of monitoring and evaluation is, therefore, important as this can contribute to an exchange of practices and lessons learned that can also inform IDP and protection operations elsewhere. 


\section{Part III.5 \\ Developing and implementing a joint protection strategy}

The steps defined in the preceding chapters apply both to agencies or individuals operating alone in certain areas as well as to situations where several actors work together.

There are, indeed, clear advantages to collaborating with a range of other actors when developing a protection strategy. A joint approach can strengthen the protection response as outlined below.

- Deepening the understanding of the situation: Pooling information from a variety of sources and sharing the benefit of specialist expertise on specific protection issues (such as child protection, GBV, the rule of law etc.) leads to a better understanding of the issues, an enhanced situation analysis (further addressed in Chapter 1 above and, thus, a sounder basis for the response.

- Maximizing the scope of response: The scale of internal displacement and the range of risks and concerns for IDPs as well as other affected populations (e.g. host communities) frequently require the combined efforts of multiple actors, each contributing their area of expertise while working together towards a common goal. Addressing all protection concerns is likely to remain a challenge, but a joint protection strategy should minimize the risk of critical gaps in the response, including geographic coverage.

- Promoting greater efficiency: Working together leads to a more coherent and mutually reinforcing response that avoids duplicating or conflicting efforts.

- Creating innovative responses: Combining varied expertise, experience, approaches and ideas can help develop new and creative activities, and ways of overcoming obstacles.

- Mobilizing resources: Raising funds for protection activities can be more effective through a combined approach to donors, presenting shared objectives. A joint protection strategy often forms part of inter-agency processes, such as the Common Humanitarian Action Plan (CHAP) or Coordinated Appeal Process (CAP).

- Measuring impact: The benefit of a range of protection perspectives and areas of expertise is invaluable when it comes to monitoring and evaluating possible improvements brought about through protection activities (further addressed in Part III.4

- Continuity and sustainability: A joint strategy can help to ensure continuity in an operation, especially in situations where security or funding constraints require some actors to scale down or temporarily suspend activities, or when there is a high turnover of staff. It also contributes to promoting the long-term impact of activities.

A joint protection strategy sets out the vision and design of a collective, comprehensive, protection response. Based on a shared analysis of the protection concerns and of the operating environment, it defines common objectives and sets out a coherent plan to achieve these objectives, drawing upon the strengths of different protection actors, allocating clear roles and responsibilities, and facilitating coordination among them in order to maximize the combined protection impact of the response. 
Jointly formulating a protection strategy and response is not only logical, it is also expected. The Humanitarian Coordinator has the responsibility to promote inter-agency coordination on IDP protection, including through the "development of a comprehensive strategic plan for responding to the ... protection needs of IDPs." The Protection Cluster (or other inter-agency coordination mechanisms in place, if there is no Protection Cluster) is best placed to facilitate and support such efforts. Indeed, the development of a joint protection strategy is an expected core functions for Protection Clusters or working groups, wherever these exist. ${ }^{2}$ The resulting joint protection strategy should then serve as a roadmap guiding its work.

\section{A JOINT PROTECTION STRATEGY}

When? As soon as possible in order to reap the benefits described above. The process does not need to be time-consuming. (See the final section below.)

How?

The same four steps implemented with any protection strategy:

1. Situation analysis and protection needs assessment (see Part III.1

2. Setting protection outcomes and objectives (see Part III.2 $\square$ )

3. Designing and implementing protection activities (see Part III.3

4. Monitoring and evaluating protection impact (see Part III.4 [D])

Who?

- The Protection Cluster, as one of its core obligations, should lead and coordinate the process:

* informing the United Nations Humanitarian Coordinator (HC); and

- in the absence of a Protection Cluster or of a protection working group, the $\mathrm{HC}$ and Country Team should identify a competent focal point to lead this effort.

Consultations should involve all actors directly engaged in protection activities, including all members of the Protection Cluster or working group as well as other stakeholders, including:

IDP and other affected communities;

civil society groups engaged in protecting and assisting IDPs;

sectoral experts and other clusters (e.g. camp management, food security, early recovery etc.), since protection is a cross-cutting issue;

- international or regional peacekeeping missions; and

relevant authorities, when feasible, depending on the situation, and their commitment to protection.

While consultations should be broad in terms of situation analysis, content of the strategy and its implementation, the actual drafting of the strategy is best undertaken by a limited number of people, acting as secretariat to the wider group and led by the chair of the Protection Cluster with possible support by the chair of any sub-clusters set up at the field level (e.g. on child protection; GBV; rule of law; housing, land and property).

How to The sequence outlined below is recommended.

organize 1. Initial consultations: to agree on the process, lead, drafters, and timeframe for the finalization.

process?

2. Collective brainstorming: to identify the elements of the strategy (preferably by means of a workshop).

3. Drafting: by the lead protection agency, possibly with the assistance of a small drafting team of representatives from other agencies.

IASC, Revised Terms of Reference of Humanitarian Coordinators, 2003.

Planning and strategy development is a core function of each of the clusters in the "cluster approach" to humanitarian response. (See Part I.3). $\square$ IASC, Generic Terms of Reference for Sector/Cluster Leads at the Country Level, November 2006,

http://www.humanitarianreform.org/humanitarianreform/Default.aspx?tabid=218. 
4. Review of draft: by all relevant partners (which also could be conducted via a workshop).

5. Finalization of document: incorporating feedback from all partners participating in the review process.

6. Adoption by the Protection Cluster.

7. Endorsement by HC and IASC Country Team.

The next steps are: resource mobilization; implementation and monitoring and evaluation, and revision of the strategy as required.

\section{What} format for the strategy?
A written document is essential to record the consensus reached with regard to a common understanding of the situation, assessment of protection concerns and agreed objectives, and the commitments made to achieve desired protection outcomes. It also serves to promote the predictability, transparency and accountability of the response, to provide a clear roadmap for activities, and to avoid misunderstandings or misinterpretations.

A strategy must be clear, concise, easy to understand and action-oriented. While there is no set format or template for a protection strategy, a number of elements can be useful to include, as outlined below.

- Executive summary: a clear and concise statement of the expected protection outcomes and the main objectives of the strategy.

Statement of basic principles (as an introduction to the strategy):

the core principles of humanitarian action - humanity, impartiality, independence and neutrality (further addressed in Part I.1 DD).

- the fundamental principle of national responsibility as well as the rights of IDPs to share in decisions affecting their lives, through community participation (further addressed in Part I.1 $\square$ ).

the rights of IDPs as set out in the Guiding Principles on Internal Displacement, and applicable international human rights law and, in situations of armed conflict, international humanitarian law, as well as relevant national laws (further addressed in Part I. $2 \square$ ).

- Overview of internal displacement: including numbers of people affected; cause of displacement; date or period during which displacement occurred; whether displacement is still ongoing; the regions affected both in terms of IDPs' areas of origin and their current locations; and the extent to which durable solutions are already underway. This information should be drawn from the situation analysis (further addressed in Part III.1 [DI).

- Assessment and analysis of the protection situation: a summary of the findings of the situation analysis and protection needs assessment, notably the priority protection concerns, populations most at risk and why, as well as the protection capacities and response to date of key stakeholders and actors, including IDP communities, national authorities, non-State actors, and the international community (further addressed in Part III.1 $\square$ ) ).

Expected outcomes and agreed objectives: based on the situation analysis and an identification of priority protection concerns, the strategy should outline the desired outcomes and objectives aimed at preventing, halting or mitigating protection violations and threats (further addressed in Part III.2 [D).

- Activities: these should be realistic, practical and appropriate to the country context, taking account of any constraints in the operating environment such as humanitarian access or security. Typically, the activities are elaborated in greater detail in an Action Plan that accompanies the strategy.

Monitoring and evaluation: A timeframe and mechanism for periodical monitoring of the strategy implementation and for revisions to be made, as necessary, should be specified. 
Timeline? The time needed to develop a protection strategy can vary from a week to a month or, in certain circumstances, longer, depending on various factors including: the operational context; the urgency of protection risks; the availability of existing information on, and analysis of, the situation and protection concerns; the number of actors to be consulted, and the formality of the process of strategy development (as working with the authorities may require governmental adoption of the strategy as an official policy document).

Clear and realistic deadlines for each step in the process should be set and observed.

Once the strategy document is completed, it becomes critical to monitor and evaluate, at regular intervals, its continued relevance as well as progress in implementation. The mid-year reviews of the CAP or more frequent deadlines can be applied.

These recommendations on the development of a joint protection strategy for IDPs also apply to the development of national strategies or national policies on internal displacement, in line with the responsibility of governments to protect, assist and secure durable solutions for IDPs. ${ }^{3}$ As already emphasized, the primary responsibility for protecting IDPs lies with the national authorities, and the ultimate goal is to ensure that IDPs can access effective national protection. More than a dozen countries have adopted national strategies or policies on internal displacement. ${ }^{4}$ International protection actors should promote and support these efforts. Indeed, in a number of cases, the international community has provided technical assistance to national authorities to assist them in formulating national laws, policies and strategies on internal displacement. Such strategies, especially when developed in partnership with the international community, provide a valuable model for international response, and promote enhanced coordination of efforts at both national and international levels.

\section{Key references}

- Protection: An ALNAP guide for humanitarian agencies, Hugo Slim and Andrew Bonwick, Overseas Development Institute, 2005.

- Protection for Conflict-induced IDPs: Assessment for Action, IASC/PCWG, February 2008.

- Addressing Internal Displacement: A Framework for National Responsibility, MOONEY Erin, Brookings -Bern Project on Internal Displacement, 2005.

- Tool for Participatory Assessment in Operations,UNHCR, 2006.

\footnotetext{
3 Brookings-Bern Project on Internal Displacement, Addressing Internal Displacement: A Framework for National Responsibility, Erin Mooney, 2005, www.brookings.edu/idp/. See also the 2009 African Union Convention for the Prevention of Internal Displacement and the Protection and Assistance of Internally Displaced Persons in Africa, Article 3.

4 For example, in Angola, Bosnia-Herzegovina, Georgia, Iraq, Nepal, and Uganda national IDP strategies (or policies) have been developed, often with the support of the international community, and adopted by national governments. Documents are available in the country profiles developed by the Internal Displacement Monitoring Centre, www.internal-displacement.org. See also the index of national and regional laws and policies on internal displacement, www.brookings.edu/projects/idp/Laws-and-Policies/idp_policies_index.aspx\#MidEast.
} 


\section{Overview}

Part IV of the Handbook provides guidance to humanitarian and human rights staff working in complex emergencies on ways to prevent and respond to specific protection risks and concerns that often arise in situations of internal displacement.

Part IV is composed of 19 chapters, each of which addresses a specific risk or problem that is commonly encountered by internally displaced persons (IDPs) and affected populations. Each chapter:

-1. describes the risk in question, analyses its impact upon the lives and well-being of IDPs, and identifies the individuals and groups most at risk;

- contains a table with suggested activities that can be undertaken by humanitarian, human rights and development actors to prevent and/or respond to the risk in question (while many of the generic activities are described in greater detail in the chapters in Part V of the Handbook);

- provides an overview of relevant legal principles and standards contained in international (and regional) human rights, international humanitarian law, and international criminal law, where applicable, and emphasizes the responsibility of the State to respect and ensure respect of these principles (obligations which, as highlighted in Part I.2, non-State actors also have in conflict situations);

- identifies key national, regional and international actors that can play a role in the response; and

- provides a list of useful references, tools and websites where further information can be found.

The chapters provide general guidance to be adapted by teams in the field to suit the context and the day-to-day reality of operations, including with regard to the roles and responsibilities of the different protection actors. 


\section{Part IV.1 \\ Forced displacement}

Key message

1. What is forced displacement?

2. What does the law say about forced displacement?

2.1 International (and regional) human rights law 138

2.2 International humanitarian law 139

2.3 National legislation 139

3. The responsibility of the State

4. The role of humanitarian and human rights actors 141

4.1 Addressing the causes of displacement 141

4.2 Mitigating any adverse impact of forced displacement. 143

5. Key actors 145

Key references \& useful websites 


\section{Key message}

Forced displacement has serious consequences for the lives, health and well-being of individuals and communities. It can occur in a wide range of circumstances and as a result of a variety of factors. Forced displacement is often, but not always, unlawful. While international law provides numerous safeguards against forced displacement, there may be circumstances in which it can serve a legitimate purpose. Even in such cases, however, it must meet certain minimum safeguards and take place in conditions of safety and dignity.

It must be underlined that all persons have a right to move freely and in safety. This right entails freedom from coercion to move or to stay in a particular place, unless provided by law, and also freedom to seek safety in another place within their country or to seek asylum in another country at any time. On their side, duty bearers and particularly State authorities have the obligation to refrain from causing arbitrary displacement and to prevent unlawful displacement from taking place while protecting the right of individuals to move freely. When displacement does occur, relevant authorities should make efforts to minimize and mitigate its adverse impact on individuals and communities and ensure a durable solution for all those affected.

Humanitarian and human rights actors can have a role in preventing or minimizing the occurrence of forced displacement. Usually these efforts will be inscribed within wider protective strategies including those targeting internally displaced persons (IDPs), communities at risk of displacement and the whole of the affected population in a given situation or region.

Note! Efforts to prevent and/or minimize forced displacement and mitigate its adverse effects must not in any way restrict or limit freedom of movement, impede people's ability to move, or influence their decision to do so.

\section{What is forced displacement?}

Forced displacement is a complex phenomenon. It can be understood as a protection risk in itself and also as a source of further protection risks. In some cases, forced displacement is also a coping mechanism of populations affected by armed conflict. This chapter deals mostly with displacement understood as a protection risk that needs in itself to be addressed. How to mitigate its consequences is the object of parts IV-VI of this Handbook. However, this chapter offers also some concise notes on this particular aspect (see part IV.2).

According to the Guiding Principles on Internal Displacement, forced displacement occurs when individuals and communities have been forced or obliged to flee or to leave their homes or places of habitual residence, in particular as a result of, or in order to avoid the effects of, armed conflict, situations of generalized violence, violations of human rights or natural or human-made disasters.

Forced displacement is caused in many cases by a mix of factors. In some cases, the line between "choice" to flee and coercion to do so is difficult to determine. Displacement includes situations where people flee pre-emptively or as a coping mechanism, whether or not in the direct presence of threats. It also includes situations where people have been forcibly removed from their homes, evicted or relocated to another place not of their choosing, whether by State or non-State actors. Also, forced displacement can include situations where displaced persons have been forced to return to their place of origin or to settle elsewhere against their will. In all cases, the defining factor is the absence of will or consent. 


\section{What does the law say about forced displacement?}

International law generally prohibits authorities and armed groups from ordering or purposefully causing any form of forced displacement, except in a few rare situations.

\subsection{International (and regional) human rights law}

International (and regional) human rights law guarantees several rights which provide safeguards against forced displacement. While there is no specific right to protection against forced displacement as such, it is inherent in a number of human rights, including the rights to freedom of movement and choice of residence, ${ }^{1}$ the right to respect for the home and for privacy, ${ }^{2}$ the right to an adequate standard of living, including food and See also Principles 5, 6, 7 and 9 of the Guiding Principles on Internal Displacement. See Annex 1of the Handbook. housing, ${ }^{3}$ and the right to respect for the family. ${ }^{4}$

\section{When is forced displacement unlawful?}

Forced displacement is only permissible on an exceptional basis and for a limited number of reasons. It is always unlawful:

when it is based on policies of apartheid, ethnic cleansing or similar practices aimed at/or resulting in altering the ethnic, religious or racial composition of the affected population; in situations of armed conflict, unless the security of the civilians involved or imperative military reasons so demand;

in cases of large-scale development projects which are not justified by compelling and overriding public interests;

in cases of disasters, unless the safety and health of those affected requires their evacuation; and

when it is used as collective punishment.

In addition, forced displacement can be unlawful if:

minimum procedural guarantees are not respected;

the manner in which it is carried out violates other rights and/or obligations that apply to the State or a party to the conflict, such as the rights to liberty and security, and the prohibition against torture, inhuman and degrading treatment; and

it negatively impacts the enjoyment of human rights for the long term.

It is important to underline that, when discussing the legality of forced displacement, it is always the act of ordering or forcing displacement (usually by an authority or an armed group) that is called into question and not the act of fleeing by those being displaced which itself is never unlawful.

See, at the international level, Art. 13 of UDHR; Art. 12 of ICCPR; Art. 5(d)(i) and (f) of ICERD; Art. 15 of CEDAW; and Art. 16 of ILO Convention No. 169 Concerning Indigenous and Tribal Peoples in Independent Countries; and, at the regional level, Art. 12 of AfCHPR; Art. 22 of AmCHR; Arts. 20 and 21 of ArCHR; and Art. 2 of Protocol 4 to the ECHR. See also Principle 14 of the Guiding Principles on Internal Displacement.

2 See, at the international level, Art. 12 of UDHR; Art. 17 of ICCPR; Art. 8(16) of CRC; and, at the regional level, Art. 10 of AfCRWC; Art. 11 of AmCHR; and Art 8 of ECHR.

3 See, for example, Art. 25 of UDHR; Art. 11 of ICESCR; Art. 5(e)(iii) of ICERD; and Art. 14(2)(h) of CEDAW; and Art. 27 of CRC; and, at the regional level, Arts. 15 and 16 of the Protocol to the AfCHPR on the Rights of Women in Africa. See also General Comments of the Committee on Economic, Social and Cultural Rights No. 4 (1991) on the right to adequate housing and No. 7 (1997) on forced evictions; and Principle 18 of the Guiding Principles on Internal Displacement.

4 See Art. 16 of UDHR; Art. 10 of ICESCR; Arts. 17 and 23 of ICCPR, Arts. 16 and 18 of CRC and at the regional level, Art. 18 of AfCHPR; Art. 17 of AmCHR; Art. 38 of ArCHR; Art. 5 of the Cairo Declaration on Human Rights in Islam; Arts. 8 and 12 of ECHR; and Art. 16 of the revised ESC. See also Principle 17 of the Guiding Principles on Internal Displacement. 
Forced displacement of people by the authorities can only be justified on an exceptional basis under human rights law and subject to strict conditions. It must be provided for by law and be necessary and proportionate to achieve a legitimate aim, such as to protect national security or public order, public health or morals, or the rights and freedoms of others (as outlined in Part V.12 ). It must be non-discriminatory and consistent with other human rights and international legal obligations of the State.

Even when such displacement can be justified, it must meet certain substantive and procedural safeguards and take place in conditions of safety and dignity. For example, any decision to displace individuals or communities must be taken by competent authorities. The authorities must assure the basic conditions for security and well-being at the place of destination before people are moved (including in the case of returns). Those affected must be informed of the reasons and procedures for displacement and given an opportunity to challenge the decision, including through independent judicial review. Wherever possible, their informed consent should be sought, their participation in planning and implementing the decision ensured and fair compensation given. ${ }^{5}$ Displacement should never be carried out in a manner that violates the rights to life, dignity, liberty and security of those affected.

Particular care must be taken to protect indigenous peoples, minorities, peasants, pastoralists and other groups with a special dependency on, and attachment to, their lands from displacement.

Certain human rights, such as freedom of movement, can be temporarily suspended by the national authorities in times of a public emergency, such as during armed conflict. ${ }^{6}$ Situations of armed conflict are governed by international humanitarian law.

\subsection{International humanitarian law}

International humanitarian law requires parties to a conflict to spare the civilian population as much as possible from the effects of hostilities and to treat all individuals in their power humanely. (See Part I.2.2 $\mathrm{D}$ ). The law specifically prohibits parties to a conflict to order the displacement of the civilian population, in whole or in part, unless the security of the civilians involved or imperative military reasons so demand, and it requires that displaced persons be allowed to voluntarily return in safety as soon as those reasons cease to exist.

The law also requires that all possible measures be taken to protect any property left behind, to ensure satisfactory conditions, including shelter, hygiene, health, safety and nutrition, while in displacement and to ensure that members of the same family are not separated. ${ }^{7}$

Depending on the context, the forced displacement of civilians can constitute a war crime and/or crime against humanity. ${ }^{8}$

\subsection{National legislation}

Many national Constitutions affirm rights relevant to arbitrary displacement, such as the right to freedom of movement and choice of residence. In addition, an increasing number of

\footnotetext{
5 Regarding the issue of fair reparation, see the Basic principles and Guidelines on Development-based evictions and displacement, http://www2.ohchr.org/english/issues/housing/docs/guidelines en.pdf. Compensation should be provided for any assessable damage, as appropriate and proportional to the gravity of the violation and the circumstances of each case. See also the Basic Principles and Guidelines on the Right to a remedy and reparation for victims of gross violations of international human rights law and serious violations of international humanitarian law.

6 See, for example, Art. 4 of ICCPR. Derogations are exceptional measures that are subject to strict requirements. See Part I.2.1

See, for example, ICRC, Rules 129-132 of Customary International Humanitarian Law - Volume I: Rules, 2005. See also Arts. 49 and 147 of the Fourth Geneva Convention; Art. 85(4)(a) and Art. 4(3)(b) of Additional Protocol I; and Art. 17 of Additional Protocol II.

8 See Art. 147 of the Fourth Geneva Convention and Art. 85(4)(a) of Additional Protocol I. See also Art. 7(1)(d); Art. $8(2)(e)($ viii) and Art. 8(2)(e)(viii) of the Statute of the ICC.
} 
governments have strengthened their legislation regarding internal displacement to bring it in line with the Guiding Principles on Internal Displacement, ${ }^{9}$ in particular establishing as crimes under domestic law those acts of displacement that amount to crimes against humanity or war crimes. ${ }^{10}$ Other State regulations may also refer to arbitrary displacement and could be found for instance in military manuals and laws relating to civilian crisis management.

\section{The responsibility of the State}

The State and its institutions have a responsibility to respect and ensure respect for their human rights obligations at all times. In times of conflict, the parties to the conflict are similarly obliged to respect and ensure respect for the rules of international humanitarian law. The most effective way to minimize the risk of displacement is to avoid conditions that might compel people to leave their homes against their will. In most cases, forced displacement could be avoided or greatly reduced if the rules of international law were respected. National authorities should ensure that the specific measures indicated below are taken.

- Take all possible measures to prevent and avoid conditions that might cause or contribute to forced displacement. This could include, for instance, ensuring respect for the rule of law, combating impunity and otherwise creating an environment conducive to the realization of rights.

- Refrain from forcing individuals and communities to leave their homes or places of habitual residence and protect them from being arbitrarily displaced by others. The authorities should seek all possible alternatives before resorting to displacement.

- When displacement is necessary and justifiable, the authorities must take action to minimize the scale of displacement and mitigate its adverse effects. In particular, the authorities should ensure to the greatest extent possible that it takes place in satisfactory conditions of safety, shelter, nutrition, health and hygiene, and that members of the same family are not separated.

- Ensure that displacement lasts no longer than required by the circumstances and that a durable solution is found for all those affected. The authorities should aim to create conditions for voluntary return and reintegration and/or settlement elsewhere in the country and facilitate them. IDPs should not be discriminated against as a result of having been displaced and should be entitled to restitution and/or compensation for property of which they may have been arbitrarily deprived.

- Provide protection and assistance to IDPs. Where the national authorities are unable or unwilling to do so, they should ensure rapid and unimpeded access by humanitarian actors to populations in need and facilitate the free passage of humanitarian assistance.

- Advocate with parties to armed conflicts and take all relevant measures, regardless of the country or countries concerned, to ensure that forced displacement of civilians does not occur unless necessary for their own protection or justified by imperative military reasons. ${ }^{11}$

9 For instance, Angola, Burundi, Colombia, Georgia and Peru. In 1997, Colombia adopted Law 387 on "measures to prevent forced displacement and to provide care, protection, support and socio-economic stability for persons displaced internally by violence in the Republic of Colombia." Although the law is consistent with the UN Guiding Principles on Internal Displacement, its implementation is problematic.

10 See, for instance, the Penal Code of Colombia, article 284A.

11 Under the Geneva Conventions of 1949 and their First Additional Protocol of 1977, States have undertaken a distinct legal obligation to ensure respect of international humanitarian law in any existing international conflict or situations of occupation. This obligation is of customary nature and is also applicable in non-international armed conflict. This obligation to "ensure respect" is not limited to behaviour by parties to a conflict but includes the requirement that States do all in their power to ensure that international humanitarian law is respected universally. 


\section{The role of humanitarian and human rights actors}

Humanitarian and human rights actors can play an important role in preventing and/or minimizing forced displacement and mitigating its adverse effects when it occurs. Such efforts should be based on an understanding of the applicable national and international legal framework and should be undertaken in close coordination with other relevant human rights, humanitarian, development and political actors. Humanitarian action must never undermine the right of every person to move freely within and out of his/her country as well as to seek asylum in another country.

\subsection{Addressing the causes of displacement}

Forced displacement is often caused by violations of human rights or, in cases of conflict, of international humanitarian law. Therefore, preventing these violations is often necessary to address displacement. However, it may be difficult for field practitioners to distinguish the violations of rights that are specifically at the root of displacement from the broader violations of rights occurring at a particular place. Selecting communities at risk of displacement for specific protective action, as opposed to developing protection strategies for the whole of an affected population, may overlook the situation of communities who suffer serious violations of rights without being at a particular risk of displacement. Thus, it is typically most essential that general protective strategies target identified threats and risks to affected populations according to their magnitude and severity rather than according to whether or not the threats/risks underlie the displacement. Nevertheless, these strategies may contain some elements that are displacement-specific, such as contingency planning. In any case, actions must be coordinated with agencies having specific mandates with regard to human rights or international humanitarian law.

Efforts to prevent or minimize unlawful displacement generally include a set of strategies or activities that seek to strengthen the rule of law as well as to prevent and respond to violations of human rights and humanitarian law. This can include building the capacities of the authorities to maintain law and order, combat impunity, ensure access to justice and promote the peaceful resolution of conflict and disputes. In times of armed conflict, special efforts must be made to ensure respect for humanitarian law by all parties to a conflict, including in particular provisions relating to the protection of civilians (as elaborated in Part I.2.2 [D]).

\section{In our work, we can ...}

Assessment

(See Part III. I $[D$ )
Ensure that protection assessments and analyses gather information about any factors or events that might result in forced displacement. Pay special attention to factors such as potential political or ethnic tensions within the country, disputes over land and other resources, incidents of violence and human rights violations, migratory movements which could result in clashes (e.g. between resident farming communities and nomadic herders), large-scale development projects and disaster-prone areas.

Share such information with relevant actors in order to inform early warning mechanisms and/or contingency planning. 


\section{Early-warning and contingency planning}

Coordination

\section{Presence}

(See Parts V.2 and $4 \square$ )

\section{Advocacy}

(See Part V.3

Mediation and dialogue

Work with other humanitarian and human rights actors to establish early warning mechanisms and develop contingency plans to respond to incidents of forced displacement. Such plans should identify the key actors, their roles and responsibilities and the strategies and/or activities which should be undertaken in case displacement occurs. All staff and partners should be familiar with contingency plans and standard operating procedures.

Where appropriate, help build the capacity of the competent authorities to maintain early warning mechanisms and develop and implement contingency plans in case displacement is imminent or already occurring.

Ensure that all preventative efforts are coordinated with other relevant human rights, humanitarian, development, political and military actors, such as peacekeeping forces where present. This includes protection working groups at all levels, the broader country team and the Humanitarian Coordinator in the country.

Maintain high visibility presence in areas at risk of displacement, if security conditions allow. Humanitarian presence can help to deter violations of human rights in some cases. Such presence, however, must be carefully evaluated. The presence of humanitarian actors can be perceived as condoning or endorsing serious human rights violations, including forced displacement.

Advocate with relevant authorities and, in times of armed conflict, with parties to a conflict, and encourage them to respect and ensure respect for human rights and humanitarian principles as outlined in the relevant bodies of international law. Emphasize their responsibility to avoid creating conditions that might lead to displacement, to refrain from forcibly displacing people and to protect them from being displaced by others, and to ensure that, if displacement occurs it takes place under satisfactory conditions of safety, health, shelter and nutrition and that members of the same family are not separated.

As needed, engage with influential stakeholders, such as regional or international organizations or relevant States, to encourage and support their involvement to minimize the risk of displacement.

Encourage open dialogue and support conflict prevention, mediation and resolution efforts at the local, regional and national levels.

Help build the capacity of civil society, communities at risk of displacement, national authorities and other stakeholders to participate in such efforts. This may include training on mediation and negotiation skills towards the peaceful resolution of conflicts.

\section{Information}

(See Part V.7 $\square$ )
Support public information campaigns that aim to inform and raise awareness of human rights and humanitarian principles. Inform the general public about forced displacement.

- In cases where displacement is imminent, work with the community to ensure that people are informed of the right to move elsewhere within the country and to leave the country in order to seek, for instance, asylum abroad. 


\begin{tabular}{|l|l|l|l}
\hline $\begin{array}{l}\text { Capacity building } \\
\text { and training }\end{array}$ (See Part V.9 & $\begin{array}{l}\text { Work with human rights and humanitarian actors to build the capacity of } \\
\text { the State, local authorities and non-State entities to respect and ensure } \\
\text { respect for human rights and humanitarian principles. This could include, } \\
\text { for instance, help to strengthen the rule of law and build the capacity of } \\
\text { the legislative, judicial, and executive branches of the State. } \\
\text { In coordination with ICRC and other relevant actors, support training for } \\
\text { armed forces and armed groups at all levels, including non-State actors, } \\
\text { on how to meet their obligations under international humanitarian law. } \\
\text { Work with civil society and community groups to strengthen their } \\
\text { capacity to raise their concerns and engage with national authorities in } \\
\text { order to prevent displacement. This may include providing training, } \\
\text { expertise or material support. Support their participation in relevant } \\
\text { regional or international fora and take other action to strengthen their } \\
\text { message and enhance the personal security of their membership. }\end{array}$ \\
\hline $\begin{array}{l}\text { Community } \\
\text { mobilization } \\
\text { (See Part V.10 }\end{array}$ & $\begin{array}{l}\text { Ensure that individuals and communities are informed about and able to } \\
\text { participate in public decision-making processes that affect their lives, } \\
\text { including identifying alternatives to displacement. } \\
\text { Support initiatives that promote self-reliance and access to basic } \\
\text { services, such as education, health care and livelihoods, that can help } \\
\text { reduce the need to seek such support elsewhere. }\end{array}$ \\
\hline
\end{tabular}

\subsection{Mitigating any adverse impact of forced displacement}

Detailed guidance on humanitarian involvement in lawful relocations or evacuations is provided in Part V.12

Efforts to prevent unlawful displacement should take place at all times. Where such efforts fail and unlawful displacement occurs, the humanitarian imperative may require that life-saving assistance and services be provided on an emergency basis. Such situations, however, may present a dilemma for humanitarian and human rights actors as their involvement may be interpreted or perceived as condoning or endorsing unlawful displacement. As a result, the neutrality and impartiality of humanitarian action may be placed at serious risk. In light of the complexity of such events and the potential political, legal and security implications, any such involvement must be cleared at the most senior level and in consultation with the Humanitarian Coordinator.

Central to such dilemmas is the issue of perception. The fact that humanitarian action is driven by impartiality may not necessarily be evident to a wide range of other stakeholders concerned. Thus, in addition to making carefully considered decisions, risks stemming from perceptions of humanitarian actors as not being neutral or impartial must be proactively managed through communication and similar strategies.

In our work, we can ...

Assessment (See Part III.I $\square$ )
Support a rapid assessment of urgent humanitarian needs arising as a result of displacement. Such an assessment can take place prior to, or during, the movement.

Identify problems requiring specialist expertise, and advocate for the timely deployment of technical experts. 


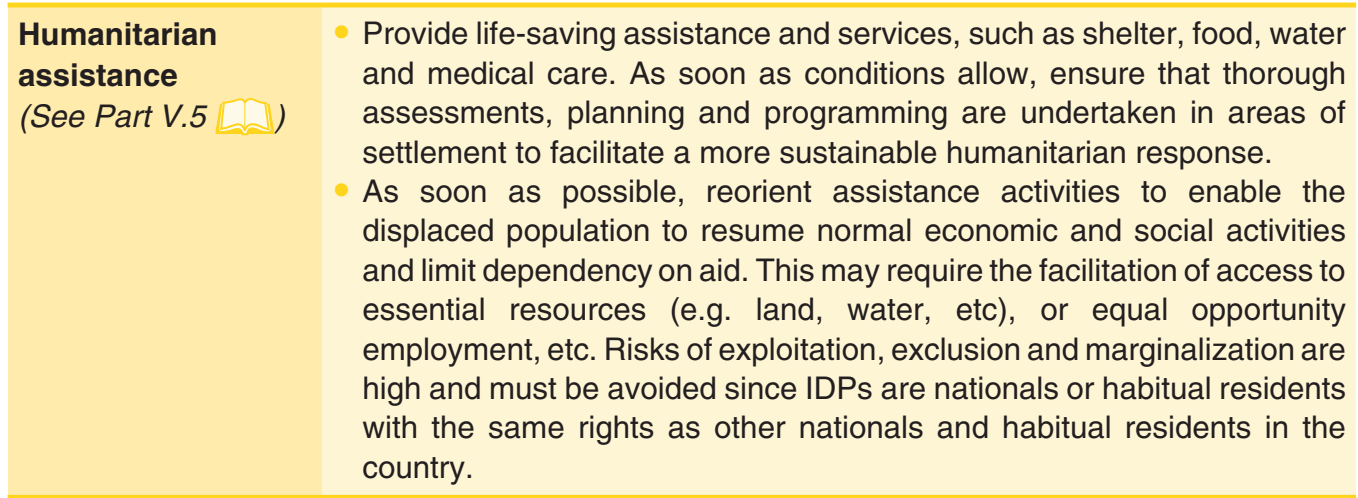

Presence and monitoring

(See Parts V.2 and 4 (D)

ocacy

(See Part V.3 $\square$ )

Family unity

(See Part IV.7 D)

Access to justice (See Part IV.18 and $V .8 \square$ )

Land and property
- Negotiate for humanitarian access to communities undergoing displacement. If a generic protection presence, such as human rights monitors, is not accepted, try to agree at least on access for humanitarian assistance purposes.

To the extent possible and if security conditions allow, monitor the forced movement of individuals and communities and ensure that accurate information is channelled to relevant actors (e.g. the protection working group, the country team and the Humanitarian Coordinator).

- Undertake continuous advocacy with all relevant stakeholders to minimize and mitigate the impact of the displacement. Those responsible for displacement should be encouraged at all times to treat the displaced population humanely and meet their needs for safety, shelter, food, water and sanitation. Special measures should be taken to meet the needs of persons with specific needs.

Repeatedly remind the authorities of their obligations to restore the conditions that would allow IDPs to consider return and the resolution of their displacement crisis while keeping in mind that, although conditions may allow for return, options for durable solutions should include on an equal basis return, relocation, and/or local integration.

Support and implement measures to avoid family separation, particularly targeting children, older persons and persons with disabilities, and ensure that family tracing and reunification activities are undertaken at the earliest opportunity.

Build the capacity of displaced individuals and communities to access justice and seek an effective remedy for any rights violated as a result of unlawful displacement. This can include providing legal counselling or other assistance to access the justice system, including traditional justice systems.

To help reduce the impact of loss of land and property, to the extent possible, inform affected individuals and communities of the importance of safeguarding personal and other documentation, including those relating to ownership or use of land and property. Encourage local communities to report on any loss of documents and property and inform them of procedures to follow to reclaim lost documents and property.

At the time of flight or as close to the time of flight as possible, assist the community in gathering and safeguarding information about ownership or use of land and property. Such information can include: copies of official records or registries; documents relating to mortgages; property or income taxes; telephone or utility bills; rental slips and photographs. 


\section{Key actors}

Efforts to prevent, minimize and mitigate the effects of forced displacement require a coordinated effort by a range of actors.

- At the national level, key actors include: displaced persons and communities; all levels of government, in particular ministries of the interior, defence, housing and social welfare, the judiciary, law enforcement authorities, and the armed forces; national human rights institutions or commissions; civil society and local NGOs. Even when they are part of the cause for forced displacement, State authorities do not lose their obligation to protect and assist people at risk in their territory. Thus, State structures at local, regional and national levels should be encouraged to meet these obligations. Where non-State actors are part of the risk of forced displacement, they should be included as key actors in efforts to prevent, minimize and mitigate the effects of forced displacement.

- At the regional level, key actors include: regional organizations, such as the African Union; regional human rights courts, commissions, and special rapporteurs; regional peacekeeping forces, where present; and influential donor or neighbouring States.

- At the international level, key actors include: various political, development, human rights and humanitarian actors, as well as peacekeeping forces where present. Relevant actors include the International Community of States, the Humanitarian/Resident Coordinator, OCHA, UNDP, OHCHR, UNHCR, UNICEF, UNIFEM, UNFPA, IOM, ICRC, and NGO partners.

\section{Key references \& useful websites}

- Addressing Internal Displacement: A Framework for National Responsibility, Brookings-Bern Project on Internal Displacement, 2005.

- Handbook for Applying the Guiding Principles on Internal Displacement, OCHA/ Brookings-Bern Project on Internal Displacement, 1999.

- Manual on Field Practice in Internal Displacement: Examples from UN Agencies and Partner Organizations of Field-based Initiatives Supporting Internally Displaced Persons, IASC Policy Paper Series, No. 1, 1999.

- Protection of Internally Displaced Persons, IASC Policy Paper Series, No. 2, 2000. 


\section{Part IV.2 \\ Threat to life, safety and security}

Key message

1. Protection from crime, violence and abuse

1.1 The international legal framework and the responsibility of the State 148

1.2 The role of humanitarian and human rights actors 149

2. Protection from the effects of armed conflict and activities of parties to a conflict.

2.1 The international legal framework and the responsibilities of parties to a conflict......152

2.2 The role of humanitarian and human rights actors 154

3. Key actors 156

Key references \& useful websites 156

Annex I 


\section{Key message}

Internally displaced persons (IDPs) and communities can face a range of serious threats to their life, safety and security at every stage of the displacement cycle. Such threats can stem from a variety of sources and include diverse actors, depending on the context. It is primarily the role of the national authorities to provide protection against such threats and to ensure that acts of crime, violence and abuse do not take place in a climate of impunity.

Humanitarian and human rights actors rarely have the mandate, the capacity or the resources to physically protect displaced individuals and communities from such threats. However, we can contribute to their protection by helping to reduce their exposure to, and mitigate the devastating effects of, such violence whenever possible.

This chapter should be read together with Part IV.4 $\square$ on gender-based violence and Part IV.5 on children associated with armed forces or armed groups. It offers guidance on ways to address three distinct but interrelated threats to life, safety and security:

- threats resulting from a breakdown of law and order, including individual or collective acts of crime, violence ${ }^{1}$ and abuse;

- threats arising in the context of armed conflict, i.e. at the hands of, or as a result of, the activities of armed forces or armed groups that are parties to the conflict; and

- threats arising as a result of communal or intra-group tension, either within the displaced population or between the displaced and the host population as, for example, a result of competition for scarce resources, such as land, water or firewood. ${ }^{2}$

\section{Key considerations}

Ensuring safety and security is the responsibility of the State and its institutions. It is important to engage with national and local authorities to the extent possible when seeking to identify, prevent and respond to security threats in order to ensure the sustainability and effectiveness of such actions.

IDPs and communities are themselves key protection actors. They have an understanding of the local context and access to information and knowledge, which others may lack. They should be consulted, and any existing coping mechanisms and strategies supported.

Sometimes the best protection strategy available to people is for them to leave. Even where measures are taken to enhance people's safety and security, they retain the right to move elsewhere within the country or to leave the country and seek asylum abroad.

\section{Protection from crime, violence and abuse}

Forced displacement often takes place in situations characterized by a breakdown in the rule of law, where national or local authorities may lack the capacity, or the willingness, to maintain law and order and to ensure the safety and security of displaced individuals and communities. Together with other factors - such as armed conflict, the collapse of institutions and infrastructure, poverty, lack of education and livelihood opportunities, and a breakdown of

\footnotetext{
In general, an act of violence, whether it takes place during conflict or not, can be defined as any act that inflicts physical, mental, sexual or other harm or suffering upon an individual or group, including threats of such acts, and that either results in, or has the likelihood of, resulting in injury, death, physical or mental disability, or deprivation.

2 This list is not exhaustive and various other threats might need to be identified and addressed. This includes, for example, threats arising in the context of natural or environmental disasters, such as fires, draught, floods, earthquakes, landslides and pollution.
} 
social norms and values - this may lead to a marked increase in crime, exploitation and abuse in both the public and private spheres.

IDPs often bear the brunt of such violence. They have frequently lost the protective presence of their homes, families and communities and lack access to life-saving assistance and services, including food, shelter and basic health care. As a result, they may find themselves at greater risk of such violence at the same time as their ability to recover from its harmful effects is undermined.

While such threats are common in both urban and rural environments, they can be particularly pronounced in large and over-crowded camps or settlements. Population density, poverty and sub-standard living conditions, combined with a lack of effective law enforcement and access to justice can create fertile ground for crime, violence and abuse at the hands of internal and external actors. Such threats can range from minor offences, such as theft, robbery and vandalism, to serious violations of human rights, including rape, physical assault and killings.

The closed environment of camps and settlements coupled with anxiety and desperation stemming from trauma, marginalization and a lack of hope, can contribute to an increase in the frequency and seriousness of such acts and undermine the coping mechanisms of individuals and communities as well as their ability to protect themselves.

\section{Table 1: Examples of common threats to life, safety and security}
Murder; killings; assassination; forced disappearance; summary or arbitrary executions; physical assault or battering. Torture or cruel, inhuman and degrading treatment and other outrages upon personal dignity; mutilation or maiming; corporal punishment.
Sexual and gender-based violence, including rape and sexual assault, abuse or humiliation; sexual exploitation, including forced prostitution and sex in exchange for aid; harmful traditional practices, such as female genital mutilation, forced and early pregnancy; and honour killings.

\author{
Abduction; kidnapping; enslavement: forced \\ recruitment; forced labor; human trafficking; \\ sexual slavery. \\ Forced displacement, forced return or \\ relocation. \\ Harassment, intimidation and coercion. \\ Destruction of livelihoods and property, \\ including land, fields, crops and livestock and \\ other objects indispensable for people's \\ survival; vandalism; and arson. \\ Theft; robbery; looting; cattle rustling; and \\ fraudulent seizure/purchase of land or \\ property. \\ Extortion; fraud; forgery; unlawful taxation; \\ and paying of "protection" money. \\ Exploitation, obstruction or diversion of \\ humanitarian assistance.
}

\subsection{The international legal framework and the responsibility of the State}

International (and regional) human rights law contains a number of provisions which are of particular relevance to IDPs, including the rights to life, liberty and security; to freedom from torture and cruel, inhuman or degrading treatment or punishment; to freedom from slavery; to equal recognition and protection of the law; and to access to justice.

The State must ensure that all relevant authorities and agents of the State respect these rights, provide protection against any violation of these rights by third parties, and ensure that individuals are provided access to appropriate remedies when violations occur. To that effect, national authorities should take all appropriate legislative, administrative and executive measures to:

- maintain law and order and strengthen civilian law enforcement, including through the training and deployment of adequate numbers of civilian police, both female and male, including in and around camps and settlements and other areas inhabited by IDPs; 
- improve access to justice and strengthen formal and informal justice institutions and mechanisms in order to combat impunity, including by ensuring the prompt and thorough investigation and prosecution of alleged offenders; and

- build the capacity of individuals and communities to protect themselves and recover from crime, violence and abuse, including by facilitating their access to life-saving assistance and services which can reduce exposure to such threats, such as adequate shelter, livelihoods, and health care.

It is worth noting that the use of force and firearms for law enforcement purposes is strictly regulated under human rights law. It must be necessary and proportionate to achieve a legitimate aim, such as to make an arrest or to protect the lives of civilians, and an official investigation must be conducted if it results in injury or loss of life. These and other rules are described in greater detail in the UN Code of Conduct for Law Enforcement Officials and the UN Basic Principles on the Use of Force and Firearms by Law Enforcement Officials. $^{3}$

\subsection{The role of humanitarian and human rights actors}

While humanitarian and human rights actors rarely have the mandate, the capacity or the resources to guarantee protection against crime, violence and abuse, they can assist national authorities and persons of concern to reduce exposure to, and limit the adverse effects of, such acts. Such efforts should seek to address the political and socio-economic causes and consequences of crime as well as crime itself. In order to ensure the sustainability of such efforts close coordination with national authorities and displaced and resident communities will be required.

\section{In our work, we can ...}

\begin{tabular}{|c|c|}
\hline $\begin{array}{l}\text { Assessment and } \\
\text { analysis } \\
\text { (See Part III.1 }\end{array}$ & $\begin{array}{l}\text { Ensure that protection assessments take into account the various threats } \\
\text { to life, safety and security of IDPs stemming from crime, violence and } \\
\text { abuse. Where possible such assessments should be conducted in } \\
\text { cooperation with security and/or law enforcement experts. It could } \\
\text { assess factors such as (i) the types of threat; (ii) those that are most at } \\
\text { risk; (iii) the actors involved and their motives; (iv) any aggravating } \\
\text { factors or conditions; (v) the capacity of the State to address the risks, } \\
\text { any obstacles encountered and the kind of support needed; (vi) the } \\
\text { impact on persons of concern, their coping strategies and the kind of } \\
\text { support they need to counter the risks involved; and (vii) any possible } \\
\text { negative unintended consequences that might result from our } \\
\text { intervention. }\end{array}$ \\
\hline
\end{tabular}

Advocacy

(See Part V.3
Advocate with all relevant stakeholders, including law enforcement agencies and ministries of justice and the interior, for adequate numbers of trained and professional civilian police, including female officers, to be deployed in camps, settlements and other civilian areas.
Support information and education campaigns/networks, whether through radio, theatre or printed media (leaflets, posters, etc.) that provide neutral security-related information and advice. Such networks should ideally be run by the community, allow information from more than one source, take illiteracy and disabilities into account, and include safeguards pertaining to manipulation for political or military purposes.

\footnotetext{
These are available at: www.ohchr.org/english/law/index.htm.
} 
Material, technical and financial support

Training
Consider providing material, technical or financial support to law enforcement agencies and relevant ministries, if appropriate. This can include material support (e.g. office space or equipment, telecommunications equipment, vehicles, or fuel), managerial support (e.g. planning, coordination), or financial support (e.g. staff incentives).

\begin{tabular}{|c|c|}
\hline Training & $\begin{array}{l}\text { Provide or support trainıng relating to human rights, codes of conduct for } \\
\text { and other security personnel. Consider whether other stakeholders could } \\
\text { benefit from similar training initiatives. }\end{array}$ \\
\hline $\begin{array}{l}\text { Reporting } \\
\text { mechanisms }\end{array}$ & $\begin{array}{l}\text { Support the establishment of adequate reporting and referral } \\
\text { mechanisms for incidents of crime, violence and human rights abuses. } \\
\text { Such mechanisms should preferably be run by national law enforcement } \\
\text { authorities. In some cases, however, such mechanisms may need to be } \\
\text { established by humanitarian or human rights actors, for instance within } \\
\text { camps and settlements. Such mechanisms must respect privacy and } \\
\text { confidentiality and be adequately supervised and monitored. Ensure that } \\
\text { the informed consent of victims/witnesses is sought prior to the sharing } \\
\text { of information, that their safety is guaranteed, and that they are referred } \\
\text { to appropriate actors for legal, medical or other assistance, as required. }\end{array}$ \\
\hline $\begin{array}{l}\text { Access to justice } \\
\text { (See Parts IV. } 18 \\
\text { and V.8 } \square \text { ) }\end{array}$ & $\begin{array}{l}\text { Improve access to, and the fair administration of, justice by building the } \\
\text { capacity of both formal and informal justice mechanisms and the } \\
\text { capacity of individuals and communities to access and benefit from such } \\
\text { mechanisms. This can include material support (e.g. office space or } \\
\text { equipment, telecommunications, vehicles, fuel, staff incentives), } \\
\text { managerial support (e.g. planning, coordination), or training (e.g. human } \\
\text { rights, standards of professional conduct). }\end{array}$ \\
\hline $\begin{array}{l}\text { Community } \\
\text { mobilization } \\
(\text { See Part V.10 })\end{array}$ & $\begin{array}{l}\text { In cooperation with the community, identify various ways to strengthen } \\
\text { the protection capacity of individuals, communities and civil society to } \\
\text { prevent, respond to and recover from violence through, for instance, } \\
\text { training, counselling and/or material support. This could include training } \\
\text { on human rights and humanitarian principles and other topics, such as } \\
\text { first aid, crime prevention, fire-fighting, mine-awareness, conflict } \\
\text { resolution, and community relations. Pay particular attention to } \\
\text { individuals and groups with specific needs, including single women and } \\
\text { girls, older persons and minorities. }\end{array}$ \\
\hline $\begin{array}{l}\text { Family unity } \\
(\text { See Part IV.7 } \square)\end{array}$ & $\begin{array}{l}\text { Ensure that any separated family members are identified, that family } \\
\text { tracing and reunification mechanisms are established, and that } \\
\text { immediate needs for protection and/or assistance are addressed. In the } \\
\text { case of separated and unaccompanied children, best interest } \\
\text { determinations may need to be conducted and alternative care } \\
\text { arrangements identified. }\end{array}$ \\
\hline $\begin{array}{l}\text { IDP community or } \\
\text { camp management } \\
\text { (See Parts V.5 } \\
\text { and V.6 })\end{array}$ & $\begin{array}{l}\text { Ensure that community and camp-management committees, including } \\
\text { relief-distribution committees, are non-discriminatory, participatory and } \\
\text { representative. Adequate safeguards against manipulation, misuse and } \\
\text { diversion of aid to political or military forces or groups must be put in } \\
\text { place. Camp rules should be drafted and disseminated by the } \\
\text { committees in cooperation with camp management authorities. }\end{array}$ \\
\hline
\end{tabular}




\section{Community-watch mechanisms}

(See Annex I to this chapter $\square$ )
Assist the community in organizing and managing, in cooperation with the police when feasible, community watch mechanisms, as described in Annex I of this chapter. These must be civilian in character, include both women and men, and should receive adequate training in basic principles of law enforcement. They should be adequately supervised, monitored and equipped.

Maintain high visibility presence in and around IDP camps, settlements and hosting areas, if security conditions permit. Beware, however, that in some cases presence can instil a false sense of safety and security among persons of concern and/or attract unwanted attention to them.

\section{Presence}

(See Part V.4

Ensure that camps, settlements and IDP-hosting areas conform, to the extent possible, with the principles of protection-based physical planning as regards site selection, site layout, distribution of aid and service design. This includes, for example, ensuring adequate distance from armed conflict or other sources of violence; security lighting; community participation in the layout of family plots; allocation of adequate space per family; safe access to resources, such as food, water and firewood; safe access to services, such as police, camp management offices, sanitation facilities, schools, markets and community centres; and establishment of child-friendly spaces. Work together with partners to ensure that gender, age and disabilities are taken into consideration.

\begin{tabular}{|c|c|}
\hline $\begin{array}{l}\text { Humanitarian } \\
\text { assistance } \\
(\text { See Part V.5 } \square \text { ) }\end{array}$ & $\begin{array}{l}\text { Advocate for, or provide, assistance and services which can reduce } \\
\text { exposure to, or mitigate the effects of, crime, violence and abuse. This } \\
\text { can include food, firewood, fuel-efficient stoves, and various non-food } \\
\text { items, particularly if IDPs are exposed to risks when acquiring such items } \\
\text { by other means. } \\
\text { Ensure that relief distribution does not create or expose IDPs to } \\
\text { additional risks. It should take place in a safe environment, and relief } \\
\text { items must be distributed equitably and in a non-discriminatory manner. } \\
\text { It should also take into account and address the specific needs of } \\
\text { women, children, older persons and those living with disabilities, as well } \\
\text { as the needs of the surrounding communities. }\end{array}$ \\
\hline $\begin{array}{l}\text { Education and } \\
\text { socio-economic } \\
\text { activities } \\
\text { (See Parts IV.15 } \\
\text { and IV. } 16 \square \text { ) }\end{array}$ & $\begin{array}{l}\text { Support socio-economic initiatives, such as education or vocational } \\
\text { training and cultural, religious and sports activities. This can help to limit } \\
\text { exposure to various threats, reduce violence within communities, help } \\
\text { individuals recover from the effects of violence, and contribute to } \\
\text { sustainable livelihoods. }\end{array}$ \\
\hline $\begin{array}{l}\text { Evacuation or } \\
\text { relocation } \\
(\text { See Part V.12 } \square)\end{array}$ & $\begin{array}{l}\text { Where necessary, facilitate the evacuation or relocation of certain } \\
\text { individuals or groups (e.g. victims, witnesses or others at risk) to a place } \\
\text { where their physical safety can be guaranteed. Evacuation and } \\
\text { relocation are usually measures of last resort, and minimum standards of } \\
\text { safety, food, health, and shelter must be met both during and after they } \\
\text { take place. Each of these security measures are typically temporary and } \\
\text { should not delay the search for a sustainable solution. }\end{array}$ \\
\hline $\begin{array}{l}\text { Health and } \\
\text { psycho-social } \\
\text { support } \\
\text { (See Parts IV.14 } \\
\text { and V. } 11 \text { ) }\end{array}$ & $\begin{array}{l}\text { Ensure that victims/survivors of crime, violence and abuse have access } \\
\text { to adequate health care and other services. This should include physical, } \\
\text { mental and reproductive health care and psychosocial support for people } \\
\text { dealing with the effects of violence, including trauma and post-traumatic } \\
\text { stress disorders. }\end{array}$ \\
\hline
\end{tabular}




\section{Protection from the effects of armed conflict and activities of parties to a conflict}

Forced displacement is not only a regrettable consequence of armed conflict. It is frequently the result of a deliberate strategy aimed at terrorizing, humiliating and destroying individuals and communities. As such, it has become both a method of warfare and, in some cases, the very objective of conflict itself. The impact upon individuals and communities is devastating. An estimated 25 million persons are currently internally displaced as a result of armed conflict, and civilian casualties of conflict in general outnumber those among military actors by almost four to one.

Violence against civilians at the hands of armed forces and armed groups is often widespread, systematic and conducted in a climate of impunity. Examples of such violence are noted below.

- Direct or indiscriminate attacks against civilians or civilian property and other unlawful means and methods of warfare, including forced displacement, mass rape, acts of terror, starvation and destruction of land, homes and other property, such as crops and livestock.

- Ill-treatment of civilians or those placed hors de combat in the power of parties to the conflict, including murder, torture and other ill-treatment, sexual assault, rape and sexual humiliation, arbitrary arrest and detention, extra-judicial killings and disappearances, extortion, harassment, the confiscation of documents, and the appropriation of land and property. Such acts might take place in areas of refuge or transit, including in and around camps and settlements, in detention or prison facilities, at checkpoints, or entry/exit points into towns and villages.

- Presence of armed actors/groups in camps, settlements and IDP-hosting areas, including their use for rest, recruitment and/or resources. Such presence negates the humanitarian character of these areas and poses a serious threat to their residents, host communities and humanitarian workers. The presence of armed actors frequently results in an increase in forced recruitment, sexual assault and exploitation, various forms of physical violence, murder, torture and ill-treatment, harassment, extortion, theft and the destruction of property, and the diversion of humanitarian aid. It might also expose the civilian population to attack and a range of punitive measures by other parties to the conflict, including restrictions on freedom of movement and access to humanitarian aid.

- Forced recruitment into armed forces or armed groups, particularly of children and adolescents who might be forced to participate in hostilities or to serve as sex slaves, spies, porters, cleaners or cooks. Such children are often compelled to witness or commit acts that might leave them traumatized and hinder their reintegration into society upon release (further addressed in Part IV.5 DU).

\subsection{The international legal framework and the responsibilities of parties to} a conflict

International humanitarian and human rights law, together with national law, provide a comprehensive legal framework governing the conduct of hostilities and the treatment of civilians in times of armed conflict.

See Principles 10 and 11 of the Guiding Principles on Internal Displacement, which are available in Annex 1 of the Handbook. For further information, see also Part I.2. 
International humanitarian law, which applies to State and non-State actors equally, comes into effect in times of armed conflict. While different legal provisions may apply depending on whether the conflict is international (between States) or non-international (between a State and non-State actors, or between such actors), the basic principles regarding the protection of civilians remain similar. ${ }^{4}$ The law contains two sets of rules of particular importance to civilians, including IDPS:

- rules limiting the means and methods of warfare which prohibit direct or indiscriminate attacks against civilians and civilian objectives and require parties to a conflict to distinguish between combatants/fighters and civilians at all times ${ }^{5}$ (further addressed in Part I.2 QD); and

- rules containing fundamental guarantees of humane treatment which oblige parties to a conflict to treat all persons who do not take part in, or who have ceased to take part in, hostilities in a humane manner and to protect them against violence to life, health and physical or mental well-being. ${ }^{6}$

All parties to a conflict, both State and non-State actors, are obliged to distinguish between civilians and combatants/fighters at all times and to respect the humanitarian nature of camps, settlements and other IDP-hosting areas. This entails taking all feasible measures to protect such areas from direct attack and the indiscriminate effects of military operations and to treat individuals in their power humanely. The State, including its armed forces and armed groups, has an obligation to ensure that military activities and the activities of members of the armed forces, whether on active duty or not, respect humanitarian law and principles relating to the protection of civilians, including by:

- providing training on humanitarian law to the armed forces;

- criminalizing violations of the law and establishing adequate legal, administrative and disciplinary structures to prevent, monitor and punish violations; and

- prosecuting and punishing (which is further strengthened by international criminal law and covers acts such as war crimes, crimes against humanity and genocide), or extraditing, upon request, those responsible for serious violations of the law. (See Part I.2.5

International (and regional) human rights law continues to apply in times of armed conflict, and the national authorities should continue to respect the rights outlined in section 1.2 above. While the State can lawfully derogate from some human rights during times of war or public emergency, such derogation is subject to strict conditions. Moreover, the rights mentioned above are non-derogable, meaning that they must be respected at all times, including during armed conflict. The obligation to respect human rights can also extend to armed groups in control of territory, particularly if they exercise State-like functions. In some cases, such groups have expressly agreed to respect human rights.

4 These are primarily based on customary law as well as the four Geneva Conventions and Additional Protocol I, which apply in international armed conflict, and Additional Protocol II, which together with Common Article 3 of the Conventions, applies in non-international conflict.

5 Prohibited acts include direct and indiscriminate attacks against civilians or their settlements; use of civilians to shield military objectives from attack or to shield, favor or impede military operations; displacement of civilian populations; acts of violence intended to spread terror; starvation of the civilian population as a method of warfare and attacking, destroying, removing or rendering useless objects indispensable for its survival; reprisals against civilians or their property and collective punishments which, in practice, often take the form of destruction of property, leading to displacement. The law also prohibits the use of means and methods of warfare that cause superfluous injury or unnecessary suffering or that cause widespread, long-term and severe damage to the natural environment or that jeopardize the health or survival of the population. This includes exploding bullets, chemical and biological weapons, blinding laser weapons and anti-personnel mines.

6 This includes: murder, mutilation, torture and cruel, humiliating or degrading treatment; rape, enforced prostitution and any form of indecent assault; and forced recruitment of children and slavery in all of its forms, including sexual slavery, exploitation and abuse. 


\subsection{The role of humanitarian and human rights actors}

Armed conflict poses a unique set of challenges to humanitarian operations. In most cases, an effective response will require a coordinated approach, involving not only human rights, humanitarian and development actors but also political and military actors at the national, regional, and international levels. In most cases, it is recommended that protection strategies and activities be coordinated with relevant security staff and with other stakeholders, including the United Nations Humanitarian Coordinator in the country as well as peacekeeping missions, where present.

In the initial stage, protection efforts often focus primarily on building the capacity of national authorities as well as that of displaced individuals and communities (as outlined in the table below). Where such efforts prove insufficient, other responses may need to be considered. In some cases, this may require advocacy and support for peace negotiations and agreements, the deployment of regional or international civilian or police monitors, or referral to relevant political bodies, such as the United Nations Security Council. ${ }^{7}$

\section{In our work, we can ...}

\begin{tabular}{|c|c|}
\hline $\begin{array}{l}\text { Early warning and } \\
\text { contingency } \\
\text { planning }\end{array}$ & $\begin{array}{l}\text { Work with security staff to establish early-warning and preparedness } \\
\text { mechanisms aimed at identifying and responding to potential security } \\
\text { threats, including military operations and the infiltration of armed } \\
\text { elements into camps, settlements and other IDP-hosting areas. }\end{array}$ \\
\hline $\begin{array}{l}\text { Advocacy } \\
\text { (See Parts II.2 } \\
\text { and V.3 } \square \text { ) }\end{array}$ & $\begin{array}{l}\text { Work with civil-military liaison officers to establish direct lines of } \\
\text { communication with armed forces and armed groups to advocate for } \\
\text { respect of relevant humanitarian principles and to explain the } \\
\text { humanitarian mandate and the need to maintain a clear distinction } \\
\text { between civilian and humanitarian action and military operations. Insist } \\
\text { that IDP camps and settlements are kept free of infiltration and are not } \\
\text { used for recruitment or material and political support. }\end{array}$ \\
\hline
\end{tabular}

Preventing the Work with the community and other partners to prevent the militarization militarization of of camps, settlements and other IDP-hosting areas. This may include (i) civilian areas using information and communication campaigns or other activities to sensitize the community of the negative impact of militarization; (ii) discussing with the community what measures can help improve their security; and (iii) ensuring that IDP camps and settlements are located away from areas of conflict or areas known to be inherently unstable or suffering from endemic violence.

Access to justice
(See Part IV.18 Advocate with the State and, where possible, non-State actors for
measures to end impunity, including the prompt and effective
investigation, prosecution and punishment of violations of humanitarian
and human rights law and national military codes. Acts that amount to
war crimes, crimes against humanity or genocide, and other serious
violations of the law require special attention.

In the context of its work with refugees, UNHCR has developed a "ladder of options" composed of soft, medium and hard approaches. The soft approach involves preventive measures, where international organizations provide support to the State to maintain safety and security; the medium approach involves the use of the international civilian or police monitors who provide technical expertise and support to local authorities, through training, mentoring and monitoring; and the hard approach involves the direct use of international peacekeeping or peacebuilding forces, authorized by the United Nations Security Council, to maintain safety and security. 


\section{Identification, neutralization and separation of armed elements}

- Where appropriate, advocate for the establishment of security mechanisms to prevent infiltration by armed forces or armed groups into civilian camps and settlements. Such mechanisms can include, depending on the circumstances (i) screening at the entry to and inside camps and settlements or when accessing assistance or services; (ii) encouraging the self-identification of combatants/fighters and their voluntary separation from the civilian population; and (iii) spot-checks, weapons searches, and, on an exceptional basis, the physical separation of such individuals from the civilian population.

The involvement of humanitarian and human rights actors in such activities must be carefully evaluated and cleared at the senior level.

Forced recruitment

Advocate for, and take other measures to prevent, the forced recruitment and use of children by armed groups.

Where children have been or are being recruited, work with specialized partners to secure their release from armed forces and/or groups. Such efforts do not have to form part of a formal disarmament, demobilization and reintegration (DDR) process but should be pursued at all times.

\section{Demobilization, disarmament, reintegration} (See Part IV.5 $\square$ )

Mine action (See Part IV.3 DU)
DDR programmes should be coordinated and implemented by specialized actors with the required expertise and resources. However, humanitarian and human rights actors can support such programmes by, for instance, (i) advocating for the establishment and adequate funding of DDR programmes where needed; (ii) advocating to ensure that such programmes are available and meet the needs of women and girls on an equal basis as those of men and boys; (iii) working with families and communities to encourage them to accept and prepare for the return and reintegration of former combatants, particularly children formerly associated with armed groups; (iv) assisting families of former combatants to reunite; and (v) ensuring that former combatants have equal access to programmes that provide psychosocial support, education, vocational training or micro-financing for small businesses.

Advocate for and support mine action activities in all mine affected areas. Mine action should be coordinated and implemented by specialized actors, such as UNMAS, that have the required expertise and resources. However, all humanitarian and human rights actors can support such activities by, for example, (i) working with specialized actors to identify mine-affected civilian areas, including IDP camps and settlements, public buildings or spaces, fields, water-points, schools, and pre-schools; (ii) providing financial or material support to mine action programmes/actors, for instance in the form of fuel, vehicles and other equipment; and (iii) including mine awareness and education in school curricula and other educational or training activities.

Peacekeeping forces and/or national armed forces can provide security to humanitarian operations, on an exceptional basis and as a last resort by, for instance, providing logistical or technical support or escorting relief convoys. Such support must be carefully evaluated and cleared at the senior level, as it may risk blurring the distinction between humanitarian and military action and undermine the actual or perceived independence, impartiality and neutrality of the former. The presence of military forces can also expose communities to attack or create other security risks, such as exposure to sexual abuse. 


\section{Safe days or} routes, and humanitarian zones (See Part V.4 Da)

\begin{abstract}
On an exceptional basis and as a last resort, consider the possibility of encouraging relevant actors to negotiate "safe routes" or "safe days" to facilitate the delivery of life-saving assistance or services to populations in need. In extreme cases, this can also include the establishment of humanitarian zones (through humanitarian negotiations with parties to a conflict or by an agreement among the latter) or security zones (secured by force). Such negotiations should only take place at the senior level following a careful assessment and clearance by experienced security staff and with the agreement of the Humanitarian Coordinator. In the past, such arrangements have failed to protect civilian populations and, instead, exposed them to serious threats. Therefore, extreme caution should be exercised when resorting to such options.
\end{abstract}

\section{Key actors}

- At the national level: internally displaced and host communities; ministries of justice, defence and the interior; law enforcement agencies; courts and other justice institutions; prison authorities; armed forces; human rights commissions and ombudsmen; parliamentary commissions and committees that legislate on, or maintain oversight over, armed forces or law enforcement agencies; civil society organizations and NGOs.

- At the regional level: any regional military and civilian peacekeeping forces; regional organizations, such as the African Union, the European Union, Economic Community of West African States, the Organization for Security and Cooperation in Europe; regional human rights commissions and courts; governments of neighbouring States, influential States in the region, and donor States.

- At the international level: any United Nations, military and civilian peacekeeping forces; staff of the United Nations security management system; security/protection staff of individual organizations and NGOs; United Nations Security Council; ICRC; UNICEF (particularly relating to the disarmament, demobilization and reintegration of child soldiers); United Nations Mine Action Service; International Criminal Court (ICC); United Nations treaty bodies and special procedures.

\section{Key references and useful websites}

- Camp Management Toolkit, Norwegian Refugee Council $2^{\text {nd }}$ edition, 2008.

- Civil-Military Relationship in Complex Emergencies: An IASC Reference Paper, IASC, 2004.

- Field Security Handbook, United Nations, 1995.

- Guidelines on the Use of Military and Civil Defence Assets to Support United Nations Humanitarian Activities in Complex Emergencies, Inter-agency Standing Committee, 2003.

- Inter-organizational Security Measure: Framework for Accountability for the United Nations Security Management System, 2002.

- Use of Military or Armed Escorts for Humanitarian Convoys: Discussion Paper and Non-binding Guidelines, Inter-agency Standing Committee, 2001.

- Working with the Military, UNHCR, 2007. 
Annex I

Community watch mechanisms

\begin{tabular}{|c|c|}
\hline Introduction & $\begin{array}{l}\text { While primary responsibility rests with the State, individuals and } \\
\text { communities can also play an important role in enhancing safety and } \\
\text { security. Community watch mechanisms (CWM) can - if adequately } \\
\text { trained, equipped and supervised - help reduce the levels of crime, } \\
\text { violence and abuse within the community. This note summarizes some } \\
\text { good practice relating to the establishment and running of CWM. It } \\
\text { should be noted, however, that CWM should generally not be used in } \\
\text { highly politicized or militarized settings owing to the risk that such } \\
\text { mechanisms can pose to individuals and communities that participate in } \\
\text { them. }\end{array}$ \\
\hline $\begin{array}{l}\text { Definition and } \\
\text { overall aim }\end{array}$ & $\begin{array}{l}\text { CWM can be defined as mechanisms that are organized and staffed by } \\
\text { members of the community with the aim of supporting civilian law } \\
\text { enforcement through a police-community partnership. Such mechanisms } \\
\text { have particular value where police and security forces are absent, } \\
\text { overwhelmed, or otherwise lack the capacity to maintain law and order. } \\
\text { In addition, they can play an important role in identifying risk factors and } \\
\text { addressing minor disputes, tensions, and conflict within the community, } \\
\text { especially in camp settings. }\end{array}$ \\
\hline $\begin{array}{l}\text { Roles and } \\
\text { responsibilities }\end{array}$ & $\begin{array}{l}\text { CWM can be assigned different roles and responsibilities depending on } \\
\text { the context and, while no one model will fit all, common functions have } \\
\text { included: patrolling; providing protection through presence; monitoring } \\
\text { and reporting; assisting victims and survivors to seek assistance and } \\
\text { report crime; registering complaints and mediating minor disputes; } \\
\text { protecting community property from theft, sabotage, or fire; assisting with } \\
\text { crowd control, for instance during relief distribution; and liaising between } \\
\text { the community and police or camp authorities. }\end{array}$ \\
\hline Not police forces & $\begin{array}{l}\text { It is important to note that CWM are neither part of, nor a substitute to, } \\
\text { effective law enforcement, and their members should under no } \\
\text { circumstances carry arms or be authorized to perform police related } \\
\text { functions, such as arresting, detaining or interrogating suspects or } \\
\text { interviewing victims and witnesses. They should be entirely civilian in } \\
\text { character, have no established links with armed forces or armed actors, } \\
\text { and be closely supervised by relevant authorities as well as the } \\
\text { community. }\end{array}$ \\
\hline
\end{tabular}


Key considerations Some of the lessons learned from previous experience with CWM projects and lessons

learned

Further information

are indicated below.

- Proper consultation and cooperation with local and other relevant authorities, including police, military and camp management authorities, must be ensured. CWM should be established with the consent of, and under the supervision of, relevant authorities, which retain primary responsibility for safety and security.

CWM should be participatory, representative and include men and women of different ages and ethnic or religious background, chosen by the community through a fair, open and transparent process.

Roles, responsibilities and reporting lines must be clearly delineated in a written memorandum of understanding between relevant stakeholders and a code of conduct should be agreed upon.

Adequate supervisory, monitoring and disciplinary systems must be put in place, including safeguards against corruption and abuse of power, such as diversion of aid and sexual exploitation and abuse.

- Adequate equipment must be provided and may include the following: support in the form of identity documents; office space or equipment; communication equipment such as phones or radios; clothing and footwear, including uniforms, rain coats and patrol boots; flashlights; whistles; bicycles or vehicles/fuel; and in some cases, modest financial incentives.

Training on human rights and humanitarian law, as well as professional conduct and basic principles of community policing, must take place.

Although nominated by the community, participants may need to be vetted by relevant authorities. To minimize the risk of corruption and enable a greater number of individuals to benefit from the project, terms of service should be limited to 12-18 months and made subject to regular but not too frequent rotation. Particularly talented participants can be retained for training or supervisory functions.

CWM must be entirely civilian in character and prohibited from carrying arms. Every effort must be made to ensure that such mechanisms neither act nor present themselves as law enforcement agents and do not become militarized or establish links with military groups or militias.

A Comparative Review of Refugee Security Mechanisms, UNHCR, ESS/EPAU, December 2004; Preserving the Civilian Character of Refugee Camps: Lessons from the Kigoma Refugee Programme in Tanzania, Jean-François Durieux, Track Two, Vol. 9, No. 3, Nov. 2000. 


\section{Landmines and explosive remnants of war}

Key message 160

1. What are landmines and explosive remnants of war? 160

2. The effects of landmines and explosive remnants of war ....................................160

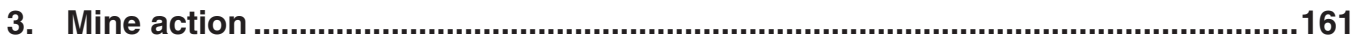

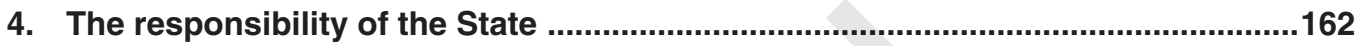

5. The role of humanitarian and human rights actors ...............................................162

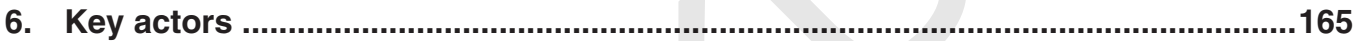

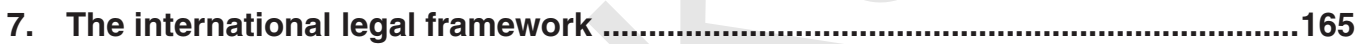

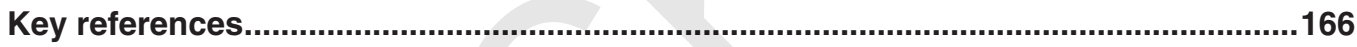

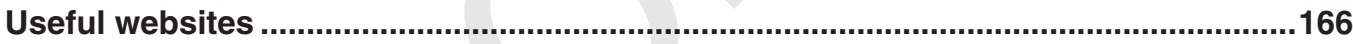




\section{Key message}

As a result of many conflicts, landmines and explosive remnants of war kill and mutilate more civilians than any other weapon. They frequently affect more civilians than military personnel and continue to do so long after the conflict has ended. Landmines and explosive remnants of war also pose a serious threat to internally displaced persons (IDPs), whether during flight, during displacement or when trying to return home or pursuing other solutions. It is imperative that mine action be fully integrated in the overall humanitarian response where landmines and explosive remnants of war are to be expected.

\section{What are landmines and explosive remnants of war?}

A landmine is an explosive device that is placed under, on or near the ground or other surface, and that is designed to explode with the presence, proximity or contact of a person or a vehicle. ${ }^{1}$ Landmines can also be triggered by tripwires, command detonation and other methods, or can self-detonate with the passage of time. They are sometimes booby-trapped by anti-handling devices to make their removal more dangerous.

Landmines are usually camouflaged and can be difficult to detect and avoid. They are often laid in patterns to create security barriers along roads and around strategic military areas or installations. In many cases, however, they are laid randomly and without record in areas that are used mainly by civilians.

Explosive remnants of war refer to all explosive ordnance that have been used or fired but have failed to explode as intended (unexploded ordnance or UXO) or that have been abandoned (abandoned unexploded ordnance or AO). ${ }^{2}$ They can be hard to detect, have no consistent shape, are often unstable, and can detonate if touched or disturbed or simply as a result of the passage of time. This includes, for example, cluster munitions which disperse or release multiple sub-munitions in mid-air, scattering them over a wide area and which, if they do not explode, can create effective "minefields."

\section{The effects of landmines and explosive remnants of war}

Landmines are relatively inexpensive to make and simple to use, but their effects on civilians, and, in many cases, humanitarian workers, can be devastating. Landmines are inherently indiscriminate in the sense that they cannot be aimed, and they cannot distinguish between the footstep of a child and that of a soldier. In fact, most of the victims of landmines and explosive remnants of war are civilians, many of them living in countries that have long been at peace.

Landmines and explosive remnants of war not only kill; they also cause severe injury and long-term disability. A landmine blast can cause severe burns, blindness, loss of limbs, and shrapnel wounds. Those who survive the initial blast often require amputations, long hospitalization, extensive rehabilitation and socio-economic assistance to enable their reintegration into society. Survivors and their families often suffer from a lack of medical care, limited access to education and public services, unemployment, discrimination and stigma owing to disability or disfiguration as a result of mines or explosive remnants of war.

\footnotetext{
More than 600 different types of landmines exist. They are grouped into two broad categories: anti-personnel (AP) mines and anti-vehicle (AV) mines, also referred to as anti-tank mines.

2 Unexploded Ordnance (UXO) include munitions (bombs, shells, mortars, grenades and the like) that have been used but which have failed to detonate as intended. Failure rate can be as low as $1 \%$ or as high as $40 \%$ depending on a range of factors, such as age of the weapon, storage condition, method of use and environmental conditions. UXOs can be found in more than 80 countries and are often more common than landmines.
} 
The presence of land mines and explosive remnants of war, or the mere threat of their presence, can also restrict freedom of movement and block access to fields, roads, water supplies, schools, health centres and other public services. Landmines, thus, can impede social and economic development and have a paralyzing effect on civilian life and humanitarian operations. Where the threat is overestimated, relief efforts may be slower and more tentative than they need to be and, where it is underestimated, significant casualties and delays can occur. It is, thus, critical that mine action be mainstreamed within any humanitarian or peacekeeping effort to ensure accurate information and an efficient, effective and timely response.

\section{Mine action}

Mine action is an umbrella term that is used to refer to various activities aimed at addressing the risks and the consequences of mines and explosive remnants of war. The primary goal of effective mine action is to create an environment in which people can live safely, in which economic and social development is unhindered, and in which the medical and socio-economic needs of victims and survivors are addressed.

\section{Mine action has five main components:}

- Landmine and explosive remnants of war clearance includes non-technical, technical and socio-economic impact surveying, mapping, marking, clearance, post-clearance documentation, community mine action liaison, and the handover of cleared land and post-clearance assessment.

- Mine-risk education (MRE) targets individuals and communities and includes public information campaigns, education and training on the dangers of landmines, It is essential in all mine-suspected and mine-contaminated areas. MRE provides information about the risks associated with landmines and teaches individuals and communities to minimize the risk when conducting normal daily activities such as tending fields, fetching food, water or firewood, or accessing education, health care and other public services. Community liaison plays a large part in MRE.

- Victim assistance covers care and rehabilitation activities that aim to meet the immediate and long-term needs of landmine survivors, their families and affected communities.

- Stockpile destruction is aimed at assisting States in destroying their stockpiles of anti-personnel landmines, by providing support for safe and sustainable stockpile-destruction and for the mobilization of resources.

- Advocacy is aimed at promoting the development of, and compliance with, international legal standards on landmines and explosive remnants of war and the ratification of instruments such as the Anti-Personnel Mine Ban Convention (APMBC), at promoting the prevention of landmine use and encouragement of "good humanitarian donorship" in mine action and at promoting respect for the human rights of mine-affected individuals and communities. Advocacy could also include supporting the prosecution for war crimes or crimes against humanity of those responsible for the use of these weapons against civilians. 


\section{The responsibility of the State}

The State has the responsibility to ensure the safety of the civilian population and respect for their lives and physical integrity. This includes ensuring the full respect for international law and standards on landmines and explosive remnants of war by its armed forces. The State must play a central and coordinating role in taking every possible measure to protect civilians from the effects of such weapons and to provide necessary assistance, including medical care and rehabilitation services, to all victims/survivors and their families.

The State should also ensure compliance with the International Mine Action Standards (IMAS). This includes facilitating access, supporting and contributing to the effective management of de-mining projects, whether carried out by local or international actors. Such activities are often overseen by a specific national mine action authority (NMAA).

Mine action in conflict situations is often a politically sensitive activity as it relates to military information. Mine agencies tasked with removing landmines are often dealing directly with explosives. Challenges may arise in situations where, for example, explosives need to be transported between areas controlled by different political or military fractions or when staff are recruited from ethnic groups associated with the "other side."

International humanitarian law requires that parties to a conflict, including non-State actors, respect standards for the use of landmines and other explosive ordnance. In many conflicts, non-State actors, such as guerilla groups, are also responsible for the indiscriminate use of landmines, or intentional direct attacks against civilian populations. Where feasible, non-State actors should be reminded of their obligations. They should be encouraged to cease the use of these weapons and disclose information on where landmines are laid and cooperate in landmine clearance and destruction.

\section{The role of humanitarian and human rights actors}

Mine action requires specialized expertise and should be coordinated by specialized actors. Within the United Nations system, the United Nations Mine Action Service (UNMAS) carries the responsibility for coordinating all aspects of mine action and for providing mine action assistance in humanitarian emergencies. ${ }^{3}$ UNMAS sets up and manages mine action coordination in countries and territories as part of peacekeeping operations and humanitarian emergencies and crises. It oversees and manages mine action programmes in several countries. Where UNMAS does not manage programmes, international de-mining agencies, as well as other United Nations agencies, including UNDP, UNICEF and UNHCR, and humanitarian and human rights actors also have an important role to play in assisting States to resolve mine issues.

3 A special framework, the Framework for Mine Action Planning and Rapid Response, which forms part of the United Nations Mine Action Strategy, facilitates the rapid deployment of mine action capabilities in emergencies. The framework is available from www.mineaction.org/section.asp?s=strategy_and_guidance. 


\section{In our work, and where appropriate, we can ...}

Assessment and analysis

(See Part III.1 $\square$ )

Coordination

- Ensure that protection assessments identify risks relating to mines and explosive remnants of war. This requires consultation with security experts, national or international mine action organizations, local NGOs, displaced and host communities and, where possible, armed forces or actors.

Ensure a participatory approach to assessment and analysis of mine-affected areas. Host populations as well as IDPs are often well aware of affected areas.

Where there is a risk of mines, notify UNMAS and other specialized agencies to ensure a thorough risk-assessment and the implementation of a mine action programme.

\begin{tabular}{|c|c|}
\hline Coordination & $\begin{array}{l}\text { Work with relevant de-mining actors, in particular UNMAS, to ensure that } \\
\text { mine action, education and awareness are adequately addressed and } \\
\text { coordinated. } \\
\text { Where appropriate, specialized mine action agencies, such as UNMAS, } \\
\text { mine action coordination centres, national mine action agencies and } \\
\text { implementing partners, can be invited to participate in the protection } \\
\text { working group. Alternative mechanisms can also be established for } \\
\text { cooperation and information-sharing. }\end{array}$ \\
\hline $\begin{array}{l}\text { Shelter } \\
(\text { See Part IV.10 } \square)\end{array}$ & $\begin{array}{l}\text { Ensure that public areas, communal buildings, camps, settlements, and } \\
\text { other areas where IDPs have sought shelter or are provided with } \\
\text { assistance or services are surveyed and, if necessary, cleared of mines } \\
\text { and explosive remnants of war prior to being used. The survey and } \\
\text { required mine clearance should also include access roads, paths, } \\
\text { surrounding fields, water points, playgrounds and other places used by } \\
\text { civilians, including children. }\end{array}$ \\
\hline $\begin{array}{l}\text { Protection } \\
\text { monitoring } \\
(\text { See Part V.2 } \square)\end{array}$ & $\begin{array}{l}\text { In mine-affected areas, work with specialized agencies in order to } \\
\text { coordinate monitoring and related activities in connection to mines and } \\
\text { explosive remnants of war. This may include supporting monitoring of the } \\
\text { population movement to allow for advanced mine action planning or } \\
\text { monitoring to ensure that warning signs, posters, and fences are placed } \\
\text { in prominent places and left intact, and that mine incidents and accidents } \\
\text { are reported. } \\
\text { Monitor areas that are under the control of different fighting parties to } \\
\text { ensure, through dialogue with communities and regular field presence, } \\
\text { that the civilian character of the IDP settlement is respected and that } \\
\text { IDPs are not being forced to hide, or accused of hiding, weapon depots } \\
\text { or arm caches that are in the area. }\end{array}$ \\
\hline $\begin{array}{l}\text { Health } \\
(\text { See Part IV.13 } \square)\end{array}$ & $\begin{array}{l}\text { Advocate to ensure that victims/survivors and their families have access } \\
\text { to medical assistance, medication, psychosocial support, and rehabilitation } \\
\text { and reintegration assistance, if needed. }\end{array}$ \\
\hline $\begin{array}{l}\text { Livelihoods } \\
(\text { See Part IV.16 } \square)\end{array}$ & $\begin{array}{l}\text { Ensure that victims/survivors and their families have access to livelihood } \\
\text { opportunities and/or support on an equal basis with others. This can } \\
\text { include material or financial assistance, for instance, in the form of food, } \\
\text { non-food items, micro-financing, etc. }\end{array}$ \\
\hline
\end{tabular}




\begin{tabular}{|c|c|}
\hline $\begin{array}{l}\text { Advocacy } \\
(\text { See Part V.3 } \square)\end{array}$ & $\begin{array}{l}\text { Advocate for ratification of and/or compliance with the Anti-Personnel } \\
\text { Mine Ban Convention and other relevant instruments, such as } \\
\text { Protocols II and V to the Conventional Weapons Convention, where } \\
\text { these have not been ratified and/or implemented. } \\
\text { Advocate with relevant national authorities and, as appropriate, } \\
\text { non-state actors, for stockpile destruction to promote the development } \\
\text { of, and compliance with, international legal instruments addressing the } \\
\text { problems of landmines and explosive remnants of war. } \\
\text { Advocate with relevant authorities to ensure that both victims/survivors of } \\
\text { mines and explosive remnants of war and their families are given access to } \\
\text { needed health care, rehabilitation, reintegration and socio-economic } \\
\text { support. }\end{array}$ \\
\hline Education & $\begin{array}{l}\text { Ensure that mine-risk education and awareness, especially that which is } \\
\text { aimed at children, is included in school curricula and other education and } \\
\text { training activities in mine-affected areas. }\end{array}$ \\
\hline $\begin{array}{l}\text { Information } \\
(\text { See Part V.7 } \square \text { ) }\end{array}$ & $\begin{array}{l}\text { Provide support to public information campaigns, education and training } \\
\text { activities that inform both displaced and host communities about the risks } \\
\text { of mines and ways to address or avoid such risks. Mine education and } \\
\text { awareness can also be included in other information campaigns and } \\
\text { training activities. This can include information related to recognition of } \\
\text { mines and explosive remnants of war and safety precautions. Such } \\
\text { activities can be implemented, for instance, through the dissemination of } \\
\text { simple leaflets, notice boards, wrapping, water bottles, etc. } \\
\text { Key messages should be illustrated in order to enable children, persons } \\
\text { with low literacy skills, and those who do not speak the local language, to } \\
\text { understand. } \\
\text { Support the local authorities in establishing a mine action focal point for } \\
\text { the dissemination of information to displaced communities regarding } \\
\text { areas being surveyed or cleared of mines. } \\
\text { Make sure that IDPs have information on where and who to contact if } \\
\text { they identify mines or explosive remnants of war in their area. } \\
\text { Provide information to IDPs on the mine action process, including the } \\
\text { timeframe for the land to be cleared and, subsequently, handed over. }\end{array}$ \\
\hline $\begin{array}{l}\text { Durable solutions } \\
\text { (See Part VI } \square \text { ) }\end{array}$ & $\begin{array}{l}\text { Get information on the conditions in return or relocation areas to ensure } \\
\text { that IDPs can make an informed decision whether or not to } \\
\text { return/relocate. } \\
\text { Before an organized return or relocation operation, ensure enough time } \\
\text { for an assessment of possible mines and explosive remnants of war in } \\
\text { the areas of destination. } \\
\text { In situations of return or relocation of displaced populations to an area } \\
\text { affected by mines and explosive remnants of war, intervene with } \\
\text { concerned authorities to ensure clearance before movement takes } \\
\text { place. } \\
\text { If IDPs start to return spontaneously, make sure that mine action } \\
\text { agencies are notified to allow for a rapid response, including mine-risk } \\
\text { education for returnees. } \\
\text { Mine clearance should prioritize access roads, homes, schools, public } \\
\text { services and their surroundings. For the sustainability of reintegration, } \\
\text { adjacent land needed for livelihood must also be cleared to an } \\
\text { acceptable radius. }\end{array}$ \\
\hline
\end{tabular}




Technical
cooperation and
assistance
(See Part V.9

Safety of staff
Provide support to, and facilitate the work of, specialized de-mining actors, both national and international. This may include information-sharing, the provision of technical support, office support, the provision of vehicles and other equipment and, in some cases, financial support and medical evacuation assistance.

Ensure that all staff and partners, including local staff and partners, receive safety training on mines and explosive remnants of war, when working in mine-affected areas. The Landmine and Explosive Remnants of War Safety Handbook and Training Programme (on a CD), which is available from UNMAS free of charge upon request, is useful in this respect (see www.mineaction.org).

\section{Key actors}

Mine action should be undertaken and coordinated by specialized agencies, such as UNMAS, with the support of other humanitarian and human rights actors as needed.

- At the national level: ministries of defense, the interior, health, education and social welfare; the national mine action authority (NMAA), local de-mining NGOs and commercial companies, civil society and religious charities.

- At the international level: UNMAS and UNICEF (for education and awareness). Other important actors include UNHCR, UNDP, ICRC, WFP, WHO, the Geneva International Centre for Humanitarian De-mining (GICHD), NGOs such as The Halo Trust, Handicap International, the Swiss Foundation for Mine Action, Mines Advisory Group, DanChurchAid, Norwegian People's Aid, Danish De-mining Group, RONCO, Landmine Action UK, and commercial firms engaged in mine action.

\section{The international legal framework}

\section{Customary international humanitarian law and the Geneva Conventions require that combatants be distinguished from non-combatants, and they prohibit any means and methods of warfare that are indiscriminate in nature, are directed against civilians or civilian property, and/or cause unnecessary suffering or superfluous injury.}

These customary rules do not prohibit the use of landmines and explosive remnants of war in all instances but rather place restrictions on

\begin{abstract}
Guiding Principle (see Annex 1 DU). "Guiding Principle 10.2: Attacks or other acts of violence against internally displaced persons who do not or no longer participate in hostilities are prohibited in all circumstances. Internally displaced persons shall be protected, in particular against: (e) the use of anti-personnel landmines".
\end{abstract} their use by parties to a conflict. Several legal instruments, indicated below, specifically address landmines and explosive remnants of war, either regulating or prohibiting their use.

- The Convention on Conventional Weapons ${ }^{4}$ and its Protocols reaffirm the customary rules mentioned above. Amended Protocol II on landmines, booby-traps and other devices also commits parties to a conflict to maintain records about the use of such devices, to remove them following the end of active hostilities, and to take all feasible precautions to protect civilians and humanitarian missions and organizations from their effects. Protocol $\boldsymbol{V}$ on Explosive Remnants of War similarly commits parties to an armed conflict to maintain records on the use of explosive ordnance during hostilities, to

Convention on Prohibitions or Restrictions on the Use of Certain Conventional Weapons Which May be Deemed to be Excessively Injurious or to Have Indiscriminate Effects, 1980. 
mark and clear all explosive remnants of war in areas under their control, and to provide assistance to facilitate the removal of explosive remnants of war in areas not under their control after the end of hostilities. Parties also commit to taking all feasible precautions to protect civilians and humanitarian actors from the effects of explosive remnants of war.

- The Anti-Personnel Mine Ban Convention ${ }^{5}$ aims to put an end to the suffering and casualties caused by antipersonnel landmines. The treaty, which has been ratified by over 150 States, bans the use, production, and trade of antipersonnel mines, and commits States to destroy their stockpiles, to clear mined areas, provide mine risk education, and ensure adequate assistance, including care, rehabilitation, and social and economic reintegration, to landmine survivors.

- The Rome Statute of the International Criminal Court, ratified by 108 States, provides for the prosecution of alleged perpetrators of war crimes and crimes against humanity and genocide. State and non-State actors who intentionally direct attacks at civilians using antipersonnel landmines could be subject to prosecution for war crimes or crimes against humanity under the Rome Statute.

- International (and regional) human rights law contains a number of provisions that are of relevance for those at risk of becoming victims of mines, as well as for survivors and their families. This includes, in particular, the rights to (and corresponding obligations of the State to ensure respect for) life, personal and physical integrity, freedom of movement, an adequate standard of living, the highest attainable standard of health and health care, and education.

- The Convention on the Rights of Persons with Disabilities reaffirms these and other rights and gives useful guidance on ways to ensure that persons with disabilities, including victims/survivors of mines and explosive remnants of war, can exercise their rights on a full and equal basis with others.

\section{Key references}

- A Guide to Mine Action and Explosive Remnants of War, Geneva International Centre for Humanitarian De-mining (GICHD), 2007.

- A Guide to the International Mine Action Standards, Geneva International Centre for Humanitarian De-mining (GICHD), April 2006.

- Gender Guidelines for Mine Action Programmes, UNMAS, 2005 (in five languages).

- Framework for Mine Action Planning and Rapid Response, UNMAS, 2004.

- Landmine and Explosive Remnants of War Safety Handbook and Training Programme: A Manual for People Working in Environments Contaminated by Landmines and other Explosive Remnants of War, UNMAS, 2005.

\section{Useful websites}

- Electronic Mine Information Network: www.mineaction.org

- International and National Mine Action Standards: www.mineactionstandards.org

- Geneva International Centre for Humanitarian De-mining: www.gichd.org

- International Campaign to Ban Landmines (ICBL): www.icbl.org

- Landmine Monitor: www.icbl.org/Im

- Survivor Corps: www.landminesurvivors.org

- International Committee of the Red Cross (ICRC): www.icrc.org

Convention on the Prohibition of the Use, Stockpiling, Production and Transfer of Anti-Personnel Mines and on Their Destruction (also referred to as the "Ottawa Treaty"), 1997. 


\section{Gender-based violence}

Key message

1. Gender-based violence in situations of internal displacement ...............................168

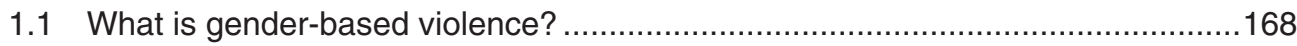

1.2 Gender-based violence and internal displacement .....................................169

1.3 What are the main causes of gender-based violence? .................................169

1.4 What are the consequences of gender-based violence? ...............................171

1.5 Who are the primary victims/survivors of gender-based violence? ...................171

1.6 Who are the main perpetrators of gender-based violence? ............................172

2. The responsibility of the State .......................................................................172

3. The role of humanitarian and human rights actors ............................................173

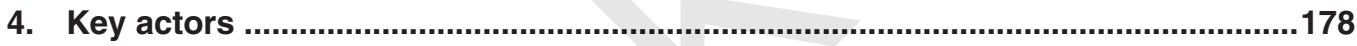

5. The international legal framework ....................................................................178

5.1 International (and regional) human rights law ..........................................178

5.2 International humanitarian law and international criminal law ..........................178

Key references................................................................................................................ 179

Useful websites ...................................................................................................... 180 


\section{Key message}

Gender-based violence (GBV) ${ }^{1}$ is a serious human rights issue that can cause long-term and life-threatening injury and trauma to victims/survivors. All humanitarian and human rights actors must ensure that efforts are made from the onset of an emergency to prevent and respond to acts of GBV and provide adequate care, treatment and support to its victims/survivors. This chapter should be read in conjunction with Part IV.2 and Part IV.8

\section{The IASC Guidelines on Gender-Based Violence Interventions in Humanitarian}

Settings provide guidance on minimum prevention and response in all sectors in emergencies. They are available at www.humanitarianinfo.org/iasc/gender. This chapter provides basic guidance but does not replace or duplicate the Guidelines, which should be used and implemented in all emergencies.

\section{Gender-based violence in situations of internal displacement}

Acts of GBV are among the most common forms of violence in many countries and are estimated to affect the lives, health and well-being of millions of women, girls, boys and men worldwide. GBV takes place in all societies and all cultures.

\subsection{What is gender-based violence?}

GBV is defined as violence that is directed against a person on the basis of their gender or sex, ${ }^{2}$ including acts that inflict physical, mental or sexual harm or suffering, threats of such acts, coercion and other arbitrary deprivation of liberty. It includes physical, sexual and psychological violence perpetrated or condoned within the family, the general community or by the State and its institutions. ${ }^{3}$ Such violence can be manifested in a variety of ways, as indicated in the table below.

\section{Overview of types of gender-based violence}

Sexual violence
rape, including marital rape; sexual abuse and exploitation; forced
prostitution; transactional/survival sex; and sexual harassment,
intimidation and humiliation, on the basis of sex, gender, or sexual
orientation.

Physical violence

Includes actual, attempted or threatened physical assault or battery; slavery and slave-like practices; forced recruitment and trafficking.

Emotional and psychological violence

Includes abuse and humiliation, such as insults, cruel and

degrading treatment, compelling a person to engage in humiliating acts, and placing restrictions on liberty and freedom of movement.

The term gender-based violence (GBV) is used throughout this Handbook. The terms sexual and gender-based violence (SGBV) and violence against women may be used in other contexts. Despite differences in terminology, the strategies and activities used to prevent and respond to such violence are similar.

2 The term "sex" refers to biologically determined and fixed differences between males and females, while "gender" refers to social differences that are learned, that can change over time, and that can vary widely both within and between cultures. Gender is a socio-economic, cultural and political variable that can be used to analyse roles, responsibilities, constraints, opportunities and needs of women and men in different contexts.

3 UNGA Declaration on the Elimination of Violence against Women, Arts. 1 and 2, A/RES/48/104 of 20 Dec 1993. 


\section{Harmful traditional practices}

\section{Socio-economic} violence
Includes female genital mutilation/cutting (FGM/C); forced marriage; child marriage; honour or dowry killings or maiming; infanticide, sex-selective abortion practices; sex-selective neglect and abuse; and denial of education and economic opportunities for women and girls.

Includes discrimination and denial of opportunities or services on the basis of sex, gender, or sexual orientation; social exclusion; obstructive legal practices, such as denial of the exercise and enjoyment of civil, social, economic, cultural and political rights, mainly to women and girls.

\subsection{Gender-based violence and internal displacement}

The conditions that often characterize forced displacement, including conflict, breakdown of the rule of law, and the collapse of family and community support structures, increase both the frequency and the brutality of GBV. Both State and non-State perpetrators may commit acts of violence with impunity during any time within the displacement cycle, thus generating increased reluctance and fear from victims/survivors to report such incidents. In the early stages, when disruptions first occur and when protection mechanisms are no longer in place, incidents mostly take the form of sexual violence involving female survivors/victims and male perpetrators. Moreover, during armed conflict, sexual violence is also often a military tactic - a weapon of war used to humiliate and demoralize individuals, to tear families apart and to devastate communities.

Later, in a more stabilized phase and during rehabilitation and recovery, other forms of GBV may occur, and/or be reported with increasing frequency (domestic violence, forced early marriage, genital mutilation, honour killings, etc...). ${ }^{4}$

\subsection{What are the main causes of gender-based violence?}

GBV is deeply rooted in discriminatory cultural beliefs and attitudes that perpetuate inequality and powerlessness, in particular of women and girls. Various other factors, such as poverty, lack of education and livelihood opportunities, and impunity for crime and abuse, also tend to contribute to, and reinforce, a culture of violence and discrimination based on gender.

Such factors are frequently aggravated in times of conflict and displacement as the rule of law is eroded and families and societies are torn apart. The result is often an increase in both the frequency and brutality of GBV. In its worst form, GBV has become a weapon of war, intentionally directed against and aimed at terrorizing, displacing and destroying certain communities or ethnic groups.

Combating GBV requires an understanding of its causes and contributing factors, which often also serve as barriers to effective prevention and response, as outlined below. 


\begin{tabular}{l|l}
\hline Causes & Common barriers to prevention and response \\
\hline $\begin{array}{l}\text { Physical } \\
\text { factors }\end{array}$ & $\begin{array}{l}\text { Lack of physical security owing to the breakdown of law and order, } \\
\text { presence of armed forces/groups, collapse of law enforcement, justice } \\
\text { institutions and family, social or community structures. Women and girls are } \\
\text { particularly vulnerable when leaving their communities in search of work, food, } \\
\text { water and/or firewood. } \\
\text { Poverty, lack of education and livelihood opportunities, and inadequate } \\
\text { access to shelter, food, water, fuel, and income generation can increase } \\
\text { exposure to GBV, including forced prostitution or survival sex. }\end{array}$
\end{tabular}

Social, cultural and political factors

Discriminatory social, cultural or religious laws, norms and practices (including witchcraft) that marginalize women and girls and fail to respect their rights.

Collapse of family, social and communal structures and disrupted roles within the family often expose women and girls to risk and limit coping mechanisms and avenues for protection and redress.

Lack of confidence and/or trust in social or public institutions, including law enforcement and justice institutions that discourage victims/survivors from seeking redress.

- Lack of technical skills among service providers to handle survivors of GBV.

\section{Legal/Judicial} barriers

Individual barriers

\section{Lack of access to justice, resulting in culture of impunity for violence and} abuse (as outlined in Part IV.18 D).

Lack of adequate and affordable legal advice and representation.

Lack of adequate victim/survivor and witness protection mechanisms.

Inadequate legal framework, including national, traditional, customary and religious law, that discriminates against women and girls, fails to guarantee their rights, or exposes them to further harm and abuse. As an example, national law may fail to guarantee a certain right (e.g. non-discrimination), fail to criminalize certain acts (e.g. rape), or narrowly interpret them (e.g. rape defined as not including marital rape). In some cases, national law also criminalizes the victim (e.g. rape defined as adultery) or criminalizes acts that allegedly are primarily associated with women (e.g. witchcraft or sorcery). In some cases, the victim/survivor faces harassment, intimidation and/or severe punishment.

\section{Threat or fear of stigma, isolation and social exclusion.}

- Exposure to further violence at the hands of the perpetrator, the community or the authorities, including arrest, detention, ill-treatment and punishment.

Lack of information about GBV, human rights and how and where to seek remedies.

Humanitarian programming obstacles
Failure to address or prioritize GBV in assessments, strategy development, planning and programming because of a lack of information or understanding about the extent or nature of GBV.

Lack of gender-sensitive design of programmes, services and facilities, including inadequate registration practices and distribution of food and non-food items.

Sexual exploitation and abuse by peacekeepers, human rights and humanitarian workers.

Other challenges including weak links with other assistance and protection programmes, lack of confidentiality, confusing reporting and referral mechanisms, and GBV committees that are isolated, under-resourced and weak, and lack support from the wider community. 


\subsection{What are the consequences of gender-based violence?}

GBV can have serious long-term and life-threatening consequences for victims/survivors. These can range from permanent disability or death to a variety of physical, psychosocial and health-related problems that often destroy the survivor's self-worth and quality of life, and expose him/her to further abuse. GBV can lead to a vicious cycle of violence and abuse as survivors risk being rejected by their families, excluded and ostracized by society, and even arrested, detained or punished - or sometimes abused again - for seeking protection, assistance or access to justice.

\begin{tabular}{lll}
\hline Examples of consequences frequently associated with gender-based violence \\
\hline Fatal & Acute physical & Chronic physical \\
\hline Homicide & Injury, including fistulas & HIV/AIDS \\
\hline Suicide & Shock & Disability \\
Maternal mortality & Disease & Chronic pain or infections \\
Infant mortality & Infection & Gastrointestinal problems \\
& & Eating or sleeping disorders \\
\hline Reproductive & & Alcohol/drug abuse \\
\hline Miscarriage & Emotional and & Social and economic \\
\hline Unwanted pregnancy & psychological & \\
\hline Unsafe abortion & Post-traumatic stress & Blaming of the victim/survivor \\
STDs, inc. HIV/AIDS & Depression & Loss of role or functions in \\
\hline Menstrual disorders & Anger, anxiety and fear & society \\
Pregnancy complications & Shame, self-hate and & Social stigma, rejection and \\
Gynecological disorders & self-blame & isolation \\
\hline Sexual disorders & Mental illness & Feminization of poverty \\
& Suicidal thoughts and & Increased gender \\
& behaviour & inequalities \\
& & Loss of livelihood and \\
& & economic dependency \\
& & Arrest, detention and/or \\
& & punishment \\
\hline
\end{tabular}

Discussing issues relating to sex or gender can be considered inappropriate in some cultures and may expose victims/survivors to risk. Victims/survivors of GBV may also have suffered severe injury or trauma, which may resurface during the interview. In general, victims/survivors should not be interviewed or questioned about their experiences except by trained counselors who have the required skills, experience and knowledge about appropriate referral and response mechanisms. The safety and best interests of the victim/survivor must be a primary consideration at all times and their informed consent must be sought for any action or disclosure of personal information.

\subsection{Who are the primary victims/survivors of gender-based violence?}

GBV affects women and men of all ages and backgrounds. Women and girls are the primary victims/survivors but men and boys are frequently targeted as well. They, however, may face different forms of violence. As an example, women and girls may be more often exposed to rape and other forms of sexual violence, while men and boys may be more likely to be forcibly recruited into armed forces or armed groups (as outlined further in Part IV.5 $\square$ ). 
Persons who have been separated from their families or communities, and/or lack access to shelter, education and livelihood opportunities, are among those most at risk of GBV. This includes unaccompanied or separated children, female and child heads-of-households, boys and girls in foster families or other care arrangements, persons with disabilities, persons in detention, working girls, girl mothers, and girls and boys born to rape victims/survivors. Persons that have been exposed to such violence are referred to as "victims/survivors."

\subsection{Who are the main perpetrators of gender-based violence?}

GBV is usually perpetrated by persons who hold a position of power or who control others, whether in the private or public sphere. In most cases, those responsible are known to the victim/survivor, such as intimate partners, members of the (extended) family, friends, teachers or community leaders. Others in positions of authority, such as police or prison officials, and members of armed forces and groups, are frequently responsible for such acts, in particular in times of armed conflict. In some cases, the perpetrators have also included humanitarian workers and peacekeepers.

\section{The responsibility of the State}

The State has the primary responsibility to prevent and respond to $\mathrm{GBV} .{ }^{5}$ This includes taking all necessary legislative, administrative, judicial and other measures to prevent, investigate and punish acts of GBV and provide adequate care, treatment and support to victims/survivors, based on the principles of respect, confidentiality, safety/security and non-discrimination. To that effect, States should ensure the measures indicated below are taken. ${ }^{6}$

- Criminalize all acts of GBV and ensure that national law, policies and practices adequately respect and protect human rights without discrimination of any kind, including on grounds of gender.

- Investigate allegations of GBV thoroughly and effectively, and prosecute and punish those responsible. Appropriate military disciplinary measures should also be enforced, and troops should be trained on the prohibition of all forms of sexual violence against civilians.

- Provide adequate protection, care, treatment and support to victims/survivors, including the evacuation of civilians under imminent threat of sexual violence to safety, access to legal counseling, health care, psychosocial support, rehabilitation and compensation for the harm suffered.

- Condemn violence against women and refrain from invoking any custom, tradition or religious consideration to evade obligations pertaining to the elimination of violence. States should pursue by all appropriate means and without delay a policy to eliminate violence against women.

- Take action to empower women and strengthen their personal, legal, social and economic independence.

- Exclude sexual crimes from amnesty provisions as part of conflict resolution processes.

- Ratify and/or implement international human rights norms and instruments, as they relate to violence against women (as provided in Part IV.4.5).

See Security Council Resolution 1820 (2008) on Women and Peace and Security, http://daccessdds.un.org/doc/UNDOC/GEN/N08/391/44/PDF/N0839144.pdf?OpenElement.

6 For more examples of possible actions, see the UN Fourth World Conference on Women Platform for Action (Beijing, 1995), www.un.org/womenwatch/daw/beijing/platform/violence.htm. 
All parties to an armed conflict, including non-State actors are prohibited from committing any act of sexual violence against civilians, including using sexual violence as a tactic of war.

\section{The role of humanitarian and human rights actors}

While primary responsibility lies with the national authorities, humanitarian and human rights actors also play an important role in preventing and responding to GBV, guided by the principles of respect, confidentiality and security. In addition to ensuring an effective response to GBV from the outset of an emergency, this entails ensuring that gender concerns are adequately integrated into, and mainstreamed at, all levels of the humanitarian response (as outlined in Part l.1 for information about gender-mainstreaming [D).

As humanitarian and human rights actors, as well as peacekeepers, we must not under any circumstances, encourage or engage in any form of sexual exploitation or abuse. We must at all times ensure that such acts do not take place by our staff or partners or as a result of our interventions. This includes any act or attempted abuse of a position of vulnerability, differential power or trust for sexual purposes as well as any actual or threatened sexual act, whether by force or under unequal or coercive conditions. Such acts include, but are not limited to, all forms of rape and sexual assault, forced prostitution, trafficking and various forms of transactional or survival sex in exchange for money, food, access to shelter, education and other services (as outlined in Part IV.8 DU). Policy guidance on disciplinary measures and codes of conduct have been developed to prevent sexual exploitation and abuse by United Nations personnel and humanitarian workers. ${ }^{8}$

Several guidelines provide useful guidance on GBV prevention and response. These include, in particular, the following: the IASC Guidelines for Gender-based Violence Interventions in Humanitarian Settings, which focus on minimum prevention and response to sexual violence in all sectors during emergencies; the UNHCR Guidelines for Prevention and Response, ${ }^{9}$ which provide a comprehensive guidance on prevention and response, including in post-emergency and early-recovery settings; and the IASC Gender Handbook, ${ }^{10}$ which sets forth standards that guide the integration of gender in humanitarian action. The table below gives some examples of possible activities that can be undertaken.

These responsibilities are further outlined in the UN Secretary-General's Bulletin: Special Measures for Protection from Sexual Exploitation and Sexual Abuse, ST/SGB/2003/13, 9 October 2003.

8 DPKO guidance and directives on disciplinary issues for all categories of personnel serving in United Nations Peacekeeping and other field missions; Secretary General's Bulletin on Special Measures for Protection from Sexual Exploitation and Sexual Abuse, October 2003; Implementation Guidelines for the Field on the Secretary-General's Bulletin on Special Measures for Protection from Sexual Exploitation and Sexual Abuse (ST/SGB/2003/13).

9 Sexual and Gender-based Violence against Refugees, Returnees and Internally Displaced Persons: UNHCR Guidelines for Prevention and Response, UNHCR, 2003.

10 Women, Girls, Boys and Men: Different Needs - Equal Opportunities, IASC, 2006,

www.humanitarianinfo.org/iasc/gender. 


\section{In our work, we can ...}

\begin{tabular}{ll}
$\begin{array}{l}\text { Assessment and } \\
\text { analysis } \\
\text { (See Part III.1 }\end{array}$ & $\begin{array}{l}\text { Ensure that protection assessments are based on participatory methods } \\
\text { and identify the major causes and consequences of GBV, the individuals } \\
\text { and groups most at risk, and existing coping mechanisms. In many } \\
\text { cases, specific GBV assessments must be undertaken by trained staff } \\
\text { with expertise in the area of GBV. }\end{array}$ \\
\hline Coordination \\
(See Part III.2
\end{tabular}

\section{Advocacy}

$($ See Part V.3 $\square)$
Advocate with relevant actors, including national and local authorities, traditional, cultural or religious bodies, armed forces and security forces, law enforcement officials, civil society groups, and others, to ensure effective prevention and response. This may include advocacy with non-State actors.
Information and communication activities

(See Part V.7 $\square$ )
- Support or undertake information activities that aim to raise awareness of GBV and that combat discrimination and other underlying causes of GBV.

- Ensure that information about GBV prevention and response, including how and where to access relevant assistance and services, is readily available for all survivors of GBV.

- Ensure that adequate, respectful and well-coordinated referral and response mechanisms from multisectoral actors (health care, psychological/social and legal advice and support) are put in place, including clear and acceptable referral and reporting mechanisms that respect confidentiality and the rights of the victim/survivor, and that these are known and available to the community. Guidance on setting up such mechanisms is available in the IASC and UNHCR Guidelines mentioned above.

Physical safety and security (See Part IV.2 [D)
Take action to improve safety and security in and around camps, settlements, villages and other areas, paying particular attention to locations where acts of GBV have occurred or are likely to occur. This includes food distribution sites, water points, areas for firewood collection, schools, public spaces, etc.

- Ensure that mechanisms are in place to guarantee the security of victims/survivors and witnesses in order to protect them against further harm. These can include traditional protective mechanisms, establishments of shelters for victims/survivors, foster care arrangements for children, or, in exceptional cases, assistance to relocate to another place. In some cases, measures may need to be taken to protect the perpetrator from violence, such as at the hands of the victim's family or clan. 


\section{Health}

(See Part IV.13 DD)

Ensure that adequate and confidential basic health care, including physical, reproductive and psychosocial health care, is available and fully accessible to all displaced women, girls, men and boys particularly victims/survivors of GBV, in camps as well as in settlements, villages or in other areas.

Community

(See Part V.10
- Build the capacity of individuals to protect themselves and recover from acts of GBV, for instance by encouraging and promoting equal participation of men and women in all community activities and supporting education and vocational training programmes, income-generating activities and literacy programmes that empower women and girls.

Build the capacity of the local community by re-building family and community support systems, particularly women's/youth groups and organizations, including by encouraging and supporting social and recreational programmes and encouraging the resumption of cultural and spiritual activities.

\section{Livelihoods}

(See Part IV.16 DD)

Support self-reliance and sustainable livelihood programmes, and ensure that these are available to victims/survivors of GBV. Such programmes can reduce the risk of GBV and mitigate its effects by facilitating the rehabilitation and reintegration of victims/survivors.

Material assistance (See Part V.5 $\square$ )

Technical advice and assistance, including training (See Part V.9

Shelter and physical planning (See Part IV.10
Try to ensure that victims/survivors of GBV and their families, as well as those most at risk of GBV, have full and equal access to needed material and other support. This can include safe shelter, livelihood support, non-food items, modest financial grants to access education or training, and/or micro-financing opportunities.

Provide training or technical advice and assistance on human rights, including on GBV prevention and response, to relevant actors, including, for instance, community leaders, civil society and NGOs, the police and armed forces, judges and lawyers, health workers, social workers and others. Material assistance may include the provision of drugs or medical equipment.

Ensure that peacekeepers, humanitarian workers and others working with displaced persons and communities receive training and sensitization on GBV, including their responsibility to prevent and respond to such acts.

Ensure that humanitarian staff and partners, including peacekeepers, are familiar with relevant codes of conduct and the prohibition against engaging in sexual exploitation and abuse of any kind. Adequate and confidential complaints mechanisms should be established and complaints promptly investigated and followed up.

Provide or advocate for the establishment of safe shelter for victims of GBV, in particular single women and unaccompanied children. Where individuals or families are provided shelter material, ensure that gender concerns are considered. As an example, women or girls should not have to travel long distances to collect the material and should have the ability to erect the shelter themselves or receive adequate assistance to do so, without being exposed to pressures for transactional sex.

Ensure that gender concerns are taken into account in the physical planning of camps and in the design and implementation of services, such as health care, education, water/sanitation and food distribution (as outlined further in Part V.5 $\square$ ). 


\section{Justice}

(See Parts IV.18

and $V .8 \square$ )

and $V .8$ )
investigated, prosecuted and resolved in accordance with established
laws and procedures.
Help build the capacity of the justice sector, including police,
prosecutors, lawyers and judges, to deal with issues related to GBV,
including training and data recording of GBV cases. In particular,
advocate for the recruitment of female police officers to deal with GBV
victims/survivors.

Legal reform Review national laws, regulations, policies, procedures and practices, including traditional and cultural practices and, based on the result, advocate with relevant stakeholders to ensure they provide adequate protection against GBV.

Where key human rights instruments, including the Convention on Elimination of All Forms of Discrimination against Women, have not been ratified by the State or where their adoption has been accompanied by reservations, advocate for the adoption and implementation of these instruments or the lifting of reservations.

\section{Education}

(see Part IV.15

Children

Durable solutions

(See Part VI $\square$ )

Ensure that victims/survivors have access to free and confidential counseling about legal and/or other avenues for redress.

Provide modest material and other support to victims/survivors and their families, where needed, to facilitate their access to justice (whether formal or through traditional justice systems, as outlined in Annex II, Part IV.18 D ). This can include assistance with legal fees, translation, travel to and from court, and/or measures to ensure the safety and security of the victim/survivor.

Provide legal advice and assistance to victims/survivors and to witnesses in sexual violence cases in courts.

Monitor and follow up on cases of GBV to ensure that these are

Promote and/or provide full and equal access for internally displaced persons and other affected individuals to safe education, and vocational and skills training, that can strengthen self-reliance and economic independence.

Promote a safe learning environment both within and around schools and other educational facilities. This may include awareness raising among children, parents, teachers and other educational staff, and relevant local authorities.

Ensure that child victims/survivors are provided with special care and assistance as appropriate. Such interventions should be guided by the key principles of the Convention on the Rights of the Child, namely the best interests of the child and the child's right to life, survival and development, non-discrimination, and participation.

Advocate with relevant actors to encourage attention to GBV in all return, relocation and reintegration frameworks, development action plans, and disarmament, demobilization and reintegration programmes. Such frameworks and action plans should contain measures to prevent and respond to GBV and provide adequate care, treatment and support to victims/survivors. 
"Do"s and "don't"s for collecting, analysing, and reporting on sexual violence

\section{A. GENERAL}

Do seek advice from data experts to agree on what information to collect, share and report, and how to do so safely and ethically.

Do verify the information wherever possible. Obtain data from at least three different sources, and always inquire about the methodology used to collect this data.

\section{B. ANALYSING DATA}

Do examine how the data match other information coming from the field, and consider how contextual factors influence their quality.

Do assess the quality of the data. Have the data been collected and analysed in methodologically sound ways? Are they applicable to a larger population? If so, to which population?

\section{REPORTING}

Do keep in mind the audience and possible use. If the data are being shared with the media, donors or policy-makers, make sure that guidance is offered on the interpretation of the data. Briefing notes may help.

Do provide the context for all data reported. If known, and safe to do so, provide information on the camps/clinics/districts where cases are reported. Be specific, e.g. "reported cases from x number of health facilities."

Do provide a comprehensive description of the incident as long as this cannot be linked back to individual survivors (including the precise date and location, information on the victims and perpetrators, ethnicity, age and sex, when it is safe to provide such information).

Do provide additional information which may have contributed to changes in the number of reported cases. For example, note if more services are available, public information campaigns have been held, or there has been an upsurge in violent attacks. Whenever possible, information on when incidents took place should be collected, and reported along with aggregated numbers.

Do label all tables, charts and maps appropriately to avoid the mis-use of the data and clearly state the sources for any data cited.

Don't share data that may be linked back to an individual or group of individuals.

Don't take data at face value: assess original sources, including their quality/reliability.

Don't assume that data reported on sexual violence or assessments of trends are necessarily accurate.

United Nations Action Guidance Note "Reporting and Interpreting Data on Sexual Violence from conflict-affected countries: Dos and Don'ts." 


\section{Key actors}

All humanitarian and human rights actors have a responsibility to prevent and respond to GBV. Ensuring an effective response requires a multi-sectoral and coordinated effort by a range of local, national and international actors.

- At the national level, key actors include displaced persons and communities; ministries for justice, health, education, social services and the family; the parliament, particularly relevant legislative or monitoring committees; health-care institutions and personnel; police and prison authorities; prosecutors; the military and para-military groups; traditional, customary or religious associations and councils; local NGOs and civil society, particularly women's and youth organizations.

- At the international level, UNICEF and UNFPA serve as focal point agencies for GBV within the Global Protection Cluster. Other important actors include OHCHR, UNDP UNHCR, DPKO, WFP, WHO, ICRC/IFRC, IOM, and many international NGOs.

\section{The international legal framework}

Acts of GBV, as well as threats or incitements to commit such acts, constitute a serious violation of international human rights and humanitarian law.

\subsection{International (and regional) human rights lawit}

International (and regional) human rights law prohibits all forms of violence and discrimination, including GBV. Any form of GBV constitutes a serious violation of human rights. Depending on the act in question, it may violate a number of rights, such as the following: the right to dignity and physical, mental and moral integrity; the right to freedom from torture and cruel, inhuman or degrading treatment or punishment; the right to liberty and security of person, and to freedom from slavery; the right to life; and the right to non-discrimination, equality and to equal protection of the law. Rape and sexual violence suffered at the hands of agents of the State, such as police or military officers, are generally considered to constitute an act of torture under human rights law.

GBV also impairs or nullifies a range of other rights, such as the rights to the highest attainable standard of physical and mental health, to an adequate standard of living, to education, and to just and favourable conditions of work. ${ }^{12}$

\subsection{International humanitarian law and international criminal law}

Many acts of GBV, including rape and any other form of sexual violence, such as sexual slavery, enforced prostitution, forced pregnancy and enforced sterilization, are strictly prohibited by international humanitarian law as well as by the military code of most States.

\footnotetext{
${ }^{11}$ In particular, the Universal Declaration of Human Rights, the Convention on the Elimination of All Forms of Discrimination against Women, the International Covenant on Civil and Political Rights, the International Covenant on Economic, Social and Cultural Rights, the Convention against Torture and Other Cruel, Inhuman or Degrading Treatment or Punishment, the Convention for the Suppression of the Traffic in Persons and of the Exploitation of the Prostitution of Others, Trafficking in persons, especially women and children Protocol to the Convention against Transnational Organized Crime. Regional instruments include the Protocol to the African Charter on Human and Peoples' Rights on the Rights of Women in Africa (Maputo, 2003), and the Inter-American Convention on the Prevention, Punishment and Eradication of Violence against Women ("Convention of Belem Do Para").

12 CEDAW Committee, General Recommendation No. 19 (1992) on Violence against Women, para. 7.
} 
Such acts constitute a serious violation of the law and a grave breach of the Geneva Conventions. ${ }^{13}$ In addition, depending on the context in which they are committed, such acts might constitute war crimes, ${ }^{14}$ crimes against humanity ${ }^{15}$ or genocide,${ }^{16}$ all of which are punishable under international criminal law. All States and non-State actors are obliged to take action to prevent such acts and investigate and prosecute those responsible, or extradite them to other States or international tribunals with jurisdiction to try such acts.

Various resolutions and declarations of the United Nations Security Council, the General Assembly and other bodies have repeatedly condemned various forms of GBV and emphasized the responsibility of the State to end impunity for war crimes and crimes against humanity, including sexual and other violence against women and girls. The Security Council has passed a series of resolutions calling upon parties to armed conflict to fully respect international law and to take special measures to protect women and children from the effects of hostilities, including any form of sexual violence, by ending for example impunity and prosecuting those responsible for such crimes. ${ }^{17}$ The Security Council has also established monitoring and reporting mechanisms on children in armed conflict, which includes rape and other sexual violence among the six gravest violations against children. ${ }^{18}$

\section{Key references}

- Guidelines for Gender-based Violence Interventions in Humanitarian Settings: Focusing on Prevention of and Response to Sexual Violence in Emergencies, IASC, available in 5 languages, 2005.

- Sexual and Gender-based Violence against Refugees, Returnees and Internally Displaced Persons: Guidelines for Prevention and Response, UNHCR, available in 5 languages, 2003.

- Gender-based Violence Tools: Manual for Assessment, Programme Design, Monitoring and Evaluation in Conflict-affected Settings, Reproductive Health Response in Crisis Consortium, 2004.

- Women, Girls, Boys and Men: Different Needs - Equal Opportunities, IASC, 2006.

- Standard Operating Procedures for Prevention of and Response to Gender-based Violence, UNHCR, 2006.

\footnotetext{
${ }^{13}$ See Rules 90, 93 and 94 of Customary International Humanitarian Law, Volume I (ICRC, 2005). Such acts are also prohibited through (i) grave breaches provisions such as Art. 147 of the Fourth Geneva Convention and Art. 85 of Additional Protocol I, which prohibit torture, inhuman treatment, and willfully causing great suffering or serious injury to body and health; (ii) Common Art. 3, which prohibits violence to life and person, cruel treatment and torture, and outrages upon personal dignity; and other provisions, such as Art. 27 of the Fourth Geneva Convention, Arts. 75-77 of Additional Protocol I and Art. 4(2) of Additional Protocol II, which explicitly prohibit attacks against women, including rape, enforced prostitution and any form of indecent assault.

${ }^{14}$ See, for example, Arts. 8(2)(a)(ii) and (iii), 8(2)(b)(xxi) and (xxii), 8(2)(c)(i) and (ii), 8(2)(e)(vi) of the Statute for the International Criminal Court (ICC Statute). Note that even a single act of sexual violence can constitute a war crime.

${ }^{15}$ Art. $7(1)(g)$ of the ICC Statute; Art. 5 of the ICTY Statute; and Art. 3 of the ICTR Statute. Crimes against humanity are crimes that are committed as part of a widespread or systematic attack against civilians, regardless of whether they are committed in times of peace or armed conflict.

${ }^{16}$ Rape, sexual violence and abuse may amount to genocide if committed with intent to destroy, in whole or in part, a particular group, as defined in Art. 6(b) of the ICC Statute; Art. 2 of the ICTR Statute; and Art. II(b) of the Convention on the Prevention and Punishment of the Crime of Genocide. This was confirmed, for instance, by the ICTR in its judgment in Prosecutor v. Akayesu (Case No. ICTR-96-4-T).

17 See Security Council Resolution 1325 (2000), op. paras. 9, 10 and 11; Resolutions of the Council on Protection of Civilians, including Resolution 1674 (2005), and on Protection of Children in Armed Conflict, including Resolutions 1612 (2005), 1539 (2004), 1460 (2003), 1379 (2001), 1314 (2000) and 1261 (1999). See, in particular, Security Council Resolution 1820 (2008) on Women and Peace and Security, http://daccessdds.un.org/doc/UNDOC/GEN/N08/391/44/PDF/N0839144.pdf?OpenElement.

${ }^{18}$ See, in particular, Security Council Resolution 1612 (2005) of 26 July 2005. For further information, see the Report of the Secretary-General on Children and Armed Conflict, A/59/695-S/2005/72, 9 February 2005.
} 
- UN Action Guidance Note "Reporting and Interpreting Data on Sexual Violence from conflict-affected countries: Dos and Don'ts," June 2008.

- IASC Guidelines for Gender-based Violence Interventions in Humanitarian Settings, IASC.

\section{Further reading}

- Abuse and Exploitation Module, Action for the Rights of Children, 2002.

- Clinical Management of Survivors of Rape: Developing Protocols for Use with Refugees and Internally Displaced Persons, WHO/UNHCR, rev. ed. 2004.

- Early Marriage: A Harmful Traditional Practice: A Statistical Exploration, UNICEF, 2005.

- Good Practices in Combating and Eliminating Violence against Women: Report of the Expert Group Meeting, UN Division for the Advancement of Women, May 2005.

- Harmful Traditional Practices Affecting the Health of Women and Children, Fact Sheet No. 23, OHCHR, 1995.

- How to Use International Criminal Law to Campaign for Gender-sensitive Law Reform, Amnesty International, 2005.

- It's in our hands: Stop violence against women, Amnesty International, 2004.

- Potential links between food aid, distribution of relief items and sexual exploitation and proposed preventive/remedial actions, UNHCR, 2002.

- Women in an Insecure World: Violence against Women: Facts, Figures and Analysis, Geneva Centre for the Democratic Control of Armed Forces, 2005.

- Women, War, Peace: Progress of the World's Women 2002, UNIFEM, 2002.

\section{Useful websites}

- United Nations Population Fund (UNFPA): www.unfpa.org

- United Nations High Commissioner for Refugees (UNHCR): www.unhcr.org

- UNIFEM Portal on Women, Peace and Security: www.womenwarpeace.org

- Reproductive Health Response in Crisis Consortium (RHRCC): www.rhrc.org

- World Health Organization (WHO): www.who.int/gender/violence/en/

- UN Action against Sexual Violence in Conflict: www.stoprapenow.org/about.html

- International Committee of the Red Cross (ICRC): www.icrc.org/eng/women

- Women's International League for Peace and Freedom (WILPF): www.peacewomen.org/wpsindex.html

- International Rescue Committee (IRC): www.irc.org 


\section{Children associated with armed forces or armed groups}

Key message

1. The impact of displacement on the risk of recruitment ......................................182

2. Why children are recruited into armed forces or armed groups?..........................183

2.1 Forced recruitment by armed actors ..........................................................183

2.2 Circumstances leading to "enrolment" into armed groups.................................183

3. The consequences for children associated with armed forces or armed groups........183

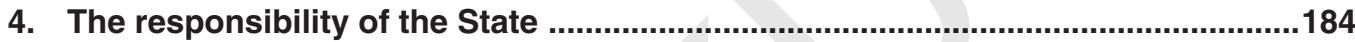

5. The role of humanitarian and human rights actors ...............................................185

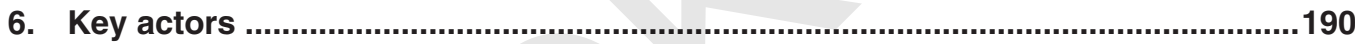

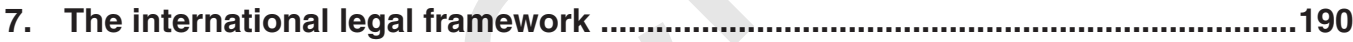

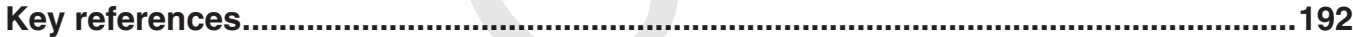

Useful websites .................................................................................................................... 193 


\section{Key message}

Hundreds of thousands of children are associated with armed forces or armed groups in armed conflicts in over 20 countries around the world. Girls and boys are used in a variety of ways providing support, as cooks or porters for example, participating in active fighting, laying mines and spying and, in many cases, they are also frequently used for sexual purposes.

This unrelenting and brutal use of children violates their rights and causes them significant physical, developmental, emotional, mental, and spiritual harm. The release, protection and reintegration of children recruited or used by armed forces or armed groups must be sought at all times, including during armed conflict. All humanitarian and human rights actors must take preventive action from the onset of humanitarian operations in a coordinated and strategic manner in order to ensure the unimpeded protection of children.

A "child" means every human being below the age of eighteen years unless under the law applicable to the child, majority is attained earlier (Article 1, Convention on the Rights of the Child).

A child associated with an armed force or an armed group refers to any person below 18 years of age ${ }^{1}$ who is or has been recruited or used by an armed force or an armed group in any capacity, including but not limited to children used as fighters, cooks, porters, messengers, spies or for sexual purposes. It does not only refer to a child who is taking or has taken an active part in hostilities. ${ }^{2}$

\section{The impact of displacement on the risk of recruitment}

Children who become internally displaced as a result of natural disasters or armed conflict are usually at greater risk of recruitment or use by armed forces or armed groups. This is due to reduced social protection and coping mechanisms, discrimination on the basis of their displaced status or their perceived allegiance with a belligerent in the armed conflict. Additionally, lack of economic, educational or other opportunities caused by displacement affecting displaced children and their families can make internally displaced children more vulnerable to recruitment.

Children separated from their families or without family are particularly exposed and, where the security situation is fragile, for example when camps for internally displaced persons (IDPs) are close to conflict areas or infiltrated by armed actors, the potential for forced recruitment through abduction of children or other means is very high. Separated or orphaned children displaced into IDP settlements and in host communities may find themselves roaming the streets and, thus, become easy targets for recruitment.

See section 7 at the end of this chapter regarding recruitment age. The Convention on the Rights of the Child and international humanitarian law absolutely prohibit the recruitment and participation of children of less than 15 years of age in armed conflicts.

2 "Armed forces" refers to the armed forces of a State. "Armed groups" refers to groups distinct from armed forces as defined by Article 4 of the Optional Protocol to the Convention on the Rights of the Child on the involvement of children in armed conflict. "Recruitment" refers to compulsory, forced and voluntary conscription or enlistment of children into any kind of armed force or armed group. 


\section{Why children are recruited into armed forces or armed groups}

Children become associated with armed forces or armed groups for many reasons, depending on the context. A situation analysis is essential in order to identify the specific causes of recruitment in any given operation. While many children are forcibly recruited, others "volunteer" because of their circumstances.

\subsection{Forced recruitment by armed actors}

State and non-State armed actors target children due to a shortage of manpower or because children are particularly useful in certain roles, for example as spies or messengers. They are also more likely to obey orders, work for food, security or status rather than wages and can be used as sex slaves or "wives" of soldiers. They are easily manipulated and sometimes forced to commit grave crimes, including murder of civilians or other child soldiers.

Children are recruited in different ways. Some are conscripted, while others are abducted or threatened to be killed or have their family members killed if they do not join. Many are arbitrarily seized from camps, streets or even from schools and orphanages.

\subsection{Circumstances leading to "enrolment" into armed groups}

War itself is a major determinant, but children may see enlistment as the only alternative when they lack access to education or employment or when their families are abusive or violent or fail to provide proper care. Girls frequently join to escape sexual violence, forced marriage, domestic violence or other forms of discrimination. In such contexts, children may see participation in armed forces or armed groups as their best option for survival for themselves, their families or communities.

Children living in highly militarized or politicized communities or areas where violence is organized or commonplace may also be vulnerable to recruitment; children often join armed actors to support or remain with their families. Many also join armed forces and armed groups out of revenge for the murder of members of their family, while others may also view membership as a way to gain perceived social recognition or status.

\section{The consequences for children associated with armed forces or armed groups}

The involvement of children in conflict exposes them to extreme and unacceptable threats to their health and well-being and violates their rights, some of which are noted below.

- Boys and girls are deprived of the opportunity to grow up with their families and to develop physically and emotionally in a familiar or protective environment.

- In combat, many children are killed, severely injured or permanently disabled, and they may be forced to witness or participate in atrocities, or take drugs before combat.

- In many contexts, children, mainly girls, associated with armed forces or armed groups are subjected to GBV and may contract sexually transmitted infections including HIV/AIDS.

- Boys are also vulnerable to sexual violence, including rape, sexual torture and humiliation and sexual slavery. ${ }^{3}$

- Children whose families are displaced are at greater risk of remaining separated from their families and communities once released.

See Shattered Lives, Immediate medical care vital for sexual violence victims, a report by Médecins Sans Frontières, March 2009. 
- Children may also be stigmatized or rejected by their families or communities. Girls face particular difficulties reintegrating, especially if they return pregnant or with children. Despite their experiences, these children usually see themselves as strong and hard working. They are resilient and able to do well in life if given appropriate help, support and encouragement.

\section{Girls and forced recruitment}

Girls constitute up to 40 per cent of children associated with armed forces or armed groups. While their experiences may lead to significant problems, particularly regarding their reintegration, their specific needs are rarely adequately addressed. Gender roles may contribute to girls' vulnerability to recruitment, which may be heightened in situations of displacement, for example by having to fetch water or firewood unaccompanied in conflict zones. Health risks may increase as they can become pregnant or give birth during their time with armed forces or armed groups.

Thus, the specific needs of forcibly recruited girls should be addressed at all stages of displacement and include the measures indicated below.

Ensure that all aspects of the prevention of recruitment, the release and the reintegration processes include concrete measures to respond to the specific needs of girls. Pay particular attention to the needs for protection and support for both girl mothers and children born to girls as a result of their recruitment by armed forces or armed groups. They may require (i) health care including reproductive health; (ii) psychosocial support; and (iii) measures to ensure they can access services including education or training programmes;

Display sensitivity in identifying and assisting girls, in order not to increase the stigma attached to their involvement with armed forces or groups.

As a preventative measure, ensure that humanitarian programmes promote gender equality and freedom of choice, and provide girls with opportunities to develop skills and generate income in non-exploitative settings (further outlined in Part V.11 $\square$ ).

\section{The responsibility of the State}

States bear the primary responsibility for providing security to, and ensuring the protection of, all children within their jurisdiction. Where States cannot meet all of their humanitarian responsibilities directly, they are charged with enabling the provision of humanitarian action by impartial actors.

States should take all necessary legislative, administrative and judicial measures to prevent and prohibit the recruitment of children into armed forces or armed groups. In particular, States should raise the age of recruitment and participation to armed forces to 18 years of age and provide clear instructions to all armed forces or armed groups not to engage in or support the forced recruitment of children. States should take all measures to criminalize such practices.

Where children have already been recruited, the State should demobilize child soldiers or facilitate the release of those children and provide them with protection, physical and psychological rehabilitation and reintegration support.

All peace agreements should include specific measures to demobilize and reintegrate all child soldiers formerly recruited by State and non-State actors into society.

Measures also include the ratification and implementation of all relevant legal instruments, in particular the Convention on the Rights of the Child, ensuring that all relevant international 
standards are respected and reflected in national law and establishing and enforcing recruitment procedures in compliance with international law, including the Optional Protocol to the Convention on the Rights of the Child on the involvement of children in armed conflict.

\section{The role of humanitarian and human rights actors}

The Paris Commitments to protect children from unlawful recruitment or use by armed forces or armed groups and the Paris Principles and Guidelines on children associated with armed forces or armed groups provide comprehensive guidance for country teams; reference should be made to the Integrated Disarmament, Demobilization and Reintegration Standards (IDDRS) (outlined below) when working in a peacekeeping environment.

While the primary responsibility for preventing and responding to the forced recruitment of children rests with the State, humanitarian and human rights actors also play an important role in supporting and facilitating State's actions, as well as in persuading and engaging non-State actors to respect the rights of children not to be forced to participate in conflicts.

Child protection actors, working together with government ministries and other bodies with a child protection mandate, should support States by providing the required technical and operational expertise and leadership in decision-making and programme implementation for the prevention of recruitment as well as for the release, demobilization and reintegration of children.

\section{All humanitarian and human rights actors, including those without expertise in the area of child protection, should} take measures to prevent and to ensure an effective response to the recruitment of children into armed forces or armed groups from the outset of an emergency. This entails ensuring that child protection concerns are adequately integrated and mainstreamed at all levels of the humanitarian response. The following matrix outlines key activities that could form part of an effective response.

\section{In our work, we can ...}

Assessment and analysis (See Part III.1 $\square$ )

\section{In Sri Lanka,}

a database was established in 2002

to collect information on children recruited in conflict-affected areas. The data was disaggregated by age, gender and district, and the database tracked the status of children (recruited, re-recruited, released, disappeared). The database constituted a powerful tool for advocacy and provided national/local authorities and humanitarian organizations with regular updates.

For more information, see: protection.oneresponse.info.

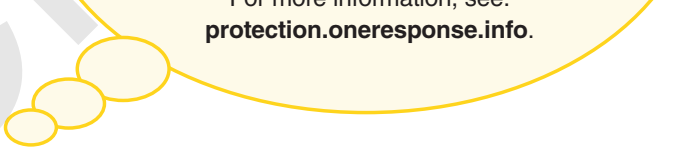


- Work closely with peacekeeping forces to prevent forced recruitment, and demobilize and reintegrate child soldiers. (For further information on demobilization in a peacekeeping environment see the Integrated Disarmament, Demobilization and Reintegration Standards. ${ }^{4}$ )

Prevention Ensure that prevention activities, which address the underlying causes of recruitment, are implemented within a broad child protection framework.

Advocate with national authorities and other stakeholders, as appropriate, to improve safety and security in and around camps, villages and other urban areas in order to prevent forced recruitment. (outlined further in Part IV.2 RD)

Develop advocacy campaigns with national civil society groups, including religious associations, to convey to key national stakeholders that the recruitment and use of children by armed forces or armed groups is not acceptable.

Develop local capacity, where possible, to follow up and monitor the situation of those children who require additional support, including girls and girl mothers, and any children at risk of re-recruitment (further discussed below, under monitoring and reporting).

Advocacy (See Part V.3 [D)
- Undertake coordinated and well-planned advocacy strategies with a range of actors, taking into consideration the sensitivity and complexity of the issue of children affected by armed conflict.

- Ensure that criteria for any release or demobilization process is based on the definition of "children associated with armed forces or armed groups" used in this document and that the objective of the release process is the early reintegration of children. These points should be clearly communicated to both armed forces and armed groups and communities, including children.

- Advocate with States to take the necessary steps to ensure that all relevant international standards are ratified, respected and reflected in national law and practice. This includes ensuring that children who leave the armed forces or armed groups by any means (including escape or capture) be provided with protection in accordance with international human rights standards (particularly where those groups acted against the State or IDP community). ${ }^{5}$

While recognizing that States have different obligations under international law, advocate, as do the majority of child protection actors, for States to raise the minimum age of recruitment to 18 years in all circumstances.

- Advocate for children associated with armed forces or armed groups to be treated in accordance with international standards for juvenile justice.

Advocate for the inclusion in all ceasefire or peace agreements of demobilization and reintegration programmes for child soldiers.

\footnotetext{
Particularly Module 5.30 on Children. The module provides policy makers, senior management, operational staff and DDR officers with guidance on the planning and implementation of child specific demobilization and integration programmes for children associated with armed forces or armed groups in a peacekeeping environment. See also Module 5.10 on Women, Gender and DDR and Module 5.20 on Youth and DDR,

5 See section 7 at the end of this chapter. 


\section{- Children associated with armed forces or armed groups}

\begin{tabular}{|c|c|}
\hline $\begin{array}{l}\text { Monitoring and } \\
\text { reporting } \\
\text { (See Part V.2 } \square \text { ) }\end{array}$ & $\begin{array}{l}\text { Support the establishment of specialized mechanisms for the systematic } \\
\text { monitoring and reporting on the recruitment (or re-recruitment) or use of } \\
\text { children by armed forces or armed groups, such as the task force on } \\
\text { monitoring and reporting chaired or co-chaired by UNICEF. }{ }^{6} \text { This is an } \\
\text { essential protection measure and also serves as the basis for actions to } \\
\text { pressure armed forces or armed groups to respect fundamental } \\
\text { humanitarian and human rights norms and for actions to end impunity for } \\
\text { those who violate those norms. Discuss roles and responsibilities for } \\
\text { monitoring and reporting such cases within the child protection group } \\
\text { and/or the country team. Such mechanisms must operate with the } \\
\text { participation of, and in cooperation with, national governments and } \\
\text { relevant United Nations and civil society actors. } \\
\text { Support the development of a database on children affected by armed } \\
\text { conflict. }\end{array}$ \\
\hline $\begin{array}{l}\text { Community } \\
\text { mobilization } \\
(\text { See Part V.10 } \square)\end{array}$ & $\begin{array}{l}\text { Develop a prevention strategy in consultation with children, families and } \\
\text { communities, which builds on their own protection initiatives and } \\
\text { responds to the reasons for recruitment. This should include (i) the } \\
\text { practical application of relevant law and standards such as the Optional } \\
\text { Protocol to the CRC; (ii) practical measures to improve children's safety, } \\
\text { for example, ensuring family unity; and (iii) programming to prevent } \\
\text { recruitment such as the provision of education and livelihood } \\
\text { opportunities. } \\
\text { Work with key members of the community to prevent propaganda or } \\
\text { active recruitment taking place in or around schools. Parents, teachers } \\
\text { and religious leaders are very important stakeholders in this respect. } \\
\text { Promote the development of plans by specialized organizations for } \\
\text { programmes to support the release and reintegration of children; this } \\
\text { should not be dependent either on the progress of any formal peace } \\
\text { process or any formal DDR process. The plans should (i) emphasize the } \\
\text { engagement of communities and build on existing resources; (ii) ensure } \\
\text { the participation of children, their families and communities; (iii) include a } \\
\text { strategy to meet the needs both of children who enter a release process } \\
\text { and those who do not; and (iv) include specific activities to meet the } \\
\text { needs of girls and their children. } \\
\text { Encourage the establishment of child protection committees - where } \\
\text { children and adults can work together to develop effective protection } \\
\text { strategies - and the formation of youth groups. }\end{array}$ \\
\hline
\end{tabular}

6 Pursuant to Security Council Resolutions 1539 (2004) and 1612 (2005), the Secretary-General, UNICEF and the Office of the Special Representative of the Secretary-General for Children Affected by Armed Conflict (SRSG-CAAC) are tasked with a lead role in the implementation of a mechanism for monitoring and reporting on the recruitment or use of children and other egregious violations against children in armed conflict. They are tasked with working alongside United Nations Peacekeeping forces and United Nations Country Teams. They act in collaboration with governments, local and international NGOs, civil society actors and other partners. In each country where children and armed conflict is an issue, a task force on monitoring and reporting will be constituted. The country-level Task Force on Monitoring and Reporting will be co-chaired by the Deputy SRSG and UNICEF Representative in situations where a United Nations peacekeeping mission is in place or by the UNICEF representative in situations without a peacekeeping mission. 


\begin{tabular}{|c|c|}
\hline $\begin{array}{l}\text { Capacity building } \\
\text { (See Part V.9 }\end{array}$ & $\begin{array}{l}\text { Support the provision of technical assistance and advice to relevant } \\
\text { stakeholders, including peacekeepers, local and national authorities and } \\
\text { community-based organizations. } \\
\text { Ensure that training is provided to all those implementing programmes or } \\
\text { working with children associated with armed forces or armed groups, for } \\
\text { example in interviewing and communicating with children. All staff } \\
\text { working with children should adhere to a code of conduct on the } \\
\text { protection of children (further addressed in Part IV.4 } \\
\text { Ensure that staff are trained and experienced in working with children, } \\
\text { that health and psychosocial needs are addressed, and that urgent } \\
\text { family tracing can be undertaken. }\end{array}$ \\
\hline $\begin{array}{l}\text { Health } \\
\text { (See Part IV.13 } \\
\text { and V.11 } \square \text { ) }\end{array}$ & $\begin{array}{l}\text { Ensure that adequate, free, confidential, accessible and "child friendly" } \\
\text { health care, including reproductive health services and HIV/AIDS testing, } \\
\text { are available. Following release or demobilization, all children should } \\
\text { undergo an assessment of their physical health, including nutritional } \\
\text { screening, and receive treatment or referral for specialist services as } \\
\text { necessary. } \\
\text { Provide appropriate medical care and support for children who have } \\
\text { been subjected to gender-based violence (further addressed in Parts } \\
\text { IV.4 and } 13 \square \text { ). Provide appropriate responses to meet the particular } \\
\text { needs of girls including those who are pregnant or girl-mothers and their } \\
\text { children. }\end{array}$ \\
\hline Interim care & $\begin{array}{l}\text { Ensure that safe and secure interim care is provided for those children } \\
\text { released or demobilized from armed forces or armed groups. They may } \\
\text { benefit from a period of time in a setting where special assistance is } \\
\text { provided by experienced staff; this might include children with medical } \\
\text { needs, girl-mothers, children whose families cannot be traced or where } \\
\text { the community is hostile to returning children. } \\
\text { Interim care is not universally necessary for all children and, where it is } \\
\text { used, it should always be planned and implemented as part of a } \\
\text { community-based programme to facilitate the return of children to their } \\
\text { communities and to promote the protection and development of } \\
\text { conflict-affected children in general, building upon the resilience and the } \\
\text { skills these children possess. }\end{array}$ \\
\hline
\end{tabular}

\footnotetext{
An example of a code of conduct developed by a coalition of organizations is Keeping Children Safe: A toolkit for child protection, by the Keeping Children Safe Coalition, 2006.
} 


\section{- Children associated with armed forces or armed groups}

\begin{tabular}{l|l}
\hline $\begin{array}{l}\text { Reintegration of } \\
\text { children and }\end{array}$ & Trace family members of child soldiers, including through the use of the \\
livelihoods & database on children affected by armed conflict. \\
(See Parts VI & Reunite or place children in a supportive family environment as soon as \\
and IV.16 & possible following preparation of the child, family and community. \\
& Assess and seek ways to address any obstacles to reintegration \\
including hostility towards returning children, medical needs or economic \\
constraints. Prepare communities to receive children, including through \\
their involvement in dialogue and conflict resolution mechanisms. \\
Reintegration programs should aim at supporting and implementing the \\
protection and rehabilitation roles of the State. \\
Develop alternatives to cash benefits to released or demobilized \\
children; and ensure that reintegration assistance generally is provided \\
through broader support to children, families and communities. \\
Assistance interventions should always build on the resilience of children \\
and aim to benefit the wider community whilst developing the capacity of \\
communities to provide a protective environment. \\
Provide educational activities that promote psychosocial well-being and \\
take into account the children's lost educational opportunities, their age \\
and stage of development, and their experiences with armed forces or \\
armed groups. \\
Conduct a technical assessment of the livelihood systems, market \\
opportunities, and household economies in the areas to which children \\
are returning in order to develop economically relevant training and \\
opportunities for economic reintegration. \\
Develop links with any governmental programmes, policies and \\
initiatives that could benefit these children and their families either \\
directly, for example through social welfare programmes, or indirectly, \\
through reconstruction and rehabilitation of national institutions and \\
other development programmes. Ensure that these programmes support \\
the inclusion of all children and do not neglect the specific situations of \\
girls, young mothers or children with a disability.
\end{tabular}




\section{Key actors}

- At the national level: In addition to the internally displaced and host communities, including children, key actors include community and youth organizations, civil society organizations, community-based organizations and NGOs; local and central government including ministries of social welfare and family, ombudsman or commissioners for children, ministries for justice, education and health; national governments (both affected countries and donor governments); human rights actors; military and security actors (State or non-State).

- At the regional level: Key actors include any regional military and civilian peacekeeping forces; regional organizations, such as the African Union, the European Union, Economic Community of West African States, the Organization for Security and Cooperation in Europe; regional human rights commissions and courts; governments of neighbouring States; influential States in the region, and donor countries.

- At the international level: Key actors include United Nations organizations, in particular the Office of the Special Representative of the Secretary-General for Children Affected by Armed Conflict (SRSG-CAAC), UNICEF, UNHCR, OCHA, DPKO; the ICRC and IFRC, United Nations Security Council, International Criminal Court (ICC); United Nations treaty bodies and special procedures; INGOs such as Save the Children.

\section{The Office of the Special Representative of the Secretary-General for Children Affected by Armed Conflict (SRSG-CAAC)}

Since the World Summit for Children in 1990, the United Nations has increasingly sought to draw international attention to the horrendous plight of children affected by armed conflict. Collaborative efforts between the Office of the Special Representative, the United Nations Children's Fund (UNICEF) and key United Nations entities, as well as Member States, regional organizations, NGOs and other civil society groups, have resulted in significant advances, actions and tangible results for children. These advances include increased global awareness of the issues concerning children affected by armed conflict; development and strengthening of international norms and standards for the protection of children; implementation of a mechanism for monitoring and reporting on recruitment or use of children and other egregious violations against children in armed conflict (pursuant to Security Council Resolutions 1539 and 1612); consistent focus and prioritization of this issue by the General Assembly and the Human Rights Council; placement of children and armed conflict on the international peace and security agenda through systematic engagement of the Security Council; and deeper mainstreaming of children and armed conflict in the United Nations system and concerted advocacy.

\section{The international legal framework}

International human rights law, particularly the Convention on the Rights of the Child, provides the core principles for protecting the rights of all children at all times; more specifically, it prohibits the recruitment and the participation in conflict of children of less than 15 years of age. ${ }^{8}$ In addition, it lays down State obligations in a number of areas which are of direct relevance to children recruited by armed forces or at risk thereof. These include the protection of separated and unaccompanied children; the recovery and social reintegration of children victim of neglect, exploitation or abuse, torture, ill treatment or punishment, as well as

8 See Art. 38(2). 
of armed conflicts; children's right to education; the prohibition of torture and the unlawful or arbitrary deprivation of liberty; and treatment under the juvenile justice system. ${ }^{9}$

The ILO Convention No. 182 on the Prohibition and Immediate Action for the Elimination of the Worst Forms of Child Labour defines children as below the age of 18 years and refers to forced and compulsory recruitment of children in armed conflict as one of the worst forms of child labour.

An Optional Protocol to the CRC on the Involvement of Children in Armed Conflict was adopted in the year 2000. It raises the minimum age for direct participation in hostilities and compulsory recruitment to 18 years; urges armed groups not to recruit or use children under the age of 18 and requires States Parties to take all feasible measures to criminalize such practices. It also calls on States to raise the minimum age and introduce strict safeguards for any voluntary military recruitment under 18 .

The Optional Protocol builds on other standards, in particular the 1999 African Charter on the Rights and Welfare of the Child. The Charter is the only regional treaty in the world which addresses the issue of child soldiers. It defines a child as anyone below 18 years of age without exception and charges States to ensure that no child takes direct part in hostilities and to refrain, in particular, from recruiting any child. ${ }^{10}$

International humanitarian law provides broad protection to children. In the event of armed conflict, both international and non-international, children benefit from the general protection provided to all civilians not participating in hostilities. Given the specific needs of children, the Geneva Conventions of 1949 and their two Additional Protocols of 1977 lay down a series of rules according them special protection; children who take a direct part in hostilities do not lose that special protection. In addition, international humanitarian law absolutely prohibits the recruitment of children younger than 15 into the armed forces or other armed groups and their involvement in hostilities in non-international conflicts. ${ }^{11}$

International criminal law, in particular the Rome Statute of the International Criminal Court (ICC) adopted in 1998, states that conscripting or enlisting children under 15 years into national armed forces or armed groups or using them to participate actively in all kinds of hostilities, is a war crime. The ICC has no jurisdiction over persons below 18 years of age.

UN Security Council Resolutions have repeatedly condemned and called for an end to the unlawful recruitment and use of children. ${ }^{12}$ States Parties to the above-mentioned treaties must ensure that their national laws are in conformity with their international obligations. They also must ensure that non-State actors comply with the prohibition to recruit or use children in armed conflicts. ${ }^{13}$

\footnotetext{
See Arts. 20, 28, 29, 39 and 40 of CRC. In addition to the CRC, the following international instruments provide protection for children in the justice system and the protection of children as witnesses: UN Standard Minimum Rules for the Administration of Juvenile Justice (The Beijing Rules) 1985, UN Rules for the Protection of Juveniles Deprived of their Liberty 1990, and the International Covenant on Civil and Political Rights 1966 (Articles 6 and 10).

10 See Art. 22(2).

11 See Art. 3(c) of the Additional Protocol II to the Geneva Conventions, applicable to non-international armed conflicts. Children younger than 15 years of age are also protected from direct involvement in international armed conflicts but, in this case, the prohibition is not absolute. Instead, parties to the conflict "shall take all feasible measures in order that children who have not attained the age of fifteen years do not take a direct part in hostilities, and in particular, they shall refrain from recruiting them into their armed forces" (see Art. 77 of the Additional Protocol I to the Geneva Conventions). The use of the term "direct part" implies that children younger than 15 years can be involved as long as it is not in direct combat. Children below the age of 15 years, for instance, could be involved as messengers, porters, etc.

12 See UN Security Council Res. 1261 (1999) 1314 (2000) 1379 (2001), 1460 (2003), 1539 (2004) and 1612 (2005).

${ }^{13}$ See Art. 4 of the Optional Protocol to the Convention on the Rights of the Child on the Involvement of Children in Armed Conflict.
} 


\section{Key references}

\section{Standards, Principles and Codes of Conduct related to personnel}

- Code of Conduct for the International Red Cross and Red Crescent Movement and NGOs in Disaster Relief, IFRC, 1994.

- Keeping Children Safe: A toolkit for child protection, by the Keeping Children Safe Coalition, 2006.

\section{Selected tools, guidelines and principles}

- The Capetown Principles and best practices on the prevention of recruitment into the armed forces and on the demobilization and social reintegration of child soldiers in Africa, 1997.

- The Paris Commitments to protect children from unlawful recruitment or use by armed forces or armed groups, 2007.

- The Paris Principles and Guidelines on children associated with armed forces or armed groups, UNICEF, 2007.

- Integrated Disarmament, Demobilization and Reintegration Standards (IDDRS), particularly Module 5.30 on children, and also Module 5.10 on Women, Gender and DDR and Module 5.20 on Youth and DDR, 2006.

- Humanitarian Charter and Minimum Standards in Disaster Response; Interagency Guiding Principles on Unaccompanied and Separated Children, The Sphere Handbook, ICRC, 2004.

- Child Soldiers, ref 0824, ICRC, 2003.

- Children and war information kit, ref. 0577K, ICRC, 2004.

\section{Further reading}

- A Fighting Chance, Guidelines and Implications for programmes involving children associated with armed groups and armed forces, Save the Children Alliance, 2004.

- Children - Not Soldiers: Guidelines for working with child soldiers and children associated with fighting forces. McCONNAN Isobel and UPPARD Sarah, Save the Children UK, 2001.

- BRETT, R. \& McCALLIN, M., Children: The Invisible Soldiers, Stockholm, Rädda Barnen, 2nd Edition, 1998.

- Promoting Psycho-social Well-Being among Children Affected by Armed Conflict and Displacement: Principles and Approaches, Geneva, SCA - Working Paper No. 1. Save the Children Alliance, 1996.

- Global Report on Child Soldiers, Coalition to Stop the Use of Child Soldiers, 2004.

- Guidelines on Mental Health and Psychosocial Support in Emergency Settings and Guidelines for Gender Based Violence Interventions in Humanitarian Settings, IASC, 2007.

- Introduction to Child Protection in Emergencies-an Inter Agency Modular Training Package, February 2009. 
Part IV .5 - Children associated with armed forces or armed groups

Useful websites

- Coalition to Stop the Use of Child Soldiers: www.child-soldiers.org

- International Committee for the Red Cross (ICRC): www.icrc.org

- United Nations Children's Fund (UNICEF): www.unicef.org

- Office of the High Commissioner for Human Rights (OHCHR): www.ohchr.org

- Special Representative of the Secretary-General for Children and Armed Conflict: www.un.org/special-rep/children-armed-conflict/fsoldiers.htm

- Office for the Coordination of Humanitarian Affairs (OCHA): www.ochaonline.un.org

- Save the Children: www.savethechildren.org/

193 


\section{Threat to liberty and freedom of movement}

Key message

1. What do we mean by the term "freedom of movement"?

2. Freedom of movement in the context of internal displacement

2.1 Practical barriers

2.2 Legal or administrative restrictions

2.3 Forced encampment

2.4 Arbitrary displacement, forced return or relocation

2.5 Arbitrary arrest and detention

3. Individuals and groups at particular risk

4. The responsibility of the State

5. The role of humanitarian and human rights actors

6. The international legal framework

6.1 Freedom of movement 200

6.2 The right to liberty and security of person 201

Key references \& useful websites 


\section{Key message}

The ability to move freely and in safety within one's country is a basic right as well as a pre-condition for the enjoyment of many other rights. Limitations on freedom of movement can have serious consequences for the lives, health and well-being of individuals and communities. Ensuring freedom of movement, thus, forms an important part of any protection strategy.

\section{What do we mean by the term "freedom of movement"?}

Freedom of movement consists of the right and ability to move and choose one's residence freely and in safety within the territory of the State, regardless of the purpose of the move. It also includes the right to leave any country and to return to one's own country. It is closely related to the right to liberty and security of person, which guarantees freedom from arbitrary arrest and detention, and the right to seek asylum in another country. Taken together, these rights mean that all persons, including internally displaced persons (IDPs), have the right to:

take flight and seek safety in another part of the country (of choice), or leave the country in order to seek asylum in another country;

move freely and in safety within the country, including in and out of camps and settlements, regardless of the purpose of the move;

voluntarily return to the place of origin or relocate to another part of the country;

not be arbitrarily displaced or forced to return or relocate to another part of the country; and

not be arbitrarily arrested or detained or forced to reside in specific camps or settlements.

Lack of freedom of movement can have serious consequences on the lives, health and well-being of displaced individuals and communities. It not only limits their ability to flee and seek safety from the effects of conflict or serious human rights abuses but furthermore impedes their ability to secure a sustainable livelihood, to access humanitarian assistance (further elaborated in Part V.4 $\square$ ) ) and find durable solutions to their displacement. Lack of freedom of movement can result in limited access to work, markets, land and basic necessities (food, water, firewood) as well as life-saving public services, such as education and health care. It may also lead to the separation of families and pose obstacles to family reunification. Further, it diminishes the possibilities for IDPs to find durable solutions, as they may not be able to go and see the conditions at their former place of residence or travel in the country to find another place in which to settle. Overall it is likely to result in increased poverty, marginalization and dependency on humanitarian aid.

\section{Freedom of movement in the context of internal displacement}

The ability to move freely and in safety is of particular importance for IDPs, who often live in or near areas of conflict and need to access vital humanitarian assistance or reside in camps and settlements where access to sustainable livelihoods and humanitarian assistance is limited and threats to life, safety and security frequent. Various obstacles may limit their freedom of movement, including (i) practical barriers; (ii) legal or administrative restrictions; (iii) forced encampment; (iv) forced population movement; (v) and arbitrary arrest and detention. 


\subsection{Practical barriers}

Practical barriers take different forms, depending on the context, but can include the following:

- Lack of safety and security stemming from crime, armed conflict, generalized violence, harassment, intimidation, or the presence of landmines and unexploded ordnance can affect the IDPs disproportionately, or they may be targeted because of perceived association with political factions or parties to a conflict. Such security risks usually persist in the aftermath of a conflict. In situations of natural disasters, unmitigated risks of further calamitous effects due to natural hazards, harassment or intimidation can also limit freedom of movement.

- Lack or loss of identity or travel documents can limit freedom of movement and expose IDPs to harassment, extortion, arbitrary arrest or detention. Replacement documentation is often difficult or impossible to obtain, for instance owing to strict administrative requirements, high fees or discriminatory practices. IDPs may also be obliged to return to their areas of origin, despite the dangers involved in obtaining new documentation (further addressed in Part IV.1

- Discrimination on the basis of gender, ethnic origin, political opinion, religion or other status, such as that of being displaced, can curtail freedom of movement. As an example, women and girls are frequently barred from obtaining documentation in their own names and may be prevented from traveling except with the permission of, or in the company of, male relatives;

- Lack of adequate infrastructure, including destroyed or damaged roads and bridges, lack of safe and affordable transport, in particular in situations of natural disasters, can hinder movement.

- Poor physical condition owing to age, ill-health or disability can also limit people's ability to travel.

\subsection{Legal or administrative restrictions}

Legal or administrative restrictions on freedom of movement by local or national authorities are often used to monitor or control movement within a country's borders. Restrictions are subject to strict criteria under human rights law. They must be provided for by law, be considered necessary and proportionate to achieve a legitimate aim (such as the protection of national security or public order, health or morals, or the rights or freedoms of others), including in the aftermath of a natural disaster, and they must be non-discriminatory and consistent with other human rights.

In situations of displacement, restrictions have sometimes been implemented in an arbitrary or discriminatory manner or been used for unlawful purposes, including to isolate or marginalize the displaced population. Common restrictions are noted below.

- General travel restrictions, either legal or administrative, which regulate movement within the country, for instance from rural to urban areas, often disproportionately affect IDPs, owing for instance to a lack or loss of documentation or financial means. These can include curfews, restricted traveling hours or days, or strict travel criteria, such as a need for specific documentation or travel permits. Illegal checkpoints put in place by uncontrolled armed elements or non-State actors also restrict the ability of IDPs to move freely.

- Targeted travel restrictions on, for example, movement in and out of camps or settlements for IDPs, are often imposed to deal with perceived or actual security threats but frequently violate the rights of those residing in the area. These can include curfews, restrictive traveling hours or days, restrictions on travel distances, strict exit/entry criteria, and documentation requirements. 
Whenever restrictions are imposed by the State, it must ensure that these comply with the criteria mentioned above. As an example, where documentation or travel permission are required, the State should ensure that these can be obtained without delay or hardship and that they are not subject to unreasonable requirements or high fees.

\subsection{Forced encampment:}

In some countries, IDPs have been forced to reside in special IDP camps or settlements, often despite the fact that they might prefer to seek shelter with members of their families, friends, or extended communities. Such camps or settlements are often poor, over-crowded and located in remote areas where access to sustainable livelihoods, basic necessities and vital services are limited or lacking entirely.

As a general rule, IDPs should be able to reside where they choose. Forced encampment, with few exceptions, is likely to constitute a grave violation of a number of human rights, including the right to freedom of movement. It may also amount to de facto detention in violation of the right to liberty and security.

\subsection{Arbitrary displacement, forced return or relocation}

Forced population movements have regrettably been used by both political and military factions to displace individuals and communities, gain control over land and natural resources, or to collectively punish a certain population group for alleged support for opposing factions. Forced population movement, as a general rule, is prohibited. It can only be lawful in a limited number of cases, such as to safeguard public safety or interest, or for reasons of military necessity, in which case it must take place in safety and meet certain minimum standards, as described in Part IV.1

\section{The principle of the voluntariness of movement entails that:}

the decision is made freely (without duress, compulsion or undue influence);

the decision is based on accurate, objective information; and

the decision is made expressly and individually (with women on equal footing with men).

It can be difficult at times to assess the voluntariness of movement, in particular in the context of large-scale return or relocation. Displaced populations may be vulnerable to outside influence or manipulation or may lack information and access to adequate food, water, shelter and other necessities. As a result, they may feel compelled to return or relocate although it may not be safe to do so. Conversely, some persons may feel compelled to stay although conditions for a safe and sustainable return exist. The voluntariness of movement needs to be assessed as thoroughly as possible in each given case (as outlined in Part VI.1 [D).

\subsection{Arbitrary arrest and detention}

Arbitrary arrest and detention, and ill-treatment while in detention, is a serious problem in many countries. Such abuse can affect IDPs disproportionately because of discrimination, distrust, stigma and/or lack or loss of documentation proving legal identity. This is frequently the case in countries where displacement has been motivated by political or ethnic factors. Poverty and marginalization can also force individuals to adopt survival strategies, such as brewing alcohol, trading goods without permission or survival sex, which breach national law and thus place them at increased risk of arrest and detention.

While the State has the right and indeed the duty to maintain law and order, including through powers of arrest and detention, such powers must be exercised in accordance with the law and 
with respect for human rights. As an example, all detainees must be treated humanely, be informed of any charges against them in a language they understand, and be given the opportunity to contest the lawfulness of the arrest before a judge. Any form of torture or ill treatment, including rape, beating or excessive use of solitary confinement, is prohibited at all times.

\section{Individuals and groups at particular risk}

Different groups may experience different obstacles or violations of freedom of movement. For instance, women and girls are often discriminated against, prevented from obtaining documentation in their own name, or harassed or subjected to sexual violence when traveling alone. Men and boys, however, may be more likely to be arbitrarily arrested and detained, forcibly recruited into armed forces/groups, or placed at risk of extra-judicial and summary executions. Ethnic and religious minorities and stateless persons as well as persons with special needs, such as unaccompanied and separated children, older persons, and persons living with disability or disease, often face additional difficulties.

\section{The responsibility of the State}

The national authorities carry primary responsibility for respecting and ensuring respect for the rights to freedom of movement, liberty and security of person. This means that the State must ensure that the rights are adequately protected in national legislation and respected by all agents of the State at the national, regional and local levels. The State must also take action to ensure that freedom of movement is not limited by third parties and that any obstacles to the full enjoyment of the right are adequately addressed.

\section{The role of humanitarian and human rights actors}

Humanitarian and human rights actors can play an important role in ensuring freedom of movement and respect for other human rights through advocacy, monitoring and capacity-building efforts, both with the authorities and with displaced individuals and communities.

\section{In our work, we can ...}

\begin{tabular}{l|l}
$\begin{array}{l}\text { Assessment and } \\
\text { analysis } \\
\text { (See Part III.1 }\end{array}$ & $\begin{array}{l}\text { Work with displaced communities and relevant colleagues, including } \\
\text { security experts, to identify and assess obstacles to freedom of } \\
\text { movement, liberty and security, and the ways in which these can be } \\
\text { addressed. }\end{array}$ \\
\hline $\begin{array}{l}\text { Presence } \\
\text { (See Part V.4 }\end{array}$ & $\begin{array}{l}\text { Ensure regular visits and the visible presence of protection staff in areas } \\
\text { or locations where freedom of movement and other rights are frequently } \\
\text { violated. This may include checkpoints, exit/entry points into camps and } \\
\text { villages, roads and paths leading to markets, schools, and other public } \\
\text { spaces. }\end{array}$ \\
\hline $\begin{array}{l}\text { Advocacy } \\
\text { (See Part V.3 }\end{array}$ & $\begin{array}{l}\text { Advocate for, and sensitize, relevant actors, including national and local } \\
\text { authorities and non-State actors, to the importance of respecting } \\
\text { freedom of movement, liberty and security, and the prohibition on forced } \\
\text { and arbitrary displacement, return or relocation of any kind. }\end{array}$ \\
\hline
\end{tabular}


Documentation

(See Part IV.9 D )
- Work with relevant authorities to ensure that IDPs have safe and effective access to documentation and/or replacement documentation, that strict documentation requirements are eased or suspended for IDPs, and that those without documentation are not arbitrarily arrested and detained. In some cases, modest financial or material assistance might be appropriate in order to assist local authorities to issue or replace lost documentation.
Safety and security (See Part IV.2 $\square$ )

Ensure that IDPs have access to information about the security situation and other factors that may affect their ability to move freely and in safety. In the context of return or relocation, this includes information about travel conditions and conditions in the place of return or intended relocation. Where appropriate, organize "Go and see" visits in consultation with the concerned displaced persons or groups and the receiving communities.

Community

(See Part V.10 D)

Work with the community to identify obstacles and take steps to strengthen its ability to move freely and in safety. This can include safe transportation; joint travel or transportation to markets, schools, and clinics; joint collection of food, water and firewood; accompanied travel, for instance for women and children; and assisted travel, for example for older persons or persons with disabilities.

- Negotiate for, and support efforts to, improve safety and security in and around camps, settlements and urban IDP areas. This may include an increase in the number of civilian police and, if present, patrols by peacekeeping forces. To safeguard their civilian character, military forces should be involved only on an exceptional basis and never within, or in the immediate vicinity of, such areas.

\section{Mine action} (See Part IV.3 ㅁ)
- Coordinate with de-mining experts and other partners, including local authorities and displaced communities, to ensure the early identification, marking and de-mining of areas inhabited by IDPs, and provide support for mine-awareness and education activities aimed at both the displaced and the wider population.

\section{Transport}

Advocate for, and assist, the authorities to improve road infrastructure and public transport to enable displaced individuals and communities to seek work, access markets, tend fields, and access education and health care. This can include repairing roads or bridges, loaning or donating vehicles, such as buses, and modest financial or material assistance, for instance in the form of fuel. In situations where harassment and violence against ethnic groups may persist, assist the authorities to introduce unified license plates that would prevent the identification of places of residence.

Consider providing modest financial or other assistance to persons in need or at particular risk to enable them to travel, for instance to work or to attend schools or health clinics. 


\begin{tabular}{|c|c|}
\hline $\begin{array}{l}\text { Persons in } \\
\text { detention }\end{array}$ & $\begin{array}{l}\text { Ensure that effective monitoring mechanisms are established to monitor } \\
\text { that conditions in detention and the treatment of individuals deprived of } \\
\text { their liberty meet established minimum standards. Such activities should } \\
\text { be undertaken in close cooperation with the ICRC or other actors with } \\
\text { expertise in monitoring prison conditions. Where needed, modest } \\
\text { financial or material assistance can be provided to improve prison } \\
\text { conditions and services. } \\
\text { Make interventions on behalf of individuals who have been arbitrarily } \\
\text { arrested or detained. This can include legal advice and assistance as } \\
\text { well as advocacy with relevant authorities to ensure respect for relevant } \\
\text { rights, including the right not to be arbitrarily arrested or detained, to be } \\
\text { informed of any charges, to be brought before a judge in order to } \\
\text { challenge the lawfulness of detention, and to a fair trial. }\end{array}$ \\
\hline $\begin{array}{l}\text { Durable solutions } \\
\text { (see Part VI } \square \text { ) }\end{array}$ & $\begin{array}{l}\text { Monitor return and relocation movements to ensure IDPs are informed, } \\
\text { the movements are voluntary, and minimum standards relating to safety } \\
\text { and security as well as the provision of basic necessities are met. Where } \\
\text { such movement is deemed involuntary, in part or in whole, ensure that it } \\
\text { is monitored, documented and reported to all relevant stakeholders, } \\
\text { including in particular the protection working group and the } \\
\text { Humanitarian/Resident Coordinator. } \\
\text { Advocate for and support development projects that aim to restore or } \\
\text { rehabilitate damaged infrastructure (roads, bridges) or public services } \\
\text { (schools, health clinics, community centres) that facilitate voluntary } \\
\text { return, resettlement or integration in the area of displacement. }\end{array}$ \\
\hline
\end{tabular}

\section{The international legal framework}

\subsection{Freedom of movement}

International (and regional) human rights law guarantees everyone the right to freedom of movement and residence within the borders of the State, and the right to leave and enter one's own country. ${ }^{1}$ It consists of the right to move and choose one's residence, freely and in safety, without undue influence or interference from the State, regardless of the length of stay or the reason or purpose of the move.

While States might have a legitimate interest in controlling or monitoring the movement of people in their territory, such restrictions are only permissible if they meet the established criteria of (i) being provided for and being in accordance with law; (ii) being necessary to achieve a legitimate aim, such as protecting national security, public order, public health or morals or protecting the rights and freedoms of
Guiding Principles (outlined further in Annex 1 of the Handbook $\square$ )

"Principle 14: 1. Every internally displaced person has the right to liberty of movement and freedom to choose his or her residence. 2. In particular, internally displaced persons have the right to move freely in and out of camps or other settlements.

Principle 15: Internally displaced persons have: (a) The right to seek safety in another part of the country; (b) The right to leave their country; (c) The right to seek asylum in another country; and (d) The right to be protected against forcible return to or resettlement in any place where their life, safety, liberty and/or health would be at risk."

See, at the international level, Art. 13 of UDHR; Art. 12 of ICCPR; Art. 5(d)(i) and (f) of ICERD; Art. 15 of CEDAW; and, at the regional level, Art. 12 of AfCHPR; Art. 22 of AmCHR; Arts. 20 and 21 of ArCHR; and Art. 2 of Protocol 4 to ECHR. 
others; and (iii) being consistent with other human rights, particularly the right to non-discrimination, and the State's other international legal obligations.

Women and girls are entitled to equal respect of freedom of movement and residence, and States are obliged to take all necessary measures to ensure that they can exercise this right on an equal basis with men and boys. ${ }^{2}$

The right to freedom of movement is also closely related to, and often a prerequisite for the enjoyment of, other human rights, including the rights to life, liberty and security, to an adequate standard of living, including health, food and water, and to property. It is also closely related to the right to seek asylum from persecution in another State. ${ }^{3}$

International humanitarian law forbids parties to the conflict to order the displacement of the civilian population in whole or in part, unless their security or imperative military reasons so demand, and it requires that displaced persons be allowed to voluntarily return in safety as soon as those reasons cease to exist. The law also requires that all possible measures be taken to protect any property left behind and to ensure satisfactory conditions while in displacement, including shelter, hygiene, health, safety, nutrition and family unity. ${ }^{4}$

\section{The right to liberty and security of person}

\section{International (and regional) human} rights law guarantees the right to liberty and security of person. ${ }^{5}$ This includes a prohibition on arbitrary arrest and detention as well as any other deprivation of liberty that is not based on and in accordance with the law. The right also includes the right to (i) be informed immediately of the reasons for arrest; (ii) be brought promptly before a judge; (iii) be able to challenge the lawfulness of detention; (iv) be brought to trial or released within a reasonable time; and, (v) in case of unlawful arrest or detention, compensation. The law also calls for the humane treatment and respect of other human rights while in detention.
Guiding Principles (outlined further in Annex 1 of the Handbook

"Principle 12: 1. Every human being has the right to liberty and security of person. No one shall be subjected to arbitrary arrest or detention. 2. To give effect to this right for internally displaced persons, they shall not be interned in or confined to a camp. If in exceptional circumstances such internment or confinement is absolutely necessary, it shall not last longer than required by the circumstances. 3. Internally displaced persons shall be protected from discriminatory arrest and detention as a result of their displacement. 4. In no case shall internally displaced persons be taken hostage".

The UN Basic Principles for the Treatment of Prisoners, the UN Standard Minimum Rules for the Treatment of Prisoners, and the UN Body of Principles for the Protection of All Persons under Any Form of Detention or Imprisonment provide useful and more detailed information about the standards that should be followed. ${ }^{6}$

\footnotetext{
See, for example, Art. 15 of CEDAW. See also General Comment No. 27 (1999) on freedom of movement (para. 6) and General Comment No. 28 (2000) on equality of rights between men and women (s.16), of the UN Human Rights Committee.

3 See, in particular, at the international level, the 1951 Convention on the Status of Refugees and its 1967 Protocol, and Art. 14 of UDHR, and, at the regional level, Art. 12(3) of AfCHPR; Art. 23 of AfCRWC; Art. 22(7) of AmCHR; and Art. 23 of ArCHR.

4 See, for example, Rules 129-132 of Customary International Humanitarian Law - Volume I: Rules (ICRC, 2005). See also Art. 49 of the Fourth Geneva Convention and Arts. 4(3)(b) and 17 of Additional Protocol II.

5 At the international level, see for example Art. 3 of UDHR; Art. 9 of ICCPR; Art. 5(b) of ICERD; Arts. 9(4) and 37 of $\mathrm{CRC}$ and, at the regional level, Art. 6 of AfCHPR; Art. 7 of AmCHR; Art. 4(c) of the Inter-American Convention on the Prevention, Punishment and Eradication of Violence Against Women; Art. 8 of ArCHR; and Art. 5 of ECHR.

6 These are available at: www.ohchr.org/english/law.
} 
International humanitarian law prohibits arbitrary deprivation of liberty, i.e. detention that is not based on and in accordance with the law. ${ }^{7}$ It also establishes extensive safeguards for the treatment of detainees during times of armed conflict. ${ }^{8}$ In particular, they must be provided with adequate food, water, clothing, shelter and medical attention, and be allowed to correspond with, and receive visits from, their families. Violations of these rules might amount to inhumane treatment, which may constitute a war crime. Women and children should also be kept separate from adult men, except where families are accommodated as family units.

\section{Key references \& useful websites}

- General Comments No. 27 (1999) on freedom of movement (Art. 12); No. 21 (1992) replaces general comment No. 9 concerning human treatment of persons deprived of liberty (Art. 10); and No. 8 (1982) on the right to liberty and security of persons (Art. 9) of the Human Rights Committee.

- Protection of detainees: "Action Behind Bars," International Review of the Red Cross, Alain Aeschlimann, Vol. 87, No. 857, International Committee of the Red Cross, Geneva, March 2005. 


\section{Part IV.7 \\ Family separation}

Key message .204

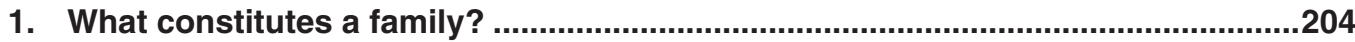

2. Family separation in the context of internal displacement ....................................204

3. Preventing and responding to family separation ..................................................206

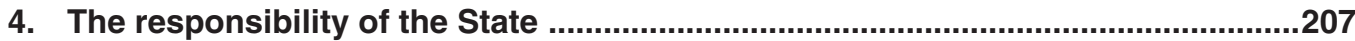

5. The role of humanitarian and human rights actors ..............................................208

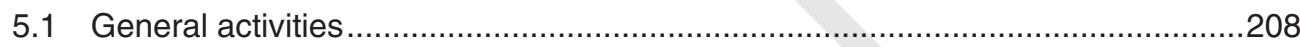

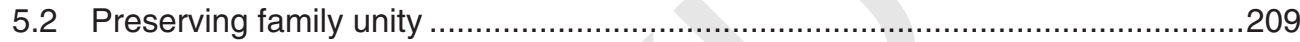

5.3 Identification, registration and documentation .................................................210

5.4 Tracing, verification and reunification ............................................................

5.5 Protection and assistance, including alternative care arrangements ..................211

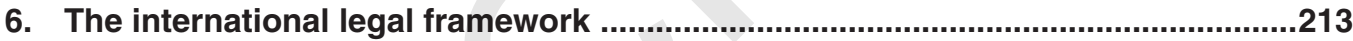

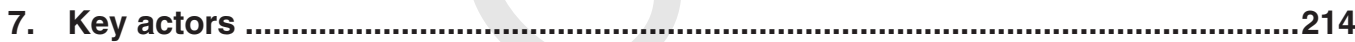

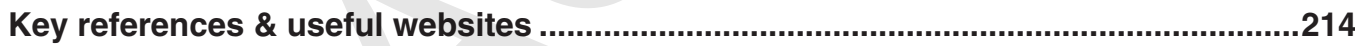




\section{Key message}

The family is a fundamental social unit that is entitled to special respect and protection. The family is also an important source of protection in itself. It unites individuals and provides important physical, social, legal, material and emotional stability and support to its members, in particular for children. Efforts aimed at preserving the unity of the family can prevent exposure to various risks and help individuals and communities rebuild their lives and minimize the adverse effects of displacement.

The Inter-Agency Guiding Principles on Unaccompanied and Separated Children provide guidance on preventing family separation, undertaking family tracing and reunification, and ensuring adequate care arrangements for unaccompanied children pending reunification. The Principles are available from http://www.unhcr.org/refworld/docid/4113abc14.html. This chapter provides basic guidance but does not replace or duplicate the Principles, which should be implemented in all emergencies.

\section{What constitutes a family?}

There is no universally accepted definition of the family and the meaning of the term may differ from one country to another. In some cultures the term refers to parents and their children only; in others, it includes a larger group of extended family members. It is important to understand and respect such differences and adopt a working definition that suits the context, as outlined below.

Use a practical, flexible and comprehensive definition that extends beyond the nuclear family in order to include relationships of social, emotional or material dependency. In some cases, this may include individuals who are not blood relatives.

Use appropriate and realistic criteria relating to documents and other evidence that may be required to demonstrate a family connection. Internally displaced persons have often lost personal documents, and alternative methods may need to be developed to confirm family connections.

Use a broad definition of terms such as "spouse" and "dependent child." As an example:

- "Spouse" should not be restricted to persons in legal unions only but extend to those who are engaged, have entered into a customary marriage, or have formed a household (cohabitation/common law couples). It may also include same sex partnerships and spouses in a polygamous marriage.

- A dependent child is normally defined as any unmarried child under the age of 18 years. However, in some cases, children over 18 years could be included if, for instance, they remain dependent upon, and continue to share, a household with their parents. No distinction should be made between children born in and those born outside marriage.

\section{Family separation in the context of internal displacement}

Families and communities are frequently torn apart as a result of forced displacement. Such separation can occur deliberately where, for instance, parents entrust the care of their children to others, often in the belief that it will be in their best interests or accidentally, including during flight or when seeking shelter and assistance in large or crowded camps, settlements and 
urban areas. Internally displaced persons (IDPs) are often forced to flee on short notice and family members, in particular young children, older relatives or persons with disabilities, may be left behind or become separated on the way.

Separation can also occur as a result of well-meaning but ill-conceived or even unlawful, humanitarian interventions. By way of example, evacuating children or facilitating adoption arrangements can lead to forced and permanent separation of children from their parents. Providing them with shelter and other assistance without making arrangements for their parents or caregivers can also lead to separation.

Separation also occurs when children are forcibly recruited into the State military or into armed groups in territories controlled by non-State entities (as outlined in Part IV. 5 [D).

Humanitarian actors must always act to ensure that children are not separated from their parents against their will or against their best interests. ${ }^{1}$

Separation from family members and lack of knowledge about the fate and whereabouts of loved ones can give rise to grief, anxiety and depression. It can also expose individuals to various, but different, protection risks depending on their age, gender and specific needs, as outlined below.

- Women and girls often suffer as a result of discrimination and lack of access to land, shelter, public services or documentation in their own names. Separation may also place them at increased risk of various forms of gender-based violence, including sexual abuse and exploitation.

- Men and boys are often at increased risk of harassment, arbitrary arrest and detention, and/or forced recruitment into armed forces or armed groups.

- Girls and boys face a wide range of protection risks as a result of separation from their families or caregivers, including neglect, abuse and exploitation, forced labor, slavery, trafficking, limited access to education, and forcible recruitment into armed forces or armed groups.

- Older persons, which may have limited ability to move or secure a livelihood, may be exposed to hunger or disease and, in some cases, may suffer abuse and exploitation.

- Persons with disabilities may face obstacles when trying to move, when seeking shelter, or when accessing assistance and services, including health care.

\section{DID YOU KNOW THAT...}

A child is any person under the age of 18 years, unless majority is attained earlier under national law.

A separated child is any child that has been separated from both parents or from other legal or customary primary caregiver/s but not necessarily from other relatives.

An unaccompanied child is any child who has been separated from both parents and other relatives and who is not being cared for by an adult who, by law or custom, is responsible for doing so.

An orphan is a child whose parents, both mother and father, are deceased. This requires careful verification and must never be assumed. Referring to a child as an "orphan" should be avoided until the fate of his/her parents and other legal or customary primary caregivers has been conclusively determined. 
Separated family members can face a number of obstacles when trying to trace and reunite with their families. Factors such as ongoing conflict and insecurity, collapse of institutions and infrastructure, lack of freedom of movement and means of communication, and responsibility toward other family members, can limit the ability to search for, and unite with, separated family members. Young children, older persons and persons with disabilities face particular obstacles in this regard. In some cases, separated family members may find themselves on different sides of a frontline or a border, which can make tracing and reunification very difficult.

\section{Preventing and responding to family separation}

Separated families and communities usually make significant efforts to find and reunite lost family members, and such efforts should be supported where possible. Local and national authorities as well as humanitarian and human rights actors also play an important role in preventing and responding to family separation. Such activities can be divided into four categories:

prevention (to be undertaken at all times);

- identification, registration and documentation (to be undertaken from the beginning of displacement and continue until displacement has come to an end);

- tracing, verification and reunification (to be undertaken by specialized agencies only); and

- temporary assistance and/or alternative care arrangements (to be provided if and as required).

Several key principles, as indicated below, should guide all efforts to prevent family separation and ensure family unity, in particular in cases involving children.

- Respect for human rights, including the principle of family unity: All men and women have the right to found a family and have their right to respect for the family observed. This requires efforts to prevent separation and to ensure rapid tracing and reunification in case it occurs, even in times of conflict and displacement.

- Principle of non-discrimination: Any direct or indirect discrimination, for instance on the basis of age, gender, ethnic or linguistic background, political opinion, birth or other status, including that of being displaced, is prohibited. In order to ensure full and equal access to assistance and services, however, efforts must be made to meet any specific needs, including those of women and girls.

- Participation, including that of children: Separated family members should be informed about the relevant procedures and kept updated about any progress made. Their informed consent should be sought for the sharing of personal information and for reunification to take place. The child's right to participation should also be respected and his/her opinion given due weight, taking into account the child's age and maturity. Children may need to be interviewed by trained staff with experience working with children.

- Best interests of the child: The principle arising from Article 3 of the Convention of the Rights of the Child, that "the best interests of the child shall be a primary consideration," should be applied in a systematic manner in any action that affects a child and must permeate both actions of general character, such as assessments, planning or budget allocations, and actions affecting individual children. In situations of internal displacement, this principle requires a careful assessment of the best interests of the child at every phase of the displacement cycle, regarding any action that may affect the child. While relevant for all children, the identification of the best interests of unaccompanied and separated children in situations of internal displacement requires special attention due to the particular risks that they may face. 


\section{Best Interest Determination Procedures}

National child protection systems usually foresee scrupulous procedural safeguards for decisions of a certain magnitude which require that the best interests of the child be identified. Such decisions include separation from parents against their will (e.g. in case of abuse or neglect), determination of custody rights or decisions on adoption. These decisions can only be taken by competent national authorities, such as the judiciary, and are subject to procedural safeguards foreseen by law.

In humanitarian crises, protection actors may also need to establish formal procedures for the determination of the child's best interests (known as BID procedures). In the context of family unity, BID procedures are to be established when considering durable solutions, alternative care arrangements, removal from family when a child's safety is in question and, in some cases, family reunification. These should be developed building on domestic child protection systems. They should ensure that decisions are taken by more than one person with relevant expertise and are based on a balancing of all relevant factors. BID procedures should ensure adequate child participation without discrimination. The views of the child should be given due weight in accordance with age and maturity.

\section{The responsibility of the State}

The family is considered a fundamental social unit and is entitled to special protection under international law as well as by most national legal frameworks. The national authorities carry primary responsibility for protecting and ensuring respect for family unity and family life (as outlined in Part IV.7.7). This includes taking any necessary legislative, administrative and other measures to prevent and respond to family separation. Examples of steps that should be taken by States are indicated below.

- Take action to prevent family separation from taking place, including by ensuring that any action or inaction by the State does not result in separation of families who wish to remain together, including during evacuations or other population movements. This may include ensuring proper registration of births, deaths and/or changes in civil status (e.g. marriage or divorce), as well as the equal rights of men and women to manage family property and care for their children. With regard to the forced recruitment of children into the armed forces, which is prohibited under international humanitarian law, prevention also includes issuing clear governmental instructions to all actors of a conflict, including non-State actors, not to resort to child conscription (further elaborated in Part IV. 5 DU).

- Enable the rapid tracing and reunification of separated family members by, for instance, establishing tracing mechanisms, facilitating inquiries, assisting separated families to reunite, and cooperating with humanitarian organizations engaged in such activities.

- Provide protection and assistance to persons who have become separated from their families as well as for the families caring for such persons, in particular where unaccompanied or separated children are involved. Children who cannot be reunited with their families should be provided with alternative care and support. Care arrangements must be regularly monitored and measures taken to protect the child from any form of violence, maltreatment, neglect or abuse.

- Make all efforts to establish and to inform next of kin of the fate and whereabouts of missing relatives. In the event of death, the authorities should endeavour to collect and return the mortal remains of dead relatives to their families or indicate the location of their burial sites. Efforts should include the establishment of mechanisms, such as truth commissions, to allow IDPs to know the fate of their missing relatives (outlined in 
Part IV.18 $[D$ ), and ensure access to justice and reparation for victims of grave human rights abuses.

\section{The role of humanitarian and human rights actors}

Humanitarian and human rights actors can support efforts to preserve family unity by helping to prevent family separation, by providing protection and assistance to those who have been separated from their families, and by supporting family tracing and reunification efforts where appropriate. Such efforts should be coordinated by actors having the required skills, expertise and experience. They should also be in line with existing guidelines on the subject, in particular the Inter-Agency Guiding Principles on Unaccompanied and Separated Children. In most cases, close cooperation with national authorities and relevant line ministries is needed.

\subsection{General activities}

\section{In our work, we can ...}

Assessment

(See Part III.1 D) response

\section{Coordination}

- Ensure that protection assessments take into account the risk of family separation, including its main causes, consequences, and those most at risk. Such assessments should also identify the means and mechanisms used by the community to prevent or respond to such separation (e.g. community-based tracing, reunification and provision of temporary care and support to those in need).

Ensure that family unity is adequately addressed by the protection working group and other coordination mechanisms if needed. This may require the establishment of a focal point or a working group that takes responsibility for coordinating the response (as discussed in section 7 below).

Ensure that the roles and responsibilities of all relevant actors are clear, that adequate standard operating procedures are in place and joint referral/response mechanisms established, and that existing common standards and tools, including the Inter-Agency Guiding Principles on Unaccompanied and Separated Children, are used and implemented (as further addressed in the reference list below).

Ensure that a referral and response mechanism is available and known to staff and partners. Such mechanisms are needed to ensure immediate registration, documentation and appropriate care, protection and assistance, of any identified separated family members, in particular unaccompanied children. Such mechanisms should be coordinated by actors with the required expertise.

\section{Monitoring}

(See Part V.2 $\square)$

Ensure that all staff and partners, including those involved in protection monitoring, know how to identify separated family members and are familiar with relevant referral/response mechanisms.

\section{Confidentiality}

- Ensure that actors working with unaccompanied and separated children and other separated individuals respect privacy and the confidentiality of information, and that measures are taken to guarantee data protection. 


\subsection{Preserving family unity}

Efforts to preserve family unity should take place during all stages of displacement. Such efforts can prevent family separation from taking place and, in case it occurs, greatly facilitate rapid tracing and reunification.

\section{In our work, we can ...}

\section{Advocacy}

(See Part V.3 $\square$ )
Advocate with relevant actors, particularly with local and national authorities, to take appropriate legislative, administrative and other measures to promote and protect the principle of family unity. This may include advocating for the recognition of customary marriages to ensure respect for the rights of women to claim custody of their children and to inherit land and property upon the death of their husbands as well as for the full and equal rights of children born out of wedlock.

\section{Community mobilization (See Part V.10 [D)}

- Work with relevant actors, including parents, community groups and local and national authorities, to raise awareness of the risks of family separation, and take measures that can help prevent separation from taking place or, where such separation occurs, that facilitate tracing and reunification. As an example, children can be taught to remember their names and those of their parents, dates of birth, addresses and other details that could assist with family tracing in the event of separation.

\begin{tabular}{l|l}
$\begin{array}{l}\text { Civil status and } \\
\text { documentation }\end{array}$ & $\begin{array}{l}\text { Work with relevant stakeholders, including local and national authorities, } \\
\text { to ensure that all births, deaths and changes in civil status (marriage, } \\
\text { (See Part IV.9 } \\
\text { divorce) are registered and documented, and that IDPs have access to } \\
\text { documentation and/or replacement documentation, if needed. }\end{array}$
\end{tabular}

Access to assistance and services

(See Part V.5
- Advocate and take other steps to ensure that families with children have access to public and/or relief assistance and services, including shelter, food, non-food items and income-generating activities, to enable them to remain together and prevent families from having to abandon or give their children away. Pay particular attention to single-headed households, especially those headed by children, single women, older persons and persons living with a disability.

\section{Programme planning and implementation}

Ensure that humanitarian programmes and projects do not cause or result in the separation of families, either deliberately or accidentally, by for example: making sure family members are accommodated and assisted together wherever possible (and that children are not accommodated separately from their families or other legal or customary primary caregivers); avoiding transferring unaccompanied or separated children from the location where they were found, unless the best interests of the child so require, as it may make tracing more difficult;and

making arrangements during the distribution of assistance to prevent the separation of families from taking place including, for instance, organized community child-care.

Take action to ensure family unity during evacuation or assisted transfer, including during return or relocation. This may include ensuring that: evacuation/transfer, reception and care are planned in advance and form part of a coordinated plan of action; and families are registered and transferred together, children are not, as a general rule, transferred without their parents or other primary caregivers and, where this is not possible, adequate reception and care arrangements are made in advance and reunification takes place as soon as possible. 


\subsection{Identification, registration and documentation}

It is important to ensure that separated family members, in particular any unaccompanied or separated children, are identified, registered and documented as early as possible. This will increase the likelihood of successful tracing and reunification and facilitate the timely provision of adequate care, support and protection to those in need.

Unaccompanied and separated children should always be registered and documented, even when they are in the safe company or care of an adult, as it is a prerequisite for tracing and reunification with the child's family. At the same time, it is important to ensure that the process does not undermine existing care arrangements or raise false expectations about assistance and support. ${ }^{2}$ The process, thus, must be explained in advance and should preferably be undertaken by experienced staff or specialized actors.

In order to ensure a consistent approach, it is important that relevant actors use existing inter-agency tools, forms and guidelines, which have been developed based on years of experience.

\section{In our work, we can ...}

Identification

Ensure that mechanisms are in place to identify separated family members, including in particular any unaccompanied or separated children. Such mechanisms should be coordinated by actors that have the required expertise (as outlined in section 7 below). However, all staff and partners should be familiar with signs indicating family separation and available referral/response mechanisms.

Registration and documentation (See Part IV.9 D)

\begin{abstract}
Ensure that separated family members are registered and documented immediately following identification. Registration may include the collection of information such as name, data and place of birth, name of parents and other close relatives, former address, present location, and a photograph. Registration records should be updated as required and kept by, or with, the separated family member, and a copy shared with actors that oversee family tracing and reunification.

Where limited time and resources are available for registration, for instance due to security reasons, priority may need to be given to very young children or children with disabilities, who may have difficulty in recalling important information at a later stage. Unaccompanied children may need to be provided with immediate care arrangements.
\end{abstract}

\subsection{Tracing, verification and reunification}

Family tracing, verification and reunification should take place as soon as possible, including in times of conflict and displacement.

Tracing can take place by different means, including by:

- the dissemination of Red Cross messages (delivered by ICRC or Red Cross/Crescent national societies);

- mass tracing, which involves displaying or disseminating name lists and/or photos;

- radio broadcasting of limited personal information, such as name, gender, age of the separated person and possibly parents/siblings;

2 This can result in a pull-factor, with parents registering their own children as separated in order to access assistance, or a push-factor, with caretakers avoiding registering unaccompanied or separated children in their care out of fear that the children will be taken away. In some cases, caretakers may reject a child in their care if expected assistance or support fails to materialize. 
1- photo tracing, which involves the dissemination of photos;

- cross-referencing tracing records with other available records, such as birth or school registers or census databases; and

- case-by-case tracing, which is mostly used for small case-loads or where other efforts have proved futile.

For confidentiality and security reasons, the current location of the separated person should be kept confidential until the family relationship has been verified and those involved have agreed to be reunited. In some cases, reunification may be neither feasible nor desired if, for instance, the separated person suffered neglect or abuse at the hands of other family members prior to separation or if reunification would place the person at risk.

Tracing, verification and reunification is usually coordinated and undertaken by specialized actors, but other humanitarian actors can facilitate and support such efforts.

\section{In our work, we can ...}

Tracing and verification

\section{Reunification}

Follow-up
Support and facilitate the work of specialized actors involved in tracing separated family members. Tracing and verification should generally be undertaken by the authorities or by specialized agencies such as ICRC or UNICEF, but other humanitarian actors can support such efforts. This can include sharing information when needed, facilitating access and/or transportation, and providing temporary care and support during the process.

Support and facilitate family reunification efforts when possible. This can include facilitating transfer or transport of separated family members or providing temporary meeting space, shelter or other assistance for reuniting families.

Support efforts aimed at establishing or re-establishing family bonds prior to, or pending reunification of, separated family members. Children and other family members may need to be provided with information about the process and, in some cases, may require short familiarization visits or periods before formal reunification can take place.

Ensure that relevant records, including those relating to the distribution of food and other assistance, are updated to guarantee needed assistance and services for the reunited family. Where children have been reunited with their families, additional measures may need to be taken to ensure, for instance that the child is enrolled in, and has access to, schools and other education or vocational training programmes.

Support community groups or structures that can provide support and assistance to families with children, including those that have experienced previous separation to facilitate reintegration and minimize the likelihood of separation occurring or recurring.

\subsection{Protection and assistance, including alternative care arrangements}

While ideal, reunification may not always be possible or feasible, either in the short or the long term. In such cases, it is important to ensure that adequate care, protection and assistance is provided to separated persons, in particular unaccompanied or separated children. This includes ensuring security and physical, social, economic and emotional support and access to services, such as education and health care. 
In the case of children, alternative care arrangements may need to be made and could include the possibilities indicated below.

- Community-based care, which builds on existing social structures, is usually the preferred option and includes extended family, previous caregivers, or a social group/community that is well known to the child.

- Foster care, which refers to a situation where children are cared for in a household outside their family, can take different forms and must be arranged carefully and in consultation with the child and the community.

- Institutional care, such as in an orphanage, is an option of last resort. It often has detrimental effects on children and can make it more difficult to prevent neglect, abuse and exploitation.

- Group living, refers to a situation where children have come together to form household units. It is not desirable but, where such arrangements exist, they can be supported through, for instance, daycare rather than residential care.

Adoption, which involves the permanent and legal or customary transfer of parental rights and responsibilities to the adopters, should only be considered once it has been established that the child is free to be adopted. In practice, this means that there is no hope for successful tracing and reunification or that the parents have given consent to an adoption. Adoption must be in line with national law and procedures and be subject to close governmental control and scrutiny. ${ }^{3}$

Alternative care arrangements, whether short or long term, must always be monitored and periodically reviewed to ensure the welfare of the child. Efforts must be made to protect children from any form of discrimination, maltreatment, neglect, abuse or exploitation, and ensure their full and equal access to education, health care and other services.

\section{In our work, we can ...}

Monitoring Ensure that adequate monitoring systems are in place to monitor the welfare of children in alternative care arrangements. This can be done through community child welfare committees or through informal means with, for instance, the help of friends, teachers and neighbours. A child in foster care should receive appropriate care and protection on an equal basis with other children in the family.

Assistance

Advocate to ensure that foster care families receive adequate support and assistance in order to enable them to care for a child. Foster children should be protected from discrimination, neglect, abuse and exploitation and have full and equal access to services, such as education and health care.

3 For further information, see pp. 55-57 of the Inter-Agency Guiding Principles on Unaccompanied and Separated Children. 


\section{The international legal framework}

\section{International (and regional) human rights law}

guarantees the right to respect for the family, including the freedom from any unlawful or arbitrary interference. As a fundamental unit of society, the family is also entitled to special protection and assistance. ${ }^{4}$

Women are entitled to equal rights with men in all matters

See Principles 16 and 17 of the Guiding Principles on Internal Displacement in Annex 1 of the Handbook relating to marriage and family relations, including the same rights and responsibilities regarding their children, whether during marriage or at its dissolution. ${ }^{5}$ Women also have an equal right to own, inherit, acquire and manage property, including family property. The full and free consent of both spouses is required before entering into marriage. The marriage of children is considered unlawful.

Children and their mothers, both before and after childbirth, should be provided with special protection and assistance. In particular, the Convention on the Rights of the Child, which is nearly universally ratified, contains many important provisions, as indicated below.

- The best interests of the child must be a primary consideration in all actions concerning children. Their right to life, survival and development, and to non-discrimination and participation must also be respected. ${ }^{6}$

- States must protect the right of children to be cared for by their parents. Children must not be separated from their parents against their will, unless such separation is deemed necessary for the best interests of the child and necessary procedural safeguards are complied with. In the event of separation, children must be provided with special protection and assistance, including appropriate care arrangements, taking into account the child's age, maturity and ethnic, religious, cultural and linguistic background. Alternative care arrangements must always be subject to periodic review. ${ }^{7}$

- States must take all appropriate legislative, administrative, social and educational measures to protect the child from all forms of physical or mental violence, injury or abuse, neglect, maltreatment or exploitation. States should also provide necessary support for the child and his/her caregivers and take action to ensure prevention, identification, reporting, referral, investigation, treatment and follow-up in all cases of maltreatment. $^{8}$

International humanitarian law requires that the family rights of protected persons be respected in times of armed conflict. In case of evacuations or other transfers of people, all possible measures must be taken to ensure that the members of the same family are not separated.

In case separation occurs, family members should be able to receive news from each other and be provided with information about the fate and whereabouts of missing relatives. All appropriate steps should be taken to facilitate the reunion of dispersed families. Separated

\footnotetext{
4 See Art. 16 of UDHR; Art. 10 of ICESCR; Arts. 17 and 23 of ICCPR, Arts. 16 and 18 of CRC; and, at the regional level, Art. 18 of AfCHPR; Art. 17 of AmCHR; Art. 38 of ArCHR; Art. 5 of the Cairo Declaration on Human Rights in Islam; Arts. 8 and 12 of ECHR; and Art. 16 of the revised ESC.

5 See, at the international level, Art. 16 of UDHR; Art. 23 of ICCPR; Art. 10(1) of ICESCR; Arts. 5 and 16 of CEDAW, and, at the regional level, Art. 18 of AfCHPR and Arts. 6 and 7 of its Protocol on the Rights of Women in Africa; Art. 17 of AmCHR; Art. 5 of Protocol 7 to ECHR.

6 These general principles are outlined in Arts. 2, 3, 6 and 12 of CRC.

See, at the international level, Arts. 7, 8, 9, 20 and 25 of CRC; and, at the regional level, Arts. 19,20 and 25 of AfCRWC; and Art. 8 of the Covenant on the Rights of the Child in Islam.

8 See, at the international level, Art. 19 of CRC, and, at the regional level, Arts. 16, 27 and 29 of AfCRWC; and Art. 17 and 18 of the Covenant on the Rights of the Child in Islam.
} 
children should be identified, registered and provided with special protection and assistance at all times. ${ }^{9}$

In the case of internment or confinement, for instance to a camp, members of the same family should be accommodated together and be allowed to correspond with their families and receive visitors, especially close relatives. ${ }^{10}$

\section{Key actors}

While various core activities, such as family tracing and reunification, should be undertaken by specialized actors, all humanitarian and human rights actors play a role.

- At the national level, key actors include IDPs and host communities; child-welfare and social support services; ministries of social affairs and education; the media, local NGOs or faith-based organizations.

- At the international level, specialized actors include the ICRC and the national Red Cross/Crescent societies; UNICEF, UNHCR, IRC, Save the Children Alliance, and World Vision International. Other actors include OHCHR, OCHA and IOM.

\section{Key references \& useful websites}

- Inter-Agency Guiding Principles on Unaccompanied and Separated Children, ICRC, 2004.

- Separated Children, Action for the Rights of Children, Save the Children Alliance/UNHCR/UNICEF and OHCHR, 1998.

- Working with Separated Children (Field Guide and Manual), Save the Children UK, 1998.

- The Lost Ones - Emergency Care and Family Tracing and Reunification of Children from Birth to Five Years, UNICEF/IRC, 2003.

- General Comment No. 19 (1990) of the Human Rights Committee on the protection of the family, the right to marriage and equality of the spouses (Art. 23), Human Rights Committee, 1990.

- General Comment No. 17 (1989) of the Human Rights Committee on the rights of the child, Human Rights Committee,1989.

- Mobility Mapping and Flow Diagrams: Tools for Family Tracing and Social Reintegration Work with Separated Children, Brigette De Lay, International Rescue Committee, 2002.

- UN Guidelines for the Appropriate Use and Conditions of Alternative Care for Children, A/HRC/11/L.13, 2009.

- UNHCR Guidelines on Formal Determination of the Best Interests of the Child, UNHCR, May 2006.

9 Rules 105, 117 and 131 of Customary International Humanitarian Law, Volume I: Rules (ICRC, 2005). See also, Arts. 25, 26, 27 and 50 of the Fourth Geneva Convention; Arts. 74 and 78 of Additional Protocol I; and Art. 4(3)(b) of Additional Protocol II.

10 See, for example, Rules 125 and 126 of Customary International Humanitarian Law, Volume I: Rules (ICRC, 2005). See also Art. 82 of the Fourth Geneva Convention and Art. 75(5) of Additional Protocol I. 


\section{Human trafficking}

Key message .....................................................................................................................216

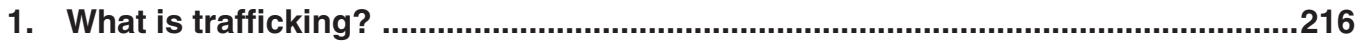

2. Trafficking in the context of internal displacement ........................................216

3. The protection implications of trafficking ….......................................................217

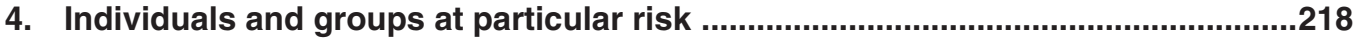

5. The international legal framework .......................................................................218

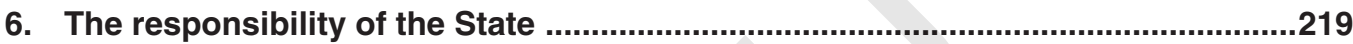

7. The role of humanitarian and human rights actors ..............................................219

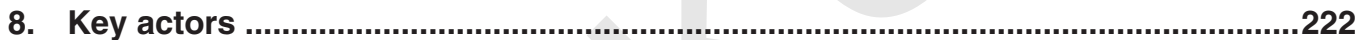

Key references.............................................................................................................222

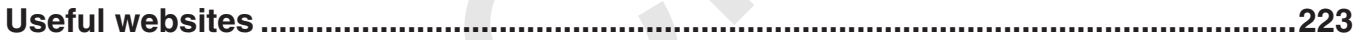




\section{Key message}

Trafficking in persons is a criminal activity and a serious violation of human rights. It is prohibited by international law and, in most cases, national law. All States have an obligation to combat trafficking and protect and assist its victims. Conflict and displacement can heighten the risk of trafficking. Humanitarian and human rights actors may play an important role in supporting counter-trafficking efforts through preventive and protective measures.

\section{What is trafficking?}

Trafficking in persons refers to the recruitment, transportation, transfer, harbouring or receipt of persons by improper means, such as the threat or use of force or other forms of coercion, abduction, fraud, deception, or abuse of power for the purpose of exploitation. ${ }^{1}$

Trafficking in the context of the sex trade is well documented and primarily affects women and children who are forced into prostitution and other forms of sexual exploitation. However, trafficking is not limited to the sex trade or to women. It includes various forms of exploitation of others, such as forced labor or services, slavery or practices similar to slavery, servitude, and the forced removal of organs.

Trafficking is distinct from smuggling, which refers to the facilitation, transportation, attempted transportation or illegal entry of a person(s) across an international border. ${ }^{2}$ The main differences are that:

- smuggling takes place with the consent of the smuggled migrant, while trafficking victims either have never consented or their initial consent has been rendered meaningless because of coercion, deception or abuse at the hands of the traffickers;

- smuggling usually ends with the arrival of the migrant at their destination, whereas trafficking involves the ongoing exploitation of the victim(s) to generate illicit profits for the traffickers; and

- smuggling is always transnational, whereas trafficking can take place within as well as across a country's borders.

\section{Trafficking in the context of internal displacement}

Forced displacement resulting from natural disasters or armed conflicts increases the risk of human trafficking by weakening or destroying family support structures, community bonds, and self-protection mechanisms that might otherwise serve as a buffer to trafficking. Because internally displaced persons (IDPs) often lack documentation and have limited access to education, livelihoods and self-reliance opportunities, they may be particularly vulnerable to traffickers who appear to offer life-saving access to employment opportunities.

IDPs who fear for their lives and wish to seek protection abroad as, for instance, refugees can also fall prey to traffickers who claim to offer a route to safety. In addition, in situations of armed conflicts, the breakdown of law and order and the inadequate or non-functioning protection mechanisms normally provided by the State or non-governmental institutions exacerbate the vulnerability of IDPs to exploitation and trafficking. In such environments, traffickers easily operate in total impunity and usually belong to State or non-State armed elements.

\footnotetext{
For a comprehensive and legally accurate definition of trafficking, please see Art. 3 of the Protocol to Prevent, Suppress and Punish Trafficking in Persons Especially Women and Children (Trafficking in Persons Protocol), which supplements the UN Convention against Transnational Organized Crime (A/RES/55/25 of 15 Nov 2000). Note that children below 18 years of age are not considered to be in a position to give informed consent and that any recruitment, transfer, harboring or receipt of children for the purpose of exploitation is considered a form of trafficking regardless of the means used.

2 Smuggling is the subject of another Protocol to the Convention against Transnational Organized Crime, i.e. the Protocol against the Smuggling of Migrants by Land, Sea and Air.
} 
Traffickers specifically target impoverished communities, including the internally displaced, in order to exploit their vulnerability. Poor and displaced families may entrust the care of their children to traffickers who promise to provide them with education or skills training but ultimately exploit them for the purposes of prostitution, forced labor or irregular adoption.

Displaced women and girls are particularly vulnerable to trafficking for forced labor or sexual exploitation during armed conflict, especially in camp situations (See Part IV.4 [D). They often struggle to survive, with inadequate access to food, shelter, health care and protection, while trying to ensure the survival of their children and other dependants, including older parents or other vulnerable relatives. Traffickers take advantage of their desperation, either by forcibly abducting them or by luring them away with false promises of a better life somewhere else. $^{3}$

Unaccompanied or separated children and children of displaced families, both girls and boys, may also be at particular risk of forced recruitment, forced labor and sexual exploitation by armed forces or armed groups (See Part IV.5 DU). Often, these risks are further compounded by an inadequate legal framework, weak law enforcement capacity, weak border control, lack of respect for human rights, and domestic violence and abuse, in particular against women and children.

Human trafficking does not end with conflicts. In post-conflict situations where the rule of law has not yet been re-established, where impunity still prevails and the economy is still ravaged, IDPs returning to their place of origin, or settling elsewhere continue to be vulnerable as they struggle to rebuild their lives. Former militia, ex-combatants or war lords may turn to human trafficking to replace losses of revenue caused by the cessation of the conflict. The presence of foreign peacekeeping or civilian forces in a post-conflict situation may also result in a sudden increase in trafficking for sexual exploitation. ${ }^{4}$

\section{The protection implications of trafficking}

Trafficking generally takes place in dangerous and degrading conditions and involves a range of human rights violations and abuses that endanger the life and physical security of victims of trafficking (See Part IV.2 $\square$ ). Severe forms of exploitation, such as abduction, incarceration, rape, sexual enslavement, enforced prostitution, forced labor, organ removal, physical beatings, torture, starvation, and the deprivation of medical treatment, are inherent to trafficking.

Victims of trafficking are often dependent upon, and intimidated by, their traffickers, who frequently confiscate their identity documents and keep them confined and isolated, thus limiting their ability to seek assistance or protection from the authorities. In addition, trust in protection by the authorities can be undermined by the fact that alleged traffickers may have connections or support from such authorities. Victims may also fear arrest and prosecution for activities in which they are forced to engage, such as prostitution or association with armed groups. Where victims have been trafficked into another country, they may fear arrest for illegal entry and face possible deportation to their home countries. Back at home, their lives might be at risk because of ongoing conflict and displacement or threats of retaliation from the traffickers. In addition, victims of sexual exploitation might also feel shame and fear to be ostracized, discriminated against or punished by their families, communities or the authorities (as outlined further in Part IV. 4

\footnotetext{
3 International Studies Association, Trafficking of Women in Conflict and Crisis, Susan Martin and Amber Callaway, February 2009.

4 Ibid.
} 


\section{Individuals and groups at particular risk}

Unaccompanied internally displaced children, child heads-of-households, single (especially female) heads-of-households, young girls, and former victims/survivors of trafficking are particularly vulnerable to the risks of trafficking during and after displacement.

Children are often trafficked for child-specific forms of exploitation, such as illegal adoption, child labor, child prostitution, child pornography, and forced recruitment into armed forces or armed groups. Other forms of exploitation to which children are often exposed include domestic service, agricultural work, mining, forced and early marriage, and begging. It is important to note that any recruitment, transfer, harbouring or receipt of children for the purpose of exploitation is considered a form of trafficking regardless of the means used.

\section{The international legal framework}

Trafficking is prohibited by international (and regional) human rights law and criminalized in the national legislation of a growing number of States. It is generally considered to amount to a form of slavery and constitutes a violation of a range of human rights, most notably the right to freedom from slavery and slave-like practices; ${ }^{5}$ to personal liberty and security; to freedom from torture and other cruel, inhuman or degrading treatment or punishment; and to freedom of movement. It also infringes on a number of other rights, such as the right to respect for the family; the right to an adequate standard of living; the right to the highest attainable standard of health; and the right to favorable working conditions, including just compensation and reasonable working hours. Trafficking also violates a number of international legal principles relating to the protection of children from forced labor and social and economic exploitation and abuse. ${ }^{6}$

Trafficking is specifically prohibited by the Protocol to Prevent, Suppress and Punish Trafficking in Persons Especially Women and Children ("Trafficking in Persons Protocol"), which supplements the UN Convention against Transnational Organized Crime. The Protocol, which seeks to prevent and combat trafficking in persons and facilitate international cooperation against such trafficking, defines criminal activities relating to trafficking, guides States on ways to combat them, and provides guidance on victim protection.

Trafficking is criminalized in the national legislation of a growing number of States, including through national criminal and labor law codes.

International humanitarian law similarly prohibits slavery and the slave trade in all its forms as well as a number of other acts to which victims of trafficking are often subjected, including torture, cruel or inhuman treatment and outrage upon personal dignity; rape and others forms of sexual violence; uncompensated or abusive labour; and arbitrary deprivation of liberty. ${ }^{7}$

\footnotetext{
The prohibition against slavery and slave-like practices is a peremptory norm of international law and a rule of customary international law. It is also widely prohibited in treaty law, including, at the international level, in Art. 4 of UDHR; Art. 8 of ICCPR; Arts. 10, 19, 21 and 32 of ICESCR; Art. 6 of CEDAW; Art. 11 of CMW; in the 1926 Slavery Convention and its Protocol; the Supplementary Convention on the Abolition of Slavery, the Slave Trade, and Institutions and Practices Similar to Slavery; and ILO Conventions No. 29 (Forced Labour), No. 105 (Abolition of Forced Labour); No. 182 (Worst Forms of Child Labour), and No. 138 (Minimum Age Convention). See also GA Resolution 57/176 of 18 Dec 2002 on Trafficking in Women and Girls. At the regional level, it is similarly prohibited in Art. 5 of AfCHPR and Art. 4 of its Protocol on the Rights of Women in Africa; Art. 6 of AmCHR; in Art. 11(a) of the Cairo Declaration on Human Rights in Islam; Art. 31 of ArCHR; and Art. 4 of ECHR.

6 See Art. 10(3) of ICESCR; Arts. 11, 19, 32, 34, 36 and 39 of CRC and its Optional Protocol to the Convention on the Rights of the Child on the sale of children, child prostitution and child pornography; ILO Conventions No. 138 (Minimum Age Convention) and No. 182 (Worst Forms of Child Labour Convention). See also, at the regional level, Arts. 24 and 29 of ACRWC; and the Inter-American Convention on International Traffic in Minors.

See Rules 90, 93 94, 95 and 99 of Customary International Law, Volume I: Rules (ICRC, 2005) as well as Common Art. 3 of the Geneva Conventions, Art. 4(2)(f) of Additional Protocol II; and Arts. 75 and 76 of Additional Protocol I.
} 
Trafficking may constitute a crime against humanity and, in armed conflict, a war crime. ${ }^{8}$ Aiding and abetting, through trafficking, the forcible conscription or enlistment of children under the age of fifteen years into the national armed forces or their active participation in hostilities also constitutes a war crime.

\section{The responsibility of the State}

All States have a responsibility to prevent trafficking, to investigate and prosecute traffickers, and to protect, assist and provide adequate redress to the victims. Respect for human rights and the best interests of the victims should be at the centre of all such efforts. The role and responsibilities of the State, summarized below, are further outlined in the Trafficking in Persons Protocol as well as in the Recommended Principles and Guidelines on Human Rights and Human Trafficking. ${ }^{9}$

- Take all appropriate national, bilateral and multilateral measures to prevent trafficking, in particular of children, for any purpose or in any form. This includes the issuance of codes of conduct or strict instructions to military and law enforcement personnel not to engage in or support trafficking activities. In addition, as trafficking can also be a transnational crime, measures should include regional cooperation with transit or destination countries to prevent trafficking, protect and assist victims, and prosecute traffickers. The State should also consider becoming a party to the 2000 Protocol to Prevent, Suppress and Punish Trafficking in Persons, Especially Women and Children.

- Enact domestic laws to criminalize trafficking and ensure the prompt investigation and prosecution of traffickers. Efforts must be made to ensure confidentiality and provide adequate protection to victims and witnesses that assist with legal proceedings.

- Include in ceasefire or peace agreements provisions aiming at preventing and prohibiting human trafficking by all State and non-State actors.

- Provide protection and assistance to trafficked persons and ensure that they receive just compensation for the harm suffered. The Protocol also encourages States to provide access to social benefits, such as housing, medical care, counseling, and legal assistance, paying attention to age, gender and the specific needs of the victims.

- Develop comprehensive policies and programmes to prevent and combat trafficking and protect victims from re-victimization. This can include research, mass media campaigns, social and economic initiatives, and measures to address risk factors to trafficking, such as poverty, discrimination, and lack of equal opportunities.

- Cooperate with other States, non-governmental organizations and other elements of society to address trafficking.

- Implement security and border controls to detect and prevent trafficking. States should ensure that their own border controls are effective and take measures to prevent the misuse of passports and other travel or identification documents.

- Take measures to discourage the demand for services that fosters the exploitative element of trafficking and provides its major source of illicit revenue.

\section{The role of humanitarian and human rights actors}

While the primary responsibility for combating trafficking rests with the State, humanitarian and human rights actors also play an important role. A comprehensive and well-coordinated counter-trafficking strategy, involving all relevant sectors and actors including the authorities,

8 See, for example, Articles $7(1)(\mathrm{c}), 7(1)(\mathrm{g}), 7(2)(\mathrm{c})$ and $8(2)(x x i i)$ of the Statute of the International Criminal Court, which define "enslavement," "sexual slavery" and "enforced prostitution" as crimes against humanity and war crimes.

$9 \mathrm{OHCHR}$, Recommended Principles and Guidelines on Human Rights and Human Trafficking, 2002 (E/2002/68/Add. 1). 
should form part of the protection response in most humanitarian settings. The UNODC Toolkit to Combat Trafficking in Persons, ${ }^{10}$ together with Recommended Principles and Guidelines on Human Rights and Human Trafficking, ${ }^{11}$ provide useful guidance in this regard. The table below also gives some ideas about possible activities (further addressed in Part IV.4 [D).

\section{In our work, we can ...}

Assessment

(See Part III.1 DU)
Ensure that protection assessments identify existing risks of trafficking within a given community as well as any factors that can increase exposure to trafficking; the individuals most at risk; the alleged traffickers; the adequacy of the national response; existing formal and informal coping mechanisms, and ways to support these.

- Raise awareness in the community about the risks associated with trafficking. This can be done by facilitating public discussion and dialogue, by supporting community groups working on the issue, and engaging in public information activities together with other partners.

Information and community mobilization (See Parts V.10 and $V .7 \square$ ) - Information about the prevention and prohibition of human trafficking should also aim at targeting non-displaced communities, armed forced and non-State actors. Work with civil-military liaison officers to establish direct lines of communication with armed forces and armed groups to ensure that IDP camps and settlements are kept free of infiltration and are not used for recruitment purposes (as outlined further in Parts IV.2 and $11.3 \square)$.

Support community-based groups and networks, and local organizations and institutions that can monitor the threat of trafficking, take action to prevent it, and support the recovery and reintegration of victims.

- Work with the community and other partners to prevent the militarization of camps, settlements and other IDP-hosting areas and prevent the forced conscription of children by, for instance, establishing early-warning systems and preparedness in case of infiltration of armed elements or relocation away from unstable or conflict areas (further addressed in Part V.2@).

\section{Referral and} response mechanisms

- Coordinate with relevant actors to ensure the establishment and maintenance of effective referral and response mechanisms at the local and national levels, including in camps and settlements.

- Coordinate with relevant actors, in particular security personnel, to establish security mechanisms to prevent infiltration by armed forces or armed groups into civilian camps and settlements (further addressed in Part IV.2 $\square$ ).

\section{Interim care and} support

(See Part V. 11
- Ensure that victims of trafficking are safe and are given access to appropriate care and services (health care, psychosocial and legal counseling, education and skills training) as well as necessary material support (safe and appropriate shelter, food and non-food items). Such support should take into account age, gender and any specific needs.

Alternative care arrangements may need to be found for unaccompanied children: under no circumstances should child victims of trafficking be detained or accommodated in detention facilities. 
Training

Legal review

Legal aid and access to justice (See Part V.8 $\square$ ) (See Part IV.16 $\square$ ) protection

Victim and witness
Provide training on human rights and on the prevention and response to trafficking to relevant actors such as IDP communities, law enforcement agencies, the judiciary, NGOs, and staff of United Nations and peacekeeping forces where these are deployed as well as to non-State actors where possible, United Nations agencies and international organizations. This should include training on the code of conduct for United Nations and humanitarian personnel as well as guidance on confidentiality and on working with child victims of trafficking.

Review national legislation and its enforcement and assess to what extent it prevents and adequately responds to the risks of trafficking, including as regards the recovery and reintegration of victims of trafficking. As appropriate, advocate with national authorities for improvements in legislation, policy or practice in this field.

Ensure that all relevant actors, including those working on gender-based violence prevention and response, are familiar with relevant national laws and regulations relating to trafficking. National labor legislation might also provide extensive recourse in situations of forced and compulsory labor.

- Ensure that victims of trafficking have access to affordable and adequate legal counseling and assistance. This includes both those victims who wish to seek compensation or payment of legally due wages, and those who have been charged with offences, such as illegal prostitution.

Assist State authorities in their efforts to strengthen the rule of law including law enforcement capabilities, to investigate trafficking activities, and prosecute and punish perpetrators (further addressed in Part IV.18 $\square$ ).

Work with the community to identify livelihood and income-generating opportunities to strengthen self-reliance and reduce the risk of trafficking. Pay particular attention to groups at risk, such as separated and unaccompanied children, single- (female-) headed-households, and prior victims of trafficking. This can include ensuring full and equal access to education for children and adolescents.

Encourage national authorities to develop adequate witness-protection measures for the benefit of any victims who cooperate in criminal prosecutions. Such protection might need to be extended to other family members.

\section{Family tracing and reunification}

(See Part IV.7 D)
Work with relevant partners, such as ICRC and UNICEF, to ensure that separated or unaccompanied children are rapidly identified, registered and documented, that best interests determinations are conducted, and that family tracing and reunification takes place or alternative care arrangements are made, as appropriate. 


\section{Key actors}

A number of actors play an important role in combating trafficking and providing assistance to victims/survivors.

- At the national level, key actors include internally displaced and host communities; law enforcement agencies, ministries of justice, labor and social services, and local NGOs and civil society.

- At the international level, key actors include UNODC, ILO, UNICEF, IOM, UNHCR, $\mathrm{OHCHR}$, various international NGOs, peacekeeping forces where present, and neighbouring States.

- In addition, at the regional level, a number of consortiums and initiatives have been created including: in Asia, the Asia Regional Initiative against Trafficking in Women and Children; the Association of Southeast Asian Nations' Declaration against Trafficking in Persons Particularly Women and Children; the Asia-Europe Meeting's Action Plan to Combat against Trafficking in Persons, Especially Women and Children; in Africa, the Economic Community of West African States' Initial Plan of Action against Trafficking in Persons; in the Americas, the Regional Conference on Migration (formerly known as the "Puebla Process"); and in Europe, the Organization for Security and Co-Operation in Europe (OSCE) and its Action Plan to Combat Trafficking of Human Beings, Office for Democratic Institutions and Human Rights (ODIHR), and the OSCE Special Representative and Co-ordinator for Combating Trafficking in Human Beings.

\section{Key references}

- Guidelines on the Protection of Child Victims of Trafficking, UNICEF.

- Handbook on Direct Assistance for Victims of Trafficking, IOM, 2007.

- Toolkit to Combat Trafficking in Persons, UN Office on Drugs and Crime, 2006.

- Ethical and Safety Recommendations for Interviewing Trafficked Women, WHO, 2003.

- Recommended Principles and Guidelines on Human Rights and Human Trafficking, E/2002/68/Add.1, OHCHR, 20 May 2002.

- Reference Guide on Protecting the Rights of Child Victims of Trafficking in Europe, UNICEF, 2006.

- OSCE Action Plan to Combat Trafficking in Human Beings, Permanent Council Decisions No. 557 and No. 685, OSCE, 2003 et 2005.

- Child-friendly Standards and Guidelines for the Recovery and Integration of Trafficked Children, ILO 2006.

- Guidelines on the Application of Art 1A(2) of the 1951 Convention and/or 1967 Protocol, relating to the Status of Refugees to the victims of trafficking and persons at risk of being trafficked, UNHCR, HCR/GIP/06/07, 7 April 2006.

- Trafficking of Women in Conflict and Crisis, Susan Martin and Amber Callaway, International Studies Association, February 2009. 


\section{Useful websites}

- United Nations for Drug and Crime (UNODC): www.unodc.org

- International Organization for Migration (IOM): www.iom.int

- United Nations Children Fund (UNICEF): www.unicef.org

- International Labour Organization (ILO): www.ilo.org

- United Nations High Commissioner for Human Rights (OHCHR): www.ohchr.org

- United Nations High Commissioner for Refugees (UNHCR): www.unhcr.org

- Organization for Security and Co-operation in Europe (OSCE): www.osce.org. See also the OSCE Office for Democratic Institutions and Human Rights (ODIHR): www.osce.org/odihr and OSCE Special Representative and Co-ordinator for Combating Trafficking in Human Beings: www.osce.org/cthb

- Special Rapporteur of the Human Rights Council on trafficking in persons, especially in women and children: www.ohchr.org/english/issues/trafficking/index.htm 


\section{Loss of civil status and nationality}

Key message

1. The international legal framework

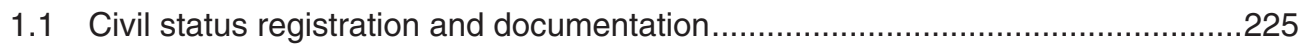

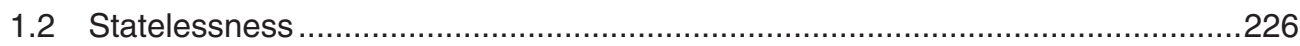

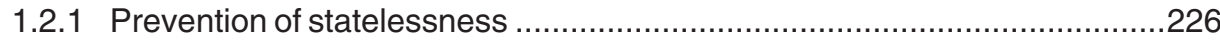

1.2.2 Protection of stateless persons …………………...............................226

2. Civil status and documentation in the context of forced displacement ................227

2.1 Obstacles to establishing and proving legal and civil status or to establishing nationality

2.2 Preventing and responding to a lack of civil status and/or documentation

3. Statelessness in the context of internal displacement ........................................229

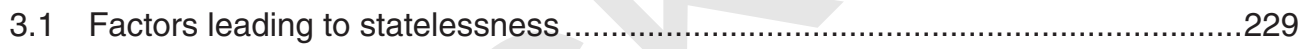

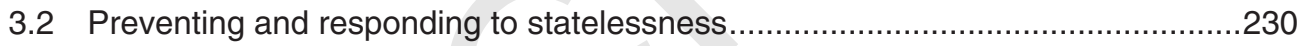

4. The role of humanitarian and human rights actors .................................................231

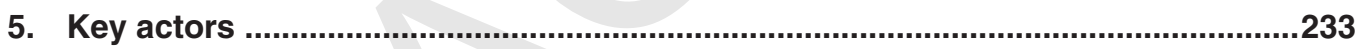

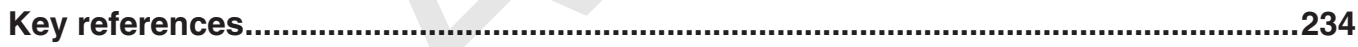

Useful websites 


\section{Key message}

Displacement often results in the loss or destruction of personal documentation and registries. Lack of documentation and other means to prove one's identity can have serious consequences for individuals and communities, including restricted freedom of movement, limited access to life-saving assistance and services, exposure to harassment or arbitrary arrest and detention, and the risk of statelessness. The issue of nationality deserves special attention as displacement can also trigger or increase the risk of statelessness or place stateless persons in an even more precarious legal position.

\section{The international legal framework}

\subsection{Civil status registration and documentation}

International (and regional) human rights law requires States to take all necessary measures to ensure the full, equal and effective enjoyment of all rights and freedoms, including the right to equal recognition of, and protection before, the law. ${ }^{1}$ This requires the authorities to ensure that everyone, including internally displaced persons (IDPs), have a legal identity, as well as the means to prove their identity if required in order to exercise their rights, for instance through civil status documentation.

This obligation is further outlined in Principle 20 of the Guiding Principles on Internal Displacement. It requires States to facilitate the issuance of new documents or the replacement of documents lost during displacement without imposing unreasonable conditions, such as the return to the area of habitual residence in order to obtain these or other required documents. The documents listed include those needed for the enjoyment of civil and political rights, protection against arbitrary arrest and detention, freedom of movement, and the right to vote, as well as economic, social and cultural rights, including education, adequate housing, and health care.

Even when IDPs are arbitrarily deprived of documents by non-State actors or private individuals, the State remains responsible for providing effective protection or safeguarding their rights.

Children are entitled to special protection and care under the law. All children should be registered immediately after birth and given a name. If a child is illegally deprived of some or all of the elements of his/her identity, States should provide appropriate assistance and protection, with a view to speedily re-establishing that identity. ${ }^{2}$

Women have equal rights as men to recognition before the law and should be provided with documentation in their own names. ${ }^{3}$ Some conventions also specifically require States Parties to ensure registration of marriages in an official registry, in order to ensure that the equal rights of both parties are fully respected during and upon dissolution of marriage. ${ }^{4}$

See Arts. 6 and 7 of UDHR; Arts. 16 and 26 of ICCPR; Art. 15 of CEDAW; Art. 5(a) of ICERD; Arts. 18 and 24 of CMW; Arts. 3 and 5 of AfCHPR; Arts. 3 and 8 of its Protocol on the Rights of Women in Africa; Arts. 3 and 24 of AmCHR; and Art. 18 of ArCHR. See also Principle 20 of the Guiding Principles on Internal Displacement. This right is generally considered non-derogable. See, for example, Art. 4(2) of ICCPR and Art. 27(2) of AmCHR.

2 See, for example, Art. 24 of ICCPR and Arts. 7 and 8 of CRC. At the regional level, Art. 6 of AfCRWC; Art. 18 of AmCHR and Art. 7 of the Covenant on the Rights of the Child in Islam.

3 This right is inherent in the non-discrimination provisions contained in most human rights instruments. See also Art. 4(2)(k) of the Protocol to the AfCHPR on the Rights of Women in Africa.

4 See, for example, Art. 16(2) of CEDAW; the 1963 Convention on Consent to Marriage, Minimum Age for Marriage and Registration of Marriages; Art. 21(2) of AfCRWC; and Art. 6(d) of the Protocol to the AfCHPR on the Rights of Women in Africa. See also GA Resolution 2018 (XX) of 1 Nov 1965 on Recommendation on Consent to Marriage, Minimum Age for Marriage and Registration of Marriages. 
International humanitarian law requires occupying powers to take all necessary steps to facilitate the identification of children and the registration of their parentage. In addition, all parties to a conflict should ensure that family or identity documents are not taken away from civilian detainees without the issue of a receipt. Deaths occurring during internment must be registered and death certificates issued. ${ }^{5}$

\subsection{Statelessness}

\subsubsection{Prevention of statelessness}

International (and regional) human rights law guarantees everyone the right to a nationality, including the right to acquire, change and retain nationality as well as the right to pass nationality on to one's children, without discrimination of any kind. ${ }^{6}$ IDPs should under no circumstances be deprived of, or prevented from, acquiring a nationality, or from passing it on to their children, because they are displaced.

The granting or withdrawal of nationality is a sovereign act of States and, as such, is regulated by national law and regulations. The right to nationality, however, requires States to take all appropriate steps, both internally and in cooperation with other States, to prevent and respond to statelessness and to ensure that everyone has a nationality.

The 1961 Convention on the Reduction of Statelessness, which aims to prevent and reduce statelessness, also specifically requires States to refrain from arbitrarily denying or depriving individuals of their nationality; to ensure non-discrimination, due process and procedural guarantees when granting or withdrawing nationality; and to facilitate the naturalization of stateless persons, to the greatest extent possible.

Women are guaranteed equal rights with men in all matters related to nationality. Neither marriage nor divorce, or change or loss of nationality by the husband during marriage, should change or otherwise affect the nationality of the wife, render her stateless or force upon her the nationality of her husband. ${ }^{7}$

All children must be registered immediately upon birth and have the right to a name and a nationality. States must also take action to preserve the identity of the child, including nationality, name and family relations, and provide assistance and protection to re-establish identity where it has been lost. ${ }^{8}$ Some conventions specifically require States to grant nationality to children born in their territory if they would be rendered stateless otherwise. ${ }^{9}$

\subsubsection{Protection of stateless persons}

Stateless persons are entitled to full and effective enjoyment of human rights and freedoms. The only exceptions to this rule relate to the right to participate in government, which can be limited to citizens of the State under the ICCPR, and to some economic rights under the

\footnotetext{
See e.g. Arts. 50, 97(6) and 129 of the Fourth Geneva Convention.
}

6 See Art. 15 of UDHR; Art. 24 of ICCPR; Art. 9 of CEDAW; Arts. 7 and 8 of CRC; Art. 5(d)(iii) of ICERD; Art. 29 of CMW; the 1954 Convention Relating to the Status of Stateless Persons; the 1961 Convention on the Reduction of Statelessness; and the 1957 Convention on the Nationality of Married Women. See also, at the regional level, Art. 23 of AfCHPR and Art. 6(g) and (h) of its Protocol on the Rights of Women; Art. 6 of AfCRWC; Arts. 18 and 20 of AmCHR; Art. XIX of AmDHR; Art. 24 of ArCHR; Art. 7 of the Covenant on the Rights of the Child in Islam; and the 1997 European Convention on Nationality.

7 The equal rights of women and men are guaranteed in the non-discrimination provisions of most human rights instruments, such as Arts. 1, 2 and 7 of UDHR; Arts. 3 and 26 of ICCPR; Art. 2 of CRC; and generally in CEDAW. More specifically, see Art. 9 of CEDAW; Arts. 1-3 of the Convention on the Nationality of Married Women; and the 1961 Convention on the Reduction of Statelessness.

8 Arts. 7(1) and 8 of CRC; Art. 24(2) of ICCPR; Art. 6 of AfCRWC; Art. 18 of AmCHR; and Art. 7 of the Covenant on the Rights of the Child in Islam.

9 See Art. 1 of the Convention on the Reduction of Statelessness; Art. 6(4) of AfCRWC; Art. 20 of AmCHR; and the European Convention on Nationality. 
ICESCR, which allows developing States to determine to what extent such rights can be guaranteed to non-nationals. ${ }^{10}$

The 1954 Convention relating to the Status of Stateless Persons specifically addresses some of the rights of stateless persons. It encourages States to accord stateless persons lawfully residing on their territory a standard of treatment comparable, in some instances, to that accorded to nationals of the State and, in other instances, to that accorded to nationals of a foreign country or aliens generally in the same circumstances. The Convention also guarantees stateless persons the right to identity and to travel documents, and it protects them from expulsion, except on grounds of national security or public order. ${ }^{11}$

\section{Civil status and documentation in the context of forced displacement}

Personal documentation and civil registries establish and provide evidence of the civil and legal status of individuals, including as it relates to birth, parentage, marriage and divorce, death, absence, guardianship and nationality. In countries where such registries do not exist or are incomplete, other traditional systems can guarantee, to a certain extent, the identity of individuals.

In situations of forced displacement, personal documentation is often lost, damaged or destroyed and both formal and traditional civil status systems seriously undermined. In some countries, civil registries may have been incomplete from the beginning, certain segments of the population may never have been registered or issued documentation, or existing documents may have ceased to be valid due to a change in the legal or administrative regime.

\subsection{Obstacles to establishing and proving legal and civill status or to establishing nationality}

Common obstacles to establishing and proving legal and civil status or to establishing nationality are indicated below.

- IDPs may experience difficulty fulfiling onerous legal or administrative requirements. Replacement documentation and/or recording of events, such as any births, marriages, divorces or deaths of relatives, is often subject to strict criteria or high fees. In some cases, it may require IDPs to return to the area of origin or to the place of habitual residence, even if these areas remain unsafe. In other cases, IDPs may be obliged to register their civil status with parallel registry offices, including offices controlled by non-State actors. Documents issued by these offices may not be recognized upon return to the place of origin. Moreover, IDPs may face discrimination or threats for not registering with the government authorities.

- Discriminatory laws or practices, in particular against women, minority groups or indigenous persons, may prevent them from recording events and acquiring documentation or replacing lost documentation. In some cases, individuals face additional discrimination as a direct result of being displaced, especially if they are viewed with suspicion or hostility by local authorities.

- National or local authorities may lack the capacity, including financial resources, technology, organizational skills and expertise, to maintain civil status registries or to issue documentation. This is especially the case where conflict or natural disasters have disrupted the functioning of public institutions or where displacement is occurring on a large scale. In some cases, the authorities may also lack political willingness or may

${ }^{10}$ Art. 2(3) of ICESCR and Art. 25 of ICCPR.

11 Arts. 27, 28 and 31 of the Convention relating to the Status of Stateless Persons. 
under-estimate the importance of civil status and related documentation. In other cases, the general confusion generated by displacement may create situations where many different actors are involved in an uncoordinated documentation process.

- Traditional systems, which often rely on witnesses and the knowledge of old people at the village or community level, can be undermined in situations of displacement owing to the separation of families and communities and the break-down of community structures and authority.

- Access to registration or documentation can be obstructed by various logistical or practical difficulties, including restrictions on freedom of movement and/or the inability to travel because, for instance, of ongoing conflicts or factors such as age or disability, lack of knowledge of the language of registration, lack of access to information on the documentation process and poor literacy.

Lack of documentation and an inability to register events relating to civil status can have serious consequences for individuals and communities. It can result in restricted freedom of movement, limited access to life-saving assistance and services, exposure to harassment, arbitrary arrest and detention, difficulties in repossessing property or in receiving compensation for lost property (as addressed in Part IV.17 $\square$ ), lack of access to voting rights and various other protection risks. As an example:

absence of birth registration and certificates can make it difficult to obtain a legal identity, which is necessary to access education, health care, and social benefits; and

a lack of death registration and certificates can make it difficult to manage, inherit and/or reclaim lost property. Where regulations regarding missing or absent persons are inadequate, the spouse and other family members may be prevented from reclaiming property, making decisions regarding their children, or marrying again.

\subsection{Preventing and responding to a lack of civil status and/or documentation}

Registration of civil status and issuance of documentation are the responsibility of the State. At times, non-State actors also undertake such activities on the territory they control, but this may add to confusion and difficulties, including protection concerns, for IDPs upon return to their place of origin.

At all stages of the internal displacement cycle, every effort must be made to preserve personal documentation and registries and to support and strengthen national systems to ensure that IDPs have full and equal access to civil status registries and documentation, including replacement documentation. This can be achieved in various ways, including by:

- building the capacity of the national system through financial or technical support and training; and

- cancelling or easing administrative requirements, and/or addressing the various obstacles faced by IDPs. As an example, in cases where freedom of movement is limited, temporary or mobile arrangements can be made to improve access to registration and documentation.

The issuance of specific legislation or documentation pertaining to displacement is not necessarily needed or desirable in all cases and, if not carefully managed, can expose displaced individuals and communities to discrimination, stigma and other risks. Where displacement specific responses are needed, care must be taken to avoid the creation of parallel systems that may result in differences in treatment and further divide the displaced from the wider population. It must also be ensured that registration and/or documentation as an IDP does not result in limitations on various rights, such as the right to freedom of 
movement or the rights to return to the area of origin, to reclaim lost property, or to vote and stand for public office.

Statutory law and customary law often overlap in plural legal systems. Each has advantages and disadvantages in resolving problems faced by IDPs. For example, customary law might offer fair and expedient mechanisms to resolve disputes, but women generally have fewer rights under customary law than they have under statutory law. The latter, in turn, often does not recognize marriages and land ownership under customary law, so widows and female-headed households often find themselves without legal standing as regards inheritance, pension or other rights that require proof of marriage and land ownership.

\section{Statelessness in the context of internal displacement}

Nationality is usually associated with civil status. The right to a nationality is often referred to as "the right to have rights" because of its importance as the basis for claiming other rights, ranging from recognition before the law to access to basic services.

Most human rights are to be enjoyed by everyone within the jurisdiction of the State, although a few rights, such as some political rights, can be limited to nationals. Non-citizens, including stateless persons, however often face practical obstacles to exercising their rights, including recognition as a person before the law, education and freedom of movement.

Becoming internally displaced does not automatically affect a person's nationality status; most IDPs remain nationals of their country. In some cases, however, there might be a close connection
A "stateless person" is a person who is not considered a national by any State under the operation of its laws. A person who technically holds a nationality but does not receive the benefits associated with nationality may be considered de facto stateless.

"Nationality/citizenship" usually refers to the existence of a legal bond between a person and a State as provided for under the State's laws. Nationality generally arises from descent (jus sanguinis), birth on the territory of the State (jus soli), naturalization, or State succession.

\section{between statelessness and internal displacement:}

- statelessness can be a cause or a contributing factor to internal displacement, such as in cases where people have been forced to flee due to discrimination, including through the arbitrary deprivation of nationality of specific communities;

- internal displacement can lead to statelessness, for instance in cases where territorial boundaries have been redrawn subsequent to displacement, or where birth registration is flawed or absent; and

- statelessness can serve as an obstacle to return or relocation, particularly when it prevents people from enjoying their rights, accessing basic services and establishing a sustainable livelihood.

\subsection{Factors leading to statelessness}

Statelessness can result from a variety of causes, including:

- discriminatory laws and practices;

a conflict of nationality laws between States;

- the transfer of territory from one State to another;

a failure to register children at birth;

- arbitrary deprivation of nationality or denationalization of individuals or groups by the State; 
administrative or procedural problems, such as excessive fees, lack of appeal or review procedures, or inability to obtain documentation; and

- individual renunciation of nationality without acquisition of another nationality.

In situations of internal displacement, failure to register children at birth and loss of documentation testifying to nationality are frequent causes of de facto statelessness.

Lack of nationality can have serious consequences for stateless persons. These are frequently exacerbated during periods of internal displacement and include the inability to claim protection from relevant authorities; arbitrary arrest and prolonged detention; unfair travel restrictions and limitations of freedom of movement; denial of employment or access to basic rights and services; inability to register marriages, the birth of children or the death of relatives; and denial of the right to stand for, or vote in, elections. On occasion, stateless persons have also been denied access to humanitarian assistance, both by relevant authorities and by the international humanitarian community.

Women often face particular difficulties due to discriminatory laws and practices relating to nationality. In some States, women who marry non-nationals are automatically deprived of their nationality, often without being able to acquire the nationality of their spouses. In addition, they might be prevented from re-establishing their former nationality in the event of a divorce, even though they may never have acquired, or have been deprived of, the nationality of their spouses.

Women are also frequently barred from passing their nationality on to their children, which might result in the child becoming stateless and, consequently, in the denial of custody rights and restricted access for the mother to her children upon divorce or death of the spouse. A failure to register and extend nationality to displaced children, children born out of wedlock, children of minority groups, and children of refugee, asylum-seeking or migrant families, places such children at a particular risk of statelessness.

\subsection{Preventing and responding to statelessness}

Although States have committed themselves to preventing and reducing statelessness, lack of nationality remains a widespread human rights violation that places the lives and well-being of millions at risk.

In situations of displacement, States should make every effort to ensure the continuity of basic civil registration mechanisms, particularly the issuance of birth certificates to IDPs as a means to prevent statelessness. Stateless persons who habitually reside in the country and who have been displaced should continue to be authorized to exercise and enjoy their rights in areas of displacement and be protected against expulsion.

An adequate humanitarian response to statelessness, in most cases, will consist of efforts to protect the right to a nationality, by making sure that States grant nationality and intervene in favor of persons whose nationality status is in dispute or in doubt, so that they are not discriminated against and are able to enjoy their rights. In exceptional cases, resettlement to a third country might need to be considered.

Some challenges in dealing with statelessness in the context of displacement are indicated below.

- Contentious ethnic and political disputes, which often are among the root causes of statelessness. In some cases, States may perceive with hostility any advocacy related to the granting of nationality as constituting interference with domestic affairs.

- Lack of interest or priority given to this issue by the relevant authorities. 
- Disruption of the rule of law and of the provision of basic services. The work of relevant agencies responsible for maintaining records and/or issuing documentation and for dealing with citizenship issues may not be sustained during the displacement period.

- Lack of awareness and understanding of the consequences of statelessness by those affected. Stateless persons may not realize that they have lost their nationality or that it may result in the deprivation of their rights. Communicating this may be difficult when those affected are illiterate or poorly educated.

- Failure to identify incidents of statelessness or to prioritize responses to statelessness.

\section{The role of humanitarian and human rights actors}

International actors working on civil status issues, including documentation, should coordinate their positions and activities to ensure that a coherent and consistent message is delivered to national interlocutors at local and national levels. Efforts should be made to assist national and local authorities in exchanging information and in coordinating actions when documentation or statelessness problems arise because of differences in practices or application of laws or regulations. Where possible, activities aimed at preventing and responding to statelessness should take place in consultation with UNHCR, which is mandated to promote the prevention and reduction of statelessness and to provide protection to stateless persons. ${ }^{12}$

Humanitarian and human rights actors can undertake the activities indicated below, relating to civil status and documentation and statelessness.

\section{In our work, we can ...}

Assessment

(See Part III.1 [D)
- Assess and monitor problems related to civil status in statutory and customary law to identify systemic shortcomings and concerns affecting IDPs.

Ensure that protection assessments identify, where relevant, (i) individuals or groups who are stateless or are at risk of statelessness; (ii) the main causes of statelessness; (iii) the main protection risks it engenders; (iv) any remedies or coping mechanisms that are already in place.

\section{Contingency}

planning and coordination
Support the authorities to develop a contingency plan that includes measures to safely store existing records, update registries, protect confidentiality and facilitate the issuance of documents in emergency situations.

Ensure that protection working groups adequately address issues of civil status, documentation, nationality and statelessness that arise. Where possible, inform and work with UNHCR, which has a mandate to promote the prevention and reduction of statelessness and to provide protection to stateless persons.

12 UNHCR's mandate with regard to statelessness is based on Art. 11 CRS, read together with General Assembly resolutions and resolutions of the agency's own Executive Committee, in particular ExCom Conclusion $\mathrm{N}^{\circ} 106$ on identification, prevention and reduction of statelessness and protection of stateless persons. 


\begin{tabular}{|c|c|}
\hline $\begin{array}{l}\text { Advocacy } \\
(\text { See Part V.3 } \square)\end{array}$ & $\begin{array}{l}\text { Advocate with relevant authorities to ensure that IDPs have access to } \\
\text { civil status registration and documentation, including replacement } \\
\text { documentation, without discrimination and without requiring that they } \\
\text { return to the area of origin or travel in or through insecure areas. } \\
\text { Encourage the authorities to cancel or ease onerous administrative or } \\
\text { other requirements and use flexible criteria and rules of evidence. } \\
\text { Based on a review of national legislation, advocate with relevant } \\
\text { authorities for the enactment, improvement or repeal of legislation to } \\
\text { ensure that it adequately protects the right to nationality. UNHCR can } \\
\text { offer technical guidance and support to authorities when preparing and } \\
\text { implementing national legislation on statelessness. } \\
\text { In cases where either the } 1954 \text { Convention relating to the Status of } \\
\text { Stateless Persons, or the } 1961 \text { Convention on the Reduction of } \\
\text { Statelessness have not been adopted by the State, or if their adoption } \\
\text { has been accompanied by reservations, advocate for the adoption and } \\
\text { implementation of these instruments or the lifting of reservations. }\end{array}$ \\
\hline $\begin{array}{l}\text { Technical advice } \\
\text { and assistance to } \\
\text { local and/or } \\
\text { national authorities } \\
\text { (See Part V.9 }\end{array}$ & $\begin{array}{l}\text { Encourage, support or undertake a review of national laws, regulations, } \\
\text { policies, procedures and practices to assist IDPs in accessing } \\
\text { documentation, and ensure that they adequately protect the right to } \\
\text { acquire a nationality, including the prevention of discriminatory } \\
\text { deprivation, renunciation or loss of nationality. } \\
\text { Provide advice to relevant authorities and make recommendations on: } \\
\text { ways to improve civil and legal status registration and documentation, in } \\
\text { particular as it relates to IDPs; } \\
\text { ways and mechanisms to protect personal data, respecting the rights to } \\
\text { privacy and confidentiality in the process of collection, registration, } \\
\text { exchange and use of personal data. } \\
\text { Where needed, consider building local and/or national capacity by providing } \\
\text { training or modest financial or material assistance or equipment to help the } \\
\text { authorities improve existing structures. } \\
\text { Where existing structures are overwhelmed or malfunctioning, assist the } \\
\text { authorities to make temporary or mobile structures or arrangements to } \\
\text { provide civil registration and documentation to IDPs and other affected } \\
\text { populations. As an example, in emergency situations, temporary } \\
\text { documentation can be provided. Such documentation should not result } \\
\text { in a delay in obtaining permanent documentation, however, and should } \\
\text { be properly recognized and accepted by law enforcement officials and } \\
\text { authorities responsible for the distribution of assistance. } \\
\text { On an exceptional basis and following a careful review and assessment, } \\
\text { support national authorities in providing displacement-specific } \\
\text { documentation to IDPs for specific purposes, such as to access certain } \\
\text { assistance or services. Such documentation is usually provided after a } \\
\text { registration or profiling exercise (further addressed in Part V.1 } \square \text { ). }\end{array}$ \\
\hline
\end{tabular}




\section{Legal aid and advice to IDPs}

(See Part V.8
- Support and build the capacity of national lawyers, paralegals, NGOs and focal points within the IDP community that can provide legal and other advice and assistance related to civil status and documentation to IDPs. This can involve creating or supporting a network of legal or paralegal aid centres.

Accompany people to documentation centres and intervene with officials in charge of registering civil status and delivering documents.

Provide help to IDPs, for example, to fill out forms, gather required documentation or alternative forms of evidence, and prepare and file complaints in court or administrative bodies.

\section{Information and} outreach

(See Part V.7 $\square$ )

Community

(See Part V.10 D)

Birth registration

Assistance

(See Part V.5

- Ensure that stateless persons are not discriminated against in the

Interventions distribution of relief and that they have equal access to all assistance and services, including food and non-food items, education, and health care, provided to persons of concern.

Support national campaigns that inform people, in their own language, about civil status requirements and procedures and about where documents can be obtained. Mobile teams can be used to facilitate access to isolated areas and to IDPs with specific needs. Information can also be disseminated through the use of the media, hotlines or legal aid centres. (See Part V.8. DU)

Engage the IDP community in identifying documentation and related protection risks specific to certain groups. This can include unaccompanied or separated children, other IDP children, ethnic minorities, indigenous peoples and widows.

- Work with the community to maximize the complementarities between customary and statutory law and mechanisms. As an example, provide support to alternative community methods/practices that conform with international human rights law in order to resolve disputes related to identity, age, parentage and ownership.

Work with the community to explain the need and value of documentation and the process to secure such documentation.

Work with the community to assess the impact of activities aimed at informing IDPs about securing documentation.

Advocate for and assist national and local authorities in ensuring that all children are registered at birth and provided with birth certificates. This can be done in various ways, including by providing advice, technical expertise, equipment and/or modest grants. Where birth registration has been delayed, arrangements must also be made to register older children.

Take action where needed to ensure that stateless persons are not harassed, discriminated against, arbitrarily arrested or detained, or otherwise placed at risk due to their lack of nationality.

\section{Key actors}

- At the national/local level: relevant ministries (i.e. interior or home affairs) civil and administrative courts and tribunals, municipal agencies responsible for maintaining records and/or issuing documentation, civil society and NGOs, lawyer's associations, and displaced individuals and communities themselves. 
- At the international level: UNHCR, which is mandated to promote the prevention and reduction of statelessness and to contribute to the protection of stateless persons; UNFPA, UNICEF, UNDP, OHCHR, the International Commission on Civil Status, the Hague Conference on Private International Law $(\mathrm{HccH})$ and NGOs such as Plan International (for birth certificates) or Norwegian Refugee Council (for Information and Legal Assistance Centers).

\section{Key references}

\section{Civil status and documentation}

- Birth Registration and Armed Conflict, UNICEF, 2007.

- Incorporating the Guiding Principles on Internal Displacement in Domestic Law: Issues and challenges. Chapter 9: Study on the Recovery of Personal Documentation, in Studies in Transnational Legal Policy, by Foley, Nesse and McCallin, Brookings-Bern Project and American Society of International Law, no 41, 2010.

- Guide pratique international de l'état civil, Commission internationale de l'état civil, 2006.

\section{Statelessness}

- The World's Stateless People: Q \& A, UNHCR, 2006.

- Special Report: The Strange Hidden World of the Stateless, Refugees Magazine, No. 147, Issue 3, 2007.

- Nationality and Reduction of Statelessness: International, Regional and National Perspectives, Refugee Survey Quarterly, Vol. 25, No. 3, 2006.

- Nationality and Statelessness: A Handbook for Parliamentarians, UNHCR/IPU, 2005.

- Women 2000 and Beyond: Women, Nationality and Citizenship, UN Division for the Advancement of Women, June 2003.

- The Human Rights of Stateless Persons, by Weissbrodt and Collins, Human Rights Quarterly, Vol. 28, Number 1, pp. 245-276, February 2006.

- Information and Accession Package: The 1954 Convention relating to the Status of Stateless Persons and the 1961 Convention relating to the Reduction of Statelessness, UNHCR, January 1999.

\section{Useful websites}

- United Nations High Commissioner for Refugees (UNHCR): www.unhcr.org/statelessness

- Commission internationale de l'état civil (CIEC): www.ciec1.org

- Hague Conference on Private International Law $(\mathrm{HccH})$ : www.hcch.net

- Universal Birth Registration Database: www.ssl.brookes.ac.uk/ubr/

- Norwegian Refugee Council: www.nrc.no/

- Brookings Institution : www.brookings.edu/ 


\section{Shelter}

Key message

1. Shelter options in situations of internal displacement ......................................236

2. Protection risks associated with inappropriate shelter .....................................237

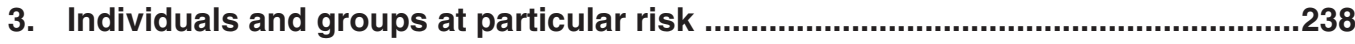

4. The international legal framework and the responsibility of the State ..................238

5. The role of humanitarian and human rights actors .............................................239

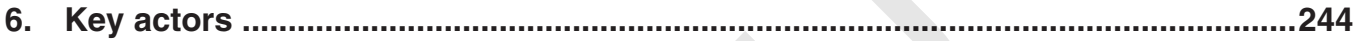

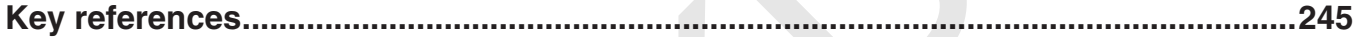

Useful websites ..........................................................................................................245

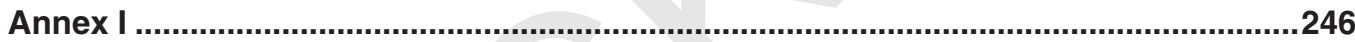




\section{Key message}

Shelter is essential to survival. It is a key protection priority. The right to shelter involves both access to adequate shelter and the sustained ability to enjoy an adequate standard of shelter. While urgent operational requirements tend to impose certain shelter solutions, the meaningful participation of the community in decisions related to shelter is essential. Groups with specific needs require additional attention to ensure their access to shelter. Gradual improvement of shelter throughout the displacement cycle is vital and can also contribute to a durable solution after displacement ends. However, shelter support alone is not sufficient, particularly for the above-mentioned groups. It needs to be complemented by infrastructure, access to basic services and livelihood support.

\section{Shelter options in situations of internal displacement}

Humanitarian interventions usually include shelter programmes that support access to emergency shelter and/or transitional shelter, depending on the stage of the operation.

When humanitarian organizations refer to shelter, they generally mean habitable, covered living space, providing a secure and healthy living environment with privacy and dignity. Examples of emergency shelter include tents, collective centres, etc. A settlement is a group of shelters. In an internal displacement context, settlements can be located in urban and rural areas, and they can be dispersed or grouped. Depending on the circumstances, internally displaced persons (IDPs) usually resort to one of the following shelter options:

\section{- Dispersed settlement:}

- Host-family arrangements (living with friends, relatives, other families or in rental accommodation);

Rural self-settlement (living in a rural context informally or on land owned collectively);

Urban self-settlement (living in an urban context informally or on land owned collectively).

\section{- Grouped settlement:}

- Collective centres (living temporarily in pre-existing structures, such as hotels, schools or public/government buildings; living in collective centres that are organized and officially recognized or that are more informal collective settlements);

- Self-settled camps: (settling without the support of the government or the humanitarian community);

Planned camps: (living on purposely-built sites, completed before or during the influx).

Where safe and appropriate, displaced populations should be supported in their respective settlement options. Their decision will be based on considerations of safety, the family's history and solidarity networks, and the extent to which a settlement provides access to water and sanitation, adequate covered and secure living space that ensures privacy, health-care services, education, recreational areas, childcare, markets and livelihood opportunities.

Generally, staying with host families is the preferred alternative for IDPs, as it builds on their own coping mechanisms and enables them to live in more dignified conditions, surrounded by extended family or friends. It is, therefore, important to ensure the participation of host communities in addressing the needs of IDPs and to recognize their contributions. Although camps are considered an option of last resort, they might be the only viable option when dealing with large influxes or when there is tension between the host and the displaced communities.

Shelter standards are different depending on the phase of the crisis. Minimum standards, notably in terms of living space, that are acceptable at the beginning of an emergency will not be adequate in a situation of protracted displacement. 


\section{Protection risks associated with inappropriate shelter}

Specific shelter modalities may seem to be the best option at a given time; yet they are only appropriate if they meet adequate standards and allow the concerned individuals or groups to live in safety and dignity. Initial conditions can deteriorate along the displacement cycle because of the inability to maintain and improve the shelter itself or because of the interaction either between groups of IDPs or between the IDPs and other affected communities. Continued monitoring and evaluation should take place to measure the standards and overall conditions of shelter and to identify possible protection risks related to inappropriate standards or a threatening environment. Such evaluations should lead to different assistance interventions as well as to the search for alternative shelter options.

\section{Risks related to inappropriate shelter options}

In host families In protracted situations, deteriorating living conditions of families hosting large number of IDPs might lead to health and psychosocial problems, as well as risks of stigmatization, harassment, economic or sexual exploitation, and violence against the displaced families.

- In areas where IDPs are not welcome, both host and displaced families might become targets of retaliation by parties to the conflict or by surrounding communities.

In dispersed settlements (urban or rural)

(See also Part IV.17 and Part V.6 $\mathrm{D}$ )
Settling amid villages, towns or in the forest may be part of a protection mechanism employed by IDPs in order to avoid attracting attention. However, it might be difficult to monitor and identify the protection concerns of IDPs in these areas due to their isolation.

Those settled spontaneously on private or public land are often under constant threat of being evicted by landlords or authorities. Again, their possible isolation may make it difficult for humanitarian actors to intervene in cases of threats of eviction, harassment or other protection concerns.

In medium-to large grouped settlements

Over time, overcrowding and degrading living conditions, lack of prospects for solutions, breakdown or poor enforcement of law and order, assistance dependency and trauma related to the causes and consequences of displacement can lead to grave protection problems.

IDPs settled in collective centres are often under threat of being evicted by landlords. Those occupying schools or religious and other public buildings are under constant pressure to leave.

Relations with the host community as well as within IDP groups might deteriorate over the sharing of limited resources, the depletion of nearby forests for firewood, the occupation of land by IDPs or the requisition of land by local authorities for the benefit of IDPs.

Tensions might also arise with the presence of an ethnically, culturally, religiously or linguistically different group of people amid a frightened community.

Despite the fact that a larger group settlement may be more secure for IDPs than dispersed and exposed shelters, a large group settlement can be easily targeted for forced recruitment and attacks, including aerial bombings.

A proliferation of high quality shelters in an area where housing standards are low can create tension with local communities unless they also benefit from the humanitarian intervention, such as by greater labor opportunities in the area of construction. 


\section{Individuals and groups at particular risk}

Displaced unaccompanied children, particularly child-headed households, are particularly exposed to protection risks related to the lack of appropriate shelter, including trafficking and various forms of violence, abuse or exploitation. Tracing their families and/or identifying foster family arrangements, thus, should begin immediately. In the meantime, all efforts should be undertaken to secure safe housing for these children and establish monitoring procedures by specialized agencies and the community itself.

Single women or female-headed households can be at greater risk of harassment, assault or exploitation if they live in shelters without proper walls, partitioning or the possibility to lock the shelter doors.

Unaccompanied older persons might have difficulties constructing their own shelters or might need to share shelter with others. Unless they receive targeted support, they can find themselves in a precarious and undignified situation of dependency. Older persons heading households and/or caring for children are also particularly vulnerable as they are subject to a double set of protection risks.

Disabled persons (both physically and mentally) also need to receive specific attention, and shelter must be adjusted to their specific needs.

During conflict, ethnic or religious minority groups might be unwelcome among the host population or within the IDP population itself and, consequently, may experience difficulty finding shelter. Displaced families who do not own land or property may face heightened protection risks, as the legal and administrative mechanisms to support them may be less clear. Such families, which include tenants of houses and apartments as well as spontaneous settlers, may constitute a large proportion of the affected populations and, very often, they are also the most deprived and defenseless among them.

\section{The international legal framework and the responsibility of the State}

The right to adequate shelter is one aspect of the right of every person to enjoy an adequate standard of living. The right to adequate housing was first recognized in the Universal Declaration of Human Rights ${ }^{1}$ and subsequently included in various international human rights instruments. ${ }^{2}$

While the right to adequate shelter applies to all persons, specific provisions exist at the international level emphasizing its applicability to IDPs. For instance, this is the case of the Guiding Principles on Internal Displacement. ${ }^{3}$ The UN Principles on Housing and Property Restitution for Refugees and Displaced Persons, known as the Pinheiro Principles, also contain specific reference to the right to adequate housing and request that States take positive measures to alleviate the difficulties faced by refugees and IDPs living in inadequate shelter. ${ }^{4}$

In some situations, the State may claim that it does not have the ability to protect the right to adequate shelter, whether due to a lack of financial resources, inexistent or ineffective law enforcement mechanisms or an inability to access parts of its territory. Nonetheless, it must

Art. 25 of UDHR.

2 Art. 11 (1) of ICESCR, Art. 27(3) of CRC; Art. 17 (1) of ICCPR, Art. 5(e)(iii) of CERD, Art. 14(2)(h) of CEDAW; Art. 43(1)(d) of CMW; Art. 20(2)(a) of AfCRWC; Art. 16 of AfCHPR Protocol on the Rights of Women; Art. XI of AmDHR.

3 Guiding Principle 18 provides that "all internally displaced persons have the right to an adequate standard of living" and that "At the minimum, regardless of the circumstances, and without discrimination, competent authorities shall provide internally displaced persons with and ensure safe access to...basic shelter and housing."

4 See Principles 2 and 8 . See also the Handbook on Implementing the Pinheiro Principles. 
demonstrate that it has made a maximum effort to use all of the resources at its disposal to satisfy the essential need for shelter. Such resources include "those available from the international community through international cooperation and assistance." This does not mean that the State needs to build houses for all of the population on its territory. As other economic, social and cultural rights, the right to shelter is progressively realized, and the State needs to take the necessary steps to respect, protect and fulfil this right.

In emergency situations, the minimum requirements that need to be fulfiled in relation to the right to adequate shelter would be privacy, security of person, health and food. ${ }^{6}$

International humanitarian law protects the right to shelter through preventive measures, mainly through the requirement that all parties to a conflict, whether they are State or non-State actors, distinguish at all times between civilian and military objectives. Concretely, it includes the prohibition from attacking civilian homes, including those of IDPs, the use of civilian homes for military operations or objectives, their pillage or destruction, including in the context of reprisals or collective punishment. ${ }^{7}$

In situations where internal displacement is ordered by the State for justifiable reasons, the law requires that positive measures be taken to protect any property left behind and to ensure satisfactory conditions while in displacement, including those pertaining to shelter. ${ }^{8}$

In international armed conflicts, international humanitarian law establishes a positive obligation to State and non-State actors to ensure the provision of shelter and other supplies essential to the survival of the civilian population. Where the civilian population is not provided with such supplies, the parties to the conflict must allow for relief actions, which are humanitarian and impartial in character. ${ }^{9}$

International humanitarian law also sets forth some essentials of humane treatment with regard to detained or interned persons which also apply to IDPs detained or interned in camps. $^{10}$ These guarantees include the "protection against weather and the dangers of the armed conflict" to the same extent as the local civilian population. The provision of shelter may be inferred from this expression.

\section{The role of humanitarian and human rights actors}

Adequate shelter is a vital component of a comprehensive protection strategy. Activities to support national authorities and IDP communities in securing access to adequate shelter must integrate relevant protection considerations. The matrix below contains general considerations applicable to all humanitarian interventions in the area of shelter, as well as specific protection considerations pertaining to each shelter option, as appropriate.

5 Ibid.

6 IASC, Gender Handbook, Different Needs - Equal Opportunities, Gender and Shelter in Emergencies.

7 Rules 7-23 of Customary International Humanitarian Law, Volume I: Rules (ICRC). See also Arts. 33 and 53 of the Fourth Geneva Convention; Arts. 51 and 52 of Additional Protocol I; Art. 4(2)(g) of Additional Protocol II; Art. 28 of the Hague Regulations. See also Art. 2(b)(xvi) of the ICC Statute.

8 See Art. 17 of Additional Protocol II.

See Arts. 69 and 70 of Additional Protocol I.

10 See Annotations to the Guiding Principles on Internal Displacement, Walter Kälin, Studies in Transnational Legal Policy No. 32, Appendix II: Compilation and Analysis of Legal Norms (Part I), Para. 189, pg. 142. 
In our work, we can ...

In all situations

Cross-cutting protection considerations
Incorporate shelter in emergency interventions: Where safe and appropriate, shelter support and assistance should be part of the early relief and emergency response to the crisis. Shelter interventions in these early stages can reduce the fluidity of the population. In doing so, they can help to mitigate or avoid additional displacement-related protection risks.

Secure land tenure: Ensure that land tenure (temporary or permanent) is secured before embarking on emergency, transitional or permanent shelter construction. (See Part IV.17 $\square$ ).

Take into account local materials, existing capacities and the environment: Consider the short- and long-term impact of temporary settlements on host communities and the environment within comprehensive planning activities. Whenever possible, locally acceptable and available materials and labor should be used to benefit the local economy, while not depleting local resources. Promote modalities of shelter that enable IDPs to upgrade their own shelters from transitional to more permanent structures, as their situation evolves.

Reinforce the community's self-help capacity: Encourage traditional construction methods, particularly in areas where the transportation of shelter material is restricted for logistical or security reasons. ${ }^{11}$ If men traditionally have been in charge of construction but women are interested in participating in construction activities, identify those who may be interested and support basic training in construction to give women the opportunity to equally participate in the process. The same is true for men if women have traditionally been in charge of building. Capacity-building can be enhanced further during the permanent reconstruction phase, by linking construction activities with training. In addition to equipping beneficiaries with knowledge of safe construction practices, this approach may also provide a livelihood opportunity, particularly in areas where large-scale reconstruction is required.

Address specific needs ensuring dignity and promoting empowerment: Try to respond to the specific needs of child-headed households and single young and older women and men without creating further stress or danger and without exposing people to stigmatization or undignified solutions. Include them in the planning and implementation phases of shelter interventions to build ownership and consensus among communities. Cash-for-work or food-for-work schemes as well as childcare arrangements can be useful to support households with specific needs in building their own shelters. Monitor the implementation of such schemes to avoid exploitative and fraudulent practices.

Coordinate closely with partners in other sectors that can affect the quality of shelter (i.e. water and sanitation, livelihoods, communal infrastructure, etc.), and promote joint planning among them. Ensure good coordination in the dialogue with members of the community. Coordinate with partners to establish child-friendly spaces where children can meet and share their experiences. Promote respect for social customs for dealing with the remains of the dead while ensuring that existing facilities such as graveyards or crematoria are adequate. ${ }^{12}$

${ }^{11}$ Items, such as cement, iron bars, nails and wood poles, might be considered strategic items and be restricted in times of conflict.

12 Graveyards should be at least 30 metres from groundwater sources used for drinking water, with the bottom of any grave at least $1.5 \mathrm{~m}$ above the groundwater table. See Sphere Humanitarian Charter and Minimum Standards. 


\section{Assessment}

(See Part III.1

\section{Monitoring and evaluation}

(See Parts III.4 and $V .2 \square$ )
- Ensure that protection or community services staff work alongside shelter specialists and site planners in all multi-sectoral assessments and specialized shelter assessments to ensure that the protection implications of shelter interventions are taken into account at the onset. In situations of armed conflict, undertake a thorough assessment of the root causes of the conflict to ensure that they are taken into account when planning for, designing or supporting the relevant shelter options.

Ensure the participation of concerned IDPs and other affected populations of different ages, gender and backgrounds as well as representatives of host communities during the assessment, to learn their different needs, concerns and perspectives.

Work with the community to identify skilled women and men and adolescent girls and boys who can support shelter construction, from both the IDP and the other affected communities. Maximize the positive impact of shelter projects on the local economy and on the environment by carefully assessing which local materials and labor can be employed.

Assess which groups in the community may not be in a position to construct, maintain or upgrade their own shelter, to develop appropriate support schemes.

- Assess how unaccompanied older persons, girls and boys are accommodated and whether they are being cared for and supported by the community.

Together with the affected communities, humanitarian organizations should define what constitutes an eligible family or household taking into account local culture and traditions. They should also define the criteria and modalities for allocating assistance among different households. Prioritizing groups should be based on an assessment of their needs and not only on the basis of their situation as occupiers, hosts or owners. Both the displaced and host populations should be involved in such decisions.

Ensure that evaluations of shelter programmes go beyond the performance levels and also examine the protection impact of such programmes. Include protection indicators in the terms of reference of such evaluations.

Conduct regular structured dialogues and discussions with individuals and groups of different ages, gender and backgrounds, particularly those with specific needs on shelter issues, to ensure that any protection concerns highlighted are discussed and resolved.

Work with the community to set up monitoring or similar mechanisms to assess the living conditions of persons with specific needs in the community, such as older persons living without adult family members or child-headed households.

Monitoring should be particularly careful in collective centres, where the lack of privacy and the often precarious living arrangements can expose women and children to situations of gender-based violence, sexual exploitation and other forms of violence and abuse.

Assess the effect of the provision of shelter on the relations between IDPs and other affected communities. See whether it contributes to reducing or exacerbating conflicts. 


\section{Host families}

- In rural settings, depending on the size of the hosted family, provide shelter materials to build a separate transitional shelter in the host compound for privacy. When appropriate, an extension to the host family shelter can be built instead. A partition should always separate the two families to avoid sources of tension or the risk of gender-based violence.

Support displaced families with technical advice to ensure their participation in the design, construction and maintenance of the shelter and to ascertain the quality of the structure. Arrange for engineers and other technical experts to monitor the safety of construction.

- If a family demonstrates an intention to host an IDP with specific needs for an extended period, provide, if appropriate, limited material assistance to the host family to assist in coping with additional persons. This will help reinforce bonds with the host community and avoid tension.

- Put in place monitoring programmes to avoid fraudulent or exploitative practices. This can be done directly or through community networks.

Secure the agreement, preferably in writing, by both the displaced and host families, as to who will own the shelter material after displacement, to avoid disputes.

\section{Dispersed settlement}

In urban settings When necessary, lobby local authorities to waive documentation requirements in lease agreements for IDPs.

- Advocate for financial institutions to support local authorities' schemes to subsidize rentals.

In rural areas

- Identify local families with specific needs for shelter support.

-When appropriate, reinforce infrastructure in the host village, such as by upgrading an access road or a bridge or drilling additional wells or communal latrines to help the community cope with the influx of IDPs.

\section{In both cases}

Closely monitor the situation of particularly vulnerable individuals or households and build peer-support networks amongst IDPs and host communities to protect and support them.

Ensure that protection and other humanitarian organizations adhere to strict standard operating procedures to safeguard confidentiality in their assistance interventions for those who wish to remain unnoticed.

When appropriate, all actors involved in assisting IDPs in dispersed shelters should ensure that their offices are well-known and recognizable through visibility signs so that individuals living in dispersed settlements can approach them directly without difficulties.

\section{Grouped settlement}

\section{Collective centres} or communal buildings
Work with the authorities and the IDP community to ensure that alternatives to inadequate shelter in communal buildings can be found quickly, (i.e. found in less than one month, if possible) pending durable solutions. Collective centres or communal buildings, such as schools and religious buildings, should be closed or relocated as soon as possible to ensure that their original function can resume. Otherwise, tension may arise between the displaced and the other affected populations.

When IDPs cannot be offered alternatives in the immediate future, work with them and with host communities to ensure that a space is organized within the compound for the school or the church to reinstate its activities and to improve the space they are occupying as transitory shelter.

Provide adequate material to enable separate partitions to be placed both between and within families staying in collective centres. Privacy is especially challenging in communal shelters. Ensure that neither women nor children are compelled to share accommodation with men who are not members of their immediate family. 
Establish a strong monitoring and referral network among agencies to prevent gender-based violence or forced recruitment and to immediately follow up on identified incidents. Communal buildings are likely to expose women and children to such risks. Sensitize communities and local authorities to the prevention of, and response to, these risks and support them in establishing a monitoring and reporting system.

Keep track of arrivals and departures in each location to avoid any fraud or duplication of assistance.

\section{Camps: site selection and layout}

(See Part V.6 and Annex I to this chapter [D)
Although land might be scarce, available sites might not meet all of the desired criteria. Sensitize the host community and responsible authorities to the long-term protection and financial implications of selecting an unsuitable site.

- Ensure that physical planning is conducted with the participation of the displaced community and that it takes full account of their protection needs. Analyse baseline data gathered from registration and profiling exercises (ensuring breakdown by age and gender, and highlighting specific needs) and build the analysis into the site planning exercise.

Site selection should also take into full account the distance of the camp from essential services and local markets, existing relationships among the different communities, traditional living arrangements and security concerns. Avoid sites located near volatile areas and, in the case of natural disasters, physically unsafe areas. Ensure that any hazards that could impact the site are mapped, mitigated and monitored.

Measures to increase the resilience of communities to future disasters should be incorporated during the reconstruction phase and should adhere to the principles of Community Based Disaster Risk Management (CBDRM). ${ }^{13}$

When designing/constructing shelter units, integrate local building practices to the extent possible and select appropriate material as a priority.

Regrouping IDPs from the same village or extended families in shelters aligned in a U-shape design allows for families to keep an eye on each other's children playing in the central area and to guard belongings against theft. Such "cluster-planned village" communities can also provide a protective environment for individuals with specific needs.

Ensure a minimum surface area per person of 45 square meters. ${ }^{14}$

Ensure that the roads giving access to the site are good in order to facilitate the delivery of humanitarian aid, the regular monitoring of IDPs and access for IDPs to nearby services and local markets.

- To minimize the impact of the camp on the environment, assess and support the natural resource management of both the displaced and host populations. Provide construction material and household energy fuels to avoid depleting local environmental resources, to protect vegetation needed to prevent soil erosion or flooding, and to safeguard agricultural lands and productive forests.

Sensitize and train communities on health and fire risks, and encourage the establishment of communal systems for fire prevention and vector control.

${ }^{13}$ For more information about CBDRM : http://www.proventionconsortium.org/?pageid=47 .

${ }^{14}$ Including kitchen/vegetable gardening space. This also includes an apportioned common area for roads, foot paths, schools, sanitation, security, firebreaks, administration, water and other storage, distribution, markets. 
Shelter design

Limited grouped settlements in existing villages
- In addition to providing physical protection against the elements, shelter should provide sufficient floor space per person. ${ }^{15}$

Avoid shared accommodation as much as possible to mitigate the risk of exploitation and abuse, particularly for single women and unaccompanied and separated children.

- Adjust shelters to the specific needs of persons with disabilities or chronically ill, female-headed households or unaccompanied older persons.

To mitigate the risk of gender-based violence, ensure that dwellings allow the separation between genders, where culturally required, or between parents and children to provide privacy and safety. Provide material for partitions. Separate facilities, such as bathing facilities and toilets, should be constructed for women and men. They should not be located in dark or isolated areas where women and children might be at risk of sexual assault.

Depending on the wishes of the IDPs, promote smaller settlements of 20-30 families in existing villages, as opposed to establishing larger camps, as it will:

contribute to a more normal living environment;

allow for better absorption of the displaced population so that IDPs can benefit from access to the village market, local medical facilities, wells and work opportunities;

reduce the cost for the government or the humanitarian community, as it eliminates the need to set up a camp and to provide all services;

ensure that all additional infrastructures provided to the IDP settlement (wells, community buildings, classrooms) also benefit the host village;

- lead to improved empowerment and autonomy of the community in securing its own protection; and

improve the possibility for local integration when IDPs opt for this as a durable solution.

- Group settlements can stimulate new forms of community and create a new social fabric. This must be supported and taken into account. Especially in a protracted situation, residents of collective centres, camps or other types of group settlements may have developed stronger community bonds and support networks among co-residents of the collective centre than in their community of origin. Thus, a durable solution may entail supporting these newer community links and support mechanisms, rather than attempting to restore and recreate links from many years ago that were disrupted as a result of displacement.

\section{Key actors}

- At the national level: displaced persons and communities; ministries of public works and infrastructure, housing, social welfare, health, education, religious affairs and interior or home affairs; social housing service agencies, national human rights commissions; engineering and architecture faculties, local industry and professional organizations.

\footnotetext{
${ }^{15}$ Shelter area per person should average $3.50-4.5 \mathrm{~m} 2$ in camp settings and no less than $1.50-2.50 \mathrm{~m} 2$ for transit and temporary housing facilities (overnight stay only). Shelter standards depend on the climate: more interior space should be provided in cold weather than in warm climates.
} 
- At the international level: UNHCR, ICRC/IFRC, UNICEF, UNDP, UNEP, IOM, NGOs specialized in shelter or protection (such as ACTED, Care, Christian Aid, Disasters Emergency Committee, HMD Responses, GOAL, International Rescue Committee, Oxfam, RedR, The Save the Children Fund, the Shelter Centre or World Vision).

- When not available locally, expertise and advice should be sought through the Global Emergency Shelter Cluster, which can field a specialist to coordinate activities in this sector.

\section{Key references}

Transitional Settlement: Displaced Populations, Oxfam, June 2005.

- Women, Girls, Boys and Men: Different Needs - Equal Opportunities. IASC Gender Handbook in Humanitarian Action, IASC, December 2006.

- Humanitarian Charter and Minimum Standards in Disaster Response, Chapter 4, Minimum Standards in Shelter, Settlement and Non-Food Items, Sphere Project, 2004.

- Protecting Persons Affected by Natural Disasters, IASC Operational Guidelines on Human Rights and Natural Disasters, 2006.

- Housing and Property Restitution for Refugees and Displaced Persons: Implementing the "Pinheiro Principles," FAO, NRC/IDMC, OCHA, OHCHR, UN-HABITAT, UNHCR, 2007.

- General Comment No. 4 of the Committee on Economic, Social and Cultural Rights, UN Document No. HRI/GEN/1/Rev.1, 29 July 1994.

- Shelter after Disaster: Guidelines for Assistance, OCHA, 1982. (In the process of beig revised).

- Handbook for Emergencies, UNHCR, $3^{\text {rd }}$ Edition, 2007.

n Needs Analysis Framework (NAF), OCHA, 2006.

\section{Useful websites}

- IASC Emergency Cluster: www.oneresponse.info/GlobalClusters/Emergency\%20Shelter/Pages/default.aspx

- United Nations High Commissioner for Refugees (UNHCR): www.unhcr.org

- United Nations Human Settlements Programme (UN-HABITAT): www.unhabitat.org

- Sphere Humanitarian Charter and Minimum Standards in Disaster Response: www.sphereproject.org 


\section{Annex I}

\section{Site selection review: issues for consideration}

\section{Potential beneficiaries}

Numbers

Characteristics (gender, age, background, language, etc.)

\section{Complementary/Supporting points}

Presence of nearby villages/communities

Accessibility for humanitarian and other service providers

Proximity to national services:

Health

Education

- Administration

Law enforcement structures (police, courts)

Electricity supply

Proximity to economic centres

Proximity to income-generating opportunities/ agriculture

Possibility to harvest wood for construction

Possibility to collect firewood for fuel

\section{Location}

Distance from major towns

Distance from the conflict or risk zone

Security and protection situation

Local health and other risks

Distance from protected areas (reserve forest, water reservoirs)

\section{Basic characteristics of the site}

6. Proposed next steps for consideration
5. Observations/Recommendations

Strengths/weaknesses of site

Area, possibility for expansion

Land use and land rights

Topography

Elevation

Soil condition

Water availability (drinking/washing/livestock)

Drainage

Sanitation possibilities

Climatic conditions

Vegetation/other environmental condition 


\section{Part IV.11 \\ Food aid and nutrition}

Key message

1. Food insecurity and malnutrition during internal displacement .............................248

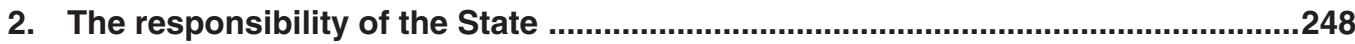

3. The role of humanitarian and human rights actors ..............................................249

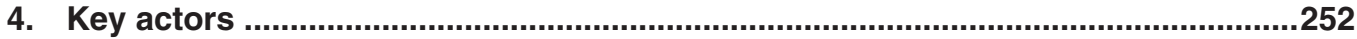

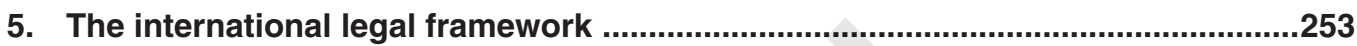

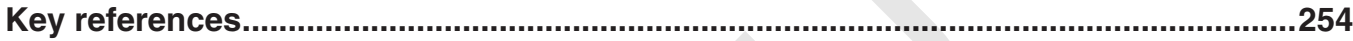

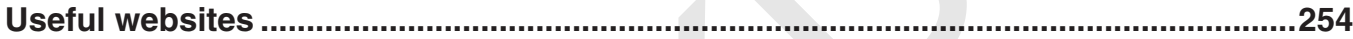




\section{Key message}

If delivered strategically and in a protection-sensitive manner, food aid will not only save lives but also help rebuild communities and foster peace and reconciliation efforts. If provided without regard to the political environment or the underlying causes of displacement and food insecurity, food aid may do more harm than good.

For food aid to be effective, it must be accompanied by other support measures, such as education on food preparation or the provision of non-food items such as cooking fuel and utensils. In addition, food security goes hand in hand with income-generation, self-reliance and development activities. This aspect of food security is addressed in Part IV.16

\section{Food insecurity and malnutrition during internal displacement}

The use of the term food security in this chapter should be understood as having physical and economic access to sufficient and sustainable food to meet their dietary needs in order to lead a healthy and productive life.

It is essential to ensure that food aid not only contributes to preserving the life and adequate nutrition levels of those affected by displacement, but also realizes its full potential to become, itself, an agent of protection.

As an agent of protection, food aid can help ensure, for example, that children, particularly girls, have access to education. School feeding programmes encourage children to attend school regularly and in greater numbers.

Access to adequate food and nutrition is, together with access to water, one of the most important humanitarian concerns for any human being. During displacement, all stages of nutrition - production, procurement, preparation, allocation and consumption of food - are disrupted. ${ }^{1}$ Communities that may have previously developed group coping mechanisms and solidarity networks to mitigate the impact of food shortages, find themselves suddenly scattered.

Poverty and food shortages can expose internally displaced persons (IDPs) to serious risks, such as the sexual exploitation of women and girls. Mothers may feel compelled to use any means to obtain food for their children, including by agreeing to sexual favours or prostitution in exchange for food or the means to obtain it.

Inadequate nutrition among children may seriously affect their physical and mental development, prevent them from attending school, and push them into child labor to contribute to the family's income.

\section{The responsibility of the State}

States should do everything possible to promote the full enjoyment of the right to adequate food for everyone within their territory. Some of these measures would be immediate; others would be long-term to progressively achieve the full realization of the right to food. In this context, States must ensure the following:

- Take steps to secure the right to adequate food whenever an individual or group is unable to enjoy this right on their own. This includes preventing discrimination

Pejic, Jelena, The Right to Food in Situations of Armed Conflict: The Legal Framework, in IRRC, December 2001,

Vol. 83, No. 844, pp. 1097-1109. 
concerning access to food and preventing malnutrition or starvation. If the State does not have the resources to do so, it should seek international support.

- Strengthen the resources citizens have and the means by which they can ensure their livelihood, including food security. This includes enforcing security measures along roads and in settlements, agricultural areas and marketplaces.

- Ensure that food not only provides the optimum nutrition required for a healthy and active life, but that it is also culturally acceptable and free from harmful substances.

- Take conflict-resolution and conflict-prevention measures to ensure access to, and sharing of, vital resources for food preparation, such as firewood.

- Abstain from taking any measure that could prevent IDPs and other affected populations from having access to food.

\section{The role of humanitarian and human rights actors}

Food aid is often the first form of humanitarian aid to protect the lives of war-affected populations. Food aid in displacement situations must focus on strengthening the capacity of national authorities to restore food security.

In the short term, this implies supporting the distribution of emergency rations and related non-food items. In the long term, it consists of assisting national actors in the development of opportunities to either generate income with which to obtain food or to produce food in the places of origin or relocation.

\section{In our work, we can ...}

Assessment and analysis (See Part III.1 $\square$ )
Liaise with national and international food-aid agencies at the very onset of a crisis. They are usually the first to have access to displaced populations and they can obtain firsthand information on the overall conditions and most pressing protection gaps.

Where not available locally, expertise and advice should be sought through the Global Emergency Shelter Cluster. They can field a specialist to coordinate activities in this sector, at least for the initial assessment/planning period to undertake an evaluation and make specific recommendations for the (re)orientation of the programme.

Ensure that any food-aid and nutrition assessments are carried out in conjunction with specialized protection and community services staff to ensure wide-ranging identification of protection risks for individuals of different ages, gender and backgrounds.

Food-aid and nutrition assessments should include tools to look beyond the food related needs and into the (potential) protection concerns of a community:

to identify the most invisible groups in the community, the power relations, and the existing specific needs of any group according to age/gender which may help to ensure that food distribution does not exacerbate vulnerability;

to ensure that the community's and individuals' own coping mechanisms are supported and, if possible, reinforced by, for example, assessing the level of "visibility" of IDPs and whether they hide to protect themselves, which will greatly affect how food is distributed and;

to ensure that the specific nutrition needs and traditions of different groups are protected, including those of children, older persons, chronically ill persons, pregnant and lactating women and indigenous groups. 
- Joint assessments on food and related sectors should include displaced populations who are not in camps or broader settlements as well as those dispersed in smaller groups and living with host families.

- The food needs and nutrition and public health conditions of the host communities should also be assessed early to avoid creating tensions. Eventually, any food-aid programme should take into account the needs of the broader community.

- Familiarity with conditions in both the area of displacement and the area of origin is of utmost importance to ensure culturally appropriate food and local procurement of food and non-food items to the extent possible.

\section{Planning and programming of food-aid and nutrition-support programmes}

In war-torn countries where infrastructure has been destroyed and markets depleted and where there is no possibility of growing or purchasing food, food warehouses and convoys have been repeatedly attacked. On occasion, IDP settlements have been attacked by fighters, either during or immediately after a food distribution, as was the case in Liberia in the late 1990s. The realization that food aid could be diverted and lead to conflict prompted some NGOs and United Nations agencies to issue the Joint Principles of Operation, a first attempt at a code of conduct for humanitarian actors that operated in Liberia in the late 1990 s and early 2000 s.

- Coordinate all food distribution activities within the country team, particularly with the CCCM, protection, health, nutrition, education and agriculture sectors/clusters or working groups, and the WFP-led logistics common service area and food sector.

- Joint planning and programming between protection and specialized food agencies and public institutions is vital to mainstream protection-related aspects in the programming of food aid.

- Avoid turning food aid into a pull factor for encampment if there are other alternatives (as addressed in Part IV.10 D). If the situation allows, a food-aid system that enables IDPs to live among host families or in a more dispersed manner should be prioritized, in spite of the greater logistical constraints it may entail.

- The possession of food should not expose IDPs to further human rights violations.

- Undertake joint planning with the community, including IDP women and men, as well as IDP leaders, to ensure that adequate measures are taken to maximize safety measures and avoid risks for the population.

Calculate the frequency of distributions to avoid any eventual protection risks; the greater the time between distributions the larger the quantities distributed, which may put IDPs and other affected populations at risk of attacks and pillage.

- Plan the location of distribution points and their distance from places of residence taking into account possible risks for recipients of food aid; recipients should not have to traverse long distances or pass through conflict zones where they may be exposed to serious safety risks. Also, distributions need to be accessible for those who are mobility challenged, such as older persons or people with disabilities. 


\section{Registration for food} distribution
Registration systems should be devised in cooperation with other agencies and should include relevant information to help address food and other protection needs.

- At a minimum, registration should be based on family groups and should include the names of all male and female adults in the family. All data should be disaggregated by age, gender, place of origin, and ethnic background.

- The practice of registering only the male head-of-household / head of family should be discouraged and certainly never used to exclude the registration of other adult family members.

- Registration should be combined with sensitization that the food provided is for the family groups and not only for the person whose name is being registered for distribution.

- Given the sensitivity of the information, personal data and lists of recipients should be kept firmly restricted to concerned actors and kept safe from unintended use.

Births should be registered in a timely manner and the necessary adjustments should be made accordingly on the lists for food distribution.

\section{Distribution} procedures
- Ensure that standard procedures are in place and well known to all, to guarantee the safety of women and children during food distribution.

- Ensure the adoption of a zero-tolerance policy for sexual exploitation and other forms of abuse of power by aid workers or those providing food aid. To this end, it is important to:

- hire female staff for key managerial positions in food-aid programmes; make sure all IDPs are aware of their entitlements and rights;

- maintain complaint referral mechanisms and mailboxes in the camps or collective settings for the population to communicate their concerns;

ensure that distributions are undertaken by a combined group of stakeholders, including men and women, to avoid corruption and deviation;

make sure women are also on the receiving end of the distributions, either in the company of their spouses or alone, to directly receive the food rations for their families;

monitor the store's management and record-keeping frequently;

provide safe waiting areas for children during lengthy food-distribution processes to avoid any forms of violence and abuse or family separation during that time; and

ensure all humanitarian staff know the consequences of abuse of power.

Provide transportation assistance, if needed, so women, children, older persons and persons with disabilities have access to food. 


\section{Monitoring of food-aid distribution and its effects}

Conduct regular food basket monitoring to assess the adequacy of food distribution systems.

- Conduct regular consultations and post-distribution monitoring with the community to assess the impact of food distributions, use of food, or protection problems that might arise during or after distributions. Involve the community in identifying solutions. Regularly monitor the use of food rations by recipients to ensure that aid is not being diverted after the distributions.

- In camp situations, consult with camp management and protection agencies on the possible presence or infiltration of armed elements and provide relevant information relating to food monitoring.

- Monitoring mechanisms should include a system for referral of detected cases that need immediate response such as medical care, legal assistance and counselling in cases of food-related sexual exploitation, abuse or corruption.

- Undertake country-wide surveys with other agencies to identify instances of food blockage by armed actors or others and discriminatory access to food aid. These should be followed up by the Protection Cluster or working group and the Humanitarian Coordinator with the relevant stakeholders.

- Monitor whether school feeding projects retain and increase the percentage of boys and girls at school, and revise the programmes as necessary.

- Monitor whether food aid has a negative impact on the level of prostitution or survival sex among women and, if so, determine possible causes such as a lack of diversity in food items or insufficient quantities.

Ensure appropriate monitoring of the nutrition status of the population by specialized agencies.

- Monitor appropriateness of food rations, such as for older persons who may not be able to easily chew or digest standard rations due to factors such as loss of teeth.
Training and awareness-raising
In order to ensure that protection is incorporated into food-aid programmes:

provide training on protection issues to those involved in food distribution and monitoring to make sure they understand all the implications of food aid and are able to anticipate and/or detect abuses;

provide training to food-aid staff and those of related sectors on the mandates and specific tasks of protection agencies as well as on referral mechanisms; and

maximize the use of food-distribution exercises as venues to promote awareness of certain protection issues, including access to education, separated children, nutrition, and female genital mutilation.

\section{Key actors}

Ensuring an effective response requires a multi-sectoral and coordinated effort by a range of local, national and international actors.

- At the national level, key actors include, in addition to displaced people and affected communities, government line ministries, such as those for social welfare, health, public health, education, religious affairs, the interior, police, and justice; faculties of medicine, 
public health, agronomy, local industries and professional organizations; local NGOs and civil society and, in particular, women's and youth organizations.

- At the international level, WFP leads and coordinates food-related issues globally. UNICEF is the lead for the global nutrition cluster. They work in close partnership with the United Nations and international organizations, such as ICRC, UNHCR, WHO, FAO, $\mathrm{OHCHR}$, and IFRC, as well as with a large group of international NGOs specialized in food and/or nutrition, such as Action contre la Faim, IRC, Oxfam, Save the Children Fund, World Vision and other agencies with expertise in the fields of food aid, nutrition, protection, public health, self-reliance, security, logistics, and education.

\section{The international legal framework}

Access to adequate food is both an individual right and a collective responsibility. The right to freedom from hunger is intrinsically linked to the right to life; at the very minimum, States must ensure that populations in their territory do not starve. ${ }^{2}$

The right to food does not mean that the State has an obligation to feed everyone. States have a general obligation to work toward the "progressive realization" of the right to food and the right to be free from hunger using the maximum number of "available resources." 3 States are also required to create conditions that guarantee food security through, for example, legislation, public policy and specific programmes.

States also have an immediate obligation to avoid discrimination in access to adequate food, including discrimination on the basis of displacement. The Guiding Principles on Internal Displacement establish that "humanitarian assistance shall be carried out in accordance with the principles of

"The right to adequate food is realized when every man, woman and child, alone or in community with others, has physical and economic access at all times to adequate food or means for its procurement.

The right to adequate food shall therefore not be interpreted in a narrow or restrictive sense which equates it with a minimum package of calories, proteins and other specific nutrients."

CESCR, General Comment 12 (1999) humanity and impartiality and without discrimination."

In humanitarian emergencies, the obligation to fulfil the right to food also applies. "Whenever an individual or group is unable, for reasons beyond their control, to enjoy the right to adequate food by the means at their disposal, States have the obligation to fulfil (provide) that right directly. This obligation also applies for persons who are victims of natural or other disasters." ${ }^{5}$ The Guiding Principles ${ }^{6}$ establish that, at the minimum, regardless of the circumstances and without discrimination, competent authorities shall provide IDPs with, and ensure safe access to, essential food, potable water, basic shelter and housing, appropriate clothing and essential medical services and sanitation.

Where States are unable to provide food assistance to prevent malnutrition and starvation, they are required to seek international assistance, including from bilateral, United Nations and NGO sources. ${ }^{7}$ States in a position to assist have a joint and individual

\footnotetext{
See Art. 25 of UDHR and Arts. 11.1 and 2 of ICESCR.

Article 2.1 of the ICESCR; see also Article 4 of the CRC.

Guiding Principle 24.1.

5 General Comment No. 12 (1999) on the right to adequate food, UN Committee on Economic, Social and Cultural Rights. See also Guiding Principle 25 which states that "The primary duty and responsibility for providing humanitarian assistance to internally displaced persons lies with national authorities."

Guiding Principle 18.2.

Art. 2.1 of the ICESCR. This is reinforced in Art. 11.2 under which States "shall take, individually and through individual cooperation" measures to fulfil the right of everyone to be free from hunger.
} 
responsibility, in accordance with the Charter of the United Nations, to cooperate in providing disaster relief and humanitarian assistance in times of emergency, including assistance to refugees and IDPs. Food aid should be provided, to the extent possible, in ways that do not adversely affect local producers and local markets, and it should be organized in ways that facilitate the return to the food self-reliance of the beneficiaries. Such aid should be based on the needs of the intended beneficiaries. Products included in international food trade or aid programmes must be safe and culturally acceptable to the recipient population. ${ }^{8}$

International humanitarian law includes the prohibition of attacking, destroying, removing or rendering useless objects indispensable to the survival of the civilian population. This prohibition is a norm of customary law and applies in both international and non-international armed conflicts. ${ }^{9}$ This includes foodstuffs, crops, livestock, drinking water installations and supplies and irrigation works. International humanitarian law also prohibits the use of starvation of the civilian population as a method of warfare, which is a customary rule that applies in international and non-international armed conflicts. ${ }^{10}$

Using starvation as a weapon of war constitutes a war crime under the Statute of the International Criminal Court. ${ }^{11}$ Under international humanitarian law, this rule does not prohibit the use of siege to achieve a military objective. However, when conducting such military operations, the parties to the conflict are to respect another customary rule: they "must allow and facilitate rapid and unimpeded passage of humanitarian relief for civilians in need which is impartial in character and conducted without adverse distinction, subject to their right of control."12

\section{Key references}

- Food Aid and Livelihoods in Emergencies: Strategies for WFP, WPF, WFP/EB.A/ 2003/5-A, 2003.

- Joint Assessment Mission Guidelines, UNHCR/WFP, $2^{\text {nd }}$ edition, 2008.

- Food and Nutrition Needs in Emergencies, UNHCR, UNICEF, WFP and WHO, 2004.

- UNHCR Handbook for Emergencies, UNHCR, $3^{\text {rd }}$ edition, 2007.

- Food Distribution Guidelines, WFP, 2003 (provisional edition).

- Nutrition in Emergencies: WFP Experiences and Challenges,

- WFP/EB.A/2004/5-A/3, WFP, April 2004.

- Targeting in Emergencies, WFP/EB.1/2006/5, WFP, 2006.

\section{Useful websites}

- Food and Agriculture Organization (FAO): www.fao.org

- Right to Food: www.righttofood.org

- World Food Programme (WFP): www.wfp.org

- United Nations Children Fund (UNICEF): www.unicef.org

8 General Comment No. 12 (1999) on the right to adequate food, UN Committee on Economic, Social and Cultural Rights.

9 Rule 54, Customary International Humanitarian Law, Vol. 1: Rules, Art. 54(2) Additional Protocol I, Art. 14 Additional Protocol II.

10 Rule 53, Customary International Humanitarian Law, Vol. 1: Rules; Art. 54(1) Additional Protocol I.

11 ICC Statute Art. 8(2)(b)(xxiv).

12 Rule 55, Customary International Humanitarian Law, Vol. 1: Rules; Arts. 54 (2) and 70 Additional Protocol I; Art. 14 and 18(2) Additional Protocol II. 


\section{Part IV.12 \\ Water and sanitation}

Key message

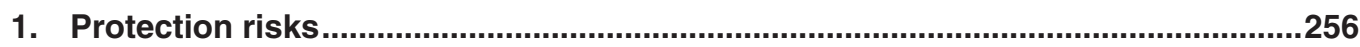

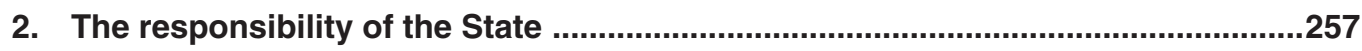

3. The role of humanitarian and human rights actors ..........................................257

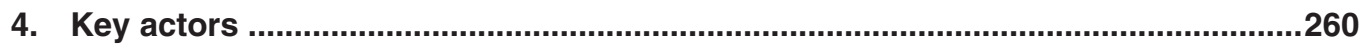

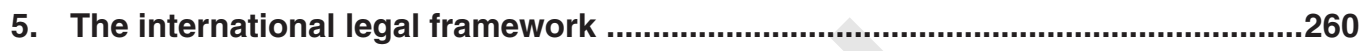

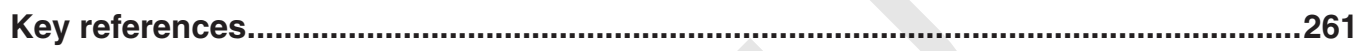

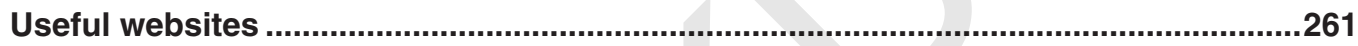

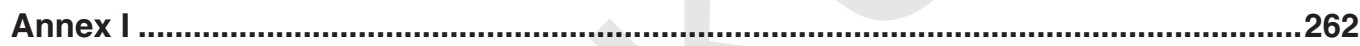




\section{Key message}

"The human right to water entitles everyone to sufficient, safe, acceptable, physically accessible and affordable water for personal and domestic uses."1

Water, sanitation and hygiene are essential to life, health and dignity and are a basic human right. During displacement, populations must urgently secure access to water, sanitation and basic hygiene facilities to ensure their survival, especially for protection against diseases, and their dignity until they can return home or find another durable solution. In certain country-specific situations, this may be unattainable, but all measures should be taken to ensure equity.

This chapter aims to give an overview of how the adequate provision of water, sanitation and hygiene (WASH) is essential for the protection of internally displaced persons (IDPs).

\section{Protection risks}

The provision of clean water, sanitation and hygiene facilities needs to be timely and adequate from the beginning of an emergency. Any water and sanitation programme implemented without simultaneously promoting proper hygiene will not effectively prevent diseases and deaths. To ensure effective protection during displacement, basic principles for the provision of water and sanitation services need to go beyond "what" is provided (e.g. more than 20 liters per person per day of clean water, or at least one latrine per 20 persons) to include "how" the services are provided. A well-planned WASH programme should ensure that protection risks are reduced and vulnerability is mitigated.

Inappropriate design and location of water, sanitation and hygiene facilities can provoke serious protection risks for displaced people, particularly women and girls but also for people with specific needs, such as older persons and persons with disabilities.

Access to water has frequently been a source of conflict within and between communities. This becomes particularly evident during displacement when there is often a scarcity of water due to a large influx of people. If not properly planned and implemented, WASH programmes may create tensions between communities if, for example, local water sources become inadvertently polluted. It is important to give careful consideration to the location of water-distribution points in a camp or setting, as different groups may attempt to take control of the water, claiming that these points are in their area of residence. The location of water-distribution points outside camps or collective centers in an urban environment could place women and girls at greater risk of sexual and gender-based violence, as they often have the primary responsibility for collecting water. Girls' education might also be disrupted if they have to fetch water during school hours because the water points are far from the camp.

Communal latrines and washing facilities located far from dwellings, without some form of lighting or without the possibility of being locked from the inside, also increase the risk of women and girls being subject to harassment, sexual assault and rape. Latrines in collective centres occupying several floors in urban buildings may be inaccessible for older persons or persons with disabilities, making them dependent on assistance from others which, in turn, could increase their vulnerability (as addressed in Parts IV.10 and V.6 [D).

In protracted displacement situations, communities may feel that they are gradually losing their independence and sense of responsibility and, as a result, start to neglect the maintenance of water and sanitation facilities, contributing to the sense that they are also losing their dignity.

General Comment No. 15 (2002) on the right to water, UN Committee on Economic, Social and Cultural Rights, E/C.12/2002/11. 


\section{Overview of additional protection risks related to WASH}

Water points can be a source of conflict; agencies should avoid centralizing water points in rural areas and should separate water points meant for humans and animals.

In rural areas, land and property ownership should be taken into consideration before drilling boreholes; standard tools and considerations should exist within the water/sanitation sector. Agencies risk legitimizing illegal occupations without these proper assessments (as outlined in Parts IV.10 and IV.17 [D).

Non-food item distributions, such as water containers for carrying and storing water safely, mosquito nets for minimizing the risk of malaria, and soap for hand-washing, which is a vital disease prevention barrier, are critical in enabling IDPs and refugees to take basic measures in protecting their health. These items may become vital commodities during conflict situations and may put communities at risk of attack. Therefore, ensure consultation with beneficiaries about the type and quality of goods and the means of distribution.

\section{Lessons learned from a water project ...}

A WASH project, aimed at increasing women's access to private latrines, used locally available materials, as recommended by the women through community participation. However, the women had to walk far from the settlement to collect these materials, which increased their vulnerability to rape. As a result, the project was modified to ensure that there were other ways of collecting the materials needed. This example shows that, with community participation, unintended harmful consequences of initiatives can be avoided to the benefit of all concerned.

\section{The responsibility of the State}

All States must take steps to ensure the availability of a sufficient and continuous supply of water of adequate quality. Water and water/sanitation facilities must also be accessible to everyone without discrimination of any kind. This includes ensuring that such facilities are located within the safe reach of all sections of the population, designed in an age- and gender-sensitive way, and affordable to all. ${ }^{2}$

\section{The role of humanitarian and human rights actors}

Any established WASH cluster or working group in an IDP operation needs to coordinate activities with relevant national ministries to ensure that interventions are properly planned and implemented jointly. Issues, such as disposal of waste and water-quality control, as well as technical aspects, such as the design of wells and latrines, need to be coordinated with the local authorities in order to foster ownership and to ensure that maintenance will be sustainable.

Good coordination between the protection cluster (or working group) and the WASH cluster (or working group) is also important. Protection officers and water and sanitation specialists need to work together to establish WASH activities that include efficient protection for IDPs.

\footnotetext{
2 See General Comment No. 15 (2002) on the right to water, UN Committee on Economic, Social and Cultural Rights, E/C.12/2002/11. See also General Comment No. 14 (2000) on the right to the highest attainable standard of health, E/C.12/2000/4. See also Resolution 60/251 of the Human Rights Council on human rights and access to water.
} 


\section{In our work, we can ...}

\section{Participation}

(See Part V.10 [D)

Contingency

planning

Monitoring

(See Part III.4
Assess, along with the displaced and host communities, the quantity of water needed in the affected area.

Mobilize women and men to participate in deciding the location, design and maintenance of water and sanitation facilities. Whenever possible, involve women and men from the host population.

In protracted situations, when water and sanitation facilities are repeatedly damaged, mobilize communities to analyse the causes of the degradation and to develop a sustainable response system.

Recruit individuals from both the host and IDP populations in order to implement projects that would benefit the local economy and in order to ensure a non-discriminatory recruitment process.

Ensure the active participation of women and girls (in separate meetings so that they can freely express their ideas and concerns) in deciding on the location and design of latrines and washing areas to maximize safety, privacy and dignity.

Sensitize the community, and ensure that both men and women take ownership and responsibility for hygiene promotion within the community. Use participatory materials and methods that allow all groups to plan and monitor their own hygiene improvements. ${ }^{4}$

Establish water and/or sanitation committees composed of $50 \%$ women, to be responsible for the maintenance of the facilities and to decide, if necessary, on a schedule for use of the facilities.

Develop emergency preparedness mechanisms at an early stage and also for the dry season which aim at identifying and responding to potential security threats linked to the provision of water and sanitation.

Ensure that water supplies and sanitation/hygiene facilities, including in schools and health posts, are monitored on the basis of international standards, such as the Sphere standards. ${ }^{5}$

- Ensure that committees monitor water-distribution points and sanitation/hygiene facilities to mitigate the risk of power abuse, corruption, and security incidents. Water should not be sold as an economic good or subjected to controlled access.

Work with State authorities to prevent displacement by ensuring access to water sources and preventing the contamination/pollution of water sources.

Ensure that problems related to water are not misused by camp authorities to induce premature return or closure of the camp.

Ensure adherence by humanitarian actors to the agency's Code of Conduct in order to minimize the likelihood of sexual exploitation/abuse, which has been associated with the delivery of aid.

3 The annex provides some useful questions to ask ourselves and our partners to ensure that our WASH programme includes a protection perspective.

4 Generally, in a camp, there should be two hygiene promoters/community mobilizers, one female and one male, per 1,000 members of the population.

5 See www.sphereproject.org/handbook/ 


\section{Acceptability, accessibility and safety of the service provided}

- Ensure that sanitation facilities, particularly in existing buildings such as collective centres, are appropriate and safe for the users, in addition to being culturally acceptable. Keep in mind an age, gender and diversity perspective as well as the need for dignity and privacy (e.g. separated cubicles for men and women or the establishment of a schedule).

- Where communal laundry facilities are necessary, create private laundering areas for women to wash and dry garments and sanitary cloths.

Distribute suitable materials for sanitary napkins and materials for their disposal. Seek the advice of women and girls in the related design and implementation.

- Make sure water-distribution points and sanitation facilities are centrally located and not too far from dwellings ${ }^{6}$ so that people with chronic illnesses or disabilities and older people can access them.

Ensure that the location of water distribution points is appropriate: water points located far from camps may pose huge logistical challenges in delivering the minimal amounts required to meet international standards; those located too close to camps increase, for example, the threat of malaria to camp residents.

Provide adapted hand pumps and light water-carrying containers for use by chronically ill or older people.

Locate facilities close to dwellings, in a secure environment and along safe access paths. Install lights or provide torches for each household.

- If water is trucked, pumped or rationed, ensure that the distribution time and duration are planned with the community, according to women's and men's convenience and cultural habits, and that they are limited to daylight hours.

Make sure that people not able to attend a queuing system, such as older persons or persons with disabilities, receive their share through outreach social workers or volunteers. Ensure that this system is monitored to mitigate abuse of power.

Take into consideration the proximity of crops and adjacent land capacity next to water points.

6 For example, water points within $200 \mathrm{~m}$ with minimum waiting time and latrines not farther than $50 \mathrm{~m}$, preferably one for each family. 


\begin{tabular}{ll}
\hline Quality and & Ensure that the water supplied is safe and drinkable by establishing a \\
reliability of & system for the regular monitoring of quality, particularly to reduce the risk \\
services & of fecal contamination. \\
Design and run facilities jointly with the community to minimize waste \\
(e.g. when fetching water) and maximize use of resources/facilities. \\
Ensure with the community that facilities are maintained, that spare parts \\
and materials are in stock, and that there are adequate water storage \\
facilities available at household and community levels in case of \\
interruptions. \\
Coordinate with specialists the training of women and men on the \\
maintenance and use of water and sanitation facilities and on how to \\
make and/or where to find spare parts. \\
Organize communal awareness-raising events and meetings, involving \\
people selected from affected communities for WASH programmes/facilities. \\
These events are an important mechanism for reaching out to communities. \\
The concept of community organization/mobilization is not always welcome \\
by stakeholders in conflict-ridden areas, and they may attempt to thwart it. \\
\hline Ensure that water and sanitation projects respect the "Do no harm" \\
principle of humanitarian intervention (further addressed in Part I.1 $\square$ ). \\
Ensure a sustainable use of the available water sources and controlled \\
winimum \\
environmental management, especially human excreta. \\
damage
\end{tabular}

\section{Key actors}

- At the national level: national line ministries for water and sanitation, public health and social welfare, local NGOs, IDPs and surrounding communities, who will be able to give firsthand information regarding the topography of the intended geographical area.

- At the international level: agencies specializing in water, sanitation and hygiene, such as UNICEF, WHO, ICRC, IFRC, and international NGOs, including ACF, CARE, IRC and Oxfam.

- Cluster and working groups on WASH, health and camp coordination and camp management.

\section{The international legal framework}

International (and regional) human rights law guarantees everyone the right to an adequate supply of safe water for personal and domestic use. The right to water is guaranteed both through the right to an adequate standard of living, ${ }^{7}$ and through the right to the highest attainable standard of health. ${ }^{8}$

\footnotetext{
See, for example, at the international level, Art. 25(1) of UDHR; Art. 11 of CESCR; Art. 14(2)(h) of CEDAW and Art. 24(2)(c) of CRC. At the regional level, see also Art. 14 of ACRWC and Art. 15 of Protocol to the AfCHPR on the Rights of Women in Africa.

8 See the legal section of Part IV.13.
} 
IDPs, regardless of whether they reside in camps or in urban or rural areas, should have full and equal access to water. Special efforts should be made to ensure the full participation of women in planning the distribution of water and other basic supplies.

International humanitarian law prohibits parties to the conflict from attacking, destroying, removing or rendering useless indispensable objects for the survival of the civilian population, including water installations and supplies. Care must also be taken to protect the natural environment, including water sources, against widespread, long-term and severe damage that might compromise the health or survival of the population. ${ }^{9}$

\section{Key references}

- Emergency Field Handbook: A Guide for UNICEF Staff, UNICEF, 2005.

- Emergency Sanitation: Assessment and Programme Design, P.A. Harvey, S. Baghri, and R.A. Reed, WEDEC, Loughborough University, 2002.

- DAVIS, J. \& LAMBERT, R., Engineering in Emergencies: A Practical Guide for Relief Workers, $2^{\text {nd }}$ ed., 2002.

- The Gender Dimensions of Internal Displacement, Women's Commission for Refugee Women and Children/UNICEF, New York, 1998.

- Gender Handbook in Humanitarian Action: Women, Girls, Boys and Men: Different Needs, Equal Opportunities, IASC, 2006.

- Guidelines for Prevention and Response to Sexual and Gender-based Violence in Humanitarian Settings, IASC, 2005.

- Handbook for Emergencies, UNHCR, $3^{\text {rd }}$ ed., February 2007.

- "The Right to Water and Protecting Refugees," Shrestha D. and Cronin A., Waterlines, Vol. 24, No. 3, p. 12-14, 2006.

- Sphere Project Humanitarian Charter and Minimum Standards in Disaster Response, 2004.

\section{Useful websites}

Right to Water, WHO: www.who.int/water_sanitation_health/rightowater/en/

Gender and Water Alliance: www.genderandwater.org

Islamic Supercourse Lectures on Health Promotion, Child Health and Islam, Islamic Global Health Network: www.pitt.edu

9 See, for example, Art. 54 of AP I; Art. 14 of AP II and Guiding Principle 10(2)(b). See also, Art. 8(2)(b)(ii), (iv), (xxv) of ICC Statute. 


\section{Annex I}

\section{Checklist to mitigate protection risks within a wash programme}

\section{Key information}

Below is a list of questions to ask when designing a WASH intervention to reduce protection risks.

\section{General}

How many people are affected and where are they? Disaggregate data by gender, age and diversity. ${ }^{10}$

- Are there significant cultural attitudes or gender dynamics that can affect the way the assistance can be provided?

- What water and sanitation practices were the population accustomed to before the emergencies?

- What are the threats for people affected and for the potential relief response? Are there special threats for women and girls?

- Who are key people to contact?

Who are individuals or groups with specific needs within the community and why?

- Is there equal access to existing facilities for all?

\section{Water supply}

Are water collection points close enough to where people live? Are they safe?

What traditional beliefs and practices relate to the collection storage and use of water?

\section{Excreta disposal}

What are the current beliefs and practices, including gender-specific practices, concerning excreta disposal?

- How do women manage sanitation issues related to menstruation? Are there appropriate materials or facilities available?

10 "Diversity" can refer to individuals or groups of various social, ethnic and religious backgrounds as well as to individuals or groups with specific needs, such as persons with disabilities, or unaccompanied and separated children. These groups differ from community to community and need to be identified in an initial assessment of the population. See Part I.1. 


\section{Part IV.}

Key message

1. Health and protection in the context of internal displacement ............................264

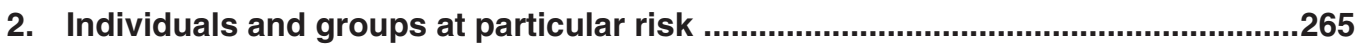

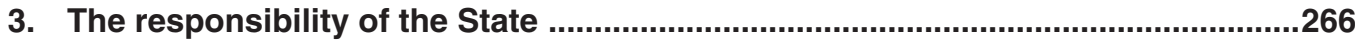

4. The role of humanitarian and human rights actors .................................................266

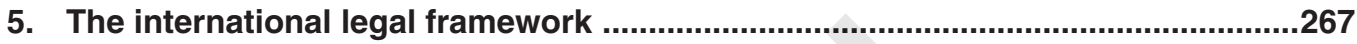

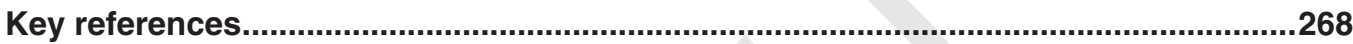

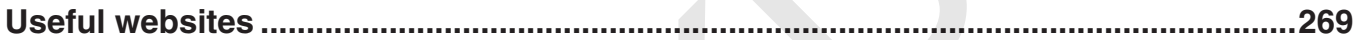




\section{Key message}

Everyone has the right to the highest attainable standard of physical and mental health. This includes not only the right to timely and appropriate health care but also to the underlying determinants of health, such as access to adequate food, water, a sustainable livelihood, shelter and sanitation. Responding to the health needs of a displaced population requires a multi-sectoral response that takes due account of the inter-linkages between health and protection.

\section{Health and protection in the context of internal displacement}

The conditions that characterize forced displacement can have a profound impact on the health and well-being of individuals and communities. Conflict, displacement and other violations of human rights, combined with lack of access to adequate shelter, sanitation, food and safe water, can seriously undermine people's ability to prevent and respond to health-related risks in their environment.

Health-related factors, such as disease, disability and malnutrition brought on by displacement, often claim more lives and cause greater suffering than the conflict itself.

Internally displaced persons (IDPs) face a variety of risks to their health and well-being both during displacement and upon return or resettlement.

\section{What is health?}

Health is generally defined as a state of complete physical, mental and social well-being and not merely the absence of disease or infirmity.

Constitution of the WHO

\section{Is there a link between health and human} rights?

A strong link binds health and human rights:

Violations or lack of attention to human rights can have serious health consequences;

Health policies and programmes and the ways in which they are implemented can promote - or violate - human rights;

Vulnerability and the impact of ill health can be reduced by taking steps to respect, protect and fulfil human rights.

25 Questions \& Answers on

Human Rights

WHO, 2002

- Physical health: Physical violence, combined with poverty and marginalization and lack of access to shelter, sanitation, food and water, can result in death, disease, disability, injury or trauma. Diseases that previously have been brought under control, such as measles, diarrhea, malaria and acute respiratory infections, can also become major epidemics as a result of displacement, particularly in crowded camp environments. Chronic conditions, such as diabetes, arthritis, high blood pressure, tuberculosis and HIV, can also reduce an IDP's quality of life and ability to sustain a livelihood.

- Mental health: Exposure to violence, separation from family members, and the loss of homes and livelihoods, can give rise to a number of psychosocial related problems, such as post-traumatic stress disorders, psychosomatic illness, depression and anxiety, which can destroy a person's quality of life and diminish resistance to disease. Such factors can also contribute to a change in behaviour, including increased substance abuse, aggression, and higher levels of sexual and domestic violence (further addressed in Part V.11

- Sexual and reproductive health: Reproductive health problems are a leading cause of death and illness among women and girls worldwide. Such problems are often compounded during displacement because of limited access to health care, erosion of traditional health practices, and exposure to violence, exploitation and abuse. This may 
lead to a rise in maternal and infant mortality, still births, and low birth weight. Sexual violence, in particular, which often increases during displacement, can have tragic consequences for women and girls. This includes health problems associated with forced and early pregnancies, unsafe abortions, obstructed labor, sterility, incontinence, vaginal fistulas ${ }^{1}$ and sexually transmitted infections (also addressed in Part IV.4 $\square$ ).

Health-related risks are often compounded by a lack of, or limited access to, health-care facilities, services and supplies, including medicine, during displacement. In many cases, IDPs cannot obtain timely and adequate health care.

- Availability: IDPs often live in poor urban areas, rural areas or crowded camps, where health care is absent, the infrastructure has been damaged, or health care workers have been wounded or displaced. Where basic health care is available, it may be incomplete (e.g. lack vaccinations, reproductive health care or psychosocial support.

- Accessibility: IDPs may not be able to access available health care for a number of reasons, including discrimination, high user fees, insecure environments, long distances, or lack of affordable transport. Older persons, persons who are mobility challenged, physically disabled and/or housebound, as well as women and girls, face additional obstacles in accessing health care. Their ability to travel may be limited, for instance because cultural norms prohibit them from travelling alone or from being treated by a male doctor. Survivors of sexual violence may also be reluctant to seek help because of fear of humiliation, stigmatization, or risk of further violence, arrest or detention (further addressed in Part IV.4 D). Conducting awareness campaigns to reduce stigma related to sensitive health issues can also help increase access to treatment.

- Affordability: IDPs may lack the resources necessary to pay for health care and medication. In some cases, this leaves them vulnerable to extortion or exploitation, including forced prostitution or survival sex in exchange for medical assistance.

- Acceptability: Cultural and religious norms and practices influence people's perception of health. Health care, thus, must be provided in a culturally acceptable way in order to be effective. In addition, health-related information must be provided in a manner and in a language that the displaced population can understand.

- Quality: Ensuring that minimum standards are maintained in health services ${ }^{2}$ during emergencies can be challenging because of a lack of qualified staff, a lack of knowledge or understanding of displacement-related health risks and the health profile of the displaced population, or a lack of respect for human rights, such as the right to privacy and confidentiality during all stages of treatment.

\section{Individuals and groups at particular risk}

Health-related risks impact people in different ways depending on a range of factors, including age and gender. As an example, young children and older persons are generally more vulnerable to disease than adults and may face additional difficulty in accessing health care. Pregnancy and childbirth, as well as exposure to harmful traditional practices or sexual violence, also pose unique challenges for women and girls. Persons living with a disability or serious/chronic illness, such as HIV or AIDS, may also need special attention and care.

Fistula occurs when the wall between the vagina and the bladder or bowel is ruptured. It can result in incontinence, severe infections and loss of control of bladder or bowel functions, which may lead to social stigma and isolation of those affected. Fistula often occurs as a result of rape or obstructed labor, in particular when associated with early pregnancy. Fistula can be repaired through surgery.

2 These are described in detail in Chapter 5 on Minimum Standards in Health Services in the Sphere Project, Sphere Handbook: Humanitarian Charter and Minimum Standards in Disaster Response, 2004. 
Such needs are often overlooked or remain unaddressed due to a lack of understanding or discrimination. It is important that differential risks and needs are assessed and taken into account when planning and implementing health-related projects.

\section{The responsibility of the State}

National authorities carry primary responsibility for ensuring the highest attainable standard of health for everyone within their jurisdiction, including IDPS. This obligation requires States to take progressive steps, to the maximum of their available resources, towards the full realization of the right to health by all appropriate means, including legislative, administrative, financial, educational and social. In particular, national authorities must aim to ensure that health-care facilities, services and supplies are available, accessible, culturally acceptable, and of good quality.

These obligations are outlined in greater detail in a General Comment on the right to the highest attainable standard of health, issued by the UN Committee on Social, Economic and Cultural Rights. ${ }^{3}$

\section{The role of humanitarian and human rights actors}

At the global level, coordination of the humanitarian response to health is primarily the responsibility of the Global Health Cluster, which is led by the World Health Organization (WHO). Given the close inter-linkages between health and human rights, it is important that protection staff and partners work with colleagues from the health sector to ensure that the right to health is respected and that a human rights perspective is integrated into all prevention and response programming.

\section{In our work, we can ...}

\begin{tabular}{|c|c|}
\hline $\begin{array}{l}\text { Assessment and } \\
\text { analysis } \\
(\text { See Part III.1 } \square)\end{array}$ & $\begin{array}{l}\text { Ensure that protection assessments and analyses take into account the } \\
\text { extent to which people are able to enjoy their right to health and the } \\
\text { underlying determinants of health, the health impact of human rights } \\
\text { violations, and any protection concerns that arise as a result of ill health. }\end{array}$ \\
\hline Coordination & $\begin{array}{l}\text { Establish a focal point for health and coordinate closely with other } \\
\text { sectors/clusters, such as protection, shelter, food, nutrition and water/ } \\
\text { sanitation/hygiene, in order to ensure that health-related protection } \\
\text { concerns are understood and addressed. }\end{array}$ \\
\hline $\begin{array}{l}\text { Advocacy } \\
(\text { See Part V.3 } \square)\end{array}$ & $\begin{array}{l}\text { Advocate with local and national authorities to ensure that health policies } \\
\text { and programmes respect, protect and aim to fulfil the right to the highest } \\
\text { attainable standard of health. This includes ensuring that everyone, } \\
\text { including IDPs, has access to appropriate health care and medication. In } \\
\text { particular, reproductive health care must be available to women and } \\
\text { girls, including survivors of sexual violence. }\end{array}$ \\
\hline $\begin{array}{l}\text { Community } \\
\text { mobilization } \\
(\text { See Part V.10 } \square)\end{array}$ & $\begin{array}{l}\text { Support cultural, social or religious activities and traditional practices that } \\
\text { play a role in safeguarding health. This might include traditional cleansing } \\
\text { and healing practices that help people overcome grief or trauma. } \\
\text { Involve displaced communities, both men and women, in assessments, } \\
\text { planning and implementation of projects. Community leaders, women's } \\
\text { groups and youth associations can also play an important role in } \\
\text { disseminating information and educating their peers about the } \\
\text { prevention and treatment of disease and other health risks. }\end{array}$ \\
\hline
\end{tabular}


Information

(See Part V.7 $\square$ )

Education

(See Part IV.15 $\square$ )

Training

- Work together with colleagues from relevant sectors/clusters to inform the IDPs, host communities, and local and national authorities, about the right to health and the link between health and human rights. Such activities could include information on the availability and location of health-care services, general practices of good health, including sexual and reproductive health, and ways to reduce various health risks, such as sexual violence. Information should be disseminated through all means available, such as radio, television, community meetings, school programmes, etc.

Advocate for health-related information to be included in school curricula and other educational or vocational training programmes. This may include information about the link between health and human rights, about hygiene, adequate nutrition, and sexual and reproductive health.

Support training in human rights and on the inter-linkages between rights and health, to health professionals and relevant authorities. This could include information about the right to health and about the rights to privacy and confidentiality.

Support training for traditional practitioners, including traditional healers, traditional birth attendants (TBAs) and practitioners of female genital mutilation, in both human rights and basic health care.

Material assistance (See Part V.5
Provide targeted assistance to individuals who cannot pay for necessary health care or medication as well as those that face particular risks. This might include young mothers, older persons, people with disabilities, survivors (or those at risk) of sexual violence, single-headed households, separated and unaccompanied children, and persons living with HIV/AIDS.

Provide financial or material assistance to relevant authorities to assist them in integrating a human rights perspective into their health policies and programmes. This might include the provision of office or medical equipment, ambulances, vehicles or fuel to access remote camps, or to enable emergency referrals for survivors of sexual violence.

\section{The international legal framework}

\begin{abstract}
International human rights law guarantees everyone the right to the highest attainable standard of physical and mental health. This includes not only the right to equal access to timely and appropriate health care but also a wide range of socio-economic factors and the underlying determinants of health, such as access to food, shelter, safe water and sanitation, safe working conditions and a healthy environment, and access to health-related education and information, including on sexual and reproductive health. ${ }^{4}$
\end{abstract}

\section{Guiding Principles (see Annex $1 \square$ ) Guiding Principle 19:}

"1. All wounded and sick internally displaced persons as well as those with disabilities shall receive ... the medical care and attention they require, without distinction on any grounds other than medical one ... [including] psychological and social services.

2. Special attention should be paid to the health needs of women, including access to female health care providers and services, such as reproductive health care, as well as appropriate counselling for victims of sexual and other abuses.

3. Special attention should also be given to the prevention of contagious and infectious diseases, including AIDS ..."

See, for example, Art. 25(1) of UDHR; Arts. 10(2), 11 and 12 of ICESCR; Arts. 23 (3), 24, 39 of CRC; Art. 5 (e)(iv) of ICERD; and Arts. 10(h), $11(1)(\mathrm{f})$ and 12, 14(2)(b) and 16(e) of CEDAW. For further discussion, see General Comment 14 (2000) of the Committee on Economic, Social and Cultural Rights on the right to the highest attainable standard of health, E/C/12/2000/4. 
International humanitarian law provides extensive protection to the sick and wounded as well as to health workers and other humanitarian personnel, hospitals, medical equipment, medical units and transportation. ${ }^{5}$ In particular, the sick and wounded must be collected, protected against ill treatment and receive, to the fullest extent practicable and with the least possible delay, the needed medical care and attention, without any distinction except on medical grounds.

The right to health is also closely related to, and dependent upon, the realization of other human rights, including the rights to non-discrimination and equality, to respect for one's privacy during consultations, examinations and care (including the confidentiality of medical information), and to freedom of movement. The right to freedom from torture or cruel, inhumane or degrading treatment or punishment also includes the right not to be subjected to harmful traditional practices, such as female genital mutilation, or forced medical treatment, such as sterilization or mandatory testing, or experimentation.

In this context, the term "health" includes not only physical but also mental and reproductive health. Reproductive health rights, for instance, require that women as well as men have access to sexual education and information about family-planning methods and services, and that they can decide freely on the number and spacing of their children. It also requires that women have access to appropriate health-care services for pre-natal care, delivery, and post-natal care, and measures to diminish maternal, child and infant morbidity and mortality.

Since women and girls have an equal right with men and boys to all aspects of health and well-being, their gender-specific needs, such as the need for reproductive health care, and risks, such as sexual violence and harmful traditional practices, should always be considered.

\section{Key references}

25 Questions and Answers on Health and Human Rights, WHO, 2002.

- Gender Handbook for Humanitarian Action: Women, Girls, Boys and Men: Different Needs, Equal Opportunities, Chapter XX (Health), IASC, 2006.

- Handbook for Emergencies, Chapter 14 (Health), UNHCR, $3^{\text {rd }}$ ed., 2007.

- Reproductive Health in Refugee Situations: An Inter-Agency Field Manual, UNHCR, 1999.

- The Right to the Highest Attainable Standard of Health, General Comment No. 14, UN Committee on Economic, Social and Cultural Rights,n E/C.12/2000/4, August 2000.

- Sphere Project Humanitarian Charter and Minimum Standards in Disaster Response, Chapter 5 (Minimum Standards in Health Services), Sphere Project, 2004.

- Guidelines for Prevention and Response to Sexual and Gender-based Violence in Humanitarian Settings, IASC, 2005.

- Clinical Management of Survivors of Rape: Developing Protocols for Use with Refugees and Internally Displaced Persons, WHO/UNHCR, rev. ed. 2004.

- Guidelines for HIVIAIDS Interventions in Emergency Settings, IASC, 2003.

This is a customary principle of IHL. See also Common Art. 3 of the Geneva Conventions; Arts. 16-23 of the Fourth Geneva Convention; Arts. 10-18 and 75(2)(a) of Additional Protocol I; and Arts. 4(2)(a), 5(1)(a), 5(2)(e) and (d), 7-12 of Additional Protocol II. 
Part IV .13 - Health

Useful websites

- Global Health Cluster: www.oneresponse.info

- World Health Organization (WHO): www.who.int

- United Nations High Commissioner for Refugees (UNHCR): www.unhcr.org

- United Nations Children Fund (UNICEF): www.unicef.org

- United Nations Population Fund (UNFPA): www.unfpa.org

- International Committee of the Red Cross (ICRC): www.icrc.org

- Physicians for Human Rights: www.physiciansforhumanrights.org

269 


\section{HIV prevention and treatment}

Key message

1. HIV and AIDS in the context of internal displacement

2. Individuals and groups at particular risk

3. A multi-sectoral response

4. The responsibility of the State

5. The role of humanitarian and human rights actors .274

6. Key actors 276

7. The international legal framework 276

Key references 277

Useful websites 278

Annex I 


\section{Key message}

HIV is a global epidemic that affects persons of all ages, gender and socio-economic status. The epidemic has serious personal, social and economic consequences for those living with HIV as well as for their families and communities. It is essential that appropriate HIV prevention, treatment, care and support is provided in all humanitarian emergencies, including in situations of internal displacement.

The IASC Guidelines for HIVIAIDS Interventions in Emergency Settings provide guidance on HIV prevention, treatment, care and support in emergency settings. They are available, in English and French, at www.aidsandemergencies.org. This chapter provides basic guidance on HIV in situations of internal displacement but does not replace or duplicate the Guidelines, which should be implemented in all emergencies.

\section{HIV and AIDS in the context of internal displacement}

Currently over 40 million people are living with HIV, many of them in countries ravaged by conflict and displacement. There is no causal link, however, between displacement and HIV. Existing data confirms that prevalence rates among internally displaced persons (IDPs) do not, in general, differ from those of the general population. HIV infection rates depend on a number of complex factors, such as existing prevalence rates within the country, overall population mobility, the level of risk-taking behaviour, access to accurate information, and access to prevention, treatment, care and support services. Factors such as gender inequality, poverty and marginalization also play a part.

The conditions that often characterize displacement, such as conflict, human rights violations and breakdown of families and communities, however, can increase the risk of a person's exposure to HIV. In particular, sexual violence and abuse can increase the risk of HIV infection.

\section{Some facts about HIV and AIDS}

The human immunodeficiency virus (HIV) is a retrovirus that infects cells of the human immune system, destroying or impairing their function. In the early stages of infection, a person has no symptoms. However, as the infection progresses, the immune system becomes weaker, and the person becomes more susceptible to opportunistic infections. The most advanced stage of HIV infection is acquired immunodeficiency syndrome (AIDS). It can take several years for an HIV-infected person to develop AIDS. Antiretroviral treatment can slow the progress of HIV infection and allow those infected to lead normal lives.

HIV is transmitted through body fluids such as blood, semen and vaginal fluids, for instance during unprotected sexual intercourse (vaginal, anal or oral), transfusion of contaminated blood, sharing of contaminated needles, and between a mother and her infant during pregnancy, childbirth and breastfeeding.

Persons living with HIV or AIDS and their

families, whether displaced or not, may face serious protection risks. They are often subject to discrimination, stigma and social exclusion as a result of their HIV positive condition and may be barred from accessing education, livelihood opportunities, and public services, such as health care. In some cases, they have seen their freedom of movement limited; been arbitrarily arrested and detained; been subjected to physical or psychological violence; and have suffered other similar violations of their rights. Their right to privacy and confidentiality, including as regards their HIV positive status, is also frequently compromised. 
Such risks may be further compounded by the situation of displacement with devastating consequences for the displaced individuals, families and communities. IDPs often face additional discrimination and have limited access to information and HIV prevention, treatment, care and support, in particular where they suffer multiple displacements. Separation of families and lack of adequate shelter, food, water and basic services, such as health care, may seriously undermine their ability to cope with the physical, social and economic impact of the epidemic. Such factors may also weaken their ability to benefit from existing HIV treatment programmes, which require a long-term effort and the ability to closely follow a certain medical scheme.

\section{Individuals and groups at particular risk}

While HIV affects people without regard to their age, gender, ethnic or religious origin, sexual orientation or other status, women and children bear the brunt of the epidemic in many ways. Discrimination, inability to negotiate safe sex, and exposure to sexual violence and abuse, including forced prostitution and survival sex, can increase the risk of HIV infection. In addition, women and girls often have limited access to HIV information, prevention, treatment, care and support. They are also more likely to suffer from stigma, social exclusion and violence as a result of an HIV positive status. The responsibility of caring for orphaned children or ill family members also falls primarily on the shoulders of women and girls, often limiting their access to education and livelihood opportunities. Their property and inheritance rights are also frequently violated, with dire economic consequences.

Children and adolescents, of both sexes, as well as older persons, and persons living with disability, are particularly vulnerable to the effects of HIV. Children and adolescents may become infected as a result of mother-to-child transmission or exposure to sexual violence or drug abuse, and may have to take responsibility for younger siblings and older relatives upon the death of their parents. Similarly, older persons often carry the burden of caring for sick relatives and children orphaned by AIDS as well as often being HIV positive themselves. In addition, people with HIV are at higher risk of deteriorating health due to the disruption of access to necessary care and support services, as well as absence of antiretroviral treatment, in situations of displacement.

\section{A multi-sectoral response}

An effective HIV response will require a multi-sectoral approach that addresses both the short-term and long-term physical, social and economic aspects of the epidemic. Comprehensive guidance on HIV prevention, treatment, care and support can be found in the Guidelines for HIVIAIDS Interventions in Emergency Settings, ${ }^{1}$ which should be implemented in all emergencies, including those involving internal displacement. For ease of reference, the table below gives examples of activities which may be appropriate and which are described in greater detail in the Guidelines. 
Examples of multi-sectoral HIV prevention, treatment, care, support, and mitigation activities

Care and support
Prevention

Treatment

- Develop HIV awareness-raising and sensitization programmes that encourage reduction in risk-taking behavior.

Ensure adequate prevention and response to sexual and gender-based violence.

- Ensure provision of post-exposure prophylaxis (PEP) to rape survivors. Implement universal precautions, such as safe blood transfusion and injection practices, in health-care settings to prevent HIV transmission.

Support the promotion and distribution of male/female condoms.

Offer voluntary, and confidential, HIV counselling and testing (VCT).

Ensure the early and effective treatment of sexually transmitted infections (STI), including ensuring links between such treatment, VCT services and tuberculosis programmes.

Prevent mother-to-child transmission (PMTCT).

Provide evidence-based sexual and reproductive health education in schools and through other means, in order to reach out-of-school adolescents.

- Ensure targeted prevention and care programmes for individuals or groups most at risk.

- Ensure the provision of antiretroviral treatment (ART).

- Ensure the provision of prophylactic and other treatment for opportunistic infections.

- Provide nutritional support for those in need.

Organize and support community-based home-care programmes.

Provide targeted support to caregivers of those living with HIV, particularly single-female or child-headed households.

Ensure family tracing and reunification for unaccompanied or separated children and adequate foster care arrangements for children orphaned by AIDS.

Mitigation

Ensure that those living with, at risk of, or otherwise affected by HIV are not discriminated against and are able to exercise their rights.

- Support information and education activities that aim to dispel misconceptions and counter prejudice, discrimination and social exclusion.

- Provide training on HIV, human rights and gender to all relevant stakeholders, including national and international actors in the health, social services, law enforcement and humanitarian sectors.

Ensure that the land, property and inheritance rights of women and children are respected.

Advocate against cultural practices that expose individuals, especially women, to the risk of HIV infection.

\section{The responsibility of the State}

Ensuring equal and effective access to HIV prevention, treatment, care and support is the responsibility of the national authorities. This responsibility flows from the duty of the State to protect, respect and fulfil its human rights obligations, particularly the right to the highest attainable standard of health. States should take all appropriate measures to ensure that such mechanisms are available, accessible, affordable and culturally acceptable to the population, including to IDPs. In addition, States must ensure that their laws, policies and practices on HIV respect human rights and that those living with HIV are not discriminated against, excluded or 
exposed to violence and abuse. These and other obligations are outlined in greater detail in the International Guidelines on HIVIAIDS and Human Rights, which provide valuable guidance to States, civil society and other stakeholders on effective national HIV policies and strategies.

\section{The role of humanitarian and human rights actors}

Given the significant protection implications of HIV, protection staff and partners have a crucial role to play in ensuring that protection concerns are integrated into the broader multi-sectoral response.

\section{In our work, we can ...}

\begin{tabular}{|c|c|}
\hline $\begin{array}{l}\text { Assessment and } \\
\text { analysis } \\
\text { (See Part III.1 } \square \text { ) }\end{array}$ & $\begin{array}{l}\text { Ensure that attention to HIV is integrated into protection assessments, } \\
\text { analyses and responses. This requires identifying the causes, contributing } \\
\text { factors and consequences of HIV; individuals and groups most at risk; } \\
\text { existing coping mechanisms and capacities; gaps in the existing } \\
\text { response; and priority areas for intervention. } \\
\text { Ensure that data is collected and analysed on the prevalence of HIV, } \\
\text { access to treatment, morbidity and mortality. }\end{array}$ \\
\hline $\begin{array}{l}\text { Advocacy } \\
(\text { See Part V.3 } \square)\end{array}$ & $\begin{array}{l}\text { Support the development and implementation of a comprehensive HIV } \\
\text { advocacy strategy that promotes respect for the rights of persons living } \\
\text { with HIV. This may include advocacy aimed at ensuring that national HIV } \\
\text { policies and programmes incorporate IDPs and that the IDPs have full } \\
\text { and equal access to public services and support, including shelter, food, } \\
\text { water and health care, and to humanitarian assistance. } \\
\text { Train and support relevant stakeholders, such as community leaders, } \\
\text { women's groups, youth associations, and networks of people living with } \\
\text { HIV, to raise awareness of HIV, combat stigma and discrimination, and } \\
\text { promote human rights, including gender equality and universal access to } \\
\text { prevention, treatment, care and support. }\end{array}$ \\
\hline
\end{tabular}

Information

(See Part V.7 D)
Support awareness raising and information activities that provide evidence-based, yet culturally sensitive, information about HIV, including information about prevention, treatment, care and support, for both women and men of all ages. and advice
Technical expertise (See Part V.9 [D)

Provide advice about the protection implications of HIV to relevant stakeholders, including national authorities, local NGOs, civil society and IDP community leaders. This can include advice to national authorities on ways to integrate human rights in national HIV policies and programmes.

Training
Support training on HIV and human rights for all relevant stakeholders, including government officials, armed forces, law enforcement officials, peacekeeping forces, IDP community members, and humanitarian workers. Training for humanitarian workers should also include codes of conduct, particularly regarding sexual violence, exploitation and abuse. 


\section{Health care}

(See Part IV.13
Advocate and take other action to ensure that health-related services, such as those indicated below, are available, accessible, affordable and provided in a culturally acceptable manner:

primary health-care services that address physical, mental, psychosocial and reproductive health;

access to treatment of sexually transmitted infections (STI) and opportunistic infections (OI);

provision of male/female condoms and continuing access to antiretroviral treatment (ART);

targeted health-care services for rape survivors, including the provision of Post-Exposure Prophylaxis (PEP);

voluntary counselling and testing programmes (which include older persons and persons with disabilities);

prevention, treatment and care services, including prevention of mother-to-child transmission for people living with HIV; and

community-run home-based care and support programmes. Privacy and confidentiality of medical information should be respected at all times.
Education

(See Part IV.15 D)

Ensure that children living with, at risk of, or otherwise affected by HIV, such as taking care of terminally ill adult family members, have full and equal access to education, vocational training and recreational activities. Pay particular attention to girls which may have more limited access to education than boys.

Ensure that education and peer-education activities raise awareness of, and provide information about, HIV prevention and response. Where possible, this should be incorporated into the school curriculum.

Livelihoods
(See Part IV.16

Targeted

humanitarian

assistance

(See Part V.5
Provide targeted material or financial assistance to individuals and families living with, or affected by, HIV, including in particular single-headed households and households headed by children or older persons.

Support community-based male/female condom promotion and distribution.

\section{Family} reunification

(See Part IV.7 [D)

Land and property (See Part IV.17

\section{Durable solutions} (See Part VI DD)
Ensure that separated and unaccompanied children are identified and registered, that determinations of the best interests of the child take place, and that they are reunited with their families, if appropriate. In some cases, adequate foster care arrangements might be required.

Help ensure that the land, property and inheritance rights of women and children are respected.

Advocate to ensure attention to HIV prevention, treatment, care and support in return, relocation, and/or (re)integration programmes run by the government, the United Nations and other partners. This may include advocacy aimed at ensuring that (former) IDPs living with HIV can continue their treatment and are not discriminated against, regardless of whether they choose to return, relocate or integrate in the area of displacement. This might require efforts to sensitize the host community or communities in areas of return to the rights and needs of persons living with HIV. 


\section{Key actors}

Effective HIV prevention and response requires coordinated efforts by a range of actors local, national, regional and international - with different mandates, expertise and operational capacity. At the field level, HIV response in displacement settings is coordinated jointly by UNHCR and UNAIDS, working closely with all relevant stakeholders. HIV is a cross-cutting issue in the "cluster approach," meaning it should be integrated and mainstreamed into the work of all clusters and sectors of the humanitarian response (further addressed in Part I.3 $\square$ ).

- At the national level, key actors include displaced individuals and communities; networks of persons living with HIV; ministries of health, education and social services; national AIDS commissions and/or programmes; health-care providers; the national human rights commission; local NGOs and civil society; religious organizations; and the media.

- At the regional level, an array of initiatives is being undertaken at the regional level such as the Great Lakes Initiative against AIDS and the Asia Pacific Network of People Living with HIV.

- At the international level, key actors include UNHCR, UNAIDS, WHO, UNFPA, OHCHR, UNICEF, WFP, FAO, World Bank, ILO, IOM, the Special Envoy of the Secretary-General for HIV/AIDS in Africa, international NGOs, networks of persons living with HIV/AIDS, and peacekeeping forces. ${ }^{2}$

\section{The international legal framework}

Ensuring that human rights are respected and protected is critical both for reducing exposure to HIV and to mitigating its adverse effects on individuals and communities. International human rights law contains a number of rights that are of direct relevance to those living with or otherwise affected by HIV. These include the rights to: ${ }^{3}$

$\begin{array}{lll}\text { life, liberty and security of } & \text { privacy; } & \text { freedom of opinion and } \\ \text { person; } & \text { work; } & \text { expression and to freely } \\ \text { non-discrimination, equal } & \text { freedom of peaceful } & \text { receive and impart } \\ \text { protection and equality } & \text { assembly and association; } & \text { information; } \\ \text { before the law; } & \text { marry and found a family; } & \text { social security, assistance } \\ \text { freedom of movement; } & \text { be free from torture and } & \text { and welfare; } \\ \text { the highest attainable } & \text { cruel, inhuman or degrading } & \text { share in scientific } \\ \text { standard of health; } & \text { treatment or punishment; } & \text { advancement and its } \\ \text { an adequate standard of } & \text { to seek and enjoy asylum; } & \text { benefits; and } \\ \text { living; } & & \text { participate in public and } \\ \text { equal access to education; } & & \text { cultural life. }\end{array}$

States have recognized the importance of gender equality, empowerment and participation of women and girls in all aspects of HIV prevention and response. ${ }^{4}$ In particular, gender-specific protection risks must be adequately addressed and special attention paid to the health needs of women and girls, including ensuring access to reproductive health care and services, and appropriate counselling and treatment in all cases of gender-based violence.

\footnotetext{
2 See UN Security Council Resolution S/1308/2000 (2000) on HIV/AIDS and Peacekeepers.

3 Based on the International Guidelines on HIV/AIDS and Human Rights (OHCHR/UNAIDS, 2006, p. 80-103) and General Comment No. 3 (2003) of the UN Committee on the Rights of the Child (CRC/GC/2003/3), para. 6. See also Principle 19(3) of the Guiding Principles on Internal Displacement. For further discussion, see UNHCR, Note on HIVIAIDS and the Protection of Refugees, IDPs, and Other Persons of Concern, 2006.

4 Declaration of Commitment on HIV/AIDS (General Assembly Resolution A/RES/S-26/2 of 2 Aug 2001), paras. 14, 37, 58-62. See also Principle 19(2) of the Guiding Principles on Internal Displacement.
} 


\section{Further reading}

- HIV/AIDS and the Rights of Children, General Comment No. 3, UN Committee on the Rights of the Child, CRC/GC/2003/3, 2003.

- Framework for the Protection, Care and Support of Orphans and Vulnerable Children Living in a World with HIV and AIDS, UNICEF, 2004,

- Enhanced Protection for Children Affected by AIDS, UNICEF, 2007.

- Educational responses to HIV and AIDS for Refugees and Internally Displaced Persons: Discussion Paper for Decision-makers, UNESCO/UNHCR, 2007.

- Gender and HIVIAIDS: Resource Pack, UNAIDS, 2006.

- HIV and Conflict: A Double Emergency, International Save the Children Alliance, 2002.

- HIVIAIDS and Children Affected by Armed Conflict (fact sheet), UNICEF, 2002.

- HIVIAIDS and Internally Displaced Persons in Eight Priority Countries, UNHCR/OCHA-IDD, 2005.

- HIV-Related Stigma, Discrimination and Human Rights Violations: Case Studies of Successful Programmes, UNAIDS, 2007.

- Note on HIVIAIDS and the Protection of Refugees, IDPS, and Other Persons of Concern, UNHCR, 2006.

\section{Useful websites}

- Joint United Nations Programme on HIV/AIDS (UNAIDS): www.unaids.org

- Global Coalition on Women and AIDS: www.womenandaids.unaids.org

- UNHCR: www.unhcr.org/hiv-aids

- UNICEF: www.unicef.org/aids

- UNFPA: www.unfpa.org/hiv/index.htm

- UNIFEM: www.genderandaids.org

- WHO: www.who.int/topics/hiv_infections/en/

- OHCHR: www.ohchr.org/english/issues/hiv/index.htm

- FAO: www.fao.org/hivaids

IOM: www.iom.int 
Relating to HIV prevention, response, care and support in the context of internal displacement

\section{Non-discrimination, equal protection and equality before the law}

Persons living with, or otherwise affected by, HIV/AIDS are entitled to full respect for their human rights without discrimination of any kind. Human rights law prohibits discrimination on a number of grounds, including on the basis of "other status," such as health status, including HIV/AIDS. Misconceptions that IDPs are associated with an increased prevalence of HIV might lead to discriminatory practices and should be dispelled.

\section{- Access to HIV and AIDS health care}

The right to the highest attainable standard of health includes non-discriminatory access to HIV and AIDS prevention, treatment, care and support, including psychosocial support. This includes access to voluntary (and confidential) HIV counselling and testing (VCT); antiretroviral therapy (ART); protection from mother-to-child transmission; and access to reproductive health care, including appropriate pre-natal, delivery and post-natal care.

\section{- Protection from arbitrary detention and unlawful restrictions on movement}

There is no public health justification for depriving liberty or restricting movement, including forced return or relocation, solely on the basis of actual or suspected HIV status. Such measures are not only ineffective, as HIV is not casually transmitted, but are also likely to be discriminatory and violate the rights to liberty and security, and freedom of movement.

\section{- Respect for confidentiality and privacy}

Personal data, including data on health status, is confidential and should not be shared without the prior informed consent of the individual concerned. Ensuring confidentiality is the responsibility of all those who have access to such information. Informed consent requires that individuals clearly understand what information will be shared, with whom, for what purposes, and what the potential consequences may be.

\section{Freedom from mandatory testing}

There is no public health justification for mandatory HIV screening. Mandatory testing violates the rights to privacy, personal integrity and security. It is also ineffective and does not prevent the occurrence or spread of HIV. Public health interests are best served by voluntary counselling and testing in an environment where confidentiality and privacy are respected.

\section{- HIVIAIDS-related needs of women, girls and boys}

Women and children are disproportionately affected by HIV and AIDS. Appropriate measures should be taken to address the particular protection problems they face, including the risk of rape, sexual violence and exploitation, social exclusion and discrimination, and violations of a number of other rights, including access to health care, property and education.

\section{- Access to HIVIAIDS information and education}

The right to the highest attainable standards of health and health care includes access not only to HIV treatment but also to HIV-related information and education, and to information about sexual and reproductive health. The rights to education and to seek, receive and impart information guarantee access to life-saving information. For children, such information must be relevant, appropriate, and timely and presented in a manner appropriate for their age. 


\section{- Access to durable solutions}

Access to, and the choice of, a durable solution to internal displacement should not be adversely affected by positive HIV status. Persons living with HIV and their families should be able to decide, freely and in safety, whether to return, integrate in the place of displacement, or settle elsewhere in the country. They should have full and equal access to HIV prevention, treatment, care and support regardless of their choice of a durable solution. 


\section{Part IV.15 \\ Education}

Key message

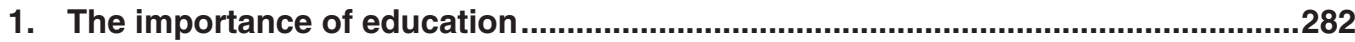

2. Obstacles to full and equal access to education in situations of internal displacement.

3. The role of humanitarian and human rights actors ...............................................283

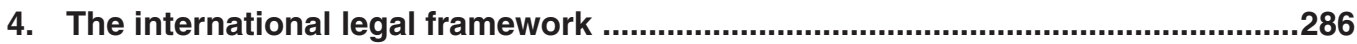

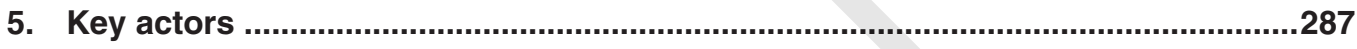

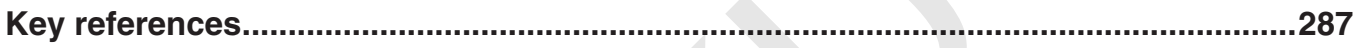

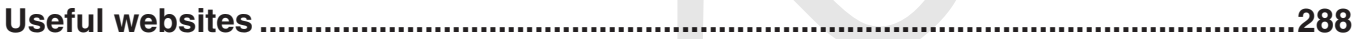

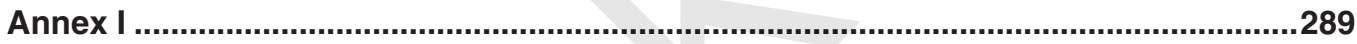




\section{Key message}

Education is both a basic human right and an essential protection tool. When provided in a safe learning environment, education can be both life-saving and life-sustaining. It can prevent exposure to serious protection risks, help individuals and communities to cope with the effects of displacement, and facilitate reconciliation and reintegration once displacement ends. It is crucial to ensure that all internally displaced persons (IDPs) children, adolescents and adults - have full and equal access to education during all stages of displacement.

The Minimum Standards on Education in Emergencies, Chronic Crisis and Early Reconstruction provide minimum standards, indicators and guidance notes on ensuring access to quality education in humanitarian settings. The Standards are available in English, French, Arabic, Spanish, Portuguese, Urdu, Japanese, Thai, Bahasa Indonesian, and Bengali at www.ineesite.org/page.asp?pid=1240.

(See also Annex I at the end of this chapter

\section{The importance of education}

Ensuring full and equal access to education in situations of internal displacement is both an aim in itself and an essential element for IDP protection. Education provides people with access to life-saving and life-sustaining skills and knowledge and, if provided in a safe learning environment, it can:

- help reduce exposure to serious protection risks, such as sexual violence and exploitation, forced recruitment, trafficking, or forced and hazardous labor;

- convey key messages about protection risks and concerns, such as landmines, sanitation and hygiene, and nutrition;

\section{Different forms of education}

Formal education usually results in the attainment of recognized certificates or diplomas. It includes primary, secondary and tertiary education, as well as formal vocational trainings.

Non-formal education is usually undertaken in less formal settings and does not necessarily lead to recognized certificates or diplomas. It includes various semi-structured recreational and learning activities in child-friendly spaces.

- provide a basis for sustainable livelihoods and successful social and economic (re)integration into society;

- mitigate the psycho-social impact of conflict and displacement by providing a degree of stability and normalcy, in particular for children and adolescents; and

- contribute to peace and reconciliation by promoting understanding and tolerance.

\section{Obstacles to full and equal access to education in situations of internal displacement}

Education, vocational training and other learning activities are often disrupted during conflict-induced and disaster-related displacement. The social networks and support systems that normally protect individuals, in particular children and adolescents, can erode. IDPs face numerous obstacles in accessing safe education, as indicated below. 
- Lack of adequate educational facilities: School buildings and/or grounds may be lacking or inadequate because, for instance, they have been damaged by a natural disaster or conflict or because they lack heating, electricity or sanitation facilities. They may also be occupied by displaced persons in need of shelter or be located in places that are inaccessible due, for instance, to a lack of safe transport. In addition, school facilities may be used for other purposes, such as to hold political rallies. Such situations deny children full access to their right to education and put them at risk of abuse and exploitation.

- Lack of resources: Loss of homes, land and livelihoods often results in poverty and marginalization and IDPs may lack the resources to pay for tuition, books, clothing, school supplies and/or meals. Children and adolescents, in particular girls, are often required to work or assist with domestic chores and, as a result, may not be able to attend school.

- Discrimination: Access to education can be limited as a result of discrimination on grounds, for instance, of gender, ethnic or linguistic background. Displacement can both compound such discrimination and give rise to additional discriminatory practices. As an example, displaced children are often unable to enrol in school in the place of displacement because they lack the necessary documentation or are unable to meet strict admissions and enrolment procedures.

- Lack of safety and security: IDPs, in particular children and adolescents, can be exposed to various protection risks en route to, or while attending, school or training as a result, for instance, of direct or indiscriminate military attacks, forced recruitment practices, or the presence of landmines.

- Lack of safe learning environments: Conflict and displacement can undermine the safety of the learning environment. Peer-to-peer violence, corporal punishment, sexual abuse or exploitation, lack of qualified staff, and inadequate monitoring and supervision within the education system, can discourage children and adolescents from attending school and contribute to high drop-out rates.

\section{The role of humanitarian and human rights actors}

Humanitarian and human rights actors play an important role in ensuring full and equal access to education. This includes advocating with national authorities who have the primary responsibility for ensuring education and, where appropriate, assisting them in ensuring that IDPs, in particular children and adolescents, have full and equal access to education, vocational training and other learning opportunities. In some cases, schools and/or vocational training programmes may also be run by humanitarian or other actors.

Internally displaced children and adolescents should have full and equal access to education, and every effort should be made to ensure their (re)integration into the national educational system. Where access to formal education has been temporarily disrupted, immediate action should be taken to provide semi-structured learning and psychosocial support in safe spaces for children and adolescents. Such activities can contribute to their physical, mental and emotional well-being and facilitate their transition back into the formal school system. The following table provides basic guidance on the steps that should be followed when addressing lack of education in emergency settings. 


\section{In our work, we can ...}

Immediate response

Initial assessment (See Part III.1 [D)

Advocacy

(See Part V.3
Work with the community to provide displaced children and adolescents with semi-structured educational activities in a safe space. Such activities should be age and gender-sensitive, and be designed, planned and implemented by, or together with, the displaced community, including displaced teachers, community leaders, parents, and older children and adolescents with basic teaching capabilities. This may include:

- basic numeracy and literacy classes;

recreational activities (sport, music, games or art) aimed at alleviating trauma and psychosocial distress;

- information about risks and ways to avoid these, including mine awareness, disease prevention, basic hygiene, etc.; and psychosocial support and referral mechanisms.

Work with national authorities, local (host) communities given their valuable knowledge on local resources, as well as the displaced community to assess if and to what extent displaced children and adolescents can be integrated into the formal educational system in the place of displacement. This may include assessing:

- the number, level and profile of displaced students and teachers; the capacity of the local school system and its ability to cater for IDPs; the obstacles experienced by IDPs (legal, economic, cultural, institutional);

any documentation and certification requirements;

the need for special or additional schooling or training for children, parents, or teachers to enable their full participation in the system, including the need for language classes, peace education, positive discipline, prevention of GBV, etc.; and

the possibilities for adult education, including training in literacy, skills development and vocational training.

Advocate with relevant authorities to ensure full and equal access to education for all, including IDPs. This may include ensuring that:

displaced persons, including children and adolescents, have full and equal access to the formal educational system, including local schools and other learning opportunities;

displaced teachers can be employed in local schools without discrimination;

strict enrolment and/or admissibility criteria are eased or applied with flexibility so as not to exclude the internally displaced (e.g. documentation requirements); and

adequate facilities and resources are provided to enable schools and other educational institutions to cater to IDPs including, for example, enlargening or improving existing school infrastructure or establishing new institutions or subsidiary classes. 
Reintegration into the formal education system

\section{Monitoring and evaluation}

(See Part V.2 and

Part III.4 [D)
Assist relevant authorities to build the capacity of the national education system in order to facilitate the integration of the IDPs at the earliest opportunity (within six to 12 months maximum). This may include:

providing support for the rehabilitation of existing institutions and/or the building of new schools and educational facilities;

providing or supporting the development of educational materials;

supporting measures aimed at ensuring safe learning environments;

providing training for teachers and instructions, including on subjects such as peace education, psychosocial support, and the prevention of gender-based violence;

providing targeted support to individuals that may face specific obstacles to accessing education or vocational training, including orphaned children, adolescent girls, and teenage mothers; and

linking education initiatives and projects for displaced persons, in particular children and adolescents, to national education programmes to ensure a smooth integration into normal school and other learning programmes.

Ensure that all education activities, both formal and non-formal, are monitored and evaluated on a regular basis through participatory methods involving students, parents, teachers and other educational staff. In particular, ensure that adequate monitoring, reporting and referral mechanisms are established in order to ensure adequate follow-up on incidents of sexual violence or exploitation, peer-to-peer violence, corporal punishment and other abuse, and increases in drop-out rates.

\section{Key considerations}

Several key considerations should guide our efforts to ensure full and equal access to education.

Equal access: Both the displaced and the host population should have full and equal access to education and, thus, all education activities should target the community as a whole, with particular attention on women's and girls' education. The creation of parallel or separate institutions or activities should be avoided where possible in order to avoid stigma and discrimination. Distribution of school kits, school materials, and/or financial support for educational purposes similarly should be made available to both groups.

- Community-based approaches: The participation of the displaced and the host community, including students, parents and teachers (of both sexes), is essential to create a sense of ownership and to ensure that activities are adapted to the local cultural and social context. The community should participate in the design, implementation and monitoring of education activities and form part of the decision-making process at all stages. The community can organize alternative childcare to enable girls to attend school, provide escorts to and from school, and help define codes of conduct for education staff. Students can also play an active role through peer-to-peer support, the dissemination of life-saving messages in a child-friendly manner, and mentoring. In order to ensure effective participation, parents and students should have access to information, be represented in school management or education committees, and be provided with training on human rights and other issues. 
- Keeping children safe: Schools and other learning spaces must be safe and secure in order to avoid exposing children and adolescents to violence, exploitation and other protection risks. This includes ensuring that:

- schools and their surroundings, including latrines, are safe, gender-sensitive and child-friendly;

- all education staff, both national and international, has decent working conditions, respects a code of conduct, and receives basic training on topics such as teaching methodology, human rights, prevention of sexual violence and exploitation, psychosocial support, and positive discipline, and the recruitment of female teachers and assistants should be promoted;

- the curriculum and teaching methodology are participatory and aim to promote peace, reconciliation and constructive dialogue, including life-skills education;

- students are informed of their rights (and responsibilities), are familiar with available monitoring and referral mechanisms, and the code of conduct governing the work of teachers and other educational staff; and

parents and any parent-teacher associations are involved in keeping their children safe, and monitoring the safety of learning spaces.

- A holistic approach - Education cannot be provided in isolation, and important linkages must be forged with other sectors, such as health, food, nutrition, and community services, in order to address the root causes of lack of access to education.

\section{The international legal framework}

International (and regional) human rights law guarantees the right to free and compulsory education for all at the elementary level. ${ }^{1}$ It encourages the development of accessible and affordable secondary education, including both general and vocational education as well as higher education. The law also prohibits any form of discrimination in this regard, including on the grounds of being internally displaced.

All States, therefore, must ensure that primary education is available to everyone and that secondary and higher education is progressively made available; that education is provided without discrimination and that it is physically and economically accessible to everyone; that education is of acceptable quality; and that it is adaptable, meaning that it is flexible and responds to the best interests of each child or adult. ${ }^{2}$

States must also take steps to ensure the full and equal participation of women and girls in all education and vocational training programmes. This includes taking all appropriate measures to eliminate discrimination against women and girls, including through various forms of affirmative action.

See, at the international level, Art. 26 of UDHR; Arts. 24(2)(e) and (f), 28 and 29 of CRC; Arts. 6,13 and 14 of ICESCR; Art. 18 of ICCPR; Art. 5(e)(v) of ICERD; Arts. 10, 11(1)(c) and 14(2)(d) of CEDAW; the Convention against Discrimination in Education; and Principle 23(3)(4) of the Guiding Principles on Internal Displacement; and, at the regional level, Art. 17 of AfCHPR and Arts. 4(d) and 12 of its Protocol on the Rights of Women in Africa; Arts. 11 and 20(2)(a) of AfCRWC; Art. 13 of the Additional Protocol to the AmCHR in the Area of Economic, Social and Cultural Rights; Art. 34 of ArCHR; and Art 2 of Protocol I to ECHR. See also the Education for All Framework and the Millennium Development Goals.

2 See, for example, General Comment No. 13 (1999) on the right to education, Committee on Economic, Social and Cultural Rights (E/C.12/1999/10). See also General Comment No. 11 on plans of action for primary education (E/C.12/1999/4) and General Comment No. 1 (2001) on the aims of education, Committee on the Rights of the Child (CRC/GC/2001/1). 
International humanitarian law requires that children be provided with special respect and protection and given the care and aid they require, including access to safe education. ${ }^{3}$ The law also prohibits direct and indiscriminate attacks or reprisals against civilian property, including schools, playgrounds and other educational facilities. ${ }^{4}$ Intentionally directing attacks against such objects can constitute a war crime in both international and non-international conflicts. $^{5}$

\section{Key actors}

At the global level, the coordination of the humanitarian response to education is primarily the responsibility of the Education Cluster, which is co-led by UNICEF and the Save the Children Alliance. A number of actors may need to be involved in order to ensure the success of education programmes, including:

- at the national level: displaced individuals and communities; ministries of education and social services; teachers' unions; students' unions: and local NGOs and civil society; and

- at the international level: UNHCR, UNICEF, UNESCO, WFP (school feeding programmes), UNFPA, UNDP, Save the Children Alliance, CARE, CCF, CRS, AED, NRC, IRC, Refugee Education Trust, and World Vision.

\section{Key references}

- Minimum Standards on Education in Emergencies, Chronic Crisis and Early Reconstruction, (available in 10 languages), Inter-agency Network for Education in Emergencies (INEE), 2004.

- Technical Kit for Emergency Education, Inter-agency Network for Education in Emergencies (INEE).

- Education in Emergencies: A Resource ToolKit, UNICEF, 2006.

- Guidebook for Planning Education in Emergencies and Reconstruction, IIEP-UNESCO, 2006.

- Safe Schools and Learning Environments: How to Prevent and Respond to Violence in Refugee Schools, UNHCR, 2007.

- "Child Friendly Schools" and "Care Support in Schools," UNICEF, UNGEL Forum, Vol. 6, Number 1, March 2006.

- The Right to Education in Situations of Internal Displacement, in Protecting Internally Displaced Persons: A Manual for Law and Policy Makers, Brookings-Bern Project on Internal Displacement, 2008.

- Guidelines on Mental Health and Psychosocial Support in Emergency Settings, IASC, 2007.

\footnotetext{
See Rule 135 of Customary International Humanitarian Law, Vol. I: Rules (ICRC, 2005). See also, Arts. 23-24, 38, 50, 76 and 89 of the Fourth Geneva Convention; Arts. 70(1), 77(1) and 78(2) of Additional Protocol I; and Art. 4(3) of Additional Protocol II.

4 See, for example, Rules 1-2, 7, 9, 11-13 of Customary International Humanitarian Law, Vol. I: Rules (ICRC, 2005). See also, Arts. 48, 51 and 52 of Additional Protocol I; Art. 13 of Additional Protocol II; and Principle 21(2)(b) of the Guiding Principles on Internal Displacement.

5 See, for example, Arts. 8(b)(ix) and 8(e)(iv) of the Statute of International Criminal Court.
} 
Handbook for the Protection of Internally Displaced Persons

Useful websites

- Inter-Agency Network for Education in Emergencies (INEE): www.ineesite.org

- Right to Education: www.right-to-education.org

- United Nations Children Fund (UNICEF): www.unicef.org

- United Nations High Commissioner for Refugees (UNHCR): www.unhcr.org

- United Nations Education, Scientific and Cultural Organisation (UNESCO):

www.unesco.org

288 


\section{Annex I}

\section{INEE minimum standards for education in emergencies, chronic crisis and early reconstruction}

The INEE Standards contain minimum standards, indicators and guidance notes on ensuring access to quality education in humanitarian settings. The Standards, which are summarized below, are divided into five categories: (1) standards common to all categories; (2) access and learning environment; (3) teaching and learning; (4) teachers and other education personnel and (5) education policy and coordination. The Standards are available at:

www.ineesite.org/page.asp?pid=1240.

\section{Minimum standards common to all categories \\ Community Participation}

Participation Emergency-affected community members actively participate in assessing, planning, implementing, monitoring and evaluating the education programme.

Resources

Local community resources are identified, mobilized and used to implement education programmes and other learning activities.

\section{Analysis}

Initial assessment

A timely education assessment of the emergency situation is conducted in a holistic and participatory manner.

Response strategy

A framework for an education response is developed, including a clear description of the problem and a documented strategy for action.

Monitoring

All relevant stakeholders regularly monitor the activities, the education response and the evolving needs of the affected populations.

Evaluation

There is a systematic and impartial evaluation of the education response in order to improve practice and enhance accountability.

\section{Access and learning environment}

Equal access

All individuals have access to quality and relevant education opportunities.

Protection and well-being Learning environments are secure, and promote the protection and mental and emotional well-being of learners.

Facilities

Education facilities are conducive to the physical well-being of learners. 


\section{Teaching and learning}

Curricula
provide formal and non-formal education appropriate to the
particular emergency situation.

\begin{tabular}{ll}
\hline Training & $\begin{array}{l}\text { Teachers and other education personnel receive periodic, relevant } \\
\text { and structured training according to needs and circumstances. }\end{array}$ \\
\hline Instruction & \begin{tabular}{l} 
Instruction is learner-centred, participatory and inclusive. \\
\hline Assessment
\end{tabular} \\
\hline $\begin{array}{l}\text { Appropriate methods are used to evaluate and validate learning } \\
\text { achievements. }\end{array}$
\end{tabular}

\section{Teachers and other education personnel}

Recruitment and selection A sufficient number of appropriately qualified teachers and other education personnel is recruited through a participatory and transparent process based on selection criteria that reflect diversity and equity.

Conditions of work

Teachers and other education personnel have clearly defined conditions of work, follow a code of conduct and are appropriately compensated.

Support and supervision

Supervision and support mechanisms are established for teachers and other education personnel, and are used regularly.

\section{Education policy and coordination}

Policy formulation and enactment

\section{Planning and}

implementation

Education authorities prioritize free access to schooling for all, and enact flexible policies to promote inclusion and education quality, given the emergency context.

Emergency education activities take into account national and international educational policies and standards and the learning needs of affected populations.

Coordination
There is a transparent coordination mechanism for emergency education activities, including effective information-sharing among stakeholders. 


\section{Part IV.16 \\ Livelihoods}

Key message

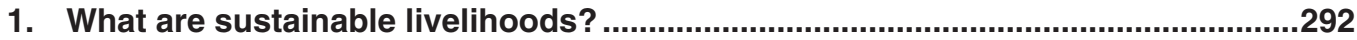

2. The disruption of livelihoods in the context of internal displacement ..................293

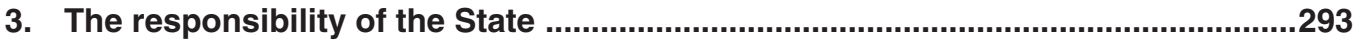

4. The role of humanitarian and human rights actors .................................................294

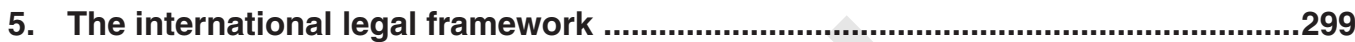

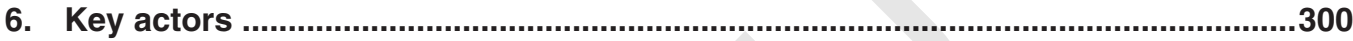

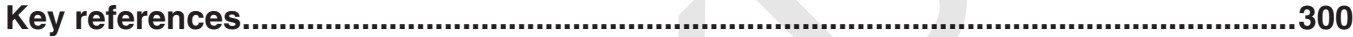

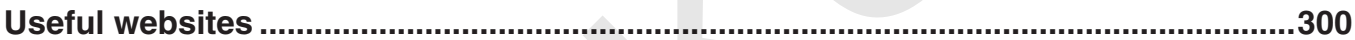




\section{Key message}

Livelihood refers to the capabilities, assets and strategies that people use to make a living, i.e. to secure food and income through a variety of economic activities.

Everyone has the right to a livelihood. For internally displaced persons (IDPs), the loss of livelihood might engender a number of protection risks, as it affects the psychosocial well-being of individuals by lowering self-esteem. Generating income during displacement not only improves the quality of life for individuals; it helps avoid protracted dependency and exposure to further discrimination and abuse.

Although livelihood programmes, as such, may not be sustainable, they should aim to sustain livelihoods in both the short term - to save lives - and the long term - to build resilience and address vulnerability.

\section{What are sustainable livelihoods?}

A sustainable livelihood is one that enables a person to: ${ }^{1}$

- cope with and recover from stress and shocks;

maintain or enhance his/her capabilities and assets;

- provide sustainable livelihood opportunities for the next generation; and

- contribute net benefits to the community in which s/he lives.

To achieve these objectives, livelihood programmes cover a range of issues including community mobilization, development of leadership skills, non-formal education, vocational training and skills-training programmes, income-generating activities, food or cash-for-work programmes, apprenticeship placement projects, micro-finance schemes, agriculture programmes, business start-up programmes, seeds and tools projects, animal husbandry projects and self-employment and job-placement programmes. ${ }^{2}$

There are also many challenges faced in supporting livelihoods, e.g. not enough markets, high unemployment, little investment, etc. The security aspects can also affect the sustainability of livelihoods in IDP and other affected communities, such as freedom of movement for economic purposes, arbitrary detention, the presence of mines in agricultural fields and roads and local markets (further addressed in Part IV.2 to $5 \square$ ).

In Somalia, IDP

women were trained on livelihood activities (e.g. milling, oil grinding, sewing, baking and petty trading), as well as basic literacy and numeracy. They were given small one-off grants to purchase raw materials. Women were, then, able to work closer to their homes and some could stop collecting firewood, which was a high-risk activity. For more information, see: protection.oneresponse.info.

Overseas Development Institute, Livelihoods, Chronic Conflict and Humanitarian Response: A Synthesis of Current Practice," Longley, C. and Maxwell, D., London, UK, 2003.

2 IASC, Women, Girls, Boys and Men, Different Needs - Equal opportunities, Gender Handbook in Humanitarian Action, December 2006. 


\section{The disruption of livelihoods in the context of internal displacement}

When IDPs can no longer rely on known ways of generating income, they have difficulty adjusting to new markets, learning new skills and fully integrating with surrounding communities. This situation triggers a larger number of protection risks, which may seriously affect many aspects of an individual's life and the life of the host community in a variety of ways, as exemplified below.

- The disruption of livelihoods might aggravate the trauma and stress already caused by conflict or disaster. Prolonged humanitarian assistance will make it more difficult to become self-reliant. The earlier livelihood interventions take place, the easier it will be for IDPs to regain their self-esteem and their ability to be self-reliant. Close cooperation between psychosocial services and livelihood-support organizations is important to ensure an innovative approach to each intervention (further explored in Part V.11 [DU).

- The lack of livelihood can also trigger family separation, with parents having to leave their children or older relatives behind to find work. Children might have to abandon their schooling to contribute to their families' income.

- Sexual abuse and gender-based violence is often a grim consequence of the lack of sustainable livelihoods, affecting particularly displaced women, girls and boys who might be forced to provide sex in exchange for food and basic supplies.

- In some displaced societies, men may find themselves unable to play their traditional role of "breadwinner," as gender roles might have been re-defined during displacement. This can lead to a loss of self-esteem, abuse of alcohol or drugs and increased domestic violence.

- Surrounding communities might perceive the presence of IDPs as a threat to their already scarce resources, leading to discrimination and exclusion, particularly in regard to the labor market.

- Interventions that focus only on identifying sustainable livelihoods for IDPs may create tension with the host population and negatively affect the ability of IDPs to find durable solutions. Livelihood interventions for the host communities, when they face similar constraints, can contribute to peaceful coexistence and ensure that the livelihood strategies intended for IDPs are sustainable.

- Authorities might view livelihood interventions as a way of consolidating a specific durable solution and hampering others. For instance, a government trying to facilitate the return of displaced persons might be concerned that livelihood support in areas of displacement might promote local integration and discourage return. A dialogue with the government can help reach the understanding that the promotion of self-reliance should be seen as the precursor to any of the three durable solutions (return, local integration or resettlement) (further addressed in Part VI $\mathrm{D}$ ).

\section{The responsibility of the State}

The government and public service providers have primary responsibility for ensuring that the environment is conducive to achieving self-reliance. IDPs, however, often face considerably more obstacles than other civilians in achieving sustainable livelihoods because of the loss of their own assets and strategies, disputes over lost land and property, and the breakdown of their previous socio-economic support networks. This requires the State to take specific 
actions to support IDPs in developing sustainable livelihoods during and immediately after their displacement. These include:

- ensuring non-discriminatory access to public services, such as health, education, social welfare and housing loans to secure a stable and dignified environment so that IDPs can become self-reliant;

- developing an appropriate legal and administrative framework to enable IDPs to have access to the labor market while taking into account their specific needs, including recognition of academic and professional credentials, non-discriminatory job-recruitment policies and psycho-social support;

- respecting and promoting the freedom of movement of IDPs for economic purposes;

- integrating the development of IDP livelihoods into national development programmes and poverty-reduction strategies; and

- securing all areas related to livelihoods and strengthening the rule of law to protect the assets and activities of IDPs in their attempts to become self-reliant.

\section{The role of humanitarian and human rights actors}

When there is a crisis, the international community tends to mobilize its efforts and resources to respond to the most urgent needs (food, water, shelter, health) of displaced and other affected populations. Livelihood interventions are broadly regarded as pertaining to the post-emergency phase. However, after the first year of displacement, when the international attention has been moved to a new crisis, many IDPs still find themselves dependent on a rapidly decreasing amount of assistance and with few opportunities for sustainable livelihoods.

Early involvement by reintegration and development actors and joint programming between them and protection agencies is vital for maximizing the protection impact of humanitarian interventions. The Protection Cluster Working Group needs to work closely with the Early Recovery and the Agriculture Clusters as well as with other relevant clusters/sectors, to develop a joint approach to development, humanitarian assistance and generic protection interventions. Livelihood interventions, thus, should be part of a multifaceted strategy to further the realization of the legal, social, cultural and economic rights of the displaced and other affected populations.

\section{In our work, we can ...}

Assessment (See Part III. 1
The steps indicated below should be taken through a joint assessment exercise:

Identify pre-displacement household livelihood strategies and economic and traditional roles, particularly with regard to the control of resources and assets, mobility, access to markets and access to and administration of resources. A thorough understanding of how income was generated prior to displacement will help ensure that livelihood interventions promote gender equality and the maximum use of existing resources within the community.

Identify, through participatory assessments, the skills and capacities as well as the economic coping strategies during displacement, focusing on various age and gender groups. Ensure that the results inform the design of livelihood projects and build on existing coping strategies specific to each group. What may be appropriate for demobilized combatants, for example, might not be appropriate for female heads-of-households or older persons. 
Be sensitive to skills and activities that might be unproductive or even seen as undesirable from different perspectives (i.e. undignified, discriminatory, unsustainable, overloading of local market, lack of markets for products produced).

Assess the livelihood situation of all groups in the local community. The results of this assessment should be used to identify areas of intervention among the most affected populations. Commission an analysis of the local market to identify local production, workforce and services in the public and private sectors.

Identify instances of discrimination in accessing vital natural resources, such as water, firewood or land, and try to understand the reasons (whether economic, political, or other) and its impact on displaced persons' access to livelihoods.

Consult with IDPs to identify the barriers they face in accessing national programmes that give access to greater livelihood opportunities, such as micro-finance institutions, housing loans, etc.

Coordination and partnerships

\section{Protection monitoring and reporting} (See Part V.2 [D)
- Promote the practical exchange of knowledge and experiences among human rights/protection staff involved in livelihood programmes to ensure protection aspects are integrated into programming and into the delivery of livelihood interventions.

Liaise with agencies promoting self-reliance, livelihood and development to ensure that livelihood-support programmes are launched from the outset of displacement along with food aid and other emergency interventions.

Within the Early Recovery Clusters or sectors, ensure cooperation between humanitarian organizations and national and local public institutions to develop a common livelihood strategy and to ensure inclusion of livelihood programmes for IDPs in national poverty-reduction strategies.

Advocate for livelihood projects that promote peaceful coexistence, reconciliation and conflict prevention, such as by setting up vocational training centres benefiting both IDPs and surrounding communities.

Promote close cooperation of psycho-social and health institutions with employment and income-generation projects to strengthen the link between trauma recovery and self-reliance.

Where feasible, mediate for the incorporation of IDP leadership and associations into existing local structures, such as municipalities or unions, to support economic and social integration.

Ensure that IDPs' reintegration and DDR programmatic interventions are well placed and linked with wider recovery efforts, including those designed to support employment, income generation and reintegration in accordance with the UN Policy on Employment, Income Generation and Reintegration.

Monitor instances of discrimination against IDPs in accessing public support schemes, such as credit schemes and agricultural programmes. Ensure that discriminatory policies and procedures are reported and addressed by the relevant actors, including national authorities, local unions, and development and humanitarian actors.

Identify instances of child labour, and ensure adequate livelihood support to families with the aim of eradicating such practices. Refer cases of children performing work that may be hazardous or harmful to their development and growth to specialized organizations so they can be immediately removed from dangerous environments. Try to find viable alternative income-generating opportunities. 
Monitor any possible increase in local commercial sex work (women and girls selling sex for their survival), and identify any possible links with the increase of IDPs and their lack of alternative and dignified livelihoods. Identify exploitative and trafficking networks, and ensure that national mechanisms for protecting victims of trafficking and exploitation are activated. Try to find viable alternative income-generating opportunities. (See Part IV.8. DD)

Closely monitor criteria and procedures for accessing livelihood support programmes and micro-finance schemes, particularly to identify instances of economic and sexual exploitation, including by humanitarian workers involved in implementing these programmes.

Monitor the viability of IDP settlements to ensure that they allow for the achievement of sustainable livelihoods. Different issues must be addressed such as the right location and the access in and out of settlements to go to fields, to markets, etc.

Monitor whether or not procedures for recognizing educational or professional qualifications of IDPs and other affected populations who lost their documentation are in place and, if so, whether they are simple, transparent and effective.

Community participation and mobilization (See Part V.10 DD)
- Identify existing community-level traditional support mechanisms, formal and informal leadership structures, self-help groups, management committees, community-run care facilities and social clubs that can be supported by the international community to maximize their capacity. This is particularly important in situations of urban displacement or rural dispersion, where it is difficult to identify and reach IDPs directly.

Support existing local and traditional livelihood strategies in host communities, and promote the participation of IDPs in their structures, such as in traditional group-based micro-finance, small holders associations, producers' associations and market committees.

Ensure differentiated livelihood support strategies to address the specific needs of IDPs and members of the host community, depending on the particular protection risks they face. Make sure that IDPs participate in the design and development of these strategies, and be aware of the needs of particular groups, such as those indicated below. Persons with disabilities, including those with pre-existing disabilities and those with disabilities resulting from trauma and/or conflict-related injuries, may require specific support to identify suitable employment opportunities.

Single heads-of-households may require additional support to access self-reliance activities through community-based daycare centres where they can leave their children while they go to work.

Youth (above 18 years old) formerly associated with armed forces or armed groups require dedicated support for their reintegration into civilian life. Generating youth employment is vital for providing an alternative to warfare as a means for survival. ${ }^{3}$ Disarmament, demobilization and reintegration (DDR) programmes should be promoted.

Older persons headed households may need assistance in securing livelihoods, including equal access to income-generating activities and micro-finance activities, and may require help in carrying out those activities which demand physical strength.

Demobilized soldiers, within the framework of DDR programmes, need dedicated support to be reintegrated into civilian life. Their specific needs must be understood and addressed to avoid stigmatization and exclusion.

This can be done, for instance, by including youth in reconstruction and rebuilding projects, such as restoration of vital transportation routes or health and education facilities. 
Ethnic minorities are often exposed to increased levels of discrimination, including by displaced communities. Supporting the development of a certain skill or area of work can lead to improved social status in the society.

Groups or individuals who prefer to remain in hiding close to their areas of origin will require tailored income-generation support that can be undertaken from their hidden locations while ensuring that their products can reach local markets.

Assist in the organizational development of IDP community groups and associations that include members of the host community. This will enable IDPs to assume an active role in their new community and provide valuable services to others. IDPs' efforts to reconstruct their livelihoods greatly depend on the reconstruction of such community-support networks.

Skills development and (re) training
Legal aid, counselling and human rights advocacy (See Part V.3 and $V .8$
- Support livelihood programmes that help develop skills that match local market needs. Target, however, the less saturated areas of the local market which may help prevent possible tensions between the displaced and host communities.

As much as possible, work to overcome traditional gender patterns for division of labor, thereby ensuring that women and men have access to non-traditional professions, such as women working in construction, as carpenters, plumbers or accountants.

Focus skill development and re-training programmes on activities that do not require using the host areas' limited natural resources as a way of facilitating reconciliation.

Support the implementation of quick orientation programmes for groups or individuals with specific needs, such as persons who are illiterate, prior to skills-training programmes to ensure that they will be able to participate subsequently in the skills-training programmes.

Support and encourage the design and implementation of two-phase skills and vocational training activities that allow participants to "graduate" from the training and have access to a start-up grant or loan to facilitate links between the skills acquired and self-reliance.

Promote re-certification and re-credentialing programmes in situations where IDPs already have the necessary skills to match local market needs but do not have professional or academic certification due to lack or loss of documentation.

\section{Provide legal aid and legal counselling to IDPs and national actors} to overcome and eradicate instances of discrimination concerning livelihoods. Often, this includes:

providing technical advice for the establishment of an adequate legal and administrative framework for local institutions;

supporting and advocating for the development of concrete measures allowing IDPs' access to opportunities and services on a comparable basis to those in the surrounding communities;

- facilitating women's access to documentation, education, health services, social assistance programmes, and employment and property rights;

providing training materials and programmes to staff of relevant ministries, local health and education providers and local social assistance offices to promote better understanding and knowledge of these rights; and

promoting the inclusion of a "fair and non-discriminatory treatment clause" in the Code of Conduct of national civil servants as well as high standards of conduct in job descriptions. 
Support IDPs in accessing natural and productive resources and assets to re-build their livelihoods. Oversee restitution and compensation mechanisms in cases of land disputes (See Part IV.18 $\square$ ).

In situations where livestock stealing has been widespread, support the establishment of a system for the restitution of the livestock that will contribute to the local reconciliation process.

Promote mechanisms to ease administrative procedures for IDPs to access employment in the public and private sectors. Ensure an appropriate balance between emphasizing the specific needs and the equal rights of IDPs to avoid undue categorization or marginalization.

- Advocate for State support for the recognition of academic and professional titles and certification, particularly of individuals who lost their documents during flight and violence. Promote technical guidance for recognition procedures, if required (See Part IV.1 $\square$ ).

- Advocate for the clear regulation and respect of labor rights. Advocate for the development of national institutions that can support "decent work conditions," such as cooperatives, unions, administrative tribunals, labor courts, and social insurance bodies. Unions and cooperatives are particularly strong public actors that seek to uphold the socio-economic rights of their workers/employees. As such, they can often become highly effective advocates for IDPs and other affected communities.

- Promote "life skills" support programmes in conflict-resolution, negotiation, peaceful coexistence.

Promote rapid and well-conceived income-generation support immediately following displacement to help restore human dignity and help people avoid illegal or unsustainable strategies.

Material, technical or financial assistance (See Part V.9
Work with relevant clusters and sectors for multi-dimensional projects covering all required services, including housing, health and employment, because livelihood needs are interlinked.

- Ensure that material and financial assistance for livelihood opportunities also involve and target individuals or groups with specific needs in host communities to avoid creating tension between IDPs and surrounding communities.

Mainstream as many livelihood projects as possible into State services through specific coordination and hand-over structures.

Advocate with relief and development agencies for the implementation of projects aimed at strengthening the absorption capacity of host communities by investing in and/or upgrading infrastructure, community services and the local economy.

Support the development of sustainable assistance and community-support projects to assist IDPs and other affected communities to care for older persons, persons with disabilities or other members of the community with specific needs in order to fill the gaps left by the disruption of family-based economies and care structures that existed prior to displacement.

Support national and international efforts to create employment and development opportunities for all in places of return or new settlement, regardless of gender, ethnicity, etc.

Agree with all stakeholders, including IDPs, on clear, transparent and protection-oriented criteria for phasing out assistance and livelihood programmes that will be handed over to long-term development programmes. Material and financial aid for livelihood programmes should continue until IDP livelihoods are self-sustaining or until support through national institutions is available and sustainable. 


\section{Evaluation and monitoring} (See Part III.4 $\square$ )
Develop and agree with relevant partners on benchmarks for self-reliance in a given displacement situation. IDPs and other affected communities should be closely consulted in order to arrive at criteria that are relevant, realistic, specific and measurable within a given period. Use these criteria to measure progress of humanitarian and early recovery interventions.

Take part in debriefings following programme evaluations and use monitoring reports to follow up on identified protection concerns that threaten the effectiveness and success of livelihood interventions, such as security threats, discrimination in accessing resources, gender inequality or lack of resources from, or training by, the public administration.

\section{The international legal framework}

The right of IDPs to access sustainable livelihoods is primarily rooted in the principle of non-discrimination, the right to an adequate standard of living, and the right to work. Access to education and adequate health care are also closely linked to the ability to develop a sustainable livelihood. In turn, achieving sustainable livelihoods is considered a prerequisite for the exercise of other fundamental rights.

The right to an adequate standard of living ${ }^{4}$ encompasses several more specific rights, including those to food, water, clothing, and housing.

The right to work $^{5}$ refers to the right of everyone to the opportunity to earn a living in a safe work environment, and also provides for the freedom to organize and bargain collectively. This right also prohibits the use of compulsory or forced labor.

The Guiding Principles on Internal Displacement $t^{6}$ establish that IDPs shall not be discriminated against as a result of being displaced, and refer to the right to freely seek opportunities for employment and participate in economic activities.

The right to an adequate standard of living and the right to work do not mean that the State is obliged to provide houses or jobs to everyone. Rather, it is a basic obligation of States to take steps, individually and through international assistance and cooperation, especially economic and technical to achieve the full realization of these rights. ${ }^{7}$

In the context of humanitarian relief operations, however, this means that the State is required to provide goods and services, such as shelter, food and water, to persons who, due to the circumstances, are unable to satisfy their basic needs. If a State is unable or unwilling to guarantee a minimum level of each right, international human rights law requires that the State seeks international assistance.

International humanitarian law includes the prohibition of attacking, destroying, removing or rendering useless objects indispensable to the survival of the civilian population. This prohibition is a norm of customary law and applies in both international and non-international armed conflicts. ${ }^{8}$ These objects include crops, livestock, drinking water installations and supplies and irrigation works. The list is not exhaustive and includes other productive assets together with medicine, clothing and shelter.

International humanitarian law also prohibits the use of starvation as a method of warfare, a customary rule that applies in international and non-international armed conflicts. Starvation

\footnotetext{
4 Art. 11 of ICESCR; See also General Comments Nos. 7, 12 and 15, Committee for Economic, Social and Cultural Rights.

Art. 23 of UDHR; Art. 5 (e) (i) of ICERD; Arts. 6 and 7 of ICESCR.

6 Guiding Principles 22 and 29.1.

Art. 2 of ICESCR.

8 Rule 54, Customary International Humanitarian Law, Vol. 1: Rules.
} 
used as a weapon of war constitutes a war crime under the Statute of the International Criminal Court. ${ }^{9}$ Under international humanitarian law, this rule does not prohibit the use of siege to achieve a military objective. However, when conducting such military operations the parties to the conflict are to respect another customary rule of international humanitarian law: they "must allow and facilitate rapid and unimpeded passage of humanitarian relief for civilians in need, which is impartial in character and conducted without adverse distinction, subject to their right of control."

\section{Key actors}

A credible livelihood programme will require that IDPs and other affected populations are at the centre of the initiatives taken and will involve close cooperation with the IASC Country Team, the government, and development actors, such as the World Bank, UNDP, ILO, FAO and bilateral agencies. There should be coordination mechanisms within the ministry in charge of internal displacement, and among other ministries, particularly those responsible for planning, finance, labor and economic development, agriculture, health, housing, education and public order. Protection and assistance programmes for IDPs should be incorporated into national development plans and poverty-alleviation initiatives.

Discussions with donors should involve suggestions regarding how they can best contribute to self-reliance and sustainable livelihoods. Members of the international community can use their influence and "good offices" with national authorities to advocate for sustainable livelihoods for IDPs.

Partnerships with the private sector can also support the small and medium enterprises of IDPs both in camps and in areas of solutions. Initiatives in this case would include, for example, sub-contracting small/micro business ventures, organized seasonal/short-term wage employment, etc.

\section{Key references}

- Gender Handbook for Humanitarian Action: Women, Girls, Boys and Men: Different Needs, Equal Opportunities, IASC, 2006.

- Handbook for Repatriation and Reintegration Activities, UNHCR, Geneva, 2004.

- Handbook for Self-Reliance, UNHCR, Geneva, 2006.

- UN Operational Guide to the Integrated Disarmament, Demobilization and Reintegration Standards.

- Building livelihoods. A field Manual for Practitioners in Humanitarian Settings, Women's Refugee Commission, New York, 2009.

\section{Useful websites}

Livelihoods Connect, Support for Sustainable Livelihoods: www.livelihoods.org

- UNDP, Crisis Prevention and Recovery: www.undp.org/cpr/we_do/early_recovery.shtml

- United Nations Disarmament, Demobilization and Reintegration Resource Centre: www.unddr.org 


\section{Part IV.17 \\ Land and property}

Key message

1. Loss of property in situations of internal displacement ...........................................302

2. The international legal framework and the responsibility of the State ...................305

3. The role of humanitarian and human rights actors .............................................307

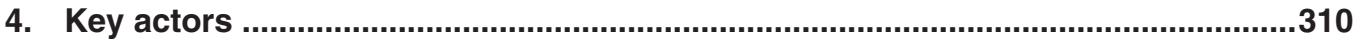

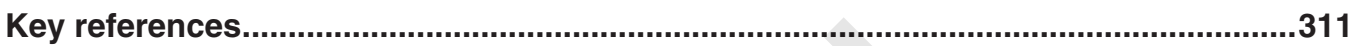

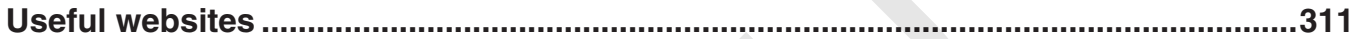




\section{Key message}

Forced displacement often leads to the loss of land, homes and other property of individuals and communities who, as a result, are deprived of their main source of physical and economic security. Disputes over land and other property are frequently among the root causes of conflict and displacement and can pose obstacles to return, reintegration and reconciliation. Efforts to address deprivation of land and property must form part of the protection response during all stages of displacement and later recovery.

The UN Principles on Housing and Property Restitution for Refugees and Displaced Persons ("the Pinheiro Principles"), together with the inter-agency Handbook on Implementing the Pinheiro Principles, provide essential practical guidance to all those who work on housing and property restitution issues.

\section{Loss of property in situations of internal displacement}

Forced displacement can be a cause as well as a consequence of deprivation of land, homes and other property. People often must leave behind land and other property when they flee and seek safety from the effects of armed conflict, human rights abuses and other events. In many cases, such property is subsequently damaged or destroyed by fighting or appropriated by parties to a conflict or by other persons, who themselves may be displaced.

Deprivation of property can also form part of a deliberate political or military strategy, a weapon of war aimed at terrorizing, punishing and displacing particular communities and altering the ethnic or religious composition of a country, in whole or in part. Disputes over land and property are also frequently among the root causes of conflict and displacement and, as a result, are often highly complex and difficult to resolve.

Property can also be lost during forced return or relocation while in displacement. Such events can take place as part of, or under the guise of, land reform, agricultural restructuring or urban planning.

Loss of land and property can have serious consequences for the lives, health and well-being of individuals and communities and expose them to various risks. Without access to land, homes and property, people are often deprived of their main source of physical and socio-economic security, including shelter, water, and food as well as the ability to earn a livelihood.

Lack of a home or a fixed residence can also restrict people's access to assistance and services, including education and health care, and limit their access to credit. As a result, 
internally displaced persons (IDPs) may suffer increased poverty, marginalization and risk of harassment, exploitation and abuse.

Women and children often suffer disproportionately from loss of land, homes and property. Discriminatory laws and practices frequently prevent women and girls from owning, leasing, renting and/or inheriting property. In case of divorce or the death of husbands, fathers or other male relatives, women and girls may be forced to leave their homes, coerced into marriage, or subjected to other harmful practices. Very few women own land titles and are at an increased risk of tenure insecurity if the husband or family members is killed in war. During displacement, which often results in the separation of families and a surge in the number of women-headed households, such discrimination might make it impossible for displaced women or girls to reclaim or repossess their homes. Lack of shelter and limited access to land and sustainable livelihoods can also heighten their specific risks of rape, forced prostitution or trafficking.

Many of the factors that lead to the deprivation of property are likely also to pose obstacles to sustainable return and reintegration. The table below lists many of the factors that need to be assessed and considered when developing and implementing strategies to prevent and/or respond to the deprivation of property.

Table 1: Factors that impact efforts to prevent and respond to deprivation of property

\begin{tabular}{|l|l|}
\hline Type & Factors \\
\hline $\begin{array}{l}\text { Political/ } \\
\text { economic factors }\end{array}$ & $\begin{array}{l}\text { Ongoing conflict and tension over land and other resources, including } \\
\text { tension that has not been satisfactorily addressed in peace negotiations. } \\
\text { Resistance to fair restitution to displaced individuals and communities } \\
\text { may persist. }\end{array}$ \\
\hline
\end{tabular}

Privatization or re-allocation of socially or publicly-owned land or housing immediately prior to, during or after the cessation of conflict, without regard to existing ownership, tenancy or occupancy rights. Such practices sometimes referred to as "land grabbing" - may be used to secure political support, consolidate ethnic cleansing, or gain financial profit by, for instance, allocating land to large business corporations. They may also be part of structural adjustment and other development aid programmes.

Formalization of customary ownership rights and land titling programmes. In informal ownership settings, restitution and compensation are often considered difficult to carry out in the absence of formal property titles. Land titling reforms can be put in place in countries affected by internal displacement as part of a development scheme or in order to address land disputes. Titling programmes often discriminate against women, minority groups and indigenous peoples who are less informed and, consequently, do not know how to use the existing legal mechanisms to defend their rights. As an example, informal titles and the rights of women and girls are often ignored during privatization and establishment of formal titles because their male relatives will fail to include their wives' names on the property titles. Criteria and procedures set up to formalize customary land rights should be carefully examined to ensure that they do not exclude IDPs (e.g. a requirement of continuous occupation for a certain number of years, which IDPs would be unable to fulfil).

Sharp increase or decrease in value of land, housing and property, making fair restitution and/or compensation difficult to achieve or subject to abuse. For instance, compensation based on pre-conflict prices might not be sufficient to acquire land or housing elsewhere at newly prevailing market values. 
Physical factors

Legal factors

Lack of safety and security in areas of origin due to ongoing violence and/or the presence of landmines or unexploded ordnance on land and roads/paths.

Secondary occupation of land and homes by, for instance, other IDPs or combatants or members of rival ethnic, national or religious groups.

Damage and/or destruction of land, housing and property, often combined with lack of available material, tools and expertise for repair and reconstruction. Disputes over boundaries of land might arise upon return, particularly when landmarks have been destroyed or removed. Checkpoints by military or irregular forces may restrict the free movement of building materials.

Discriminatory laws, rules and regulations that target certain ethnic or religious groups and restrict their ability to reclaim lost property.

Gender or age discrimination rooted in discriminatory laws or cultural beliefs and practices that prevent women from owning, inheriting, controlling or making use of property, including upon divorce or upon the death of their husbands, fathers or other male relatives.

Inappropriate use of laws and regulations related to properties left behind by IDPs, resulting in seizure of vacated property after certain, often short, periods of time. Such laws have been abused to punish people for fleeing or to prevent people of certain ethnic, religious or other groups from returning and reclaiming property, thus consolidating practices of deliberate displacement or ethnic cleansing. Where such "abandonment," regardless of its duration, is the result of armed conflict, violence, discrimination or other violations of rights, it should not be held against the owner or result in a loss of rights.

Forced or fraudulent housing sales, rental contracts or exchanges made under duress prior to or during flight, often without real compensation.

Existence of complex and parallel systems of ownership/tenure based on different sources, such as law, custom, tradition, or religion. These can take different forms, ranging from legal title or tenancy/occupancy rights in socially-owned properties, to permanent or temporary user rights in extended family-, collectively- or traditionally-owned properties. In situations of legal pluralism, IDPs will tend to use customary mechanisms rather than judicial ones because the former are usually closer, quicker, cheaper and more immediately enforced than the latter. This may create problems for certain groups such as women, who may be less protected under traditional mechanisms and may not have ready access to formal mechanisms.

Institutional /

administrative factors
Lack of documentation or records and/or destruction of cadastral or other title records. In some cases, people may never have possessed documents attesting to title or tenancy rights. In other situations, these documents may have been destroyed, lost or confiscated in the course of displacement.

Lack of clarity regarding, or conflicting, jurisdiction for land and property dispute resolution mechanisms, including tension between national, provincial and local government institutions, as well as customary mechanisms.

Lack of resources to pursue property claims, including lack of financial, legal and social support for individuals - particularly women and children — to pursue their legal claims. 
Lack of expertise, capacity and/or capability within central and local State institutions, including courts, tribunals or other dispute resolution mechanisms, making it difficult to resolve competing claims over property in a fair and efficient manner and/or establish specialized mechanisms to do so. Implementation of restitution programmes or land reform can also be hindered by the weakness of central institutions or their absence at the local level. Corruption may also impair equitable administration or fair dispute resolutions.

Lack of enforcement mechanisms, including absence, inability or unwillingness of police and law enforcement authorities to respect and enforce decisions regarding the restitution of property.

Cultural factors

Discrimination and/or harmful traditional norms and practices including with conflict resolution mechanisms that may infringe on the rights of women, such as prohibitions for women to inherit property, requirements of celibacy or of marriage to relatives of a deceased husband, and/or imposition of traditional but sometimes harmful "cleansing" rituals for the purported community benefit.

\section{The international legal framework and the responsibility of the State}

International (and regional) human rights law guarantees several rights of particular importance for those who have been, or are at risk of being, deprived of their land and property.

The right to peaceful enjoyment of property includes the right to own, acquire (through purchase, gift or inheritance), manage and enjoy property, without discrimination of any kind. Women should have equal rights with men in all matters relating to property. ${ }^{1}$ National authorities should refrain from arbitrarily depriving people of their property, protect such property from illegal interference by third parties, and ensure restitution and/or compensation of lost property to the rightful owners following a period of unlawful dispossession. The right to restitution and/or compensation is not conditional on the physical return of the owner to the area where the property is located but remains valid even when a person chooses not to return and opts, instead, to resettle and integrate elsewhere. This right to restitution can prove particularly difficult to enforce in situations of long-term displacement and where land rights are held informally and are normally dependent on continued use of the land.

Deprivation of property is not necessarily arbitrary or unlawful in all cases. The authorities may have a legitimate interest in regulating or seizing private or communal property. In order to be lawful, however, any such action must meet certain conditions. It must have a basis in law and serve a legitimate aim, such as protecting the public interest, and be proportionate to achieving this aim. It must also respect certain substantive and procedural safeguards. For example, evictions must be preceded with a timely warning and evictees must be given the opportunity to challenge the eviction order. Even when evictions are deemed lawful, those affected should be provided with fair compensation. ${ }^{2}$

The right to restitution and/or compensation for lost property (outlined in the table below) is further reinforced by the right to an effective remedy for wrongful acts and violations of

See, for example, Art. 17 of UDHR; Art 16(2)(h), and 15(2) of CEDAW; Arts. 13-19 of ILO Convention No. 169; Art. 14 of AfCHPR and Art. 6(j), 7(d) and 21 of its Protocol on the Rights of Women in Africa; Art XXIII of AmDHR: Art. 21 of AmCHR; Art. 25 of ArCHR and Art 1 of Protocol 1 to the ECHR. The right is further affirmed in various resolutions of the General Assembly, Security Council and the Human Rights Council (formerly Commission), as well as its Sub-Commission; and in the case law of the regional human rights courts. See also Principles 3-7 of Pinheiro Principles and Principle 21 of the Guiding Principles on Internal Displacement.

See also Principle 17.1 of Pinheiro Principles. 
human rights. ${ }^{3}$ Other important rights in this context include the right to return, ${ }^{4}$ which includes not only the right to return to the area of origin but more specifically to return to one's home or place of habitual residence, the right to freedom of movement and to choose one's residence, the right to respect for the home, and the right to an adequate standard of living, including housing and food. ${ }^{5}$

\section{"Restitution" or "Compensation"?}

Restitution, which refers to the return of lost property to its rightful owner, is generally the preferred remedy as it both redresses the wrong done and facilitates return and reintegration in the area of origin. The right to restitution is not restricted to those holding legal title or claim to property but also extends to other forms of ownership or title, such as tenancy, occupancy or user rights in collective or communal property.

The legitimate rights of third parties that may be affected by the restitution of land and property need to be taken into account, in particular those who acquired land or property in good faith and are obliged to leave it once it is restored to the original owners.

Compensation, in cash or in kind, can be given in lieu of restitution in cases where restitution is either impossible or impracticable, such as for reasons of security or public interest and or when IDPs "consciously and voluntarily choose or express a clear preference for compensation-based durable solutions, on the understanding that this may conclude the restitution process for them and result in them being unable to submit future housing and property restitution claims." ${ }^{\prime 6}$ The wish of IDPs to opt for compensation instead of restitution should be taken into consideration, particularly in situations where displacement has lasted for a long period of time and no improvement of security conditions are foreseeable. Caution should be exercised, however, to ensure that compensation is not politically manipulated and used as way to prevent return of displaced population. It can be difficult to calculate the value of lost property, in particular if the value has changed during displacement, but efforts nevertheless must be made to ensure that any compensation is adequate and fair.

Lessons learned: Experience indicates that compensation is less successful than restitution. In many cases, IDPs either remain displaced or are displaced a second time because of difficulties to integrate and secure a sustainable livelihood in areas of relocation. In addition, land and other property may have a symbolic, cultural or religious value which compensation can rarely address. Compensation can also be associated with restitution, to rebuild a destroyed property for instance.

Restitution and/or compensation usually take place through existing judicial, administrative or traditional mechanisms. Where such mechanisms are non-existent, malfunctioning or over-burdened, special land and/or property claims commissions can be established. Efforts to address land and property disputes should always be accompanied by mediation and reconciliation efforts, which can help to reduce the risk of renewed conflict and displacement.

See Art. 8 of UDHR; Art. 2(3) of ICCPR; Art. 6 of CERD; Art. 30 of CRC; Art. 75(1) of the ICC Statute; and, at the regional level, Arts. 10 and 25 of AmCHR; Art. 7 of AfCHPR and Art. 25 of its Protocol on the Rights of Women in Africa, and Art. 13 of ECHR. See also Arts. 35 and 26 of the Articles on State Responsibility, as well as resolutions of the Council, formerly Commission on Human Rights, including 2005/35. See also Principle 2 of Pinheiro Principles.

See Art. 13(2) of UDHR; Art. 12(4) of ICCPR; Art. 16(3) of ILO Convention No. 169; and, at the regional level, Art. 12(2) AfCHPR; Art. 22(5) of AMCHR; and Art. 3(2) of Protocol IV to the ECHR. See also Principle 10 of the Pinheiro Principles and Principle 28 of the Guiding Principles on Internal Displacement. The right also has been affirmed in resolutions of the UN Security Council, General Assembly and Human Rights Council (formerly Commission) and its Sub-Commission; as well as in the case law of the regional human rights courts.

See Pinheiro Principles. See also Principles 21 and 29 of Guiding Principles on Internal Displacement.

Handbook on Housing and Property Restitution for Refugees and Displaced Persons. Implementing the Pinheiro Principles, Inter-Agency, March 2007. See Key References Section. 
Standards: Regardless of the form that they take, restitution and/or compensation mechanisms as well as land reform schemes should meet certain minimum standards, as outlined below.

Remain independent, impartial and transparent; respect standards of due process, and use all appropriate forms of remedies, including both restitution and fair and equitable compensation. Such mechanisms should not be prejudiced by, or promote the return or non-return of, IDPs.

Be accessible to all of those who have been deprived of their property, regardless of their current place of residence or socio-economic status; be free of charge; and enable submission of claims in all relevant languages. Displaced individuals and communities must be informed of such mechanisms through sufficient and appropriate outreach and public information.

Decisions should be respected by political, judicial and administrative authorities and be enforced by law enforcement authorities, while taking into account the rights of secondary occupants and evictees by providing, where appropriate, alternative land or housing.

Their mandate should cover all residential sectors and address different types of land, housing and property rights, and these rights should extend not only to those with legal title to property but also to tenants, usage rights holders, dwellers and customary rights holders.

International humanitarian law requires all parties to a conflict, whether they are State or non-State actors, to distinguish at all times between civilian objectives and military objectives. International humanitarian law prohibits:

- direct and indiscriminate attacks and other acts of violence against civilian objectives;

- using civilian property to shield military operations or objectives;

- pillage and/or destruction of private and public property; as well as

- targeting private property as the object of reprisals or collective punishment.

Military objectives are generally defined as being limited to those objectives which by their nature, location, purpose or use make an effective contribution to military action and whose partial or total destruction, capture or neutralization, in the circumstances ruling at the time, offers a definite military advantage.

\section{The role of humanitarian and human rights actors}

Safeguarding land, housing and property rights should form part of the protection strategy during all stages of displacement and later recovery. These rights are integral to any attempt to restore justice and the rule of law in post-conflict settings and to ensure a safe, sustainable and dignified return. With the realization of these rights, IDPs are more likely to be able to earn their livelihood, to be less dependent on humanitarian assistance, and to be less exposed to further violations.

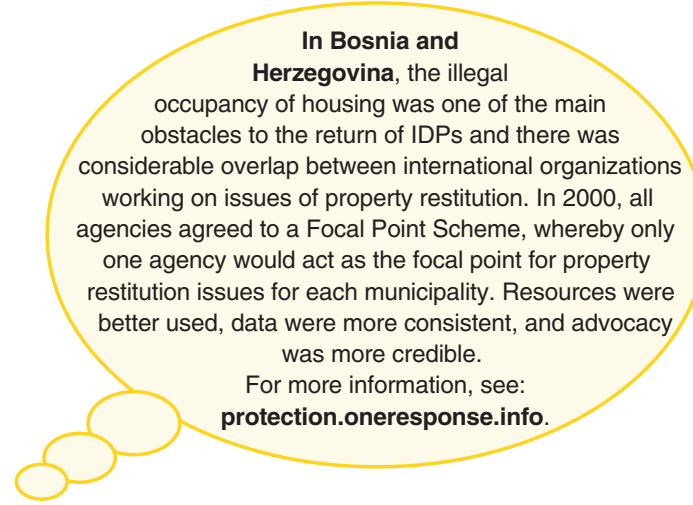

See Rules 7-23 of Customary International Humanitarian Law, Volume I: Rules (ICRC, 2005). See also, Arts. 33 and 53 of the Fourth Geneva Convention; Arts. 51 and 52 of Additional Protocol I; Art. 4(2)(g) of Additional Protocol II; Art. 28 of the Hague Regulations. See also Art. 2(b)(xvi) of the ICC Statute. 
Safeguarding property-related rights in situations of internal displacement requires multi-sectoral efforts that aim to:

- prevent arbitrary deprivation of property;

- preserve property which has been abandoned or lost during displacement; and

- provide an effective remedy for the arbitrary deprivation of property, in the form of restitution and/or compensation.

\section{In our work, we can ...}

Assessment and analysis (See Part III.1 $\square$ )

Prevention
- Ensure that protection assessments and analyses adequately address land and property issues, and support specialized land and property assessments where they take place. This could include analyses of (i) the different legal, cultural or traditional systems of ownership, tenancy and use of land and property; (ii) distribution of land among different population groups; (iii) any disputes or root causes of conflict related to land or property; (iv) existing laws, practices and mechanisms for restitution and/or compensation; (v) the obstacles IDPs face or are likely to face when trying to preserve or reclaim property.

Encourage relevant authorities and other actors to respect property rights and refrain from evicting or displacing individuals and communities from their land or property. All actors should monitor and intervene to ensure that relevant procedural safeguards are complied with when displacement is unavoidable and lawful, and that individuals have access to appropriate remedies.

- Encourage relevant actors to take measures to protect property rights once displacement has occurred. Such measures could include a temporary freeze on the purchase or transfer of land and property in areas affected by, or at high risk of, displacement and/or the organization of public information and outreach campaigns to discourage the secondary occupation or damage of abandoned land and property.

- Collect information as soon as possible, for instance during registration, regarding land, housing and other property that IDPs may have lost or been forced to abandon. Where security conditions allow, specific property assessments or property registration exercises could be conducted.

\section{Contingency-} planning

Encourage the authorities to take measures to ensure that displacement does not result in the loss or destruction of land and property registries, cadastral records and/or personal documents that can provide proof of ownership or tenancy or user rights. This may include ensuring that registries and records are kept in a safe location and that back-ups/copies are regularly taken and safely stored elsewhere.

Legislation
- Undertake a comprehensive review of national laws, policies and practices, including traditional and cultural practices, regarding land and property. Advocate with relevant authorities to ensure that the rights to land and property are adequately protected in national legislation, without discrimination of any kind, including on grounds of gender. The authorities should be encouraged to incorporate relevant international standards and principles, including the Pinheiro Principles. 


\section{Capacity building}

(See Part V.9
Training

Build the capacity of land/property registry offices and/or existing judicial, administrative, traditional and other mechanisms to resolve land and property disputes in a fair, effective and timely manner and with respect for international law and standards. This can include the provision of training, technical and operational expertise, and modest financial or material assistance, including office and other equipment. Such efforts should draw on lessons learned in other contexts.

-Where existing mechanisms are malfunctioning or over-burdened, consider supporting the establishment of specialized tribunals or commissions that can address property-related claims. Such mechanisms must respect basic substantive and procedural safeguards, and be fair and non-discriminatory.

\begin{tabular}{|c|c|}
\hline Training & $\begin{array}{l}\text { Support, facilitate or undertake training programmes in human rights, } \\
\text { including housing, land and property rights, for IDPs, national and local } \\
\text { authorities, the national human rights commission, NGOs, and civil } \\
\text { society organizations. }\end{array}$ \\
\hline $\begin{array}{l}\text { Information and } \\
\text { communication } \\
\text { activities } \\
(\text { See Part V.7 } \square)\end{array}$ & $\begin{array}{l}\text { Support information activities that provide IDPS and affected } \\
\text { communities with information about property rights and any available } \\
\text { mechanisms for reclaiming or seeking compensation for lost property. } \\
\text { Inform displaced individuals and communities about the importance of } \\
\text { safeguarding documents and any other material that provide evidence of } \\
\text { their title to land and other property. }\end{array}$ \\
\hline $\begin{array}{l}\text { Legal advice and } \\
\text { assistance } \\
(\text { See Part V.8 } \square)\end{array}$ & $\begin{array}{l}\text { Support legal aid clinics and networks of lawyers and paralegals to } \\
\text { provide legal advice and assistance to IDPs and returnees. In addition to } \\
\text { advice, such centres and networks can assist individuals in completing } \\
\text { administrative requirements, filing documentation, appearing before } \\
\text { tribunals or commissions, and negotiating a settlement and reconciliation } \\
\text { amongst opposing sides. }\end{array}$ \\
\hline $\begin{array}{l}\text { Physical safety } \\
(\text { See Part IV.2 } \square)\end{array}$ & $\begin{array}{l}\text { Advocate with relevant national, regional and local authorities and other } \\
\text { actors, including peacekeeping missions where present, to guarantee } \\
\text { the security and safety of persons that have, or wish to, return and/or } \\
\text { reclaim their land or property. } \\
\text { Liaise with relevant national and international actors to ensure that any } \\
\text { mine-affected areas are identified, assessed, and cleared at the earliest } \\
\text { opportunity. This should include land, homes, public spaces, such as } \\
\text { schools and market sites, roads, and paths (e.g. those used by women } \\
\text { and children to collect water or firewood). Women and young girls and } \\
\text { boys are often at a special risk of sexual violence, and their safety } \\
\text { concerns with voluntary return must be addressed. }\end{array}$ \\
\hline $\begin{array}{l}\text { Monitoring } \\
\text { (see Part V.2 } \square)\end{array}$ & $\begin{array}{l}\text { Monitor any potential negative impact of land titling, distribution or } \\
\text { restitution programmes to prevent further violations of rights, particularly } \\
\text { where such systems aim to establish legal title over land, housing or } \\
\text { property that was previously publicly, collectively or communally } \\
\text { owned/used. Pay particular attention to the ability of women, children } \\
\text { and indigenous peoples to claim and document title. }\end{array}$ \\
\hline
\end{tabular}




\begin{tabular}{|c|c|}
\hline $\begin{array}{l}\text { Shelter I } \\
\text { livelihoods } \\
\text { (See Parts IV.10 } \\
\text { and } 16 \square \text { ) }\end{array}$ & $\begin{array}{l}\text { Advocate for the allocation of land to displaced individuals and } \\
\text { communities during displacement to facilitate self-reliance and } \\
\text { sustainable livelihoods. This can include the allocation of } \\
\text { government-owned land or the purchasing of or loan of privately-owned } \\
\text { land. Special efforts must be made to reach an agreement with } \\
\text { landowners having IDPs on their land to reduce tensions and avoid } \\
\text { secondary displacement. } \\
\text { Advocate for and support programmes that provide transitional, } \\
\text { temporary or permanent housing to meet immediate needs for shelter. } \\
\text { Such programmes can involve repairs of damaged housing, construction } \\
\text { of new housing, or the identification of public property that can serve as } \\
\text { temporary shelter. The use of temporary shelter should not in any way } \\
\text { undermine a person's right to restitution or compensation for lost } \\
\text { property. Shelter and reconstruction programmes should include } \\
\text { provisions that ensure an adequate level of tenure security for } \\
\text { beneficiaries (secure renting arrangements) who do not own the repaired } \\
\text { premises. }\end{array}$ \\
\hline $\begin{array}{l}\text { Community } \\
\text { mobilization and } \\
\text { reconciliation } \\
(\text { See Part V.10 } \square)\end{array}$ & $\begin{array}{l}\text { Encourage and support national consultations, including all relevant } \\
\text { stakeholders, aimed at identifying challenges or obstacles to accessing } \\
\text { remedies and finding fair and practical solutions to land, housing and } \\
\text { property-related claims. } \\
\text { Work with and support local authorities, civil society and other } \\
\text { community groups to address issues relating to land and property, } \\
\text { including through active dialogue, mediation, community mapping and } \\
\text { reconciliation efforts. Support community efforts to allow "space" for } \\
\text { shelter and livelihood activities for the landless. }\end{array}$ \\
\hline $\begin{array}{l}\text { Durable solutions } \\
\text { (See Part VI } \square)\end{array}$ & $\begin{array}{l}\text { Advocate for the inclusion of provisions on housing, land and property } \\
\text { rights, and restitution and/or compensation, as a component of peace } \\
\text { agreements, development and/or voluntary return agreements, policies } \\
\text { and programmes. } \\
\text { Encourage authorities to allocate land to displaced individuals and } \\
\text { communities who cannot, or choose not to, return to their areas of origin. } \\
\text { Allocation should be permanent and the new owners/users provided with } \\
\text { documentation confirming ownership or tenancy/user rights, to provide } \\
\text { security and to avoid evictions and renewed displacement. Single } \\
\text { heads-of-households and older persons should be allocated land on an } \\
\text { equal basis with others. } \\
\text { Ensure that land reform programmes or land allocation schemes are } \\
\text { implemented in a way that does not deprive IDPs from their pre-war } \\
\text { housing, land and property. This may require adapting eligibility criteria } \\
\text { and procedures to the specificity of displaced populations (i.e. adapting } \\
\text { residency and documentation requirements). }\end{array}$ \\
\hline
\end{tabular}

\section{Key actors}

- At the national level: displaced individuals and their communities; ministries of housing, interior, justice and social affairs, courts and tribunals, administrative or specialized property tribunals or commissions, traditional, customary or religious councils, national human rights commissions, social/housing service agencies, legal or paralegal networks, and civil society. 
- At the international level: FAO, IOM, OHCHR, UNDP, UN-HABITAT, UNHCR, the World Bank, regional developmental banks, and various NGOs, such as the Norwegian Refugee Council. The United Nations Human Rights Council also has a Special Rapporteur on the right to adequate housing, ${ }^{8}$ a Special Rapporteur on the situation of human rights and fundamental freedoms of indigenous people, and a Special Rapporteur on the right to food who can also play a role.

\section{Key references}

- Principles on Housing and Property Restitution for Refugees and Displaced Persons (Pinheiro Principles), UN Sub-Commission on the Promotion and Protection of Human Rights, E/CN.4/Sub.2/2005/17, 28 June 2005.

- A Handbook on Implementing the Pinheiro Principles on Housing and Property Restitution for Refugees and Displaced Persons, Inter-Agency, 2007.

- Quick Guide to Post-Conflict Land Issues, Early Recovery Cluster/GLTN/UN-Habitat, Draft, June 2009.

- Checklist for Humanitarian Coordinators on Land, Housing and Property Issues, Protection Cluster/HLP Sub-Working Group, August 2009.

- "Housing and Property Restitution for Returnees," Refugee Survey Quarterly, Vol. 19, No. 3, UNHCR and Oxford University Press, 2000.

- " "Property and Possessions," in Protecting Internally Displaced Persons: a Manual Law and Policymakers, Brookings-Bern Project on Internal Displacement, October 2008.

\section{Useful websites}

- Protection Cluster: Housing, Land and Property Sub-Working Group: http://oneresponse.info/GlobalClusters/Protection/LHP/Pages/ Land\%20Housing\%20and\%20Property.aspx

- Centre on Housing Rights and Evictions (COHRE): www.cohre.org

- Internal Displacement Monitoring Centre (IDMC): www.internaldisplacement.org

- International Organization for Migration (IOM): www.iom.int/pressproject

- Shelter Centre: www.sheltercentre.org

- United Nations Human Settlements Programme (UN-HABITAT): www.unhabitat.org

n United Nations High Commissioner for Refugees (UNHCR): www.unhcr.org

8 In full, "the Special Rapporteur on the right to adequate shelter as a component of the right to an adequate standard of living." 


\section{Part IV.18 \\ Justice}

Key message

1. What is justice?

2. Lack of access to justice in the context of internal displacement 314

3. The responsibility of the State

4. The role of humanitarian and human rights actors

5. Key actors 318

6. The international legal framework 319

Key references. 322

Useful websites 322

Annex I 323

Annex II 325

Annex III .327 


\section{Key message}

Access to justice is a basic right as well as a key means of defending other human rights and ensuring accountability for crimes, violence and abuse. Justice plays an important role in combating impunity, ending discrimination and poverty, and paving the way for peace and national reconciliation. Efforts to strengthen the rule of law and ensure full and equal access to justice for all, including internally displaced persons (IDPs), should form part of the humanitarian response from the outset of an emergency. IDPs may also have no or limited access to justice because of their displacement. Beyond the humanitarian response to strengthen the rule of law, a specific response to promote access to justice for IDPs should also be planned as early as possible.

\section{What is justice?}

The exact meaning of the term might differ from one country to another; ideas of justice, however, are common to all cultures and generally include notions of fairness, accountability and equity of outcome.

For the purpose of this chapter, access to justice can be defined as the ability to obtain an adequate remedy for any harm suffered, whether at the hands of an individual, a group, or another entity. Such remedies can take different forms, ranging from restitution or compensation for the harm done (restorative or restitutive justice) to penalties or punishment of those responsible (retributive or punitive justice). ${ }^{1}$

Systems of justice, formal and informal, generally are composed of two frameworks.

"[We have] learned that the rule of law is not a luxury and that justice is not a side issue. We have seen people lose faith in a peace process when they do not feel safe from crime. We have seen that without a credible machinery to enforce the law and resolve disputes, people resorted to violence and illegal means. And we have seen that elections held when the rule of law is too fragile seldom lead to lasting democratic governance. We have learned that the rule of law delayed is lasting peace denied..."

Kofi Annan, Secretary-General of the United Nations, Access to Justice Practice Note (UNDP, 2004).

- A normative framework (a body of law), which consists of national law (constitutional, federal, provincial and municipal, and often customary traditional or religious law) together with international and regional law. All States have an obligation to ensure that their national law gives effect to, and is in conformity with, their international legal obligations, including human rights law.

- An institutional framework, which includes both formal (State-run) justice mechanisms, such as courts and tribunals, and quasi-judicial or alternative mechanisms, such as religious courts, tribal councils or grievance committees (outlined further in Annexes I and II to this chapter $\square$ ). In some countries, temporary mechanisms are also established to deal with transitional justice (outlined further in Annex III to this chapter). A complementary role can also be played by international or regional bodies, such as the International Criminal Court.

All systems of justice should respect human rights, both in terms of process and outcome. States have a range of human rights obligations which their legislative, judicial and executive branches are bound to respect and protect. International involvement with, and support for, systems of justice similarly must be guided by human rights standards.

This chapter focuses on rule of law and access to justice and does not address other forms of justice, such as social or distributive justice. 


\section{Lack of access to justice in the context of internal displacement}

The ability to access justice is essential to combat impunity and prevent and respond to protection risks and concerns. IDPs and other affected populations, however, often lack or have limited access to justice owing to a number of factors. Armed conflict, generalized violence and collapse of institutions and infrastructure frequently result in a breakdown in the rule of law and access to justice. In some cases, an otherwise functioning justice system may remain out of reach for displaced individuals and communities owing to discrimination, marginalization and poverty.

Having fled their homes and lost their livelihoods as well as the protective presence of their families and communities, IDPs might find themselves at an increased risk of violence, exploitation and abuse at the same time as their access to justice and other remedies is curtailed because of displacement.

Table 1: Common obstacles to ensuring full and equal access to justice

Type Specific Obstacles

Discrimination Discriminatory social and cultural norms and practices, particularly on grounds of gender, age, religion, ethnic, religious or linguistic background, or other status, such as displacement, can result in a lack of access to, and/or discriminatory treatment within, the justice system.

Chronic under-representation of women and minority groups in the justice and law enforcement sectors can contribute to a lack of attention to, and understanding of, protection risks faced by these groups.

Normative obstacles

Institutional/ administrative obstacles
National laws that do not protect or inadequately protect human rights. For instance, national laws might fail to recognize a certain right (e.g. protection from rape), define it narrowly (e.g. define rape as not including marital rape), or criminalize the victim of a violation (e.g. define rape as adultery).

Confusing or complicated legal framework because of overlaps or incompatibility between national law and traditional or religious laws. The latter may be unrecorded or not widely known and, thus, be open to manipulation or abuse.

Lack of a clear institutional and procedural framework and/or professional and ethical standards and codes of conduct governing the work of justice institutions.

Amnesty laws: while negotiating or signing peace deals, political leaders may grant immunity from prosecution for gross human rights violations committed by members of former warring groups or members of previous regimes, often in contradiction with the country's own constitutional law and human rights law. For example, in Argentina in 1981, judges ruled that the amnesty laws blocking the prosecution of crimes committed during the military dictatorship were unconstitutional. In 2001, the Inter-American Court of Human Rights held that the amnesty laws adopted by the Peruvian government conflicted with the American Convention on Human Rights.

Breakdown of infrastructure and institutions because of conflict, violence and insecurity, and/or lack of human and financial resources, including lack of qualified staff and basic supplies, such as office space, computers, paper, and telecommunication equipment.

Lack of oversight and accountability mechanisms capable of preventing and addressing corruption, patronage, malpractice and abuse in the justice system.

Weak enforcement capacity, including relating to the arrest of offenders and the investigation and prosecution of cases. 
Lack of independent appeals procedures for review of judicial and administrative decisions.

Lack of adequate victim and witness protection resulting in exposure to further physical, psychological, economic or other harm.

$\begin{array}{ll}\text { Political } & \text { Lack of separation of powers and independence of the justice sector. } \\ \text { obstacles } & \text { Politicization or militarization of public institutions, including segregation } \\ \text { along ethnic or religious lines, which may become a source of insecurity, } \\ \text { intimidation or violence. } \\ \text { Lack of political will to bring perpetrators to justice for graves breaches to } \\ \text { international human rights and humanitarian law. For reasons of political } \\ \text { expediency, and sometimes arguing the need for peace and reconciliation in } \\ \text { post-conflict situations, the prosecution of alleged perpetrators of serious } \\ \text { human rights abuses has often been overlooked by governments. }\end{array}$

Individual Lack of affordable and adequate legal aid for disadvantaged individuals and obstacles groups, particularly women/girls and minority groups.

- Lack of public confidence in the justice and political system because of actual or perceived bias, corruption, abuse or lack of effectiveness and efficiency.

Lack of public information and understanding about rights, institutions and procedures for accessing justice.

Lack of legal, financial and social resources and support, making it difficult for displaced individuals, particularly women, to pay for legal aid or transportation to attend court hearings. Lack of education and/or literacy skills can also limit access to justice.

Fear of reprisals, trauma, religious beliefs, social stigma or ostracism often prevents individuals, especially women, from seeking justice, particularly in cases involving gender-based violence.

Victims and witnesses and their families and wider communities can be exposed to serious risks as a result of their efforts to seek justice. This includes acts or threats of physical violence, destruction of property, harassment, intimidation, and/or social exclusion at the hands of the perpetrators, the authorities and/or the community itself. IDPs and other disadvantaged individuals or groups, including minority groups, are often particularly vulnerable to such threats.

Note! Seeking justice is not without risks. Always ensure that the victim/survivor is aware of the risks involved, respect confidentiality and seek informed consent before taking action or disclosing personal information. The safety and best interests of the victim must be a primary consideration at all times.

In addition, men and women who speak out and seek justice for acts of gender-based violence, such as sexual violence, often face further violence, punishment or ostracism. Survivors of rape are sometimes forced to marry their rapists or are arrested, detained and sentenced to imprisonment or other forms of punishment, including in some cases death.

\section{The responsibility of the State}

The State has primary responsibility for maintaining law and order and ensuring full and equal access to justice for everyone within its jurisdiction. This includes ensuring that all institutions and agents of the State, including the courts, the police, prosecutors and prison authorities, respect and protect human rights. To that effect, States are required to:

- take all appropriate legislative, administrative and other action to prevent violations of rights; 
- investigate violations effectively, promptly, thoroughly and impartially;

- prosecute or take other action against those allegedly responsible;

- provide the victims with full, equal, effective and safe access to justice; and

- ensure that remedies are provided and enforced by institutions of the State.

\section{The role of humanitarian and human rights actors}

Efforts to improve access to, and the administration of, justice should take place within a broader framework aimed at strengthening the rule of law in the country concerned. However, specific responses to issues of justice affecting IDPs can also be designed. It is important that such efforts take into account and support the primary role of the State and that they are coordinated with all relevant actors, including humanitarian and human rights actors. The need for immediate results must also be balanced with longer-term structural and system-wide improvements. The table below lists some activities that could prove helpful in this regard.

\section{In our work, we can ${ }^{2}$...}

\section{General}

Assessment and analysis

(See Part III.1 $\square$ )

\section{Coordination}

\section{Legislative reform}

\section{Legal reform}

- Ensure that protection assessments include the following: matters relating to the rule of law and access to justice, including whether IDPs and other affected individuals can access justice and obtain remedies for any harm suffered; the main obstacles they face in this regard and activities that can be undertaken to improve their capacity to access the justice system; and the capacity of the justice sector and other relevant institutions, such as the police, prosecutors, and the prison system.

Ensure that matters relating to the rule of law and access to justice are addressed by the protection working group, and that they are closely coordinated with all relevant actors, particularly with national authorities, national and international humanitarian and human rights actors and, as appropriate, peacekeeping forces.

Review national laws, policies and practices to assess to what extent human rights are adequately protected. As appropriate, advocate with relevant authorities and offer assistance to revise or adopt new laws, policies or practices, ensuring their conformity to international human rights law and the principle of the independence and impartiality of the judiciary, and oppose any legal discriminatory provisions that prevent access to justice for IDPs. Where key human rights instruments have not been ratified by the State or where their adoption has been accompanied by reservations, advocate for the adoption and implementation of these instruments or the lifting of reservations.

Engage with alternative justice mechanisms, such as religious or traditional dispute-resolution bodies, and seek ways to ensure that these respect human rights, particularly the rights of women and children. 


\begin{tabular}{l|l}
\hline Public information and outreach \\
$\begin{array}{l}\text { Information and } \\
\text { communication } \\
\text { activities }\end{array}$ & $\begin{array}{l}\text { Support public information and outreach programmes aimed at ensuring } \\
\text { that IDPs and other affected individuals are aware of their rights, in } \\
\text { (See Part V.7 } \\
\text { particular the right to equal access to justice, and that local or national } \\
\text { judicial or administrative bodies are aware of and respect these rights. } \\
\text { These programmes should include information about human rights and } \\
\text { humanitarian principles in general, the rights of IDPs and other affected } \\
\text { individuals, the relevant international and domestic laws relating to IDP } \\
\text { rights, the responsibility of the State and its institutions to respect such } \\
\text { rights, and avenues available for redress, whether through the formal or } \\
\text { the informal justice system, and procedural or practical steps to access } \\
\text { such avenues. Activities can include public awareness and educational } \\
\text { programmes, including information campaigns, workshops, trainings, } \\
\text { and integrating human rights in school curricula. }\end{array}$ \\
\hline $\begin{array}{l}\text { Mainstreaming of } \\
\text { rule of law and } \\
\text { access to justice }\end{array}$ & $\begin{array}{l}\text { Advocate with relevant actors to ensure that rule of law and access to } \\
\text { justice by IDPs are included in peace negotiations and agreements, in } \\
\text { relocation and integration frameworks and agreements, and in } \\
\text { development plans and programmes. }\end{array}$
\end{tabular}

\section{Supporting and strengthening the capacity of persons of concern to access justice}

Legal assistance

(See Part V.8 $\square$ ) and advice

Ensure that legal aid is available, affordable and adequate, and that it is provided in an appropriate language. This can be done by supporting the establishment of legal clinics and information centres, including mobile clinics, and/or by supporting and training networks of lawyers or paralegals that provide free legal advice and assistance.

\section{Material or financial assistance}

Provide modest material or financial assistance to disadvantaged individuals in order to enhance their access to justice. This could include modest financial grants to pay for legal fees, interpretation, or travel costs to and from court.
Safety and security (See Part IV.2 D)

Take steps to ensure the safety and security of IDPs who are victims/survivors as well as those who are witnesses seeking justice. This may include supporting the authorities or civil society groups to develop victim/witness-protection programmes, advocating with relevant authorities to guarantee their safety, accompanying them to and from court, observing court proceedings and, in exceptional circumstances, assisting them in relocating to a place where their safety can be guaranteed.

\section{Rights of the accused}

Take steps through, for instance, advocacy and monitoring, to ensure that the rights of arrested or detained IDPs on criminal or other charges are respected. These include the rights not to be ill treated, to be informed of the charges, to be brought promptly before a judge and to have a fair trial. (See section 6.)

Protection monitoring: This will include monitoring of court cases and of compliance by State judicial bodies with national, international human rights law and standards. 


\section{Reforming and building the capacity of the justice sector and other institutions}

Institutional reform Advocate for and support, as appropriate, the reform of institutions of justice as well as other relevant institutions, including the police, prosecutors and prison authorities. (See Annexes I-III to this chapter $\square$.)

Advocate for, and support the establishment of, an independent national human rights institution and, where it already exists, support its effective functioning. Also, support the work of mediators and ombudsmen.

\section{Technical advice and expertise} (See Part V.9 $\square$ )

Material or financial assistance $($ See Part V.5 $\square)$

\begin{abstract}
Provide technical advice and expertise to build the capacity of the justice sector in the field of human rights and international humanitarian law, including as it relates to displacement. This can be done by providing advice or legal briefs, holding trainings, workshops and seminars, and exchanging or loaning staff on a temporary basis. (See Annexes I-III to this chapter $\square$.)

Consider providing such human rights capacity-building support to other related institutions as well, particularly the police and prison authorities and traditional justice mechanisms, civil society organizations and communities. (See Annexes I-III to this chapter $\square$.)
\end{abstract}

Consider providing modest material or financial assistance to formal and informal justice institutions, or to police, prosecutors, or prison authorities, if appropriate, to facilitate and strengthen their work. This can include the establishment of mobile courts, office space, office or communication equipment, computers, vehicles or fuel. Such assistance should be temporary, be governed by a formal agreement, and subject to continuous monitoring and evaluation.

In countries where the judicial institutions and infrastructure have been destroyed or have collapsed, a restoration of the justice system would need major coordinated efforts and assistance, including the physical rebuilding of structures, the acquisition of basic equipment, training of new judicial officers or lawyers, and ensuring adequate salaries to prevent corruption.

\section{Key actors}

Enhancing the rule of law and access to justice requires concerted efforts by a range of actors as indicated below.

- At the national level: the courts at all levels; police, prosecutors and prison authorities; ministries of justice, the interior, and education; parliament; bar associations and networks of lawyers and paralegals; national human rights institutions; university law departments; NGOs and civil society groups; traditional, customary or religious councils and associations; the media; IDP communities and affected populations; and the public.

- At the regional level: courts and commissions, such as the African Court and the African Commission on Human and Peoples' Rights, the Inter-American Court and Commission on Human Rights, and the European Court of Human Rights. 
- At the international level: UNDP, OHCHR, DPKO and peacekeeping forces on the ground; UNHCR, UNICEF, UNODC, United Nations human rights treaty bodies and special procedures of the Human Rights Council, including the Special Rapporteur on Independence of Judges and Lawyers, and the International Criminal Court and NGOs.

\section{The international legal framework}

International (and regional) human rights law contains several guarantees, some of which are indicated below, that are of particular importance to ensure full and equal access to justice.

- The right to an effective remedy ${ }^{3}$ calls for full, equal and effective access to justice and adequate reparation for violations of human rights. The right to a remedy extends not only to the direct victim but may also extend to the immediate family or dependents and persons who suffered harm in intervening to assist victims. Reparations should be just and proportional to the gravity of the violation and can involve restitution (restoration to the previous situation), compensation (e.g. for physical or emotional suffering or economic loss), rehabilitation (e.g. medical care), satisfaction and guarantees of non-repetition.

- The right to equal recognition of and equality before the law ${ }^{4}$ requires that everyone, including IDPs, has access to, and is accorded fair and non-discriminatory treatment before, courts and tribunals. In many cases, fulfiling this right will require the State to take affirmative action to ensure that IDPs are able to access formal or informal justice mechanisms. It might also require affirmative action on behalf of women, children and marginalized groups, such as ethnic, religious or linguistic minorities, older persons or persons with disabilities.

Human rights law also protects the rights of those who are arrested or detained: the right to liberty and security prohibits arbitrary arrest and detention and provides minimum guarantees to those detained; and the right to humane treatment protects individuals while they are in detention. The right to a fair trial establishes the minimum substantial and procedural principles (due process) applicable in criminal cases. ${ }^{5}$

States must ensure that the right of access to justice and fair and impartial proceedings are reflected in domestic laws. Most constitutions and national laws normally contain these guarantees. Advocacy activities aimed at ensuring respect of these rights for IDPs and legal challenges against abuses should also be based on domestic legal provisions that offer adequate guarantees.

\footnotetext{
The right to an effective remedy is implicit in the obligation to respect, protect and fulfil human rights, and is recognized as a general principle of international law. It is also specifically guaranteed in various provisions, including, at the international level, in Art. 8 of UDHR; Arts. 2(3), 9(5) and 14(6) of ICCPR; Art. 6 of ICERD; Arts. 12, 13 and 14 of CAT; Art. 39 of CRC; and Principle 7(3)(f) of the Guiding Principles on Internal Displacement; and, at the regional level, Arts. 7 and 21(2) of AfCHPR and Arts. 8 and 25 of its Protocol on the Rights of Women in Africa; Arts. 10, 15, 27, 63 and 68 of AmCHR; Art. 4(g) of the Inter-American Convention on the Prevention, Punishment and Eradication of Violence Against Women; Art. 9 of the Inter-American Convention to Prevent and Punish Torture; Arts. 9 and 16 of ArCHR; Art. 19 of the Cairo Declaration; and Arts. 5(5), 13 and 41 of ECHR.

At the international level, Arts. 6 and 7 of UDHR; Arts. 16 and 26 of ICCPR; Art. 5 of ICERD; Art. 15 of CEDAW; and Principle 20 of the Guiding Principles on Internal Displacement; and, at the regional level, Arts. 3 and 5 of AfCHPR and Arts. 3(1) and 8 of its Protocol on the Rights of Women in Africa; Art. 17 of AmDHR; and Art. 3 of AmCHR. For further information, see General Comment No. 32 (2007) of the Human Rights Committee on Article 14: Right to equality before courts and tribunals and to a fair trial (CCPR/C/GC/32).

5 Based on Arts. 10 and 11 of UDHR; Arts. 9 and 14 of ICCPR; Art. 5(a) of ICERD; Art. 15 of CEDAW; and Art. 40 of CRC; and, at the regional level, Arts. 7 and 26 of AfCHPR; Arts. 17 and 30 of AfCRWC; Art. 8 AmCHR; Art. 7 of ArCHR; Arts. 6 and 7 of ECHR and Arts. 2, 3 and 4 of Protocol 7. For further information, see General Comment No. 32 (2007) of the Human Rights Committee on Article 14: Right to equality before courts and tribunals and to a fair trial (CCPR/C/GC/32).
} 


\section{The right to a fair trial: An overview}

\begin{tabular}{|c|c|}
\hline $\begin{array}{l}\text { Receive equal treatment before courts and } \\
\text { tribunals. } \\
\text { Have access to a fair and public hearing by a } \\
\text { competent, independent and impartial tribunal } \\
\text { established by law. } \\
\text { Be presumed innocent until proved guilty. } \\
\text { Be informed promptly and in detail, in a language } \\
\text { one understands, of the nature of the charges. } \\
\text { Have adequate time and facilities to prepare a } \\
\text { defense and to consult with the counsel of } \\
\text { one's own choosing. } \\
\text { Be tried without undue delay and in person. } \\
\text { Defend oneself in person or through legal } \\
\text { counsel of choice, with legal counsel being } \\
\text { offered without charge if necessary or the } \\
\text { interests of justice so require. } \\
\text { Have access to free interpretation, if needed. }\end{array}$ & $\begin{array}{l}\text { Examine or have examined witnesses on the } \\
\text { same conditions as the adverse party. } \\
\text { Not be compelled to testify against oneself or } \\
\text { to confess guilt. } \\
\text { Not be convicted for any act that did not } \\
\text { constitute a criminal offence at the time it took } \\
\text { place. } \\
\text { Not be convicted for any offence for which one } \\
\text { has already been convicted or acquitted. } \\
\text { Have a conviction reviewed by an } \\
\text { independent appeal court. } \\
\text { Benefit from any subsequent decrease in } \\
\text { punishment. } \\
\text { Be compensated for any miscarriage of } \\
\text { justice. }\end{array}$ \\
\hline
\end{tabular}

Children who come into contact with the justice system are entitled to special treatment that takes into account their age, well-being and need for special protection. This applies both to children who are victims/survivors of crimes as well as children who come into conflict with the law. Juvenile justice which is aimed at reconciliation rather than retribution promotes the use of community solutions, rather than judicial proceedings, and alternatives to custodial sentencing, such as counselling, probation and community service. ${ }^{6}$

International humanitarian and criminal law also contain important legal principles. In general, States are considered responsible for grave breaches of the Geneva Conventions and their Additional Protocols committed by State agents, including its armed forces and other entities that exercise governmental authority or act under instructions from the State or under its direction or control, during international and non-international armed conflicts. States are expected to make full reparation for any loss or injury caused. ${ }^{7}$

Serious violations of the international humanitarian and criminal law, including war crimes, crimes against humanity and/or genocide, can also give rise to individual criminal responsibility and to the prosecution of State and non-State actors for grave breaches or war crimes, crimes against humanity and/ or genocide committed during armed conflicts as well as during times of peace. This includes both the individuals who committed the crime and commanders and other superiors who either ordered or knew, or had reason to know, that their subordinates were about to commit or were committing such crimes and neither took all necessary and reasonable measures in their power to prevent such crimes nor punished the persons responsible. ${ }^{8}$

Genocide, war crimes and crimes against humanity are subject to universal jurisdiction; thus, any State has the power and duty to prosecute and punish offenders. The mandate of international or mixed criminal tribunals clearly shows that non-State actors can incur individual responsibility for any international crime.

${ }^{6}$ See, in particular, Arts. 37 and 40 of CRC; and, at the regional level, Art. 17 of AfCRWC. See also United Nations, Rules for the Protection of Juveniles Deprived of their Liberty; United Nations, Guidelines for the Prevention of Juvenile Delinquency (Riyadh Guidelines); United Nations, Standard Minimum Rules for the Administration of Juvenile Justice (Beijing Rules); Guidelines on Justice in Matters involving Child Victims and Witnesses of Crime (ECOSOC Res. 2005/20 of 22 July 2005); and Guidelines for Action on Children in the Criminal Justice System (ECOSOC Res. 1997/30 of 21 July 1997).

See, for example, ICRC, Rules 149 \& 150 of Customary International Humanitarian Law, Volume I: Rules, 2005.

8 See, for example, ICRC, Rules 151-155 of Customary International Humanitarian Law, Volume I: Rules, 2005. 
Basic rules, principles and/or guidelines relating to access to justice and the rule of law (Available at www2.ohchr.org/english/law/index.htm)

Basic Principles and Guidelines on the Right to a Remedy and Reparation for Victims of Gross Violations of International Human Rights Law and Serious Violations of International Humanitarian Law

Set of Principles for the Protection and Promotion of Human Rights through Action to Combat Impunity

Declaration of Basic Principles of Justice for Victims of Crime and Abuse of Power

UN Principles relating to the Status of National Institutions (Paris Principles)

Basic Principles on the Independence of the Judiciary

Basic Principles on the Role of Lawyers

Guidelines on the Role of Prosecutors

Principles on the Effective Prevention and Investigation of Extra-legal, Arbitrary and Summary Executions

Code of Conduct for Law Enforcement Officials

Basic Principles on the Use of Force and Firearms by Law Enforcement Officials

Body of Principles for the Protection of All Persons under Any form of Detention or Imprisonment

Basic Principles for the Treatment of Prisoners

United Nations Minimum Rules for Non-custodial Measures (the Tokyo Rules)

United Nations Rules for the Protection of Juveniles Deprived of their Liberty

United Nations Standard Minimum Rules for the Administration of Juvenile Justice (the Beijing Rules)

United Nations Guidelines for the Prevention of Juvenile Delinquency (the Riyadh Guidelines)

ECOSOC Guidelines on Justice in Matters involving Child Victims and Witnesses of Crime ECOSOC Guidelines for Action on Children in the Criminal Justice System

International humanitarian law also prohibits the conviction or sentencing of persons except following a fair trial affording all essential judicial guarantees. ${ }^{9}$ This includes: a right to a trial by an independent, impartial and regularly constituted court; presumption of innocence; information on the nature and cause of the accusation; and necessary means of defense, including access to legal assistance and interpretation, if required. Depriving a person of his/her right to a fair trial during an armed conflict constitutes a grave breach of the Geneva Conventions and can amount to a war crime. ${ }^{10}$

9 See, for example, ICRC, Rules 100-102 of Customary International Humanitarian Law, Volume I: Rules, 2005. See also Common Art. 3 to the Geneva Conventions; Arts. 5 and 66-75 of the Fourth Geneva Convention; Art. 75 of Additional Protocol I; and Art. 6(2) of Additional Protocol II.

10 See, for example, Art. 147 of the Fourth Geneva Convention; Art. 85(4)(e) of Additional Protocol I; Art. 8(2)(a)(vi) and (c)(iv) of the Statute of the International Criminal Court. 


\section{Key references}

- Access to All: A Practitioner's Guide to a Human Rights-based Approach to Justice, UNDP, 2005.

- Access to Justice: Practice Note, UNDP, 2004.

- General Comment No. 32 (2007) of the Human Rights Committee on Article 14: Right to equality before courts and tribunals and to a fair trial , UN Human Rights Committee, CCPR/C/GC/32, August 2007.

- The Administration of Justice in Refugee Camps: A Study of Practice, Rosa da Costa, UNHCR, 2006.

- Guide to International Human Rights Mechanisms for Internally Displaced Persons and Their Advocates, Brookings-Bern Project on Internal Displacement, 2006.

- Human Rights in the Administration of Justice: A Manual on Human Rights for Judges, Prosecutors and Lawyers, OHCHR/International Bar Association, 2003.

- Rule-of-Law Tools for Post-Conflict States, on prosecution, truth commissions, monitoring of legal systems, and vetting, OHCHR, 2006.

- Juvenile Justice: Modern Concepts of Working with Children in Conflict with the Law, Save the Children, 2006.

- Reconciliation after Violent Conflict, IDEA, 2003.

\section{Useful websites}

- United Nations Development Programme (UNDP): www.undp.org

- International Centre for Transitional Justice (ICTJ): www.ictj.org

- International Criminal Court (ICC): www.icc-cpi.int

- International Criminal Tribunal for Rwanda (ICTR): www.un.org/ictr

- International Criminal Tribunal for the former Yugoslavia (ICTY): www.un.org/icty

- Reports of the Special Rapporteur on the Independence of Judges and Lawyers: www.ohchr.org/english/issues/judiciary/index.htm 


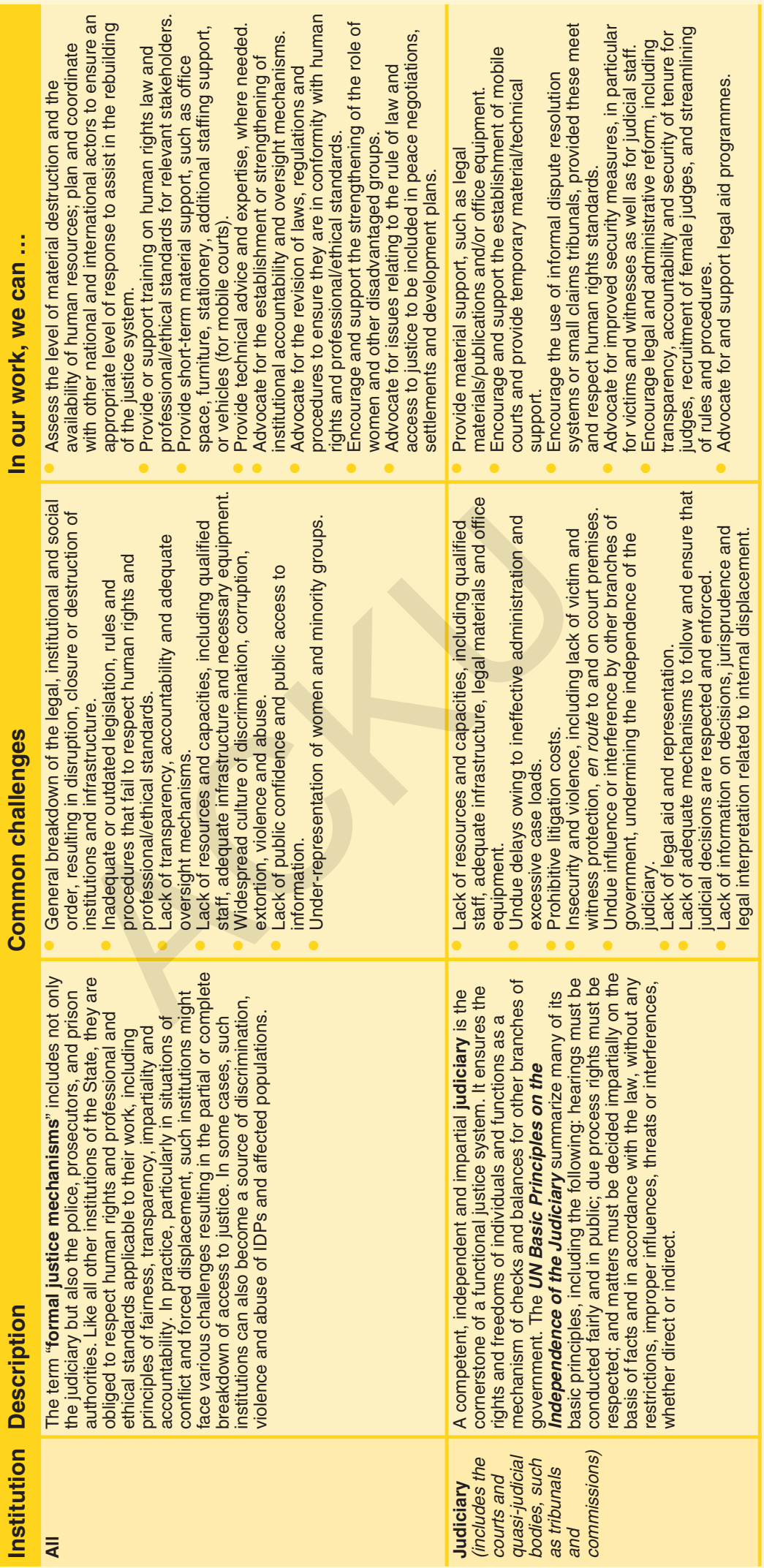




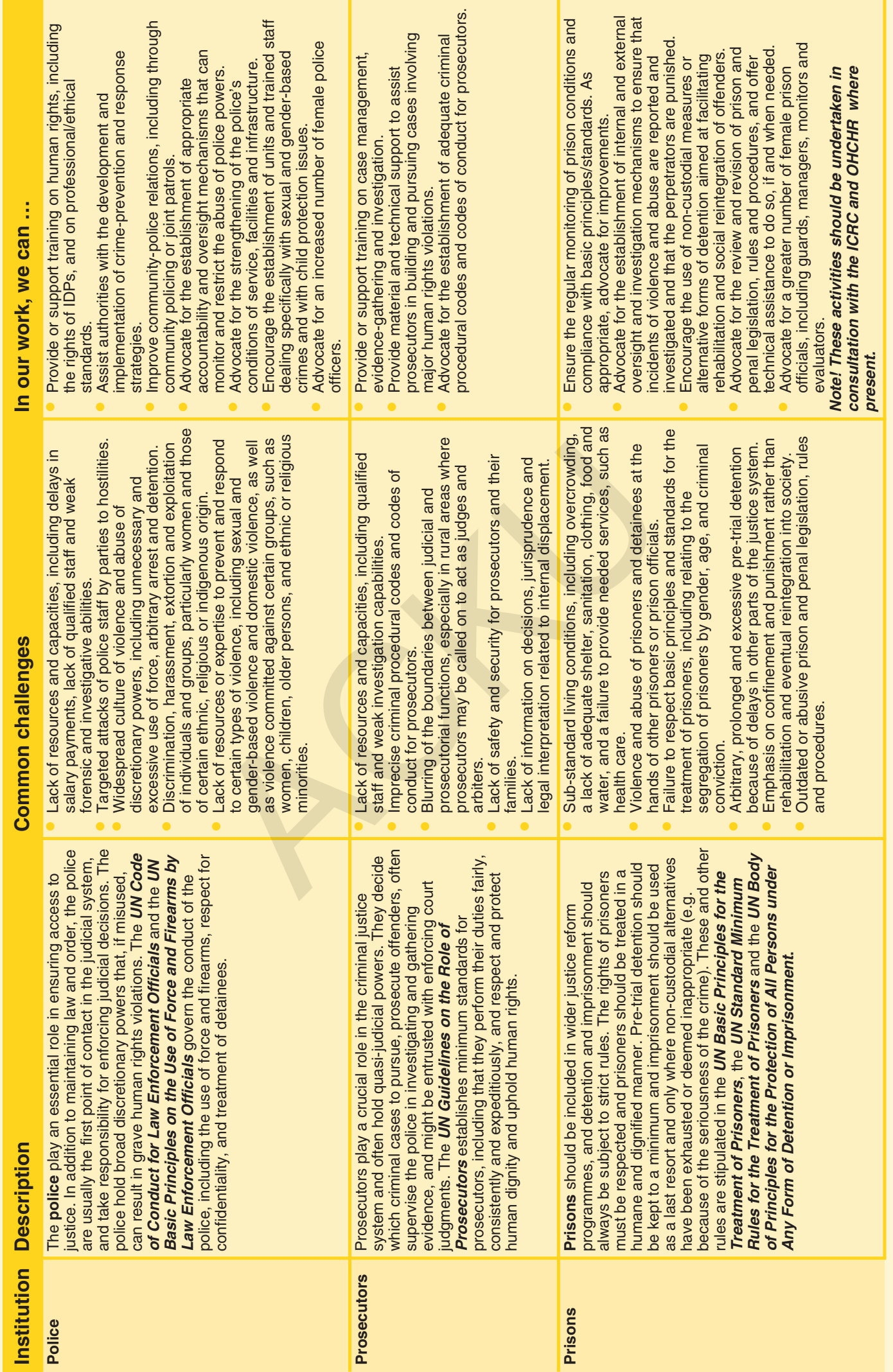


A range of traditional, customary or religious dispute resolution systems (DRS) operate in most societies, particularly in the developing world, where up to $80 \%$ of disputes might be handled by religious courts, tribal councils, groups of elders, grievance committees or community leaders. Such mechanisms can play an invaluable role in ensuring access to justice. Their main advantage lies in the fact that they might be more accessible and acceptable from a cultural or religious perspective, consume less time and resources, focus on restitution and compensation rather than punishment, and use methods, such as mediation, negotiation and arbitration, that can foster social cohesion and reconciliation.

DRS should not be seen as a substitute for formal justice institutions but rather as a complementary system aimed at improving access to justice. DRS are particularly well suited to resolve minor conflicts and disputes between people living in the same community where reconciliation and restoration, rather than retribution and punishment, are needed. Formal justice, on the other hand, is best equipped to provide the legal and procedural guarantees needed in cases involving serious crimes, including torture, rape or murder, or serious penalties, such as long-term imprisonment. However, some countries have also resorted to a combined mechanism. For instance, to speed up the delivery of justice in the wake of the genocide in Rwanda, the Gacaca, originally a village assembly presided over by village elders to resolve minor disputes, was reactivated to prosecute thousands of alleged perpetrators of serious crimes (further addressed in Annex III on Transitional justice

Any involvement with DRS, however, must be guided by human rights standards. In general, such mechanisms should only be supported where they are consistent with the rule of law and respect the human rights of all groups in society. The use of DRS can raise a number of concerns. They frequently reflect and reinforce prevailing power relationships that perpetuate discrimination based on gender, age, caste, religion or ethnicity. In particular, women and girls are routinely excluded from such bodies or, where admitted, often lack real authority and decision-making power. In some cases, particularly in internal displacement contexts when community structures have been disrupted, DRS might be relatively new or might include neo-traditional institutions that lack cultural and moral legitimacy, despite claims to the contrary. Other concerns are indicated below.

- Limited respect for basic human rights, including the principle of non-discrimination and recognized standards of fair trial and due process. In particular, DRS might fail to address and provide redress for violations that predominantly affect women and girls, such as rape, domestic violence and women's property or inheritance rights.

- Use of customary or religious rules that criminalize acts that do not constitute a violation of national law (e.g. sorcery, rape defined as adultery) or fail to criminalize and punish acts that do violate national law (e.g. rape and sexual violence, harmful traditional practices, female genital mutilation, and forced and early marriage).

- Use of remedies and/or punishments that are disproportionate to the offence or fail to respect the rights or the best interests of the victim. Compensation might be provided to the family or clan rather than the individual victim(s), or it might be provided at the expense of the victim (e.g. by forcing the victim to marry the rapist to restore family honour). Similar concerns might apply to punishment, which may be excessive (e.g. capital punishment for adultery); overly lenient (small fines for capital crimes, such as murder or child rape); amount to torture or ill-treatment (e.g. chopping of limbs); be unfair (e.g. confiscation of a family's food ration cards); or violate the rights of a third party (e.g. by offering a daughter or sister of the accused for marriage). 
- Sub-standard detention and/or prison facilities and conditions and ill treatment of detainees, including lack of food, shelter, clothing and access to medical care.

- Lack of confidentiality, transparency and accountability; lack of legal aid and representation; inadequate record-keeping; failure to provide reasons for decisions; and lack of appeal procedures.

- Provided that our involvement with DRS is guided by human rights standards, a number of activities can be undertaken to build the capacity of DRS to play a positive protection role. These include:

- raising awareness of, and provide training on, human rights and relevant standards of fair trial, due process and punishment, and minimum standards of detention and imprisonment;

- supporting efforts aimed at reconciling and strengthening the link between traditional and religious norms and practices and human rights standards through, for instance, research and constructive dialogue with and within the community;

- working with the community to ensure that DRS are truly representative and non-discriminatory towards women and minority groups, including by ensuring that they address violations faced by such groups and respect their rights;

- providing DRS with technical or material support, such as providing meeting space, office equipment, and/or modest incentives or compensation for their work; and

- advocating for a closer link between DRS and formal justice mechanisms to ensure adequate support, supervision and oversight. 


\section{Annex III}

\section{Transitional justice}

In many conflict and post-conflict societies, coming to terms with the legacy of large-scale human rights abuses and atrocities is a major challenge. Confronting the past, providing justice to victims and bringing perpetrators to account is an integral element of peace-building, reconciliation and restoration of the rule of law. It is also an important part of beginning the long-term process of healing among individuals, families and communities.

Peace and justice should be seen as mutually reinforcing imperatives, rather than mutually exclusive aims. Failing to address questions of justice can reinforce a culture of impunity, cause further injustice to victims and survivors, and, in some cases, might undermine rather than strengthen post-conflict reconciliation and peacebuilding in the longer term.

There are several ways to address past abuses in post-conflict societies, often through a form of transitional justice. The term transitional justice refers to judicial and non-judicial mechanisms or processes that communities adopt to come to terms with a legacy of past abuses during conflict or authoritarian rule. Transitional justice is not a special form of justice but justice adapted to societies transforming themselves after a period of pervasive human rights abuses. It generally involves a combination of complementary judicial and non-judicial strategies, some of which are highlighted below, that might differ from one society to another.

prosecution of alleged perpetrators of widespread or systematic human rights abuses before national courts, hybrid tribunals (such as the Special Court for Sierra Leone and the Extraordinary Chambers in the Courts of Cambodia) or international courts (such as the permanent International Criminal Court);

truth commissions ${ }^{11}$ or other truth-seeking initiatives, including investigating and reporting on past abuses, holding public meetings, recording survivor and witness testimonies, exhuming victims' remains, conducting historical research, and making recommendations on reparation or institutional reforms;

- reparation programmes for survivors providing restitution, compensation, and rehabilitation, actual or symbolic, as appropriate, for abuses suffered;

- commemoration of victims and survivors through ceremonies or the construction of memorials or museums, often through the conversion of sites of former abuse, such as prisons or detention camps;

- reconciliation initiatives, including healing ceremonies for victims and individual acts of acknowledgment, apology, symbolic payment or community service by perpetrators; and

institutional reform aimed at building fair, effective and transparent public institutions to safeguard against further abuse, often including vetting (i.e. the screening and dismissal of abusive, corrupt or incompetent officials from public institutions, including the judiciary, the police, military and other security services).

The choice of transitional justice mechanisms depends on the context as well as on the type, nature and scale of the abuses committed. However, experience suggests that combined mechanisms, with the active participation of victims and perpetrators, are more effective in the search for truth and justice.

11 Truth commissions have been established in Argentina, Chile, Ecuador, El Salvador, Ghana, Guatemala, Liberia, Morocco, Nigeria, Panama, Peru, Rwanda, Sierra Leone, South Korea, South Africa and East Timor. 
Transitional justice mechanisms have often been negotiated, developed and implemented with little regard for the important contribution of, and the harm suffered by, women and girls. Rape, gang rape, forced prostitution, forced pregnancy and some other forms of sexual violence may constitute torture, genocide, mutilation, and enslavement, under international law. Such acts, however, generally have not been treated with the same seriousness as other war crimes. Neglect of patterns of gender-based abuse has entrenched impunity, limited the reach of reparation programmes, and undermined the legitimacy of transitional justice initiatives.

Strategies to strengthen transitional justice mechanisms include:

- ensuring that questions of transitional justice, including for women and girls, are addressed in peace negotiations and settlements;

- establishing or supporting the work of courts, tribunals, truth commissions and other justice mechanisms through financial, material or technical assistance; and

- providing support to grassroots peacebuilding and reconciliation efforts. 


\section{Political participation and the right to vote}

Key message .330

1. Political participation in the context of internal displacement .............................330

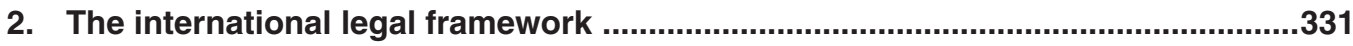

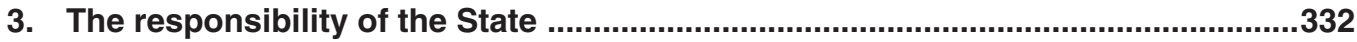

4. The role of humanitarian and human rights actors ............................................332

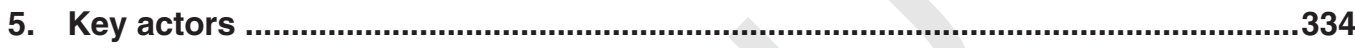

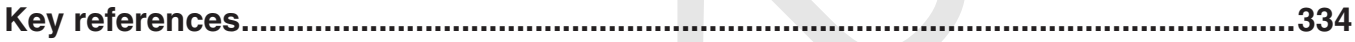

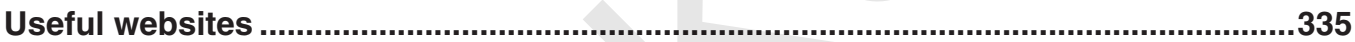




\section{Key message}

All persons, including internally displaced persons (IDPs), have the right to participate in the governmental and public affairs of their country, which includes having the right to vote and to stand for election to public office. Internal displacement, however, can make it difficult for individuals to exercise their rights to political participation, particularly in elections. As a result, IDPs risk being denied a voice in the political and economic decisions that affect their lives.

\section{Political participation in the context of internal displacement}

The term "political participation" includes any form of engagement in the political and public life of a community, including seeking and holding public office, participating in the work of political parties or opposition groups, and voting and standing for elections. When conducted in a fair and inclusive manner, elections can pave the way for peace, national reconciliation and good governance, thus fostering long-term stability and durable solutions to displacement.

In practice, however, IDPs often cannot exercise their electoral rights, whether during displacement or upon return to their areas of origin or settlement elsewhere in the country. This can result in disenfranchisement and exclusion from the political and public life of the country which, in turn, can exacerbate the discrimination and marginalization that displaced persons and communities often experience. Some of the obstacles that displaced voters often face are described below.

- Restrictive residency requirements: National electoral regulations generally link the exercise of electoral rights to the place of residence. Displacement, which by definition entails a temporary or permanent loss of residence, thus makes it difficult for IDPs to register and vote; in some cases, they may even be required to return to their areas of origin, which often remain unsafe. Registering to vote in the area of displacement is often difficult owing, for instance, to strict residency or documentary requirements, or it may be altogether unfeasible, as it can result in the loss of humanitarian assistance or the automatic de-registration in the area of origin, creating obstacles to return.

Lack of documentation: Identity documents, which are often needed in order to register and vote, are frequently lost, destroyed or confiscated during displacement. It can be difficult to obtain replacement documentation, and it may require IDPs to return to their areas of origin. Certain individuals and groups may have lacked documentation prior to displacement or may be denied documentation owing to discriminatory laws and practices. Women and girls, for example, are often unable to acquire documentation in their own names and must register as dependents of spouses or male relatives, which violates their rights and leaves them without the means to prove their identity, especially in the case of family separation or death of these relatives.

- Discrimination: Discriminatory laws and practices, which may have contributed to displacement in the first place, can mar all aspects of the electoral process. In some cases, displaced voters or certain groups of displaced voters, such as ethnic minorities, have been deliberately barred from voting, have been given access to fewer or more remote polling stations with shorter voting hours, have been subjected to cumbersome registration procedures, or have lacked access to electoral information in a language they understand.

Conflict and insecurity: Elections sometimes take place in a climate of ongoing violence or communal tensions. Voters and candidates have been threatened, harassed or assaulted at all stages of the electoral process: during voter registration; when obtaining replacement documentation; while en route to or at polling stations; during the 
electoral campaign; or when taking office. Elections can only be free, fair and legitimate if voters can participate without fear of risk, intimidation or harm.

- Lack of access: Access to polling stations is often limited in situations of displacement owing to a lack of security, long distances, a lack of safe and affordable transport, or inadequate voting arrangements, such as an insufficient number of polling stations. Women, older persons, and persons with disabilities face particular obstacles in this regard.

- Lack of information: IDPs, in particular those residing in camps or settlements, often lack information in a language they understand about political processes, parties and voting arrangements.

\section{The international legal framework}

The right to political participation, which is guaranteed in international and regional human rights law, includes the right to participate in government and public affairs, to vote and stand for election, and to have equal access to participate in public service. ${ }^{1}$ (See also Principles 22(1)(d) and 29(1) of the Guiding Principles on Internal Displacement, Annex 1 of the Handbook Da.)

Certain limitations on the right to political participation are permissible, but they must be reasonable, objective and non-discriminatory. For example, the right to vote can be limited to citizens who have attained the age of majority under national law. Any form of discrimination, including on the basis of gender, ethnic origin, religion or political opinion, however, is prohibited, as are any restrictions on grounds of income, education, literacy, disability, descent, property status, political affiliation or displacement. IDPs, thus, have a full and equal right to political participation, including the right to vote, both while they are displaced and upon their return or settlement elsewhere in the country. Where residency requirements apply, they must not exclude IDPs or any other voters without a permanent residence. ${ }^{2}$

Women have equal rights with men in all matters relating to political participation. States should take all necessary steps to ensure that women are able to exercise their political rights and participate at all stages of the electoral process as well as during negotiations and the implementation of peace agreements and early recovery and development programmes. ${ }^{3}$

International law also protects a number of other rights which are important to ensure meaningful political participation, including the rights outlined below.

- The right to freedom of opinion and expression, including the right to seek, receive and impart information in a language of one's choosing, without threat of harassment, coercion or violence. It implies the freedom to discuss, support and oppose ideas, candidates or political parties, including through the media, without risk of censorship or restraint, although propaganda for war and violence or advocacy of national, racial or religious hatred should never be tolerated. ${ }^{4}$

See Art. 21 of UDHR; Art. 25 of ICCPR; Art. 5(c) of ICERD; Arts. 7 and 8 of CEDAW; Arts. 41 and 42 of CMW. At the regional level, see also Art. 13 of AfCHPR and various articles of its Protocol on the Rights of Women in Africa; Art. 23 of AmCHR; Art. XX of AmDHR; Art. 4(j) of the Inter-American Convention on the Prevention, Punishment and Eradication of Violence Against Women; Art. 19 and 33 of ArCHR; and Art. 3 of Protocol 1 to ECHR.

2 See General Comment No. 25 (1996) of the UN Human Rights Committee on the right to participate in public affairs, voting rights and the right to equal access to public service (Art. 25), paras. 3 and 11.

3 Discrimination between women and men is prohibited in the non-discrimination clauses of all major human rights instruments. See also Art. 7 of CEDAW; the Convention on the Political Rights of Women; Art. 9 of the Protocol to the AfCHPR on the Rights of Women in Africa; as well as SC Resolution 1325 (2000), op. para. 8.

4 See Arts. 19 and 20 of UDHR; Art. 19 of ICCPR; Art. 5(d)(viii) of ICERD; Arts. 12, 13 and 17 of CRC; Art. 13 of CMW and Principle 22(1)(a) of the Guiding Principles on Internal Displacement; and, at the regional level, Art. 9 of AfCHPR; Art. 7 of AfCRWC; Art. 13 of AmCHR; Art. IV of AmDHR; and Art. 10 of ECHR. See also General Comment No. 10 (1983) of the UN Human Rights Committee on Freedom of expression (Art. 19). 
- The right to peaceful association and assembly, which includes the right to form and join organizations and associations, including political parties, to debate political and public affairs, and to hold peaceful demonstrations and meetings. ${ }^{5}$

- The right to freedom of movement, which includes the right to move freely, without fear or threat of harm, including for the purposes of campaigning, voting or assuming public office (See Part.IV.6 6 ).

Elections should be free and fair, based on universal and equal suffrage and held by secret ballot, enabling voters to express their will freely and without violence, intimidation or threat. Internationally recognized electoral standards and principles should be respected, and mechanisms for independent and impartial review and appeal should be available.

\section{The responsibility of the State}

The State has a responsibility to ensure that IDPs are able to exercise their rights to political participation, both while they are displaced and upon their return or relocation, on an equal basis with other citizens in their country. In order to facilitate their participation, the authorities can:

- reform national law and administrative procedures to enable IDPs to register and vote in the area of displacement, without facing any adverse consequences;

- establish absentee registration and voting arrangements for IDPs to enable them to participate in elections in their area of origin while they are displaced;

- enhance security en route to, and at, polling stations, including by ensuring that adequate numbers of trained police officers, both female and male, are deployed;

- conduct targeted public information and outreach campaigns to inform displaced voters about available registration and voting arrangements;

- ensure that safe and affordable transportation to and from polling stations is available for displaced and other voters; and

- request international assistance to organize, supervise and monitor fair elections, where needed. ${ }^{6}$

\section{The role of humanitarian and human rights actors}

International assistance can be valuable where the State has limited capacity or lacks technical expertise and resources to ensure free and fair elections, including the full and equal participation by displaced voters and candidates. Election assistance and monitoring is a specialized area of international cooperation and should be coordinated by actors that have the required expertise and experience (further examined in the section on key actors below). However, all humanitarian and human rights actors can play an important role, including by assisting the State as well as displaced candidates and voters to participate safely in elections on a full and equal basis with others in their country.

5 See Art. 20 of UDHR; Arts. 21 and 22 of ICCPR; Art. 14(2)(e) of CEDAW; and Art. 15 of CRC; and, at the regional level, Arts. 10 and 11 of AfCHPR; Art. 8 of AfCRWC; Arts. 15 and 16 of AmCHR; Art. 4(h) of the Inter-American Convention on the Prevention, Punishment and Eradication of Violence against Women; Art. 28 of ArCHR; and Art. 11 of ECHR. The right is reflected in Principle 22(1)(c) of the Guiding Principles on Internal Displacement.

6 For detailed guidance on the specific legislative, administrative and institutional measures that States can take to ensure the electoral rights of IDPs, see papers by J. Grace and E. Mooney referenced at the end of this chapter. 


\section{In our work, we can ...}

Assessment and analysis

(See Part III.1 $\square$ )
Ensure that protection assessments identify (i) any legal, administrative or practical obstacles to political participation by IDPs, paying particular attention to residency, registration and documentation requirements;

(ii) the groups most at risk of exclusion from political and public affairs;

(iii) the protection impact of a lack of participation with regard to specific groups within the community, including on the basis of age, gender or other background; and (iv) key local, national and international actors that can help to address these obstacles.

\section{Community participation and mobilization}

Ensure that women, girls, boys and men of diverse backgrounds are consulted and take active part in planning, implementing and evaluating humanitarian projects and programmes. This can contribute to creating a culture of participation in public affairs among the population and the authorities.

Election monitoring Election observation and monitoring requires technical expertise and should be undertaken by specialized agencies/NGOs. Humanitarian and human rights actors can support their efforts by, for instance, (i) encouraging election monitors to pay attention to the ability of IDPs to exercise their political rights; (ii) sharing information about any obstacles faced by IDPs; and (iii) providing advice and helping to address such obstacles.

\begin{tabular}{|c|c|}
\hline $\begin{array}{l}\text { Advocacy } \\
\text { (See Part V.3 } \square)\end{array}$ & $\begin{array}{l}\text { Advocate with relevant authorities for fair, transparent and inclusive } \\
\text { political processes. Encourage the authorities to respect the political } \\
\text { rights of IDPs, and take any obstacle they may face into account when } \\
\text { developing and implementing electoral policies, practices and frameworks. } \\
\text { This may include (i) legal and administrative reform; (ii) establishment of } \\
\text { absentee registration and voting arrangements; (iii) easing of residency, } \\
\text { documentation and other restrictive requirements; and (iv) ensuring that } \\
\text { women are issued documentation in their own names. Advocate with } \\
\text { national and local law enforcement agencies and with regional and } \\
\text { international actors, if present, for measures to ensure safety during all } \\
\text { phases of the electoral process. }\end{array}$ \\
\hline $\begin{array}{l}\text { Information, } \\
\text { education and } \\
\text { communication } \\
\text { activities } \\
(\text { See Part } V .7 \square)\end{array}$ & $\begin{array}{l}\text { Support voter-education campaigns aimed at informing IDPs and other } \\
\text { affected communities about (i) their political rights; (ii) where, when and } \\
\text { how to register and vote, including any absentee voting arrangements; } \\
\text { and (iii) the availability of complaints and appeal mechanisms. Such } \\
\text { campaigns must reach both women and men of different ages and } \\
\text { backgrounds in areas where IDPs are located, including in camps and } \\
\text { settlements; be conducted in a language which they understand; and } \\
\text { take place through appropriate information channels. As an example, the } \\
\text { use of radio may be more appropriate than printed media among groups } \\
\text { with limited literacy skills. }\end{array}$ \\
\hline $\begin{array}{l}\text { Technical advice } \\
\text { and assistance } \\
\text { (See Part V.8 } \square \text { ) }\end{array}$ & $\begin{array}{l}\text { Help build the capacity of the authorities to conduct free and fair } \\
\text { elections. Technical advice and assistance can be provided by specialized } \\
\text { actors, but humanitarian and human rights actors can support such } \\
\text { efforts by, for instance, providing information about the obstacles faced } \\
\text { by IDPs and the ways to address them. In some cases, material or financial } \\
\text { assistance can be provided, for example to establish absentee voting } \\
\text { mechanisms or to facilitate voter transportation. }\end{array}$ \\
\hline
\end{tabular}




\begin{tabular}{ll}
\hline Training & $\begin{array}{l}\text { Support training about the rights of IDPs, including the right to political } \\
\text { participation, and standards for free and fair elections, for relevant } \\
\text { stakeholders, including government officials, particularly electoral officials } \\
\text { and law enforcement agencies, IDP communities, particularly community } \\
\text { leaders, both female and male, and local NGOs and civil society. }\end{array}$ \\
\hline $\begin{array}{l}\text { Presence and } \\
\text { monitoring } \\
\text { (See Parts V.2 }\end{array}$ & $\begin{array}{l}\text { Maintain visible protection presence in areas of displacement during and } \\
\text { immediately after elections, if security conditions allow. Visible protection } \\
\text { and } 4 \square)\end{array}$ \\
$\begin{array}{l}\text { presence can encourage participation and discourage election-related } \\
\text { fraud, violence and abuse. }\end{array}$
\end{tabular}

\section{Key actors}

- At the national level: displaced individuals and communities; national electoral commissions; ministry of justice and the interior; national courts and tribunals; law enforcement agencies; national human rights institutions; local NGOs and civil society, including the media.

- At the regional level:

- in Africa: the African Union's Election Unit; at the sub-regional level, the Economic Community of West African States (ECOWAS) and the Southern African Development Community (SADC);

- in the Americas: the Organization of American States (OAS) Unit for the Promotion of Democracy; and

- in Europe: the Office for Democratic Institutions and Human Rights (ODIHR) of the Organization for Security and Cooperation in Europe (OSCE); the European Commission for Democracy through Law (Venice Commission) of the Council of Europe; and the European Union.

- At the international level: United Nations Electoral Assistance Division (EAD) of the Department of Political Affairs; International Organization for Migration (IOM), particularly its project on Political Rights and Enfranchisement System Strengthening (PRESS); International Institute for Democracy and Electoral Assistance (IDEA); Inter-Parliamentary Union (IPU); the Commonwealth Secretariat; and the United Nations Office of the High Commissioner for Human Rights (OHCHR). In addition, a number of international NGOs, such as the International Foundation for Electoral Systems (IFES) and the Carter Center, provide electoral assistance and undertake election-observation missions.

\section{Key references}

- Safeguarding IDP Voting Rights, by Mooney E. and Jarrah B., in Forced Migration Review, Vol. 23, 2005.

- Incorporating the Guiding Principles on Internal Displacement into Domestic Law: Issues and Challenges, Chapter 13: Political Participation Rights in Particular the Right to Vote, by Jeremy Grace and Erin Mooney, Brookings-Bern Project on Internal Displacement and American Society of International Law, 2010.

- Peacebuilding through the Electoral Participation of Displaced Populations, by Jeremy Grace and Erin Mooney, in Refugee Survey Quarterly, Volume 28, Number 1 pp. 95-121, 2009.

- Enfranchising Conflict-forced Migrants: Issues, Standards, and Best Practices, by J. Grace and J. Fischer, Participatory Elections Project (PEP), Discussion Paper No. 2, IOM, 2003. 
- Displaced and Disenfranchised: Internally Displaced Persons and Elections in the OSCE Region, by E. Mooney and B. Jarrah, in 29 Ethnopolitics 36, 2005.

- Internally Displaced Persons' Voting Rights in the OSCE Region, by E. Mooney and B. Jarrah, Brookings-SAIS Project on Internal Displacement, 2004.

- Enhancing Women's Participation in Electoral Processes in Post-conflict Countries, UN Office of the Special Adviser on Gender Issues and Advancement of Women, UN Doc. EGM/ELEC/2004.

- Women and Elections: Guide to Promoting the Participation of Women in Elections, United Nations, 2005.

- Training Manual on Human Rights Monitoring, Chapter XIV: Election Observation, OHCHR, 2001.

\section{Useful websites}

- Electoral Assistance Division (EAD) of the United Nations Department of Political Affairs: www.un.org/Depts/dpa/ead/

- European Commission for Democracy through Law (Venice Commission) of the Council of Europe: www.venice.coe.int/site/main/Elections_Referendums_E.asp

- Inter-Parliamentary Union (IPU): www.ipu.org/dem-e/overview.htm

- International Institute for Democracy and Electoral Assistance (IDEA): www.idea.int/

- - Office for Democratic Institutions and Human Rights (ODIHR) of the Organization for Security and Cooperation in Europe (OSCE): www.osce.org/odihr-elections/

- Political Rights and Enfranchisement System Strengthening (PRESS) project of the International Organization for Migration (IOM): www.geneseo.edu/ iompress/ 


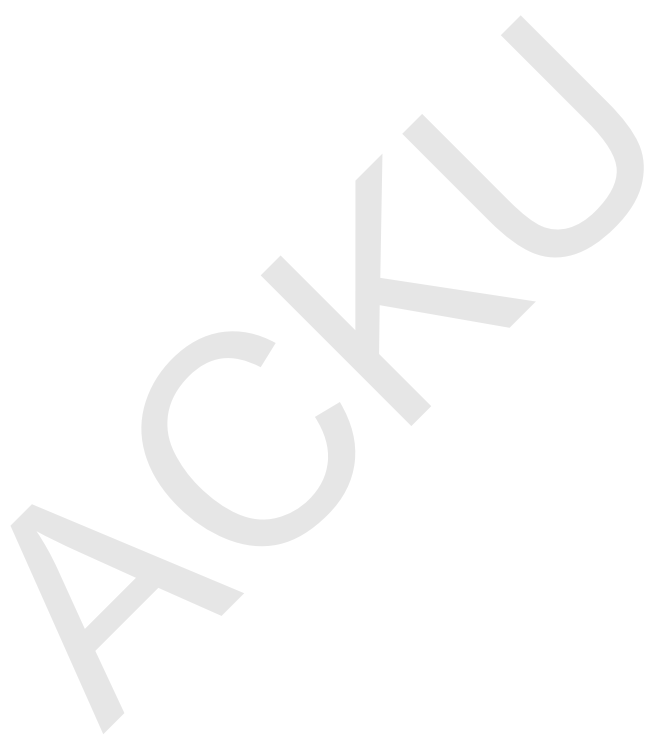




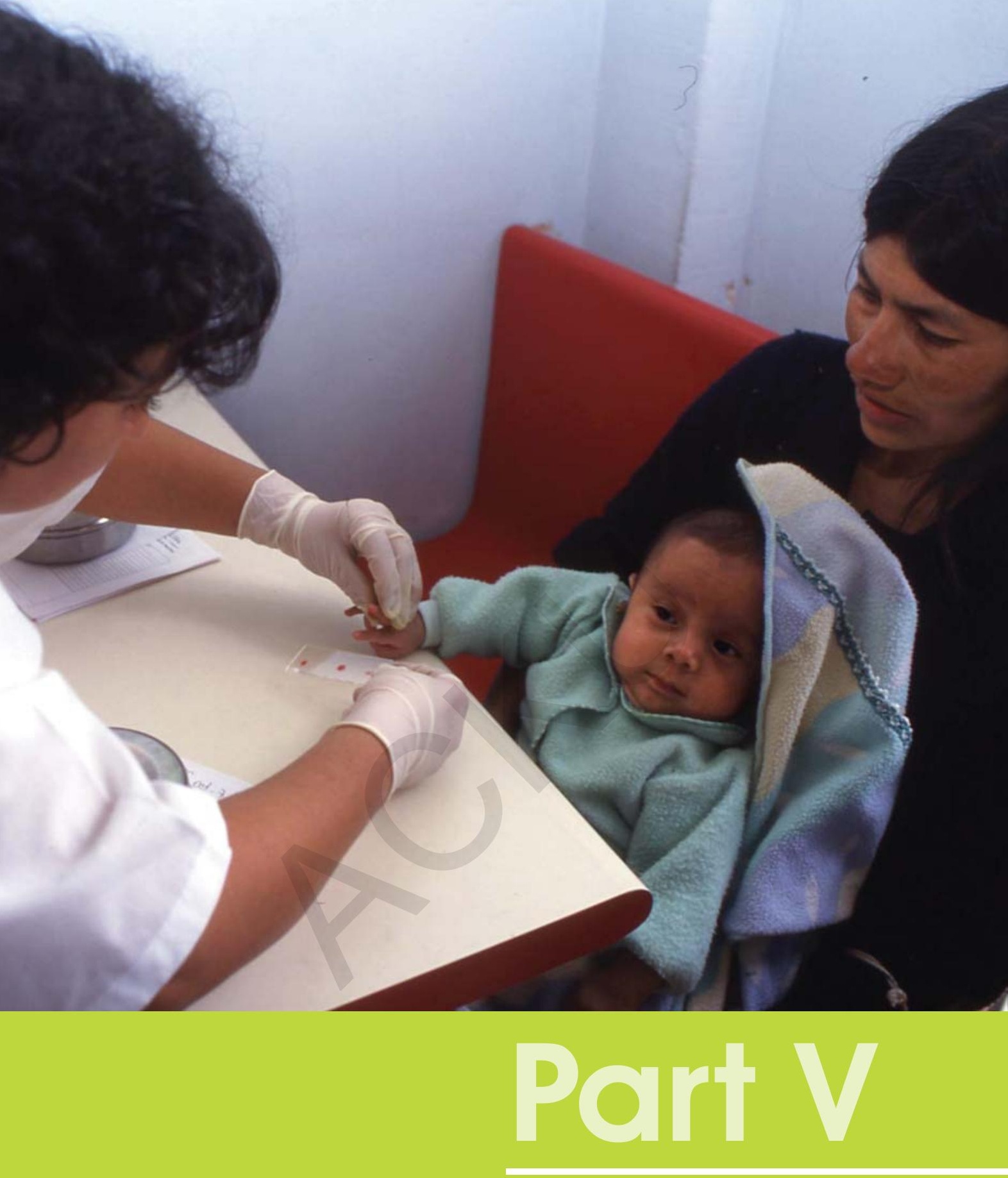

\section{ACTIVITIES AND TOOLS FOR PROTECTION}




\section{Overview}

The humanitarian response to situations of armed conflict or natural disasters involves a broad range of generic protection and assistance activities, which are usually strategically combined, as illustrated in Part III of the Handbook. The way in which humanitarian actors plan, implement or combine these activities may have a vital impact on the situation of the civilian population.

Part $\mathrm{V}$ of the Handbook offers guidance to help staff in the field maximize the potential of such activities for protecting internally displaced persons (IDPs) and other affected populations of different ages, sex and backgrounds. While it focuses on 13 activities, presented in 13 different chapters, Part V is not an exhaustive account of possible interventions. Activities herein have been selected following close consultation with the contributing organizations to the provisional release of the Handbook. The protection potential of such activities and their prevalence in IDP field operations were important criteria leading to the final selection.

The Chapters aim to highlight ways in which each activity can support IDPs and other persons of concern in realizing their rights. They also provide suggestions to build and strengthen the capacity of national authorities and communities at different levels to fulfil those rights. In doing so, they aim to help mitigate the potential for additional protection risks created through these activities. Part V is closely interlinked with Part IV, which deals with specific protection risks, and both parts complement each other.

Suggestions provided in these chapters are wide-ranging as they address humanitarian staff in field operations of varied nature and purposes. Therefore, humanitarian actors in the field will need to make a judgement call in the allocation of roles and responsibilities as appropriate. 


\section{Part V.1 \\ Profiling of internally displaced persons}

1. What is profiling and why profile internally displaced persons? .339

2. Main methodologies .340

3. Key protection considerations and challenges when undertaking profiling activities

Key references. .345

Useful websites .345 


\section{What is profiling and why profile internally displaced persons?}

Profiling internally displaced persons (IDPs) is a collaborative process in which data on individuals or groups who have been internally displaced is collected, with the purpose of informing advocacy on their behalf, improving protection and assistance interventions and, ultimately, finding a durable solution to displacement.

Data gathering, at all stages of the displacement cycle

For more comprehensive guidance on profiling see Guidance on Profiling of Internally Displaced Persons (2008). and, in particular, at the onset of an emergency, is important for a better understanding of an IDP situation and for ensuring the improved planning of protection and assistance programmes, including finding durable solutions for displaced persons. Profiling IDPs can reveal vulnerable individuals and groups and enable better targeting and designs of programmes to assist and protect them. It also helps prevent possible diversions of assistance.

The level of detail gathered through profiling will vary depending on the context. At a minimum, core data includes the number of IDPs disaggregated by age and gender, ${ }^{1}$ and their location(s). However, IDP profiling is not only about numbers. Additional information may include, but is not limited to, the following: the cause(s) of displacement; the patterns of displacement; protection concerns; key humanitarian needs; and possible solutions for the group or individual concerned.

Profiling may overlap with needs assessments, but they are different. A needs assessment is intended to gather and analyse a wide variety of data in order to obtain a comprehensive overview of humanitarian needs and protection concerns (further addressed in Part III.1 Da). Profiling, on the other hand, is primarily intended to identify the number and location of IDPs among other population groups, although information about urgent needs can be gathered as well. Profiling and needs assessments are different but complementary exercises that can be carried out in tandem, if appropriate and desired.

IDPs are entitled to the same rights as other citizens or habitual residents of their country. Profiling should not result in the creation of a real or perceived "IDP status." Such misperceptions may place IDPs at risk, contribute to discrimination and stigma, and exacerbate community tensions. It may also give the impression that IDPs are being singled-out for preferential treatment, or it could create incentives for others to present themselves as displaced in order to access assistance or services.

These might only be best estimates in many cases, especially in sudden emergencies or where IDPs are located in areas difficult to access. Estimates might be from primary or secondary sources and will need to be verified later with more systematic methodologies. 


\section{Profiling or registration?}

Registration is one of several profiling methodologies. It involves the gathering and recording of detailed personal data with the aim of identifying the person at a later time as is done, for instance, to facilitate the delivery of assistance and protection.

Registration is not necessarily required, and sometimes not even desirable, in IDP contexts; rather the benefits of registration depend on factors such as the actual need for detailed data, the role of the government, and the period during which the information will remain valid. Where registration is needed, all efforts must be made to explain the purpose of registration to displaced persons and seek their informed consent for the collection, registration and use of data.

Appropriate data-protection mechanisms must be put in place to safeguard confidentiality and protect those registered from potential protection risks, including violence, discrimination or stigma.

\section{Main methodologies}

IDP profiling is based on sound data collection. As IDP situations can vary widely, they will not all require, or even allow for, the same scope or type of data collection. Data collection methods must be conceptually sound as well as practical and well documented. They should facilitate the tracking of displaced persons and obtain realistic, commonly agreed estimates of their numbers and profiles.

The chart below gives an overview of the most practical and widely used methodologies, including both quantitative (numerical) and qualitative (non-numerical) methods. Quantitative methods are based on statistical designs, are comparable to one another, and are often complemented with qualitative methods. Note that most methods require some kind of triangulation, that is, a comparison of other data received in the same situation but gathered through different methodologies.

Methodology

\section{Description}

Quantitative methods. These methods collect (mainly) numerical data on the whole population or part of it, although the results can often be extrapolated for the whole population.

Desk review

Desk review involves the assessment and analysis of existing data from all available sources, both locally and internationally. It provides important background information and helps to assess what further data is needed. It can include a review of various types of data, such as statistics, reports, evaluations, news reports, governmental registers (e.g. tracking births, deaths, marriages, residence, voting, census), information provided by civil society organizations and so forth.

The IDMC database on internal displacement, covering over 50 countries, can be a useful source as well and is available at:

www.internal-displacement.org. 


\begin{tabular}{|c|c|}
\hline $\begin{array}{l}\text { Rapid population } \\
\text { estimates }\end{array}$ & $\begin{array}{l}\text { Such methods are suitable for estimating the numbers and basic } \\
\text { characteristics of a population in a short period of time, such as during } \\
\text { ongoing movement. Although ground access is generally needed for } \\
\text { accurate estimates, some estimates can be made without such access. } \\
\text { Rapid population estimates are most useful when applied to a well-defined } \\
\text { geographic area. Key methods are outlined below. } \\
\text { Area survey using aerial/satellite imaging is used to gain a broad } \\
\text { picture of an ongoing movement, to estimate numbers, or to see from } \\
\text { what people are fleeing and to where they are moving. These surveys } \\
\text { are useful when the need for information is uraent and access is limited. } \\
\text { Flow monitoring entails counting people as they pass a given point } \\
\text { (crossroads, bridges, mountain passes, etc.). This method can be } \\
\text { comprehensive as it can be used continuously, without interruption, or it } \\
\text { can be based on spot checks, which entails counting at the same location } \\
\text { at certain times of the day or week. This approach is useful when } \\
\text { estimating numbers during mass movement (e.g. during an exodus or } \\
\text { return). } \\
\text { Dwelling count involves counting the number of huts/houses/tents in a } \\
\text { given area to obtain an estimate of the number of the people in that area. } \\
\text { This approach can also be combined with a survey to obtain additional } \\
\text { information on the residents. } \\
\text { Head count is used to count the number of people settled in a given } \\
\text { area. This method is labour intensive in comparison to a dwelling count. } \\
\text { Dwelling/Head count using sampling methods, with the help of } \\
\text { sampling methods, }{ }^{2} \text { entails counting a subset of dwellings or of the } \\
\text { population, and it extrapolates the results to estimate the overall population } \\
\text { figure. }\end{array}$ \\
\hline Surveys & $\begin{array}{l}\text { Surveys involve the collection of data on a sample or part of the general } \\
\text { population and, then, generalizing the results. This approach can be } \\
\text { used at both the household and the individual levels. They are useful } \\
\text { when the population and ground conditions are stable, allowing for the } \\
\text { collection of additional information. } \\
\text { Surveys can be used to identify IDPs within a larger population group or to } \\
\text { identify individuals and groups with specific needs within the IDP } \\
\text { population. In this case, a cross-section of the whole population would be } \\
\text { interviewed to compare differences in socio-economic status or exposure } \\
\text { to risks between IDPs and the local population. }\end{array}$ \\
\hline
\end{tabular}

2 "Sampling" is the process of selecting a representative portion (or a "sample") out of the total ("sample universe"). It can drastically reduce the cost of the exercise in terms of time and human and other resources, while preserving the accuracy of the data to the maximum extent possible. In addition, profiling can be done using primary sources (data that agencies collect themselves) or secondary sources (data that come from the reports of others) or, for best results, a combination of both. 


\begin{abstract}
Registration
- The primary goal of registration is to establish the identity of persons through detailed data collection at the individual or household level. The level of detail and use of data will differ among humanitarian organizations, depending on the purpose of registration. For example, registration for the purpose of delivering assistance generally requires less detail than registration relating to specific protection interventions.

- Registration often takes place in a phased approach, first at the family/household level and then at the individual level. In most cases, registration data will have to be regularly updated (continuous registration).

Note! Informed consent must be sought for any collection, registration or use of data. The purpose of registration must be explained to all concerned prior to its taking place. Also note that registration interviews are not "status determination" interviews; IDPs have the same rights and entitlements as other citizens and residents in their country and do not need to "apply" or "be granted" a special status to receive protection and/or assistance.
\end{abstract}

\title{
Population census
}

Censuses are usually conducted by national governments every 10 years. A census covers the entire population of a country and, in addition to individual data, gathers a set of relevant socio-economic data. Humanitarian actors can support a census and, for instance, request that data relating to IDPs is also collected to improve protection and assistance interventions.

Qualitative methods involve the collection of (mainly) non-numerical data and are not based on statistical concepts. They complement quantitative methods and are particularly useful for triangulating and interpreting results.

Interviews

Focus group discussions: Focus group discussions are structured discussions, using the same set of questions, with different groups within the population. It involves separate discussions with women and men, of different ages, and diverse backgrounds (ethnicity, language, religion, with disability, etc.). They are helpful to gain a better understanding of people, their concerns and capacities, and to help ensure that the information collected represents the views of all the different groups within the society. (See Part III.1

- Key informant interviews: Key informant interviews are usually conducted with a small number of pre-selected individuals who may hold relevant information. Interviews should include both men and women of different ages and diverse backgrounds, as with focus group discussions.

Caution! The safety of displaced individuals, families and communities must be a primary consideration at all times. The rights to privacy and confidentiality must be respected, and informed consent is to be sought for the collection, registration and use of information. This requires that the purpose of profiling and intended use of information is clearly defined and explained prior to the profiling commencing. Adequate mechanisms for data protection and confidentiality must also be put in place. This includes ensuring that records are stored in secured and restricted areas, rooms and/or computerized systems. 


\section{Key protection considerations and challenges when undertaking profiling activities}

Regardless of the methodology chosen certain common protection standards must be taken into account and applied.

Support the role of The primary responsibility for providing protection and assistance to national authorities displaced persons and other affected communities lies with the national authorities. (See Part I.1 $\mathrm{D}$ ) Creating parallel structures and information systems may not be sustainable, thus, where possible national structures should be supported. This is all the more important where humanitarian actors have limited access to displaced populations.

Different considerations, however, may apply in cases where the authorities are unable or unwilling to provide protection and assistance, or where the information collected might put the displaced community at risk.

- Assess national data gathering systems and, where possible, work with and support such systems rather than create a parallel system.

\section{Ensure IDP/host community participation $^{3}$}

Both the displaced and the host community (men and women of different ages and diverse backgrounds) should be consulted in order to ensure that their views or concerns are accurately reflected (further addressed below). Clearly explain the purpose of profiling, including through information campaigns or through IDP governance committees. Failing to do so may undermine the accuracy of the profiling, increase reluctance or refusal of IDPs to participate and have adverse effects for displaced individuals and communities (further addressed in Part III.1 [D).

- When possible, ensure the participation of men and women of different ages and diverse backgrounds in all phases of the profiling exercise (planning, implementation, analysis).

- Experience has shown that IDP self-profiling can yield very useful data. It may also provide opportunities to identify community-based protection mechanisms in need of support and gaps to be filled.

- Consider in advance how the profiling will be perceived by the IDP community, the local community, local authorities and other actors, and take action to minimize any risk of tension, discrimination or stigma arising against the IDP community.

\section{Reach common objectives with partners}

Different partners may enter the profiling exercise having different requirements, objectives and divergent plans for follow-up.

- Ensure that all partners agree on the purpose of the profiling and the procedures and that the targeted result is improved protection of, and/or assistance to, the relevant population.

- Be inclusive; try to incorporate the expertise of other sectors/clusters in profiling exercises, and share the results with relevant humanitarian partners.

Usually, profiling targets IDPs, as their situation is unknown and data on host communities is normally available on official records. However, appropriate profiling can also target surrounding communities to get a better appraisal of the IDP situation as well as an updated overview of the situation of the communities. 


Respect privacy
and seek informed
consent

Protect confidentiality

"Profile" our team members

Some IDPs may prefer to remain anonymous and not be identified as being displaced, either for reasons of privacy or because of a fear of discrimination, stigma or various forms of violence, including forced evictions or arrest and detention.

- Always seek informed consent from individuals on the collection, registration and use of data. This requires that the purpose of profiling and the intended use of resultant information are clearly defined and explained prior to their taking place.

- Assess what impact the profiling exercise may have on IDPs and their communities prior to its taking place. Where IDPs either oppose the exercise or their safety and security may be put at risk, profiling may need to be limited to secondary data analysis.

Profiling and other information gathering often involve the collection and management of sensitive and confidential information. Inadequate data security and data-protection measures can both violate people's right to privacy and place them at risk. The safety and best interests of IDPs must be a paramount consideration at all times.

- Ensure that confidentiality guidelines are adopted and implemented and that the confidentiality of data is secured at all times.

- Ensure that the use, exchange and transfer of personal data respect confidentiality guidelines and applicable national and international legal provisions pertaining to the right to privacy and/or data protection.

- Ensure that all staff, in particular staff who collect and process personal data, are fully informed of the duty to respect confidentiality.

Teams undertaking profiling may need to gather data from individuals of different ages, gender and backgrounds, who may have suffered as a result of conflict, displacement and human rights abuses.

- Detailed interviewing of victims/survivors of human rights abuses should never be undertaken by those undertaking profiling. Interviewing requires skills, a solid understanding of protection, and knowledge of available referral and response mechanisms. It should only be undertaken by trained staff. When specific protection concerns arise during the profiling exercise, ensure follow-up or referral of these issues to trained staff.

- Ensure that profiling teams include individuals of different ages, gender and ethnic, religious, linguistic and other backgrounds to facilitate outreach and to counter possible mistrust, fear or perceptions of partiality.

\section{Keep in mind} 'invisible' IDPs
While some IDPs may seek safety in camps, settlements or public areas and buildings where they can easily be identified, others may be nomadic, seek shelter with friends, family members or "host families" in urban or rural areas, or may have been displaced for a long period of time. They, thus, may be difficult to locate or distinguish from the resident population. Certain individuals or groups, such as women, children, older persons and persons with disabilities, often remain "hidden" or lack freedom of movement. As a result, they are sometimes neglected or ignored by humanitarian programmes.

- Ensure that profiling exercises do not overlook certain IDP groups, such as those living with host families or in rural areas, or certain individuals, such as women, children, older persons or persons with disabilities. Increase outreach efforts. 
Different methodologies are usually required to gather data on visible and invisible IDPs. Use census data covering the area from which people have fled (if available), rather than making a head count of only those IDPs who are visible and easy to access. More detailed profiling can take place at a later stage.

- Household surveys can be useful in such circumstances, as they enable the collection of more detailed information, including not only IDPs but also host families.

- Information indicating an increase in numbers of people living in certain areas or accessing certain services can also be useful.

Ensure data is gathered according to age and gender
The disaggregation of data according to age and gender is necessary to be able to assess the specific situation or needs of men and women of different age groups.

- Make an effort to obtain information specific to men, women, girls and boys to minimize the possibility of overlooking specific needs related to age and gender.
Formulate specific mechanisms for IDPs on the move

\section{Coping with} pressures related to numbers
Population movements during displacement can change continuously, and it can be difficult to distinguish between those who are still on the move, those who have settled temporarily, and those who are moving back and forth between their homes and hiding places or camps.

- In addition to other methodologies, it can be helpful to form a dedicated "population movement committee." Such committees, which include participation by local authorities, NGOs and civil society, try to obtain regular data on new IDP movements.

- Ensure the close monitoring, control and verification in beneficiary registration process, in particular when dealing with IDPs moving between sites to avoid potential errors or double registration.

Profiling may bring to light that previously known numbers were underestimated or, in some cases, overestimated. There may be political or financial pressure either to limit or to inflate numbers. Numbers may also be used or misused for political or other purposes.

- Such pressures are best overcome if all involved ensure that profiling exercises are methodologically sound and undertaken in a collaborative, transparent and inclusive way.

\section{Key references}

- Guidance on Profiling of Internally Displaced Persons, IDMC, November 2007.

- Improving IDP Data: Prerequisite for More Effective Protection, by E. Rasmussen, in Forced Migration Review, p.16-17, December 2006.

- Handbook on Registration, UNHCR, 2003.

- Directive 95/46/EC on the protection of individuals with regards to the processing of personal data and on the free movement of data, the European Parliament and the Council of Europe of 24 October 1995.

\section{Useful websites}

- Internal Displacement Monitoring Centre: www.internal-displacement.org 


\section{Part V.2 \\ Protection monitoring}

Key message

1. Why undertake protection monitoring?

2. The key principles of protection monitoring ..............................................................348

3. How protection monitoring is undertaken in a context of internal displacement.

4. Who monitors protection?

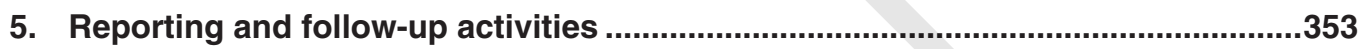

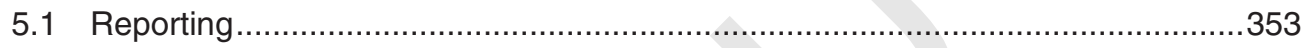

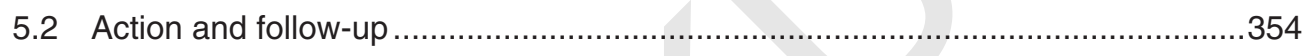

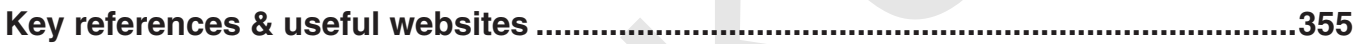

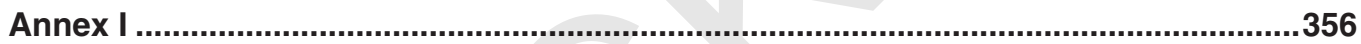




\section{Key message}

Protection monitoring in a context of internal displacement generally involves collecting, verifying and analysing information in order to identify violations of rights and protection risks encountered by internally displaced persons (IDPs) and other affected populations for the purpose of informing effective responses. There are risks to protection monitoring, and there are situations in which protection monitoring may not be an appropriate activity. Protection monitoring should be coordinated and undertaken by agencies with a specific expertise to do so, generally in cooperation with other relevant United Nations agencies, members of civil society, national and local government, as well as IDPs themselves and other affected populations. Perhaps most importantly, protection monitoring is not an end in itself, but is undertaken for the purpose of taking protective action that will improve respect for the human rights of the persons monitored.

\section{Why undertake protection monitoring?}

The immediate objective of protection monitoring is to assist and guide evidence-based action by relevant national and international actors in order to ensure the full respect of the rights of IDPs and other affected populations. These actions might include specific interventions on behalf of individuals and groups, the planning and implementation of humanitarian assistance operations or protection interventions and advocacy or other activities by international actors and national and international civil society.

Actions by relevant international and national actors must seek, to the extent feasible, to persuade and assist national authorities to assume their obligations towards IDPs and other affected populations. Thus, the ultimate goal of protection monitoring is to reinforce the responsibility of State actors and relevant non-State actors to protect these populations.

Protection monitoring is distinct but also closely related to protection assessments. ${ }^{1}$ The box below shows some of the differences and also the points of contact between both activities.

\section{Protection monitoring and protection assessments}

In general, protection monitoring is distinct from protection assessments in a number of ways, as outlined below.

Protection monitoring seeks to identify and measure events, trends and changes in the protection situation over a period of time, while a protection assessment is intended to produce a general picture of the protection situation at a particular date.

Protection monitoring seeks to inform specific protection interventions, while a protection assessment may provide the basis for a general protection strategy or for a cycle of protection programming.

Protection monitoring takes place at regular intervals over an extended period of time. A protection assessment may also take place more than once. However, a decision to undertake a renewed protection assessment is taken on an ad-hoc basis when a previous assessment is deemed no longer valid because, for example, of the passage of time or a change in circumstances.

It is also important to distinguish between protection monitoring and programme/project monitoring. The latter, in general, will try to measure progress to a specified objective which is attributable to project outputs, using a number of predefined indicators, while protection monitoring measures the general protection situation of a given population and its evolution over time. However, in some cases, data from protection monitoring may be useful for programme/project monitoring, particularly in the case of protection projects such as legal advice or measures to prevent and reduce gender-based violence. 
It is essential, however, to keep in mind a number of important points of contact between protection monitoring and protection assessments.

A protection assessment may provide a baseline for protection monitoring which, in turn, can assist in adjusting over time the results of the assessment;

protection monitoring can assist in measuring the impact of protection strategies or programmes designed on the basis of protection assessments; and

results from protection monitoring may trigger adjustments in protection strategies or programmes, or even signal the need to launch a renewed protection assessment.

It is important to design protection monitoring mechanisms, when feasible, in such a way as to maximize interaction with protection assessments by, for instance, ensuring that indicators are comparable and mechanisms to store, manage and analyse data are compatible.

\section{The key principles of protection monitoring}

Protection monitoring is undertaken through a series of steps that usually include: the collection of information on protection problems and violations of rights; ${ }^{2}$ analysis of the information to produce regular or ad hoc reports, including for instance statistics to identify trends; and preparation of the information for deciding protection responses. In all cases, it is of the essence that protection monitoring agencies have the necessary capacity, skills and willingness to comply with adequate standards for the collection and management of protection information.

Acting on the findings of protection monitoring is not, in itself, part of a monitoring system. However, protection monitoring is never to be undertaken without the certainty that an agency with the adequate mandate, capacity and skills will take appropriate follow-up action to protection problems revealed by monitoring including, for instance, advocacy activities.

In many situations, different agencies will undertake data collection, analysis and follow-up action. If this is the case, clear rules for the division of responsibilities and mechanisms for the coordination of efforts need to be laid out on the basis of the mandate, resources, capacity and skills of the different actors involved in protection monitoring. These may include:

- regular meetings of protection agencies to analyse findings and agree on follow-up action (for instance agreeing on priority issues for advocacy);

- regular meetings with authorities to convey advocacy messages; and

- the establishment of referral networks for individual cases.

Protection monitoring may entail significant costs and risks. Valuable time and resources are invested not only by monitoring agencies but more importantly by participating IDPs and other affected populations. The mere presence of monitors may trigger important side effects. It can raise undue expectations among the communities being monitored. In areas affected by armed conflict, it can also have a moderating effect on armed actors (protection by presence) or, on the contrary, it can fuel their animosity thereby creating additional risks for IDPs and monitors alike and contributing to reduced humanitarian space.

Protection actors, therefore, must consider carefully a number of factors before establishing a protection monitoring system. They should clearly define the specific objectives they are pursuing, the information necessary to fulfil them, the level of detail and reliability required, and whether or not regular and reliable sources already exist for parts or all of this information. For

In most cases, an adequate understanding of a protection problem involves also assessing the response being given to it by duty bearers and other actors. In these cases, information regarding responses and their effectiveness must also be collected by protection-monitoring systems. 
instance, registration or profiling systems may already yield valuable information about the magnitude and characteristics of displacement and the needs of displaced persons. It is also essential to establish the form of monitoring to be undertaken, as shown in the box below.

Protection monitoring can take different forms according to the goal pursued. Some of these are indicated below.

General or community-level monitoring, which assesses changes in the overall protection situation in a community, a village, a region or a country, might offer information about specific incidents and affected individuals, but general monitoring focuses on understanding trends and patterns in order to inform and improve programming and project implementation. It can be undertaken by most field staff with adequate training as long as basic protection considerations are taken into account.

Incident or individual-level monitoring, which aims to document human rights violations suffered by victims and survivors, requires the collection of sensitive and often confidential information from victims/survivors or witnesses and might reveal specific protection problems that require immediate response and referral. Ideally, such monitoring contains a case -management component. It should always be undertaken by trained protection/human rights monitors. Incident monitoring should not duplicate existing, well-functioning national structures.

The form of the intended monitoring needs to be defined before designing the monitoring system, since the standards, methodologies and information management protocols vary widely according to the level of the information sought.

An adequate assessment of risk needs to be undertaken early in the design phase of a monitoring system and before each monitoring activity. Monitoring agencies are responsible for managing these risks in an appropriate way.

Applying the general principles explained in Part 1.1 of the Handbook $\square$, protection monitoring must be independent, impartial and conform to the "do no harm" concept. Monitors must respect the principle of confidentiality, protect their sources, be sensitive to the feelings and traumas of victims and witnesses, and not make promises they cannot fulfil. IDPs and affected populations must be made aware of the purposes of the information collected and, whenever feasible, of the follow-up action undertaken. The burden on these communities needs to be minimized by reducing any duplication of monitoring efforts and sharing relevant data and analysis among humanitarian organizations, as long as confidentiality rules permit. Monitoring agencies should respect the proper functioning of national and local authorities and seek ways to support local capacity building.

Protection monitoring agencies should take any steps necessary to ensure the safety of their monitors, particularly if there is a potential for reprisal or retribution. They should be transparent with State and appropriate non-State interlocutors as well as other relevant actors about the nature of their work. However, this duty for transparency does not entail the sharing of confidential information or any other information when this may create or worsen risks for IDPs and affected populations or the monitors themselves.

Benchmarks and indicators used for monitoring must be based on the rights defined and guaranteed by national laws as well as relevant international human rights and humanitarian law instruments and regional treaties (including particularly the African Union Convention for the Protection and Assistance of Internally Displaced Persons in Africa). A number of authoritative policy documents relating to IDPs also provide a useful basis for monitoring, such as the Guiding Principles for Internally Displaced Persons and the Framework for Durable 
Solutions. Monitors should be familiar with the international and regional mechanisms and mandates established for the protection of human rights and, when applicable, that of protected persons under international humanitarian law.

As a general rule, when the quantity of information produced by monitoring reaches an amount not permitting manual analysis (e.g. because of covering a wide geographical area, or a high number of persons), a database will be needed to store, combine and analyse data. Monitors, then, will need to use formal data collection tools focusing on quantitative information or questions eliciting closed answers to facilitate automated management of the information. In these cases, formal monitoring should always be adequately balanced with more qualitative and even informal methodologies such as desk reviews, regular contacts with key informants and the IDP population at large, etc.

Detailed guidance on information management cannot be provided in the context of this concise note. However, whenever a monitoring system is expected to involve formal data collection tools or usage of a database, it is essential that data management specialists be closely involved in the design process.

\section{How protection monitoring is undertaken in a context of internal displacement}

Internal displacement is often a result of violations of human rights or international humanitarian law and may itself constitute a violation of rights. At the same time, internal displacement always bears important consequences in terms of the enjoyment of rights by the IDPs. Internal displacement is, therefore, in itself a protection concern that protection monitoring systems need to measure. In some cases, displacement is a one-off phenomenon and rapid needs assessment mechanisms will be able to ascertain its magnitude and characteristics. This is, however, rarely the case. In most contexts, displacement follows complex patterns that are extended in time and space, and it is nearly impossible to foresee with any accuracy its occurrence. Protection monitoring systems, therefore, should strive to measure the dynamics of displacement over time, including the numbers of persons being displaced (taking into account the age and gender breakdown), the causes and patterns of displacement and the places of origin and destination. Movement that needs to be measured may also include secondary displacement or spontaneous return or settlement elsewhere in the country.

Protection monitoring can be conducted under different modalities. The choice will be determined by contextual and operational factors, such as the type of setting, the size of the population being monitored, the specific operational purpose of the monitoring activity, and the resources (both human and financial) available for monitoring. Monitoring can take place within camps or collective centres, in rural areas or in urban settings. While always based on the same international standards, monitoring can focus on certain aspects of any given situation. For example, within camps, monitoring can examine distribution systems, the physical locations and layout of camps, health facilities, the situation of vulnerable groups, physical protection, including sexual and gender-based violence and abuse, and issues related to psychological assistance and social welfare. When IDPs are in host communities, it is important to look at the impact they may have in the protection situation of these communities themselves.

Monitoring activities should also cover the various phases of the displacement cycle and should include persons already displaced, persons at risk of displacement, returnees, and affected host populations. In many cases, the monitoring of the conditions under which return takes place is an essential part of protection monitoring with IDPs. 
Different monitoring approaches may be required to monitor these different types of populations and situations. Particularly for communities at risk of displacement and persons who have returned, are settling locally or have settled in other parts of the country, protection monitoring for IDPs should be coordinated or even mainstreamed within wider monitoring systems for the whole of the affected population. For instance, general human rights monitoring systems in areas of origin will yield useful information about the causes of displacement. At the same time, the implementation of these systems in areas of return or local settlement will provide information on possible patterns of discrimination of the IDP population and the degree to which durable solutions are being achieved, provided the results can be broken down by type of population (IDP / non-IDP).

No one approach to monitoring is appropriate for all situations; yet for each situation, the approach used to gather specific pieces of information should be clearly recorded. That will make it easier to verify the data collected and to confirm that the approach used successfully captured the protection concerns specific to the situation.

\section{Some approaches for monitoring protection}

As a first step, define the specific objectives that monitoring is intended to fulfil, and whether or not reliable information necessary for these objectives is already available from other sources. As an instance, in some cases registration systems may already provide regular and valuable information about the dynamics of displacement over time, its causes, and the age and gender breakdown of displaced persons. Information provided by protection assessments and profiling exercises should also be taken into account. In addition to this, methods for gathering information may include:

Spot-checks or camps/settlement walkabouts, home visits;

Direct contact by victims or witnesses;

Surveys of areas of displacement, return or settlement, in total or in random sample;

Informal or semi-structured interviews with individuals in random sample;

Community, camp-management meetings or focus group discussions (with IDPs, host communities, other relevant groups) (see Part III.1

Complaints mechanism within agencies;

Liaison with national human rights institutions;

Reviewing police or camp security incident records or logbooks;

Questionnaires to communities;

Information collected directly from protection interventions, such as Legal Advice Clinics, Women's Protection Centres or other systems for case management;

Regular meetings among humanitarian organizations and with local actors;

Review and analysis of reports and documentation by other parties, such as situation reports, protection reports, sub-agreement monitoring reports and press reports.

While the context and operational purpose will determine how the monitoring is conducted, as a general practice, protection monitors should ensure the following.

- Collect background information: Monitors must have a good understanding of the social, political, cultural and economic contexts, including issues such as the root causes of the displacement, political actors, ethnic tensions, and the role of non-State actors. (See also Part III.1.

- Develop contacts and networks, and establish a presence in the community: Monitors must establish a network of contacts and sources of information. These will 
generally include members of the displaced and host communities, government officials at various levels, journalists, civil society groups, parliamentarians, and international actors. Such contacts provide both background and case-specific information; they also play a key role in advocacy and follow-up action. Networks of contacts established by other clusters/sectoral groups can also be used and expanded.

- When appropriate, collect and document testimonies and complaints: Information-gathering requires pursuing all credible leads regarding protection concerns, including individual incidents. Monitors should be available and ready to move at any time to receive information, when appropriate, directly from a victim or a witness. The safety of victims and witnesses and of staff as well as the "do no harm" principle should be a key consideration when doing so, particularly immediately after an incident, when tension and risks might still be high. An Annex on interviewing victims or witness of violations is attached to this chapter (Annex I).

- Identify and prioritize issues to pursue: Monitors should analyse the range of reported violations and protection risks and prioritize on the basis of established criteria those that will be pursued in the framework of protection monitoring.

- Ensure the accuracy of information concerning an alleged violation: Monitors are rarely direct witnesses to violations; they usually learn of such incidents from victims or other witnesses. Monitoring, thus, requires techniques for collecting accurate and precise indirect information. Monitors must check the accuracy of information received, regardless of whether it is from an interview with a victim, a witness statement, the media, or other sources. To ensure the accuracy of the substance of the information, the monitors should confer with other relevant and trusted actors (preferably more than one), witnesses, organizations or associations that have knowledge of the matter, including by collecting relevant documentation such as medical reports.

\section{Who monitors protection?}

Protection monitoring can be undertaken by different groups of actors or by just one main actor. When monitoring is undertaken by several actors with a range of protection and non-protection expertise, it should be coordinated by one single actor with the required expertise. Having staff from various agencies and organizations involved in monitoring can enhance the coverage and quantity of information collected and increase the number of sources of data.

In order to avoid duplication of efforts, inappropriate sharing of confidential data and adequate coordination, monitoring activities should be conducted through an agreed inter-agency framework that includes the clear identification of roles, division of labour based on mandate and expertise, and agreements on the property and use of data resulting from monitoring.

Protection monitoring should be coordinated by actors and staff with specific protection and technical expertise to ensure appropriate quality control, methodological consistency, and normative and ethical rigour. Agencies with specialized monitoring staff include $\mathrm{OHCHR}$, UNHCR, UNICEF, human rights components of United Nations peace missions, situation-specific mandates given by UN Security Council resolutions, and ICRC. Amnesty International, Human Rights Watch and several other NGOs are also specialized in protection-monitoring activities. National human rights institutions also monitor, document, and react to rights violations.

National staff members are highly valuable resources in protection monitoring. They are likely to have more information, local language skills and a deeper understanding of the background and impact of the internal displacement crisis. Monitors and their agencies, however, must remain aware that real or perceived cultural, religious and other affinities of national staff may 
encourage or, conversely, constrain victims and witnesses from reporting incidents. National staff or their families are also exposed to potential risks of retribution, including from within their own communities.

The ideal protection monitoring presence is, thus, a mix of national and international staff. Sensitive demarches with national interlocutors should be undertaken by international staff whenever such demarches might expose national colleagues to greater risk.

Protection monitoring can be enhanced by including non-specialized individuals and agencies, such as shelter NGOs, water engineers and logistics staff, as sources of information given that they have wider access or more human resources. However, their involvement should normally be limited to gathering information at the community or area level. They should not be requested to collect sensitive information relating, for instance, to gender-based violence, etc. Agencies responsible for protection monitoring should establish clear and reasonable expectations on the level, accuracy and nature of the information required, and communicate them clearly to the agencies requested to collect the information.

Where individual victims or witnesses come to the attention of such monitors, the role of the non-specialists would generally be restricted to ensuring that the initial report is channelled to appropriate specialists for a full interview and any relevant follow-up. This division of labour is necessary to ensure that victims are not asked to recount painful experiences repeatedly, to preserve the confidentiality of the information, and to ensure that any legal advice given is accurate and appropriate.

In some cases, national bodies such as national Human Rights Commissions or local NGOs have the capacity, willingness and legitimacy to conduct protection monitoring in a way that complies with applicable standards. In these cases, international and non-governmental actors should not unnecessarily duplicate or undermine their efforts and, whenever possible, they should provide them support for the establishment or improvement of monitoring systems.

\section{Reporting and follow-up activities}

\subsection{Reporting}

Reporting is an important element of the monitoring function. While detailed guidance on reporting cannot be provided in this Handbook, there are some general principles that apply to any reporting methodology and to any individual report. Reporting in the context of protection monitoring must be accurate, objective, precise, prompt and action-oriented. It should include information on initial response(s) and recommendations for further responses by the organization or through an inter-agency approach. A distinction is normally made between internal and external reporting, as outlined below.

- Internal reports:

periodic reports (e.g. situation reports) document a situation, the work accomplished and plans;

- emergency reports alert managers of the need for action, likely on an ad hoc basis, and they include basic facts and recommendations;

- interview reports/questionnaires record the results of an interview and specify the reliability of the source; and 
- incident reports provide an overview of all information collected about an incident.

\section{- External reports:}

- reports addressed to the government as a means of working with the government to improve its protection of IDPs;

- reports shared within the wider humanitarian community, the United Nations (the United Nations Country Team, the Protection Cluster, the Security Council, the Human Rights Council, treaty mechanisms, or country/thematic rapporteurs) and other relevant actors, such as the diplomatic community, which can help shape policy and programming activities by other actors; and

- public reports used as a general source of public information and advocacy tool.

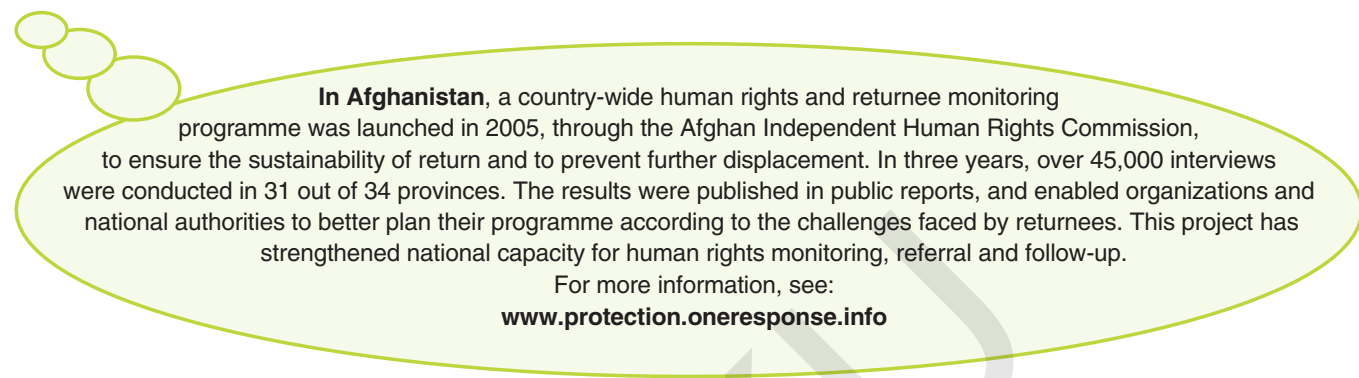

Because external reports are generally compiled on the basis of several internal reports, it is crucial that the internal reports provide detailed information, use consistent terminology, and adopt consistent approaches to information so that the officer who prepares the external report can rely on the facts gathered and can draw useful general conclusions regarding trends in the evolving human rights situation. External reports should not include confidential information on victims and sources.

\subsection{Action and follow-up}

Monitoring is not an end in itself but rather an activity to produce information that needs to be acted upon, particularly when it refers to specific violations of rights. Usually protection agencies will have a systematic process to decide upon follow-up action after the findings of monitoring have been properly analysed. However, as a general rule, protection monitors should take immediate action on gross human rights violations and protection risks affecting the physical safety of individuals or groups. This may mean, inter alia, referring the case to specialized agencies, national human rights institutions or civil society groups, reporting the case immediately to senior management, intervening with the national authorities to find a solution, undertaking advocacy work with non-State actors, etc.

Standard operating and referral procedures for follow-up action should be established at the inter-agency level in each field operation. (See also Parts IV and V Wof this Handbook for detailed guidance on addressing specific human rights violations identified in the course of monitoring activities and humanitarian interventions.)

Other ways to act upon monitoring information are noted below.

- Continue advocacy with duty bearers for compliance with recommendations included in reports. In many cases, continued protection monitoring will itself shed light on efforts by duty bearers to comply with recommendations and assume their protection responsibilities. When the intended results are not achieved, the advocacy strategy may need to be adjusted (also addressed in Part V.3 [D). 
- Carry out protective actions for individual cases identified, or referring them to agencies with the appropriate mandate and capacity to act upon them;

- Adjust strategies and protection interventions;

- Identify a need for a renewed protection assessment, either to adjust or revise a strategy, or for purposes of protection programming on a specific issue.

\section{Key references \& useful websites}

- A significant portion of the material in this chapter is adapted from The OHCHR Training Manual on Human Rights Monitoring, Professional Training Series No. 7, $\mathrm{OHCHR/United} \mathrm{Nations,} \mathrm{New} \mathrm{York} \mathrm{and} \mathrm{Geneva,} 2001$

- Enhancing UNHCR's Capacity to Monitor the Protection, Rights and Well-Being of Refugees: Main Report, Kelley, N., Sandison, P. and Lawry-White, S., UNHCR/EPAU, Geneva, June 2004.

- Implementing the Collaborative Response to Situations of Internal Displacement: Guidance for United Nations Humanitarian and/or Resident Coordinators and Country Teams, IASC, Geneva Sept 2004.

- Operational Protection in Camps and Settlements: A Reference Guide to Good Practices in the Protection of Refugees and Other Persons of Concern, UNHCR/DIPS/SOSS, Geneva, 2006.

- Policy Paper Series No. 2: Protection of Internally Displaced Persons, IASC, United Nations, New York, 2000. 


\section{Annex I}

\section{Interviewing victims and witnesses}

The challenge of interviewing in protection monitoring is to respect the dignity of the interviewee while remaining an objective, neutral and non-judgmental recorder of significant data.

Interviewing victims and witnesses of violations is a complex and delicate activity that should only be carried out by appropriately trained protection staff.

Protection monitors should consider:

1. whom to interview;

2. how to initiate an interview;

3. who should conduct the interview;

4. how to determine the language in which the interview should be conducted;

5. who should translate;

6. where the interview should take place, in order to protect the witness;

7. how the interview should be recorded so that the information is both objectively documented and protected;

8. how to handle cultural differences, such as notions of time, place and truth, that might inhibit communication;

9. how to interview without creating unrealistic expectations regarding access to justice, to humanitarian assistance, to resettlement, etc.; and

10. how to respond appropriately, whether directly or by referral to other specialist agencies, when the interviewee needs immediate attention.

All monitors need to:

- develop a rapport with the interviewee;

- explain the interview process and the mandate of the organization or of the inter-agency approach;

- discuss the ground rules for the interview;

- talk about how the witness might be protected (without creating false expectations) after the interview;

- anticipate how the information will be used;

- encourage the witness to tell his/her story truthfully in his/her own words before asking specific questions.

In all cases, monitors need to seek the written consent of interviewees before attributing the information provided to them.

Monitors must be trained to identify and respond appropriately to the particular needs and traits of some categories of interviewees, including victims of torture, women, children, and persons with disabilities. Monitors will also need to be in a position to assess the credibility of the witness or the victim in order to ensure that the information collected is reliable.

When establishing protection-monitoring system(s) for an IDP situation, the coordinating or lead agency should establish standard operating procedures, backed up by training to determine when interviews should be conducted by specialists. It should also develop that specialist capacity appropriately. 


\section{Part V.3 \\ Advocacy}

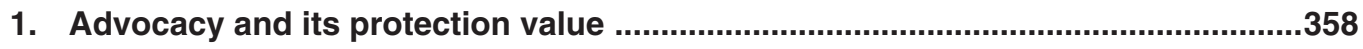

2. Key considerations for an advocacy strategy to improve protection ...................358

3. Challenges in advocating for the protection of internally displaced persons ........363

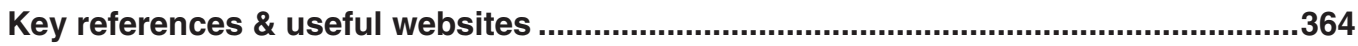




\section{Advocacy and its protection value}

Practiced by most stakeholders in humanitarian crises, advocacy is a set of activities aimed to promote change to bring policy, practice or law in compliance with international standards. In situations of internal displacement, advocacy is a vital tool to influence decision makers and stakeholders to adopt practices and policies that ensure the protection of internally displaced persons (IDPs).

Advocacy is a central building block of most comprehensive protection strategies. If strategically combined with other protection activities, such as information-dissemination, monitoring or negotiation, it can greatly contribute to transforming the underlying systems and structures that affect IDPs.

\section{Key considerations for an advocacy strategy to improve protection}

Most of the work of developing an advocacy strategy takes place before taking public action on the issue. An effective advocacy strategy ${ }^{1}$ includes:

1. determining the objectives of advocacy;

2. identifying the best target groups to address and focal points within these groups; and

3. determining the modalities and the tactics for the advocacy activities.

\section{Objectives}

We should set realistic and clear objectives. This will require dividing a specific protection objective into a set of sub-objectives to be achieved through different and complementary mechanisms, as outlined below.

- To define the desired outcome, it is essential to become thoroughly familiar with the issue of concern, including legal, policy and other issues related to the protection risks at hand. Protection monitoring can be very useful to identify protection trends and patterns, which may inform advocacy activities and contribute to measuring the impact of advocacy efforts on the lives of those concerned (further addressed in Part V.2 [D).

- When facing a particular protection risk, such as a lack of access to public services because IDPs lack documentation, we should try to figure out what is the expected change. Too often, we focus our advocacy efforts on protection concerns without promoting the best solution. A good understanding of the local legal and justice system, including the traditional justice system where it exists, is important to advocate for effective solutions to situations of inequality or conflict (further addressed in Part IV.18 $\square$ ).

- IDPs' real-life experiences and needs will be central to determine both the nature of the problem and the potential solution(s). Describing the problem and asking different members of the communities to come up with possible solutions is a good way to build a larger constituency to support advocacy efforts. Therefore, while continuing to document and discuss the relevant protection concerns, it is important to involve others in finding creative solutions to the problem.

- Other variables, such as gender, age, ethnicity, socio-economic background, or disability may also influence discrimination, violence or other protection risks experienced by IDPs. It is, thus, necessary to analyse the specific risks and needs of particular individuals or groups and build them into the formulation of the advocacy objectives.

Parts of this section have been adapted from Norwegian Refugee Council, Handbook: Information, Counselling, Legal Assistance, 2004, pp. 26-29. 
Two organizational goals, described below, should always be part of the advocacy strategy.

- Increasing community participation: It is important to reach out to individuals or groups, including IDPs and members of other affected populations, who are not actively advocating for the same objectives but who would have an interest in the issue. They should be given an opportunity to work on something that personally concerns them and in which they have vested interests. (See Part V.10.

- Promoting a coordinated inter-agency approach to the advocacy strategy: It is important to promote the participation of other protection-mandated organizations as well as those in other clusters/sectors who have shared concerns. Civil society groups and national institutions should also be involved to the greatest extent possible. Peacekeeping missions can be involved and support the strategy when they are present in the country. We should determine the advocacy role of the agencies involved as well as the key common messages, priorities and arguments. We should also assess the best approaches and risks that may be associated with the approaches.

- We should try to reach agreement about potential areas of compromise and non-negotiable issues. Those involved must be willing to abandon advocacy activities if the only way to achieve part of the plan is to compromise on the non-negotiable issues. Otherwise, if advocacy activities take off without a clear vision of the desired outcomes, there is a risk of achieving undesirable solutions, making existing problems worse, or creating new ones for the IDPs or the other affected populations. (See Part II.2 on negotiations.

\section{Advocacy targets}

An advocacy strategy for protection should target stakeholders who have or can have an influence on the protection concerns of IDPs or other affected populations with the aim of bringing about a change. Examples of different target groups are noted below.

- National decision and policy makers, such as national authorities from the executive, legislative and judicial branches, law enforcement authorities, community leaders, both official and de facto, opinion leaders such as traditional and religious leaders, non-State actors, rebel groups and paramilitary groups.

- Local actors and institutions that might play a key role in achieving the intended objective (e.g. doctors, nurses, school masters or teachers if the objective is to eliminate discrimination in accessing public services, such as health or education).

- Individuals or groups who might have an interest in the issue at stake and who would join and strengthen existing advocacy efforts (e.g. IDPs and members of other affected communities, local civil society groups, the business sector and the media). As discussed above, much of the early part of an advocacy strategy involves building community support for the issues at stake.

- The international community, which may include foreign governments with regional and/or domestic influence (as advocacy activities are usually conducted via their embassies in the country, consulates or other offices, such as government development agencies), regional and international courts, relevant human rights bodies and mechanisms, humanitarian organizations, such as the United Nations, and NGOs.

- It is important to determine who has the de facto and de jure power to make the desired decision and understand how that person relates to other people in the community's power structure. This can be done through a mapping exercise. If there are various decision makers, we should discuss with our partners our respective relationships (both current and historic). This will help identify who, among advocacy partners, is the best placed to address each interlocutor. 
- We should identify particular authorities or institutions that might be closer to our views or objectives. Governments or authority structures are not homogeneous, and it is helpful to develop a relationship with a broad range of actors who could eventually support the relevant advocacy goals, either by influencing key decision makers from within their own institutions or by providing useful advice on how to influence change.

\section{Key approaches to advocacy for protection services}

\section{- Formal versus informal advocacy}

- Informal advocacy activities take place all of the time in humanitarian crises in the form of talks and discussions among key stakeholders. Even though it might not be formally acknowledged, humanitarian workers, particularly those with a protection mandate, members of the affected populations and local authorities, spend most of their time advocating with their respective interlocutors. Each discussion, even at the most informal level, can have an impact on other stakeholders. Given the political sensitivity of IDP protection advocacy work, the potential effect of all positions and activities undertaken, even at the informal level, must be carefully considered at all times.

Formal advocacy activities can be carried out through position statements, analytical documents or letters to the authorities, by humanitarian organizations and community leaders, or by filing court cases (addressed further in Part V.8 Wu). These activities can help ensure accuracy in the wording of advocacy messages, thereby countering rumours and can have a multiplying effect since they can be widely disseminated among other stakeholders.

\section{Soft versus hard advocacy}

" "Soft" advocacy activities, such as awareness-raising, training activities and quiet diplomacy, are usually the preferred option to persuade stakeholders to introduce change or expand the use of good practices for the protection of IDPs. It can also be useful to mobilize other individuals or groups in support of advocacy efforts for a specific cause. Such activities are usually preferred in long-term advocacy strategies and for situations that require social change. When there are serious protection risks, the sole use of soft advocacy activities is insufficient.

- "Hard" advocacy, consisting of stronger persuasion methods such as public reports, press releases, personal testimonies and denunciation letters, even if confidential, should be used when a stronger approach is required. It can be effective in denouncing corruption, discrimination or the harmful treatment of IDPs and other affected populations. The use of hard advocacy should be determined on a case-by-case basis. It could disrupt dialogue with key stakeholders, prompt a denial of humanitarian access to vital areas, or heighten the risks to the affected populations or humanitarian staff. The decision, thus, should be carefully weighed against the urgency and seriousness of the protection concerns. If it is determined that hard advocacy should be used, do so in a timely manner before the situation becomes too grave or before any damage done becomes irreparable.

\section{Risks and benefits of public advocacy}

Careful public advocacy can enhance a mission's protection of civilians in many ways:

sanctioning abusers through public exposure;

giving positive reinforcement to reformist factions in government;

establishing a mission as a credible authority on civilian-protection needs;

setting the tone of national debate on civilian protection;

helping to create appropriate expectations of the mission within the local population;

reducing local suspicion and counteracting accusations of bias, through education;

promoting awareness of protection needs and human rights;

- encouraging involvement of civil society in the promotion of protection and human rights; 
- raising the profile of isolated groups and individuals at risk; and

- strengthening international concern, increasing the quota of international political will to take necessary action.

Sometimes, however, public advocacy can create friction and even result in retaliation. Missions considering these strategies also have to weigh the risks, including:

- retaliation against the mission by accused armed actors, including threats,

- harassment or attacks that could limit the possibilities of implementing other

- protective strategies;

- retaliation by closing off access to regions or vulnerable populations;

- expulsion of the whole mission, or individual personnel being declared persona non grata;

- retaliation against local contacts and sources;

- alienation of key contacts; and

- closing off dialogue with the government, which should be the main guarantor of protection.

(See Proactive Presence: Field Strategies for Civilian Protection, Centre for Humanitarian Dialogue, 2006).

\section{Quiet versus public interventions}

- Quiet advocacy, such as quiet diplomacy for the transfer of land to IDPs, or confidential letters denouncing discrimination against individuals, can allow authorities and other relevant stakeholders to take corrective action and "save face"; they can also help maintain frank but discreet communication with both sides in a conflict. Humanitarian actors must preserve impartiality and neutrality to ensure continued dialogue, access and open channels of cooperation. ${ }^{2}$ At times, this may prevent them from making public statements on protection concerns. Perceived silence from the humanitarian community may discourage local advocacy groups from undertaking their own advocacy efforts, as they might feel isolated and, therefore, at greater risk. ${ }^{3}$ At the same time, the perception that specific humanitarian actors might not be raising protection concerns with the relevant stakeholder risks undermining the trust of the local population, who may cease to regard humanitarian actors as impartial.

- Public advocacy, if used carefully, can be effective in improving the protection of IDPs. It includes a wide range of "soft" public advocacy activities that can enhance protection for IDPs, such as public awareness campaigns on human rights and the sensitization of communities to IDP returns. They can be instrumental in raising the profile of communities at risk of displacement or human rights violations, promoting awareness of the consequences of displacement and the rights of IDPs, and encouraging the involvement of civil society, and the commitment of the international community to address such issues.

\section{Key considerations for the implementation of an advocacy strategy ${ }^{4}$}

- In selecting the right approach to deliver advocacy messages, it is important to refer to, and apply attitudes and skills presented in, Part II of this Handbook. In addition, we should ensure the stepts noted below.

2 Proponents of this view hold that a protection advocacy role is more the function of the media and human rights NGOs, such as Amnesty International or Human Rights Watch. See discussion in Protect or Neglect? Toward a More Effective United Nations Approach to the Protection of Internally Displaced Persons, an evaluation by Simon Bagshaw and Diane Paul, Brookings-SAIS Project on Internal Displacement and the United Nations, OCHA-IDD, November 2004, p. 40.

Ibid, p. 42.

4 Many of these points have been adapted from Women's Human Rights Step by Step, Women Law and Development International and Human Rights Watch Women's Rights Project, 1997. 
- Watch for potential risks to persons of concern, IDP and human rights advocates and humanitarian staff. Because internal displacement usually unfolds in the midst of tension, violence and volatility, it is important to assess thoroughly the potential negative impact of the different approaches on the safety and security of persons of concern, their families, IDP and human rights advocates and humanitarian staff. In the case of individual advocacy initiatives, it is vital to ensure the safety of the victim, witness and key sources, to maintain confidentiality and to respect the wishes of the victim or witness regarding advocacy action on his/her behalf. It is essential to elicit feedback from persons of concern about the proposed advocacy actions. (See Part V.3.3 and Part V.7.

- Calculate the timing to intervene in light of the expected impact. Reversing a finalized decision is always far more challenging and unlikely to happen in the short term. Try to launch advocacy campaigns to influence decision makers before a final decision has been made.

- Identify agencies or groups in other communities or countries that have undertaken a similar advocacy strategy. A large number of operational partners and civil society groups can provide valuable information about their experiences to strengthen the advocacy strategy. Some of them might also be instrumental in influencing the government response.

Build community support in the early part of the strategy. It is important to plan to concentrate efforts on direct contact with individuals and small groups at the beginning of the strategy to inform and reinforce the overall advocacy campaign from the outset. This will also leave time for more substantive activities during the later stages of the strategy.

- Do not assume that the other interlocutors are knowledgeable about the issues. We should be aware that the target audience will probably not have the same in-depth understanding of the issue at hand as the humanitarian actors. Given that, it is important to formulate advocacy tools, documents and messages that enable the target audience to understand the protection issue at hand. If necessary, we should develop an information plan about the problem or concern, explaining the desired outcome, addressing possible objections to change, and identifying potential sources of support. (See Part V.7.

- Understand what each interlocutor can or cannot do for the relevant issues we pursue through advocacy. It is important to avoid overwhelming our target interlocutors with requests that are beyond their control or area of influence. We should mobilize them to take concrete actions and maintain motivation and commitment.

- Formulate effective advocacy messages. Such messages have two parts: an appeal on the merits ("this issue is important because...") and an appeal to self-interest ("... if you allow access to this group...tension in this area will decrease and you will be able to focus more on development projects").

- Consider using appropriate advocacy tools. ${ }^{5}$ Such tools may include delivering messages through the media, strengthening the ability of local organizations to advocate, discussing problems directly with policy makers, or advocating through other partners or coalitions.

- Involve the media as appropriate. It is often useful to manage a flexible approach with the media, gradually increasing its involvement, as the team decides to go more public on the issue. This will help to maintain control of public focus on the specific issue, thereby managing potential risks. It is important to contact well-known reporters or editors whom the organization or partners think might be objectively interested in the issue, and keep them up-to-date on basic developments so that they can step in at key moments.

See Advocacy Tools and Guidelines, Promoting Policy Change, Sofia Sprechmann and Emily Pelton, CARE, January 2001, www.care.org/getinvolved/advocacy/tools.asp. 


\begin{abstract}
- Always follow up on advocacy meetings. It is important to send a letter to the relevant interlocutor summarizing the key advocacy messages transmitted during the meeting and any decisions taken. We should debrief our organization/cluster/working group immediately after advocacy meetings and be transparent about this with our interlocutors. Depending on confidentiality requirements and the sensitivity of the protection concerns at hand, debriefings can be public or remain confidential.

Review the advocacy strategy during implementation and adjust it as necessary. In doing so, it is important to review the initial objectives of the advocacy strategy and check their practicality and validity against the present situation. We should assess the impact of the advocacy strategy, including whether it has led to positive changes in the situation of affected populations. We should also seek feedback from relevant stakeholders, including affected communities, partner agencies, the media, and public and national authorities, as appropriate. (See Part III.4 [D)
\end{abstract}

\title{
3. Challenges in advocating for the protection of internally displaced persons
}

Internal displacement situations often present difficulties for advocacy, particularly when there are serious protection issues at stake.

- Security concerns have an increasingly important impact on protection advocacy strategies. Concern for the security of staff members on the ground can affect the ability of organizations to raise protection concerns publicly. This presents a potential dilemma, since the failure to address human rights issues can, in turn, undermine the effectiveness of humanitarian programmes. The safety and security of staff and IDPs always take precedence over any advocacy strategy. When public denunciation or advocacy by humanitarian organizations risks negative impact for the security of IDPs and staff on the ground, alternative strategies, including low-key advocacy should be considered as well as measures to mitigate risks. Response strategies to the potential impact of advocacy on security should be closely coordinated among the various local and international humanitarian organizations. Depending on the context, responses to security concerns may involve various activities from assessment, coordination, monitoring, enhancing security measures in and around camps, settlements, compounds, including through community mobilization, to interventions with the relevant State and non-State authorities. (See Part IV.2.

- Advocacy activities targeting influential States are often crucial for increasing diplomatic pressure on concerned governments to address protection issues. Potentially influential countries might share, in principle, a common position with the humanitarian community; yet strong commercial or geo-political ties with the concerned State can make it difficult for them to intervene when required.

- For some actors, it can be extremely challenging to balance broad interventions, such as a political role in conflict resolution in a given country or between different States, with single advocacy actions, such as publicly intervening or advocating in relation to an individual human rights situation. It may be a strategic decision in some situations to use soft and low-key advocacy so as not to disrupt wider efforts to resolve the conflict.

- Potential negative impacts of advocacy should be thoroughly assessed. "Hard" advocacy may result in retaliation by the concerned State or non-State actors, which could include the denial of access, refusal of continued dialogue or the expulsion of humanitarian workers. It is important to carefully calculate the risks and consider the options in the short as well as in the long run. Thorough knowledge and understanding of State and non-State actors and their dynamics as well as the costs and benefits of a humanitarian presence for them would enable a better assessment of potential reactions to public criticisms and of 
risks. Some humanitarian organizations have managed to continue both public critique and close relationships with criticized parties, with continued effective access and field presence and activities.

- When advocacy fails, i.e. when advocacy "does not produce the desired outcome," the international community might be faced with difficult decisions, such as whether to continue maintaining a presence in the country or whether to tie continued humanitarian assistance to real improvement in the protection of IDPs. (See Parts V.4 and V.5. WD)

\section{Checklist: Humanitarian advocacy}

Ensure that your advocacy is impartial, based objectively on real violations and threats, targets the right actors and is well timed.

Put a very high value on the accuracy and credibility of the information on which you base your advocacy campaign. Look respectable and be authoritative when you present your case in private and in public.

Protect your sources - both among your staff and within the local community - and work on the principle of informed consent with regard to statements that you intend to make. People concerned need to approve how and when you use their words and experience.

Recognize a possible trade-off between humanitarian access and humanitarian advocacy, and involve your staff and the communities that you are trying to protect in such decisions.

Ask what role your agency can play to give civilian communities the voice they need to change the decisions that affect their lives. Can you use your position of influence to bring these communities into meetings and discussions? Think how you could use your resources to build networks of community groups so that collectively they can have a stronger voice.

Judge carefully when loud or quiet advocacy strategies are best and, as appropriate, apply different advocacy measures depending on the interlocutor and level of intervention.

(Protection: An ANALP Guide for Humanitarian agencies, Hugo Slim, Andrew Bonwick, 2005)

\section{Key references \& useful websites}

- Guide to International Human Rights Mechanisms for Internally Displaced Persons and their Advocates, Fisher, D., The Brookings-Bern Project on Internal Displacement, June 2006.

- Humanitarian Negotiations with Armed Groups: A Manual for Practitioners, United Nations, New York, 2006.

- Proactive Presence: Field Strategies for Civilian Protection, Mahoney, L., Centre for Humanitarian Dialogue, Geneva, 2006.

- Protect or Neglect? Toward a More Effective United Nations Approach to the Protection of Internally Displaced Persons, an evaluation by Simon Bagshaw and Diane Paul, Brookings-SAIS Project on Internal Displacement and the United Nations, OCHA-IDD, November 2004. 
- Protection: An ALNAP Guide for Humanitarian Agencies, Slim, H. and Bonwick, A., ALNAP, Overseas Development Institute, London, 2005.

- Protection of Internally Displaced Persons, Policy Paper Series, No. 2, OCHA/IASC, United Nations, New York, 2000.

- Advocacy Tools and Guidelines, Promoting Policy Change, Sofia Sprechmann and Emily Pelton, CARE, January 2001.

- Civilian protection and humanitarian advocacy: strategies and (false?) dilemmas, Humanitarian Exchange Magazine, Issue 39, June 2008. 


\section{Part V.4 \\ Humanitarian access and presence}

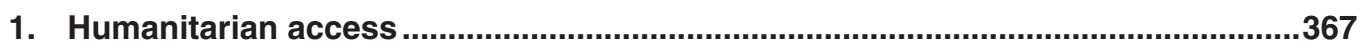

2. Humanitarian presence and its role as a protection tool .........................................370

3. Key considerations for maintaining a protective and strategic presence ............371

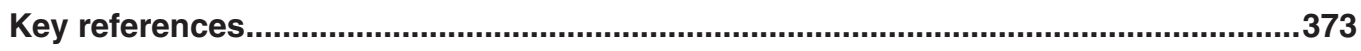

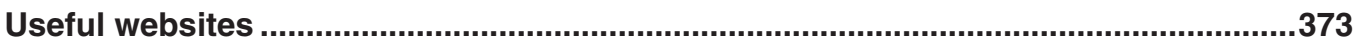

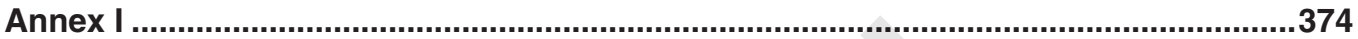




\section{Humanitarian access}

Gaining access to internally displaced persons (IDPs) is essential to identifying and ultimately responding to their protection and assistance needs and is generally a precondition for any humanitarian action. Humanitarian access should be understood both from the perspective of the affected population having access to protection and assistance, as well as the humanitarian actors having access to those requiring assistance and protection. The freedom of movement of the affected population is, thus, essential to ensure adequate access to humanitarian assistance.

There are often multiple and varied constraints on access. These may be related to the operating environment (e.g. difficult terrain, absence of roads and airstrips, ongoing armed conflict) or a result of deliberate efforts to restrict humanitarian activities or witnessing functions. The latter, for instance, may take the form of excessive bureaucracy to grant access to humanitarian organizations to certain populations or areas; deliberate attacks on humanitarian personnel; or the lack of acknowledgement of humanitarian needs by part of the population.

In armed conflict situations, humanitarian negotiations are a critical element in a strategy to gain access to IDPs and other affected populations and to ensure sound conditions for an effective protection presence and for sustainable assistance and protection activities. (See box below.)

There are usually three levels at which humanitarian actors negotiate access: a high or strategic level; a mid or operational level; and a ground or frontline level.

Negotiations for humanitarian access normally take place between humanitarian actors, such as staff of United Nations agencies, NGOs, the ICRC or, at a more formal level, with the country team, led by the Humanitarian Coordinator or Resident Coordinator in the absence of the latter, and government authorities, military personnel, and armed groups and civilians. If United Nations peacekeeping missions are present, these can also engage or provide support in such negotiations, depending on the context.
"The overall purpose of humanitarian negotiations is to ensure the impartial protection of, and the provision of assistance to, civilians affected by armed conflict and other people rendered hors de combat, as stipulated by international humanitarian law, human rights law and refugee law. Humanitarian negotiations are conducted:

by humanitarian actors, such as members of appropriately mandated and impartial organizations like United Nations agencies, NGOs or the International Committee of the Red Cross (ICRC);

for humanitarian objectives, including humanitarian access, protection, assessment and assistance, as set out in international humanitarian law;

in countries affected by armed conflict, either of an international or non-international character; and

with the parties to the conflict, that is, those with power and responsibility for the conduct of war, for the humane treatment of civilians and those hors de combat and for the distribution of assistance."

Excerpt from Humanitarian Negotiation: A handbook for securing access, assistance and protection for civilians in armed conflict, p.19 (under key references below).

Negotiating with State and/or

non-State actors for access to, and freedom of movement of, the affected population is a difficult and challenging task, as it involves seeking concessions in a hazardous context. The environment is particularly hostile and risky, and the counterparts of the humanitarian actors are usually not concerned with human rights and humanitarian principles. On the contrary, they may fear that allowing access would reveal human rights and humanitarian law violations that are being committed. Reaffirming the core principles of humanitarian action (humanity, 
neutrality and impartiality) and explaining the role, mandates and activities of humanitarian organizations is, thus, essential in negotiating access.

Negotiating access with non-State actors proves particularly challenging if they have complex and unpredictable structures or lack knowledge about basic humanitarian principles. Negotiating with non-State actors may also arouse a variety of ethical or moral dilemmas as well as suspicion by other parties. ${ }^{1}$ In addition, good coordination among humanitarian actors in negotiating access is important, as armed groups may be attempting to play off different humanitarian organizations and pit them against each other to gain political or material advantages.

Since the State has the primary duty to protect IDPs, humanitarian actors cannot substitute for that responsibility and must normally negotiate with the State to gain access to the territory controlled by armed groups, within the State boundaries, first as a preliminary step before negotiating access to affected populations with these armed groups. Depending on the context, it could be useful to explore the involvement of the government in negotiating access to IDPs in areas controlled by non-State actors. It is also important to highlight that humanitarian access can change depending on who has effective control of the territory.

The implementation of access agreements often requires contact and further negotiations with a myriad of actors, including the local community, both bound and not bound by these access agreements. Consequently, staff working at the country and regional/field levels need to develop sound negotiating skills through adequate training in negotiating skills and a good understanding of humanitarian principles of humanity, neutrality, impartiality, transparency and independence, and of issues related to humanitarian access and presence. (See Part II.2.

The following table provides basic guidance for humanitarian negotiations on access and should be read in connection with the section on negotiations in Part II.2 of this Handbook.

The safety of humanitarian workers must be considered as a priority before attempting to engage in negotiations in conflict areas. It could be useful to discuss this table within the inter-agency team and national interlocutors at the local level to ensure a shared understanding.

\begin{tabular}{l|l}
$\begin{array}{l}\text { Negotiating access } \\
\text { Be prepared } \\
\text { for access } \\
\text { negotiations }\end{array}$ & $\begin{array}{l}\text { Develop a negotiating strategy and ensure the activities, indicated below, at } \\
\text { a minimum. } \\
\text { Conduct a thorough situation analysis, understanding both your own, as } \\
\text { well as your negotiating partner's position and interests, particularly } \\
\text { vis-à-vis the civilian population, activities of humanitarian organizations, the } \\
\text { parties to the conflict, and the potential delivery of humanitarian supplies } \\
\text { and resources. Focus on how interests can be reconciled (principled } \\
\text { agreements) and how your counterpart can be influenced (i.e. through } \\
\text { advocacy, humanitarian expertise, mobilization of allies and acting } \\
\text { consistently and credibly to build trust). }\end{array}$
\end{tabular}

\footnotetext{
The potential political or security implications connected with establishing a dialogue with a party to a conflict should be considered when negotiating with both State and non-State actors. See United Nations, Humanitarian Negotiations with Armed Groups: A Manual for Practitioners, New York, 2006, p. 10.

See Part II.2.

3 For key points for humanitarian negotiations, see Part II. 2 of this Handbook and Centre for Humanitarian Dialogue, Humanitarian Negotiation: A handbook for securing access, assistance and protection for civilians in armed conflict, p 150-151, Mancini-Griffoli and Andre Picot, Geneva 2004.
} 
Identify which actors (both State and non-State) have authority to grant access as well as who among them has the authority to negotiate or to act as intermediaries. Understand power relations, and identify a counterpart who is receptive to humanitarian values, has implementation power and with whom a good personal rapport can be built. Identify potential "allies," for instance religious groups, local NGOs or the local community, and consider negotiating through a third party if the counterpart is not accessible. Keep in mind that such sensitive negotiations may take time and building trust and confidence is an essential part of the process.

Develop a coordinated approach with humanitarian partners to identify: who among humanitarian actors should lead the negotiations or act as intermediaries;

constraints on access;

- key objectives, strategies and tactics;

- key arguments, including reaffirming core humanitarian principles (further addressed in Part $1.1 \square$ ) and the obligations of parties in conflict, including non-State actors, to ensure that humanitarian assistance reaches affected populations.

bottom line for the negotiation; and

non-negotiable parameters (further addressed below).

Agree with
partners on
"non-negotiable
parameters"

Carefully gauge and state the purpose of access
- Ensure that all humanitarian partners agree on a series of non-negotiable parameters. These should include: core humanitarian principles (further addressed in Part $1.1 \square$ ); the prohibition of payment in exchange for access; the ability to conduct independent assessments, monitoring and evaluating aid distribution; respect for basic organizational policy principles; and rules on armed personnel. Where possible, try to reach "principled agreement" where both parties can achieve their objectives without having to make concessions.

Approach negotiations with a set of previously-agreed working principles regarding humanitarian access, such as the sustainability of access.

- Highlight the importance of access as a precondition for humanitarian action; emphasize the necessity of meeting the humanitarian needs of a population rather than of gaining access to a particular territory.

- Emphasize the centrality of upholding humanitarian principles (humanity, impartiality, and neutrality) as the basis for gaining access. It is especially important that humanitarian actors explain their roles, mandates, and programmes and demonstrate their neutrality to the counterparts. Explaining the principle of neutrality can be a key to gaining access to the IDPs and other affected populations. ${ }^{4}$

- Be cautious of potential attempts by counterparts to incorporate political and security issues within humanitarian negotiations. These matters should be referred to those with authority to negotiate on such issues.

Especially if there is a risk that access will be denied altogether, present the objectives of access in a balanced way during the negotiations. Access and esence gained for the purpose of baseline needs assessments or emergency assistance can provide a vital starting point for protection work. ${ }^{5}$

\footnotetext{
4 Humanitarian actors should also be aware of controversies surrounding the concept of neutrality. Neutrality does not mean inaction when humanitarian actors witness atrocities being committed by the warring factions. See Parts $I .1$ and V.5 $\square$ of this Handbook as well as Marion Harroff-Tavel, Principles under fire: does it still make sense to be neutral?, Humanitarian Exchange, December 2003.

5 Negotiating access primarily for the purposes of protection work can be a sensitive issue in new crises where there has been no time for building confidence between humanitarian actors and national authorities.
} 


\begin{tabular}{|l|l|l|}
\hline $\begin{array}{l}\text { Negotiations do } \\
\text { not confer } \\
\text { recognition }\end{array}$ & $\begin{array}{l}\text { Maintain transparency with all parties to ensure that all understand that } \\
\text { access negotiations are of a strictly humanitarian character and do not in } \\
\text { any way confer recognition upon the group or its aims. }\end{array}$ \\
\hline $\begin{array}{l}\text { Prioritize safety } \\
\text { aspects }\end{array}$ & $\begin{array}{l}\text { Emphasize safe and unimpeded access during the negotiations, including } \\
\text { the safety of cargo, agency staff, partners and affected populations. Seek } \\
\text { reliable guarantees for the safety of humanitarian workers. }\end{array}$ \\
\hline $\begin{array}{l}\text { Include key } \\
\text { logistical aspects } \\
\text { in the negotiations }\end{array}$ & $\begin{array}{l}\text { Ensure that negotiations include key logistical aspects associated with } \\
\text { access, that is, the details of how access will actually work, such as the } \\
\text { frequency of convoys, and the duration of humanitarian presence. } \\
\text { Consider liaison arrangements that ensure free passage through } \\
\text { checkpoints to reach the intended beneficiaries. } \\
\text { Seek formal clarity on how parties communicate agreed access procedures } \\
\text { within their respective organizations. }\end{array}$ \\
\hline
\end{tabular}

In the event that access to the affected area is denied despite negotiation efforts or because of security concerns, it is important to continue to monitor the protection situation in the area, and attempt to reach the affected populations through alternative mechanisms, such as working through local NGOs or institutions (further addressed in Part IV. 2 DU). Where the denial of access is likely to lead to massive and systematic human rights abuses that could amount to genocide, war crimes or crimes against humanity, the UN Security Council can consider the establishment of temporary security zones and safe corridors, to protect civilians and secure safe and unimpeded access by humanitarian personnel to vulnerable populations. ${ }^{6}$

When access is granted, establishing humanitarian presence in situations of internal displacement will be essential for conducting an effective humanitarian operation and implementing a successful protection strategy.

\section{Humanitarian presence and its role as a protection tool}

The term "humanitarian presence" refers to the actual deployment of humanitarian organizations in a given location to assist populations in the midst of a humanitarian crisis. While in all of these situations humanitarian presence can play an important protection role, presence alone is not sufficient. If not planned and implemented strategically, on the basis of a common vision of protection by all humanitarian partners, this presence may have little or no impact on the protection of affected communities; rather, it may place these communities at greater risk. In some cases, it may even become an excuse for political inaction and embolden perpetrators.

Generally, a field presence can be a deterrent to potential abusers in the ways outlined below. $^{7}$

- Humanitarian actors can bear witness to events and expose perpetrators to internal sanctions, prosecution, and moral or political judgments.

- A field presence can provide the space to put into effect rules and systems protecting IDPs and other affected populations.

- A field presence restricts the political space available to perpetrators by increasing the cost of abusive actions and limiting options. For example, potential perpetrators might be concerned about their superior's reaction, damage to their political reputation and post-conflict prospects, or the loss of benefits gained from international collaboration.

Security Council Resolution 1296 on the Protection of Civilians in Armed Conflict, April 2000.

See, Henry Dunant Centre for Humanitarian Dialogue, Proactive Presence: Field Strategies for civilian protection, Mahony, Liam, Geneva, 2006. 
- Independent of each agency's mandate, a humanitarian presence may have psychological value. Affected populations often feel reassured when representatives of the international community can witness their situation and report on it.

In the event that international humanitarian actors may not be able to establish a sustained presence in the conflict area, due to insecurity or unwillingness of the controlling authorities to allow such presence, other alternatives may be explored to monitor the condition of IDPs and other affected populations and to provide vital assistance. These can include organizing mobile teams to regularly access the area or working in cooperation with local NGOs or institutions that have a presence in the area or can reach the affected populations.

\section{Key considerations for maintaining a protective and strategic presence}

Depending on the situation and the mandate of the specific agency, humanitarian presence may have the objective of accompanying populations at risk; monitoring and reporting human rights situations; as well as contributing to the protection and assistance of IDPs and other affected populations.

The following table outlines key considerations to maximize the protective impact of a humanitarian presence and to help assist in avoiding any undesired effects of a humanitarian presence that may place local communities and civilians in general at greater risk.

\begin{tabular}{|c|c|}
\hline \multicolumn{2}{|c|}{ A protective and strategic presence } \\
\hline $\begin{array}{l}\text { Common } \\
\text { assessment, } \\
\text { planning and } \\
\text { coordination } \\
\text { (see Part III.1 } \square \text { ) }\end{array}$ & $\begin{array}{l}\text { All humanitarian actors must have a shared vision of how the core } \\
\text { principles of humanitarian action - humanity, neutrality, and impartiality } \\
\text {-will be applied to the specific operation. Ensure that all staff members } \\
\text { are aware and understand the practical implications of such a shared } \\
\text { vision (further addressed in Part I.1 } \\
\text { All humanitarian actors in the operation (both protection and } \\
\text { non-protection mandated agencies) should agree on basic parameters } \\
\text { to ensure a protective presence. This is essential to maximize the level of } \\
\text { influence on relevant parties, guard against the potential manipulation of } \\
\text { individual agencies by the various parties, and maximize the protection } \\
\text { impact of relief interventions. This implies: } \\
\text { agreeing on key objectives for the humanitarian presence in the country; } \\
\text { reaching a shared understanding of protection gaps (further addressed in } \\
\text { Part III.1 and } 5 \text { agreeing upon a strategy to address identified protection gaps, } \\
\text { coordinating leadership and different responsibilities for protection } \\
\text { (further addressed in Part III.5 } 5 \text { ); } \\
\text { ensuring that all staff members are aware of the different activities and } \\
\text { the potential risks associated with the strategy in light of the political and } \\
\text { security situation; } \\
\text { ensuring the training of all humanitarian staff on the core humanitarian } \\
\text { principles and the fundamentals of protection work (further addressed in } \\
\text { Part I.1 } 1 \text { taking into consideration the potential risks and sensitivities linked to } \\
\text { different staff members' ethnic, religious, linguistic or perceived } \\
\text { affiliations, which is particularly important when presence through } \\
\text { national staff only is allowed. }\end{array}$ \\
\hline
\end{tabular}




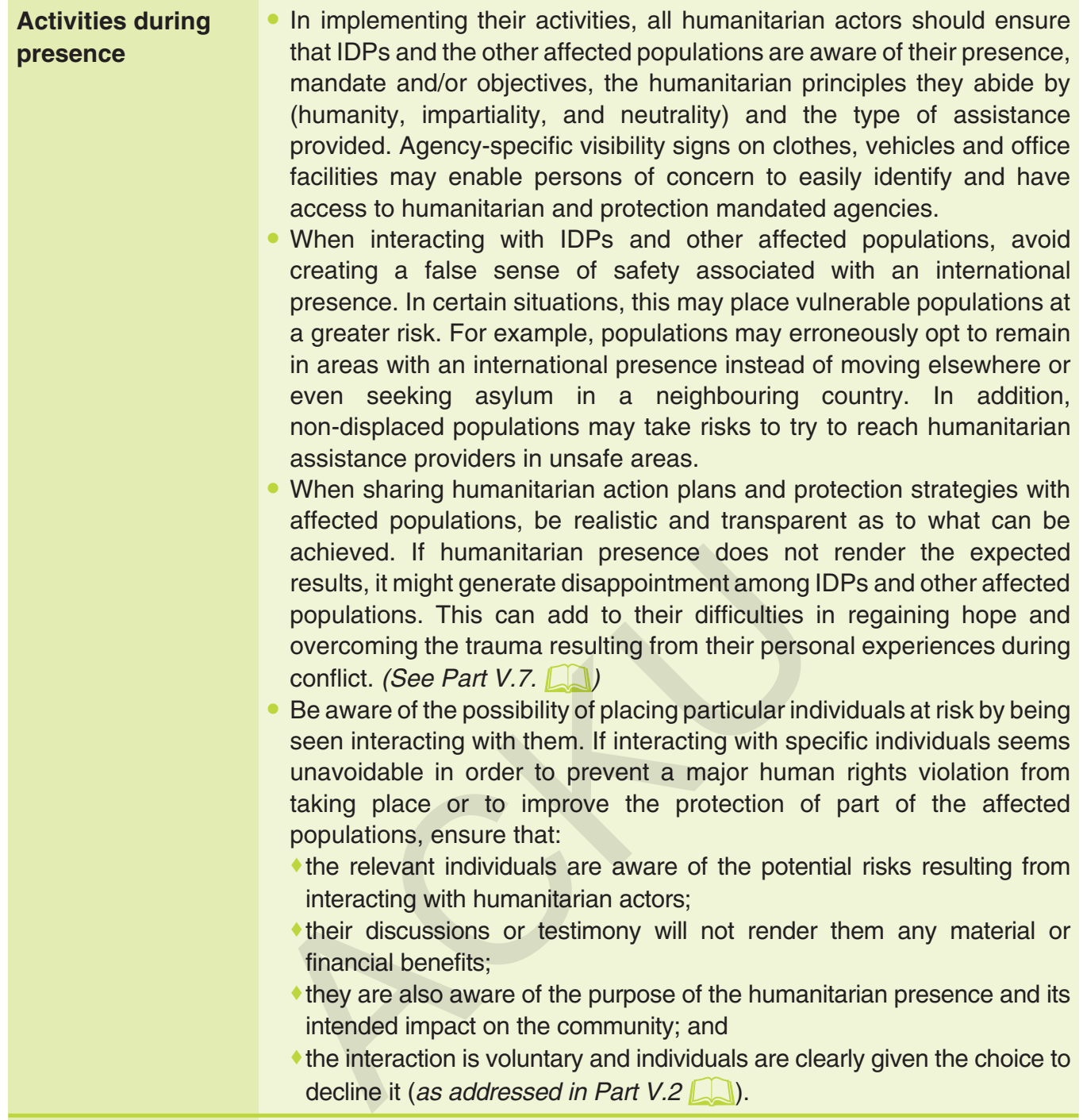

Impact analysis (see Part III.4
- Programme evaluations should analyse the impact of the humanitarian presence. In particular, they should assess whether:

presence is reduced to a "witnessing" function of serious and systematic human rights violations, which might provide a sense of impunity and increase risks to the victims, witnesses, humanitarian workers and affected populations in general;

presence puts individuals or affected communities at risk; and

presence unduly prolongs displacement by pursuing protracted encampment policies and concentrating assistance in areas away from those where IDPs can find durable solutions. 
In any of the above cases, humanitarian actors need to take determined action to avert such undesired effects of their presence. This may imply: - revising operating modalities to address negative impacts when, for example, humanitarian assistance to IDPs creates situations of discrimination or tension vis-à-vis other affected populations or when expanding humanitarian support to all affected populations can ensure that IDPs can leave camps or sites and integrate with the rest of the population without draining local resources; and

- in certain extreme circumstances, necessitating the withdawal of humanitarian actors to allow for political action where, for instance, an international humanitarian presence has repeatedly failed to curb systematic violence and abuse or when security risks have reached a level that no longer permits the presence of humanitarian actors.

\section{Key references}

- Humanitarian Negotiation: A handbook for securing access, assistance and protection for civilians in armed conflict, Mancini-Griffoli and Andre Picot, Centre for Humanitarian Dialogue, Geneva 2004.

- Proactive Presence: Field Strategies for Civilian Protection, Mahoney, L., Centre for Humanitarian Dialogue, Geneva, 2006.

- Humanitarian Negotiations with Armed Groups: A Manual for Practitioners, United Nations, New York, 2006.

- Protect or Neglect? Toward a More Effective United Nations Approach to the Protection of Internally Displaced Persons, an evaluation by Simon Bagshaw and Diane Paul, the Brookings-SAIS Project on Internal Displacement and the United Nations, OCHA-IDD, November 2004.

- Protection: An ALNAP Guide for Humanitarian Agencies, Slim, H., and Bonwick, A., ALNAP, Overseas Development Institute, London, 2005.

\section{Useful websites}

- Centre for Humanitarian Dialogue: www.hdcentre.org

- Programme on Negotiation, Harvard Law School: www.pon.harvard.edu

- United Nations Children Fund (UNICEF): www.unicef.org

- Reliefweb (OCHA): www.reliefweb.int

- Overseas Development Institute: www.odi.org.uk

- United Nations High Commissioner for Refugees: www.unhcr.org

- United Nations Office for the Coordination of Humanitarian Affairs: www.ochaonline.un.org

- International Committee of the Red Cross: www.icrc.org 


\section{Annex I}

\section{Checklist for humanitarian negotiations}

- Does the security situation allow for negotiations on the ground? If not, are there alternative places where such negotiations can be conducted?

- What are your objectives? Are they consistent with the needs of the IDPs and the affected population? Are they consistent with your mandate and the work of other agencies?

Who is your counterpart? Do you have access to him/her? Is your counterpart receptive to humanitarian principles? Who can have influence on him/her? How can you garner his/her support?

What are your counterpart's positions, bottom line and interests? What are yours? Are they compatible? If not, how can they be reconciled without compromising on non-negotiable principles?

What is your strategy to convince your counterpart? What are your arguments? What are your tactics?

- How can you build a relationship of trust and confidence with your counterpart? Are there cultural elements and differences that could compromise the negotiation? How can you resolve such differences? 


\section{Humanitarian assistance}

1. The protection value of humanitarian assistance ...............................................376

2. Key protection considerations regarding humanitarian assistance .....................376

2.1 Core humanitarian principles: humanity, impartiality, independence .................376

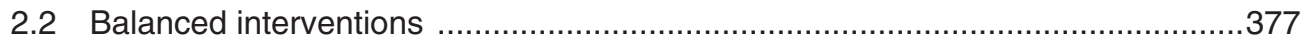

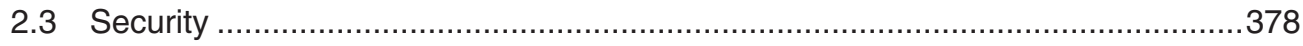

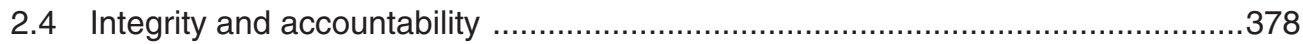

3. Ensuring a protective approach to planning and delivering humanitarian assistance ..............................................................................................378

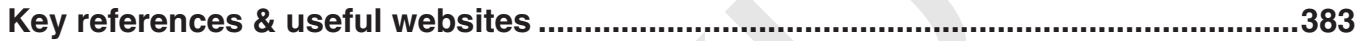




\section{The protection value of humanitarian assistance}

Generally, humanitarian assistance consists of providing relief services or commodities either directly or indirectly via the supply of advice or resources through a local authority or partner organization. ${ }^{1}$

Humanitarian assistance has a wide protection capacity, as its aim is to address the urgent needs of the target populations, thereby improving their human rights situation. Yet, if the planning and delivery of humanitarian assistance are not guided by protection objectives and basic humanitarian principles, the safety and dignity of civilian populations can be put at serious risk and the humanitarian character of assistance undermined. Conscientiously planning and delivering humanitarian assistance through a protection lens ${ }^{2}$ can greatly expand its protection capacity.

Humanitarian assistance can also be a determining factor in the search for durable solutions. For example, adequate and timely humanitarian assistance during displacement can help internally displaced persons (IDPs) regain the ability to develop sustainable livelihoods and thereby prepare them for reaching earlier solutions. A well-balanced assistance programme can also avoid dangerous secondary displacements to unsafe locations and contribute to the development of conditions for return or relocation. (See Part VI.

National governments are responsible for the protection and assistance of IDPs. Humanitarian actors, therefore, should try to avoid acting as substitutes for national authorities. While life-sustaining essentials should always be provided if the State is not doing so, humanitarian organizations must orient longer-term interventions towards reinforcing the capacity and the responsibility of national authorities to assist the population on their territory. This includes advocating for national policies, public services and targeted assistance programmes to respond adequately to protection needs.

Humanitarian actors should also ensure that assistance ultimately strengthens the ability of internally displaced and other affected communities to realize their rights and of civil society groups to support them to that end. (See Part V.9 and V.10.

\section{Key protection considerations regarding humanitarian assistance ${ }^{3}$}

\subsection{Core humanitarian principles ${ }^{4}:$ humanity, impartiality, independence}

Humanitarian assistance must be provided in accordance with the principles of humanity, neutrality and impartiality ${ }^{5}$ (as addressed further in Part I.1 [DU). In simple terms, this means the following: ${ }^{6}$

Adapted from Slim, H., and Bonwick, A., A Guide for Humanitarian Agencies, August 2005.

See section 3 of this Chapter.

3 References to humanitarian assistance in this chapter include those life-sustaining essentials that States and humanitarian actors provide to displaced populations, such as clothes, bedding materials, cooking items, etc. The overall protection considerations on humanitarian assistance contained in this Chapter, however, also apply to the provision of shelter, water and sanitation as well as food distribution, all of which are also dealt with in more detail in other chapters of the Handbook.

See Guiding Principle 24.1.

5 GA Resolution 46/182, 19 December 1991, Strengthening of the coordination of humanitarian emergency assistance of the United Nations.

6 See also ICRC, Neutrality and neutrality in humanitarian assistance, Denise Plattner, International Review of the Red Cross. 
- Humanitarian assistance must be provided to prevent and alleviate human suffering, to protect life and health and to ensure respect for the human being.

- The criteria for the distribution of humanitarian assistance must not be based on nationality, race, religion, or political point of view. It must be based on need alone. Neutrality, that is not taking sides directly or indirectly, allows humanitarian aid to be given impartially.

- Humanitarian organizations must formulate and implement their own policies independently of government policies or actions, or those of non-State actors. Humanitarian assistance should not be diverted, in particular for political or military reasons.

These principles sometimes come under fire: various sides of a conflict may perceive humanitarian assistance as helping their enemy or undermining their own political or military goals, in which case they view the assistance as not being neutral and impartial. International military support to remove obstructions by warring parties to the access and delivery of humanitarian assistance also undermine the neutrality of humanitarian action.

Even if these principles are sometimes difficult to apply, especially in rapidly changing situations, they are unambiguous. Their application ensures the integrity of relief operations and it contributes to safeguarding the safety of the assisted populations and of humanitarian staff.

These principles should guide a continued assessment of the potential consequences of humanitarian action which, at times, may lead to the conclusion that assistance should NOT be provided. This may be the case in situations in which humanitarian access might be denied in one location while strategically permitted in another, leading to a worsening of inter-communal tension or discrimination. This may also be the case in situations in which reductions in food rations to an IDP settlement are used to force relocation or premature return. Other situations include pressure to establish assistance points in certain strategic locations to reclaim control over a territory and use IDPs as human shields or to control population movements for other political or military purposes in violation of the rights of IDPS.

The application of the principles of humanity and impartiality will also make it necessary for humanitarian actors to carefully consider if and when an assistance project initially planned for IDPs needs to be substantially expanded to other groups or to the civilian population as a whole.

\subsection{Balanced interventions}

Protection and assistance activities by the different humanitarian actors should all be part of one coordinated strategy, put in place through the cluster approach. The country team, led by the Humanitarian Coordinator $(\mathrm{HC})$ or the Resident Coordinator if there is no $\mathrm{HC}$, can determine the specific coordination arrangements for humanitarian assistance. The local or national protection working group should ensure that protection concerns and issues are adequately mainstreamed at all stages of the planning and delivery of humanitarian assistance. All humanitarian actors must have a common commitment so that both humanitarian assistance and generic protection interventions (such as monitoring and reporting or following up on human rights violations) can take place at the same time without undermining each other.

This can be particularly necessary, for instance, in situations where public denunciation or advocacy reports, become necessary at one point to raise awareness about grave and systematic human rights violations against a particular group or the population as a whole. In such cases, it is essential that ALL humanitarian actors, United Nations and NGOs, agree on a common advocacy approach and operational strategy. The fact that open denunciation may 
put at risk humanitarian assistance or access altogether requires a solid unanimous approach from the country team, otherwise threatening the safety of staff and the integrity of humanitarian interventions. (See also Part V.4

A balanced approach also requires all humanitarian actors to orient their programmes towards the achievement of durable solutions. From the beginning of an emergency and through the implementation of their programmes, they should work in coordination and partnership with development and early recovery partners.

\subsection{Security}

Humanitarian interventions could inadvertently aggravate or create risks for the target population and/or surrounding communities. The presence of humanitarian actors, the location of warehouses with food and non-food items as well as the chosen assistance modalities can increase the risk to affected communities by, for example, drawing unwanted attention to assisted communities from armed groups or agents of persecution.

Armed actors may systematically infiltrate and use civilian IDP camps, settings and IDP-hosting areas as a convenient base to supplement their rations, or to rest, putting civilians as well as humanitarian assistance providers at great risk of being subjected to a wide range of human rights abuses, such as threats to life and physical integrity, sexual exploitation and abuse, and forced recruitment (as addressed in Part IV.2, IV.4 and IV.5 Da). In this regard, the constant monitoring of activities and timely interventions with relevant actors are indispensable in order to ensure the humanitarian character of these IDP settings. (See Part II.2.

\subsection{Integrity and accountability}

Humanitarian assistance programmes need to be accompanied by scrupulous monitoring systems to identify and prevent corruption and fraud in the distribution of aid and to avoid a spiral of extortion, abuse and exploitation. In particular, equal access to humanitarian assistance by displaced women and children as conditions for the granting of goods or assistance benefits can help prevent sexual exploitation and abuse. All efforts should be made to inform affected communities, especially women and children of their entitlements, and to ensure equal access to, and control of, resources by both heads of households. Particular attention should be paid to prevent the diversion of assistance to combatants during conflict or the use of such assistance for political ends. The misuse of humanitarian aid can give rise to the perception of non-neutrality, thus potentially endangering the safety of IDPs, other affected populations and humanitarian personnel. Humanitarian personnel taking part in assistance activities must be well aware of the practical implications of the core humanitarian principles as well as of their respective codes of conduct and the consequences of breaching them.

\section{Ensuring a protective approach to planning and delivering humanitarian assistance}

To maximize the potential protection value and benefits of humanitarian assistance, it is vital to ensure that protection concerns are mainstreamed into the planning and programming cycle of any humanitarian assistance programme. The following matrix suggests ways in which we can accomplish that. 


\section{Assessing needs for assistance with a protection perspective (see Part III.1 [D)}

- Ensure that non-protection staff members who take part in assessments are adequately trained on the protection implications and the risks as well as the protection potential of humanitarian assistance.

- Try to reach a shared perspective on key protection gaps and objectives with all protection and non-protection actors. To this end, joint situation assessments are useful to identify the full spectrum of protection concerns affecting persons of concern.

- At the peak of emergencies, ensure that rapid assessments are systematically undertaken from an age, gender and diversity perspective and that they include some degree of participatory inquiry, even if limited. This will help set up an adequate procurement and delivery process during the initial planning stages of assistance programmes to respond to the needs of women, men, girls and boys of different ages, gender and backgrounds.

- Do not make assumptions about family size or structure. In emergencies, families are not always made up of two parents with several children. Often, households are headed by one parent or a grandparent with children and cousins. Take care to ensure that members of the new family unit are not put at additional risk by not receiving adequate assistance.

- Through participatory assessment during the post-emergency phase, try to understand community dynamics and other relevant factors, such as gender roles, traditional practices, discriminatory laws or customs, and common patterns of abuse that may affect the delivery of assistance to some individuals or groups. This will ensure that humanitarian assistance reaches those in the community who are not as visible to the humanitarian organizations.

- Establish any assistance needs that are specific to the cultural and daily practices in affected communities, such as cooking practices and fuel sources before the displacement; type of clothes that women and men used to wear, including any specific clothing items essential for their daily needs; hygiene products used or needed; and the coping mechanisms for single-headed households to access daily necessities, including non-food items, prior to displacement.

- Establish whether there are smaller groups or families remaining outside camps or settlements and identify any individuals, such as older persons and people with limited physical mobility, who are not able to flee as far as the camps. Ensure that these people also receive humanitarian assistance on a continued basis.

\section{Planning and delivering assistance with a protection perspective (see Part III.5}

- Integrate lessons learned: Before deciding on specific assistance modalities, seek lessons learned and best practices about humanitarian assistance programmes in other operations with comparable protection risks and patterns of displacement.

- Promote dignified settlement opportunities: Assistance delivery programmes should avoid creating a pull factor towards encampment if other viable alternatives exist, such as staying with host families.

- Carefully consider the root causes of conflict: Ensure that the analysis of the root causes of conflict is integrated into the definition of assistance priorities and modalities in order to prevent unnecessary tension and to foster coexistence through the delivery of assistance. (For instance, if unequal access to water for cultivation was among the root causes of conflict, humanitarian actors should prioritize access to water in communities receiving displaced populations.) 
- Strengthen national responsibility: Make every effort to develop assistance programmes that strengthen existing local and national services or policies, particularly with a view to durable solutions. Some examples of the ways by which this can be achieved are outlined below.

- Design nutritional centres, schools and sanitation services that can be integrated into the national system as soon as the State is ready to assume its responsibility.

- If the issuance of personal documentation is required to facilitate distribution and prevent abuse, avoid developing a parallel documentation system to that of the State. Rather, support, directly or through partnerships with specialized agencies, the ability of the State to provide affected populations with identity documents. Apart from facilitating the relevant distributions, this may also facilitate accessing other rights. (See Part IV.9.

- Avoid dependency on assistance: Plans for assistance delivery should promote a balance between assistance and livelihoods through coordination between protection and reintegration agencies. Such cooperation should also serve to improve the conditions in areas of return or settlement. ${ }^{7}$ For instance, procurement and delivery of assistance can be oriented towards promoting local products and supporting local employment. Vocational training on traditional and new crafts using local materials will allow for the sustainable manufacture of goods and access to local markets.

- Build on the community's self-protection strategies: Older persons are often crucial interlocutors to understand these strategies, due to their understanding of the existing threats and their knowledge of the community.

- In some cases, being identified as IDPs or being spotted receiving humanitarian assistance can put displaced persons in life-threatening situations. This can be the case for displaced individuals or groups in areas where they constitute an ethnic minority and where there is a lack of governance or effective security apparatus (such as areas in Somalia or in Iraq). Special distribution systems of basic subsistence items must be developed on the basis of thorough consultation and joint planning with the community. Such systems usually involve complex and lengthy distribution procedures; yet, they can save lives.

- Some displaced communities may need to limit their movements to avoid security risks, and assistance should be planned to help them avoid such risks. For example, if members of a displaced community risk being attacked by collecting firewood in remote areas, humanitarian assistance programmes should prioritize the provision of energy-saving cooking stoves or alternative fuels to reduce the need for such movements.

- In some cases, the provision of cash grants could trigger attacks against particular segments of the population which may be perceived as vulnerable or defenceless, such as older persons, widows, etc.

- Conversely, a project for clothes distribution that prioritizes families with special needs can improve the situation of separated children in foster care, as it may broaden opportunities for monitoring the situation of children, identify further needs, and establish referral mechanisms for children identified as having additional needs.

- Take into consideration the local culture and climate: Ensure that assistance distributed (clothes, bedding materials, cooking items) is appropiate to cultural practices and climatic conditions. Ensure that it is sufficient in quantity and that it enables safe practices. To the extent possible, ensure that existing local practices are taken into account.

- Be identifiable and accessible: Humanitarian actors should be easily identifiable through visibility signs and regular presence during distribution exercises. Their offices should be accessible to local authorities, IDP leaders and individuals wishing to discuss assistance-related matters. 
- Ensure that assistance does not divide the community: Objective criteria for assistance based on specific needs should be set together with representatives of the community and broadly disseminated. Discuss with those parts of the community who may feel negatively affected, including the other affected communities, and explain the principles of humanity and the impartiality of humanitarian assistance in clear and unambiguous terms. It is vital to promote cohesion within the community so that it retains its ability to develop common protection strategies.

- Build on the key role of women in their families: Work with other partners and the community to ensure that they acknowledge the key role of women in the health and well-being of their families. Ensure that all support this role by ensuring women's equitable access to assistance. Such access will be ensured by women receiving the commodities directly or together with their partners or other relatives.

- Take into account specific needs: Ensure that assistance programmes are organized around distribution points or areas, and also foresee alternative arrangements to reach persons who may not be able to attend, such as:

older persons and persons with disabilities, who may not be mobile at all or may have restricted mobility;

- women of all ages taking care of many dependants on their own who may have restricted mobility and limited physical strength to carry food and non-food items and little time for participation in community affairs, including general distributions; and

- women and adolescents who may fear attending meetings or distributions on their own for security reasons, including gender-based violence from members of their own or surrounding communities or from armed elements.

- Avoid exposing the community to attacks: The type and amount of assistance provided on each occasion may attract attacks by armed actors. Infrequent distributions of large quantities of assistance are more likely to draw attacks than if such assistance is provided in smaller quantities or at more frequent intervals. Leaving vehicles and other equipment at settlements or sites over night or during longer periods can also expose the community to insecurity.

- Ensure that all members of the community are well informed: Make sure that both women and men know well in advance the quantity and variety of items they should receive as well as how the distribution method is supposed to work. Ensure that they are continuously informed on any changes in the system or the quantities of assistance. Use public information and notice information boards clearly indicating entitlements to non-food items and the distribution site, date and time. Take into account different levels of literacy in selecting methods for information-dissemination (as addressed in Part V.7 $\square$ ).

- Plan for orderly and safe distributions: In cases of large-scale distribution, work with the community to designate crowd controllers who can monitor queues, and provide a separate queue for persons and groups with specific needs (such as those not able to stand in line for various reasons, e.g. older persons, pregnant women or persons with disabilities). Clearly designate the person at each site who will be responsible for security decisions and for ordering the evacuation and/or abandonment of supplies. That person should be known to all staff and be visible.

- Deal quickly and fairly with cases of cheating and disorder: Tackling corruption can put staff and the relevant organization at risk. Ensure that staff responsible for control and management is experienced and qualified. Ensure transparency and accountability in contracting and recruiting staff for the distribution of assistance. 
- Support durable solutions: Where the general conditions of return are given and IDPS have started to return or expressed their willingness to do so, assistance delivery points should be close to areas of origin to facilitate voluntary return and reintegration of the displaced communities. The same should apply to relocations.

- Mainstream environmental issues in the programming and delivery of assistance: Badly planned humanitarian aid can damage the environment and increase the risk of future conflicts over access to land, firewood or water. ${ }^{8}$ A well-designed humanitarian assistance programme, taking into account sustainable natural resource management, will allow IDPs and affected communities to sustain their livelihoods and decrease poverty. Building community acceptance and skills for engaging in diversified and more environmentally friendly livelihoods is essential.

\section{Evaluating and monitoring the protection impact (see Part III.4 $\square$ )}

- Work with all partners for the adoption of concrete measures to avoid abusive distribution systems, such as warehouse monitoring and post-distribution household surveys.

- Ensure that the monitoring of assistance distribution is done both by agency staff and representatives of the affected communities.

- Enable beneficiaries to transmit their concerns and suggestions regarding the quality of assistance or its modalities. Hold regular discussions with community members on the distribution mechanisms and make modifications, wherever feasible. Irregularities in the distribution cycle undermine the confidence of the affected community and increase the need to circumvent the system.

- Work together with humanitarian actors in the different sectors to ensure that their programme evaluation and monitoring activities measure not only performance levels, that is the quantities of material distributed, but also their protection impact, such as:

- the ability of such programmes to promote the dignity and self-reliance of persons of concern and the community or whether they are reinforcing dependency and risk, thus prolonging displacement;

- the different impact of assistance on persons of different ages, gender and backgrounds, particularly those who are less visible or unrepresented, including in terms of equality, non-discrimination, appropriateness to cover their specific needs and any changes required;

- whether targeted assistance related to sensitive issues inadvertently identifies and places individuals at risk of stigmatization or physical harm, such as targeted assistance to HIV-AIDS patients or gender-based violence survivors; ${ }^{9}$ and

- any other undesired effect, either on those receiving assistance, their relatives, surrounding populations or the relationship between different communities.

- Suggestion and complaint boxes could be set up along the areas of displacement. Random visits to households and displacement sites to obtain firsthand information on the impact of assistance should be conducted regularly.

- Ensure that ongoing evaluations of humanitarian assistance programmes develop and use "protection impact" indicators linked to the objectives set by the Protection Cluster/Sector. 


\section{Key references \& useful websites}

- Beyond Firewood: Fuel Alternatives and Protection Strategies for Displaced Women and Girls, Women's Commission for Refugee Women and Children, March 2006.

- Making Protection a Priority: Integrating Protection and Humanitarian Assistance, Inter Action's Protection Working Group, April 2004.

- Commodity Distribution, UNHCR Division of Operational Support, June 1997.

- Different Needs - Equal Opportunities, Gender and Non-Food Items in Emergencies, IASC Gender Handbook, 2006.

- Humanitarian Charter and Minimum Standards in Disaster Response, Chapter 4, Minimum Standards in Shelter, Settlement and Non-Food Items, Sphere Project, 2004.

- Camp Management Toolkit, Norwegian Refugee Council Camp Management Project, Oslo, 2004.

- Growing the Sheltering Tree: Protecting Rights Through Humanitarian Action, Inter-Agency Standing Committee, Geneva, 2002.

- Protection: An ALNAP Guide for Humanitarian Agencies, Slim, H., and Bonwick, A., Overseas Development Institute, London, 2005.

- Humanitarian Aid and Neutrality, Nicholas Morris, Conference on the Promotion and Protection of Human Rights in Acute Crisis, London, 11-13 February 1998.

- Principles under fire: does it still make sense to be neutral?, Marion Harroff-Tavel, Humanitarian Exchange, December 2003.

- Environment and Humanitarian Assistance Key Sheet, Irish Aid. 


\section{Coordination and management of camps and collective settings}

1. The protection value of the coordination and management of collective settings

2. Key responsibilities for camp coordination, management and administration

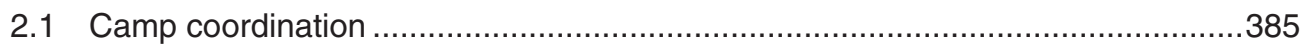

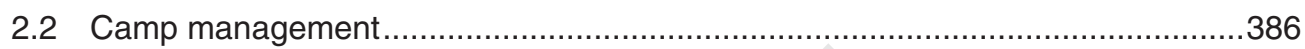

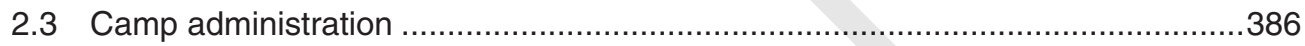

3. Key considerations for the creation of a protective environment in camps and camp-like settings

Key references

Useful websites 


\section{The protection value of the coordination and management of collective settings}

Collective shelter, especially where accommodating large numbers of people, can pose challenges to the well-being and dignity of internally displaced persons (IDPs). Nonetheless, when alternative accommodation is not available, camps or other collective accommodation such as settlements or shelters must be established.

Appropriate coordination and management of

If undertaken with a protection perspective and in close partnership with protection actors, camp management and coordination can ensure that displaced individuals enjoy their human rights as well as their fair and unhindered access to available humanitarian services. camps and collective shelters can alleviate many of the difficulties faced by IDPs and provide them with a link to humanitarian actors fostering accountability at the camp and inter-camp levels.

Well-managed camps and camp-like settings can strengthen physical, legal and material protection, and security. They also facilitate access to humanitarian assistance, including food, clean water, life-sustaining commodities, medical services and education.

\section{Key responsibilities for camp coordination, management and administration}

Appropriate coordination and management of camps and collective accommodations is primarily the responsibility of national authorities. In practice, States often welcome humanitarian actors who support them, through building capacity to ensure the protection and assistance of displaced populations. International agencies, NGOs and others should fill existing gaps only when a State lacks the capacity or the willingness to do so.

Camp coordination involves overseeing the humanitarian response in or between several camps or settlements; camp management takes place at the camp level. Both functions can be performed by the national authorities and humanitarian actors although, in the latter case, national authorities must acknowledge their overall responsibility.

Where country operations have adopted the IASC cluster approach and, if agreed with national authorities, responsibility for camp or site coordination rests with a designated lead agency. (See Part I.3. $\square$ ) At the global level, UNHCR is the lead agency for camp coordination and management in situations of armed conflict, and IOM provides the same leadership in natural disasters.

\subsection{Camp coordination}

The coordination of camps and camp-like settings involves bringing together relevant humanitarian actors to ensure activities are complementary and support IDPs in realizing their basic rights. Such coordination entails the following:

- coordinating with national authorities on the development and support of national or regional plans for the establishment and management of camps and other collective accommodations;

- ensuring that the roles and responsibilities of each actor are well understood by other humanitarian actors as well as by IDPs and surrounding populations;

- negotiating humanitarian access to camps and other settings; 
- monitoring the implementation of internationally accepted standards, including the SPHERE Humanitarian Charter and Minimum Standards in Disaster Response;

- promoting linkages between humanitarian activities in camps and national public services, such as education, health, public works, etc. with a view to ensure their sustainability and to extend their benefits to the different communities; and

- supporting humanitarian actors and national authorities by

- designating camp management agencies after consultation and prior to, or simultaneously with, setting up the camp;

- improving information management by systematic and coordinated collection, analysis and dissemination of baseline data on displaced populations, humanitarian services and their providers, as well as identification of humanitarian gaps (further explored in Part V.1 [DD); and

- supervising partners through monitoring and evaluating the protection impact of services provided.

\subsection{Camp management}

Camp management includes those activities in a single camp or other setting related to:

- coordinating humanitarian services and assistance;

- establishing and supporting IDP governance structures that represent the diversity of the displaced population and involve the active participation of IDPs;

- promoting community mobilization and participation in all aspects related to living in collective accommodation;

- promoting and facilitating constructive relationships and dialogue between the host and IDP communities; and

- monitoring and advocating safe and non-discriminatory access to facilities and services by all camp residents.

This function requires regular presence in the camp to perform the following tasks:

- creating opportunities for information exchange between humanitarian actors and the displaced community in the camp, the host community and national authorities;

- establishing mechanisms for regular discussion with IDPs of different ages, gender and backgrounds, to fully understand their needs and concerns as well as existing gender roles, resource sharing, ownership and decision-making practices;

- establishing regular coordination mechanisms, including meetings and information-sharing channels, at the camp level;

- ensuring, through ongoing monitoring and reporting, adequate maintenance of site infrastructure and the agreed delivery of services by all partners; and

- gathering and sharing baseline data on the IDPs (using a commonly agreed format) with relevant humanitarian actors. ${ }^{2}$

\subsection{Camp administration}

\section{Camp administration involves the functions of governments and national civilian authorities related to supervising activities in camps, including:}

- providing security, ensuring maintenance of law and order, and maintaining the civilian character of IDP camps; 
- designating, opening and closing camps and other settings;

- securing land and occupancy rights for camps, and resolving disputes arising from the appropriation of land in order to prevent claims against IDPs or agencies working in the camps;

- issuing civil documentation, permits and licenses (birth certificates, ID cards, travel permits, etc.) to citizens hosted in camps;

- registering IDPs in camps, including in urban settings, to facilitate the delivery of assistance and protection (further addressed in Part V.1 [D);

- preventing eviction, relocation or any further displacement of those living in the camp before they can return home or are offered other residence that conforms to international standards; and

- facilitating camp access for humanitarian actors, including the timely provision of any required documentation.

In Somaliland, a lack of adequate street lighting exposes IDPs to crime, theft, violence and abuse when moving around after dark. To address this issue, the Emergency Shelter Cluster worked with the IDPs to install 60 solar-powered street lighting units in two IDP settlements in Hargeisa. Replacement of batteries is not costly, and IDPs maintain the lamps themselves. A similar projects was put in place in IDP sites and relocation areas in Sri Lanka.

\section{Key considerations for the creation of a protective environment in camps and camp-like settings}

All humanitarian actors working in camps and similar settings must promote protection for the camp residents and surrounding communities. Protection concerns must be taken into account in addressing the following issues:

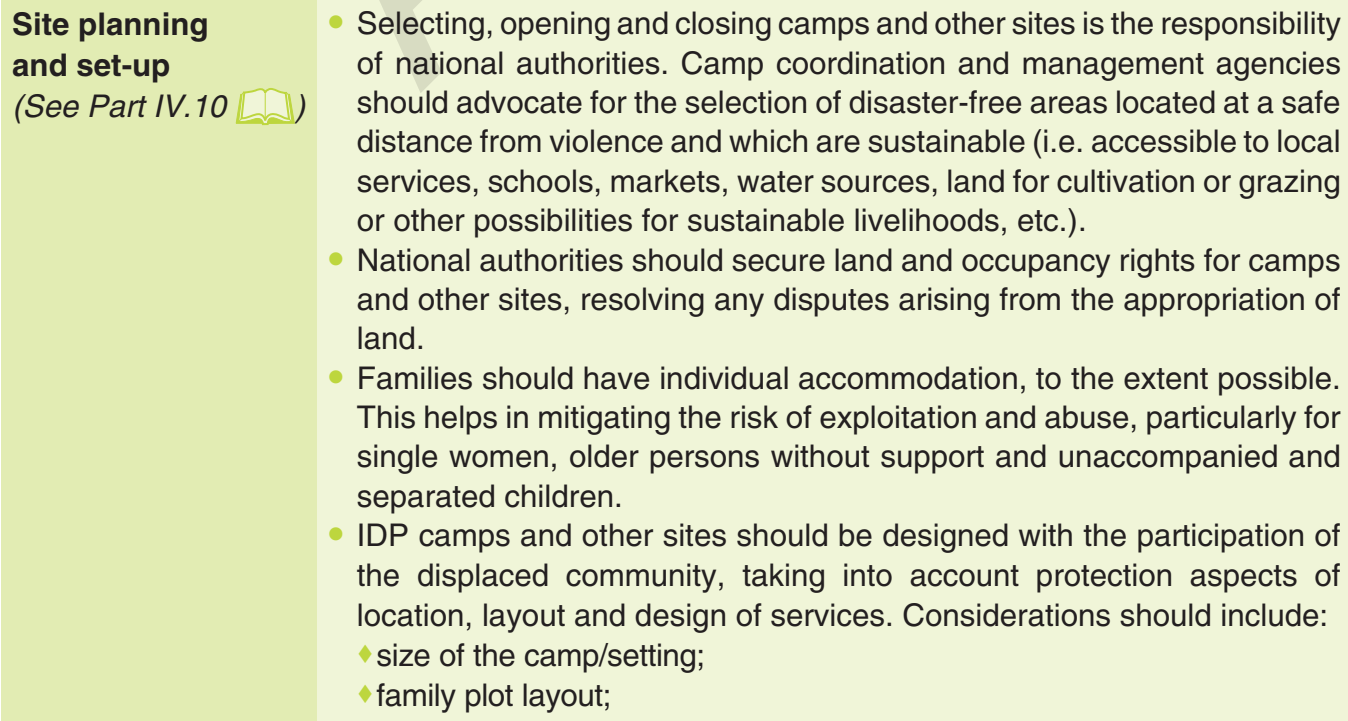

Site planning and set-up (See Part IV.10 DD)

- Selecting, opening and closing camps and other sites is the responsibility of national authorities. Camp coordination and management agencies should advocate for the selection of disaster-free areas located at a safe distance from violence and which are sustainable (i.e. accessible to local services, schools, markets, water sources, land for cultivation or grazing or other possibilities for sustainable livelihoods, etc.).

- National authorities should secure land and occupancy rights for camps and other sites, resolving any disputes arising from the appropriation of land.

- Families should have individual accommodation, to the extent possible. This helps in mitigating the risk of exploitation and abuse, particularly for single women, older persons without support and unaccompanied and separated children.

- IDP camps and other sites should be designed with the participation of the displaced community, taking into account protection aspects of location, layout and design of services. Considerations should include: size of the camp/setting;

family plot layout; 
safe access to services, including sanitation facilities (in particular for women and girls), schools, camp/site management offices, markets and community centres;

security lighting; and

establishment of child-friendly spaces.

- National authorities should allow freedom of movement outside and beyond the surroundings of camps and other sites. Humanitarian actors should ensure that their interventions do not hamper the freedom of movement of the IDPs (i.e. avoiding construction of closed sites, unsafe locations, etc.). Under certain conditions, restrictions on the freedom of movement are permissible if they are provided for by law and are necessary to protect other particular rights (further addressed in Part IV.6 [D).

Coordination
between all
partners
(See Part I.2

\section{Community} mobilization (See Part V.10 [D)
- All humanitarian actors involved in a camp or other setting should work together to ensure that humanitarian programmes fit within the overall national IDP framework or policy (if the State and/or the coordinating agency has developed one).

- All humanitarian actors should have a shared vision and a good understanding of the protection concerns in different camps and camp-like settings. This will avoid interventions that increase protection gaps or pose additional risks.

- Interaction between those responsible for different sectors is important for protection-mandated partners, who often need to intervene on the basis of concrete activities by other sectors (i.e. addressing gender-based violence issues in relation to distribution of assistance).

- Promoting a general understanding of the role and capacities of protection-mandated agencies helps to build confidence between these agencies, IDPs and national authorities.

- Using governance structures or community leaders, all humanitarian actors should systematically involve the IDP community in the planning, implementation and delivery of services.

- All humanitarian actors should develop an in-depth knowledge and understanding of the community living in the camp or site. This includes utilizing their capacities for the planning and implementation of activities and services in the camp. Camp managers should assess capacity-building needs within the community and ensure that they are adequately tackled with community leaders and all humanitarian actors.

- IDPs of different ethnicity, gender, age or background should be represented in governance structures. Camp managers should provide leadership training and support to camp governance structures. If necessary, camp managers should establish IDP governance structures.

- Camp managers and other humanitarian actors should support women, adolescent girls and boys to strengthen their leadership capacities and facilitate their meaningful participation in decision-making instances in the community.

- Interaction and dialogue between the IDP and host community should be promoted to prevent or ease tensions. 


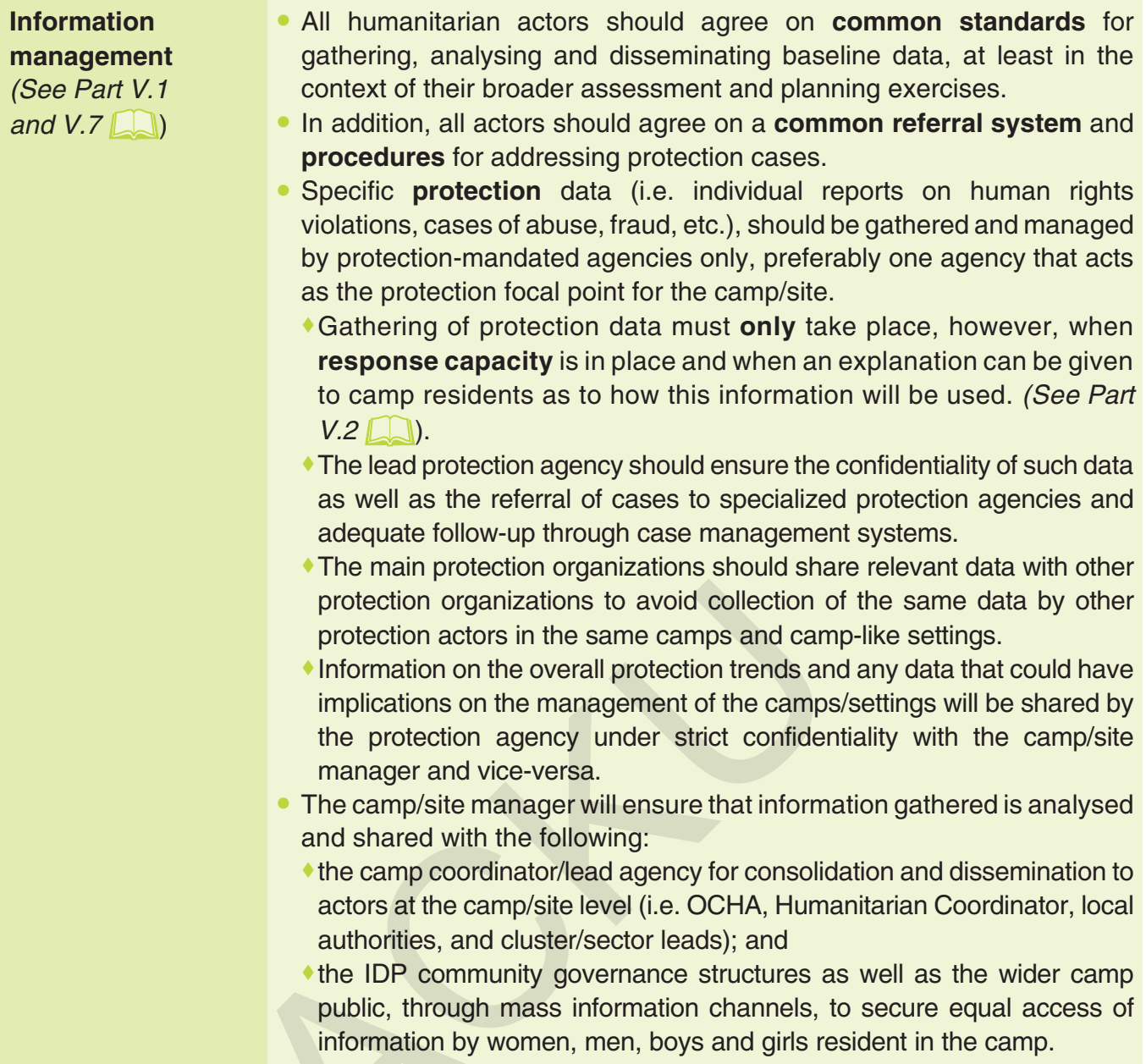

\section{Humanitarian} assistance (See Part V.5 $\square$ )
- Registration and documentation systems in camps and other sites should ensure smooth assistance distribution using coupons or ration cards, rather than specific IDP personal documents, which could lead to the stigmatization of displaced nationals.

- Planning and implementing assistance distribution should include protection considerations, including equal access by all IDPs, the IDP situation vis-à-vis surrounding communities and the eventual need of the latter for humanitarian assistance (further addressed in Part V.5 $\square$ ).

- All protection-mandated agencies, service providers and IDPs should agree on standard operating procedures to manage fair and efficient assistance distribution.

- All assistance and services provided should promote self-reliance, in order to avoid longer-term dependency on aid, and to the earlier achievement of durable solutions.

- Camp managers should monitor the delivery and use of assistance to ensure that camp residents have non-discriminatory access to facilities and services.

- Camp managers should establish and publicize a system for complaints regarding access to humanitarian assistance. 


\begin{tabular}{|c|c|}
\hline $\begin{array}{l}\text { Security } \\
(\text { See Part IV.2 } \square \text { ) }\end{array}$ & $\begin{array}{l}\text { National authorities have the responsibility to ensure the safety and } \\
\text { security of IDPs within their jurisdiction, including in areas affected by } \\
\text { armed conflict or controlled by non-State actors. All parties to an armed } \\
\text { conflict, both State and non-State actors should respect and ensure } \\
\text { respect for the safety and security of IDPs and other affected populations } \\
\text { (further addressed in Part I.1 } \square \text { ). } \\
\text { Authorities may lack the capacity or the willingness to provide protection } \\
\text { for IDP camps and other sites. In situations of armed conflict, this is } \\
\text { aggravated by continuing violence and the collapse of institutions and } \\
\text { infrastructure. Particularly in such cases, humanitarian actors should } \\
\text { explain to all camp residents their role and mandate and the } \\
\text { responsibility of all parties to the conflict to respect and ensure the safety } \\
\text { and security of the civilian population. } \\
\text { Camp management agencies, with the active participation of IDPs } \\
\text { should monitor, identify potential security threats, including those } \\
\text { originating from the host community, and put in place measures to } \\
\text { prevent such threats. } \\
\text { Camp management agencies can support and negotiate with authorities } \\
\text { to increase police security services in camps and to provide police } \\
\text { training (including female officers). } \\
\text { Community-based initiatives should be encouraged to communicate } \\
\text { information through radio, theatre or printed media providing objective } \\
\text { security information and advice. } \\
\text { Camp managers should support the development of community policing } \\
\text { programmes. Such teams should include women, training on basic } \\
\text { principles of law enforcement, and adequate supervision, monitoring and } \\
\text { equipment (further addressed in Part IV.2 } \text { ). }\end{array}$ \\
\hline $\begin{array}{l}\text { Presence of armed } \\
\text { actors/groups in } \\
\text { humanitarian } \\
\text { settings } \\
\text { (See Part IV.2 } \square \text { ) }\end{array}$ & $\begin{array}{l}\text { Staff of all agencies should be trained to monitor and report on the } \\
\text { presence of armed actors/groups in humanitarian settings. } \\
\text { Camp management should work with security staff to establish early } \\
\text { warning and preparedness mechanisms which identify and respond to } \\
\text { potential security threats, including armed conflict and the infiltration of } \\
\text { armed actors into camps and other sites. } \\
\text { Camp managers should consult regularly with camp residents, including } \\
\text { camp leaders and security committees, on security issues and discuss } \\
\text { measures they feel can contribute to improved security; this should } \\
\text { contribute to the IDPs' sense of shared responsibility for their own } \\
\text { security. } \\
\text { Preventive security measures can reduce opportunities for attacks on } \\
\text { camps or infiltration by armed elements. Such preventive measures may } \\
\text { include the following: } \\
\text { establishment and training of IDP camp security committees; } \\
\text { information and communication campaigns or other activities to sensitize } \\
\text { the community on the negative impact of militarization; and } \\
\text { location of camps away from areas of active conflict or continuing } \\
\text { instability. } \\
\text { Camp management, in coordination with protection agencies, should notify } \\
\text { authorities immediately should armed elements enter camp locations. }\end{array}$ \\
\hline
\end{tabular}




\section{Preventing forced recruitment}

(See Part IV.5 DD)

Access to justice

(See also

Part IV.18 DD)
- Camp management agencies play a central role in monitoring and reporting incidents of forced or attempted recruitment, especially of children, as well as of indoctrination attempts or campaigns. Such information should be shared under strict confidentiality with protection-mandated agencies.

- Situational analysis should identify groups or persons at risk of recruitment by armed forces or armed groups and should assess possible agents of recruitment and tactics used.

- Community awareness and community-based efforts can help to prevent recruitment. The provision of adequate levels of assistance and fair distribution mechanisms are equally important.

- Programmes which promote family livelihood activities, formal and informal training, recreational activities, and health care for all children, including girls, can reduce children's vulnerability to recruitment. Camp management agencies should encourage development of such activities.

- Because schools can be recruiting grounds for armed elements, special measures should be taken to protect and monitor schools. Educational opportunities, including for girls, should be reinforced.

- The individual registration and documentation of children, especially unaccompanied or separated children, are important protection tools and can help to prevent the recruitment of children. Registration data can help to ensure that any recruitment in the camp or in the schools is detected early, allowing for preventive measures to be taken.

- Camp management should pay special attention to children associated with armed groups, as they are at particular risk of re-recruitment. ${ }^{3}$

- All humanitarian actors and camp residents should be aware of the applicability of the national legal system. In some cases, camp/site residents may bring with them traditional or non-formal justice or dispute settlement mechanisms. Such systems may also be developed in camps when there is limited or no access to national justice systems.

- Serious crimes, such as murder, rape, assault, child abuse or exploitation should always be handled through the national justice system.

- Alternative or traditional justice systems are often useful to settle petty crimes and juvenile justice issues. Camp management and protection actors working in camps and camp-like settings should develop an understanding of such systems. They should establish a dialogue with the relevant leadership of such systems to ensure that they fully respect human rights standards.

- Camp management agencies and other humanitarian actors do not have authority to deal with crimes committed by or against IDPs. However, they do have a responsibility to advocate for non-discriminatory access by camp residents to the national justice system.

- If access to courts is hampered by the remoteness of camp or site locations, humanitarian actors can support local authorities by providing them with transportation or fuel or by creating mobile national courts to visit the relevant areas on a regular basis. 
- The camp or site management and protection-mandated agencies should advise residents about law enforcement mechanisms applicable to them and how to access them. Specialized partners (i.e. mobile legal clinics) can be brought in, if required. (See Part V.8 $\square$ )

Durable solutions (See Part VI DU)
- Camp administrators (local authorities) are responsible for issuing civil documentation, permits and licenses (birth certificates, ID cards, travel permits, etc.) which enable IDPs to enjoy basic rights, and to access a durable solution to their situation of displacement. Humanitarian actors should support the efforts of local authorities in this field.

- All humanitarian activities in camps should promote self-reliance and sustainable livelihoods. This focus should be built into all assessment and planning processes. The ability of potential service providers to orient their interventions in practice towards these goals should be part of the core selection criteria.

- When the majority of IDPs in a site has found a durable solution, closure strategies should be developed jointly with IDPs and national authorities. Such strategies need to ensure that the protection concerns of the remaining camp or site residents are taken into account.

- Camp management should make particular efforts to find durable solutions for persons with special protection needs.

\section{Key references}

- Guidance Note on the Management of Collective Centres-CCCM Global Cluster 2007.

- Inter-Agency Gender Handbook - CCCM Chapter, IASC, 2006.

- Sphere Guidelines - Humanitarian Charter and Minimum Standards in Disaster Response, Sphere Project, 2004.

- Need Analysis Framework, (NAF) - CCCM Chapter, IASC Cap Sub-working Group, April 2007.

- The Camp Management Toolkit - The Camp Management Project 2008.

- Operational Protection in Camps and Settlements, A Reference Guide of good Practices in the Protection of Refugees and Other Persons of Concern - UNHCR 2006.

- Practical Guide to the Systematic Use of Standards and Indicators in UNHCR Operations, UNHCR, 2nd Edition, February 2006.

\section{Useful websites}

- Camp Coordination and Camp Management Cluster: www.oneresponse.info/GlobalClusters/Pages/default.aspx

- Humanitarian Reform: www.oneresponse.info

- The Camp Management Project: www.flyktninghjelpen.no

- United Nations High Commissioner for Refugees, (UNHCR): www.unhcr.org

- United Nations Children Fund (UNICEF): www.unicef.org

- Reliefweb (OCHA): www.reliefweb.int 


\section{Part V.7 \\ Disseminating information}

1. The protection value of access to information .....................................................394

2. Possible means for disseminating information .........................................................394

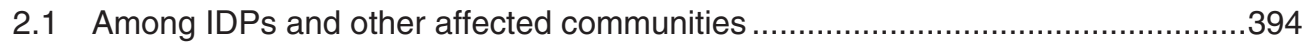

2.2 With governments and other institutional partners ............................................394

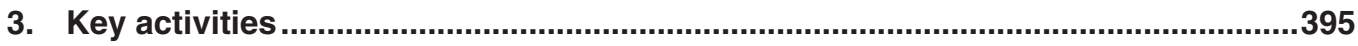

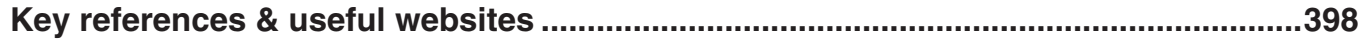

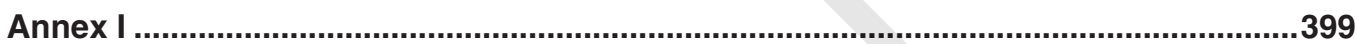




\section{The protection value of access to information}

The right to seek, receive and impart information is a basic human right. It also has considerable protection value. Access to accurate, reliable and timely information helps individuals and communities make sound decisions, develop sustainable survival strategies, and seek a durable solution to displacement. It also helps safeguard against manipulation and abuse.

Displaced individuals and communities often lack, or have limited access to, timely and accurate information. Ensuring their right to information and, in some cases, providing relevant information, can support the efforts and strengthen the capacity of individuals and communities to protect themselves.

Ensuring access to, and/or providing information in, situations of internal displacement can be challenging, in particular where displacement has been motivated by political factors. Such efforts must be undertaken with care in order to avoid creating tensions or placing individuals and communities or humanitarian actors at risk.

\section{Possible means for disseminating information}

Information can be conveyed and exchanged through a variety of means. The choice will depend on a number of factors, such as the nature of the information, the source, the target audience and the socio-economic and cultural environments.

\subsection{Among IDPs and other affected communities}

- Individual counselling, household visits

- Group meetings, support groups, group counselling, awareness-raising, sensitization campaigns

- Community representatives/leaders and other multipliers, such as community associations/centres, churches, mosques, temples, health staff, humanitarian assistance delivery sites, legal aid centres

- Programme-related activities, including education (meetings with parents/grandparents/ caregivers, classroom dissemination) and health care (waiting rooms, vaccination campaigns)

- Family tracing and messaging services, such as those established by ICRC

- Media (radio/TV/newspapers, public broadcasts, sms)

- Cultural and artistic performances

- Posters, leaflets and newsletters

- Audio tapes, videos or films

\subsection{With governments and other institutional partners}

- Bilateral and multilateral meetings and briefings

- Standard reporting mechanisms, such as situation reports

- Contingency planning, programmes and agendas

- Workshops and seminars

- Humanitarian hubs for humanitarian information-exchanges and networking

- Cluster meetings

- Web dissemination (compiled reports on the OCHA website, Reliefweb, virtual communities of practice, databases, maps) 
networks of national partners

- Networks and regular venues for local and international agencies and other actors

- Official media, including radio, TV, newspapers

Specialized/targeted newsletters

\section{Key activities}

- Disseminating information for use as a protection tool will entail:

- determining what concrete information is needed by different stakeholders and for which purposes;

- selecting the appropriate timing and dissemination channels for the different stakeholders; and

- avoiding causing any harm through information-dissemination activities.

Annex I of this chapter $\square$ contains a checklist with useful questions to ask when developing an effective and protection-oriented strategy to disseminate information.

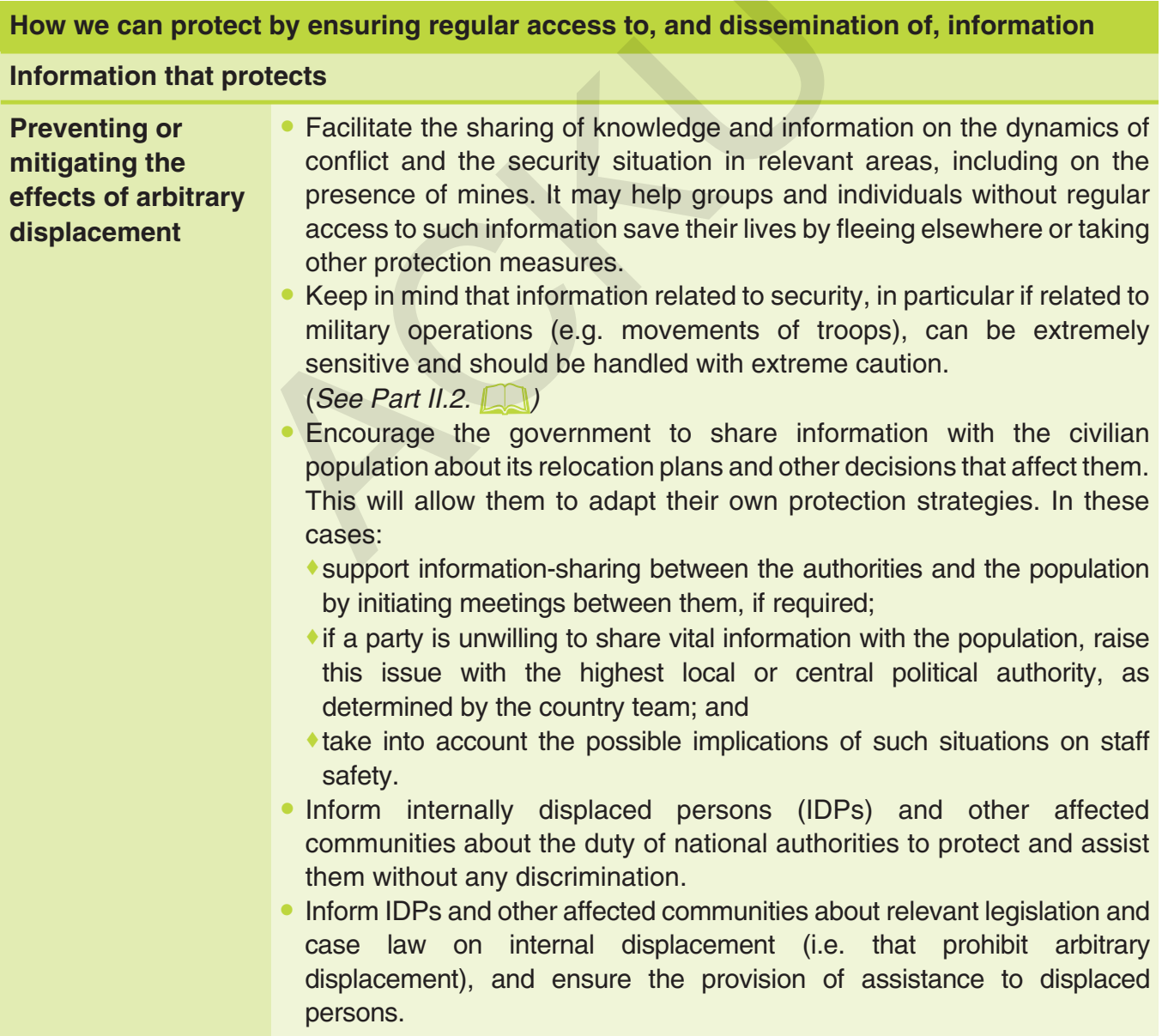

For guidance on sources, methods and standards for gathering, protecting and evaluating the reliability of information, see Part V.1 and Part V.2. 
- Disseminate information about the location of transit centres or points of delivery of humanitarian assistance to avoid dangerous secondary displacements and to enable prompt access to relief.

- Ensure that IDPs and other affected populations understand their right to seek asylum abroad.

Improving
protection and
enjoyment of rights
during
displacement

- Dispel rumours by providing objective and accurate information and, if possible, access to reliable sources of information.

Discuss and plan with affected communities, information campaigns on protection risks that may affect particular individuals or groups. This can facilitate the timely adoption of specific measures to prevent such risks and to access relief and redress mechanisms quickly when such risks arise. Examples are provided below.

Women, girls and boys at risk of sexual exploitation, forced prostitution, or abuse: The community should be informed of the equal rights of women and girls to access national and international protection and assistance efforts, the fact that humanitarian assistance is provided free of charge, equal rights to participation, the methods used by trafficking networks, and national institutions responsible for the care and protection of victims of trafficking and exploitation and for preventing and responding to such abuses.

- Men, children, and adolescents at risk of forced recruitment or forced labour: The community should be informed of organizations or national institutions mandated to protect against forced recruitment or forced labour as well as the existing legal framework, and legal aid projects focusing on this issue.

- Provide information on the availability of legal aid projects or information centres, and on existing procedures for issuing replacement identity documents, procedures for land, housing and property restitution, and support for family reunification.

- Raise the profile of national and international assistance and distribution programmes and eligibility criteria for housing, food, water, sanitation, medical care, education and work opportunities or commercial activity in local markets.

\section{Facilitating or promoting durable solutions (See Part VI DD)}

- Ensure that all IDPs are aware of the principle of voluntary return and the right to settle in another part of the country.

- Provide information on the situation in areas of return/settlement elsewhere, including security, availability of assistance, availability of food, housing, water, work, pension and social benefits, health and education, the state of infrastructure, the condition of housing, and land and property ownership and use.

- Assess and inform the displaced populations of travel conditions (the presence of mines, water sources and medical centres) along transit routes to the areas of return or resettlement.

- Disseminate information among affected populations on the right to vote, participate in community/public/government affairs, and freedom of association, religion, thought and conscience - all without being subject to discrimination. 
Avoiding harm

\begin{tabular}{l|l} 
Averting & Assess the accuracy and reliability of information received. This may \\
misinformation & require research, analysis and cross-checking of information from \\
& various sources. \\
& Remain aware of politicized media or interlocutors, particularly in conflict \\
& situations.
\end{tabular}

Managing sensitive information

\section{Avoiding a monopoloy of information}

- Ensure that information reaches persons of different ages, genders and backgrounds. Even though it could seem more expeditious to rely on a few persons or structures in the community, such as IDP leaders, adults and men, to transmit information, seek a diversity of multipliers.

- Spend substantial time in communities of concern in order to have access to different groups and individuals, broaden possibilities of dissemination, and identify further information needs, through discussions and dialogue with groups and individuals. Ensure feedback is received on the best ways to communicate information to concerned audiences, taking into consideration the experience from possible previous information-dissemination activities.

- Make efforts to reach remote or dispersed IDPs and affected communities, including IDPs in urban settings or living in areas that are inaccessible to humanitarian workers.

- The timing and location chosen for disseminating information must be reconciled with family and work obligations as well as with access to transportation.

Adapt the content and modalities of information to individuals of different ages, gender and backgrounds and any group with specific needs. These can be individuals with physical conditions that limit their mobility as well as children, minority groups, women, youth, older persons and single-headed households. Examples are provided below.

Women IDPs (often including teenage girls): Not only should women have access to information on an equal basis as men, but they might also require specific types of information, such as information relating to mine action. Rather than focusing only on the main roads, which might be most useful for male IDPs, focus also on the areas where women collect firewood, grow crops, fetch water, and wash clothes.

Children and youth must be kept informed (through their relatives, communities, teachers or others) on decisions that may affect them or that are made on their behalf. In particular, they must be consulted and informed about alternative living arrangements and tracing activities available to them. It is essential to adapt the method of dissemination to the age, gender and backgrounds of children so that they understand key messages. 
Older persons: Particular attention should also be given to the access that older persons have to information, as they may not be literate or may be disabled (i.e. partial hearing or housebound). In addition, older persons may have problems working in the same languages in which their children work, and information may need to be in less commonly used languages or dialects.

Socio-cultural awareness
- Ensure that the location or method chosen for disseminating information does not stigmatize or otherwise deter persons from accessing the information.

- Information regarding domestic violence may be disseminated discreetly at medical clinics, daycare centres, and training events.

- Information and assistance for HIV/AIDS patients and survivors of gender-based violence is best provided in a manner and place where persons are not afraid of being identified. Mobile information and counselling clinics are often useful.

- Messages should be worded in culturally appropriate terms. Be aware of the potential misunderstandings caused by "word-by-word" translations.

- Remain aware of how the specific age, gender and political, ethnic or religious affiliations of national colleagues, interpreters or local partners can influence the access to, and the receptivity of, IDPs to the information provided.

\section{Key references \& useful websites}

- Humanitarian Disasters and Information Rights: Legal and Ethical Standards on Freedom of Expression in the Context of Disaster Response, Article 19, 2005.

- Operational Protection in Camps and Settlements: A Reference Guide of Good Practices in the Protection of Refugees and Other Persons of Concern, Chapter 4 on Information Dissemination, UNHCR, 2006.

- Left to their Own Devices: The Impact of Informal Informational and Communication Networks on Security in Tanzanian Refugee Camps, A.R. West and L.W. Wambugu, Article 19, 2003. 


\section{Annex I}

\section{Checklist for information-dissemination}

- What information is needed by IDPs and other affected populations at this stage?

- What will be the protection impact of this information?

- Who should transmit this information to them? Is it the task of humanitarian actors, or should local authorities be encouraged and supported to do so? Will this choice affect the target audience's perception of the neutrality and impartiality of humanitarian actors?

- How will IDPs and other affected communities help design the dissemination strategy?

- How will NGOs and other partners be involved to ensure clear and consistent messages and to avoid the overlap of efforts and resources?

Which channels will be used to disseminate the information? How do people access information?

- What are the most appropriate information channels to ensure the safety of the targeted audience and to avoid its stigmatization? Has the targeted audience indicated what type of information channel they prefer or find more secure?

- How will the dissemination of information be made sustainable and not remain a one-off exercise?

1 How will the strategy ensure that the information reaches those with specific needs or those most marginalized within the IDP community?

- How will the illiterate be informed?

- Is the information being shared reliable? Is it culturally appropriate?

- Are the messages delivered in a respectful, unequivocal and non-patronizing manner?

- Can the audience provide feedback to those disseminating the information?

- How can feedback be managed?

- What media sources will be engaged: radio, print, posters, megaphones, teachers, community leaders?

- How will the host community be engaged? Would it be helpful to conduct an information campaign to raise awareness of the challenges and risks faced by IDPs? 


\section{Legal assistance and advice}

1. Legal counselling and assistance in the context of internal displacement ..........401

2. Key types of legal aid programmes for internally displaced persons ..................401

2.1 Legal information programmes ........................................................401

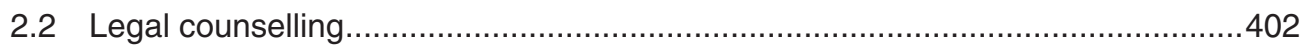

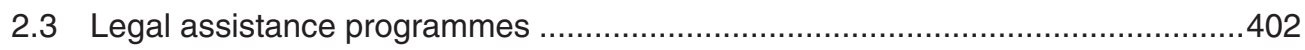

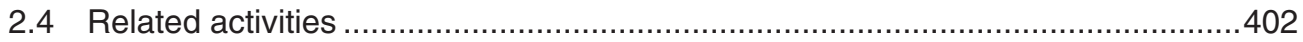

3. Key considerations when establishing effective legal aid programmes ...............403

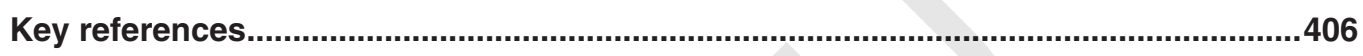

Useful websites ....................................................................................................406 


\section{Legal counselling and assistance in the context of internal displacement ${ }^{1}$}

As internally displaced persons (IDPs) seek remedies to address rights violations, they may need assistance to understand local laws and procedures, to choose and access appropriate mechanisms, or to obtain legal counsel and representation. Legal information and advice can be particularly important to IDPs who are unfamiliar with the law in the region to which they have been displaced, who have lost or lack the necessary documentation to access remedies, or who do not have sufficient financial resources to pursue the enforcement of their rights. In such circumstances, legal assistance programmes can play a crucial role to support IDPs in accessing public services, humanitarian assistance programmes or the justice system itself (further addressed in Part IV.18 [D).

Legal aid programmes can also contribute to building a protection environment conducive to finding durable solutions. For example, by resolving property disputes, IDPs may be able to return to their area of origin (further addressed in Part VI $\mathrm{D}$ ).

In general, when designing legal assistance programmes, it may be useful to pursue a local remedy under alternative dispute mechanisms, if these exist. Confidentiality and informed consent should form the basis of all programmes.

\section{Key types of legal aid programmes for internally displaced persons}

\subsection{Legal information programmes}

Legal information programmes seek to familiarize IDPs with existing formal legal systems (regulations, laws and customs regulating civil/administrative, criminal and human rights matters), particularly as they relate to their displacement.

Through legal information programmes, we may:

- set up legal information offices or mobile clinics in displaced communities;

- facilitate communication between IDP communities to overcome legal barriers, particularly if one community has had prior success;

- publish reports on issues relating to the rights of IDPs;

create and support information networks of national partners, including public officials, institutions, lawyers, NGOs, and community elders to ensure understanding of their duties vis-à-vis IDPs;

- collect and distribute information on precedent-setting cases, new procedures, State programmes specifically benefiting IDPs, etc.; and

In Azerbaijan,

Legal Centers provide free legal aid, information and counselling to IDPs and returnees on issues such as restitution or compensation of property, lost documentation, registration and access to social services. Visits by mobile legal teams, formed by local NGOs, are also arranged for IDPs who can not reach the Legal Centers, and phone lines are available for legal information and advice. The project has built awareness and understanding among IDPs with regard to their rights while also improving relations with different governmental bodies.

A similar project was put in place in Colombia through law students in the framework of the practice required for the diploma.

For more information, see: protection.oneresponse.info.

This chapter is based on and takes excerpts from Norwegian Refugee Council, Handbook on Information, Counselling, Legal Assistance (ICLA), 2004 edition.

See Part V.7 
- conduct mass information campaigns using radio, TV, press, newsletters, posters, or leaflets to distribute important information to displaced communities.

\subsection{Legal counselling}

Legal counselling programmes seek to advise IDPs on their legal options to address a specific rights violation or to claim a legal entitlement. Such programmes can provide individual counselling through mobile units or in permanent centres. While some programmes specifically target services at relevant minority or sub-groups with specific needs within the IDP population, broader meetings with IDP and host community populations may be appropriate to address certain legal issues in some circumstances. The primary functions of a legal counsellor would be to:

- provide individual advice to IDPs by listening to the situation, explaining the situation in legal terms, and discussing potential legal mechanisms to address the problem;

- explain potential benefits and risks associated with various options, and provide guidance about the best method to address challenges; and

- clarify incorrect information that may be circulating in the community.

\subsection{Legal assistance programmes}

Legal assistance programmes provide direct support to IDPs to overcome legal obstacles, access entitlements, obtain redress for rights violations and resolve disputes through appropriate channels. Some responsibilities that may be associated with the provision of such legal assistance are indicated below.

- Act as legal counsel for displaced persons in relevant administrative procedures. Administrative procedures are commonly used to address cases involving human rights, property restitution or land tenure rights, documentation required for citizenship or identity documentation, or social benefits such as employment or pension rights.

- File legal complaints with courts and provide in-court representation through staff or outside counsel. Legal representation may be particularly useful in cases of neglect, deliberate obstruction of justice, or unlawful actions such as arbitrary arrest or detention.

- Exercise power of attorney or accompany clients to gather documents from public offices or documentation centres in the area of displacement or in the IDP's area of origin.

- Prepare and file "test cases" in domestic, regional and international courts and human rights bodies ${ }^{3}$ on behalf of IDP clients (also addressed in Part I.2 [D]).

- Assist clients with the submission of cases, representation and mediation in "informal," "traditional" or "tribal" justice mechanisms.

\subsection{Related activities}

Capacity-building activities ${ }^{4}$ can:

- strengthen the knowledge of national and local governmental actors about their obligation to respect, protect and fulfil the rights of IDPs in a manner consistent with international law;

3 This includes taking cases to international courts, such as the European Court of Human Rights in Strasbourg, international treaty bodies such as the United Nations Human Rights Council in Geneva, or United Nations committees guarding treaties like Minority Rights, Elimination of all Racial Discrimination and the Committee on Economic and Social Rights.

4 See Part V.9. 
- provide technical assistance and advice on legislation, implementation regulations and procedures;

- give financial support to start legal/administrative proceedings (i.e. legal services, administrative fees, expenses or "incentives" that may be necessary to broaden legal aid programs to IDPs); and

- strengthen the capacity and skills of local organizations so they might better assist IDPs and promote respect for their human rights.

\section{Advocacy $^{5}$}

Based on an understanding of individual cases, advocacy campaigns can be launched for the protection of particular rights of the IDPs. Experience has shown that specific and actual case-based advocacy programmes have greater impact and stronger credibility. Given the sensitivity of many IDP rights-related issues, advocacy campaigns should be discussed, agreed upon and supported throughout the relevant organization.

\section{Key considerations when establishing effective legal aid programmes}

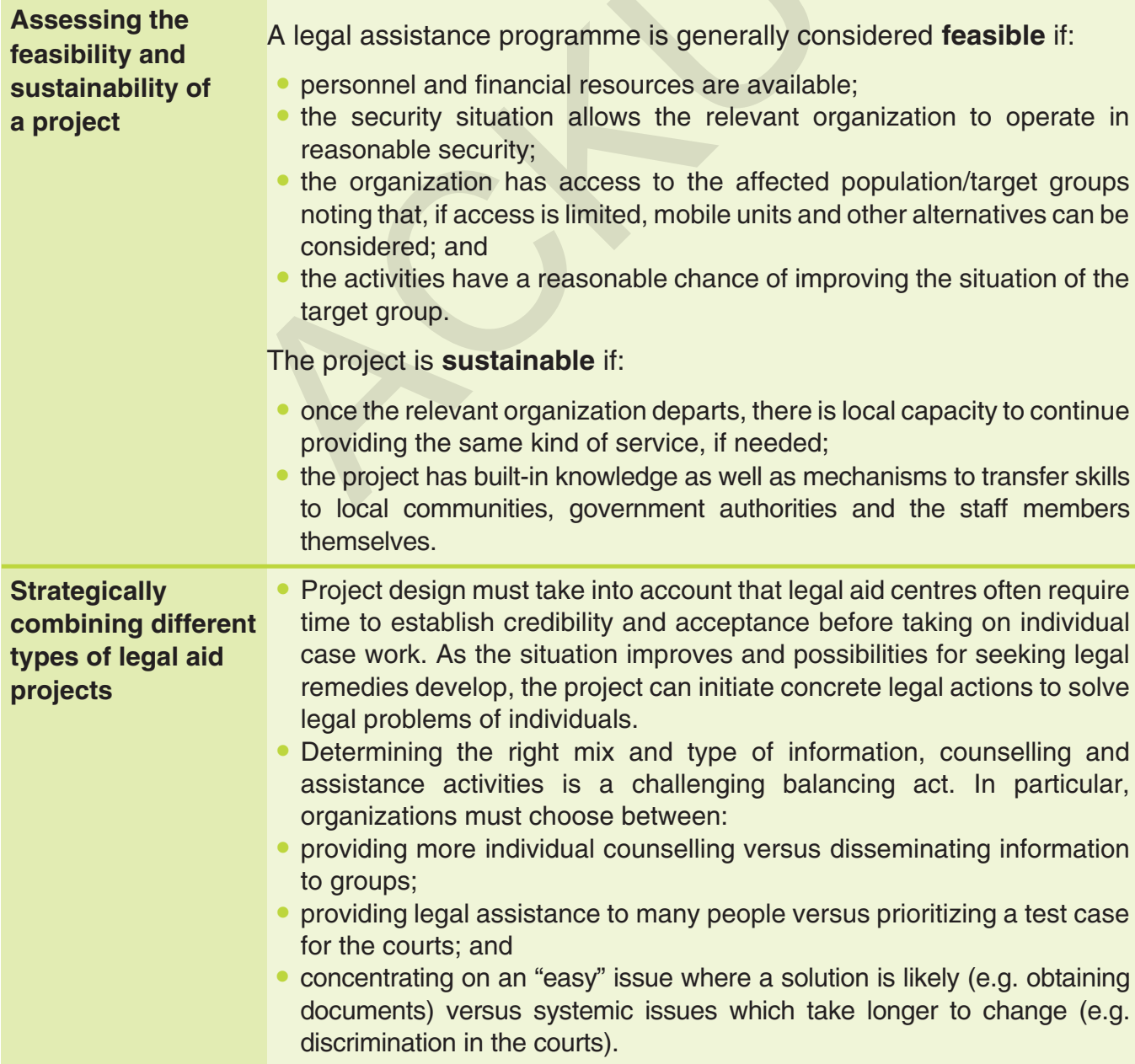
noting that, if access is limited, mobile units and other alternatives can be considered; and

- the activities have a reasonable chance of improving the situation of the target group.

The project is sustainable if:

- once the relevant organization departs, there is local capacity to continue providing the same kind of service, if needed;

- the project has built-in knowledge as well as mechanisms to transfer skills to local communities, government authorities and the staff members themselves.

Strategically combining different types of legal aid projects

Project design must take into account that legal aid centres often require time to establish credibility and acceptance before taking on individual case work. As the situation improves and possibilities for seeking legal remedies develop, the project can initiate concrete legal actions to solve legal problems of individuals.

- Determining the right mix and type of information, counselling and assistance activities is a challenging balancing act. In particular, organizations must choose between:

- providing more individual counselling versus disseminating information to groups;

- providing legal assistance to many people versus prioritizing a test case for the courts; and

- concentrating on an "easy" issue where a solution is likely (e.g. obtaining documents) versus systemic issues which take longer to change (e.g. discrimination in the courts). 
- The choice for one or another type of programme will depend on the potential positive impact of particular activities on IDPs. Generally, legal aid programmes should combine information and counselling, as both are integral to successful legal interventions.

- In conflict and immediate post-conflict situations, legal assistance activities often target a large number of clients and focus on providing general information in the absence of legal and civil infrastructure to pursue individual cases.

- If individual cases become repetitive, this may indicate a systemic problem with a particular law or institution; in such cases, information and advocacy campaigns may be useful.

- If solutions to individual claims are achieved, legal information and training programmes can contribute to enable broader groups to benefit as well from the same solution or strategy to address the problem.

- In some situations, it may be more appropriate to seek a remedy within an alternative dispute mechanism as opposed to formal legal mechanisms. As long as such remedies are in accordance with international human rights law and principles, they can be applied either as an interim measure or in a manner that complements the existing official system (further addressed in Part IV.18 [D).

Coordination with other programmes and actors
- All agencies involved in protection, assistance and legal aid activities should work in a collaborative and concerted way to minimize overlap and to fill gaps. For example, if return becomes a durable solution for a large number of IDPs, information and counselling on land tenure, compensation or restitution could be key components in a shelter programme.

- The perception that IDPs and other actors have with regard to the credibility of organizations providing legal assistance should also be monitored. Staff involved in legal aid projects should clearly set realistic expectations by stating how their organization can and cannot assist IDPs.

\section{Managing information}

- Protecting the confidentiality of personal information and obtaining informed consent to share such information is essential to build trust and confidence and to ensure that affected populations are not put at risk.

- Information used in legal aid projects must be reliable and accurate, which means that it must be verified and updated. This can be particularly difficult during conflict or in post-conflict situations, when things change quickly and transparency is often lacking.

- While electronic recordkeeping, such as databases, can support assessment, monitoring and analysis, it is essential that all mechanisms safeguard confidentiality. Such information should also be cross-checked, whenever possible, and evaluated in light of its source.

- A system to refer potential clients or issues to specialized organizations should be established, both on a case-by-case basis and thematically.

- A thematic compilation of good practices and relevant jurisprudence can also strengthen legal advice actions.

- Standard operating procedures should be developed and disseminated to ensure access to legal redress and/or specialized legal assistance for different protection risks (i.e. for land, housing and property restitution cases, gender-based violence, documentation procedures, etc.). 


\begin{tabular}{|c|c|}
\hline $\begin{array}{l}\text { Staffing the } \\
\text { projects }\end{array}$ & $\begin{array}{l}\text { Recruiting local staff contributes to the sustainability of programmes, the } \\
\text { development of local capacities, and a greater understanding of the local } \\
\text { legal system. } \\
\text { When hiring local lawyers, one should seek to avoid weakening State } \\
\text { institutions by depleting local capacity. } \\
\text { Where appropriate, strike a balance between recruiting newly graduated } \\
\text { lawyers and experienced local lawyers; while experienced lawyers may } \\
\text { bring credibility and legitimacy to the project and facilitate dialogue with } \\
\text { key actors, it is also important to expose a new generation of lawyers to } \\
\text { the principles of human rights law which they will retain throughout their } \\
\text { professional life. } \\
\text { Where possible, hiring practices should also aim for an appropriate ethnic } \\
\text { and gender balance among national staff, taking into account political and } \\
\text { cultural sensitivities in the country or region. }\end{array}$ \\
\hline \multirow[t]{2}{*}{$\begin{array}{l}\text { Developing } \\
\text { soft skills } \\
\text { (See Part II.2 } \square \text { ) }\end{array}$} & $\begin{array}{l}\text { Noting that many IDPs and affected populations seeking advice may } \\
\text { have been traumatized by a conflict situation, all staff members need to } \\
\text { develop basic knowledge of the symptoms of trauma as well as general } \\
\text { counselling techniques to address them. } \\
\text { Legal aid workers should also be equipped to deal with the stress that } \\
\text { can result from being exposed to accounts of rights violations and } \\
\text { trauma. } \\
\text { All staff in legal assistance programmes should be aware of the limitations } \\
\text { of their competencies when it comes to an IDP's need for professional } \\
\text { psychological and medical counselling. }\end{array}$ \\
\hline & $\begin{array}{l}\text { Some basic tips: } \\
\text { - Never turn anyone away. If approached by someone outside the target } \\
\text { group, politely redirect the person to other organizations that may be of } \\
\text { assistance. } \\
\text { Focus on key issues with clear and simple questions. } \\
\text { Be prepared and always answer questions accurately, even if it requires } \\
\text { follow-up or research. } \\
\text { Provide comprehensive information, encouraging clients to ask follow-up } \\
\text { questions. Many may not be aware of the information they need to know. } \\
\text { If needed, spread discussions over several meetings. It is not necessary } \\
\text { to bring everything up in the first consultation. } \\
\text { Try to reach IDP sub-groups at high risk or those most in need of } \\
\text { information and counselling. } \\
\text { Do not attempt to be superhuman. Even counsellors are allowed to admit } \\
\text { that an issue is difficult to handle. If your organization does not have the } \\
\text { capacity to answer a specific issue, contact a network colleague for advice, } \\
\text { ensuring the query does not compromise confidentiality. }\end{array}$ \\
\hline
\end{tabular}




\section{Key references}

- Information, Counselling, Legal Assistance (ICLA), Norwegian Refugee Council, 2004 edition.

- National Human Rights Institutions and Internally Displaced Persons: Illustrated by the Sri Lankan Experience, by Gomez, Mario, Brookings-SAIS Project on Internal Displacement, July 2002.

- Housing and Property Restitution for Refugees and Displaced Persons, Implementing the Pinheiro Principles, FAO, IDMC, OCHA, OHCHR, UN-HABITAT, UNHCR, 2007.

- Property restitution in practice: The Norwegian Refugee Council's experiences, by Ingunn Sofie Aursnes, and Conor Foley, NRC, April 2005.

- Incorporating the Guiding Principles on Internal Displacement into Domestic Law: Issues and Challenges :Study on the Recovery of Personal Documentation (chapter 9), in Studies on Transnational Legal Policy no 41, by Conor Foley, Paul Nesse, Barbara McCallin, Brookings-Bern Project on Internal Displacement and the American Society of International Law, 2010.

\section{Useful websites}

- Norwegian Refugee Council: www.nrc.no

- Internal Displacement Monitoring Centre: www.internal-displacement.org

- Brookings Institution SAIS Project on Internal Displacement: www.brookings.edu

- United Nations High Commissioner for Refugees: www.unhcr.org

- Reliefweb (OCHA): www.reliefweb.int 


\section{Part V.9 \\ Capacity building}

1. Definition .408

2. Why capacity building is important for the protection of internally displaced persons 408

3. Building and strengthening national capacity to address internal displacement.

3.1 The capacity of national authorities 409

3.2 The protection capacities of internally displaced persons and other affected communities

3.3 The protection capacities of civil society, including national NGOs

Key references \& useful websites .415

Training resources .415 


\section{Definition}

Too often, capacity building tends to be equated with training. Certainly, training is a means to this end, but capacity building is much more. It entails:

"The creation of an enabling environment, with appropriate policy and legal frameworks, institutional development, including community participation (of women in particular), human-resources development and strengthening of managerial systems.

Specifically, this requires efforts in three main areas:

- equipping individuals and communities with the understanding, skills and access to information, knowledge and training that enables them to perform effectively;

- developing effective management structures, processes and procedures within organizations and for managing relationships among different organizations and partners;

- putting in place institutional, legal and regulatory frameworks to enable organizations, institutions and agencies at all levels and in all sectors (public, private, and community) to enhance their capacities.

Capacity building, therefore, is not a single activity or an end in itself. It is a long-term, continual process aimed at reinforcing human, institutional and community performance, skills, knowledge and attitudes on a sustainable basis. ${ }^{2}$

\section{Why capacity building is important for the protection of internally displaced persons}

Protection of internally displaced persons (IDPs) and all other persons within their own countries is a national responsibility. In many humanitarian crises, however, the authorities lack adequate capacity, will, interest or readiness to adequately fulfil their duty to protect. Building or rebuilding the protection capacity of national and local authorities is essential both for an effective response to, and recovery from, existing humanitarian crises and for the prevention of future crises.

In territories occupied by armed elements, it is also important to engage non-State actors in "...simply strengthening the skills of the government does not necessarily create an accountable government. In partnering with government agencies, it is essential that humanitarian agencies do not ignore partnership opportunities with national organizations. A strong civil society provides an important check on government power."

Brooke Allen, Time to Reassess Capacity-Building Partnerships, FMR, No. 28, 2007, p. 4. respecting the rights of IDPs.

Capacity building must be a core element of any protection strategy, including in situations of internal displacement.

Capacity building must extend beyond the government. Supporting the development of a vibrant civil society, including local human rights and humanitarian NGOs, 
community-based organizations and an independent media, is just as important. Indeed, this will complement and reinforce efforts to enhance the protection capacity of the authorities.

Supporting the capacities of IDPs and other affected persons is absolutely critical. It is an integral element of enabling IDPs and other affected populations to exercise and claim their rights; it contributes to operationalize a rights- and community-based approach, which is fundamental to effective protection (further addressed in Part I.1 and Part V.10 [D).

\section{Building and strengthening national capacity to address internal displacement}

In general, capacity-building activities in situations of internal displacement should aim to promote and support an effective national protection response to internal displacement. At a minimum, this means a response that conforms to international standards and addresses the protection risks faced by IDPs. The specific activities should target the three main levels highlighted at the beginning of this note, namely, the individual, managerial and institutional levels.

\subsection{The capacity of national authorities}

The Framework for National Responsibility ${ }^{3}$ identifies 12 steps that governments can take to address material displacement (also addressed in Part I.1 $\square$ ). Using this Framework as a guide, the matrix below provides some ideas for activities to build and strengthen the protection capacities of the government and public institutions in the 12 areas. Such activities may be limited when the government is unwilling to be engaged. In such case, advocacy and the capacity building of other national actors could be reinforced. In areas controlled by armed groups, some activities listed below, such as training and dissemination of information on the rights of IDPs and international humanitarian law, could also be undertaken to engage these non-State actors.

In Colombia, a number of activities were implemented, based on a

well-established local and institutional framework, to further expand the expertise of the Ombudsman and Procurator Offices in dealing with internal displacement. Activities included training, support for strategy

development, support for the design of policies and projects, the creation of a specialized IDP unit, etc. These activities led to various initiatives at the field level and to a gradual change in attitudes within the government.

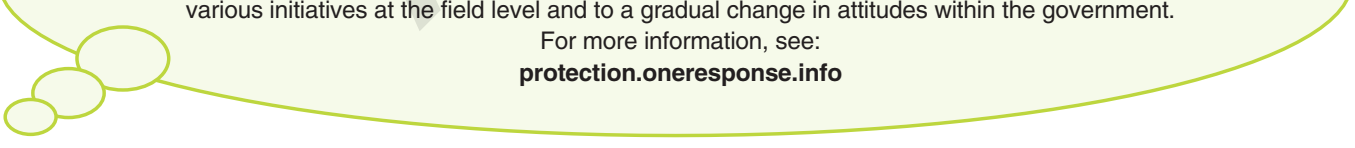

The 12 steps

1. Prevention of arbitrary displacement (See Part IV.1 DD)

\section{Suggested capacity-building activities}

- Engage in a constructive dialogue with government officials, including security forces and other relevant actors, as appropriate, in order to raise awareness on, and prevent conditions and activities that may lead to, arbitrary displacement.

Ensure governments and other authorities are aware of the basic guarantees and conditions to be met in situations of displacement, including by:

- disseminating information on the application of international human rights and international humanitarian law standards; 
providing training on applicable standards and measures for mitigating the adverse effects of displacement, including the importance of maintaining family unity in emergency situations; and

providing advice on contingency planning and on the procurement, storage and delivery of emergency assistance.

- Support the development or strengthening of early-warning mechanisms (often put in place by local NGOs and community networks) that alert populations under threat to imminent risk and establish effective channels for communicating this information so early protective responses can be initiated.

2. Raise national awareness of the problem

(See Part V.10

\section{Data collection}

- Facilitate the dissemination of information about the protection concerns of IDPs and other affected communities, particularly among all relevant branches of government.

- Support the efforts of IDP representatives, including women, minorities, and youth, and other affected populations to advocate for their rights, while taking into account any security risks that may arise.

- Support community-mobilization activities aimed at building awareness and momentum among national stakeholders, encouraging all actors to help achieve commonly agreed objectives to enhance the protection of IDPs and other affected populations.

- Consider including government officials in inter-agency participatory assessments to raise awareness of the protection risks and capacities of IDPs and other affected populations. (See Part III.1. DD)

- Provide technical support for efforts to gain an understanding of trends and protection concerns, such as through IDP profiling, in camps and in non-camp and urban settings where displacement often is less visible. (See Part V.1.

- Raise awareness of the need to disaggregate data by age, gender and other indicators essential for addressing the specific needs of different groups of IDPs.

- Insist upon and, as necessary, offer technical support on data management and protection to ensure the privacy, confidentiality and safety of individuals and communities during and following data collection.

- Conduct monitoring to ensure that data collected is not used in a discriminatory manner or for unlawful purposes.

4. Training on the rights of IDPs and other issues affecting IDPs (i.e. protection during armed conflict, security, landmines, health, hygiene, etc...)
- Support training on the rights of IDPs, as summarized in the Guiding Principles on Internal Displacement and international humanitarian law, including the protection of civilians during armed conflict.

- Promote "training of trainers" events to maximize a "multiplier effect."

- Provide training for government officials at the national, regional and local levels, and include the military, police and camp administrators, other relevant authorities, such as non-State actors who also have protection responsibilities under international law, and staff of national human rights institutions, parliamentarians, civil society and IDP communities.

- Consider bringing diverse actors together for a joint training session, which can help foster cooperation among them.

- Tailor training to address identified gaps in knowledge or skills, such as to provide more in-depth discussion of particular protection issues, and consider discussing possible response strategies. 
Facilitate the translation into local languages and the dissemination of training materials on IDP protection, including the Guiding Principles.

- Promote contact among government officials, civil society, and IDP representatives from other countries to exchange knowledge on best practices and lessons learned.

5. A national legal framework for upholding the rights of IDPs

- Encourage and support efforts by the government and civil society, such as lawyers' associations, to review the compatibility of national legislation, decrees and policies with the Guiding Principles on Internal Displacement and with international human rights and international humanitarian law, offering technical assistance as required.

- Support the assessment of the ability of IDPs to access their rights and subsequent efforts to promote the adoption of legal and procedural safeguards or amendments to overcome any legal barriers. Bring this information to the attention of the government. (See Part IV.18.

- Support clinics that provide legal assistance and information on the rights of IDPs, and ensure their sustainability. (See Part V.8. DD)

6. A national policy or plan of action

- Facilitate open and constructive consultations between affected communities and the authorities to define the actions that need to be taken through a national policy or plan of action.

- Share the results of participatory assessments and protection-risk analysis with the authorities to help inform national policy and programmes.

- Support government efforts to develop a national policy to address internal displacement.

- Advocate for international support for the implementation of a national policy and plans of action that would enhance the protection of IDPs.

7. Institutional focal point on IDPs

Advocate for the designation of an institutional focal point responsible for coordinating the national response to internal displacement.

- Cooperate with the IDP institutional focal point, and support its efforts through technical and material assistance, as appropriate.

- Encourage meaningful dialogue and partnership between this office and IDPs and with civil society working with the displaced.

\section{A role for} national human rights institutions
- Encourage national human rights institutions to integrate protection issues relating to internal displacement into their work.

- Raise awareness among the staff of national human rights institutions of the particular protection concerns that can arise during displacement.

- Provide technical and material support, as appropriate, to these institutions to monitor, report, and follow up on rights violations.

\section{Participation of IDPs in} decision-making (See Part V.10
- Encourage and support the formation of IDP associations, including IDP women's associations, to strengthen IDPs' own efforts to address their concerns and advocate for their rights.

- Where feasible, include national and local authorities in the discussion with IDPs and other affected communities about the results of participatory assessment exercises, so that all can jointly decide on the best activities to address protection gaps.

- Foster humanitarian space for dialogue among the authorities, IDPs and civil society organizations. 
10. Support durable solutions (See Part VI DD)

11. Resource mobilization

Raise awareness among State institutions of the need to promote the self-reliance of IDPs and other affected populations as early as possible. Avoid creating parallel assistance or support structures. Ensure, instead, that humanitarian efforts are, or subsequently can be, integrated into national assistance programmes.

- Assess the socio-economic integration of IDPs and possible discrimination, advocating for and supporting efforts by the authorities to address any such concerns.

- Undertake protection assessments in areas of return or resettlement to identify risks, and assist the national authorities in establishing protection mechanisms, particularly related to the rule of law, and in ensuring that return or resettlement is voluntary and done in safety and with dignity.

- Advocate for the establishment of mechanisms for property restitution, compensation or other forms of reparation, and offer technical assistance, as needed.

- Promote the sharing of best practices with other countries in post-conflict situations.

- Coordinate with national and local authorities, other humanitarian actors, both local and international, and donors in formulating a strategy for the disengagement of humanitarian actors and a smooth and timely transition from humanitarian to development assistance.

- Advocate for and support government efforts to allocate adequate national resources to address internal displacement.

- Share inter-agency assessments and planning documents, to the extent possible, to assist with national planning and budgeting.

- Support governments that demonstrate efforts to protect IDPs in mobilizing resources, through donor relations and fundraising. Donor governments, however, may be unable to transfer material support in an environment of armed conflict.

- Make use of staff secondment schemes to deploy specialized humanitarian and development expertise to government institutions.

\section{International} cooperation when national capacity is insufficient
- Assist the authorities in assessing national capacity to protect IDPs through the sharing of baseline data, identified trends and other relevant information.

- Offer support to the authorities to address gaps in the response. Such support can come in the form of technical assistance (such as the deployment of staff with required expertise), material support (such as information technology, or vehicles to reach and assist IDPs in remote areas) or financial grants.

- Some general guidelines are indicated below.

Such support should be granted within the framework of a broader protection strategy to fill identified gaps and address priorities.

- The simultaneous provision of training activities or technical support can help strengthen the effectiveness of this assistance.

- Care must be taken to ensure that the actors and institutions whose capacities are being reinforced are committed to using these capacities to enhance the protection of rights. It is essential to develop a monitoring system to assess the effectiveness and protection impact of these efforts. - Support should be provided in the context of more comprehensive, community-wide efforts, so as to avoid discriminating against other affected communities and thereby creating inequalities and tensions. 


\subsection{The protection capacities of internally displaced persons and other affected communities}

From the outset and throughout all of the stages of a displacement crisis, humanitarian efforts need to build upon and reinforce the existing capacities of IDPs and other affected communities. (See Part V.10. DD)

Even where humanitarian organizations have no alternative but to implement an activity directly, it is essential to empower the community as well. This is not only the most effective way of ensuring the long-term sustainability of such activities; it is also fundamental for community-based and rights-based approaches to protection.

\section{Some tips for capacity-building activities with IDPs and affected communities}

Train community members on the use of participatory methods, and ensure age, gender and diversity balance among participants.

Work with the community to identify the different capacities and skills of the members, and agree on the areas in which training and other capacity-building opportunities are needed.

Listen to, and build on, the creative ideas of different age groups on how to disseminate information on key protection concerns, and foster their leadership skills.

Build bridges between formal civil society groups and members of displaced and other affected communities to support advocacy campaigns on key protection concerns.

Ensure that all segments of the affected population benefit from training and capacity-building opportunities. If a particular group is found to be excluded, determine why and work with communities to address the issue.

Assist community leaders in informing all members about their responsibilities as duty-bearers and rights-holders. Raise awareness of values, such as inclusiveness and respect for all, gender and diversity awareness, and the rights of children and older persons.

Identify appropriately skilled partners to deliver training, and ensure that they transmit values according to rights- and community-based approaches.

Follow up on how training participants are applying the skills acquired and whether they are training others.

Discuss with persons in charge of managing community projects whether they require particular support or training. Promote transparent accounting mechanisms.

\subsection{The protection capacities of civil society, including national NGOs}

Although IDPs and other affected populations are already an inherent part of civil society, their direct involvement with organized civil society groups is particularly beneficial. Partnerships with local NGOs or institutions devoted to the promotion and defense of human rights are particularly valuable. These groups, especially those that have been operational for some time, tend to have detailed knowledge of the protection situation and of the dynamics of the conflict and its root causes. They can also often identify potential entry points and opportunities for protection advocacy with national institutions and authorities.

Local NGOs, especially those engaged in humanitarian action, tend to have much greater and more regular access and contact with IDP communities and other affected populations than do international agencies. This generally gives them a better sense of the communities' concerns.

Beyond human rights and humanitarian NGOs, there are often many other civil society bodies that can help promote protection and respect for the rights of the IDPs and other affected 
populations. Such groups might include journalists, trade unions, groups of researchers, student unions, professional associations, such as bar associations and other lawyers' groups, medical associations, social workers, and ethnic or faith-based associations. These actors often have a significant presence and constituencies throughout the country and can be instrumental in raising awareness and influencing public policies.

The aim should be to engage with as broad and diverse a spectrum of civil society groups as possible. Having the benefit of a range of views and perspectives helps to deepen our knowledge of the situation, ensure that information is shared, thus improving its reliability, and help safeguard against bias in our assessments or in the perception of our work.

\section{Some tips for capacity-building activities with civil society groups and national NGOs}

- Undertake a thorough assessment of existing civil society groups and NGOs to focus on partnerships with those whose activities can have an impact on the protection of IDPs and affected populations. Focus on their capacities and analyse the impact of their past activities.

Provide material and financial resources to civil society groups, advocating for IDP protection to support specific protection activities as well as their own institutional capacity. Promote the sustainability of their efforts, and enhance coordination among different groups.

Identify key resource persons at the local, national and international levels who can provide specialized training to civil society groups in thematic areas. Any training activities should be defined jointly with civil society groups to ensure that it builds on their existing knowledge and capacities and addresses gaps and priority concerns. Such training might include programmes to:

- address particular protection concerns, such as sexual and gender-based violence, child recruitment, property rights;

- develop skills for specific protection activities, such as human rights monitoring and reporting, conducting advocacy, and ensuring that national legislation and policies conform with international standards; or

enhance skills essential to the organization's work, such as mobilizing volunteers, fundraising, delivering aid and managing budgets.

Support networks of civil society groups within the country and the region as well as with international human rights institutions and NGOs.

Promote constructive dialogue and a sense of partnership between civil society groups and government institutions, particularly with the government focal point on IDPs, the police, lawmakers and national human rights institutions.

Promote an understanding of the humanitarian character of the work of NGOs with the aim to enhance their safety when undertaking humanitarian and human rights work. Monitor whether human rights defenders and civil society groups can exercise the right to freedom of expression and association and can undertake their work without risk. Follow up with the authorities in case of any violations. 


\section{Key references \& useful websites}

- Addressing Internal Displacement: A Framework for National Responsibility, Brookings-Bern Project on Internal Displacement, 2005.

- Enhancing Southern Capacity: Rhetoric and Reality, Forced Migration Review, No. 28, July 2007.

- Evaluation of UNHCR's Role in Strengthening National NGOs, UNHCR, EPAU/2001/01, 2001.

- National Human Rights Institutions and Internally Displaced Persons: Illustrated by the Sri Lankan Experience, Brookings-SAIS Project on Internal Displacement, 2002.

\section{Training resources}

- IDP Training materials developed by the Norwegian Refugee Council's Internal Displacement Monitoring Centre and OHCHR: www.internal-displacement.org/

- Annual Course on the Law of Internal Displacement, organized by the office of the UN Secretary-General's Representative on the human rights of IDPs, at the International Institute of Humanitarian Law, San Remo, Italy (target groups include civilian and military national authorities): www.iihl.org

- Essentials of Migration Management for Policy Makers and Practitioners: Course Manual, International Organization for Migration, 2004 (includes a module on internal displacement).

- Compendium of Course Curricula on Internal Displacement, compiled by The Brookings Project on Internal Displacement, 2002:

www.brookings.edu/fp/projects/idp/resources/syllabi.htm 


\section{Part V.10 \\ Community mobilization}

1. Why community mobilization is important for internally displaced persons..........417

2. Key activities to mobilize communities ....................................................................

2.1 Community mapping of management structures...............................................417

2.2 Community-based representation ................................................................ 418

2.3 Supporting community-based protection responses and solutions ......................419

2.4 Working with the community on sensitive issues .............................................

2.5 Supporting community action plans and teams..............................................420

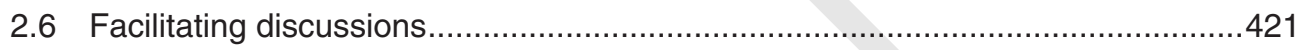

2.7 Community-based monitoring and evaluation ...............................................422

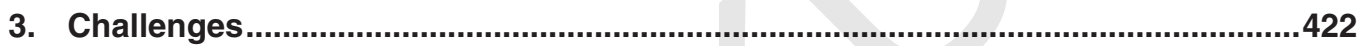

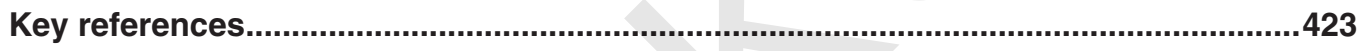

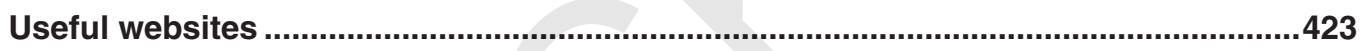

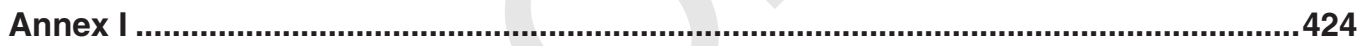




\section{Why community mobilization is important for internally displaced persons}

During displacement, existing traditional support mechanisms within a community, such as extended families, friends, neighbours or other social networks, are often disrupted. For internally displaced persons (IDPs), this adds to the conflict and disaster-related stress they experience and contributes to reducing their self-esteem and sense of control over their lives. As a result, it is difficult for communities to overcome protection risks inherent to displacement.

Community mobilization aims to restore feelings of self-worth and responsibility among the affected population. Ultimately, it should empower communities to develop their own protection responses, enjoy their rights, and find solutions. Wherever necessary, the international community should support this process. Communities will mobilize themselves when they have trust and confidence in a process and when they see benefits emerging from it.

\section{Community mobilization in a displacement context involves:}

- working with the displaced community and its leaders, in IDP camps and settlements and in host communities;

understanding the dynamics and structures within the community; and

building on the capacities and strengths of its members in order to find solutions to identified concerns.

Other affected populations, such as host families and residents in surrounding areas, may be concerned that the presence of IDPs will lead to increased military activity or conflict-related violence or be a drain on already limited resources, services and infrastructure. Potential conflicts may emerge from tensions between the host community and the IDPs. Community-mobilization activities need to encourage a dialogue between IDPs and surrounding populations to develop joint activities, based on common goals and interests, thereby fostering peaceful coexistence and helping to rebuild and revitalize communities. These kinds of activities should be supported and carried out at all stages of the displacement cycle from initial movement to return or settlement in a new location.

\section{Key activities to mobilize communities}

Before embarking on community-mobilization activities, national and international staff should receive training. The training should provide guidance on attitudes, skills and techniques (further addressed in Part II. 1 and $2 \square$ ) and give an orientation on national or regional cultural practices and sensitivities. The findings of the situation analysis are a good basis on which to build (further addressed in Part III.1

Always remember that community members have firsthand knowledge about the issues they face. Our role should be to stimulate and support ideas and activities, not to impose them.

The following activities should be adapted to each specific situation and do not need to be undertaken in a chronological order.

\subsection{Community mapping of management structures}

Understanding existing structures and ground rules within communities will guide humanitarian workers on how to establish a well-functioning partnership with the community and help identify issues to address. 
- Observe the composition of communities and their formal and informal leaders. Note their age, gender, ethnicity, religion and political affiliation. Assess if these are the regular leaders, whether they are respected and whether there are others.

- Jointly with the community, map the structures, coping mechanisms and support systems. Identify to whom the community turns when facing a problem and on whom they count to organize the response.

- Work with the community to identify the strengths and skills of its members, agree on gaps and capacity-building needs.

- Find out the level of participation of women, children, particularly adolescents, and groups with specific needs, including minority groups.

- Invest time and effort in understanding how structures, mechanisms, and various justice systems, including traditional justice deal with taboos and individual rights. Discuss issues with leaders to understand why certain groups or individuals are excluded, if any.

- Give feedback on the mapping to the community in order to validate findings and cross-check the community's own perceptions.

\subsection{Community-based representation}

While it is essential to work with communities through their representative committees, or to support the establishment of new ones, we should remain aware that committees will always develop their own internal dynamics. They might tend to serve the interests of only one part of the community. In addition, a committee elected at the start of an operation might not be so popular or representative of the community 10 years later. All committees need to be monitored by the community members and have fair and transparent election processes.

- Regardless of their attitude, never antagonize existing formal and informal community leaders as this might jeopardize our access to communities or their participation in planned activities. Instead, find ways to work with them, using negotiation skills and techniques (further addressed in Part II.2 $\square$ ), seek their support for non-sensitive activities, such as the creation of sports clubs or older persons' groups, to build confidence and gradually expand the dialogue.

- Work with leaders and community members from all backgrounds to identify ways to disseminate information to everyone in the community.

- Analyse the ground rules for interaction with any of the leaders and committees: the extent to which they are representative of the IDP community as well as who attends meetings, who speaks and who dares to question statements.

- Initiate discussions with groups that are neglected or marginalized, and seek their views on how they see their integration within the community.

- Identify and highlight community values that support inclusive approaches to show that these are not "alien" concepts but already existing in traditional values.

- Note who in the community can influence leaders and is open to change. Build their leadership and negotiating skills, and support them in persuading leaders about the benefits of sub-committees, sub-area representatives, or the inclusion of new members in the existing leadership.

- If this fails or takes time, community mobilization can still take place by involving current leaders in activities and gradually developing a network of "focal points" in the community to create a broader representative base.

- As and when dialogue has reached sufficient maturity, and when IDPs are likely to remain in place for some time, initiate discussions or workshops with the community on 
governance, including representative and time-limited leadership, and on human rights and gender equality.

- Depending on the receptivity to the subject, determine the right time to encourage volunteers to organize fair elections and invite elections observers. Support the community in monitoring the process to ensure transparency and prevent intimidation.

- Avoid creating committees for the sake of committees. Clearly understand the needs and issues affecting people, and work with them to agree on clear goals and ensure that the leaders support the initiative. The involvement and sense of ownership of the concerned people and leaders is essential to avoid misunderstandings that may result in potential security risks for staff involved in community mobilization activities.

- Take into account the constantly changing composition of the community in situations of continued displacement, and encourage communities to revalidate the composition of their leadership regularly to reflect these changes.

\subsection{Supporting community-based protection responses and solutions}

normally, communities and individuals develop mechanisms to respond to most of the protection issues they face. It is, therefore, essential to identify these mechanisms and build on them to ensure that they are inclusive and incorporate human rights. It is also important to identify groups that might not be given full attention by the community and might have specific protection problems. Work with community members and representatives to learn how the community responds to protection risks facing various groups, such as older persons, different ethnic groups, youths, and persons with mental and physical disabilities. Participatory assessments are a useful way to do so (as addressed in Part III.1 [D). Involve those members of the community in analysing the root causes of the risks and whether these come from within or outside the community.

- Provide support in tackling both internal and external threats through targeted training and community empowerment, as outlined below.

- Work with community leaders to inform all members about their responsibilities as duty-bearers and as right holders. For example, train special focal points within the population to disseminate information on rights and obligations, on mine-awareness or crime prevention.

Build the capacity of the community to handle procedures for civil documentation, land titling, and compensation. To do so, develop the expertise of selected focal points who will assist their peers and make related information accessible to the public.

- Encourage direct meetings among the IDP community and external stakeholders involved in mitigating protection risks, including local authorities, police, registrars, and host communities.

- Assist the community in organizing and managing community-watch systems (as addressed in Part IV.2 DD).

- Provide guidance to community members on documenting existing good practices and participatory methods ${ }^{1}$ and on how to collect, verify and analyse information on specific protection issues to determine a course of action. ${ }^{2}$

- Keep an open dialogue and agree with the community on the mechanisms that will be established to address identified protection concerns, and ensure follow-up and monitoring. 
- Generate debates on durable solutions envisaged by the displaced communities. Ensure that all members have access to objective and accurate information on various options available (as addressed in Parts V.7 and VI DD).

- Provide regular feedback on agencies' interventions, progress and difficulties.

\subsection{Working with the community on sensitive issues}

A number of protection issues will be highly sensitive within the community as they relate to security, taboos, cultural beliefs, economic assets and financial interests. Such issues require caution and should be tackled by experienced staff.

- On the occasion of routine activities and meetings, regularly present and explain the position of humanitarian organizations on human rights and international legal standards.

- Avoid appearing judgmental about community practices; show respect and be culturally sensitive.

- Identify individuals within the community who are open to new ideas, especially among leaders, and explore ways of beginning a constructive dialogue with them.

- Ensure privacy in meetings of a sensitive nature to enable concerned individuals to speak freely.

- Focus on the reasons behind the issue/practice, and discuss this in addition to the consequences and effects of such practices with the community.

- Work with the community to identify small areas for change, such as alternative practices that uphold values or address concerns without violating rights.

- Engage men in issues relating to the empowerment and equality of women. Use focus groups to discuss issues such as masculinity or gender-based violence.

- Work with community leaders, organize mass-information campaigns, awareness-raising activities, training, theatre activities with groups of men, women, boys and girls of different ages and backgrounds.

- Involve host communities in these discussions and activities, particularly when they face similar problems or when issues create tensions between the two communities.

\subsection{Supporting community action plans and teams}

When the community has shown full ownership of the protection-response strategy, it is time to draw up a community action plan, based on the analysis of rights, the prioritization of protection risks and solutions, the identified needs, and the available financial resources (further addressed in Part III.1 [D).

- Ensure the interests of the different groups, including minority groups and host communities, have been represented, and that children have been consulted in an appropriate manner. ${ }^{3}$ If the level of participation remains insufficient, discuss what arrangements will be made to address the outstanding issues or go back to some of the activities under "supporting community-based protection responses and solutions."

- Train and help the community to articulate its own action plan with clear timeframes, methodologies, division of roles, as well as a budget and any needs for assistance to achieve their chosen solution. 


\section{Tips on building community action plans}

The first step in developing a community action plan is to identify the protection problems and assistance needs that have been prioritized by the community. Then, ask the following questions:

- What actions are required to deal with the problem?

What outcome or change is desired and will this remove the cause or the symptom?

Who will benefit? Are we being inclusive?

Does the project support individual human rights and strengthen the protection of all of the community members?

What resources (material, financial, human) are needed from the community itself and from outside?

Who will provide these resources?

How will the resources be administered? Who will keep the accounts?

A community-based Approach in UNHCR Operations, UNHCR 2008

- Support flexible and efficient responses through the creation of small action teams composed of volunteers and developed around important issues, such as children's rights, the environment, and a men's group on HIV/AIDS.

- Use the action teams to emphasize the contributions of each segment of the population, including older persons in charge of daycare, literacy and cultural activities, to combat marginalization.

- On sensitive issues, define a broader scope for the action team, such as an "education team" to review more general issues, but also monitor specific drop-out rates, underage recruitment into the military or armed groups, and gender-based violence risks.

- Facilitate joint planning and actions between IDPs or former IDPs and their surrounding communities to ease integration and foster good relations. These could include organizing a documentation exercise to issue identity cards for all communities in the area or setting up a joint vocational training centre or a reforestation project.

- Use representative committees and action teams established during displacement as key catalysts to rebuild communities in return or new settlement areas.

- Support self-reliance strategies as essential for all affected communities to regain stability and confidence in the future (further addressed in Part IV.16 [D).

\subsection{Facilitating discussions ${ }^{4}$}

Different methods are appropriate in different contexts.

- Focus groups are useful for exploring group responses to a topic of common concern, but they may be inappropriate for sensitive topics, such as gender-based violence.

- Semi-structured discussions or discussions at an individual or household level are appropriate for obtaining more personal, detailed information and analysing problems that will not easily emerge in a group discussion.

Using different methods at different times will elicit various perspectives on protection risks and provide an opportunity to cross-check the reliability of the information and confirm an understanding of the situation. 


\subsection{Community-based monitoring and evaluation}

The community should directly monitor the impact of activities implemented by themselves and by humanitarian organizations on their behalf. This will reinforce their sense of ownership and confidence over achieved results. It will also help quickly identify and address problems in implementation that otherwise might create tensions.

- Work with leaders to agree on effective monitoring systems by the community, and develop an inter-agency monitoring system.

- Continuously monitor and identify emerging protection needs and concerns. Prioritize and incorporate the required response in the overall plan of action.

- Undertake regular participatory evaluations using focus groups and other methods. Keep evaluation tools simple, and ensure the participation of all groups.

- Build on previously agreed plans and findings of participatory assessments to note progress and identify weaknesses.

- Agree with the community on the adjustments or remedial measures needed to address weaknesses and fill gaps and jointly assess the impact of such measures over time.

- Discuss attitudinal changes among teams or sub-groups within communities on the basis of their level of initiative over a period of time, autonomy, and assertiveness in interventions.

- Ensure that all staff members wear individual identification so that their attitudes and quality of services can be monitored and evaluated by persons of concern.

- Follow up and share outcomes of evaluations with the community. Document learning and achievements, and ensure they are shared with all agencies.

\section{Challenges}

Community mobilization is a long-term process. It takes time, skills and resources for humanitarian organizations to build a strong working relationship with IDPs. IDPs are often scattered over large areas and can easily become "invisible" in the care of host families or in urban settings. The humanitarian community needs to commit itself, from the beginning of an operation, to engage in a partnership with persons of concern and to ensure that they participate in activities that affect their lives.

Affected communities do not necessarily know the difference between one agency and another. While respecting each other's mandate, coordination among the different agencies, in order to "speak with one voice" and to decide on key principles for how to engage with the community, is essential. Agencies referring to different leadership structures or setting up parallel channels risk undermining the work of partners and creating confusion within the community. Agencies should use and build on community groups and action teams established through community-mobilization programmes to benefit from their understanding of key protection issues and reinforce their legitimacy.

In highly politicized and volatile situations, IDPs may be reluctant to be identified as "community leaders," as this might expose them to security risks. Action teams represent a more informal and less sensitive approach for members of the community to act on their community's behalf. 


\section{Key references}

- A community-based Approach in UNHCR Operations, UNHCR 2008.

- Participation by Affected Populations in Humanitarian Action: Practitioners' Handbook, Active Learning Network for Accountability and Performance in Humanitarian Action, 2003.

- Tools for Community Participation: A Manual for Training Trainers in Participatory Techniques, L. Srinivasan PROWWESS, UNDP, New York, 1993.

- Reinforcing a Community Development Approach, UNHCR, EC/51/SC/CRP.6, 15 February 2001.

\section{Useful websites}

- Food and Agriculture Organization of the United Nations: www.fao.org/Participation

- United Nations Children Fund (UNICEF): www.unicef.org

- United Nations Development Fund for Women (UNIFEM): www.unifem.org

- United Nations High Commissioner for Refugees (UNHCR): www.unhcr.org

- United Nations Population Fund (UNFPA): www.unfpa.org

- Women's Commission: www.womenscommission.org 


\section{Annex I}

\section{Discussing the issue}

\section{Communicating with adults}

- Meet with women, men, boys and girls from different ages and backgrounds in order to allow them to freely express themselves and to ensure that protection risks specific to a certain age and/or gender group become visible.

- Inform the group in advance that you would like to talk to them and ask for a suitable time to ensure that they do not have to take time away from household tasks or income-generating activities. Be on time!

- Ensure that the leaders in the community are aware that the meeting is taking place.

- Make sure that you have enough time for the meeting and that you are assembling in a private area so that individuals feel relaxed and can express their concerns without worrying that others are listening.

- If, in a focus group, a person raises a sensitive issue, it is often best to follow up separately in a one-to-one setting with that person.

- During the discussion, the following steps should be taken.

- Introduce yourself to the group and explain why their participation is important, that participating is voluntary, what will happen with the information, the importance of confidentiality, and how the participants will receive feedback afterwards.

In the beginning of the meeting, introduce themes that are neutral and of common concern as a way to open the discussion.

Ask open questions such as how, what, where, why as much as possible, especially to clarify or confirm understanding. Do not judge people who speak; accept what they say.

Avoid using leading statements and questions.

Avoid dominating the discussion; ask simple questions and only one question at a time.

Ensure that everybody in the group has the opportunity to talk. Be sensitive to cultural norms so that nobody feels rushed or excluded. Be aware of persons dominating within the group.

- Steer the group towards analysing the causes of the risks, the skills they have at their disposal to resolve their problems, and the role of the community in developing solutions.

\section{Communicating with children}

Children and young people should always be included in participatory assessments. Girls and boys have needs and abilities that are significantly different from those of adults. It is essential to ensure that each child participates in the assessment voluntarily and that parents have given permission for younger children to participate. Communicating with children has some particular requirements, as outlined below.

- Being at ease with children, engaging with them in whatever style of communication suits the individual, such as by sitting on the ground, through play, going for a walk, and tolerating expressions of distress, aggression.

- Using simple language and concepts appropriate to the child's age, stage of development, and culture. 
Part V.10 - Community mobilization

- Accepting that children who have had distressing experiences might find it extremely difficult to trust an unfamiliar adult. It might take time and patience before the child has enough trust to communicate openly.

- Understanding that children might view their situation in distinctly different ways from adults: Children might fantasize, invent explanations for unfamiliar or frightening events, express themselves in symbolic ways, or emphasize issues that might seem unimportant to adults.

- Being sensitive to gender, culture, ethics, and the power relations between adults and the child.

- Encouraging the involvement of colleagues/partner staff members who are familiar with working with children in a participatory way.

425 


\section{Part V.11}

\section{Mental health and psychosocial support}

1. The importance of psychosocial support

2. What is psychosocial support?

3. Psychosocial support in situations of internal displacement

4. Challenges

Key references \& useful websites 


\title{
1. The importance of psychosocial support
}

Being displaced by conflict or natural disasters can have severe adverse effects on the physical, social, emotional and spiritual well-being of a person. Exposure to violence or disaster, loss of, or separation from, family members and friends, deterioration in living conditions, the inability to provide for one's self and family, and lack of access to services, can all have immediate and long-term consequences for individuals, families and communities, including post-traumatic stress disorders, psychosomatic illness, depression, anxiety and even violence. ${ }^{1}$

Protection strategies, therefore, should include interventions to protect and promote mental health and psychosocial well-being. Because these types of interventions focus on highly sensitive issues, they must be conducted in a socially and culturally appropriate way and take into account the age, gender and diverse backgrounds of all members of the communities. Interventions should promote resilience among populations, respect the confidentiality and informed consent of the affected individuals, and be based on human rights principles as well as on the principles of participation and "do no harm" (further addressed in Part I.1.5

\section{What is psychosocial support?}

The IASC Task Force on Mental Health and Psychosocial Support in Emergency Settings developed Guidelines in 2007 on mental health and psychosocial support. This chapter is largely based on these inter-agency guidelines, which should be referred to for more detailed interventions. ${ }^{2}$

The IASC Guidelines define mental health and psychosocial support as two complementary approaches covering "any type of local or outside support that aims to protect or promote psychosocial well-being and prevent or treat mental disorder." The word "psychosocial" captures the interrelation between psychology (individual thinking, emotions, feelings and behaviour) and the social world or environment in which we evolve (culture, traditions, spirituality, interpersonal relationships in the family or community, and life tasks, such as school or work).

The IASC Guidelines also clarify that mental health and psychosocial support require various levels of interventions, ranging from broad programmes on basic services and security issues, to community and family support interventions and increasingly focused and specialized mental health services. It is, therefore, necessary to distinguish between interventions that benefit the population at large (non-specialized services) from those interventions that require specialized expertise.

\begin{abstract}
All humanitarian actors are expected to contribute to non-specialized responses and to ensure that coordinated referral and response mechanisms are put in place when more specialized interventions are required (further addressed in the pyramid and table below). Coordination among actors is crucial to ensure broad and effective prevention and response mechanisms.
\end{abstract}

\footnotetext{
In some cases, such factors might contribute to a change in behaviour, including increased substance abuse, aggression and higher levels of sexual and domestic violence.

2 IASC, Guidelines on Mental Health and Psychosocial Support in Emergency Settings, 2007.
} 


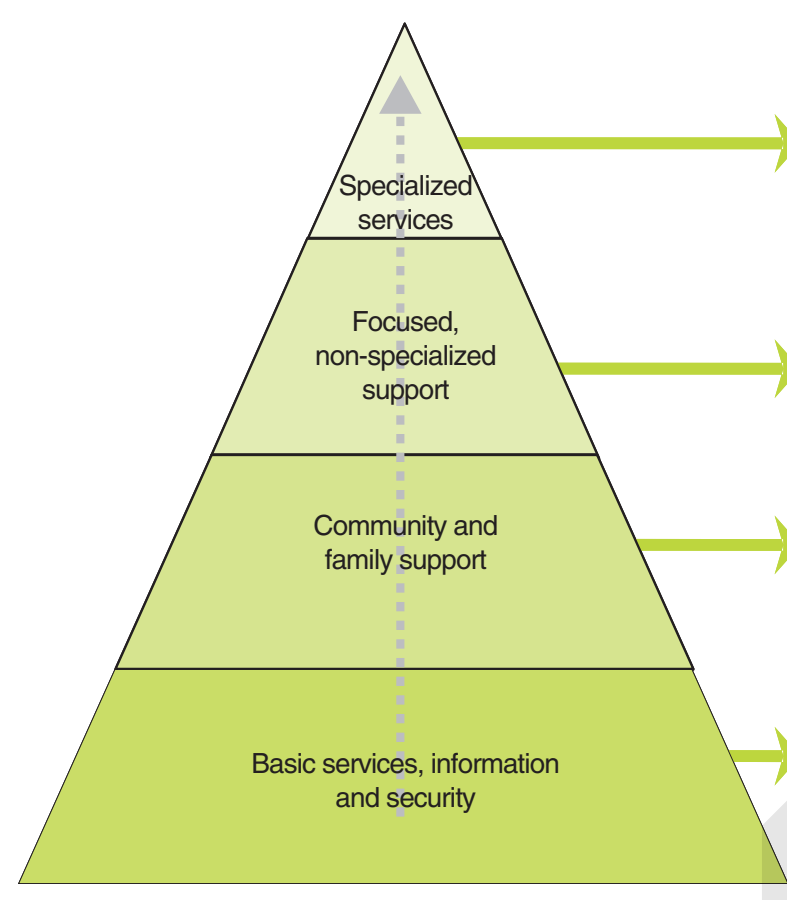

4. Specialized services are needed for a small but often neglected percentage of persons experiencing significant distress that disrupts their ability to function on a daily basis. This should be provided by trained professionals only.

3. A smaller percentage of the population, with particularly stressful reactions, will require more focused and non-specialized support, with attention to the individual, family or group. This psychological first aid should be provided by health and social workers.

2. Persons who have experienced the loss of family and community support through death, separation and loss of livelihood opportunities will require specific support to restore the protection that these systems provide. These interventions might include family reunions, healing rituals for reconciliation, and/or vocational training.

1. All displaced persons require access to food, shelter, water, hygiene, functioning governance systems, health care, information and security in order to re-establish well-being and mitigate further psychosocial harm.

\section{Psychosocial support in situations of internal displacement}

The State has the primary responsibility for ensuring the psychosocial well-being of the population on its territory, and for providing specialized services through mental health structures. In times of armed conflict, generalized violence or natural disaster, it might not have the capacity to handle additional needs and might require temporary assistance from the international community.

Strategies to protect and promote the psychosocial well-being of internally displaced persons (IDPs) and other affected populations should mobilize existing care systems and capacities within the community to promote the restoration of a sense of normality. The re-establishment of family and community life and the protection from further harm are central to that end.

\section{General}

- Ensure that assessments, including in emergencies, always include a component on mental health needs, individuals at risk and available resources among the displaced and other affected populations, looking at:

existing sources of psychosocial and mental health support, whether in the formal health system or within supportive community structures;

current capacities and activities of organizations on the ground with regard to psychosocial support and mental health; and

programming needs and strengths, including the functionality of referral systems across sectors.

No assessment should attempt "diagnosis" unless with qualified personnel (clinical psychologists, psychiatrists or medical staff). 
Coordinate with specialized partners to ensure that assessments foresee "fast track" systems for the referral of persons identified as having specific needs or being at heightened risk. ${ }^{3}$ Persons with pre-existing mental illnesses should be immediately prioritized for rapid response. (See Part III.1.

- Coordinate with the primary health-care providers, both governmental and NGO-run, to ensure equal access to mental health-care services to displaced or affected communities and individuals. (See Part IV.13. WU) Where such services are not available or are overwhelmed, assist governmental authorities and NGOs to increase reception capacity or establish mental health clinics in IDP settlements.

- Advocate for integrated, specialized, community-based psychosocial support in ongoing programming, emergency preparedness and contingency planning.

- Ensure that mental health and psychosocial support concerns are part of the relevant clusters/sectoral agendas. Solicit the Health Cluster/Working Group as well as the Protection Cluster/Working Group to provide basic orientation on psychosocial and mental health to non-specialized humanitarian actors. (See Part I.3.

- To prevent further harm, ensure that information on mental health and psychosocial support programmes is formulated in a culturally sensitive manner and in an appropriate language. Verify that Standard Operating Procedures for referrals are in place and that agencies respect confidentiality safeguards.

Basic services and security
Coordinate with all sectoral programmes to ensure access to basic services (health, education, food, water, shelter, livelihood support) by all IDPs, regardless of age, gender, language, religion or other background. The way basic services are provided will highly impact the well-being of persons of concern. (See Part V.5.

- Strengthen access to safe and supportive education: Involve all members of the community in needs assessments, design of activities and actual responses across sectors. Encourage their feedback, their participation in monitoring all programmes and open channels of communication so that they can express their concerns, emerging needs or proposed community initiatives. (See Part III.4. [D)

- Organize focus group discussions and other consultations on security issues; encourage the community's initiatives to secure its self-protection, and provide support when required. When appropriate, promote a dialogue between local law enforcement authorities and the affected communities in this regard. Advocate with appropriate authorities for the establishment of security measures requested by the community. (See Part IV.2. $\square$ )

Strengthen
community and
family support
(see Part V.10

- Assess the social dynamics within the IDP community in order to identify the existing support structures and build on them. The participation of local staff in such initiatives can be of great support.

- Disseminate information about support mechanisms and activities within the community.

- Ensure that psychosocial initiatives:

help communities understand that they are experiencing normal reactions to abnormal situations;

reduce the impact of stress; and

- Include communication and problem-solving skills training for affected communities so that they can seek and obtain concrete help. 
- Identify cases of family separation, and initiate immediate registration and family tracing to ensure early reunification. (See Part IV.7. $\square$ )

- Identify persons at risk in institutional settings, including orphanages, older persons' homes, mental health institutions and prisons or detention centres. Provide for their protection and, when appropriate, alternative community-based care.

- Facilitate appropriate cultural, spiritual and religious healing practices, and other community self-help activities.

- Establish or improve access to safe and supportive formal and non-formal educational opportunities for girls and boys, since education provides a safe and stable environment for children affected by armed conflicts and restores a sense of normalcy, dignity and hope. It is important to restart formal and informal education at all stages of the displacement cycle as soon as possible. Develop separate activities for adolescents and youth who often receive insufficient attention by, for instance, providing catch-up courses and accelerated learning for those who were formerly associated with armed forces or armed groups and who have missed out on education. Expand capacities for psychosocial support within formal and non-formal educational settings.

- When appropriate, consider feeding programmes at schools. Food in education can directly benefit psychosocial well-being by increasing concentration.

- Encourage the re-establishment of cultural and religious events and activities in order to support social networks and recreational activities for girls and boys.

- Involve adults and adolescents in concrete, useful activities, such as constructing/organizing shelter, organizing family tracing, distributing food, teaching children, or providing vocational training and livelihood-support activities.

- Advocate for, and support the development of, community-based skills development programmes to promote self-reliance and adequate livelihoods for persons who have lost their traditional families and community-support networks.

- Whenever possible, work towards the development of inter-generational responses to reduce marginalization and the deterioration of mutually respectful relations between older persons and youth/children.

Focused non-specialized support
- Arrange training activities with health specialists on psychological first-aid interventions for local primary health-care workers. Encourage school staff, such as administrators, counsellors, teachers and health workers, to refer children with severe mental health and psychosocial difficulties to appropriate mental health and psychosocial support in the community.

- Raise awareness on substance abuse. All humanitarian staff, including local staff, should be able to contribute to overall sensitization in this area.

- Promote the availability of appropriate psychological, legal, social, economic, educational and medical support to survivors of human rights violations, and encourage their participation in family and community activities. 


\begin{tabular}{l} 
Ensure that interventions in mental health and psychosocial support \\
empower women and girls as well as individuals or groups with specific \\
needs, including older persons; enable them to play an active role in \\
organizing their lives, attaining self-sufficiency and reducing dependency. \\
Such interventions should incorporate follow-up during and after local \\
integration, return or settlement in another area. \\
Specialized \\
services \\
displacement in collaboration with the community and relevant \\
specialists. Review the status of pre-existing mental health and related \\
disorders in the community and pre-existing services and their current \\
status. \\
Identify supportive community structures that might assist in identifying, \\
referring and supporting persons of all ages needing specialized \\
services. \\
Work with specialists to ensure that non-specialized humanitarian actors \\
are sensitized and trained to identify and refer mental health cases to \\
specialized programming. \\
Broaden the availability of specialized mental health care through \\
general and community-based mental health services. \\
Ensure patients' rights to the confidentiality of information or data and \\
informed consent, including the right to refuse treatment. \\
Advocate for, and assist in, the re-establishment or creation of support \\
and services when they do not exist. \\
Build on linkages among agencies, protection and Health Clusters or \\
Working Groups and national health authorities to promote further training \\
and capacity building of local mental health professionals when required. \\
\hline
\end{tabular}

\section{Challenges}

- A lack of mental health structures in certain locations may undermine the effectiveness of the response. Advocacy with the central government should be used to address this problem, when necessary.

- A lack of specialized personnel in government services or in the aid community may result in non-specialized staff undertaking activities for which they have not been trained. In these cases, the Global Health and Protection Clusters should organize the secondment of expertise to the operation.

- A lack of understanding of, and respect for, local cultural norms and practices by humanitarian workers may cause harm if responses are inappropriate or if local capacities are undermined by setting up external support mechanisms.

- The denial of mental health problems and stigma may contribute to obstacles to access health care. 


\section{Key references \& useful websites}

- IASC Guidelines on Mental Health and Psycho-social Support in Emergencies, IASC, February 2007.

- The 'TOT': A Global Approach for the Training of Trainers for Psycho-social and Mental Health Interventions in Countries Affected by War, Violence and Natural Disasters, by Baron, N., in Intervention: International Journal of Mental Health, Psycho-social Work and Counselling in Areas of Armed Conflict, No. 4, 2006.

- The Community Participatory Evaluation Tool for Psycho-social Programmes: A Guide to Implementation, by Bragin, M., in Intervention: International Journal of Mental Health, Psycho-social Work and Counselling in Areas of Armed Conflict, No. 3, pp. 3-24, 2005.

- Children in Crisis: Good Practices in Evaluating Psycho-social Programming, by Duncan, J., and Arntson, L., Save the Children Federation, Inc., Washington, D.C. 2004.

- Palestinian Code of Conduct for Psycho-social Interventions, 4 October 2001.

- Psycho-social Care and Protection of Tsunami Affected Children: Inter-Agency Guiding Principles, January 2005.

- Psycho-social Intervention in Complex Emergencies: A Conceptual Framework and A Framework for Practice, the Psycho-social Working Group, Edinburgh, 2003.

- Psycho-social Training CD-ROM, the Psycho-social Working Group, Edinburgh, 2006.

- Working with Children in Unstable Situations: A Guiding Manual for Psycho-social Interventions (Draft), Refugee Studies Centre, Oxford University and UNICEF, 2002.

- Promoting Psycho-social Well-being among Children Affected by Armed Conflict and Displacement: Principles and Approaches, Save the Children, 1996.

- Technical Notes: Special Considerations for Programming in Unstable Situations, UNICEF, 2000.

- Handbook of Psycho-social Assessment for Children and Communities in Emergencies, UNICEF East Asia and Pacific Office and Regional Emergency Psycho-social Support Network, 2005.

- Guidance on the Use of Standardized Specific Needs Codes, UNHCR, IOM, 28/2007/FOM30/2007.

- Mental Health in Emergencies: Mental and Social Aspects of Health of Populations Exposed to Extreme Stressors, World Health Organization, Geneva, 2003. 
Part V.12

Humanitarian evacuations

1. Protecting civilians during evacuations

.434

2. Key protection considerations

. .435

3. Key challenges

.439

Key references \& useful websites

.440

433 


\section{Protecting civilians during evacuations}

Humanitarian evacuations usually take place in situations of natural disaster. ${ }^{1}$ In situations of armed conflict, however, humanitarian evacuations are strictly a measure of last resort.

Civilians in conflict situations may find themselves caught between, or even targets of, the fighting parties. While some may be able to flee from insecure areas using their own means, others including those already displaced may be unable to reach an area of relative safety. Humanitarian evacuations often have serious security, ethical, political and logistical implications. In particular, participation by humanitarian actors in forced evacuations raises the issue of criminal liability of "aiding and abetting" unlawful displacement and other human rights violations including "ethnic cleansing." Conversely, "non-intervention" may result in higher casualties among the civilian population.

\section{Bosnia-Herzegovina 1992-93:}

"... Political insistence on the right to stay should not in practice prevent people in danger from seeking safety. In many areas, remaining minorities wanted only one thing - to leave, and to be helped to leave. This created a serious dilemma for UNHCR and ICRC. While the organizations wanted to avoid becoming part of the conflict objective of ethnic relocations, they also recognized that assisting people to leave was often the only way to save lives. As High Commissioner Sadako Ogata put it, "if you take these people you are an accomplice to ethnic cleansing. If you don't, you are an accomplice to murder."

Kirsten Young, "UNHCR and ICRC in the former Yugoslavia: Bosnia-Herzegovina"

Humanitarian actors, in cooperation with States, have resorted to emergency evacuations or transfers as exceptional measures in extreme circumstances, when there was no other way of providing urgent assistance or protection in the face of severe threats to life and security.

Experience has shown that poorly planned or executed humanitarian evacuations may result in a failure to protect and a significant loss of life.

Planning humanitarian evacuations requires careful consideration of the potential negative impact on the human rights of evacuees and individuals in other affected communities. These rights include the right to seek safety within, and outside of, one's borders; to be protected from ethnic cleansing and arbitrary displacement; and the freedom to choose one's place of residence. ${ }^{2}$ Humanitarian evacuations can also undermine the core humanitarian principles underlying humanitarian action-humanity, impartiality and neutrality.

Different scenarios in which humanitarian actors have provided direct assistance or support to relevant authorities include:

- relocation of populations from endangered areas, such as camps, conflict or disaster areas, to another part of the country, an approach that is justified for reasons of public security, health or safety, and other risks to life, including the presence of armed elements and health risks caused by overpopulation;

- humanitarian evacuation of the wounded, sick and other civilians, including internally displaced persons (IDPs), trapped by armed conflict, an approach that is traditionally carried out by the ICRC and national Red Cross and Red Crescent Societies; and

For guidance on evacuations and other life-saving measures in situations of natural disaster, see Brookings-Bern Project on Internal Displacement, Human Rights and Natural Disasters, Operational Guidelines and Field Manual on Human Rights Protection in Situations of Natural Disaster, March 2008.

See Part I.1. 
- international humanitarian transfer or evacuation of individuals or groups of persons at particular risk of imminent attack or serious human rights violations into another country. ${ }^{3}$

In conflict situations, it is part of the ICRC's core mandate and traditional role to negotiate with parties to the conflict for the safe evacuation or transfer of the wounded, the sick and civilians, including IDPs, trapped in conflict. United Nations agencies and other international organizations, such as IOM, may also be involved in large-scale humanitarian evacuations and transfers in disaster and conflict situations. ${ }^{4}$

\section{Key protection considerations}

The context in which transfers and relocations can take place may vary significantly. A detailed situation analysis, including the motivations of the main actors, is necessary in each case to determine to what extent assistance might make humanitarian actors accomplices to human rights and international humanitarian law violations (i.e. by contributing to the displacement or the "ethnic cleansing") and to what extent immediate assistance is needed as a life-saving measure for the affected populations. An in-depth, even if fast, assessment of all factors having a potential impact on the transfer and relocation will also be critical to ensure that the diplomatic, protection, relief, security and logistics machinery that may need to be put in place, stands up to the challenges of the operation.

The operational experience gained to date highlights the need for humanitarian actors to respect a number of common standards. The suggested points below will need to be considered in the event that humanitarian actors decide to participate in humanitarian evacuations.

Coordinated
assessments
and analysis
(See Part III.1 $\mathrm{D}$ )

In planning evacuations, transfers and relocations, diplomatic advocacy and negotiation efforts with national and international actors are critical to ensure that the measures indicated below are taken.

- Organize with national and international partners effective informationsharing mechanisms.

\footnotetext{
3 Humanitarian Transfer Programmes (HTP) and Humanitarian Evacuation Programmes (HEP) consist of assistance and protection measures undertaken by humanitarian actors and cooperating States to move people to safety, in neighboring countries within a "region" (HTP) and outside the "region" (HEP), respectively. These programmes are different from existing Refugee Resettlement Programmes, which mainly deal with individually recognized refugees and with clearly defined refugee groups in a country of asylum, and are undertaken annually by States independently of other States and humanitarian actors, although in coordination with them, according to their own criteria for humanitarian programmes.

${ }^{4}$ Much of this experience has been gained in situations where refugees or asylum-seekers have been in imminent danger in a first country of asylum. In some of these cases, endangered persons were moved away from areas under attack to safer areas within the country (e.g. Sierra Leonean and Liberian refugees relocated from Guinea's border areas in 2001) and, in other cases, they were moved to safety in third countries (e.g. Kosovo refugees in Macedonia in 1999, Uzbek asylum-seekers in Kyrgyzstan in 2005).
} 
- Develop a joint analysis of risks and gaps. Individual actors' analysis of the situation may be influenced by their mandates, interests and capacities and they might promote different approaches or priorities as a result. To strengthen the emergency response, it will be vital to ensure that such joint analysis is done at the earliest stages.

- Discuss with all stakeholders, as appropriate, including with the local communities, the best way to ensure protection before, during and after the evacuation. Consideration should be given to every possible scenario, including what can go wrong during the evacuation, to minimize the risks to the life and integrity of civilians.

- Ensure that all operational partners are aware of, and agree on, who should be included in programmes, destinations, transportation and reception conditions.

Selection of relocation site and/or host communities (See Parts IV.6 and V.6)

- Consult with relevant authorities and partners within coordination structures to identify a relocation site and/or host community. Where possible, include IDPs and members of surrounding and host communities in the selection and planning process.

- Ensure that site viability assessments include core protection and self-reliance considerations, including the following: distance from areas of conflict or presence of armed actors; access to social services; basic infrastructure; livelihood activities; proximity to other communities; and any aspects that could create potential protection risks to the evacuees. ${ }^{5}$

- Hold discussions with representatives of the host community and individuals of different ages, gender and backgrounds to ascertain whether the host community accepts the settlement of the evacuees.

- Discuss and negotiate with relevant authorities:

concrete and effective measures to ensure safety and security at the new location;

national protection mechanisms and the commitment to activate them as required; and

- humanitarian access and protection monitoring.

\section{Freedom of} movement and information (See Part V.7 and $V .10 \square$ )
- Establish appropriate monitoring and community mobilization mechanisms to ensure that the evacuation of individuals is based on their voluntary decision, informed by an understanding of the risks and consequences of evacuation, transfer or relocation. This includes the choice not to return to, or settle in, any place where their life, safety, liberty and/or health may be at further risk. ${ }^{6}$ If feasible, planning should allow members of the IDP community to visit the new site.

(See Part IV.1.

- Work with relevant local authorities, parties to the conflict, humanitarian organizations, and community leaders to ensure that the evacuees are allowed to move and settle in other parts of the country as they wish, both during and after evacuation or relocation.

5 For example, in some cases, crossing areas of a different ethnic composition or walking long distances to schools, food-or water-supply points, or green areas may expose IDPs to a high incidence of physical attacks as well as gender-based and other forms of violence.

6 The IASC Guidelines guard against becoming involved in involuntary evacuations, transfers and relocations. "Unless it is necessary for the protection of affected persons against very serious and imminent threats to their lives, their physical integrity or health, evacuations against their will, or prohibitions against their return, should not be supported by organizations providing protection and assistance to persons affected by natural disasters, even if they have been ordered by the competent authorities." 
Discuss with relevant authorities, agencies, and representatives of the affected communities how the different agencies can help disseminate information to all segments of the affected communities. Information should address the reasons for evacuation, anticipated procedures and timeframes, destinations, and the potential consequences of choosing to move or to stay.

- Identify any restrictions on freedom of movement and settlement through human rights/protection monitoring in the new locations during and after evacuation movements. ${ }^{7}$ (See Part V.2. DD)

\section{Negotiations for safe access and passage} (See Part V.4 DD)

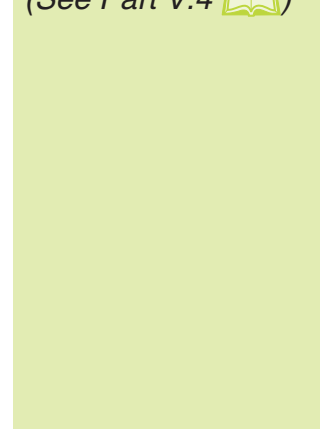

Obtaining reliable guarantees from the parties to the conflict to permit the safe evacuation of civilians across the frontlines is a challenge, particularly where the parties to the conflict are using civilians as pawns. Even small-scale attempts to evacuate civilians sometimes require arduous negotiations before the warring parties allow the evacuees to leave.

- Safeguarding the core humanitarian principles of humanity, impartiality and neutrality during negotiations for safe access and passage will require solid coordination among all humanitarian actors.

- To ensure that all actors speak with one voice, one agency should be assigned to lead the negotiations on behalf of the country team.

- Humanitarian actors should undertake contingency planning for eventual breaches of agreements on safe access and passage by parties to the conflict. Meticulous forward planning will be critical to minimize the potential loss of life and any other risks to the civilian population and humanitarian staff.

\section{Logistics for ensuring safety and dignity}

Implementing evacuation and relocation operations requires complex logistical coordination in areas of origin, transit and destination, among relevant United Nations agencies, international humanitarian organizations, national/local authorities and civil society actors, and in some cases, third States.

- Take concrete measures to ensure that the transfer will be done in safety and with dignity, including with regard to persons with specific needs, such as persons with disabilities, older persons, pregnant women, and separated/unaccompanied children.

- Ensure that health care, food and shelter are provided during transit and in the destination areas.

- Raise the awareness of donor countries of the complexity of existing challenges in a timely manner, to ensure that there is sufficient financial support from the outset to boost operational capacity and meet the protection goals of the evacuation. 


$\begin{aligned} & \text { Land, housing } \\ & \text { and property } \\ & \text { (See Part IV.17 }\end{aligned}$
$\begin{aligned} & \text { Advocate with national authorities and with the parties to the conflict to } \\ & \text { ensure that they assume their responsibility for safeguarding property, } \\ & \text { homes and common assets left behind. These should be protected } \\ & \text { against destruction and from arbitrary and illegal appropriation, } \\ & \text { occupation or use. } \\ & \text { Where possible, assist communities in safeguarding land, housing and } \\ & \text { property registration documentation. Where no official records exist and if } \\ & \text { security conditions allow, help communities undertake an ad hoc } \\ & \text { emergency property assessment or the steps necessary for informal } \\ & \text { certification before or immediately after evacuation. If necessary, advocate } \\ & \text { for national authorities to legally recognize the property left behind and } \\ & \text { issue appropriate certification. }\end{aligned}$

Family unity (See Part IV.7 DD)
Under no circumstances should families be separated as a result of relocation or evacuation movements, particularly if children are involved.

- Take practical steps to prevent the separation of children from their families (i.e. encourage parents to teach their children their full names and addresses of destination; give parents light ropes to tie around their wrists and those of their children; provide parents with identity tags to attach to their children's clothes or around their necks or wrists and rehearse with them on how and at what point to put them on their children). ${ }^{9}$ These practical steps are equally suitable for older persons who are mobility challenged and emotionally, mentally or physically fragile.

- Evacuated persons should be registered and their evacuation monitored. Evacuated separated children should be properly identified and registered and their whereabouts monitored.

- Assist adult family members wishing to remain together in preventing separation from each other.

\section{Establishment of selection criteria for evacuation}

- A careful "pros" and "cons" evaluation of selection criteria for evacuation is required. Selection criteria and mechanisms to determine such criteria would be dependent on the particular contexts. Informed consent by the community and the concerned individuals on the final selection criterion is also essential.

- Establish organized systems with specialized agencies and/or experts (i.e. medical doctors in cases of medical evacuations, UNICEF and ICRC for the evacuation of children) to target and prioritize cases according to vulnerability and special protection needs. Focus, in particular, on detainees, persons with medical needs, families with young babies, pregnant women with children, unaccompanied minors, women-at-risk, and older persons.

8 See Implementing the Pinheiro Principles, Interagency Handbook on Housing and Property Restitution for Refugees and Displaced Persons, March 2007.

9 For detailed guidance, particularly on preventing family separation of babies and small children, see UNICEF, The lost ones; Emergency care and family tracing for separated children from birth to five years, Child Protection Programme Division, April 2007. 
Ensure transparency, fairness and consistency in the application of selection criteria for evacuation procedures. This is vital to minimize confusion, tensions and the perception that the selection process is unfair.

- Avoid, and advocate strongly against, the establishment of rapid processing systems, which frequently function on a "first come, first served" basis. While this is often the easier option in large-scale evacuations, such systems do not allow for the priority processing of persons or groups with especially urgent protection needs.

\section{Protection monitoring and advocacy} (See Part V.2 and $3 \square$ )
Establish enhanced monitoring and presence in both the new relocation site, and the area of origin, where individuals who stayed behind may be subject to increased persecution and grave human rights violations.

- Ensure that individuals who chose to remain close to their homes, such as older persons whose relatives were evacuated, have access to ongoing support and assistance. Such situations should be referred to the relevant national institutions or local support networks and, if relevant, to humanitarian and human rights actors.

Humanitarian actors should maintain a dialogue with relevant authorities to develop necessary measures to secure the new location, to avoid possible protection risks, to activate national protection mechanisms, and to maintain international presence and protection monitoring.

\section{Key challenges}

Deciding, designing and implementing evacuation, transfer or relocation movements can involve formidable challenges. Below are just a few considerations that should be analysed through an inter-agency approach.

\section{- Erosion of the principle of asylum}

Depending on the context, assisting in the relocation or evacuation of civilians within a country in conflict might have the effect of eroding the principle of access to asylum outside the country, at least temporarily. The right to seek asylum should remain an option for all individuals or groups both before and after a relocation or evacuation movement. Steps should be taken to provide information on this alternative both to the civilian population and parties to the conflict. The fact that asylum-seekers may have been internally displaced, even if due to a humanitarian evacuation, should not negatively affect their claim for asylum.

\section{- Patterns of arbitrary displacement and targeted human rights violations}

In some circumstances, assisting with the evacuation or relocation of civilians or providing humanitarian assistance during such evacuations or relocations might not be especially controversial, particularly if the situation is not politically charged, such as in a natural disaster context. However, when the population movement is part of a forced displacement policy or a deliberate strategy in an internal armed conflict, such as ethnic cleansing, humanitarian actors will face serious moral and political dilemmas in deciding involvement. ${ }^{10}$ Humanitarian actors should try to avoid becoming involved in involuntary evacuations, transfers and relocations unless it is necessary for the protection of affected persons against very serious and imminent threats to their lives, their physical integrity or health (as addressed further in Part IV.1 $\square$ ), and informed consent of the would-be evacuees has been secured. ${ }^{11}$

\footnotetext{
${ }^{10}$ Even situations where natural causes are responsible for the displacement can be manipulated after the fact to pursue political or other objectives that violate the rights of IDPs. For this reason, it is important to have a clear situation analysis before assisting with population transfers.

11 Quoted from Protecting Persons Affected by Natural Disaster: IASC Operational Guidelines.
} 


\section{Negotiating access to populations at risk, and safe evacuations, with State and non-State actors}

Securing authorization from government authorities or non-State actors may prove particularly difficult. A coordinated effort among specialized protection agencies is needed for such negotiations, while reaffirming the principle of humanity, neutrality and impartiality of humanitarian assistance with the concerned authorities. (See Part V.4.

\section{- Coordination among humanitarian actors}

Evacuations in situation of conflict may involve the participation of a large number of humanitarian actors, including NGOs. It is important to establish standard operating procedures for such activities and ensure adherence by all humanitarian actors to the principle of neutrality and impartiality.

- Time

In some circumstances or in situations of imminent threat, very short notice is given by national authorities or non-State actors for the evacuation of people. A rapid response from humanitarian actors is crucial in assessing the situation and in providing life-saving assistance.

\section{- Security of humanitarian workers}

While being involved in evacuation and providing humanitarian assistance, humanitarian workers may no longer be viewed by warring factions or the population as being impartial and neutral and, consequently, may become the target of attacks. It is essential that information on the principles of neutrality and impartiality of humanitarian action be widely disseminated among the population and the relevant national actors. Obtaining reliable guarantees for the safety and security of humanitarian actors by the warring factions should also be a priority.

\section{Key references \& useful websites}

- Protecting Persons Affected by Natural Disasters: IASC Operational Guidelines on Human Rights and Natural Disasters, IASC, June 2006.

- Evacuation of Children from Conflict Areas: Considerations and Guidelines, UNICEF and UNHCR, Geneva, 1992.

- UNHCR and ICRC in the former Yugoslavia: Bosnia-Herzegovina, by Young, K., International Review of the Red Cross, Vol. 83, No. 843, September 2001.

- Strengthening Protection in War: A Search for Professional Standards, by Sylvie Giossi Caverzasio, ICRC, 2001. 


\section{Part V.13 \\ Peaceful coexistence}

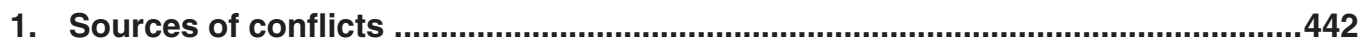

1.1 Conflict within IDP communities ……............................................................. 442

1.2 Conflict between IDP communities and surrounding populations (host and return)

1.3 Conflict between IDP, host communities and the international community.....

1.4 Impact of hostilities on IDP and other civilian communities..............................443

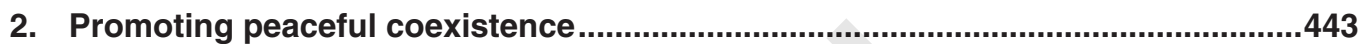

3. Role and key activities of international actors ........................................................445

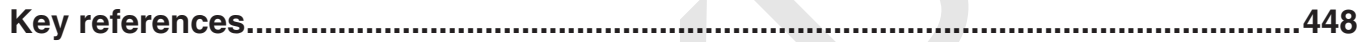

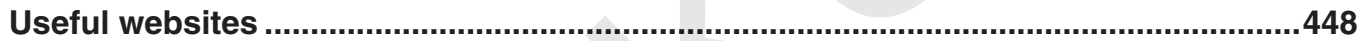




\section{Sources of conflict}

Relationships that prevail within internally displaced communities, as well as between these communities and their surrounding host communities, can critically affect their protection and security. Possible tensions in such environments (and in humanitarian crises in general) can lead to conflicts, of which certain causes and effects are outlined below.

\subsection{Conflict within IDP communities}

- minority groups, such as ethnic, religious or political minorities and indigenous populations facing increased racism, exclusion and stereotyping in situations of displacement;

n displaced women, children, older persons and persons with disabilities at an increased risk of discrimination, abuse and gender-based violence;

- perceived or actual inequalities in the distribution of assistance to different groups of displaced persons between, for exampls, IDPs uprooted by conflict and disaster-displaced communities, or between newly-arrived and longer-term IDPs;

- criminal groups or individuals (e.g. tribal leaders, community leaders, camp managers) within camps who extort resources from, exploit or terrorize inhabitants;

n sexual exploitation and violence (e.g. by camp managers, community leaders, food distributors); and

- recent arrivals perceived as representing a security threat for previously settled displaced communities.

\subsection{Conflict between IDP communities and surrounding populations (host and return)}

- underlying tensions based on differences between the IDPs and host or return populations (e.g. ethnic, religious, racial, tribal);

- perceptions that IDPs are sympathizers with a particular party to the conflict or political group and fears that IDPs are a potential source of insecurity;

- fears of military incursions or reprisal if IDPs are fleeing a conflict;

- upheaval and potential social unrest caused by the disorderly arrival of large numbers of people;

- competition over limited resources, such as water, land, food, firewood etc., and concerns about the depletion of scarce resources especially where IDP camps or settlements are set up close to surrounding villages or where large numbers of IDPs return to the same community;

- overburdening of public services, e.g. schools (which are often used as emergency IDP shelters) and health centres breeding resentment;

- perceived association by host communities of arrival or return of IDPs with a rise in social problems, crime, sexual exploitation and violence, etc. and, likewise, IDPs' perception that local communities are responsible for these problems;

- jealousy over perceived or actual preferential treatment, including disparities in access to aid; and

- large-scale seasonal movements of pastoralists with their livestock causing clashes with IDP communities in some countries, especially where these migrations traverse land or use water points used by IDPs, or where they are associated with increased crime and sexual violence against IDP communities. 


\subsection{Conflict between IDP, host communities and the international community}

- potential impact of international assistance on local culture or other established codes of conduct;

- expectations on the part of host communities, and particularly local governments, for reimbursement of expenses incurred while providing space and services for IDPs as well as compensation for both physical and environmental damage caused by IDPs (e.g. repair of school buildings and other facilities that served as IDP shelters);

- the engagement of the international community with local government officials can be seen as running counter to the interests of other parties to the conflict (e.g. independence movements), leading to significant pressure on IDPs; and

- conflict over expectations and perceived treatment of different groups (further addressed in Part V.5 [D).

\subsection{IImpact of hostilities on IDP and other civilian communities}

- attacks by military, local militia and other non-State actors on civilians, including stealing their property;

- gender-based violence against IDPs and other civilians by military, local militia or other non-State actors;

- trauma and other psychosocial problems, especially amongst children who have witnessed violence and are old enough to attach meaning to displacement;

- forced secondary displacement of IDPs by military, local militia or other non-State actors with the aim of gaining strategic advantage;

- use of civilians, including IDPs, as human shields by military, local militia or other non-State actors; and

- impact of private security providers on conflict dynamics (further addressed in Part IV.2 [D).

\section{Promoting peaceful coexistence}

"Peaceful coexistence," as applied to pre-conflict, conflict and post-conflict situations, has been defined as "moving beyond the notion of mere tolerance, to a definition of coexistence that incorporates equality, diversity, and interdependence. It refers to building relationships between different ethnic, religious, or social groups based on mutual trust, respect and recognition with a focus on social cohesion, inclusion and integration.... Activities to promote peaceful coexistence include a range of initiatives to ensure that communities and societies can live more equitably and peacefully together, such as conflict prevention and management, post-conflict and conflict transformation work, conflict-sensitivity, peacebuilding, reconciliation, multicultural, and pluralism work."'

It can take various forms, with specific projects aimed at building community cohesion or a community-based, conflict-sensitive approach to development or assistance projects that focuses on coexistence. Humanitarian work requires not only assessing the practical or

\footnotetext{
"Peaceful co-existence as applied to pre-conflict, conflict and post-conflict situations means moving beyond the notion of mere tolerance, to a definition of co-existence that incorporates equality, diversity, and interdependence. It refers to building relationships between different ethnic, religious, or social groups based on mutual trust, respect and recognition with a focus on social cohesion, inclusion and integration.... Activities to promote peaceful coexistence include a range of initiatives to ensure that communities and societies can live more equitably and peacefully together, such as conflict prevention and management, post-conflict and conflict transformation work, conflict-sensitivity, peace building, reconciliation, multicultural, and pluralism work." Definition based on Coexistence International: What is Coexistence?, www.brandeis.edu/coexistence/work/coexist.html.
} 
material outcome of projects but also how they contribute to peacebuilding within communities, and whether they help to reunite or further divide communities.

The principles of "do no harm" and a conflict-sensitive approach should underpin all humanitarian, human rights and development action within IDP and host communities. To achieve the goal of enhancing peacebuilding within and between communities, an organization must first understand the context in which it is operating, notably the elements of underlying conflict that may not be immediately visible and the impact of its interventions on the given context.

Without identifying and understanding the underlying causes of conflict, any long-term solutions will be elusive and inter and intra-communal disputes can easily re-ignite and quickly escalate into violence. The process of conflict resolution, thus, can be as important as, or more important than, finding a solution to an immediate problem. For this, international actors need to build on existing mechanisms for community dialogue and dispute resolution, as these are more likely to be effective and sustainable than creating new mechanisms.

There are various ways to promote and support peaceful coexistence and community cohesion, as outlined below.

Encourage regular dialogue within IDP communities and between IDP and host communities in order to promote relations of trust and mutual respect.

Strengthen local mechanisms for the fair distribution of natural and economic resources, and raise awareness about the sustainable use of existing resources.

Ensure equal access to local public services, and build the capacity of inclusive, responsive and conflict-sensitive public services.

Consider the special needs of groups exposed to discrimination and exclusion, including women, children, ethnic minorities and indigenous populations. (For example, communication strategies to promote sustainable natural resource management or access to public services should take account of indigenous languages.)

Build upon existing community mechanisms for dialogue and dispute resolution (elder committees, members of the displaced and host communities, etc.). If such mechanisms do not exist or are no longer considered credible by the community, new mechanisms need to be developed through a community-based process.

Target aid on the basis of needs, explaining this, and address any problems of diversion of aid as these arise.

Adopt a community-based approach which not only provides protection and assistance to IDPs, but also supports host families and benefits the broader local community. (See Part V.10.

Support confidence-building between communities, through programme design and implementation (e.g. social housing projects for IDPs which include individuals with special needs from the local community).

Support the local justice system, provided it is functioning properly, and ensure equal access for IDPs and members of the host community.

Promote community-driven reconstruction and development initiatives that help build social capital ${ }^{3}$ and enhance the prospects of sustainable peace.

Mary Anderson, How aid can support peace - or war, 1999

3 The concept of social capital refers to the social resources upon which people draw in pursuit of their livelihood objectives. 


\section{Role and key activities of international actors}

International actors have an important role to play in promoting and supporting peaceful coexistence. International humanitarian, human rights and development actors should ensure that their interventions do not exacerbate existing tensions or create new tensions but rather support peacebuilding within and between communities. Regular consultation with IDPs and local communities as well as ongoing formal and informal conflict analysis exercises are important for achieving this goal.

Building on the considerations and approach defined in the preceding section, a range of specific steps can be taken by international humanitarian, human rights and development actors to promote peaceful coexistence and social cohesion between communities. They are listed below.

\begin{tabular}{|c|c|}
\hline & In our work, we can ... \\
\hline $\begin{array}{l}\text { Assessment and } \\
\text { analysis } \\
(\text { See Part III.1 } \square)\end{array}$ & $\begin{array}{l}\text { Ensure that all assessments take account the protection and assistance } \\
\text { needs of both the displaced and host communities on an equal basis, } \\
\text { through an objective process that avoids any discrimination. Where } \\
\text { possible, include representatives of both communities in assessments } \\
\text { seeking to identify potential sources of tension as well as areas of } \\
\text { common interest. } \\
\text { Carry out ongoing formal and informal conflict analysis exercises as part of } \\
\text { efforts to support peacebuilding within and between communities. It is } \\
\text { important to understand not only the immediate causes of conflict but also } \\
\text { underlying causes of conflicts in order to seek long-term solutions. }\end{array}$ \\
\hline $\begin{array}{l}\text { Information and } \\
\text { communication } \\
\text { activities } \\
(\text { See Part V.7 } \square)\end{array}$ & $\begin{array}{l}\text { Identify and solicit the cooperation of "bridge-builders" and existing } \\
\text { community mechanisms to enhance dialogue both within displaced } \\
\text { communities and between IDPs and host/return communities. } \\
\text { Depending upon the cultural context, these may include traditional, } \\
\text { religious or women leaders. } \\
\text { Help establish open and transparent channels of communication and } \\
\text { dialogue between communities. Provide facilities for community dialogue } \\
\text { to enhance mutual understanding, trust and relationship building } \\
\text { between both communities. } \\
\text { Help organize cultural and social activities and exchanges or joint } \\
\text { councils or committees that bring together representatives of different } \\
\text { communities to discuss and resolve matters of mutual interest and } \\
\text { concern. } \\
\text { Support information campaigns and other activities that provide culturally } \\
\text { sensitive information regarding ways to minimize the adverse effects of } \\
\text { displacement, and facilitate the peaceful coexistence and integration of } \\
\text { displaced persons in areas of displacement or return. } \\
\text { Provide full and culturally accessible information on procedures to obtain } \\
\text { humanitarian assistance as well as the type and quantity of aid provided } \\
\text { in order to avoid misperceptions of inequality and to reduce tensions } \\
\text { within and between communities as well as with humanitarian } \\
\text { organizations. } \\
\text { Provide information on how to access formal and informal conflict } \\
\text { prevention, mediation and resolution mechanisms. }\end{array}$ \\
\hline
\end{tabular}




$\begin{array}{ll}\text { Confidence- } & \begin{array}{l}\text { Undertake activities to build understanding and confidence between } \\ \text { building measures }\end{array} \\ \text { communities, by highlighting the positive impact that the presence of IDPs } \\ \text { can have for the host or return community, such as improved access to } \\ \text { assistance and services, or by ensuring that the implementation of projects } \\ \text { (the building of new schools, social housing projects, etc.) is undertaken } \\ \text { jointly and benefits both IDP and local communities. }\end{array}$

Access to
assistance and
services
(See Part V.5

- Ensure, wherever possible, that displaced and host/return communities have full and equal access to humanitarian assistance, basic services, including water, food, education and health care, and livelihood opportunities. A comprehensive and integrated approach to assistance and services, based on an objective assessment of humanitarian needs, is essential and can help reduce tension between the communities. Clearly and publicly explain that assistance is provided on the basis of needs, targeting the most needy, in accordance with humanitarian principles of impartiality and neutrality.

- Design programmes to ensure that marginalized or at-risk members of the community (e.g. single mothers, people with disabilities, indigenous people and ethnic minorities) have equal access to assistance.

- Support and help improve local infrastructure and services, such as schools and health clinics, and avoid creating parallel structures for IDPs wherever possible. Ensure and explain that projects undertaken to improve roads, bridges, water and sewage systems, communication systems, sports facilities and other infrastructure can benefit both populations.

\begin{tabular}{l|l}
\hline $\begin{array}{l}\text { Access to natural } \\
\text { resources }\end{array}$ & $\begin{array}{l}\text { Establish clearly defined and agreed arrangements for access to natural } \\
\text { resources and other assets likely to come under pressure due to the } \\
\text { presence of the displaced population, in competition with the host/return } \\
\text { community for scarce resources. }\end{array}$ \\
& $\begin{array}{l}\text { Establish mechanisms for resolving disputes over access to natural } \\
\text { resources. }\end{array}$ \\
\hline Economic and & $\begin{array}{l}\text { Support development initiatives of benefit to both host/return and displaced } \\
\text { social development } \\
\text { communities, including livelihoods, environmental projects, employment } \\
\text { and income-generating opportunities. }\end{array}$ \\
\hline Community & $\begin{array}{l}\text { Strengthen the capacity of displaced and host/return communities to } \\
\text { participate in decision-making processes that concern livelihoods and } \\
\text { medium-term reconstruction and development priorities. Ensure } \\
\text { maximum participation by all members of the community, including } \\
\text { women and marginalized and discriminated groups, in decision-making } \\
\text { processes. Allow adequate time for such consultations. } \\
\text { Promote community ownership and self-reliance in all humanitarian and } \\
\text { development projects. }\end{array}$ \\
\hline
\end{tabular}




\section{Conflict prevention, mediation and resolution}

Build upon, or support the establishment of, community-based dialogue, complaint and conflict resolution methods/mechanisms, which include representatives of all affected communities, to address and resolve any disputes that may arise both within IDP communities and between displaced and host communities. This is usually most effective if linked to existing structures and mechanisms at the local level, such as community centres, local peace councils, district peace committees, and elder councils, and should include both women and men of varying ages and backgrounds. Such mechanisms can be given modest support, for instance in the form of meeting space, transport and/or refreshments during meetings. Humanitarian workers should make special efforts to engage with, and listen to, these groups, giving due consideration to the views they express.

- Encourage these mechanisms to pay particular attention to addressing any disputes that may arise over the use of land and other resources at an early stage.
Durable solutions

\section{Law enforcement}

Protection of the environment
- Promote integration and peaceful coexistence with the host community and with return communities to ensure that IDPs have access to sustainable solutions to their plight. This involves identifying and taking steps to address potential sources of conflict with host and return communities, building the capacity of existing dispute mechanisms and providing support to set up new mechanisms as required and ensuring that host and return communities also benefit from reconstruction and reintegration assistance programmes.

\begin{tabular}{l} 
law enforcement agencies, to take action to prevent and respond to any \\
potential increase in crime, violence and abuse, and in a \\
non-discriminatory way. This can include various forms of \\
police-community initiatives and crime prevention strategies. \\
Ensure that the displaced community is informed of any laws, regulations \\
or customs that may apply, such as on the use of land or the collection of \\
water and firewood. \\
Support existing mechanisms, or help set them up, to ensure that the \\
police and other law enforcement agents are held accountable for \\
abuses against IDPs or members of the local community. \\
Promote the rule of law by providing information on humanitarian and \\
human rights law and supporting mechanisms to enhance social justice. \\
\hline Protection of the \\
environment
\end{tabular}




\section{Key references}

- Building Peace: Practical Reflections from the Field Edited by Craig Zelizer, Robert A. Rubinstein, 2009.

- UNHCR Handbook for Repatriation and Reintegration Activities, UNHCR Geneva, May 2004.

- Conflict and Migration: The Georgian-Abkhaz Case in the European Context Conference organized by the Heinrich-Boell Foundation, the Center for Citizen Peacebuilding at the University of California, Irvine and Conciliation Resources, Istanbul, 18 - 19 June 2008.

\section{Useful websites}

nerghof Research Center for Constructive Conflict Management: www.berghof-center.org

n Citizen Peace Building at University of California Irvine: www.socsci.uci.edu/ cpb/

- Coexistence International, Brandeis University: www.brandeis.edu/coexistence/

- Peace Media Clearinghouse (a resource for practitioners working on conflict, IDP and refugee issues): www.peacemedia.usip.org/

- Conciliation Resources: www.c-r.org/

- Heinrich Boell Foundation: www.boell.org/home.asp

- International Alert: www.international-alert.org/

- Search for Common Ground: www.sfcg.org/

- Peace and Collaborative Development Network: www.internationalpeaceandconflict.org

- World Bank, Post Conflict and Reconstruction Unit: www.worldbank.org 


\section{Overview}

The humanitarian response to situations of internal displacement involves different protection and assistance activities for which Part V provided guidance. These activities are aimed at addressing specific protection risks or responding to specific sectoral objectives. However, the ultimate objective must always be to find durable solutions. Achieving a durable solution to internal displacement implies that all displaced persons are able to enjoy the full spectrum of human rights and, as a result, are able to rebuild their lives.

Chapter 1 of Part VI briefly presents the different solutions that can bring an end to internal displacement and the conditions for the sustainability of such solutions.

Chapter 2, then, elaborates on how to plan and implement durable solutions. Different approaches can be used, but each of them must respect key principles, be context-sensitive, and be solutions- and rights-based. They must also be coherent with all other approaches, such as development plans or peace processes, that are being developed concommittantly.

Finally, Chapter 3 provides concrete suggestions for interventions by humanitarian, human rights and development actors, based on the Framework for Durable Solutions for Internally Displaced Persons. 


\section{Part VI \\ Durable solutions}

1. Definitions and principles .451

2. Planning and implementing durable solutions 452

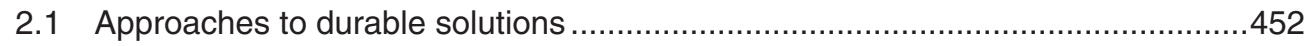

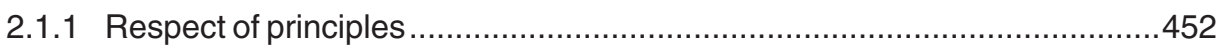

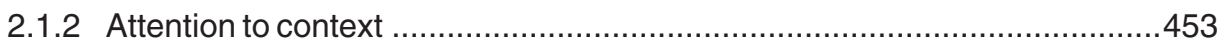

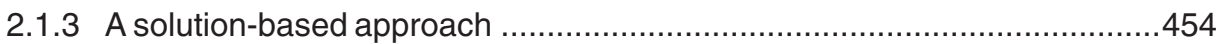

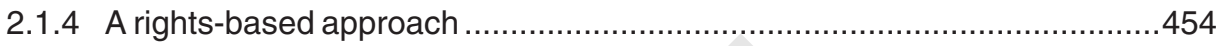

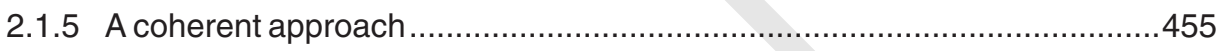

2.2 Coordination and planning mechanisms for durable solutions ...........................458

3. The Framework for Durable Solutions and its operationalization ........................458

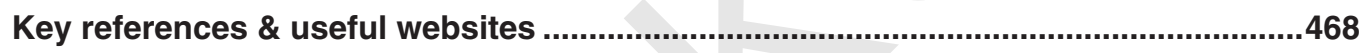

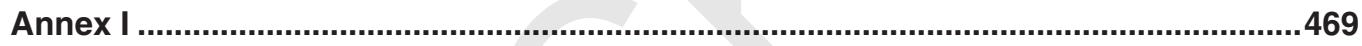




\section{Definitions and principles}

Achieving a durable solution to internal displacement means that internally displaced persons (IDPs) no longer have any specific assistance and protection needs that are directly linked to their displacement and can enjoy their human rights without discrimination on account of their displacement.

A solution to internal displacement can be achieved through one of three modalities:

v sustainable return to the place of origin;

nustainable local settlement in the area where IDPs have taken refuge; or

- sustainable settlement elsewhere the country. ${ }^{1}$

There is no inherent hierarchy between the three types of solutions, and solutions can only be "durable" if a number of conditions are fulfiled. ${ }^{2}$ In general, IDPs who have achieved a durable solution will enjoy without discrimination the following rights:

- long-term safety, security and freedom of movement;

- an adequate standard of living, including at a minimum access to adequate food, water, housing, health care and basic education;

access to employment and livelihoods; and

a access to effective mechanisms that restore IDP's housing, land and property or provide them with compensation.

In a number of contexts, it will also be necessary for IDPs to benefit, without discrimination, from the following to achieve a durable solution:

- access to, and replacement of, personal and other documentation;

- voluntary reunification with family members separated during displacement;

- participation in public affairs at all levels on an equal basis with the resident population; and

- effective remedies for displacement-related violations, including access to justice, reparations and information about the causes of violations.

Achieving these conditions will often be a gradual, long and complex process of addressing humanitarian, human rights, development and, in some cases, peace challenges. Political and security related factors, such as ongoing armed conflict, may hamper durable solutions and even lead to protracted or renewed internal displacement.

Measuring the achievement of durable solutions requires a careful examination of the conditions enumerated above as well as the process implemented to achieve them. In many contexts, these conditions will not be completely achieved in a long period of time, or may only be achieved through long-term reconstruction and development processes. Therefore, they should be considered as criteria to assess the degree to which a durable solution has been

\footnotetext{
The Guiding Principles on Internal Displacement refer to two solutions: "return" and "resettlement" in another part of the country." The latter option refers to settlement elsewhere in the country other than in one's place of origin. It encompasses the option for IDPs to settle permanently in the locality where they first arrived while displaced as well as the possibility to move to another part of the country altogether. Given that the term "resettlement" has a very specific meaning in the refugee context, as it refers to relocation outside the country of asylum, this Handbook refers to, and would generally recommend, that in contexts of internal displacement, the terms "local settlement" and "settlement elsewhere" be used instead.

2 Cf. UNDG Guidance Note on Durable Solutions for Displaced Persons (refugees, internally displaced persons, and returnees), UNDG Programme Group, October 2004.
} 
achieved. This assessment needs to be carried out at the country level or according to groups of IDPs, depending on the causes and circumstances of displacement. It is important to bear in mind that different criteria will have different weight according to the particular context: reparations may be key when displacement is linked to serious human rights violations, but it may be less important or completely irrelevant for persons displaced by floods. However, in all cases, the fact that most IDPs have returned or settled in safety and dignity in parts of their country will not mean that all IDPs have found a durable solution. Durable solutions are inextricably linked to restoring the full enjoyment of rights to IDPs and they, therefore, are predicated upon families and individuals; thus, ascertaining the individual achievement of a durable solution will require an analysis at the individual level.

\section{Planning and implementing durable solutions}

\subsection{Approaches to durable solutions}

Assisting States and the IDPs themselves in achieving durable solutions for internal displacement is a complex and multi-faceted challenge that demands a particular approach. Particular principles need to be carefully adhered to, while paying attention to the specific context in which IDPs find themselves. It is essential to adopt a solutions-based and rights-based approach. Finally, different efforts towards durable solutions and the various actors involved in them, including humanitarian, human rights, protection and development actors, need to be well coordinated at the national and international levels.

\subsubsection{Respect of principles}

Plans, programmes and activities seeking to achieve durable solutions should adhere to a number of principles. The most important principle is the principle of national responsibility for addressing internal displacement, which involves the duty to establish the conditions enabling durable solutions. This is affirmed in Principle 28 of the Guiding Principles on Internal Displacement:

Competent authorities have the primary duty and responsibility to establish conditions, as well as provide the means, to allow internally displaced persons to return voluntarily, in safety and with dignity, to their homes or places of habitual residence, or to resettle voluntarily in another part of the country. Such authorities shall endeavour to facilitate the reintegration of returned or resettled internally displaced persons.

The principles that generally guide the search for durable solutions are indicated below.

- The primary responsibility to provide durable solutions to IDPs needs to be assumed by the national authorities. International humanitarian and development actors have complementary roles.

- The authorities concerned should grant and facilitate rapid and unimpeded access to humanitarian and development actors in order for these actors to be able to help IDPs benefit from a durable solution.

- The needs, rights and legitimate interests of IDPs should be the primary considerations guiding all policies and decisions on durable solutions.

- All relevant actors need to respect the right of IDPs to make an informed and voluntary choice on what durable solution to pursue and to participate in the planning and management of durable solutions. 
- The choice of all IDPs to locally integrate or settle elsewhere in the country, in the absence of the option to return, must not be regarded as a renunciation of his/her right to return should that choice later become feasible.

- Under no circumstances, should IDPs be encouraged or compelled to return or relocate to areas where their life, safety, liberty or health would be at risk.

- IDPs seeking a durable solution must not be subject to discrimination for reasons related to their displacement.

- Likewise, populations and communities that (re)integrate IDPs and whose needs may be comparable to them, must not be neglected in comparison to IDPs.

- IDPs who have benefited from a durable solution continue to be protected by international human rights and humanitarian law.

\subsubsection{Attention to context}

At the same time as adhering to the mentioned principles, any approach to durable solutions for IDPs needs to be context-sensitive, and the factors indicated below need to be carefully examined.

- The causes of displacement: Particularly when IDPs seek to re-establish their lives in their places of origin, the causes for displacement will need to be understood and addressed. In a context of armed conflict, this may require the re-establishment of sustainable safety and security, and a peace process or peacebuilding measures. When this is not feasible in the short -term and a majority of IDPs wish to integrate locally, it is important that durable solution policies duly recognize this choice of a solution as a priority. In a context of natural disasters where the area of origin is permanently at risk, national authorities may legitimately consider sustainable settlement in other areas of the country as the preferred solution.

- The length of displacement: In cases of protracted displacement, particular efforts may be needed for the reintegration of displaced communities, including for instance the IDPs' acquisition of new skills to help them access labour markets. This is particularly applicable for cases where IDPs find particular obstacles to adapt to a new economic, social and cultural environment in places where they intend to settle, be it in places of origin or elsewhere in the country. At the same time, it is important to pay attention and reinforce the mechanisms IDPs themselves may have found to adapt to their current environment, particularly in cases where a sizeable proportion of them have been born in the place of displacement.

- The displacement setting (whether it is urban or rural, or in a camp or a non-camp situation) in addition to other criteria: Camps and collective centres are not ideal settings, and only very rarely will they represent a durable shelter solution. However, progress toward the identification of a durable solution may already be made by ensuring freedom of movement and access to livelihoods from an early stage for IDPs.

- The way displacement has affected different populations: Particularly (but not exclusively) for indigenous peoples and other persons with a special attachment to their land, displacement may represent a serious breakdown of culture, productivity modes and social structures. Durable solution strategies should seek to preserve and re-establish these as much as possible. At the same time, displacement may also create particularly serious risks for disabled persons or persons who are traditionally disenfranchised, such as women, children and minority groups. Durable solution strategies and programmes will need to address these differences and may even represent opportunities to reduce discrimination and foster empowerment of particular population groups. In general terms, durable solution plans and programmes need to be sensitive to the particular needs of persons according to their gender, age and factors of diversity, such as ethnic background or religious faith. 


\subsubsection{A solutions-based approach}

Supporting durable solutions to internal displacement can never begin too early. In some particular contexts, it is true that a particular breakthrough, such as a peace agreement, will need to happen for the full realization of a durable solution. However, there is no particular point in time or event that marks the beginning of efforts for durable solutions. IDPs may successfully integrate locally in urban areas while conflict is active in rural regions of the country. Indeed, humanitarian action, including in the area of protection, must be inspired by the goal of durable solutions from the outset of any operation.

It is essential that an analysis of the causes of displacement and, as far as possible, the wishes of IDPs as for the modalities for durable solutions be already included in the first phases of a needs assessment and that protection, assistance and development interventions are tailored accordingly. The adoption of an early recovery approach and the involvement of development actors in the early phases of displacement, paying particular attention to the primary responsibility of national authorities, are also paramount. In cases where refugees are voluntarily repatriating, efforts for their reintegration must be coherent with durable solution programmes for IDPs, avoiding discrimination between the two groups even in cases where durable solutions do not happen at the same time or in the same places.

In a post-conflict environment, coherence must be ensured between efforts to achieve durable solutions for IDPs and broader programmes for rehabilitation and for the development, disarmament, demobilization and reintegration (DDR) of former combatants, strengthening the rule of law and institutional building. However, transition processes are rarely linear. Pockets of violence may persist, or entire regions or countries may lapse back into conflict causing renewed displacement. The existence of rehabilitation and development programmes and the fact that durable solutions are underway in some regions or for specific groups of IDPs should not obscure the need for contingency planning or humanitarian approaches when displacement continues to occur. While a level of generalization is necessary for planning purposes, durable solutions are not an abstract and general "phase" for the totality of the IDP population, but rather refer to groups of IDPs according to the causes and circumstances of displacement and to individual IDPs according to their particular needs, rights and vulnerabilities.

\subsubsection{A rights-based approach}

Durable solutions are above all about the restoration of rights for IDPs. Therefore, any effort towards durable solutions must adopt a rights-based approach. In essence, this means that all interventions for durable solutions must be actively designed in order to further the realization of human rights; human rights standards (e.g. those of access to economic and social rights, such as health, education and housing) must guide the programming for durable solutions, and programmes for durable solutions must contribute to developing the capacity of States to meet their obligations and those of the IDPs themselves to claim their rights.

The adoption of a rights-based approach is a responsibility of all humanitarian and development actors. National and international protection and human rights actors have a responsibility to advocate and assist other key stakeholders and particularly national authorities in the adoption of such an approach. Toward this end, mechanisms to monitor IDPs' access to rights are instrumental, and their findings should systematically feed advocacy, planning and programming by protection and human rights actors. Particularly in countries with a significant level of institutional development, monitoring agencies will need to acquire a capacity to analyse the sufficiency and effectiveness of national public policies, planning and budgeting mechanisms and the institutional performance of national authorities to meet the needs and rights of IDPs. 
When feasible, international actors must also actively assist States in developing their capacities to protect and fulfil IDP rights. For instance, in this sense, it is important that efforts by humanitarian actors to provide legal advice or property restitution mechanisms for IDPs are well coordinated with wider efforts by development actors and national authorities for judicial, legislative and institutional reform and for the reinforcement of the rule of law.

\subsubsection{A coherent approach}

Efforts towards durable solutions naturally involve a wide number and diversity of actors, including national authorities, civil society, the IDPs themselves, and international bodies and organizations. Achieving an adequate level of coherence is essential to durable solutions, since unconnected and isolated actions will not achieve the desired impact. It is important to avoid a number of misconceptions. In particular, there should be no rigid distinction between short-term humanitarian relief and longer-term development initiatives, and there is not a definitive point in time for the "hand-over" from relief to development.

Ultimately, durable solutions depend on more structural and wide-ranging processes such as peace processes and rehabilitation and development programmes, which do not necessarily focus on IDPs. Determining how to engage in these processes often poses a dilemma for protection and humanitarian actors. In most cases, these processes have a higher political priority, more resources for investment, and, in the long term, more potential for impact than IDP-targeted interventions with limited resources. At the same time, their capacity to target the specific needs of IDPs may be limited, and integrating an adequate rights focus into them may require important investment in time and resources. However, it is essential that the particular needs of IDPs and the main obstacles to achieving durable solutions are duly mainstreamed in these processes. The adoption of an early recovery approach and the early involvement of development actors in efforts to assist and protect IDPs are important factors to achieve this end. At the same time, protection and humanitarian actors need to develop the necessary skills and advocacy capacities to analyse the potential impact of these processes on durable solutions and constructively advocate for the inclusion of IDP concerns in them.

\section{- Development plans and processes}

Displacement-specific development interventions may be needed in some situations, particularly when the proportion of IDPs is high among the overall population and when their needs are both distinct and more acute. Another important consideration to take into account is the impact of a displacement-specific strategy in the relationship between IDPs and the host community and, when applicable, in reconciliation processes. For example, a housing and income-generation project for IDPs that also benefits the most vulnerable among the host community will be more needs-based and will also contribute to social harmony.

In some cases, particularly when IDPs return or are integrated in poverty-stricken areas (such as conflict-affected rural areas, or urban slums), area-based development programmes will be necessary. It is important that they nevertheless take into account the specific situation of IDPs. For instance, demand-based and participatory local development projects need to take into account the particular organizational structures that IDPs may have developed and may even contribute to reinforce them; a high concentration of IDPs may be considered one of the criteria to select target areas; social housing programmes may need to establish simpler access requirements for IDPs who have lost their personal documentation.

In any case, and irrespective of whether or not IDP-specific programmes or area-based programmes are established, the specific needs, rights and desires of IDPs need to be mainstreamed in recovery and development needs assessments, projects and strategies, such as the United Nations / World Bank Post Disaster Needs Assessment (PDNA) and Post Conflict Needs Assessment (PCNA), Common Country Assessments and UNDAF. At the 
same time, humanitarian and development actors should advocate for, and assist authorities in, integrating IDP needs into local, regional and national development plans and programmes.

\section{- Human rights}

Given the centrality of restoring national protection for the achievement of durable solutions, human rights, protection and development agencies have a particular responsibility to assist and advocate with governments for the protection of the human rights of IDPs. Central to this objective is the mainstreaming of issues of IDP rights into human rights programmes and structures in central governments or autonomous State bodies, such as National Human Rights Commissions. These can be assisted, for instance, in developing particular IDP strategies and in their monitoring outreach to IDPs. The same is valid for national human rights NGOs. In general, international protection and human rights actors must design their monitoring, advocacy and intervention activities in such a way as to avoid duplicating or undermining efforts by legitimate national actors. For example, international actors may want to assist a National Human Rights Commission in establishing their own monitoring systems for IDPs targeting, for instance, particular return, local integration or other settlement areas.

In many contexts and with time, the human rights situation of IDPs becomes difficult to distinguish from that of the local populations. In these situations, the "displacement lens" needs to be progressively replaced by a broader human rights perspective, as required solutions lie in legislative and social reforms, adequate access to services and welfare systems, enactment of pro-poor policies, respect for civil and political rights and the realization of economic and social rights of poor populations more generally.

Particular attention must be paid to post-conflict situations and situations where displacement was a result of, or was closely linked to, serious violations of rights. In these cases, State responses to issues such as the right to a remedy and reparations and transitional justice may have a key impact on durable solutions. Protection and human rights actors should actively advocate for, and assist governments in, adequately integrating IDP issues into these processes. Before engaging in advocacy or programming, however, it is essential that international actors calibrate very carefully the likely outcomes of these processes, the political will and good faith behind them, and the desires and plans of IDPs themselves.

\section{- Peace processes and peacebuilding}

When a close relationship exists between conflict and displacement, peace processes may be necessary to overcome obstacles to durable solutions, particularly but not exclusively as regards return. Protection actors need to advocate with, and assist mediator and main negotiating parties to ensure that, peace agreements help advance durable solutions, by effectively addressing safety and security; housing, land and property issues; reconciliation and peacebuilding; post-conflict reconstruction and development; and remedies for violations suffered by IDPs. IDPs should be actively involved in the negotiation of peace, through consultation or direct or indirect participation. Peace agreements should use clear and consistent definitions pertaining to internal displacement, reflect the needs and legitimate interests of IDPs, specify the roles and obligations of relevant actors with regard to IDPs, and ensure the participation of IDPs, as appropriate, in their implementation and monitoring.

There is also a direct relationship between durable solutions for IDPs and peacebuilding. Community reconciliation and confidence-building mechanisms will be key to the sustainability of solutions, particularly in situations where return, local integration or settlement elsewhere puts in contact communities that remain perceived to be linked to different parties in the conflict. At the same time, effective judicial or non-judicial conflict resolution mechanisms, such as for land and property issues, and non-discriminatory and needs-based humanitarian and development interventions are essential to reduce the potential for social conflict among IDPs and host communities when there is competition over scarce resources. 


\section{Protracted internal displacement}

Despite the increased international and national attention to situations of internal displacement over the last decade, millions of IDPs live in situations of protracted displacement. Some of the top countries affected by protracted internal displacement include Colombia, Somalia and Turkey.

\section{Internal displacement is protracted when:}

- the process for finding durable solutions is stalled; and/or

- IDPs are marginalized as a consequence of violations or a lack of protection of human rights.

IDPs who are able to benefit from a durable solution usually do so on their own. Some of those who remain displaced in protracted situations tend to be vulnerable, poor, unemployed, without assets and living in inadequate temporary shelter with little to no support.

\section{Particular protection concerns}

IDPs in protracted situations may face particular protection needs, some of which are indicated below.

\section{Lack of permanent housing}

Temporary housing may initially be sufficient but is likely to become dilapidated over time as there is usually little incentive for IDPs to maintain it.

\section{- Lack of a stable income}

IDPs may not be able to practice their livelihood in their area of displacement and have to compete for scarce resources from a marginalized position.

\section{- Problems restoring documents}

IDPs may have trouble obtaining documents because of burned or moved archives and time-consuming alternative procedures. The lack of documents prevents IDPs from receiving social benefits or conducting legal transactions.

\section{- Inability to exercise property rights}

Absent or ineffective property restitution or compensation mechanisms leave IDPs without the means to improve their lives. Mechanisms may not benefit all of the dispossessed, thereby increasing the vulnerability of some IDPs. In customary systems, occupants and users of land left behind by IDPs may be prioritized.

\section{- Discrimination}

IDPs may be viewed as outsiders even years after arrival in their area of displacement and may experience greater difficulty accessing employment, services and benefits than non-displaced local residents who have established social networks. Xenophobia may also rise over time when IDPs flee to areas where they are a minority.

\section{Limitations on the free choice of durable solution}

A focus on return as the only durable solution may dissuade IDPs from investing in their current situation or lead to premature and unsustainable return. It may also limit IDPs' access to adequate housing and livelihoods. 


\subsection{Coordination and planning mechanisms for durable solutions}

In some contexts it will be advisable to establish specific coordination structures for durable solutions processes. This may be particularly relevant when durable solutions efforts are concentrated in particular moments in time or specific geographical regions when, for instance, a peace agreement unblocks possibilities for return and reintegration or when there is extensive planning for settlement in other parts of the country. In other cases, durable solutions need to be planned and managed from existing IDP coordination structures. When national authorities have not established them, or when institutional responsibilities are unclear, advocacy and capacity-building efforts to establish national coordination structures are an integral part of efforts towards durable solutions. National authorities may want to allocate coordination and implementation responsibilities for IDPs under one single institution, such as one ministry or one department under the Executive. In other models general policy, planning and coordination is centralized, while line ministries, other government bodies and the territorial administration assume responsibility for sectoral and local planning, coordination and implementation. Both models have advantages and disadvantages, and a number of mixed solutions are possible. It is, however, essential that one national institution bears clear responsibility for general policy, planning and coordination, that national and local coordination mechanisms exist, and that national mechanisms are developed for the continuous monitoring of the achievement of durable solutions by the IDPs.

International humanitarian, protection, human rights and development actors must ensure that a clear allocation of responsibilities and coordination structures for durable solutions for IDPs persists even after an eventual dismantling of humanitarian coordination structures. Coordination structures for international actors need to relate as far as possible to national coordination structures, avoiding unnecessary bureaucracy, duplications and overlap. At the same time, even when durable solutions are well underway, delicate protection and human rights issues may persist that warrant independent coordination mechanisms for protection actors.

In terms of legal, policy and planning instruments by national authorities, different approaches are possible. The adoption of specific national legislation on IDPs may be an important step towards durable solutions. However, before embarking on advocacy or technical advice to draft and enact specific IDP legislation international agencies need to establish the extent to which the current legal framework already responds to IDP rights or its potential to mainstream these rights by processes of legislative revision. In any case, legislative reform must not create discrimination towards the wider affected population.

On the policy level, it is generally advisable that a national government establishes IDP strategies that articulate the general policy, managerial, programmatic and budgetary choices and mechanisms for the protection, assistance and durable solutions for IDPs, including all relevant sectors. Advocacy and advice to establish such strategies are centrepieces of efforts towards durable solutions by protection agencies.

\section{The Framework for Durable Solutions and its operationalization}

Some of the difficulties faced by international actors engaging in the identification and implementation of durable solutions are conceptual: there has historically been little clarity as to the definition and criteria for durable solutions and how concretely to achieve them. A Framework for Durable Solutions for Internally Displaced Persons, originally developed in 2007 and subsequently revised in 2009 , seeks to provide clear answers to these questions. The Framework purports to foster a better understanding of the concept of durable solutions, to provide general guidance on the process through which a solution needs to be pursued and 
the criteria marking its achievement, and to assist in determining to what extent a durable solution has been achieved. It primarily targets international, local inter-governmental and non-governmental actors. However, the Framework may also provide useful guidance to governments and the IDPs themselves.

This Chapter draws heavily on the Framework, and its definition and criteria for durable solutions as well as the principles on which they must be based have been mentioned above. In the matrix below, the criteria and the elements of process contained in the Framework are used in order to frame the suggested activities for humanitarian and development actors to support and foster durable solutions efforts.

\section{Benchmarks relating to process \\ Suggested actions to support these processes towards durable solutions}

Voluntary and informed choice of a location for a durable solution

National and local authorities, humanitarian and development actors need to provide IDPs with all information they require to choose a durable solution, while also ensuring that IDPs can exercise this choice without coercion.
- Always advocate for the maximum number of options for durable solutions to be made available to IDPs, not simply the choice to return.

- Ensure that IDPs have access to objective, accurate information on the prevailing conditions in areas of potential return or settlement and that this information reaches all members of the IDP community, including those with no formal role in the power structures of the community, such as women, youth, older persons and children, as well as IDPs in different locations, including camps and non-camp settlements, rural and urban areas.

Employ a variety of methods to disseminate information through mass-information campaigns, such as through radio and TV broadcasting, pamphlets, posters, and street drama. Be sure that this information is in a language and format that all IDPs, even illiterate persons, can understand (further addressed in Part V.7 Da).

- Monitor information campaigns, whether formal or informal, by national and/or local authorities and even IDP community leaders, and take immediate and decisive measures to counteract inaccurate public statements that are politically manipulative, such as those suggesting that IDPs have no choice of solution or those that could raise false expectations, including expectations pertaining to the conditions in the different locations or on the assistance to be provided. Before taking action, consider the implications of such approaches for the safety of IDPs and staff. Measures to be taken can include:

- interventions with the local authorities or media;

discussions with the community on the prevailing situation in the areas concerned; and

- distributions of pamphlets providing objective information to IDPs in IDP settlements.

- Obtain, in advance, a sense of the attitude and possible concerns of receiving communities. Ensure that IDPs are made aware of the situation and possible concerns of their respective receiving community. Support measures to address these concerns and build confidence among the community and returning or newly arriving IDPs.

- Ensure that decisions are made individually by all adult members of a family and that older persons' and children's views are heard as well. This can be achieved by undertaking surveys for return or relocation, dropping the use of the term "head-of-family" for assistance and opinion surveys, and ensuring that support to families is granted on the basis of consensus. 
- Ensure that IDPs are informed of their right to voluntary and sustainable return, local settlement or settlement in other parts of the country. (See Part V.7. [D)

- Monitor how durable solutions are promoted and implemented by the authorities, local communities, IDP leaders and the media, ensuring there is no coercion or pressure on IDPs. (See Part V.2. $\square$ )

- Advocate assertively and in a timely manner against any cases of potential or actual forced return or settlement. (See Part V.3. $\square$ )

- Advocate and intervene against the suspension of assistance in areas of displacement when it results in putting undue pressure on IDPs to opt for a particular solution against their will. Assistance in this case is not limited to food, but also education and vocational training. (See Part V.5. $\square$ )

- Confirm voluntary return/settlement by ensuring the establishment of a system in which all adult IDPs sign a form attesting that their movement is voluntary prior to receiving transport assistance by national authorities and/or the international community.

- Provide space for individuals or groups to express their views about their chosen solution, particularly for those who do not agree with the view of the majority, including youth who, especially in protracted situations, often prefer to settle locally rather than return, as their parents might want. This is particularly important in highly politicized settings, where the issue of available durable solutions can be manipulated and misrepresented by different interest groups.

- Ensure that individuals who opt for different solutions than the majority in their community are protected and supported in their choices, including by ensuring they have access to accurate information on the support that will be available and by negotiating with local authorities to maintain or establish appropriate support structures until those durable solutions are realized.

\section{Participation of IDPs in the planning and management of durable solutions}

IDPs must be consulted and participate extensively in the planning and management of the processes supporting a durable solution. All parts of the IDP population, including women, children (according to their age and maturity), persons with special needs and persons who are potentially marginalized, must be fully included.
- Ensure that visits to assess conditions for return or settlement elsewhere are organized by the local authorities well in advance to enable IDPs to meet with key stakeholders and members of the communities where they wish to return or settle.

- Advocate with, and provide support to, relevant institutions to ensure that IDP representatives, including persons of different ages, gender or backgrounds who wish to take part in such visits have access to the necessary documentation, means of transport and any other support that might be required for them to undertake such visits. This may involve measures such as daycare for children whose parents wish to take part in the visits and appropriate meeting facilities for persons with disabilities.

Advocate for the inclusion of representatives of receiving communities in the preparations for IDP visits to foster local ownership of the return or settlement and reintegration process.

- Encourage discussions during the visits about identifying possible areas of settlement that meet the minimum conditions of protection and basic services.

- Promote and ensure, to the extent possible, a humanitarian presence during the visits to foster discussions among all parties about what support IDPs and other affected communities might require for their (re)integration. (See Part V.4.

Organize, to the extent feasible, informal exchanges between children from the IDP communities and communities of return or settlement, such as sporting or cultural events, to promote confidence and reconciliation among the communities. 
Local communities that receive IDPs and other affected populations also need to be consulted.

\section{Access to actors supporting durable solutions}

National authorities should grant and facilitate safe, unimpeded and timely access to non-governmental and international humanitarian and development actors assisting IDPs to return, locally integrate or settle elsewhere in the country.
- Ensure participatory planning that includes women, minorities, youth and older persons, and ensure that all of their views, which might vary widely, are considered. (See Part III.5.

- Ensure that IDPs have access to humanitarian organizations and other appropriate actors, such as development agencies. Monitor any impediments they may face in this context. (See Parts V.2 and V.4. $\square$ )

- Ensure that the results of participatory assessments relating to durable solutions are incorporated into national and international planning. (See Part III.1.

- Support a dialogue between authorities (national and local) and IDP representatives to ensure that development plans take into account the views and (re)integration needs of displaced populations.

- Initiate programmes specifically designed to explain the return or settlement process to children, addressing their concerns, fears and expectations, and develop programmes to address these concerns both before and after return or settlement.

- Ensure dialogue with the local communities, including representatives of religious institutions, women's groups and education committees about concrete actions to make the planning and management of return/settlement as collaborative as possible between IDPs and receiving communities. (See Part III.1. DD)

- Promote the transparency and accountability of national authorities and humanitarian organizations, through information sharing and joint evaluations, regarding the programmes and budgetary allocations for durable solutions. (See Part III.4. ED)

- Advocate with national and other relevant authorities for safe, unimpeded and timely access by humanitarian, human rights and development actors, both domestic and international, to areas of IDP return, settlement and reintegration. (See Part V.4. 


\begin{tabular}{|c|c|}
\hline $\begin{array}{l}\text { National and local } \\
\text { authorities, } \\
\text { humanitarian and } \\
\text { development actors } \\
\text { should set up } \\
\text { effective } \\
\text { mechanisms to } \\
\text { monitor the process } \\
\text { of supporting durable } \\
\text { solutions and } \\
\text { determining what } \\
\text { remains to be done } \\
\text { to achieve a durable }\end{array}$ & $\begin{array}{l}\text { - Study the extent to which information relevant to the assessment of } \\
\text { durable solutions may be available through existing information systems, } \\
\text { such as human rights monitoring mechanisms covering areas where } \\
\text { IDPs are returning or settling in other areas. } \\
\text { - Mainstream the monitoring of durable solutions into such mechanisms } \\
\text { by, for instance, integrating the benchmarks and criteria described in the } \\
\text { Framework for Durable Solutions. } \\
\text { alternatively, create new monitoring mechanisms, using the benchmarks } \\
\text { and criteria developed by the Framework for Durable Solutions. }\end{array}$ \\
\hline $\begin{array}{l}\text { Peace processes } \\
\text { and peacebuilding } \\
\text { involve IDPs and } \\
\text { reinforce durable } \\
\text { solutions } \\
\text { Where relevant, } \\
\text { IDPs should } \\
\text { participate in peace } \\
\text { processes. Their } \\
\text { rights, needs and } \\
\text { legitimate interests } \\
\text { need to be } \\
\text { addressed in peace } \\
\text { agreements and } \\
\text { peacebuilding } \\
\text { strategies emerging } \\
\text { from these } \\
\text { processes, which } \\
\text { often predetermine } \\
\text { whether and how } \\
\text { durable solutions will } \\
\text { be ensured. }\end{array}$ & $\begin{array}{l}\text { Advocate for measures to address the root causes of displacement, } \\
\text { including the resolution of conflict. Where feasible, encourage actors } \\
\text { with expertise in conflict resolution to promote dialogue between the } \\
\text { different parties. } \\
\text { Support the incorporation of the issue of solutions to displacement in } \\
\text { peace negotiations and other political agreements. } \\
\text { Support the establishment of national reconciliation initiatives, making } \\
\text { sure there is national ownership to the process and that it involves all } \\
\text { relevant stakeholders. } \\
\text { In consultation with IDPs and the local community, support the design } \\
\text { and implementation of programmes and activities that promote dialogue, } \\
\text { peaceful coexistence and common goals among returning/settling IDPs } \\
\text { and receiving communities. } \\
\text { Enhance the capacity of local authorities to prevent and resolve } \\
\text { inter-communal conflicts through peaceful means, such as arbitration or } \\
\text { mediation, when receiving communities are opposed to the return or } \\
\text { settlement of IDPs. } \\
\text { Identify possibilities for immediate and medium-term multi-sectoral } \\
\text { recovery and rehabilitation projects in previously damaged or politically } \\
\text { marginalized areas where forced displacement has taken place and in } \\
\text { return-impacted areas. } \\
\text { Ensure that there are effective demobilization and reintegration } \\
\text { programmes for former combatants, and work with receiving } \\
\text { communities, including IDPs, to avoid any stigmatization or exclusion. } \\
\text { When necessary, ensure that children formerly associated with armed } \\
\text { groups are given support for reintegration. }\end{array}$ \\
\hline
\end{tabular}




\begin{tabular}{|c|c|}
\hline $\begin{array}{l}\text { Criteria to } \\
\text { determine the } \\
\text { achievement of } \\
\text { durable solutions }\end{array}$ & Suggested actions to achieve progress in meeting the criteria \\
\hline $\begin{array}{l}\text { Long-term safety } \\
\text { and security } \\
\text { IDPs who have } \\
\text { achieved a durable } \\
\text { solution enjoy } \\
\text { physical safety and } \\
\text { security on the basis } \\
\text { of effective } \\
\text { protection by } \\
\text { national and local } \\
\text { authorities. This } \\
\text { includes protection } \\
\text { from those threats } \\
\text { which caused the } \\
\text { initial displacement } \\
\text { or may cause } \\
\text { renewed } \\
\text { displacement. The } \\
\text { protection of IDPs } \\
\text { who have achieved a } \\
\text { durable solution } \\
\text { must not be less } \\
\text { effective than the } \\
\text { protection provided } \\
\text { to populations or } \\
\text { areas of the country } \\
\text { that are not affected } \\
\text { by displacement. }\end{array}$ & $\begin{array}{l}\text { In advance of return/settlement, support demining efforts by ensuring } \\
\text { that mine surveys and demining activities are implemented, particularly } \\
\text { along main roads, areas to be used by children on their way to and from } \\
\text { school, and by women in their search for firewood, water or livelihood, } \\
\text { and that mine-awareness programmes are offered to returning/settling } \\
\text { IDPs. (See Part IV.3. } \\
\text { Monitor and accompany the return or settlement of IDPs, when safe to do } \\
\text { so, to ensure the movement is voluntary and that it occurs in safety and with } \\
\text { dignity. Where this is not the case, report the facts to the authorities and, if } \\
\text { unresolved, to the international community. (See Part V.2 and } 4 \text {. } \square \text { ) } \\
\text { Ensure that the authorities have established effective law and order } \\
\text { mechanisms in places of IDP return/settlement to prevent and respond } \\
\text { rapidly to any incidents of violence or unrest. When required, support } \\
\text { training for relevant authorities, including police and military, to manage } \\
\text { such incidents in non-violent ways. (See Part IV.2. } \square \text { ) } \\
\text { In collaboration with relevant international and national actors: } \\
\text { encourage efforts to strengthen the rule of law in areas of IDP } \\
\text { return/settlement; enhance the capacity of legal and judicial institutions } \\
\text { through technical and material support; and train local police and } \\
\text { municipal authorities on freedom of movement and choice of residence } \\
\text { as well as on the implications of the principle of non-discrimination. }\end{array}$ \\
\hline
\end{tabular}




\begin{tabular}{|c|c|}
\hline $\begin{array}{l}\text { Enjoyment of an } \\
\text { adequate standard } \\
\text { of living } \\
\text { without } \\
\text { discrimination } \\
\text { IDPs who have } \\
\text { achieved a durable } \\
\text { solution enjoy } \\
\text { without } \\
\text { discrimination an } \\
\text { adequate standard } \\
\text { of living, including at } \\
\text { a minimum shelter, } \\
\text { health care, food, } \\
\text { water and other } \\
\text { means of survival. }\end{array}$ & 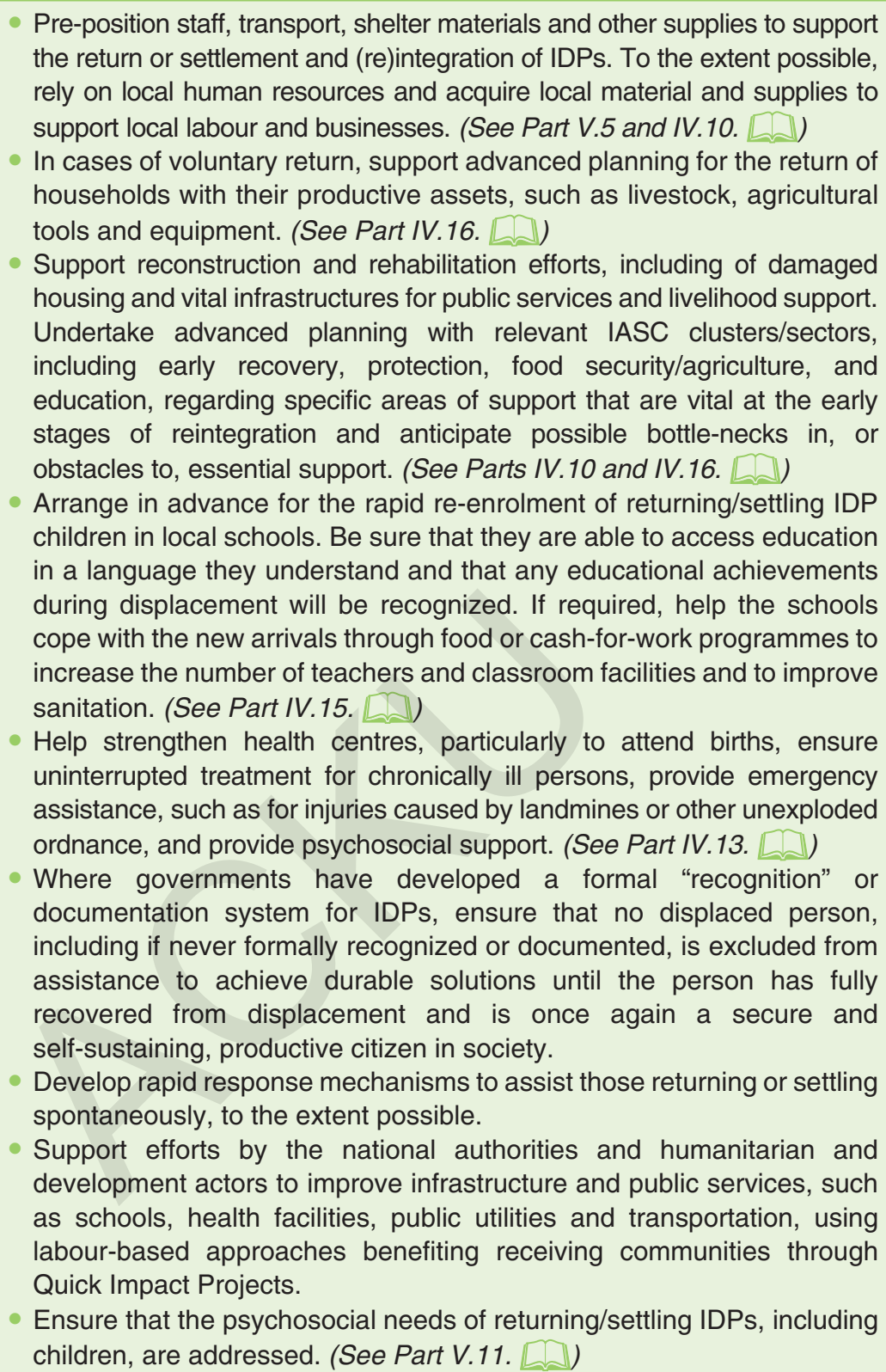 \\
\hline
\end{tabular}




\section{Access to livelihoods and employment}

IDPs who found a durable solution also have access to employment and livelihoods.

Employment and livelihoods available to IDPs must allow them to fulfil at least their core socio-economic needs, in particular where these are not guaranteed by public welfare programmes.
- Advocate for the incorporation of support to IDP reintegration and to areas of return/settlement in development plans (CCA/UNDAF, Poverty Reduction Strategy Papers, national development plans).

- Stress the importance of prioritizing interventions aimed at achieving self-reliance, not only of IDPs but within the local community, including the most vulnerable, and advocate for development assistance for vocational and skills training, and technical assistance to develop small businesses, micro-finance schemes, etc. (See Part IV.16. [D)

- Promote the use of gender-sensitive, local labour-based methods to develop infrastructure so that cash is brought into the local community. (See Part V.5.

- Ensure that emergency assistance continues to be delivered at the same time as plans for development go forward. (See Part V.5. [D)

- Create a clear strategy and funding mechanisms for transitional programming.

Support national institutions to identify specific needs within the returning or relocating population well in advance of the respective movements in order to develop targeted reintegration programmes in a timely manner.

- Advocate with development actors to establish sustainable support mechanisms for persons with specific needs, such as female-headed households, youth, older persons, persons with disabilities and minorities, with the aim of improving their immediate well-being and promoting self-reliance.

- Encourage development actors to enhance the capacity of all relevant central, regional and local authorities to carry out their long-term responsibility to support the (re)integration of IDPs.

- Promote communication among different countries that have undergone similar IDP return / settlement processes to exchange lessons learned and best practices.

- Offer assistance, technical and material, to the authorities in planning, managing and implementing IDP return/settlement and reintegration, including in undertaking joint needs assessments. (See Parts V.5, V.9 and III.4.

- Support the assessment of possible institutional options to manage IDP returns, relocations and reintegration regimes (dedicated ministry or department within existing ministry), and promote the creation of an inter-ministerial / departmental taskforce for reintegration.

- Indicate to the authorities to what extent and in what specific areas international assistance could be available to support IDP return/settlement and reintegration. (See Part V.5. $\mathrm{DD}$ ) 


Effective and
accessible
mechanisms to
restore housing,
land and property
IDPs who have
achieved a durable
solution have access
to effective
mechanisms for
timely restitution of
their housing, land
and property,
regardless of
whether they return
or opt to locally
integrate or settle
elsewhere in the
country.

- Ensure the protection of IDPs' right to claim restitution of their land or property in areas of return or compensation for its loss if restitution is not possible. Information on this right should be provided to all IDPs, concerned communities and the authorities through legal advice activities or public information programmes. (See Part V.8. $\square$ )

- Support national authorities in developing and implementing mechanisms for restitution of, or compensation for, land and property. Ensure that national authorities deal with property disputes in a neutral, fair manner that also takes into account the needs and rights of the secondary occupiers. The utilization of local conflict resolution techniques to address such circumstances has proven to be effective in such situations. (See Part IV.17. DD)

- Monitor the access that IDPs and other affected communities have to justice and national/local protection mechanisms. Provide support and guidance on how to access these mechanisms, including through national human rights institutions. (See Part IV.18. DD)
Access to personal and other documentation without discrimination

IDPs who have achieved a durable solution have access to personal and other documentation necessary to access public services, reclaim property and possessions, vote or pursue other purposes linked to durable solutions.
Support the restoration of local civil registries and other registries that relate to IDPs' civil and legal status as well as their titles to land and other property, if they are damaged or destroyed. Doing so is critical to facilitate potential reintegration, family reunification, access to public services, and recovery of or compensation for land, housing and property. It will also contribute to the resolution of cases of statelessness. (See Part IV.9.

Advocate for the lifting of administrative requirements to obtain documentation or for their adaptation to the particular situation of IDPs.

- In coordination with relevant authorities, organize documentation campaigns for IDPs, taking into account the needs of other vulnerable and affected populations.

\section{Family reunification}

IDPs who wish to reunite with family members from whom they were separated have been able to do so and can seek a durable solution together.
Promote and support efforts to maintain family unity and to ensure family reunification throughout and after the return or relocation movements, while respecting the personal choice of adults who do not wish to remain or to reunite with their partners. (See Part IV.7. $\square$ ) 


\begin{tabular}{|c|c|}
\hline $\begin{array}{l}\text { Participation in } \\
\text { public affairs } \\
\text { without } \\
\text { discrimination } \\
\text { IDPs who have } \\
\text { achieved a durable } \\
\text { solution are able to } \\
\text { exercise the right to } \\
\text { participate in public } \\
\text { affairs at all levels on } \\
\text { the same basis as } \\
\text { the resident } \\
\text { population and } \\
\text { without } \\
\text { discrimination owing } \\
\text { to their } \\
\text { displacement. }\end{array}$ & $\begin{array}{l}\text { Promote the inclusion of IDPs in local governance structures. Ensure } \\
\text { that IDPs can exercise their right to political participation in areas of } \\
\text { return/settlement. } \\
\text { Support needs for strengthening civil society organizations as well as } \\
\text { IDP and other affected communities in key areas of displacement and } \\
\text { return. (See Part V.10. } \\
\text { Advocate for the inclusion of IDPs, respecting their particular organizational } \\
\text { structures, in demand-based and participatory development schemes. }\end{array}$ \\
\hline $\begin{array}{l}\text { Access to effective } \\
\text { remedies and } \\
\text { justice } \\
\text { IDPs who have been } \\
\text { victim of violations of } \\
\text { international human } \\
\text { rights or } \\
\text { humanitarian law, } \\
\text { including arbitrary } \\
\text { displacement, must } \\
\text { have full and } \\
\text { non-discriminatory } \\
\text { access to effective } \\
\text { remedies and } \\
\text { access to justice, } \\
\text { including, where } \\
\text { appropriate, access } \\
\text { to existing } \\
\text { transitional justice } \\
\text { mechanisms, } \\
\text { reparations and } \\
\text { information on the } \\
\text { causes of violations. }\end{array}$ & $\begin{array}{l}\text { Advocate, when applicable, for the full consideration of IDPs as victims } \\
\text { and for their inclusion, as appropriate, in existing remedies and } \\
\text { mechanisms for reparations. } \\
\text { Assist governments in adapting existing remedies and mechanisms for } \\
\text { reparations to the specific needs and particular situation of IDPs. } \\
\text { When justified by the particular situation of IDPs, assist governments in } \\
\text { setting up specific remedies for IDPs having suffered violations of } \\
\text { international human rights or humanitarian law, including arbitrary } \\
\text { displacement. } \\
\text { Work with governments to establish reparation measures for IDPs } \\
\text { including, as appropriate, truth commissions, access to justice, } \\
\text { compensation and satisfaction mechanisms, etc. }\end{array}$ \\
\hline
\end{tabular}


Handbook for the Protection of Internally Displaced Persons

Key references \& useful websites

- Framework on Durable Solutions for Internally Displaced Persons, IASC, 2010.

- Guiding Principles on Internal Displacement, UNHCR, 1998.

- Implementing the Collaborative Response to Situations of Internal Displacement: Guidance for United Nations Humanitarian and/or Resident Coordinators and Country Teams, pp. 35-63, IASC, 2004.

- Guidance Note on Durable Solutions for Displaced Persons (Refugees, Internally Displaced Persons, and Returnees), UNDG Programme Group, October 2004.

- UN Transitional Strategy Guidance Note, March 2007.

- IASC Early Recovery Cluster's note of guidance on Early Recovery.

- Protection of conflict induced IDPs - Assessment for Action, February 2008.

- United Nations General Assembly Resolution 60/180, the Peace-building Commission, December 2005.

468 


\section{Annex $1^{3}$}

\section{Iraq reconstruction needs assessment: Checklist for reintegration}

\section{Populations and target groups}

Rapid development of demographic (age, gender, place of origin, ethnicity, etc.) and socio-economic profiles (professions, trades, skills, education, assets, etc.) of prospective returnee populations in neighbouring asylum countries, within Iraq and outside the region.

$\checkmark$ Articulation of reintegration profiles of the returning population of working age (urban, rural, professional, skilled, semi-skilled, unskilled, women, men and youth).

$\checkmark$ Identification of particular vulnerabilities and disabilities within the returning population that may hinder reintegration.

\section{Probable return and reintegration dynamics}

$\checkmark$ Formulation of probable scenarios for, and quantification of, return movements of refugees and IDPs (both spontaneous and assisted) to the northern, central and southern regions for the next six, 12 and 36 months.

$\checkmark$ Identification and profiling of populations considered most likely to move rapidly and spontaneously, and anticipation of seasonal surges (pre- and post-winter).

$\checkmark$ Broad assessment of the absorption capacity in main anticipated areas of return and key challenges for immediate, short- and medium-term reintegration requirements in essential sectors (shelter, water, sanitation, food assistance, employment, health, education, winterization, etc).

\section{Institutional and capacity development}

$\checkmark$ Overall assessment of existing national, governorate, and local institutions, resources and capabilities to manage the refugee and IDP return and reintegration process.

$\checkmark$ Examination of possible institutional options to manage a refugee/IDP return and reintegration regime (dedicated ministry or department, lodging within existing ministry, e.g. ministry of the interior) and creation of an inter-ministerial/departmental task force for reintegration.

Assessment of policy formulation capabilities and analytical skills, and knowledge of refugee and displaced persons and of refugee and international humanitarian law within the existing public administration (central, governorate and local levels) and civil society.

Identification of capacity development, infrastructure/hardware requirements and training needs at institutional, systemic and individual levels within existing and possibly new public institutions for immediate return processing (documentation, permits, licenses, registration, etc.) and reintegration (protection, legal issues, mass information, communications and monitoring).

Evaluation of public management capabilities for designing, implementing and monitoring large relief, urgent rehabilitation and recovery programmes for returning displaced populations and assessment of short-term technical and materialassistance needs.

${ }^{3}$ Annex 3, UNDG Guidance Note on Durable Solutions for Displaced Persons (Refugees, Internally Displaced Persons, and Returnees). 


\section{Reintegration programming}

Sectoral and thematic

Assessment of key sectoral needs (shelter, water, sanitation, food assistance and security, employment, health, education, winterization, etc.) at the local level in identified areas of high return over the next 6,12 and 36 months.

Assessment of capacities and needs (technical, financial and human) to manage and address key protection issues (physical security and welfare, including threats from mines and unexploded ordnance, legal mechanisms and resources to recover land and property, family tracing and reunion, sensitive political affiliations, confessional and ethnic sensitivities, vulnerabilities and disabilities).

$\checkmark$ Assessment of local economic, environmental and natural resource situations and additional needs in key return locations [urban and rural labour markets, state of local infrastructure (productive, marketing, energy, communications, sanitation and social), state of social services (health, education and welfare)].

$\checkmark$ Assessment of development needs for strengthening civil society organizations and social capital at the community level in key areas of displacement and return.

Intervention strategy and programme design

Assessment of policy options for designing dedicated interventions for return- and displacement-affected areas and for mainstreaming return and reintegration concerns into national programmes.

$\checkmark$ Assessment of possibilities for a public investment programme to create new or improve existing productive asset base (economic and social infrastructure) to build livelihood possibilities and social protection in return-impacted areas (north, centre and south) for returning refugees, IDPs and local populations.

Assessment of possibilities for launching community-driven development programmes enhancing reintegration prospects through local governance and management of small-scale, community-level micro-projects in areas of high return.

Identification of possibilities for immediate and medium-term multi-sectoral recovery and rehabilitation projects in previously damaged or politically marginalized areas where forced displacement has taken place.

Assessment of labour-intensive emergency employment programmes, including affirmative action, targeting policies to include returning refugees, IDPs and return-impacted areas.

$\checkmark$ Assessment of the establishment of micro-finance institutions, savings and credit lines to support micro, family, and small enterprises in return areas.

$\checkmark$ Assessment of the need for public safety nets, subsidies and food distribution among vulnerable returning and host community populations over the coming 6, 12 and 36 months.

$\checkmark$ Assessment of needs to support an accessible justice programme (infrastructure, running costs for personnel and training) giving returnees and IDPs affordable access to legal advice centres for assistance with land and property recovery, civil problems, etc.

$\checkmark$ Assessment of the public investment programmes for vocational and employment training and skills-development programmes for youth populations among returning refugee and IDPs. 



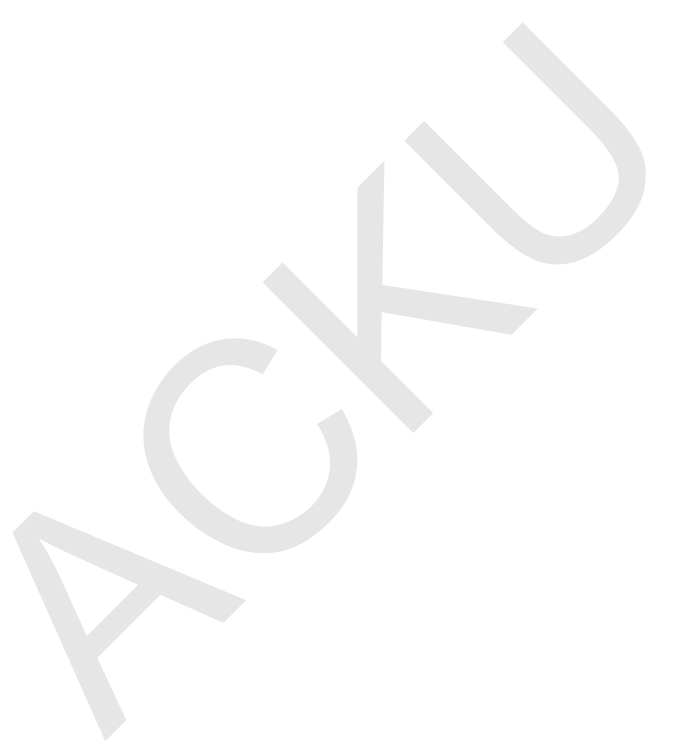




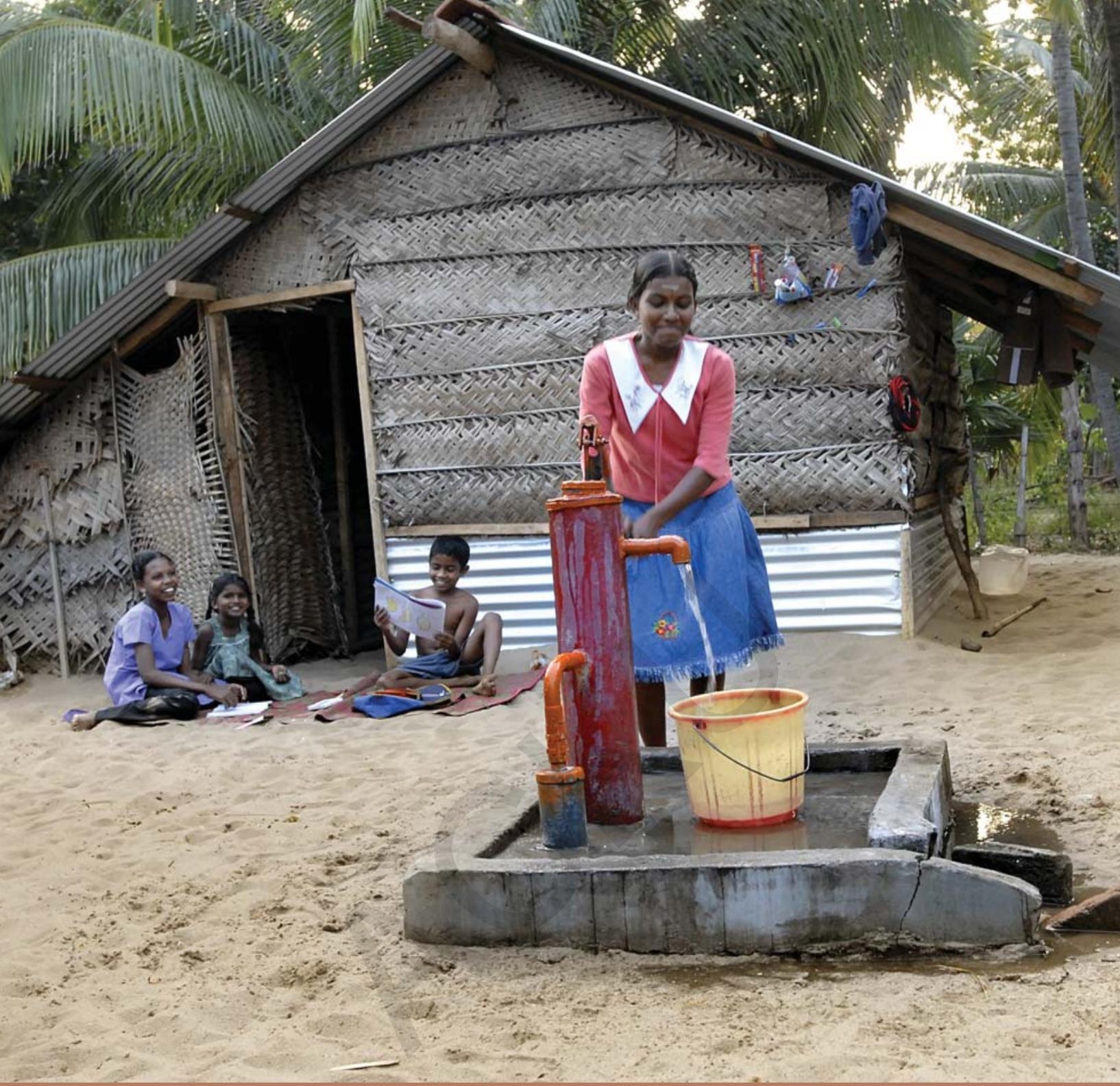

\section{ANNEXES}




\title{
Annex 1 \\ Guiding Principles on Internal Displacement
}

\author{
(U.N. Doc. E/CN.4/1998/53/Add2(1998))
}

Available in 40+ languages at www.brookings.edu/projects/idp/gp_page.aspx

\section{Introduction - Scope and Purpose}

1. These Guiding Principles address the specific needs of internally displaced persons worldwide. They identify rights and guarantees relevant to the protection of persons from forced displacement and to their protection and assistance during displacement as well as during return or resettlement and reintegration.

2. For the purposes of these Principles, internally displaced persons are persons or groups of persons who have been forced or obliged to flee or to leave their homes or places of habitual residence, in particular as a result of or in order to avoid the effects of armed conflict, situations of generalized violence, violations of human rights or natural or human-made disasters, and who have not crossed an internationally recognized State border.

3. These Principles reflect and are consistent with international human rights law and international humanitarian law. They provide guidance to:

(a) The Representative of the Secretary-General on internally displaced persons in carrying out his mandate;

(b) States when faced with the phenomenon of internal displacement;

(c) All other authorities, groups and persons in their relations with internally displaced persons; and

(d) Intergovernmental and non-governmental organizations when addressing internal displacement.

4. These Guiding Principles should be disseminated and applied as widely as possible.

\section{Section I. General Principles}

\section{Principle 1}

1. Internally displaced persons shall enjoy, in full equality, the same rights and freedoms under international and domestic law as do other persons in their country. They shall not be discriminated against in the enjoyment of any rights and freedoms on the ground that they are internally displaced.

2. These Principles are without prejudice to individual criminal responsibility under international law, in particular relating to genocide, crimes against humanity and war crimes.

\section{Principle 2}

1. These Principles shall be observed by all authorities, groups and persons irrespective of their legal status and applied without any adverse distinction. The observance of these Principles shall not affect the legal status of any authorities, groups or persons involved. 
2. These Principles shall not be interpreted as restricting, modifying or impairing the provisions of any international human rights or international humanitarian law instrument or rights granted to persons under domestic law. In particular, these Principles are without prejudice to the right to seek and enjoy asylum in other countries.

\section{Principle 3}

1. National authorities have the primary duty and responsibility to provide protection and humanitarian assistance to internally displaced persons within their jurisdiction.

2. Internally displaced persons have the right to request and to receive protection and humanitarian assistance from these authorities. They shall not be persecuted or punished for making such a request.

\section{Principle 4}

1. These Principles shall be applied without discrimination of any kind, such as race, colour, sex, language, religion or belief, political or other opinion, national, ethnic or social origin, legal or social status, age, disability, property, birth, or on any other similar criteria.

2. Certain internally displaced persons, such as children, especially unaccompanied minors, expectant mothers, mothers with young children, female heads of household, persons with disabilities and elderly persons, shall be entitled to protection and assistance required by their condition and to treatment which takes into account their special needs.

\section{Section II. Principles Relating to Protection From Displacement}

\section{Principle 5}

All authorities and international actors shall respect and ensure respect for their obligations under international law, including human rights and humanitarian law, in all circumstances, so as to prevent and avoid conditions that might lead to displacement of persons.

\section{Principle 6}

1. Every human being shall have the right to be protected against being arbitrarily displaced from his or her home or place of habitual residence.

2. The prohibition of arbitrary displacement includes displacement:

(a) When it is based on policies of apartheid, "ethnic cleansing" or similar practices aimed at/or resulting in altering the ethnic, religious or racial composition of the affected population;

(b) In situations of armed conflict, unless the security of the civilians involved or imperative military reasons so demand;

(c) In cases of large-scale development projects, which are not justified by compelling and overriding public interests;

(d) In cases of disasters, unless the safety and health of those affected requires their evacuation; and

(e) When it is used as a collective punishment.

3. Displacement shall last no longer than required by the circumstances. 


\section{Principle 7}

1. Prior to any decision requiring the displacement of persons, the authorities concerned shall ensure that all feasible alternatives are explored in order to avoid displacement altogether. Where no alternatives exist, all measures shall be taken to minimize displacement and its adverse effects.

2. The authorities undertaking such displacement shall ensure, to the greatest practicable extent, that proper accommodation is provided to the displaced persons, that such displacements are effected in satisfactory conditions of safety, nutrition, health and hygiene, and that members of the same family are not separated.

3. If displacement occurs in situations other than during the emergency stages of armed conflicts and disasters, the following guarantees shall be complied with:

(a) A specific decision shall be taken by a State authority empowered by law to order such measures;

(b) Adequate measures shall be taken to guarantee to those to be displaced full information on the reasons and procedures for their displacement and, where applicable, on compensation and relocation;

(c) The free and informed consent of those to be displaced shall be sought;

(d) The authorities concerned shall endeavour to involve those affected, particularly women, in the planning and management of their relocation;

(e) Law enforcement measures, where required, shall be carried out by competent legal authorities; and

(f) The right to an effective remedy, including the review of such decisions by appropriate judicial authorities, shall be respected.

\section{Principle 8}

Displacement shall not be carried out in a manner that violates the rights to life, dignity, liberty and security of those affected.

\section{Principle 9}

States are under a particular obligation to protect against the displacement of indigenous peoples, minorities, peasants, pastoralists and other groups with a special dependency on and attachment to their lands.

\section{Section III. Principles Relating to Protection During Displacement}

\section{Principle 10}

1. Every human being has the inherent right to life which shall be protected by law. No one shall be arbitrarily deprived of his or her life. Internally displaced persons shall be protected in particular against:

(a) Genocide;

(b) Murder;

(c) Summary or arbitrary executions; and

(d) Enforced disappearances, including abduction or unacknowledged detention, threatening or resulting in death.

Threats and incitement to commit any of the foregoing acts shall be prohibited. 
2. Attacks or other acts of violence against internally displaced persons who do not or no longer participate in hostilities are prohibited in all circumstances. Internally displaced persons shall be protected, in particular, against:

(a) Direct or indiscriminate attacks or other acts of violence, including the creation of areas wherein attacks on civilians are permitted;

(b) Starvation as a method of combat;

(c) Their use to shield military objectives from attack or to shield, favour or impede military operations;

(d) Attacks against their camps or settlements; and

(e) The use of anti-personnel landmines.

\section{Principle 11}

1. Every human being has the right to dignity and physical, mental and moral integrity.

2. Internally displaced persons, whether or not their liberty has been restricted, shall be protected in particular against:

(a) Rape, mutilation, torture, cruel, inhuman or degrading treatment or punishment, and other outrages upon personal dignity, such as acts of gender-specific violence, forced prostitution and any form of indecent assault;

(b) Slavery or any contemporary form of slavery, such as sale into marriage, sexual exploitation, or forced labour of children; and

(c) Acts of violence intended to spread terror among internally displaced persons.

Threats and incitement to commit any of the foregoing acts shall be prohibited.

\section{Principle 12}

1. Every human being has the right to liberty and security of person. No one shall be subjected to arbitrary arrest or detention.

2. To give effect to this right for internally displaced persons, they shall not be interned in or confined to a camp. If in exceptional circumstances such internment or confinement is absolutely necessary, it shall not last longer than required by the circumstances.

3. Internally displaced persons shall be protected from discriminatory arrest and detention as a result of their displacement.

4. In no case shall internally displaced persons be taken hostage.

\section{Principle 13}

1. In no circumstances shall displaced children be recruited nor be required or permitted to take part in hostilities.

2. Internally displaced persons shall be protected against discriminatory practices of recruitment into any armed forces or groups as a result of their displacement. In particular any cruel, inhuman or degrading practices that compel compliance or punish non-compliance with recruitment are prohibited in all circumstances.

\section{Principle 14}

1. Every internally displaced person has the right to liberty of movement and freedom to choose his or her residence. 
2. In particular, internally displaced persons have the right to move freely in and out of camps or other settlements.

\section{Principle 15}

Internally displaced persons have:

(a) The right to seek safety in another part of the country;

(b) The right to leave their country;

(c) The right to seek asylum in another country; and

(d) The right to be protected against forcible return to or resettlement in any place where their life, safety, liberty and/or health would be at risk.

\section{Principle 16}

1. All internally displaced persons have the right to know the fate and whereabouts of missing relatives.

2. The authorities concerned shall endeavour to establish the fate and whereabouts of internally displaced persons reported missing, and cooperate with relevant international organizations engaged in this task. They shall inform the next of kin on the progress of the investigation and notify them of any result.

3. The authorities concerned shall endeavour to collect and identify the mortal remains of those deceased, prevent their despoliation or mutilation, and facilitate the return of those remains to the next of kin or dispose of them respectfully.

4. Grave sites of internally displaced persons should be protected and respected in all circumstances. Internally displaced persons should have the right of access to the grave sites of their deceased relatives.

\section{Principle 17}

1. Every human being has the right to respect of his or her family life.

2. To give effect to this right for internally displaced persons, family members who wish to remain together shall be allowed to do so.

3. Families which are separated by displacement should be reunited as quickly as possible. All appropriate steps shall be taken to expedite the reunion of such families, particularly when children are involved. The responsible authorities shall facilitate inquiries made by family members and encourage and cooperate with the work of humanitarian organizations engaged in the task of family reunification.

4. Members of internally displaced families whose personal liberty has been restricted by internment or confinement in camps shall have the right to remain together.

\section{Principle 18}

1. All internally displaced persons have the right to an adequate standard of living.

2. At the minimum, regardless of the circumstances, and without discrimination, competent authorities shall provide internally displaced persons with and ensure safe access to:

(a) Essential food and potable water;

(b) Basic shelter and housing;

(c) Appropriate clothing; and

(d) Essential medical services and sanitation. 
3. Special efforts should be made to ensure the full participation of women in the planning and distribution of these basic supplies.

\section{Principle 19}

1. All wounded and sick internally displaced persons as well as those with disabilities shall receive to the fullest extent practicable and with the least possible delay, the medical care and attention they require, without distinction on any grounds other than medical ones. When necessary, internally displaced persons shall have access to psychological and social services.

2. Special attention should be paid to the health needs of women, including access to female health care providers and services, such as reproductive health care, as well as appropriate counselling for victims of sexual and other abuses.

3. Special attention should also be given to the prevention of contagious and infectious diseases, including AIDS, among internally displaced persons.

\section{Principle 20}

1. Every human being has the right to recognition everywhere as a person before the law.

2. To give effect to this right for internally displaced persons, the authorities concerned shall issue to them all documents necessary for the enjoyment and exercise of their legal rights, such as passports, personal identification documents, birth certificates and marriage certificates. In particular, the authorities shall facilitate the issuance of new documents or the replacement of documents lost in the course of displacement, without imposing unreasonable conditions, such as requiring the return to one's area of habitual residence in order to obtain these or other required documents.

3. Women and men shall have equal rights to obtain such necessary documents and shall have the right to have such documentation issued in their own names.

\section{Principle 21}

1. No one shall be arbitrarily deprived of property and possessions.

2. The property and possessions of internally displaced persons shall in all circumstances be protected, in particular, against the following acts:

(a) Pillage;

(b) Direct or indiscriminate attacks or other acts of violence;

(c) Being used to shield military operations or objectives;

(d) Being made the object of reprisal; and

(e) Being destroyed or appropriated as a form of collective punishment.

3. Property and possessions left behind by internally displaced persons should be protected against destruction and arbitrary and illegal appropriation, occupation or use.

\section{Principle 22}

1. Internally displaced persons, whether or not they are living in camps, shall not be discriminated against as a result of their displacement in the enjoyment of the following rights:

(a) The rights to freedom of thought, conscience, religion or belief, opinion and expression;

(b) The right to seek freely opportunities for employment and to participate in economic activities;

(c) The right to associate freely and participate equally in community affairs; 
(d) The right to vote and to participate in governmental and public affairs, including the right to have access to the means necessary to exercise this right; and

(e) The right to communicate in a language they understand.

\section{Principle 23}

1. Every human being has the right to education.

2. To give effect to this right for internally displaced persons, the authorities concerned shall ensure that such persons, in particular displaced children, receive education which shall be free and compulsory at the primary level. Education should respect their cultural identity, language and religion.

3. Special efforts should be made to ensure the full and equal participation of women and girls in educational programmes.

4. Education and training facilities shall be made available to internally displaced persons, in particular adolescents and women, whether or not living in camps, as soon as conditions permit.

\section{Section IV. Principles Relating to Humanitarian Assistance}

\section{Principle 24}

1. All humanitarian assistance shall be carried out in accordance with the principles of humanity and impartiality and without discrimination.

2. Humanitarian assistance to internally displaced persons shall not be diverted, in particular for political or military reasons.

\section{Principle 25}

1. The primary duty and responsibility for providing humanitarian assistance to internally displaced persons lies with national authorities.

2. International humanitarian organizations and other appropriate actors have the right to offer their services in support of the internally displaced. Such an offer shall not be regarded as an unfriendly act or an interference in a State's internal affairs and shall be considered in good faith. Consent thereto shall not be arbitrarily withheld, particularly when authorities concerned are unable or unwilling to provide the required humanitarian assistance.

3. All authorities concerned shall grant and facilitate the free passage of humanitarian assistance and grant persons engaged in the provision of such assistance rapid and unimpeded access to the internally displaced.

\section{Principle 26}

Persons engaged in humanitarian assistance, their transport and supplies shall be respected and protected. They shall not be the object of attack or other acts of violence.

\section{Principle 27}

1. International humanitarian organizations and other appropriate actors when providing assistance should give due regard to the protection needs and human rights of internally dis- 
placed persons and take appropriate measures in this regard. In so doing, these organizations and actors should respect relevant international standards and codes of conduct.

2. The preceding paragraph is without prejudice to the protection responsibilities of international organizations mandated for this purpose, whose services may be offered or requested by States.

\section{Section V. Principles Relating to Return, Resettlement and Reintegration}

\section{Principle 28}

1. Competent authorities have the primary duty and responsibility to establish conditions, as well as provide the means, which allow internally displaced persons to return voluntarily, in safety and with dignity, to their homes or places of habitual residence, or to resettle voluntarily in another part of the country. Such authorities shall endeavour to facilitate the reintegration of returned or resettled internally displaced persons.

2. Special efforts should be made to ensure the full participation of internally displaced persons in the planning and management of their return or resettlement and reintegration.

\section{Principle 29}

1. Internally displaced persons who have returned to their homes or places of habitual residence or who have resettled in another part of the country shall not be discriminated against as a result of their having been displaced. They shall have the right to participate fully and equally in public affairs at all levels and have equal access to public services.

2. Competent authorities have the duty and responsibility to assist returned and/or resettled internally displaced persons to recover, to the extent possible, their property and possessions which they left behind or were dispossessed of upon their displacement. When recovery of such property and possessions is not possible, competent authorities shall provide or assist these persons in obtaining appropriate compensation or another form of just reparation.

\section{Principle 30}

All authorities concerned shall grant and facilitate for international humanitarian organizations and other appropriate actors, in the exercise of their respective mandates, rapid and unimpeded access to internally displaced persons to assist in their return or resettlement and reintegration. 


\section{Annex 2}

\section{Natural Disasters and the Protection of Internally Displaced Persons}

\section{Key message}

The protection of persons affected by natural disasters, including internally displaced persons, has long been a neglected area in disaster response. It is, however, well known that disasters create renewed protection risks and often exacerbate previous human rights violations. It is the responsibility of the State to prevent these risks and protect the human rights of persons internally displaced and others affected by natural disasters, with the assistance of humanitarian organizations if they are unable to assume fully such responsibilities. The IASC Operational Guidelines on Human Rights and Natural Disasters provide useful guidance to human rights and humanitarian actors in this regard.

\section{What is a natural disaster?}

Several definitions of natural disasters exist. The IASC Operational Guidelines on Human Rights and Natural Disasters (as outlined at the end of this section, below) define a natural disaster as "the consequences of events triggered by natural hazards that overwhelm the local response capacity and seriously affect the social and economic development of a region." The International Disaster Response Law Guidelines put forward by the IFRC define a disaster as "a serious disruption of the functioning of society, which poses a significant, widespread threat to human life, health, property or the environment, whether arising from accident, nature or human activity, whether developing suddenly or as the result of long-term processes, but excluding armed conflict."

\section{Introduction}

In recent years, a spate of natural disasters has brought the importance of delivering timely, coordinated and needs or rights-responsive humanitarian assistance to the fore. As in conflict situations, in the immediate aftermath of a disaster, a primary challenge is the complexity of managing several critical areas of relief simultaneously: organizing evacuations, providing emergency shelter, distributing food and medical supplies, etc. Compounding this complexity is that those affected by natural disasters often face urgent protection needs that may not be immediately visible to those coordinating emergency assistance. Persons displaced or affected by a disaster and who were already displaced before the disaster (as a result of armed conflict for instance), are at special risk as they may have lost community support structures, traditional ways of life, family members and, importantly, the ability to provide for themselves and their families through their normal livelihoods.

Protection, including human rights concerns, in the aftermath of natural disasters is a crucial, albeit thus far neglected, area. The focus on rescuing victims, distributing relief items and ensuring that the injured receive medical care has often meant that other protection issues have been overlooked. When human rights considerations are not addressed during the initial stages of a humanitarian response, there is a greater risk that violations will not only occur but that they will continue to occur after the emergency phase is over. Moreover, previously exist- 
ing human rights concerns and violations are often exacerbated during, and in the aftermath of, a disaster. Some of the human rights concerns include discrimination in aid distribution, exploitation, physical and other forms of violence, including gender-based violence, issues related to land, housing and property rights, and the denial of basic rights as a result of a breakdown in law and order, of loss of documentation, etc. Designing and implementing protection activities and, in general, adopting a human rights-based approach in crisis intervention, is key to an effective and sustainable response. A human rights-based approach does not mean that priority must shift away from rescue activities, aid delivery and the primary objective of saving lives; rather, it requires that human rights considerations be mainstreamed into each stage of the humanitarian response effort, including preparedness, disaster risk reduction, early recovery and durable solutions for the internally displaced and other affected persons. ${ }^{2}$

\section{Legal and protection framework applicable in natural disasters}

Human rights and fundamental freedoms are inherent entitlements of all people. International human rights law places a duty upon states and their agents ${ }^{3}$ to protect, respect and fulfil these rights without distinction of any kind, such as on the basis of race, colour, sex, language, religion, political or other opinion, national or social origin, property, birth or other status. ${ }^{4} \mathrm{Al}-$ though, in the context of public emergencies, authorities may need to suspend or restrict certain freedoms, such measures must be of an exceptional and temporary nature and the State authorities must demonstrate that the situation amounts to a public emergency and derogations must be limited to those strictly required by the exigencies of the situation. ${ }^{5}$ Moreover, certain rights can never be derogated from. (See Part I.2.

There are several human rights instruments applicable in natural disasters, including the 1948 Universal Declaration on Human Rights (UDHR). Many of its provisions are considered to form part of international customary law or, otherwise, have been integrated in treaty-based law, such as the 1966 International Covenant on Civil and Political Rights and International Covenant on Economic, Social and Cultural Rights.

At the regional level, the African Union Convention for the Protection and Assistance of Internally Displaced Persons in Africa ${ }^{6}$ clearly notes the need to address displacement caused by natural disasters, "which have a devastating impact on human life, peace, stability, security, and development." In the Preamble, the AU Convention states that "States Parties shall devise early warning systems, in the context of the continental early warning system, in areas of potential displacement, establish and implement disaster risk reduction strategies, emergency and disaster preparedness and management measures and, where necessary, provide immediate protection and assistance to internally displaced persons." It goes on to state in Article 4 (4) that forced evacuations in the case of natural or human-made disasters are prohibited in cases where they "(...) are not required by the safety and health of those affected" and, in Article 12 (3), states that "A State Party shall be liable to make reparation to internally displaced persons for damage when such a State Party refrains from protecting and assisting internally displaced persons in the event of natural disasters." In the Great Lakes region, the Protocol on the Protection and Assistance to Internally Displaced Persons establishes a legal basis for the implementation of the Guiding Principles in national law and specifically states the responsibil-

2 Preferably at the contingency planning and preparedness phase.

Including political, military and public sector actors.

Universal Declaration of Human Rights, Article 2, 1948.

International Covenant on Civil and Political Rights (ICCPR), Article 4. For more information, see HRC General Comment 29.

6 African Union Convention for the Protection and Assistance of Internally Displaced Persons in Africa, Adopted by the Special Summit of the African Union in Kamapla, Uganda (22 October 2009), will enter into force as soon as it is ratified by $15 \mathrm{AU}$ member states. 
ity of Member States to mitigate, to the extent possible, the consequences of displacement caused by natural disasters and natural causes. ${ }^{7}$

Some countries, such as Somalia, Sri Lanka, Democratic Republic of the Congo, Central African Republic, Afghanistan, and Pakistan, have been plagued by both armed conflict and natural disasters. When a natural disaster strikes an area affected by an international or domestic armed conflict, a further source of legal protection is international humanitarian law ${ }^{8}$. There are additional challenges to be overcome when mounting a disaster response in a conflict zone, including: greater difficulty in assisting affected populations in returning to their homes; potential secondary displacement; difficulties in accessing affected populations and delivering humanitarian aid; and security risks posed to humanitarian personnel.

Besides legally binding international instruments, specific international guidance has also been produced on protection and human rights in natural disasters, taking into account internally displaced persons. These instruments include: (i) the 2006 IASC Operational Guidelines on Human Rights and Natural Disasters, which were designed to assist intergovernmental and non-governmental humanitarian actors in ensuring that human rights principles and protection standards are integrated into disaster response, recovery and reconstruction efforts; ${ }^{9}$ (ii) the 1998 Guiding Principles on Internal Displacement ${ }^{10}$ which identify rights and guarantees relevant to the protection of individuals before displacement, during displacement and in return, relocation and reintegration; (iii) the 2005 Framework for National Responsibility, containing guidance in designing an effective national response and developing the steps to address problems of internal displacement; and (iv) the 2009 Framework for Durable Solutions for Internally Displaced Persons, which provides clarity on the concept of durable solutions for IDPs, how to achieve it, and the criteria that mark its attainment.

These texts are not binding as such. However, they contain binding international law obligations under treaty and customary law and provide important practical guidance for those working in disaster situations. In particular, the 1998 Guiding Principles have become the accepted standard for humanitarian and human rights actors both nationally and internationally. They were recognized by the 2005 World Summit as an important international framework for the protection of internally displaced persons, and an increasing number of States have incorporated them into national legislation.

Other documents, such as the Humanitarian Charter and Minimum Standards in Disaster Response (Sphere Standards), remain important sources of reference for protecting the rights of persons affected by natural disasters.

Finally, the Representative of the UN Secretary General on the Human Rights of IDPs, Prof. Walter Kälin, outlined in his 2009 report to the Human Rights Council (A/HRC/10/ 13/Add.1) specific protection needs of persons displaced by natural disasters, including cross-cutting protection concerns and protection of all categories of rights.

7 Protocol on the Protection and Assistance to Internally Displaced Persons. International Conference of the Great Lakes Region, 30 November 2006, art. 3.

8 See Part I.2.

9 "Protecting Persons Affected by Natural Disasters: IASC Operational Guidelines on Human Rights and Natural Disasters," IASC June 2006, p. 10, currently under revision.

${ }^{10}$ IASC Operational Guidelines on Human Rights and Natural Disasters states that persons affected by natural disasters are covered by the 1998 Guiding Principles on Internal Displacement. (See principle A.1.5.) 


\section{Groups that may face particular protection concerns}

A major concern in the immediate aftermath of a natural disaster is the protection of certain groups that may be particularly vulnerable in given contexts: IDPs, women, children, minorities, persons living with HIV, older persons, and persons with disabilities. Key risk areas include the illegal adoption of orphans, trafficking of minors or women, gender-based violence, the exploitation of children, violence against marginalized groups, and discrimination in the distribution of humanitarian aid. There is strong evidence that, in natural disasters, certain groups are at a much higher risk than others. A study of 4,605 natural disasters occurring in 141 countries found that women are more likely to die in natural disasters and their aftermath, and that this relation was strongest in contexts where gender equality was poor and women had less access to social and economic rights. ${ }^{11}$ Similarly, children are also more likely to die or be exposed to violence and exploitation in natural disasters than adults. In natural disaster situations, aid often goes, at least initially, to the strongest. Little thought may be given to the accessibility of clean water, sanitation and other basic needs of older persons and persons with injuries or disabilities. Internally displaced persons staying outside of camps, such as in host families, may be neglected in the distribution of aid. Critical health care for persons living with HIV/AIDS or tuberculosis can be interrupted. Reproductive health care for women and girls can be neglected, contributing to higher infant and maternal mortality rates and increased transmission rates of HIV/AIDs.

\section{Some particularities of displacement in natural disasters}

As we have seen above, protection and human rights concerns for displaced persons and other affected populations in natural disasters can be very similar to those existing during armed conflict. However, in many cases, internal displacement may present specific particularities in a context of natural disaster, as outlined below.

- In some cases, including for instance hydro-meteorological disasters, risk is highly seasonal and linked to well-defined geographic characteristics, such as low-lying areas prone to flooding, or high-slope areas prone to landslides. In these instances, risk is more predictable than during armed conflict, which increases the effectiveness of risk-reduction measures. This also means that prevention of forced displacement may be more effective in natural disaster settings as compared to armed conflict.

- Some of the risk-reduction measures may include evacuations of persons who are IDPs themselves or who will become so after the evacuation. It is essential to ensure that evacuations are carried out according to protection standards and human rights principles. In particular, protection and human rights actors must ensure that evacuations do not result in hasty permanent relocations with little consultation with, or information to, the affected communities and limited prospects of sustainability.

- In sudden-onset natural disasters, contrary to most armed conflicts, the specific threat at the root of the displacement may disappear in a very short period of time, such as during an earthquake or typhoon. This means that possibilities for durable solutions for persons internally displaced by the disaster may occur in a matter of days after the disaster has hit. It is essential that humanitarian and human rights actors are prepared for, and adapted to, this eventuality. They, therefore, should advocate and provide assistance for adequate planning for rights-based durable solutions at an early stage in the humanitarian crisis.

\footnotetext{
1 Eric Neumayer and Thomas Plümper, "The Gendered Nature of Natural Disasters: the impact of catastrophic events on the gender gap in life expectancy," 1981-2002, presented to the Royal Geographic Society, London, September 2006.
} 
- People displaced by natural disasters may no longer be able to return to areas not suitable for habitation. The relocation of families and communities to new areas may ultimately be unsuccessful if people are relocated to areas without access to basic services and adequate livelihoods. The relocation should also ensure adequate security of tenure and compensation for lost properties to the extent possible.

It is important that human rights and humanitarian actors pay adequate attention to the particularities of displacement in natural disasters settings and adapt their planning and priorities accordingly. At the same time, a number of caveats are necessary. The points above refer to sudden-onset natural disasters; yet, slow-onset disasters such as drought, desertification and climate change are also powerful causes of displacement in complex patterns that often are difficult to identify. At the same time, on many occasions, people are displaced by both natural disasters and conflict. For example, it may be the case that those previously displaced by conflict have resettled in disaster-prone areas and are, therefore, more likely to be displaced by subsequent disaster.

\section{Key rights and protection needs}

The consequences of natural disasters and protection needs resulting from them are often similar to those seen in armed conflict: death or serious injury; loss of, or separation from, family; loss of home, social networks, community and livelihood; exploitation; discrimination in aid; sexual violence; loss of documentation leading to denial of services; unsafe or involuntary return/relocation and other harm. A non-exhaustive list of key rights and protection needs is provided below: ${ }^{12}$

$\begin{array}{ll}\text { Right to physical security and integrity } & \text { Right to basic necessities } \\ \begin{array}{ll}\text { - Protection from the effects of natural disasters } & \text { - Right to adequate shelter } \\ \text { - Protection from physical violence and abuse } & \text { - Right to adequate food / water } \\ \text { - Protection from cruel, inhumane and degrading } & \text { - Right to adequate education } \\ \text { treatment } & \text { - Right to adequate health services } \\ \text { - Protection from arbitrary arrest and detention } & \text { - Provision of psychosocial programmes to meet } \\ \text { - Protection from illegal guardianship and } & \text { identified needs } \\ \text { adoption (with special attention to children } & \text { - Non-discrimination in the provision and access } \\ \text { separated from parents due to natural disaster) } & \text { to basic services } \\ \text { - Protection from trafficking } & \text { - Protection against abuse linked to services } \\ \text { - Protection from sexual abuse, violence and } & \text { (e.g. sex for survival) } \\ \text { exploitation } & \text { - Dignified burial / storage of dead bodies with } \\ \text { - Protection from forced recruitment } & \text { adequate identification systems } \\ \text { - Protection from forced labour / exploitation } & \text { - Protection from corruption and aid diversion } \\ \text { - Protection from forced / early marriage } & \\ \text { - Protection from domestic violence } & \\ \text { - Right to freedom of movement and residence } & \\ \text { - Protection against arbitrary displacement } & \\ \text { - Right to access to justice } & \\ \text { - Protection against family separation } & \\ \text { - Restoring family links (family tracing } \\ \text { and reunification) }\end{array} \\ \text { - Protection activities for unaccompanied / } \\ \text { separated children }\end{array}$

${ }^{12}$ Adapted from the IASC Operational Guidelines on Human Rights and Natural Disasters, 2006. 


$\begin{array}{ll}\text { Other economic, social and cultural rights } & \text { Other civil and political rights } \\ \text { - Right to work / access livelihoods } & \text { - Protection of housing and property rights } \\ \text { - Right to participation in cultural life } & \text { - Access to housing, land and property restitution } \\ \text { - Right to form community-based organizations } & \text { - Access to housing for non-proprietary rights } \\ & \text { holders (renters, squatters and the homeless) } \\ \text { - Protection from involuntary or unsafe return or } & \text { resettlement } \\ \text { - Right to recognition as a person before the law } & \text { - Right to documentation / replacement of lost } \\ & \text { documentation } \\ \text { - Freedom of association and expression } & \text { - Right to participate in electoral processes } \\ \text { - Freedom of religion } & \text { - Access to information pertaining to natural } \\ & \text { disaster and protection / safety measures } \\ \text { - Access to personal documentation and birth } & \text { registration }\end{array}$

\section{The responsibilities of the State in natural disasters}

For the case of people who have been displaced by natural disasters but have not crossed an international border, the domestic legal system is the principal framework defining their rights and entitlements, and the State is the primary duty bearer. The rights of people internally displaced by disasters are also enshrined in international human rights to which the State concerned is subscribed. ${ }^{13}$ Even though major human rights treaties do not include specific provisions regarding the protection of people displaced by disasters, they apply to the protection of IDPs, regardless of the cause of displacement. ${ }^{14}$ People displaced within their country by slow-onset disasters ${ }^{15}$ may also have specific protection needs, even though it may be more difficult to distinguish them from economic migrants. Adequate protection is therefore also due for them under human rights law.

Rights may be defined in a variety of legal instruments, including legislation, policies, regulations or national constitutions. Instruments that are relevant to disaster response may already exist or may be developed in response to the disaster. In either situation, these instruments should reflect a State's obligations under international law (i.e. the obligations to respect, protect and fulfil human rights) and ensure that persons affected by disaster enjoy their rights on an equal basis with others. ${ }^{16}$

It is well understood that exposure to natural disasters is much higher for persons whose basic social and economic rights, and particularly the right to adequate living conditions, is not sufficiently guaranteed. This is the case, for instance, of slum dwellers. While the State has an obligation to implement concrete risk-reduction measures and deliver relief to victims of disasters, ultimately the best preventive measures lie in an adequate response to developmental and poverty reduction needs, which constitute as well a human rights obligation.

It is important to highlight that under-development or resource constraints do not allow states to ignore their human rights obligations. Although a lack of resources may prevent States from

13 "Protecting Persons Affected by Natural Disasters: IASC Operational Guidelines on Human Rights and Natural Disasters," IASC June 2006, p. 10, currently under revision.

${ }^{14}$ Walter Kälin, Protection of Internally Displaced Persons in Situations of Natural Disasters, A/HRC/10/13/Add.1.

${ }^{15}$ According to the glossary of Reducing disaster risk: a challenge for development, UNDP, 2004, a slow-onset disaster is "a disaster event that unfolds alongside and within development processes. The hazard can be felt as an ongoing stress for many days, months or even years. Drought is a prime example."

16 Ibid. 
fully realizing certain human rights, they are still required to guarantee the rights that are essential to survival, such as food, water, shelter, sanitation and access to medical assistance. They are also required to take steps to the best of their available resources to fulfil their obligations regarding other social, economic and cultural rights. Where this is not feasible or resources are insufficient, they should request international assistance and play a key role in facilitating assistance to those in need. ${ }^{17}$

\section{The role of humanitarian and human rights actors}

Humanitarian organizations have the obligation to support States' efforts to provide humanitarian assistance and protection to displaced persons and others affected by natural disasters and to ensure coordination of their efforts among themselves and with national and local authorities.

The relevant Inter-Agency Standing Committee Guidance Note ${ }^{18}$ stipulates that, in the event of a natural disaster at the country level, the three protection mandated agencies (UNHCR, UNICEF and OHCHR), will undertake consultations on the designation of a protection lead among them, under the auspices of the Humanitarian Coordinator/Resident Coordinator based on the available capacities in each individual agency to coordinate and implement protection activities on the ground. ${ }^{19}$

The various parts of this handbook, notably Part III on the development of a protection strategy, Part IV which describes to protection risks, Part $V$ regarding generic protection activities and Part VI on durable solutions, can also be applied in natural disaster responses. More specifically, in the event of a natural disaster, the protection activities indicated below should be a particular focus.

- Systematically assess, monitor and analyse the vulnerability of those affected by natural disasters, identify specific protection risks and needs, and plan accordingly the necessary response in a coordinated way.

- Act to reduce threats and engage authorities to take responsibility for protection.

- Ensure the full participation of affected persons in disaster preparedness, response and recovery, and build upon existing capacities. The community is always the "first responder" and, yet, may feel overwhelmed and overrun by international actors.

- Further reinforce the capacities of affected persons in light of the additional challenges posed by the disaster.

- Reduce exposure to protection threats and minimize the time that people are exposed to risk by, for instance, moving quickly to identify and protect separated and unaccompanied children.

- Establish adequate identification, protection and referral mechanisms for persons with special needs, such as persons who are victims or are at risk of gender-based violence, older persons and persons with disabilities.

- Analyse the humanitarian response, and advocate for the adequate consideration of protection concerns and the adoption of a human rights perspective. This includes ensuring that humanitarian action is non-discriminatory, adequate and does no harm (e.g. by considering carefully any participation in forced evacuations, as addressed in part V.12) and that assistance is available, acceptable, accessible and adaptable.

17 Ibid., p 19.

18 IASC Guidance Note, 26 November 2006.

19 Detailed Standard Operating Procedures for Designating a Protection Sector/Cluster Lead Agency in the Event of a Natural Disaster at Country Level has recently been developed in this regard and are pending IASC endorsement. 
- Evaluate the pros and cons of cooperation with military forces involved in rescue, "heavy lift" and logistical activities to enable access in remote or difficult areas and/or moving large quantities of relief supplies quickly. Natural disasters may provide an opportunity to take advantage of such capacities, to create positive liaisons with the military and to introduce protection and rights concepts in a less politically charged environment. At the same time, the presence of military groups near IDPs may heighten vulnerability to sexual violence and exploitation, the recruitment and trafficking of children and restrictions on freedom of movement while also creating an atmosphere of intimidation. This risk is especially high in situations where the disaster occurs in an area of internal armed conflict, or where the proximity of the military can also render IDP camps or settlements military targets for non-state armed groups. ${ }^{20}$

- Implement protection monitoring and reporting mechanisms that yield data used for results-based activities early on in natural disasters. Data is often collected without adequate analysis and follow-up. Communities should be informed about how to report rights violations and how to obtain help regarding specific problems, such as missing family members.

- Ensure that adequate measures for durable solutions for internally displaced persons are taken early on in the response, and are adequately integrated in the recovery process, such as in the framework of the Post-Disaster Needs Assessment.

\section{Key operational guidance on protection in natural disasters: The IASC Operational Guidelines on Human Rights and Natural Disasters}

The Guidelines provide guidance to international agencies and NGOs on how to ensure that disaster relief and reconstruction efforts are conducted within a framework that protects and advances human rights. They include user-friendly operational guidelines organized by four groups of rights:

- protection of life, security of the person, physical integrity and dignity;

- protection of rights related to basic necessities of life;

- protection of other economic, social and cultural rights; and

- protection of other civil and political rights.

The guidance offered is based on human rights law, the Guiding Principles on Internal Displacement, the Red Cross/Red Crescent and NGO Code of Conduct, the IASC IDP Policy and the SPHERE Humanitarian Charter and Minimum Standards in Disaster Response.

In March 2008, a pilot version of a Field Manual on Human Rights and Natural Disasters was released to accompany the Operational Guidelines. The Manual's main intention is to introduce the human rights dimension into the fieldwork in a disaster context by providing practical examples and operational steps. The Field Manual and the Operational Guidelines themselves are currently under revision and are expected to be published in mid-2010.

${ }^{20}$ Comments adapted from Walter Kälin, "Protection of Internally Displaced Persons in Situations of Natural Disaster: A Working Visit to Asia by the Representative of the United Nations Secretary-General on the Human Rights of Internally Displaced Persons", 27 February to 5 March 2005, p. 17. 


\section{Key references and useful websites}

- IASC, Operational Guidelines on Human Rights and Natural Disasters, www.humanitarianinfo.org/IASC/downloaddoc. aspx .docld=3429

- A Field Manual to the Operational Guidelines complements the IASC Operational Guidelines. A revised version will be available in mid-2010.

- Global Protection Cluster (Taskforce on Protection in Natural Disasters), www.humanitarianreform.org/Default.aspx?tabid=748

- OHCHR and UNDP, "Checklists for Integrating Human Rights in Natural Disaster Management in the Pacific" (2007), www.preventionweb.net/english/professional/publications/v.php?id=9577

- HelpAge International/UNHCR, "Older people in disasters and humanitarian crises: Guidelines for best practice," www.helpage.org/Emergencies/Resources?autocreate_RelatedHelpage PublicationList_start $=11$

- UNDP and Disaster Risk Reduction, www.undp.org/cpr/disred/english/publications/rdr.htm

- European Commission Humanitarian Aid (ECHO) and Netherlands Red Cross, "Good practices and lessons learned in community and school based disaster preparedness in Central Asia" (2008),

www.preventionweb.net/english/professional/trainings-events/edu-materials/ v.php?id=10062

- Shanta Memorial Rehabilitation Centre (SMRC) "Summary of the e-discussion: disabled and other vulnerable people in natural disasters" (undated), www.preventionweb.net/english/professional/trainings-events/edu-materials/ v.php?id=9711

- UN High Commissioner for Refugees, Guiding Principles on Internal Displacement, 22 July 1998, E/CN.4/1998/53/Add.2,

www.unhcr.org/refworld/docid/3c3da07f7.html [accessed 29 March 2010]

- IDLO, Manual on International Law and Standards Applicable in Natural Disaster Situations (2009),

www.idlo.int/english/Resources/publications/Pages/Details.aspx? ItemsID=87

- Code of Conduct for the International Red Cross and Red Crescent Movement and NGOs in Disaster Relief (1995), www.ifrc.org/Docs/idrl/l259EN.pdf

- IFRC, Defusing Disaster: Reducing the Risk (Calamity is Unnatural) (2007), www.ifrc.org/Docs/pubs/disasters/resources/reducing-risks/defusing-disaster-en.pdf

- IFRC, Disaster Response and Contingency Planning Guide (2007), www.ifrc.org/Docs/pubs/disasters/resources/preparing-disasters/disasterresponse-en.pdf

- UNICEF (on behalf of IASC), Growing the Sheltering Tree: Protecting Human Rights through Humanitarian Action (2002), www.oxfam.org.uk/reources/downloads/emerg_manuals/ growingtheshelteringtree.pdf

- Global Protection Cluster Working Group, Handbook for the Protection of Internally Displaced Persons (2007), www.ocha.unog.ch/humanitarianreform/Default.aspx?tabid=294

- Humanitarian Charter and Minimum Standards in Disaster Response (2004), www.sphereproject.org/content/view/27/84/lang,English/ 
- International Emergencies Disaster Database, www.emdat.be

- IFRC, International Disaster Response Laws, Rules and Principles Programme, www.ifrc.org/what/disasters/idrl/research/casestudies.asp

- IFRC, Law and Legal Issues in International Disaster Response: A Desk Study (2007), www.reliefweb.int/rw/lib.nsf/db900SID/EVOD-78PH4N/\$FILE/ ifrc-06nov.pdf?OpenElement

- IFRC, The Global Alliance for Disaster Risk Reduction: Building Safer, Resilient Communities, www.ifrc.org/Docs/pubs/disasters/resources/reducing-risks/global-alliancereduction.pdf

- United Nations Disaster Assessment and Coordination Handbook (2006), www.ochaonline.un.org/OCHAHome/AboutUs/Coordination/UNDACSystem/ UNDACHandbook/tabid/6012/language/en-US/Default.aspx

- Housing and Property Restitution for Refugees and Displaced Persons: Implementing the Pinheiro Principles, FAO, IMDC, OCHA, UN-HABITAT, UNHCR (2007), www.ohchr.org/Documents/Publications/pinheiro_principles.pdf 


\section{Annex 3 \\ Acknowledgements}

This Handbook benefited from the valuable contributions of colleagues from a total of 134 organizations / bodies in some 20 countries. The list of contributors is provided below.

\section{Afghanistan}

- Norwegian Refugee Council (NRC), and

- United Nations High Commissioner for Refugees (UNHCR).

\section{Bosnia and Herzegovina}

- Bosnia and Herzegovina Women's Initiative,

- Catholic Relief Services,

- Danish Refugee Council,

- European Commission,

- Hilfswerk Austria,

- Independant Bureau for Humanitarian Issues,

- International Committee of the Red Cross (ICRC),

- International Commission on Missing Persons,

- International Organization for Migration (IOM),

- Organization for Security and Cooperation in Europe (OSCE),

- ProCap,

- The Office of the High Representative,

- United Nations Development Programme (UNDP),

- United Nations High Commissioner for Refugees Kosovo (UNHCR),

- United Nations High Commissioner for Refugees Serbia (UNHCR),

- Vasa Prava,

- World Bank, and

- World Vision.

\section{Democratic Republic of Congo}

- United Nations Organization Mission in the Democratic Republic of Congo (MONUC), and

- ProCap.

\section{Ethiopia}

- International Organization for Migrations (IOM). 


\section{Haiti}

- International Organization for Migrations (IOM).

\section{Headquarters}

- Action Aid,

- Centre for Humanitarian Dialogue (CHD),

- Christian Children's Fund (CCF),

- Danish Refugee Council (DRC),

- Geneva Centre for the Democratic Control of Armed Forces (DCAF),

- Global Camp Management and Camp Coordination (CCCM) Cluster,

- HelpAge International,

- International Organization for Migration (IOM),

- InterAction (American Council for Voluntary International Action),

- Internal Displacement Monitoring Centre (IDMC/NRC),

- International Labour Organisation (ILO),

- International Rescue Committee (IRC),

- Jesuit Refugee Service (JRS),

- Norwegian Refugee Council (NRC),

- Office of the United Nations High Commissioner for Human Rights (OHCHR),

- United Nations Office for the Coordination of Humanitarian Affairs (OCHA),

- Representative of the Secretary-General on the Human Rights of Internally Displaced Persons (RSG-IDP),

- Save the Children International,

- The Shelter Centre,

- United Nations Children's Fund (UNICEF),

- United Nations Development Programme (UNDP),

- United Nations High Commissioner for Refugees (UNHCR),

- United Nations Human Settlements Programme (UN-HABITAT),

- United Nations Mine Action Service (UNMAS),

- Women's Commission on Refugee Women and Children, and

- World Food Programme (WFP).

The International Committee of the Red Cross (ICRC) also provided much valued advice and support. UNHCR facilitated the process in coordination with the Global Protection Cluster Working Group (PCWG).

\section{Indonesia}

- International Organization for Migrations (IOM).

\section{Iraq}

- International Organization for Migrations (IOM). 


\section{Kenya}

- Danish Refugee Council,

- International Rescue Committee (IRC),

- Kenya Land Alliance,

- Kenyan Red Cross Society,

- Ministry of Special Programmes,

- Office for the Coordination of Humanitarian Affairs (OCHA),

- Refugees Consortium of Kenya,

- Save the Children UK,

- Sustainability Challenge Foundation,

- United Nations High Commissioner for Refugees (UNHCR), and

- United Nations Children's Fund (UNICEF).

\section{Liberia}

- Association of Female Lawyers of Liberia (AFELL),

- Concerned Christian Community (CCC),

- Christian Children Fund (CCF),

- Danish Refugee Council (DRC),

- International Rescue Committee (IRC),

- Liberia Refugee Repatriation \& Resettlement Commission (LRRRC),

- Medical Emergency Relief Cooperative International (MERCI),

- Minister of Gender and Development (MoGD),

- Norwegian Refugee Council (NRC),

- OXFAM,

- United Nations High Commissioner for Refugees (UNHCR),

- United Nations Mission on Liberia (UNMIL), and

- World Food Programme (WFP).

\section{Nepal}

- ProCap.

\section{Nigeria}

- International Organization for Migrations (IOM). 


\section{Philippines}

- Bangsamoro Center for Law and Policy,

- Bangsamoro Development Agency,

- Bantay Ceasefire (Ceasefire Watch),

- Community and Family Services International/Mindanao and Headquarters,

- International Justice Mission,

- International Organization for Migration,

- Institute for Bangsamoro Studies,

- Mindanao Commission on Women,

- Mindanao People's Caucus,

- OXFAM GB, Philippines,

- Tanggapang Panligal ng Katutubong Pilipino (Legal Center for Indigenous Filipinos), and

- Western Mindanao State University.

\section{Somalia}

- Africa Rescue Committee (AFREC),

- Norwegian Refugee Council (NRC),

- Office for the Coordination of Humanitarian Affairs (OCHA),

- Relief International (RI),

- United Nations Population Fund (UNFPA),

- United Nations High Commissioner for Refugees (UNHCR), and

- United Nations Children's Fund (UNICEF).

\section{Sudan}

- Cooperative Housing Foundation,

- Food and Agriculture Organization (FAO),

- International Organization for Migrations (IOM),

- Medecins Sans Frontieres (MSF),

- Norwegian Refugee Council (NRC),

- Office for the Coordination of Humanitarian Affairs (OCHA),

- Oxfam,

- Samaritan's Purse,

- United Nations High Commissioner for Refugees (UNHCR),

- United Nations Children's Fund (UNICEF), and

- World Food Programme (WFP). 


\section{Sri Lanka}

- Consortium of Humanitarian Agencies (CHA),

- Danish Refugee Council (DRC) Jaffna, Mannar, Kilinochchi/ Vavuniya,

- International Committee of the Red Cross (ICRC), Colombo, Batticaloa,

- International Labour Organization / International Programme on the Elimination of Child Labour (ILO/IPEC),

n Non-violent Peaceforce, Vallaichchenai, Trincomalee, Colombo,

- Norwegian Refugee Council (NRC),

- Norwegian Refugee Council / Information, Counselling and Legal Assistance programme (NRC/ICLA),

- Office of the High Commissioner for Human Rights (OHCHR),

- ProCap,

- Sarvodaya - Legal service, Partner Coordination, Programs,

- Save the Children Sri Lanka,

- Swiss Foundation for Mine Action (FSD),

- United Nations Development Programme (UNDP),

- United Nations Children's Fund (UNICEF),

- United Nations High Commissioner for Refugees (UNHCR) Colombo, Kilinochchi / Vavuniya, and

- ZOA Refugee Care.

\section{Timor-Leste}

n International Organization for Migrations (IOM).

\section{Uganda}

- American Refugee Committee (ARC),

- Arbeiter-Samariter-Bund (ASB),

- The Association of Volunteers in International Service (AVSI)

- GOAL,

- International Rescue Committee (IRC),

- Office of the High Commissioner for Human Rights (OHCHR),

- United Nations Population Fund (UNFPA),

- United Nations High Commissioner for Refugees (UNHCR), and

- United Nations Children's Fund (UNICEF).

\section{Zimbabwe}

- International Organization for Migrations (IOM). 


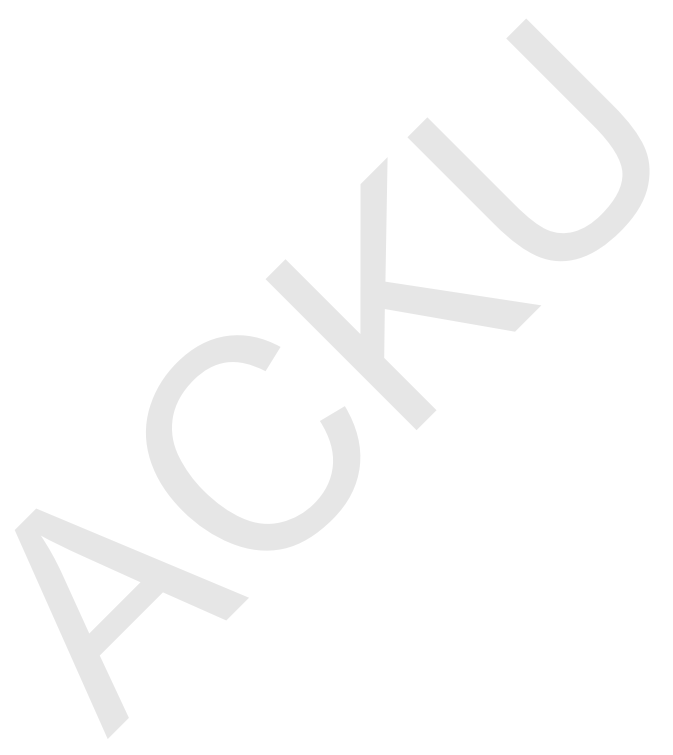




\section{Glossary}

\section{Abduction}

\section{Abuse}

Accountability

Age, Gender and Diversity Mainstreaming

\section{Arbitrary} Detention

\section{Armed Conflict}

The removal, seizure, apprehension, taking custody, detention or capture of a child (under 18 years) temporarily or permanently by force, threat or deception for involvement in armed forces or armed groups, for participation in hostilities, for sexual exploitation or for forced labour. Outside the context of children in armed conflict, individuals may also be abducted for sexual exploitation, child or early marriage, forced marriage, forced adoption, or forced labour.

(UN Task Force on Children in Armed Conflict, Rights of the Child: Report of the OHCHR on the Abduction of Children in Africa, E/CN.4/2006/65, 8 February 2006, para. 10, for first sentence)

The misuse of power through which the perpetrator gains control or advantage of the abused, using and causing physical or psychological harm or inciting fear of that harm. Abuse prevents persons from making free decisions and forces them to behave against their will. [See also Sexual Abuse.]

(UNHCR, Sexual and Gender-Based Violence against Refugees, Returnees and Internally Displaced Persons: Guidelines for Prevention and Responses, May 2003,

\section{www.unhcr.org/refworld/docid/3edcd0661.html)}

The act of taking responsibility for one's actions in relation to agreed upon expected results.

The meaningful participation of persons of concern to humanitarian agencies, of all ages and backgrounds, in the design, implementation, monitoring and evaluation of policies and operations so that these impact equitably amongst them. The overall goals are gender equality and the enjoyment of the rights of all persons of concern of all ages and backgrounds.

(UNHCR, Operational Protection in Camps and Settlements. A Reference Guide of Good Practices in the Protection of Refugees and Other Persons of Concern, June 2006)

A detention that (i) has no valid legal basis; (ii) is intended to deny the detainee the exercise of the fundamental rights guaranteed by either domestic or international law; or (iii) occurs in such a manner that essential procedural guarantees are not observed so that the arrest and detention gains an arbitrary character, even if it was legal originally. [See also Detention.]

(OHCHR, Fact Sheet No. 26, The Working Group on Arbitrary Detention, May 2000)

An armed confrontation between the armed forces of States (international armed conflict) or between governmental authorities and organized armed groups or between such groups within a State (non-international armed conflict). Other situations of violence, such as internal disturbances and tensions are not considered armed conflicts.

(ICRC, Exploring Humanitarian Law: Glossary, January 2009, www.ehl.redcross.org/resources/downloads/glossary.pdf) 
Armed Force The military organization of a State with a legal basis and supporting institutional infrastructure (salaries, benefits, basic services, etc.).

(UN, Integrated DDR Standards, December 2006, www.unddr.org/iddrs/download/full_iddrs.pdf)

Armed Group A group that has the potential to employ arms in the use of force to achieve political, ideological or economic objectives; is not within the formal military structures of a State, State-alliance or intergovernmental organization; and is not under the control of the State(s) in which it operates.

(UN, Integrated DDR Standards, December 2006, www.unddr.org/iddrs/download/full_iddrs.pdf)

Arranged

Marriage

Asylum

Asylum-seeker

Capacity Building

Child

Child Marriage
A marriage involving the intervention of someone outside the future couple, usually the parents of the future spouses or a broker. This brokerage can occur at the request of either or both future spouses or of the family, or at the parents' instigation. In certain communities and countries, it is customary for the parents to organize the marriage. Unlike with forced marriage, the ultimate choice of accepting the arrangement rests with each of the future spouses. It may, however, be difficult to ascertain to what extent it is possible for them to choose and to make up their minds in a properly informed manner. [See also Child Marriage and Forced Marriage.]

(Council of Europe, Parliamentary Assembly, Forced Marriages and Child Marriages, 20 June 2005)

The grant, by a State, of protection on its territory to persons outside their country of nationality or habitual residence who are fleeing persecution or serious harm. Asylum encompasses a variety of elements, including non-refoulement, permission to remain on the territory of the asylum country, humane standards of treatment and eventually a durable solution. [See also AsylumSeeker.]

An individual who is seeking international protection. In countries with individualized procedures, an asylum-seeker is someone whose claim has not yet been finally decided on by the country in which s/he has submitted it. Not every asylum-seeker will ultimately be recognized as a refugee, but every refugee is initially an asylum-seeker. [See also Asylum.]

A process by which individuals, institutions and societies develop abilities, individually and collectively, to perform functions, solve problems and set and achieve their goals.

Any human being below the age of 18 years, unless under the law applicable to the child, majority is attained earlier. [See also Child Soldier.]

(Convention on the Rights of the Child 1989, Article 1)

The union of two persons at least one of whom is under 18 years of age. [See also Arranged Marriage and Forced Marriage.]

(Council of Europe, Parliamentary Assembly, Resolution 1468 (2005), Forced Marriages and Child Marriages) 
Children

associated with

armed forces (or

Child Soldier)

Civil Society

Cluster Lead

Agency (country level)

\section{Coercion}

\section{Community}

Any person below 18 years of age who is or has been recruited or used by an armed force or armed group in any capacity, including but not limited to children, boys and girls, used as fighters, cooks, porters, messengers, spies or for sexual purposes. It does not only refer to a child who is taking or has taken a direct part in hostilities. Child soldiers are also referred to as child combatants or children associated with armed forces or fighting groups. [See also Child.]

(UNICEF, The Paris Principles: Principles and Guidelines on Children Associated With Armed Forces or Armed Groups, February 2007)

A broad range of voluntary civic and social organizations and institutions that form the basis of a functioning society.

(London School of Economics, Centre for Civil Society)

Cluster Approach A mechanism for addressing gaps and strengthening the effectiveness of humanitarian response through building partnerships. The cluster approach aims to ensure greater leadership and accountability in key sectors where gaps in humanitarian response have been identified, and to enhance partnerships among humanitarian, human rights and development actors, including the United Nations, non-governmental and other organizations. The cluster approach also aims to provide a more predictable, effective and accountable inter-agency response to ensuring protection and assistance for internally displaced persons and other affected populations in complex emergencies or natural disasters at the global (headquarters) and country levels.

(OCHA, Humanitarian Reform - Cluster Approach, www.ocha.unog.ch/humanitarianreform/Default.aspx?tabid=70)

This is an agency or organization that has been designated by the Resident and/or Humanitarian Coordinator $(\mathrm{RC} / \mathrm{HC})$ as the cluster lead agency for a particular sector at the country level, following consultations with the Humanitarian Country Team. (A cluster lead agency at the country level need not necessarily be the same agency/organization as the Global Cluster Lead Agency for that sector.) [See also Cluster Approach, Emergency Relief Coordinator and Global Cluster Lead Agency.]

(74th meeting of the IASC Working Group - July 2009)

The act of compelling a person to do, or to abstain from doing, something by a show of physical force, threats, intimidation, extortion or other forms of duress which prey on fear or desperation. Coercion may be inherent in certain circumstances, such as armed conflict or military presence.

(International Criminal Tribunal for Rwanda, Prosecutor v. Akayesu, ICTR-96-4-T, 1998, www.trim.unictr.org/webdrawer/rec/2291/)

A group of people that recognizes itself or is recognized by outsiders as sharing common cultural, religious or other social features, backgrounds and interests, and that forms a collective identity with shared goals.

(UNHCR, UNHCR Manual on a Community Based Approach in UNHCR Operations, March 2008) 
Community

Development

Community

Policing

Compensation

Confidentiality

Consent Approach
Complex

Emergency

A process which builds on the capacities and skills of community members to manage representative and fair structures that can respond to both immediate and long-term protection risks and needs, and to develop solutions while upholding individual rights.

(UNHCR, UNHCR Manual on a Community Based Approach in UNHCR Operations, March 2008)

A philosophy, management style, and organizational strategy that promotes pro-active problem solving and police-community partnerships to address the causes of crime and fear as well as other community issues.

(California Attorney General's Office)

Community-Based A way of working that is based on an inclusive partnership with communities of persons of concern that recognizes their resilience, capacities and resources. It mobilizes and builds on these to deliver protection, assistance and solutions while supporting community processes and goals.

(UNHCR, UNHCR Manual on a Community Based Approach in UNHCR Operations, March 2008)

A form of reparation that refers to a legal remedy whereby a person receives monetary payment for harm suffered. When appropriate, compensation may be given in lieu of restitution, including when it is in reality either impossible or impracticable to restore a person's property or house, or when a person knowingly and voluntarily accepts compensation in lieu of restitution. Monetary compensation, however, should be seen as a last resort and, when used as a measure of restorative justice, must be adequate, fair and just.

(COHRE, Defending the Housing Rights of Displaced Persons in Colombia, 2005,

\section{www.cohre.org/store/attachments/COHRE\%20Displaced\%20 Persons\%20in\%20Colombia\%202005.pdf)}

A humanitarian crisis in a country, region or society where there is total or considerable breakdown of authority resulting from internal or external conflict and which requires an international response that goes beyond the mandate or capacity of any single agency and/or the ongoing United Nations country program.

(OCHA Humanitarian Negotiations with Armed Groups, a Manual for Practitioners, January 2006, www.ochaonline.un.org/humanitariannegotiations/Chapter1-2.htm)

The obligation that information pertaining to a person disclosed in a relationship of trust will not be disclosed or otherwise made available to unauthorized persons or entities in ways that are inconsistent with the understanding of the original disclosure or without prior permission.

Making an informed choice to agree freely and voluntarily to do something. Consent is not given if agreement is obtained through abuse of power, force or threat of force, and other forms of coercion, abduction, fraud, deception or misrepresentation. 
Consolidated

Appeals Process

(CAP)

Convention

Customary

International Law

Derogation

Detention

Disarmament, Demobilization and Reintegration (DDR)

Discrimination against Women
A programming process through which national, regional and international relief systems (including United Nations operational agencies; and, where appropriate to the situation, the International Committee of the Red Cross (ICRC), the International Federation of Red Cross and Red Crescent Societies (IFRC), the International Organization for Migration (IOM), non-governmental organizations, bilateral donors, as well as appropriate national and regional structures) are able to mobilize and respond to selective major or complex emergencies that require a system-wide response to humanitarian crises.

(IASC, Consolidated Appeal Process Guidelines, April 1994)

\section{See Treaty.}

International legal norms that derive their authority from the constant and consistent practice of States, rather than from formal expression in a treaty or legal text. In order for State practice to contribute to the formation of customary international law, that practice should be conducted with a sense of legal obligation (opinio juris). Customary international law is binding on all States regardless of whether they have ratified any relevant treaty, save for States which are "persistent objectors".

(Statute of the International Court of Justice, 1998, Article 38(1)(b))

Under international human rights law, States party to a convention may derogate from (i.e. temporarily suspend their observance of) certain human right, but only in exceptional circumstances and under certain strict conditions. No derogations are permitted from certain core rights, such as the right to life or freedom from torture and from slavery. [See also Treaty.]

(ICCPR, Article 4, www2.ohchr.org/english/law/ccpr.htm; ECOSOC, UN Sub-Commission on Prevention of Discrimination and Protection of Minorities, Siracusa Principles on the Limitation and Derogation of Provisions in the International Covenant on Civil and Political Rights, Annex, UN Doc. E/CN.4/1984/4, 1984, Articles 39-51)

Restriction on freedom of movement, usually through enforced confinement of an individual by government authorities. (IOM, Glossary on Migration, International Migration Law, Series 2004) [See also Arbitrary Detention.]

A process that contributes to security and stability in a post-conflict recovery context by removing weapons from the hands of combatants, taking the combatants out of military structures and helping them to integrate socially and economically into society by finding civilian livelihoods.

(UN, Integrated DDR Standards, December 2006, www.unddr.org/iddrs/download/full_iddrs.pdf)

Any distinction, exclusion or restriction made on the basis of sex which has the effect or purpose of impairing or nullifying the recognition, enjoyment or exercise by women, irrespective of their marital status, on a basis of equality of men and women, of human rights and fundamental freedoms in the political, economic, social, cultural, civil or any other field. [See also Non-Discrimination.]

(Convention on the Elimination of All Forms of Discrimination against Women, 1979, Article 1) 
Domestic

Violence

Durable Solutions

\section{Early Marriage \\ Early Recovery}

\section{Empowerment}

Enforced Disappearance Coordinator (ERC)
Violence that occurs within the private sphere, generally between individuals who are related through blood, intimacy or law. Domestic violence is nearly always a gender-specific crime, perpetrated by men against women, and can take various forms, including physical, psychological and sexual violence. It can include economic deprivation and isolation which may cause imminent harm to the safety, health or well-being of the victim.

(UN General Assembly, Declaration on the Elimination of Domestic Violence against Women, GA/RES/58/147, February 2004)

The means by which the situation of internally displaced persons can be satisfactorily and permanently resolved to enable them to live normal lives. Achieving a durable solution to internal displacement means that displaced persons enjoy the full spectrum of human rights and, as a result, are able to rebuild their lives, whether through return to the place of origin; local settlement in the area where they have taken refuge; or settlement elsewhere the country. [See Local Settlement, Return and Settlement.]

\section{See Child Marriage.}

A multidimensional process guided by development principles that begins in a humanitarian setting, and seeks to build on humanitarian programmes and catalyze sustainable development opportunities. It aims to generate and/or reinforce nationally owned processes for post-crisis recovery that are resilient and sustainable. It encompasses the restoration of basic services, livelihoods, transitional shelter, governance, security and rule of law, environment and other socio-economic dimensions, including the reintegration of displaced populations.

(Cluster Working Group on Early Recovery, Guidance Note on Early Recovery, April 2008)

Emergency Relief The Emergency Relief Coordinator, who is also the United Nations Under-Secretary-General for Humanitarian Affairs, is responsible for ensuring inter-agency coordination of humanitarian action, both in complex emergencies and in natural disasters. A core function of the ERC is to ensure that all humanitarian issues are effectively addressed. The ERC advocates for protection and assistance, mobilizes political and financial support for humanitarian action, provides briefings to the Security Council, and engages in dialogue with governments, humanitarian agencies, and other relevant actors. [See also Inter-Agency Standing Committee.]

A process or phenomenon that allows people to take greater control over the decisions, assets, policies, processes and institutions that affect their lives. The five main principles of empowerment are awareness, participation, mobilization, access and control.

The arrest, detention, abduction or any other form of deprivation of liberty by agents of the State or by persons or groups of persons acting with the authorization, support or acquiescence of the State, followed by a refusal to acknowledge the deprivation of liberty or by concealment of the fate or whereabouts of the disappeared person, which place such a person outside the protection of the law.

(International Convention for the Protection of All Persons from Enforced Disappearance, 2006, Article 2) 
Evacuation

Evaluation

Family

Reunification

Family Unity

Female Genital Mutilation (FGM)

Food Security

Forced Eviction
Facilitation or organization of transfer of individuals or groups from one area/locality to another in order to ensure their security, safety and well-being.

A systematic and objective analysis and assessment of an organization's policies, programmes, practices, partnerships and procedures, focused on planning, design, implementation and impacts.

The process of bringing together families, particularly children and older dependants, with their family or previous care-provider for the purpose of establishing or re-establishing long-term care. [See also Family Unity.]

(Inter-agency Working Group on Unaccompanied and Separated Children, Inter-Agency Guiding Principles on Unaccompanied and Separated Children, January 2004)

The right to family unity and family life is inherent in the universal recognition of the family as the fundamental group unit of society. Respect for the right to family unity requires not only that States refrain from action which would result in family separations, but also that they take measures to maintain the unity of the family and reunite family members who have been separated. [See also Family Reunification.]

(UNHCR, Summary Conclusions: Family Unity, Global Consultations Expert Roundtable, Geneva, Switzerland, November 2001, www.unhcr.org/refworld/docid/470a33bed.html)

A practice involving partial or total removal of the external female genitalia or other injury to the female genital organs for non-medical reasons. FGM is classified into four types (i) partial or total removal of the clitoris and/or the prepuce (clitoridectomy); (ii) partial or total removal of the clitoris and the labia minora, with or without excision of the labia majora (excision); (iii) narrowing of the vaginal orifice with creation of a covering seal by cutting and appositioning the labia minora and/or the labia majora, with or without excision of the clitoris (infibulation); and (iv) all other harmful procedures to the female genitalia for non-medical purposes, for example pricking, piercing, incising, scraping and cauterization. The term is also called "female genital cutting" and "female genital mutilation/cutting."

(World Health Organization, Eliminating Female Genital Mutilation. An Interagency Statement, February 2008,

www.unhcr.org/refworld/docid/47c6aa6e2.html)

Food security exists when all people, at all times, have physical and economic access to sufficient, safe and nutritious food to meet their dietary needs and food preferences for an active and healthy life.

(World Food Summit 1996; UN Food and Agriculture Organization)

The permanent or temporary removal of individuals, families and/or communities against their will from the homes and/or land which they occupy, without the provision of, and access to, appropriate forms of legal or other protection.

(UN CESCR, General Comment No. 7: The right to adequate housing: forced evictions, 20 May 1997, para. 3) 
Forced Marriage The union of two persons at least one of whom has not given their full and free consent to the marriage. [See also Arranged Marriage and Child Marriage.]

(Council of Europe, Parliamentary Assembly, Resolution 1468 (2005), Forced Marriages and Child Marriages)

\section{Gender}

Gender-Based Violence (GBV)

Gender Equality

Gender Sensitivity
The social attributes and opportunities associated with being male and female and the relationships between women and men and girls and boys, as well as the relations between women and those between men. These attributes are socially constructed and are learned through socialization processes. They are context-/time-specific and changeable. Gender determines what is expected, allowed and valued in a woman or a man in a given context. In most societies, there are differences and inequalities between women and men in responsibilities assigned, activities undertaken, access to and control over resources, as well as decision-making opportunities. Gender is part of the broader socio-cultural context. Other important criteria for socio-cultural analysis include class, race, poverty level, ethnic group and age.

(Office of the Special Adviser on Gender Issues and Advancement of Women (OSAGI), UN Department of Economic and Social Affairs)

Violence that is directed against a person or a group of persons on the basis of their gender or sex. It includes acts that inflict physical, mental or sexual harm or suffering, threats of such acts, coercion and other deprivations of liberty whether occurring in public or private life. [See also Sexual and Gender-Based Violence, Sexual Violence and Violence Against Women.]

(UN General Assembly, Declaration on the Elimination of Violence against Women, A/RES/48/104, December 1993)

The equal rights, responsibilities and opportunities of women and men and girls and boys. Equality does not mean that women and men will become the same, but that women's and men's rights, responsibilities and opportunities will not depend on whether they are born male or female. Gender equality implies that the interests, needs and priorities of both women and men are taken into consideration - recognizing the diversity of different groups of women and men. Gender equality is not a "women's issue" but should concern and fully engage men as well as women. [See also Age, Gender and Diversity Mainstreaming and Gender Sensitivity.]

(Office of the Special Adviser on Gender Issues and Advancement of Women (OSAGI), UN Department of Economic and Social Affairs)

The ability to perceive existing gender differences, issues and inequalities and to incorporate these into strategies and actions. [See also Age, Gender and Diversity Mainstreaming and Gender Equality.]

(PRIME II partnership of leading global health-care organizations dedicated to improving the quality and accessibility of family planning and reproductive health-care services globally, Gender Sensitivity Assessment Tool for Family Planning/Reproductive Health Curricula, 2003) 
Genocide

Global Cluster Lead Agency

Good Practice

Guiding

Principles on

Internal

Displacement

Harmful

Traditional

Practices

Host Community
Any of the following acts committed with intent to destroy, in whole or in part, a national, ethnical, racial or religious group, as such, including: killing members of the group; causing serious bodily or mental harm to members of the group; deliberately inflicting on the group conditions of life calculated to bring about its physical destruction in whole or in part; imposing measures intended to prevent births within the group; or forcibly transferring children of the group to another group.

(Convention on Prevention and Punishment of the Crime of Genocide, 1948, Article 2, and ICC Statute,1998, Article 6)

This is an agency/organization at the global level that has been designated by the IASC as the cluster lead agency for a particular sector. See also Cluster Approach, Cluster Lead Agency and Emergency Relief Coordinator.]

(74th meeting of the IASC Working Group - July 2009)

An innovative, interesting and inspiring practice that has the potential to be transferred in whole or in part to other contexts.

(UNHCR, Handbook for Planning and Implementing Development Assistance for Refugees (DAR), January 2005)

A series of principles that identify rights and guarantees relevant to the protection of persons from forced displacement and to their protection and assistance during displacement, as well as during return or settlement and reintegration. They reflect and are consistent with international human rights and humanitarian law and provide guidance to the Representative of the Secretary-General on (the Human Rights of) internally displaced persons, States, other authorities, intergovernmental and non-governmental organizations when addressing internal displacement.

(UN Secretary-General, Guiding Principles on Internal Displacement, E/CN.4/1998/53/Add.2, 11 February 1998)

Traditional cultural practices which reflect values and beliefs held by members of a community for periods often spanning generations. Every social grouping in the world has specific traditional cultural practices and beliefs, some of which are beneficial to all members, while others are harmful to a specific group, such as women. These harmful traditional practices include female genital mutilation (FGM); forced feeding of women; early marriage; the various taboos or practices which prevent women from controlling their own fertility; nutritional taboos and traditional birth practices; son preference and its implications for the status of the girl child; female infanticide; early pregnancy; and dowry price. Despite their harmful nature and their violation of international human rights laws, such practices persist because they are not questioned and take on an aura of morality in the eyes of those practising them.

(OHCHR, Fact Sheet No. 23, Harmful Traditional Practices Affecting the Health of Women and Children, August 1995)

A community that hosts large populations of refugees or internally displaced persons, typically in camps or directly integrated into households. 
Human Rights

Human Rights Defender

Human Rights Monitoring

Humanitarian

Assistance

(Relief)

Humanitarian

Country Team
Agreed international standards that recognize and protect the inherent dignity and the equal and inalienable rights of every individual, without any distinction as to race, colour, sex, language, religion, political or other opinion, national or social origins, property, birth or other status. They may form part of customary international law and/or may be set out in various national, regional and international legal instruments.

(UDHR, 1948, Preamble and Article 2)

A person who, individually or with others, acts to promote or protect human rights.

(OHCHR, Factsheet No. 29, Human Rights Defenders: Protecting the Right to Defend Human Rights, April 2004)

The active collection, verification and immediate use of information to address human rights problems. Human rights monitoring includes gathering information about incidents, observing events (elections, trials, demonstrations, etc.), visiting sites such as places of detention and refugee camps, discussions with Government authorities to obtain information and to pursue remedies and other immediate follow-up. The term includes evaluative activities at the United Nations headquarters or operation's central office as well as firsthand fact-gathering and other work in the field. In addition, monitoring has a temporal quality in that it generally takes place over a protracted period of time.

(OHCHR, Training Manual on Human Rights Monitoring, 2001)

Aid that seeks to save lives and alleviate the suffering of a crisis-affected population. Humanitarian assistance must be provided in accordance with the basic humanitarian principles of humanity, impartiality and neutrality. In addition, the United Nations seeks to provide humanitarian assistance with full respect for the sovereignty of States. Assistance may be divided into three categories - direct assistance, indirect assistance and infrastructure support - which have diminishing degrees of contact with the affected population. [See also Humanitarian Principles and Inter-Agency Standing Committee (IASC).]

(OCHA, Glossary of Humanitarian Terms in relation to the Protection of Civilians in Armed Conflict, 2003,

www.ochaonline.un.org/OchaLinkClick.aspx? link=ocha\&Docld=100572)

The Humanitarian Country Team (HCT), under the leadership of the Humanitarian Coordinator $(\mathrm{HC})$, is the centrepiece of the new humanitarian coordination architecture established by Humanitarian Reform. The HCT is composed of organizations that undertake humanitarian action in-country and that commit to participate in coordination arrangements. Its objective is to ensure that the activities of such organizations are coordinated, and that humanitarian action in-country is principled, timely, effective and efficient, and contributes to longer-term recovery. The overall purpose is to alleviate human suffering and protect the lives, livelihoods and dignity of populations in need.

(75 ${ }^{\text {th }}$ IASC Working Group, Guidance for Humanitarian Country Teams, 18 November 2009) 
Humanitarian

Principles

Humanitarian

Space

Impunity

Indigenous

People

Inter-Agency

Standing

Committee (IASC)
The principles according to which humanitarian assistance must be provided, namely the principles of humanity, neutrality and impartiality. Adherence to these principles reflects a measure of accountability of the humanitarian community. [See also Humanitarian Assistance (Relief).]

(OCHA, Glossary of Humanitarian Terms in relation to the Protection of Civilians in Armed Conflict, 2003, www.ochaonline.un.org/OchaLinkClick.aspx?link=ocha\&Docld=100572)

A conductive humanitarian operating environment. The perception of adherence to the key operating principles of neutrality and impartiality in humanitarian operations represents the critical means by which the prime objective of ensuring that suffering must be met wherever it is found, can be achieved. Consequently, maintaining a clear distinction between the role and function of humanitarian actors and that of the military is the determining factor in creating an operating environment in which humanitarian organizations can discharge their responsibilities both effectively and safely. Sustained humanitarian access to the affected population is ensured when the receipt of humanitarian assistance is not conditional upon the allegiance to, or support to, parties involved in a conflict but is a right independent of military and political action. [See also Humanitarian Assistance and Humanitarian Principles.]

(OCHA, Glossary of Humanitarian Terms in relation to the Protection of Civilians in Armed Conflict, 2003,

\section{www.ochaonline.un.org/OchaLinkClick.aspx?link=ocha\&Docld=100572)}

The impossibility, de jure or de facto, of bringing the perpetrators of violations to account - whether in criminal, civil, administrative or disciplinary proceedings - since they are not subject to any inquiry that might lead to their being accused, arrested, tried and, if found guilty, sentenced to appropriate penalties, and to making reparations to their victims.

(UN Commission on Human Rights, Report of the independent expert to update the Set of principles to combat impunity, E/CN.4/2005/102/Add.1, 8 February 2005)

Peoples in independent countries who are regarded as indigenous on account of their descent from the populations which inhabited the country, or a geographical region to which the country belongs, at the time of conquest or colonization or the establishment of present State boundaries and who, irrespective of their legal status, retain some or all of their own social, economic, cultural and political institutions.

(ILO Convention (No. 169) concerning Indigenous and Tribal Peoples in Independent Countries, 27 June 1989, Article 1(b))

The primary mechanism for inter-agency coordination of humanitarian assistance. Under the leadership of the Emergency Relief Coordinator, the IASC develops humanitarian policies, agrees on a clear division of responsibility for the various aspects of humanitarian assistance, identifies and addresses gaps in response, and advocates for effective application of humanitarian principles. [See also Emergency Relief Coordinator and Humanitarian Assistance.] 
Intergovernmental An association of States established by and based upon a treaty, which Organization (IGO) pursues common aims and which has its own special organs to fulfil particular functions within the organization, such as the African Union, Council of Europe and European Union. [See also Non-Governmental Organization.]

Internally

Displaced

Persons (IDPs)

Justice

Livelihoods

\section{Local Settlement}

Persons or groups of persons who have been forced or obliged to flee or to leave their homes or places of habitual residence, in particular as a result of, or in order to, avoid the effects of armed conflicts, situations of generalized violence, violations of human rights or natural or human-made disasters, and who have not crossed an internationally recognized State border. [See also Guiding Principles on Internal Displacement.]

(UN Secretary-General, Guiding Principles on Internal Displacement, E/CN.4/1998/53/Add.2, 11 February 1998)

An ideal of accountability and fairness in the protection and vindication of rights and the prevention and punishment of wrongs. Justice implies regards for the rights of the accused, the interests of victims and the well-being of society at large. It is a concept rooted in all national cultures and traditions and, while its administration usually implies formal judicial mechanisms, traditional dispute resolution mechanisms are equally relevant. [See also Rule of Law.]

(UN Security Council, Report of the Secretary-General, The rule of law and transitional justice in conflict and post-conflict societies, S/2004/616, 23 August 2004, para. 7)

The combination of the resources used and the activities undertaken in order to live. The resources might consist of individual skills and abilities (human capital), land, savings and equipment (natural, financial and physical capital, respectively), and formal support groups or informal networks that assist in the activities being undertaken (social capital).

(Department for International Development, Sustainable Livelihoods Guidance Sheets, 2001)

One of three durable solutions available to IDPs whereby they can voluntarily settle in the areas where they have found safety and enjoy the full spectrum of human rights. [See also Durable Solutions.]

Mental Health and A composite term to describe any type of local or outside support that Psychological Support aims to protect or promote psychosocial well-being and/or prevent or treat mental disorder. Although the terms mental health and psychosocial support are closely related and overlap, for many aid workers they reflect different, yet complementary, approaches. Aid agencies outside the health sector tend to speak of supporting psychosocial well-being. Health sector agencies tend to speak of mental health, yet historically have also used the terms psychosocial rehabilitation and psychosocial treatment to describe non-biological interventions for people with mental disorders.

(IASC, IASC Guidelines on Mental Health and Psychosocial Support in Emergency Settings, 2007, p. 1) 
Migrant

Military

Recruitment

Millennium

Development

Goals

Monitoring

National Human Rights Institution (NHRI)
At the international level, no universally accepted definition of migrant exists. The term migrant is usually understood to cover all cases where the decision to migrate is taken freely by the individual concerned for reasons of "personal convenience" and without the intervention of an external compelling factor. This term, therefore, applies to persons and their family members moving to another country or region to better their material or social conditions and improve the prospect for themselves or their family.

(IOM, Glossary on Migration, 2004, www.iom.int/jahia/webdav/site/myjahiasite/shared/shared/mainsite/ published_docs/serial_publications/Glossary_eng.pdf)

Compulsory, forced or voluntary recruitment into national or other armed forces or armed group. The conscripting or enlisting of children under the age of 15 years into the national or other armed forces or armed group, or using them to participate actively in hostilities constitutes a war crime under the Rome Statute of the International Criminal Court. The Optional Protocol to the Convention on the Rights of the Child on the involvement of children in armed conflict prohibits direct participation in armed conflict of persons below 18 years and establishes a ban on their compulsory recruitment.

(OCHA, Glossary of Humanitarian Terms in relation to the Protection of Civilians in Armed Conflict, 2003,

www.ochaonline.un.org/OchaLinkClick.aspx?link=ocha\&Docld=100572)

A set of timebound and measurable goals and targets for combating poverty, hunger, disease, illiteracy, environmental degradation and discrimination against women adopted at the United Nations World Summit in September 2000. The Summit's Millennium Declaration also outlined a wide range of commitments in human rights, good governance and democracy.

UN, United Nations Department of Public Information, Implementing the Millennium Declaration Factsheet, October 2002)

An ongoing review and control of the implementation of a project to ensure that inputs, work schedules and agreed activities proceed according to plans and budgetary requirements.

(UNHCR, Handbook for Planning and Implementing Development Assistance for Refugees (DAR) Programmes, January 2005, www.unhcr.org/refworld/docid/428076704.html)

An administrative body which has an ongoing, advisory authority in respect to the promotion and protection of human rights at the national and/or international level. NHRIs may take the form of human rights commissions, ombudsmen, or specialized national institutions to protect a specific at-risk group.

(OHCHR, Fact Sheet No. 19, National Institutions for the Promotion and Protection of Human Rights, April 1993) 
Nationality

Non-

Discrimination

Non-

Governmental

Organization

(NGO)

Non-refoulement

Participatory Assessment
The legal bond between a person and a State. Nationality affords the State jurisdiction over the person and affords the person the protection of the State. Generally, nationality can be established at birth by a person's place of birth (jus soli) and/or bloodline (jus sanguinis), or can be acquired through naturalization. The concept is also known in certain national jurisdictions as "citizenship".

(European Convention on Nationality, 1997, Articles 2, 6 and 7, www.conventions.coe.int/Treaty/en/Treaties/Html/166.htm)

An approach that aims to ensure that all persons are equal before the law and are entitled to the equal protection of the law without distinction based on race, colour, sex, language, religion, political or other opinion, national or social origin, property, birth or other status. The term anti-discrimination implies a more proactive approach to tackling the causes and impacts of discrimination.

(UDHR, 1948, Articles 2 and 7)

An organized entity that is functionally independent of, and does not represent, a government or State. It is normally applied to organizations devoted to humanitarian and human rights causes, a number of which have official consultative status at the United Nations. [See also Intergovernmental Organization.]

(OCHA, Glossary of Humanitarian Terms in relation to the Protection of Civilians in Armed Conflict, 2003,

www.ochaonline.un.org/OchaLinkClick.aspx?link=ocha\&Docld=100572)

A core principle of international human rights and refugee law according to which States are prohibited to return individuals, including asylum-seekers and refugees, in any manner whatsoever, to territories where they are at risk of persecution, torture, or other forms of irreparable harm. Such return measures could include inter alia interception, rejection at the frontier or indirect refoulement. The most prominent expression of the principle of non-refoulement is Art. 33 (1) of the 1951 Convention relating to the Status of Refugees. This principle is part of customary international law and is, therefore, binding on all States whether or not they are parties to the Convention or other relevant international refugee law or human rights instruments. The Guiding Principles on Internal Displacement have a similar provision in the national context: internally displaced persons have the right to be protected against forcible return to, or settlement in, any place where their life, safety, liberty and/or health would be at risk.

(Convention Relating to the Status of Refugees 1951, Article 33, ; UNHCR, Summary Conclusions on Non-Refoulement, (Global Consultations on International Protection, Cambridge Expert Roundtable, Cambridge, UK, July 2001), June 2003; UN Secretary-General, Guiding Principles on Internal Displacement, E/CN.4/1998/53/Add.2, 11 February 1998)

A process of building partnerships with women and men of concern of all ages and backgrounds, by promoting meaningful participation through structured dialogue.

(UNHCR, UNHCR Tool for Participatory Assessment in Operations, May 2006) 
Efforts aimed at preventing the outbreak, recurrence or continuation of armed conflict and, therefore, encompassing a wide range of political, developmental, humanitarian and human rights programmes and mechanisms. These require short- and long-term actions tailored to address the particular needs of societies sliding into conflict or emerging from it, and focused on fostering sustainable institutions and processes in areas such as sustainable development, the eradication of poverty and inequalities, transparent and accountable governance, the promotion of democracy, respect for human rights and the rule of law, and the promotion of a culture of peace and non-violence.

(UN Security Council, Statement by the President of the Security Council on "Peacebuilding: Towards a Comprehensive Approach, S/PRST/2001/5, February 2001)

Pastoralists

(Pastoral

Communities)

Peaceful

Co-xistence

Profiling (IDPs)

Protection
Pastoralism is a way of life based primarily on raising livestock. Pastoral communities are those in which 50 percent of the combined total value of marketed production and the value of subsistence production consumed within the household comes from livestock or livestock-related activities. Mostly found in Africa's vast arid and semi-arid regions, pastoral systems are characterized by a high degree of mobility, guided by the need for managed access to water and grazing land, often without regard to State borders.

(OCHA, A Pastoral Policy Framework for Africa, AU Initiative, accompanied by OCHA,

\section{www.ochaonline.un.org/rocea/PastoralPolicy/tabid/4428/language/ en-US/Default.aspx)}

A concept which refers to building relationships between different ethnic, religious or social groups based on mutual trust, respect and recognition with a focus on social cohesion, inclusion and integration, in pre-conflict, conflict and post-conflict situations. Activities to promote peaceful coexistence include a range of initiatives to ensure that communities and societies can live more equitably and peacefully together, such as conflict prevention and management, post-conflict and conflict transformation work, conflict-sensitivity, peacebuilding, reconciliation, and multicultural and pluralism work.

\section{(Coexistence International (NGO created by Brandeis University)}

A collaborative process whereby data on individuals or groups who have been internally displaced is collected, with the purpose of informing advocacy on their behalf, improving protection and assistance interventions and, ultimately, finding a durable solution to displacement.

A concept that encompasses all activities aimed at obtaining full respect for the rights of the individual in accordance with the letter and spirit of international human rights, refugee and humanitarian law. Protection involves creating an environment conducive to respect for human beings, preventing and/or alleviating the immediate effects of a specific pattern of abuse, and restoring dignified conditions of life through reparation, restitution and rehabilitation.

(OCHA, Glossary of Humanitarian Terms in relation to the Protection of Civilians in Armed Conflict, 2003,

www.ochaonline.un.org/OchaLinkClick.aspx?link=ocha\&Docld=100572) 
Protection

Cluster Working

Group (PCWG)

\section{Protection}

Monitoring

Racial

Discrimination

Rape

Ratification
The main forum at the global level for coordinating all protection activities in humanitarian action. Chaired by UNHCR as the global protection cluster lead, the PCWG's members include United Nations humanitarian, human rights and development agencies, as well as non-governmental and other international organizations active in protection. The role of the PCWG is to lead standard- and policy-setting relating to protection, identify and disseminate good practices, and support the development of strengthened protection capacity. [See also Cluster Lead.]

(OCHA, Humanitarian Reform - Cluster Approach: Protection Cluster Working Group, www.oneresponse.info/GlobalClusters/Protection)

The collection, verification and analysis of information in order to identify human rights violations and protection risks encountered by IDPs and other affected populations. Protection monitoring generally takes place over an extended period of time at both the community-level - assessing changes in the overall protection in a community, village, region or country, or at the individual level - documenting human rights violations suffered by individuals. Protection monitoring is coordinated and undertaken by agencies with a specific mandate and expertise, in cooperation with United Nations agencies and members of civil society, particularly those directly affected: internally displaced persons and others.

Any distinction, exclusion, restriction or preference based on race, colour, descent or national or ethnic origin which has the purpose or effect of nullifying or impairing the recognition, enjoyment or exercise, on an equal footing, of human rights and fundamental freedoms in the political, economic, social, cultural or any other field of public life. [See also Non-Discrimination.]

(International Convention on the Elimination of All Forms of Racial Discrimination, 1965, Article 1)

The invasion of the body of a person by conduct resulting in penetration, however slight, of any part of the body of the victim or of the perpetrator with a sexual organ, or of the anal or genital opening of the victim with any object or any other part of the body. The invasion can be committed by force, or by threat of force or coercion, such as that caused by fear of violence, duress, detention, psychological oppression or abuse of power, against such person or another person, or by taking advantage of a coercive environment, or against a person incapable of giving genuine consent.

(ICC Elements of Crime, 2002, Articles 7(1)(g)-1, 8(2)(b)(xxii)-1 and $8(2)(e)(v i)-1)$

The act undertaken on the international plane, whereby a State establishes its consent to be bound by a treaty. Most multilateral treaties expressly provide for States to express their consent to be bound by signature subject to ratification, acceptance or approval. Providing for signature subject to ratification allows States time to seek approval for the treaty at the domestic level and to enact any legislation necessary to implement the treaty domestically, prior to undertaking the legal obligations under the treaty at the international level. Upon ratification, the State becomes legally bound under the treaty. [See also Treaty.]

(OHCHR, Glossary of Treaty Body Terminology) 
Reconciliation

Refugee

Registration

Rehabilitation

Reintegration
An element of conflict resolution and peacebuilding involving the promotion of confidence building and co-existence. The process of achieving reconciliation generally involves five interwoven and related strands: (i) developing a shared vision of an interdependent and fair society; (ii) acknowledging and dealing with the past; (iii) building positive relationships; (iv) significant cultural and attitudinal change; and (v) substantial social, economic and political change. It can be a challenging and long-term process for communities deeply divided along political or ethnic lines. While reconciliation must grow between and within communities, it can benefit from international support, especially when people and/or political leaders are unable or unwilling to initiate it.

(UNHCR, Handbook for Repatriation and Reintegration Activities, May 2004)

A person who meets the eligibility criteria under the applicable refugee definition, as provided for in international or regional refugee instruments, under UNHCR's mandate, and/or in national legislation. Contrary to internally displaced persons, refugees are outside their country or origin/habitual residence.

The process of recording, verifying, and updating information on persons of concern to humanitarian agencies with the aim of protecting and documenting them and of implementing durable solutions. Registration is not required, and sometimes not even desirable, in IDP contexts; rather, the benefits of registration depend on factors such as the actual need for detailed data, the role of the government, and the period during which the information will remain valid. Informed consent must be sought from IDPs for the collection, registration and use of data, and appropriate data protection mechanisms must be put in place to safeguard confidentiality and protect those registered from potential protection risks, including violence, discrimination or stigma.

(UNHCR, UNHCR Handbook for Registration, September 2003)

Actions which enable the affected population to resume more or less "normal" patterns of life. These actions constitute a transitional phase and can occur simultaneously with relief activities as well as with further recovery and reconstruction activities.

\section{(ILO, Generic Crisis Response Modules, 2001)}

In the context of internal displacement, reintegration refers to a process which enables IDPs to regain the physical, social, legal and material security needed to maintain life, livelihood and dignity and to resume a normal life either following their return to their place of origin, settlement in their place of displacement or elsewhere in the country. IDPs have the right to reintegration assistance regardless of the solution they choose. Reintegration is also a process by which ex-combatants acquire civilian status and gain sustainable employment and income as the final phase of a disarmament, demobilization and reintegration (DDR) process. [See also Disarmament, Demobilization and Reintegration (DDR), Local Settlement, Return and Settlement.] 
Representative of The Representative of the United Nations Secretary-General is charged the United

Nations with (i) engaging in coordinated advocacy in favour of the protection and respect of the human rights of IDPs; (ii) continuing and enhancing

Secretary-General dialogues with Governments as well as non-governmental organizations on the Human

Rights of

Internally

Displaced

Persons

Reproductive Health

Return (to the place of origin)

\section{Returnees}

Rights-Based Approach

Rule of Law

Self-reliance and other actors; (iii) strengthening the international response to internal displacement; and (iv) mainstreaming the human rights of IDPs into all relevant parts of the United Nations system.

A state of complete physical, mental, and social well-being, and not merely the absence of disease and infirmity, in all matters relating to the reproductive system and to its functions and processes. Reproductive health, therefore, implies that people are able to have a satisfying and safe sex life, the capacity to reproduce, and the freedom to decide if, when, and how often to do so.

One of three durable solutions available to IDPs whereby they can return voluntarily and in safety and dignity to their homes or places of habitual residence and enjoy the full spectrum of Human Rights to the same degree as persons in the same location who were not displaced. [See also Durable Solutions.]

(UN Secretary-General, Guiding Principles on Internal Displacement, E/CN.4/1998/53/Add.2, 11 February 1998)

IDPs who have returned to their homes or places of habitual residence.

A conceptual framework that integrates the norms, standards and principles of the international human rights system into the policies, programmes and processes of development and humanitarian actors. It focuses on both outcomes and processes and is founded on the principles of participation and empowering individuals and communities to promote change and respect for rights.

A principle of governance according to which all persons, institutions and entities, public and private, including the State itself, are accountable to laws that are publicly promulgated, equally enforced and independently adjudicated, and which are consistent with international human rights norms and standards. It also requires measures to ensure adherence to the principles of supremacy of law, equality before the law, accountability to the law, fairness in the application of the law, separation of powers, participation in decision making, legal certainty, avoidance of arbitrariness and procedural and legal transparency. [See also Justice.]

(UN Security Council, Report of the Secretary-General, The rule of law and transitional justice in conflict and post-conflict societies, S/2004/616, 3 August 2004, para. 6)

The social and economic ability of an individual, a household or a community to meet essential needs (including food, water, shelter, personal safety, health and education) in a sustainable manner and with dignity - developing and strengthening livelihoods of people of concern, and reducing their vulnerability and long-term reliance on humanitarian assistance.

(UNHCR, Handbook on Self-Reliance, August 2005) 
Separated Child A child separated from both parents or from his/her previous legal or customary primary caregiver, but not necessarily from other relatives. These, therefore, may include a child accompanied by other adult family members. [See also Unaccompanied Child.]

(Inter-agency Working Group on Unaccompanied and Separated Children, Guiding Principles on Unaccompanied and Separated Children, January 2004)

Settlement

(elsewhere in the country)

Sex

Sexual Abuse

Sexual

Exploitation

Stateless Person

Statelessness

Survivor
One of three durable solutions available to IDPs whereby they can voluntarily resettle in another part of the country and enjoy the full spectrum of human rights. [See also Durable Solutions.]

The biological characteristics which define humans as female or male. These sets of biological characteristics are not mutually exclusive as there are individuals who possess both, but these characteristics tend to differentiate humans as males and females. In general use in many languages, the term sex is often used to mean "sexual activity" but, for technical purposes in the context of sexuality and sexual health discussions, the above definition is preferred.

(World Health Organization, Defining sexual health - Report of a technical consultation on sexual health, 28-31 January 2002, 2006,

www.who.int/reproductivehealth/topics/gender_rights/ defining_sexual_health.pdf)

Any actual or threatened physical intrusion of a sexual nature, whether by force or under unequal or coercive conditions. [See also Abuse and Sexual Exploitation.]

(UN Secretary-General, Special measures for protection from sexual exploitation and sexual abuse, ST/SGB/2003/13, October 2003)

Any actual or attempted abuse of a position of vulnerability, differential power, or trust, for sexual purposes, including, but not limited to, profiting monetarily, socially or politically from the sexual exploitation of another.

(UN Secretary-General, Special measures for protection from sexual exploitation and sexual abuse, ST/SGB/2003/13, October 2003)

A person who is not considered a national by any State under the operation of its law. [See also Statelessness.]

(Convention Relating to the Status of Stateless Persons 1954, Article 1)

The condition of not being considered a national by any State under the operation of its law. [See also Stateless Person.]

Any person who has suffered acts of violence, including gender-based violence and who self-identifies with having lived through this violence. This term is used to highlight the strength and resilience of victims of violence and to acknowledge that the term victim may imply powerlessness and stigmatization. [See also Victim.] 
Torture

Trafficking in

Persons

Transitional

Justice

Treaty
Any act by which severe pain or suffering, whether physical or mental, is intentionally inflicted on a person for such purposes as obtaining from him or a third person information or a confession, punishing him for an act he or a third person has committed or is suspected of having committed, or intimidating or coercing him or a third person or, for any reason based on discrimination of any kind, when such pain or suffering is inflicted by or at the instigation of or with the consent or acquiescence of a public official or other person acting in an official capacity. It does not include pain or suffering arising only from, inherent in or incidental to lawful sanctions.

(Convention against Torture and Other Cruel, Inhuman or Degrading Treatment or Punishment, 1984 Article 1)

The recruitment, transportation, transfer, harbouring or receipt of persons, by means of the treat or use of force or other forms of coercion, of abduction, of fraud, of deception, of the abuse of power or of a position of vulnerability or of the giving or receiving of payments or benefits to achieve the consent of a person having control over another person for the purpose of exploitation. Such exploitation includes, at a minimum, the exploitation of the prostitution of others or other forms of sexual exploitation, forced labour or services, slavery or practices similar to slavery, servitude or the removal of organs.

(Protocol to Prevent, Suppress, and Punish Trafficking In Persons, Especially Women and Children, 2000, Article 3)

The full range of processes and mechanisms associated with a society's attempts to come to terms with the legacy of large-scale past abuses in order to ensure accountability, serve justice, and achieve reconciliation. These may include judicial and non-judicial mechanisms, with differing levels of international involvement (or none at all) and individual prosecutions, reparations, truth-seeking, institutional reform, vetting and dismissals, or a combination thereof. [See also Rule of Law.]

(UN Security Council, Report of the Secretary-General, The rule of law and transitional justice in conflict and post-conflict societies, S/2004/616, 3 August 2004, para. 8; UN Commission on Human Rights, Study by the Office of the United Nations High Commissioner for Human Rights on Human Rights and Transitional Justice Activities Undertaken by the Human Rights Components on the United Nations System, E/CN.4/2006/93, February 2006, para. 5)

A binding international agreement concluded between States or international organizations with treaty-making power and governed by international law, whether embodied in a single instrument or in two or more related instruments and whatever its particular designation. Accordingly, conventions, agreements, protocols, and exchange of letters or notes may all constitute treaties. The fact that such agreement is not in written form does not affect its legal force. [See also Derogation and Ratification.]

(Vienna Convention on the Law of Treaties 1969, Articles 2(1)(a), 3 and 26; Vienna Convention on the Law of Treaties between States and International Organizations or between International Organizations 1986, Articles 2(1)(a), 3 and 26) 
Unaccompanied Child

United Nations Human Rights Treaty Bodies

United Nations Peacekeeping Mission/Operation
A child who has been separated from both parents and other relatives and is not being cared for by an adult who, by law or custom, is responsible for doing so. [See also Separated Child.]

(Inter-agency Working Group on Unaccompanied and Separated Children, Guiding Principles on Unaccompanied and Separated Children, January 2004)

Committees of independent experts appointed to monitor the implementation by States parties of the core international human rights treaties. They are created in accordance with the provisions of the treaty that they monitor. There are eight human rights treaty bodies: (i) Human Rights Committee (HRC) (not to be confused with the Human Rights Council or the Commission on Human Rights); (ii) Committee on Economic, Social and Cultural Rights (CESCR); (iii) Committee on the Elimination of Racial Discrimination (CERD); (iv) Committee on the Elimination of Discrimination Against Women (CEDAW); (v) Committee Against Torture (CAT); (vi) Committee on the Rights of the Child (CRC); (vii) Committee on Migrant Workers (CMW); and (viii) Committee on the Rights of Persons with Disabilities (CRPD). The treaty bodies perform a number of functions, including consideration of State parties' reports and individual complaints or communications. In addition to the States' reporting procedure, some of the treaty bodies may perform additional monitoring functions through three other mechanisms: the inquiry procedure, the examination of inter-state complaints and the examination of individual complaints. The Committees also publish their interpretation of the content of human rights provisions, known as general comments on thematic issues or methods of work.

(OHCHR, Glossary of treaty body terminology)

United Nations field operation that often consists of several components, including a military component, which may or may not be armed, and various civilian components encompassing a broad range of disciplines. Depending on their mandate, peacekeeping missions may be required to: deploy to prevent the outbreak of conflict or the spill-over of conflict across borders; stabilize conflict situations after a ceasefire to create an environment for the parties to reach a lasting peace agreement; assist in implementing comprehensive peace agreements; lead states or territories through a transition to stable government based on democratic principles, good governance and economic development.

(OCHA, Glossary of Humanitarian Terms in relation to the Protection of Civilians in Armed Conflict, 2003,

www.ochaonline.un.org/OchaLinkClick.aspx?link=ocha\&Docld=100572)

Victim

Victims are persons who, individually or collectively, have suffered harm, including physical or mental injury, emotional suffering, economic loss or substantial impairment of their fundamental rights, through acts or omissions that constitute violations of international human rights law or international humanitarian law. [See also Survivor.]

(UN General Assembly, Basic Principles and Guidelines on the Right to a Remedy and Reparation for Victims of Gross Violations of International Human Rights Law and Serious Violations of International Humanitarian Law, GA/RES/60/147, 2005; Declaration of Basic Principles of Justice for Victims of Crime and Abuse of Power, GA/RES/40/34, 1985) 
Violence Against Any act of gender-based violence that results in, or is likely to result in, Women physical, sexual or psychological harm or suffering to women, including threats of such acts, coercion or arbitrary deprivation of liberty, whether occurring in public or in private life. It encompasses, but it is not limited to (i) physical, sexual and psychological violence occurring in the family, including battering, sexual abuse of female children in the household, dowry-related violence, marital rape, female genital mutilation and other traditional practices harmful to women, non-spousal violence and violence related to exploitation; (ii) physical, sexual and psychological violence occurring within the general community, including rape, sexual abuse, sexual harassment and intimidation at work, in educational institutions and elsewhere, trafficking in women and forced prostitution; (iii) physical, sexual and psychological violence perpetrated or condoned by the State, wherever it occurs. [See also Gender-Based Violence and Sexual and Gender-Based violence.]

(UN General Assembly, Declaration on the Elimination of Violence against Women, GA/RES/48/104, 1993, Articles 1 and 2) 


\section{Index}

A

Abuse, 59, 173, 180, 321

Additional Protocols, 32-33, 139-140, 153, 179, 191, 201, 214, 218, 239, 254, 268, 286-287, 307, 321

Additional Protocol I, 32-33, 139-140, 153, 179, 191, 201, 214, 218, 239, 254, 268, 286-287, 307,321

Additional Protocol II, 32-33, 139-140, 153, 179, 191, 201, 214, 218, 239, 254, 268, 286-287, 307, 321

Advocacy, 63, 71, 75, 92, 142, 144, 149, 154, 161, 164, 174

Humanitarian advocacy, 63, 71, 75, 92, 142, 144, 149, 154, 161, 164, 174

Public advocacy, 186, 198, 209, 232, 266, 274, 284, 319, 333, 357-358, 362-363, 365, 403, 431, 459

African Charter on the Rights and Welfare of the Child, 41, 191

African Union, 41, 57, 134, 145, 156, 190, 334, 349

Age, 6, 13, 17-18, 48, 51, 80, 89, 116, 118, 145, 192, 204, 212, 214, 218, 225, 257, 268, 288, 306, $311,352-353,365,372-373,376,383,392,422,432$

Angola, 38, 134, 140

Anti-Personnel Mine Ban Convention (APMBC), 161, 164, 166

Appeal, 54, 131, 61

Armed

Armed actor(s), 75, 76, 78, 107, 108, 152, 157, 181-183, 252, 348, 361, 378, 381, 390, 436

Armed forces, 9, 13, 28-31, 33, 35, 55, 74-76, 78-79, 107-108, 110, 122, 143, 145, 147, 152-157, 162-163, 170-172, 174-175, 180-191, 198, 205, 207, 217-220, 252, 274, 296, 320, 348, 361, $367-368,378,381,390-391,409,421,430,436,462$

Armed group(s), 12-13, 28, 29, 31, 35, 54-55, 56, 74, 78, 107-108, 138, 143, 147, 152-155, 171, 181-189, 191-193, 205, 217-218, 220, 296, 364, 367-368, 373, 378, 391, 409, 421, 430, 462

Arrest, 171

Assessment, 11-13, 15, 49-52, 63, 65, 67, 71, 75, 85, 89, 100-102, 109, 113, 115, 117-120, 122, $124,126-127,130,132-133,141,143-144,149,156,161,163-164,170,174,177,188-189$, 206, 208, 220, 231-232, 241, 249-250, 257, 262, 266, 274, 284, 289, 294-295, 308, 316, 333, 339-340, 347-351, 355, 363, 367, 369, 371, 377, 379, 389, 392, 404, 410-412, 414, 419, 422, $424,428-429,431,435-436,438,445-446,452,454-455,461-462,465,469$

Needs assessment, 11, 13, 50, 52, 63, 71, 115, 117-118, 122, 124, 132-133, 339, 350, 369, 429, 454-455, 465, 469 
Participatory assessment, 8, 12, 118-120, 127, 139, 294, 379, 410-411, 422, 424, 442, 461 Rapid assessment, 56, 61, 67, 81, 118-120, 133-134, 141, 143, 149, 163, 174, 179, 185, 198, $208,220,231,241,249,254,261,266,274,277,290,294,308,316,333,424,430,432,445$, $455,469-471$

Standard assessment, 118

Azerbaijan, 401

B

Basic Principles and Guidelines on Development-based evictions and displacement, 139

Basic Principles and Guidelines on the Right to a remedy and reparation for victims of gross violations of international human rights law and serious violations of international humanitarian law, 139, 321

Benchmark, 349, 460

Best Alternative to a Negotiated Agreement (BATNA), 94-98

Birth certificate, 230, 233-234, 387, 392

Birth registration, 233

Bosnia and Herzegovina, 38, 307

Burundi, 140, 55

C

Cambodia, 34, 327

Capacity-building / capacity building, 19, 30, 48, 62, 69, 71, 73, 77, 124, 143, 188, 198, 240, 309, $318,349,388,402-408,407,408,409,413-415,418,431,458$

Central African Republic (CAR), 34, 55, 260, 287, 362, 365

CESCR (Committee on Social, Economic and Cultural Rights), 26, 266,

$26,28,138,213,218,227,238,253,260,267,286,299$

Charter of the United Nations, 11, 254

Child-headed household, 238, 240, 241, 273

Children, 13, 17, 31, 37, 42, 47, 54, 179-185, 187-193, 204, 212-214, 216, 218-219, 222-223, 225, 245, 253-254, 261, 269, 272, 277-278, 283, 287-288, 293, 320-322, 373, 383, 391-392, 397, $423-425,432,440$

Children associated with armed forces/armed groups, 181, 183, 185, 187, 189, 191, 193

Citizenship, 234

Civil status, 209, 224-225, 227, 234 
Cluster, 12-13, 18, 46, 48, 50-52, 58-62, 69, 75, 80, 105, 118, 123, 132-133, 178, 245, 249, 252, $260,266,269,287,294-295,311,354,382,387,392,394,429,431,469$

Collective centre, 236, 242

Colombia, 38, 42, 140, 382, 401, 409, 457

Communal building, 243

Communication, 87, 89, 97, 110, 398

Community

Community mobilization, 124, 220, 292, 363, 386, 416-419, 436

Community-based, 12, 17, 79, 143, 145, 150-151, 156-157, 161, 175, 187, 190, 199, 351, 388, 390-391, 394, 416-419, 421-423, 425, 428, 432, 446, 457

Displaced community/ies, 12-13, 164, 198-199, 220, 236, 243, 266, 284, 297, 343, 380, 382, 386-387, 401-402, 417, 420, 442, 445-447, 453

Host community/ies, 51, 79, 124, 152, 163-164, 182, 236, 240-242, 250, 298, 343, 420, 436, 441-445, 447, 456

International community, 5, 9-10, 34, 45, 69, 96, 134, 239, 294, 296, 300, 359, 361, 364, 371, $417,428,443,460,463$

Local community/ies, 8, 15, 120, 127, 144, 237, 371, 403, 436, 442, 445-446, 460-461

Community-Based Disaster Risk Management (CBDRM), 243

Compensation, 139, 306, 325

Confidentiality, 16, 208, 401

Conflict prevention, 447

Conflict resolution, 79

Contingency planning, 231, 258, 394

Convention

Convention on the Rights of the Child (CRC), 23, 176, 182, 184-185, 191, 213, 218, 277,

Geneva Conventions, 28, 30, 31, 75, 139-140, 153, 165, 179, 191, 201, 202, 214, 218, 226, 239 , 268, 287, 307, 320-321

Convention Against Torture (CAT), 22, 178

Convention for the Protection and Assistance of Internally Displaced Persons, 39, 349

Convention on Conventional Weapons, 165

Convention on the Elimination of All Forms of Discrimination against Women (CEDAW), 138, 178, 200-201, 213, 218, 225-226, 238, 260, 267, 286, 305, 319, 331-332

Convention on the Rights of Persons with Disabilities, 17, 23, 166

Convention Against Transnational Organized Crime, 178, 216, 218 
Handbook for the Protection of Internally Displaced Persons

Convention on the Reduction of Statelessness, 226, 232 Convention Relating to the Status of Stateless Persons, 226-227, 232, 234

Coordination, 52, 61-62, 65, 71, 73, 78, 80, 87, 99-100, 110, 142, 163, 174, 186, 193, 208, 266, 290, 295, 316, 373, 384-385, 387-389, 391-392, 404, 427, 440, 450, 459

Council of Europe, 42, 334-335, 345

Counseling, 172, 176, 219-221

Crime, 22, 24, 27, 33-34, 39, 70, 72, 139-140, 146-151, 153-154, 157, 161, 166, 179, 183, 191, $196,202,219,254,287,300,313-314,320-321$, 324-325, 328, 370, 387, 391, 419, 442, 447

Crime(s) against humanity, 34, 178-179, 216, 220, 222-223, 320-321

War crime(s), 22, 33, 139-140, 153-154, 161, 166, 179, 191, 202, 219, 254, 287, 300, $320-321,328,370$

Criminal law, 20, 31-32, 68, 136, 153, 178-180, 191, 320

D

Darfur, 55, 57, 318

Death certificate, 226

Death registration, 228

De-mining, $165-166$

Demobilization, 155, 185-186, 192, 300

Democratic Republic of Congo (DRC), 32, 56, 58, 78, 123

Detainee, 198, 202, 226, 324, 326, 438

Detention, 201, 321, 324

Development, 11, 17, 37, 42, 116, 134, 139, 286, 292, 322, 334, 361, 365, 373, 383, 423, 448, 455

Disability(ies), 14, 18, 25, 147, 160, 166, 171, 189, 196, 198, 209, 228, 264, 265, 272, 331, 342, 358

Disarmament, demobilization and reintegration (DDR), 155, 185, 187, 192, 295-296, 454, 296

Discrimination, 17, 178, 196, 272, 278, 283, 286, 305, 314, 324, 330-331, 402, 457

Dispersed settlement, 236, 242

Displacement, 8-15, 20-23, 38-39, 41-42, 45, 47, 51, 56, 58, 69, 74, 78-80, 113, 117, 120, $122-124,131,134,135-145,147,153,160,167-169,181-182,184,194-198,200-201$, 203-204, 206, 209-210, 215-218, 224-225, 227-232, 235-237, 239-240, 242, 244, 247-250, 253, 256, 258, 263-265, 270-272, 275-276, 279-284, 291-296, 298-308, 310-314, 318, 323-325, 329-332, 334, 339-340, 344-347, 349-352, 354, 358, 361-363, 370, 372, 376, 379, 
382, 387, 392, 394-396, 400-402, 406-413, 415, 417, 419, 421, 426, 428, 430-431, 434-435, $439,442-443,445,449,451-457,460,462-464,467,470-471$

Forced displacement, 32, 136-138, 140-143, 145, 152, 169, 204, 224, 227, 264, 323, 439, 462, 470

Arbitrary displacement, 1-3, 8, 10, 13, 17, 20, 23, 28-29, 34-40, 42, 46, 49-50, 59-60, 69-71, 74, 76, 78, 80-81, 133-134, 137-140, 145, 152, 178, 192, 213, 225, 234, 238-239, 253, 261, 276, 283, 286-287, 299, 305-306, 311, 319, 322, 330-332, 334-335, 451-452, 455, 468

Diversity, 6, 14, 262

Documentary review, 115, 118

Documentation, 199, 234, 406

DPKO (Department of Peacekeeping Operations), 17, 58, 60, 67, 173, 178, 190, 319

Durable solutions, 164, 176, 200, 275, 310, 392, 447, 450-455, 457, 459, 461, 463, 465, 467, 469, 471,473

\section{E}

Early recovery, 47, 50-51, 62, 64, 66, 69-70 132, 299, 331, 454-455, 464

Early Recovery Cluster, 118, 295, 311, 469

Early-warning, 142

Education, 47, 151, 164, 176, 246, 267, 275, 278, 281-283, 285-290, 391

Environment, 48, 166, 287, 382-383

European Union, 156, 190, 334

Exclusion, 1, 13, 14, 144, 169, 170, 271, 272, 273, 279, 293, 296, 315, 330, 333, 442, 444, 462

Exploitation, 59, 148, 173, 178, 180

Explosive remnant, 160

$\mathbf{F}$

Family, 9, 144, 150, 203-205, 207, 209-211, 213-214, 221, 275, 394, 438, 467

Family reunification, 195, 207, 211, 396, 467

Family unity, 187, 201, 203, 206-209, 410, 467

Host family(ies), 236, 242

FAO (Food and Agriculture Organization), 47, 245, 253-254, 276, 278, 300, 311, 406, 423

Female-headed household, 229, 238, 244, 465

Food aid, 247, 249, 251, 253-254

Food insecurity, 248 
Handbook for the Protection of Internally Displaced Persons

Forced recruitment, 9, 13, 148, 153, 155, 168, 182, 184-186, 205, 207, 217-218, 237, 243, 282-283, 378, 391, 396

Freedom

Freedom of movement, 194-195, 200, 436

Freedom of opinion, 276, 331

G

Gender, 6, 14, 17, 46, 48, 80, 89, 166-169, 173, 175, 177, 179-180, 184-185, 192, 239, 245, 261, $268,278,292,300,304,335,382-383,392$

Gender-Based Violence (GBV), 15, 35, 49, 57, 73, 93, 122, 124, 131-132, 147-148, 167-176, 178-179, 183, 188, 192, 205, 221, 241-244, 256, 273, 276, 284-285, 293, 315, 324, 347, 350, $353,381-382,388,398,404,414,420-421,442-443$

Genocide, 179, 320

Georgia, 134, 140, 448

Guiding Principles on Internal Displacement, 8, 49, 59, 69-70, 76, 78, 133, 137-138, 140, 145, 152, 178, 192, 200-201, 204, 212-214, 225, 234, 238-239, 253, 261, 267, 276, 286-287, 299 , 305-306, 319, 331-332, 334, 349, 406, 410-411, 432, 451-452, 469

H

Harassment, 1, 9, 70, 148, 152, 168, 170, 196, 199, 205, 225, 228, 237, 238, 256, 303, 315, 324, 331,361

Health, 46-47, 151, 163, 175, 179-180, 184, 188, 192, 246, 261, 263-269, 275, 287, 427, 429, 431-432

HIV/AIDS, 48, 51, 63, 66, 171, 183, 188, 267-268, 271-272, 276-279, 398, 421

Housing, 238, 245, 302, 306, 311, 406, 438

Human rights, 6-13, 15, 17, 20-26, 28-30, 32-33, 35-37, 39, 41-43, 45-46, 48-49, 51-53, 55-59, 63, $65,68-69,77-79,81,84,88,93,102,107,110,118,126-127,133,135-150,152-156$, 158-159, 161-162, 165-168, 170, 172-173, 175-176, 178, 181-182, 185-187, 190, 194-198, 200-201, 203, 206, 208, 213-219, 221, 224-226, 229-231, 233, 235, 238-239, 244, 247, 249-250, 255, 257, 260, 263-268, 270-271, 273-274, 276-277, 279, 281, 283, 285-286, 291 , 294-295, 297, 299, 301-302, 305-307, 309-313, 319, 323-327, 329, 331-334, 347, 349-352, 354, 361-363, 367, 370-372, 376-378, 385, 389, 391, 401-405, 408-411, 413-415, 419-421, $427,430,434-435,437,439,444-445,447,449,451-454,456-458,461-462,466-467$

Human Rights Council, 223, 257, 305-306, 311, 402

Human rights law, 279, 319 
Humanitarian

Humanitarian access, 366-367, 369, 371, 373

Humanitarian assistance, 144, 151, 375-379, 381, 383, 389

Humanitarian Coordinator, 17, 50, 56, 60, 62, 94-95, 101, 107-109, 117, 120, 132, 142-144, 154, $156,252,311,367,377,389,433-435,437,439$

Humanitarian evacuation, 433-435, 439

Humanitarian presence, 142, 366, 370

Humanitarian zone, 156

I

IASC (Inter-Agency Standing Committee), 7, 12-13, 17-18, 45-46, 50-52, 60-62, 64, 80 102, 107, $111,132-134,145,156,168-169,173-174,179-180,192,239,245,261,268,271-272,277$, $287,292,300,355,365,383,385,392,427,432,436,439-440,465,469$

ICC (International Criminal Court), 73, 138-139, 156, 179, 190-191, 200-201, 213, 218, 225-227, 238-239, 254, 261, 286, 300, 306-307, 319, 322, 331-332

ICCPR, 138-139, 200-201, 213, 218, 225-227, 238, 286, 306, 319, 331-332

ICERD, 138, 200-201, 225-226, 267, 286, 299, 319, 331

ICESCR, 138, 213, 218, 227, 238, 253, 267, 286, 299

ICRC (International Committee of the Red Cross), 7-8, 17, 45, 51, 73, 76, 78, 80, 101, 104, 110, 139, $143,145,156,165-166,179-180,190,192-193,200-202,214,218,221,239,245,253,260$, $269,287,307,320-321,324,352,367,376,394,434-435,438,440$

Identification, 155, 203, 210, 429, 470-472

Identity, 9, 330

Loss of Identity, 196

IFRC (International Federation of Red Cross and Red Crescent Societies), 17, 45, 47, 51, 104, 178, $190,192,245,253,260$

ILO (International Labour Organization), 138, 191, 218, 222-223, 276, 300, 305-306

Information dissemination, 358, 381, 395, 397-398, 399

Institutional framework, 3, 5, 42, 100, 102, 313, 409

Integrated missions, 55, 67

Inter-Agency Guiding Principles on Unaccompanied and Separated Children, 204, 212, 214

International Committee of the Red Cross, 18, 45, 156, 166, 179-180, 190-191, 202, 219, 254, 269, $287,300,313,321-322,327,367,373$

International Humanitarian Law (IHL), 17, 73, 77-78, 139, 179, 201-202, 214, 239, 254, 268, 287. 299, 307, 320-321, 415 
Handbook for the Protection of Internally Displaced Persons

International Mine Action Standards (IMAS), 161-162, 166

IOM (International Organization for Migration), 45, 47, 62, 101, 145, 178, 214, 222-223, 245, 276 , 278, 311, 334-335, 385, 415, 432, 435

$\mathbf{J}$

Justice

Access to Justice, $80,313,322$

Joint United Nations Programme on HIV/AIDS, 278

$\mathbf{K}$

Khartoum, 37, 40

$\mathbf{L}$

Land and Property, 302, 311

Landmine, 159-161, 163, 165-166

Leadership, 87, 98, 111

Legal assistance, 71, 317, 400-403, 405

Liberty and Security of Person, 178, 195, 198, 201-202, 276

Livelihood, 163, 175, 221, 254, 275, 291-295, 297, 299-300

Local integration, 32, 54, 68, 117, 144, 244, 293, 431, 456

M

Malnutrition, 9, 248-249, 253, 264

Marginalization, 1, 9, 36, 144, 148, 195, 197, 264, 271, 283, 298, 303, 314, 330, 421, 430

Marriage, 180, 225

Mediation, 142

Military, 61, 80, 107, 109-111, 156, 307

Militia, 158, 217, 443

Mine, 49, 99, 110, 155-156, 159, 162, 166, 199

Mine-Risk Education (MRE), 161, 164

Minimum Standards on Education in Emergencies, 282, 287

Minority(ies), 13, 72, 139, 150, 198, 233, 297, 319, 324, 330, 402, 410, 434, 442, 444, 446, 462, 466 
Monitoring, 57, 63, 74, 76-77, 79-80, 113, 125-127, 129, 132, 134, 179, 187, 208, 212, 241, 252, $258,285,289,309,311,335,345,349-350,352,354-355,406,415$

Movement, 50, 62, 78, 192, 350

N

National authorities, 53, 70, 140, 266, 305, 387-388, 390, 459, 462

National Human Rights Institution (NHRIs), 57, 73-75, 81, 406, 415

National responsibility, 9-10

Nationality, 226, 229, 234

Natural disaster, 45, 52, 78, 81, 84, 113, 116, 126, 182, 196, 216, 227, 243, 283, 453

Natural resources, 197, 295, 297

Negotiation, 76, 80, 87, 93-94, 111, 116, 364, 367-368, 370, 373, 437

NGO (Non-Governmental Organization), 11, 45-46, 50, 52-53, 62, 65, 67, 78, 80, 94, 99, 101, 108, $120,145,156,163,165,175,178,187,190,192,214,219,221-222,233-234,245,250,253$, 260, 274, 276, 287, 309, 311, 318-319, 333-334, 345, 352-353, 361, 367, 369-371, 377, 385, $399,401,407-408,410,413-415,429,440,456$

Non-state actors, 164

Non-state armed actors, 75-76, 78, 183

Normative framework, 313

Nutrition, 47, 254

0

OCHA (Office for the Coordination of Humanitarian Affairs), 46, 58, 60-63, 76, 101, 104-105, $110-111,145,190,193,214,245,278,361,364-365,373,389,392,394,406$

OHCHR (Office of the High Commissioner for Human Rights), 7, 11, 17-18, 47, 51, 73, 76, 78, $80-81,145,178,180,193,214,219-220,222-223,234,245,253,276-278,311,319,322,324$, $334-335,352,355,406,415$

Older person, 13, 205, 238, 265, 296, 380, 398

Ordnance(s), 160, 162, 165, 196, 304, 464, 470

OSCE (Organization for Security and Cooperation in Europe), 80, 156, 190, 222-223, 334-335

$\mathbf{P}$

Peacebuilding, 334, 448

Peaceful coexistence, 441, 443, 445, 447

Peacekeeping forces, 58-59, 63, 72, 100, 116-117, 132, 142, 145, 156, 186, 190, 199, 221-222, $274,276,316,319$ 
Handbook for the Protection of Internally Displaced Persons

Peacekeeping mission, 44, 55, 57-59, 67, 154, 187, 309, 367

Peru, 140, 327

Physical security, 7, 33, 70, 170, 217, 470

Planned camp, 236

Police, 80, 324

Political participation, 329-331, 333, 335

Post-traumatic stress, 171

Prevention, 49, 134, 135, 173, 178-179, 186, 201, 224, 226, 261, 268, 273, 277, 409

Principles and Guidelines on Children Associated with Armed Forces or Armed Groups (Paris Principles), 35, 73, 75, 185, 192, 321, 391

Principles on Housing and Property Restitution (Pinheiro Principles), 238, 245, 302, 305-306, 308 , $311,406,438$

Prisoner, 201, 321, 324

Profiling, 338-341, 343-345

Property, 238, 245, 302, 306, 311, 406, 438

Protection, 5-23, 26-30, 32-37, 39-47, 49-59, 62-64, 67-74, 76-78, 81, 83-86, 88, 93, 96, 99-108, 113-127, 129-134, 135, 137-138, 140-142, 144, 147-151, 153-154, 156-157, 163, 169-172, $174,176,178,182,184-192,195-196,198,200,204-205,207-208,210-221,225-226,228$, 230-231, 233-234, 236-246, 248-253, 256-258, 262-264, 266, 268, 271, 274-277, 279, 282-283, 286-287, 289, 292-296, 298-299, 302, 307-308, 314-318, 320-322, 333-334, 337-340, 342-373, 375-382, 384-397, 399, 401, 403-404, 407-414, 416-417, 419-422, 424, 428-431, 433-440, 442, 444-445, 449, 451-452, 454-458, 460, 463-464, 466, 469-470

Protection cluster (PCWG), 47-48, 51-56, 61, 66, 80, 93, 108, 134, 257

Protection needs assessment, 115, 117, 118, 122, 124, 132-133

Protection strategy, 83, 101, 113-114, 116-117, 119-120, 130-134, 147, 195, 239, 307, 347, $370,408,412$

Protocol

Additional Protocols I and II to the Geneva Conventions, 28, 139, 153, 179, 191, 201, 214 , $218,239,254,268,287,307,321$

Great Lakes Protocol on the Protection and Assistance to Internally Displaced Persons and Model Law, 40

Optional Protocol on the sale of children, child prostitution and child pornography, 23

Optional Protocol to the Convention on the Rights of the Child on the involvement of children in armed conflict, 23, 182, 185, 187, 191 
Protocol against the Smuggling of Migrants by Land, Sea and Air, 216

Protocol to Prevent, Suppress and Punish Trafficking in Persons Especially Women and Children, 216, 218-219

Protocol to the African Charter on Human and Peoples' Rights on the Rights of Women in Africa, $39,213,225-226,238,260,286,305-306,319,331$

Protocol on the Prevention and Suppression of Sexual Violence against Women and Children, 40

Protocols II and V to the Conventional Weapons Convention, 164-165

Protocol on the Property Rights of Returning Persons, 40

Protocol relating to the Status of Refugees to the victims of trafficking and persons at risk of being trafficked, 222

Protocol to the Convention against Transnational Organized Crime, 216

Psychosocial support, 426, 428

Public services, 9, 36, 160-161, 164, 195, 200, 205, 271, 274, 277, 294, 464, 466

Q

Qualitative method, 340

Quantitative method, 342

$\mathbf{R}$

Reconciliation, 322

Reconstruction, 282, 287, 448

Recruitment, 182, 290

Red Crescent Society, 78

Red Cross, 18, 45, 50, 62, 78, 166, 180, 192-193, 202, 210, 214, 269, 367, 373, 376, 434, 440

Registration, 185-186, 189, 192, 210, 214, 225, 228, 234, 251, 285, 295, 300, 340, 342, 345, 389, $391,448,471$

Reintegration, 23, 25, 34, 36, 38, 55-56, 117, 140, 143-144, 148, 151-152, 155-156, 160, 163-164, 166, 175-176, 182, 184-187, 189-190, 192, 194, 211, 214, 220-221, 229, 275, 277, 279, 282, 285, 294-296, 300, 302-303, 306, 317, 324, 332, 451, 452-454, 458-459, 460-462, 464-466, 469-470

Relocation, 23, 117, 143-144, 148, 151, 164, 176, 197-200, 209, 220, 229, 249, 275, 279, 302, 306, $317,332,376-377,382,387,395,434-439,451,459,465-466$

Remnants of war, 9, 25, 159-166

Resident Coordinator, 50, 55, 60, 145, 200, 355, 367, 377, 469 
Handbook for the Protection of Internally Displaced Persons

Responsibility of the State, $20,26,45,135-136,140,146-148,159,162,167,172,179,181,184$, $194,198,203,207,215,219,228,235,238,247-248,255,257,263,266,270,273,291,293$, $301,305,312,315,317,329,332$

Restitution, 238, 245, 302, 306, 311, 406, 438

Return, 173, 179, 311, 470

Reunification, 211, 214

Rule of law, 49

Rwanda, 327

\section{S}

Safe corridor, 370

Scenario analysis, 116

Security Council, 14, 55-57, 67, 172, 179, 187, 190-191, 276, 305, 352, 370

Security zone, 156

Setting

Collective setting, 251, 384-385, 387, 389, 391

Emergency setting, 271, 283

Urban setting, 14, 242, 350, 387, 397, 410, 422

Settlement, 245, 311, 355, 383, 392, 398

Collective settlement, 236

Dispersed settlement(s), 236, 237, 242

Group settlement(s), 9, 23, 26, 34, 36, 38, 41, 56, 70, 72-74, 76-77, 122, 127, 140, 144, 153-155, 163, 174-175, 182, 195-197, 199-200, 204, 220, 230, 236-237, 240, 242, 244-245, 249-250, 257, 264, 293, 296, 298, 309, 311, 323, 328, 330-331, 333, 451, 453, 456, 458-465, 467

Temporary settlement, 240

Urban settlement, 122

Sexual exploitation, 9, 59, 148, 158, 173, 175, 180, 216-217, 237, 241, 248, 251-252, 258, 277 . 296, 378, 396, 442

Shelter, 46, 163, 175, 235-237, 239, 244-245, 249, 310-311, 383, 387

Emergency shelter, 236

Sierra Leone, 327 
Situational analysis, situation analysis, 11, 88, 113, 115-120, 122, 124, 130-131-133, 183, 185, 368, $391,417,435,439$

Slavery, 218

Social capital, 470

Somalia, 292, 380, 457

Somaliland, 78, 387

Sphere, 18, 59, 192, 240, 245, 258, 261, 265, 268, 383, 392

Sri Lanka, 185, 387, 406, 415

State actors, $10,69,77,83,94,108,120,135,145,153-154,162,166,173,179,184-185,191$, $196,221,225,228,239,320,347,363,367-368,390,408,410,440,443$

Stateless, 224, 226-227, 229-232, 234

Stigma, 278

Stockpile destruction, 161

Strategy, 113, 162, 408, 466, 469

Sudan, 55, 57, 78

Sustainable/sustainability, 12, 57, 69, 71, 79, 84, 129, 144, 151, 161, 175, 195, 197, 229, 248, 257-258, 260, 264, 282, 291-296, 298-300, 303, 306-307, 310, 451, 453, 457, 460, 465

Sustainable return, $57,197,303,451,457,461$

$\mathbf{T}$

Torture, 148, 178, 319

Tracing, 203, 210-211, 214, 238

Trafficking, 178, 215-220, 222-223

Trafficking in Persons Protocol, 216, 218-219

Training, 60, 64, 73-74, 76, 78, 80, 150, 158, 165-166, 192, 221, 252, 267, 274, 290, 309, 334-335, $355,407,410,415,423,432$

Transitional justice, 325, 327-328

Travel document, 196, 227

Turkey, 457

U

UDHR (Universal Declaration of Human Rights), 138, 178, 200-201, 213, 218, 225-226, 238, 253, $260,267,286,299,305-306,319,331-332$

Uganda, 123, 134 
UN (United Nations), 7, 11-12, 14-15, 17-18, 44-45, 47, 50-51, 55-56, 58, 67, 76-78, 80-81, 99, $101-103,108-111,117,132,134,140,145,154-156,158,161-163,165-166,168,172-173$, $177,179-180,187,190-193,201,211,214,216,220-223,231-232,234,238,245,250$, 253-254, 256-257, 260-261, 266, 268-269, 275-278, 288, 300, 311, 313, 320-322, 334-335, $345,347,352,355,361,364-365,367-368,370,373,376-377,382-383,385,392,398,402$, $406,408,415,423-424,429,432,434-435,437-438,440,448,451,455,469-470$

UN Basic Principles for the Treatment of Prisoners, 201, 324

UN Basic Principles on the Independence of the Judiciary, 323

UN Body of Principles for the Protection of All Persons under Any Form of Detention or Imprisonment, 201, 324

UN Code of Conduct for Law Enforcement Officials, 149, 324

UN Standard Minimum Rules for the Treatment of Prisoners, 201, 324

Unaccompanied minor, 33, 438

UNAIDS, 48, 276-278

UNDP (United Nations Development Programme), 47, 49, 80-81, 145, 162, 165, 178, 234, 245 , $287,300,311,313,319,322,408,423$

UNEP (United Nations Environment Programme), 48, 245

UNFPA (United Nations Population Fund), 18, 48-49, 145, 178, 180, 234, 269, 276, 278, 287, 423

UN-HABITAT, 245, 311, 406

UNHCR (United Nations High Commissioner for Refugees), 7, 12, 17, 47, 51, 61, 81, 102, 111, $134,145,154,156,158,162,165,173-174,178-180,190,214,222-223,231-232,234,245$, 253-254, 261, 268-269, 276-278, 287-288, 300, 311, 319, 322, 345, 352, 355, 373, 382-383, $385,392,398,406,408,415,423,424,429,432,434,440,448,469$

UNICEF (United Nations Children's Fund), 7, 47, 51, 78, 102, 145, 156, 162, 165, 178, 180, 187 , 190, 192-193, 211, 214, 221-223, 234, 245, 253-254, 260-261, 269, 276, 278, 287-288, 319, $352,373,392,423,432,438,440$

UNIFEM (United Nations Development Fund for Women), 80, 145, 180, 278, 423

United Nations Humanitarian Information Centre, 117

UNMAS (United Nations Mine Action Service), 49, 155-156, 161-163, 165-166

V

Vetting, 322, 327

Violence, 17, 152, 168, 173, 178-180, 192, 201, 261, 268, 287, 319, 324, 331-332, 382, 432

Voluntariness of movement (Principle of), 197 
Voluntary return, 56-57, 140, 200, 309-310, 382, 396, 461, 465

Vote (right to), 225, 329-331, 333, 335

W

WASH (Water, sanitation and hygiene), 47, 256, 258-260, 262

Welfare, 191

WFP (World Food Programme), 47, 165, 178, 250, 253-254, 276, 287, 382

WHO (World Health Organization), 47, 165, 178, 180, 222, 253-254, 260-261, 264, 266, 268-269, 276,278

Women, 17, 122, 138, 168, 172-173, 178-180, 185, 192, 201-202, 205, 213, 216-219, 222, 225-226, 230, 234, 238, 245, 260-261, 268, 278-279, 138, 168, 172-173, 178-180, 185, 192, 201-202, $205,213,216-219,222,225-226,230,234,238,245,260-261,268,278-279,286,292,300$, $303,305-306,309,319,330-332,335,351,361,383,396-397,423$

Work (right to), 299

World Bank, 276, 300, 311, 448, 455

$\mathbf{Y}$

Yugoslavia, 322, 434, 440 